Florida International University FIU Digital Commons

5-11-2011

\title{
Local Biomass Control on the Composition and Reactivity of Particulate Organic Matter in Aquatic Environments
}

Olivia Pisani

Florida International University, opisa001@fiu.edu

DOI: $10.25148 /$ etd.FI11072802

Follow this and additional works at: https://digitalcommons.fiu.edu/etd

\section{Recommended Citation}

Pisani, Olivia, "Local Biomass Control on the Composition and Reactivity of Particulate Organic Matter in Aquatic Environments" (2011). FIU Electronic Theses and Dissertations. 446.

https://digitalcommons.fiu.edu/etd/446 


\section{FLORIDA INTERNATIONAL UNIVERSITY}

Miami, Florida

\section{LOCAL BIOMASS CONTROL ON THE COMPOSITION AND REACTIVITY OF PARTICULATE ORGANIC MATTER IN AQUATIC ENVIRONMENTS}

A dissertation submitted in partial fulfillment of the

requirements for the degree of

DOCTOR OF PHILOSOPHY

in
CHEMISTRY
by
Oliva Pisani

2011 


\section{To: Dean Kenneth Furton}

College of Arts and Sciences

This dissertation, written by Oliva Pisani, and entitled Local Biomass Control on the Composition and Reactivity of Particulate Organic Matter in Aquatic Environments, having been approved in respect to style and intellectual content, is referred to you for judgment.

We have read this dissertation and recommend that it be approved.

$\begin{array}{r}\text { José Almirall } \\ \hline \text { William Anderson } \\ \hline \text { John Berry } \\ \hline \text { Piero Gardinali } \\ \hline \text { Rudolf Jaffé, Major Professor }\end{array}$

Date of Defense: May 11, 2011

The dissertation of Oliva Pisani is approved.

\begin{tabular}{r}
$\begin{array}{r}\text { Dean Kenneth Furton } \\
\text { College of Arts and Sciences }\end{array}$ \\
\hline Interim Dean Kevin O'Shea \\
University Graduate School
\end{tabular}

Florida International University, 2011 


\section{DEDICATION}

I dedicate this dissertation to my nonno, Luciano Landini. Without your love and support, the completion of this work would not have been possible. I love you and miss you dearly. 


\section{ACKNOWLEDGMENTS}

I wish to thank my major professor and advisor, Dr. Rudolf Jaffé for giving me the opportunity and pleasure to work in his research group. It has been a wonderful journey and learning experience and without his guidance and enthusiasm, the completion of this dissertation would not have been possible. I am grateful to my committee members Dr. Jose Almirall, Dr. William Anderson, Dr. John Berry and Dr. Piero Gardinali for their cooperation and support. I would like to particularly thank Dr. Anderson for his help with the stable isotope analyses and for providing his technical input and assistance, which led to the improvement of my dissertation.

Sincere thanks are extended to the numerous collaborators who kept me interested and motivated throughout the completion of my graduate studies. I wish to thank Dr. William Louda and Dr. Len Scinto for the use of their laboratories and valuable input on interpretation of the results. I would like to thank Dr. Walter Dodds for his help in sample collection and for providing me with a wonderful tour of Konza Prairie. Many sincere thanks go to Dr. Bernd Simoneit for offering his priceless expertise in biomarker identification. I especially wish to thank Dr. Youhei Yamashita for sharing his knowledge of dissolved organic matter dynamics in the Everglades and for offering his friendship and kind words of encouragement.

The funding of this work by the National Science Foundation (NSF) through the FCE-LTER program is greatly appreciated. The FCE-LTER is also acknowledged for providing salary support through a research assistantship and travel funds to present this work at professional meetings. The department of Chemistry \& Biochemistry at Florida International University is greatly acknowledged for providing teaching assistantship 
support and the Dissertation Year Fellowship that helped me complete my dissertation. I wish to acknowledge the Southeast Environmental Research Center for performing elemental analyses of my samples and for providing field support.

I would like to thank the field crew who took me to the Everglades and provided valuable assistance in sample collection, especially Rafael Travieso, Adam Hines and Olga Sanchez. Most of all, many thanks are given to Damon Rondeau for teaching me how to stay safe in the field. I would like to express my sincere gratitude to Mark Kershaw for his technical assistance and to Carrie Rebenack and Diana Johnson for their help with carbon and nitrogen measurements. I also thank Jay Munyon for working late nights with me and for helpful discussions on Everglades' ecosystem respiration as it related to my dissertation work.

I wish to thank the extraordinary members of the Organic Geochemistry Group for their friendship, support and constant willingness to help. I especially want to thank Dr. Laura Belicka for always offering her assistance with biomarker identification and GC/MS troubleshooting. Many thanks are extended to Dr. Kaelin Cawley and Dr. Meilian Chen for their kind words of encouragement, especially in the past few months. Special thanks go to my good friend and fellow graduate student, Yan Ding, for always being so cheerful and for being a pleasure to know and work with. I would like to thank my former lab members Kathleen Parish, Dr. Min Gao and Dr. Yunping Xu for offering their guidance at the beginning of my graduate studies. Finally, I wish to thank my good friend Dr. Nagamitsu Maie for teaching me the importance of hard work and for sharing his love for the Everglades. 
I am also grateful to Dr. Evelyn Gaiser, Dr. Tiffany Troxler and Greg Koch for sharing their knowledge of the Everglades ecosystem. Many thanks go to Cidya Grant and Panne Mongkronsri from Florida Atlantic University for their generous help with pigment analyses. I am very grateful to Linda Powell for her technical assistance and to Mike Rugge for providing his expertise in creating beautiful maps of the Everglades. I thank my best friend Greg Losada for constantly talking to me about floc and the Everglades. I also thank Greg for always believing in me and for being so patient and understanding during the time I spent completing my dissertation. Finally, I thank my family for their endless love and support. 


\title{
ABSTRACT OF THE DISSERTATION \\ LOCAL BIOMASS CONTROL ON THE COMPOSITION AND REACTIVITY OF PARTICULATE ORGANIC MATTER IN AQUATIC ENVIRONMENTS
}

\author{
by
}

Oliva Pisani

Florida International University, 2011

Miami, Florida

\section{Professor Rudolf Jaffé, Major Professor}

Freshwater ecosystems have been recognized as important components of the global carbon cycle, and the flux of organic matter (OM) from freshwater to marine environments can significantly affect estuarine and coastal productivity. The focus of this study was the assessment of carbon dynamics in two aquatic environments, namely the Florida Everglades and small prairie streams in Kansas, with the aim of characterizing the biogeochemistry of OM. In the Everglades, particulate OM (POM) is mostly found as a layer of flocculent material (floc). While floc is believed to be the main energy source driving trophic dynamics in this oligotrophic wetland, not much is known about its biogeochemistry. The objective of this study was to determine the origin/sources of OM in floc using biomarkers and pigment-based chemotaxonomy to assess specific biomass contributions to this material, on a spatial (freshwater marshes vs. mangrove fringe) and seasonal (wet vs. dry) scales. It was found that floc $\mathrm{OM}$ is derived from the local vegetation (mainly algal components and macrophyte litter) and its composition is controlled by seasonal drivers of hydrology and local biomass productivity. 
Photo-reactivity experiments showed that light exposure on floc resulted in photodissolution of POC with the generation of significant amounts of both dissolved OM (DOM) and nutrients ( $\&$ P), potentially influencing nutrient dynamics in this ecosystem. The bio-reactivity experiments determined as the amount and rate of $\mathrm{CO}_{2}$ evolution during incubation were found to vary on seasonal and spatial scales and were highly influenced by phosphorus limitation.

Not much is known on OM dynamics in small headwater streams. The objective of this study was to determine carbon dynamics in sediments from intermittent prairie streams, characterized by different vegetation cover for their watershed $\left(\mathrm{C}_{4}\right.$ grasses $)$ vs. riparian zone $\left(\mathrm{C}_{3}\right.$ plants). In this study sedimentary $\mathrm{OM}$ was characterized using a biomarker and compound specific carbon stable isotope approach. It was found that the biomarker composition of these sediments is dominated by higher plant inputs from the riparian zone, although inputs from adjacent prairie grasses were also apparent. Conflicting to some extent with the River Continuum Concept, sediments of the upper reaches contained more degraded OM, while the lower reaches were enriched in fresh material deriving from higher plants and plankton sources as a result of hydrological regimes and particle sorting. 


\section{TABLE OF CONTENTS}

CHAPTER

PAGE

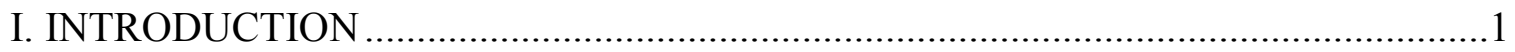

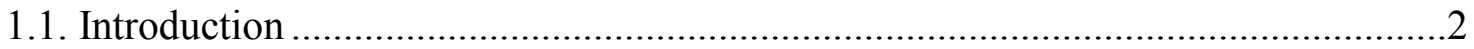

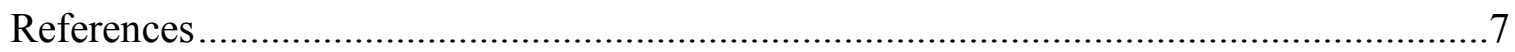

II. MOLECULAR CHARACTERIZATION OF FLOCCULENT MATERIAL IN THE FLORIDA COASTAL EVERGLADES .............................................................9

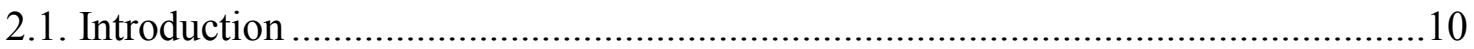

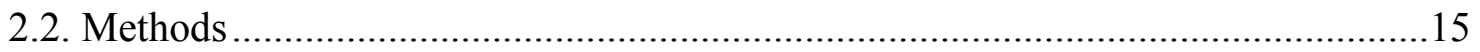

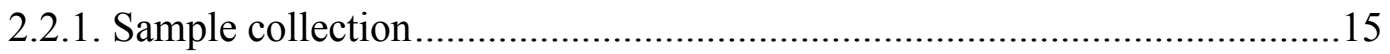

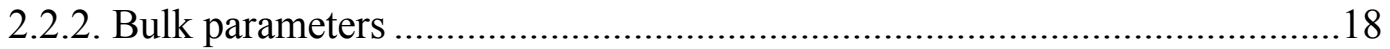

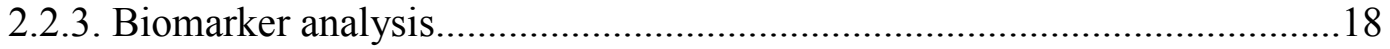

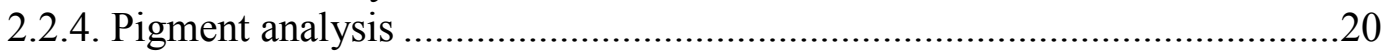

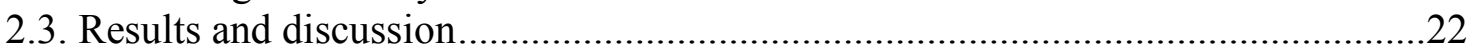

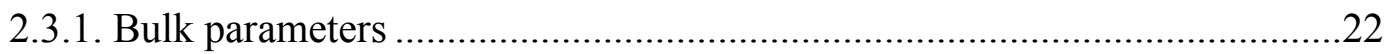

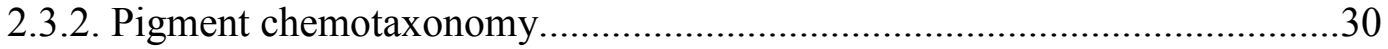

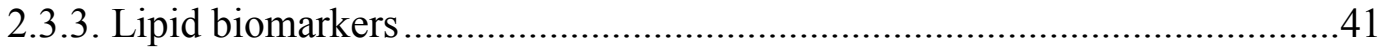

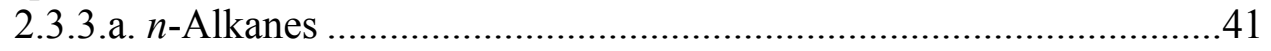

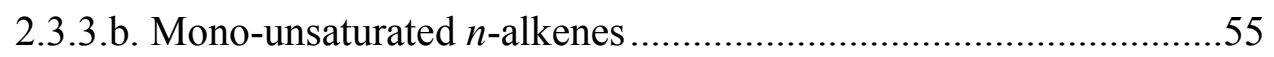

2.3.3.c. $\mathrm{C}_{20}$ and $\mathrm{C}_{25}$ highly branched isoprenoids ....................................63

2.3.3.d. Botryococcene isoprenoids .........................................................68

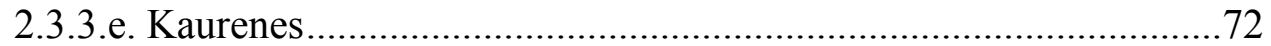

2.3.4. Environmental sources of specific biomarkers ............................................74

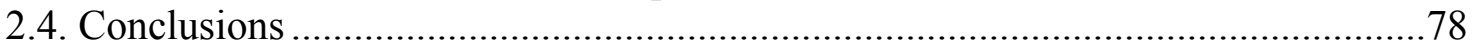

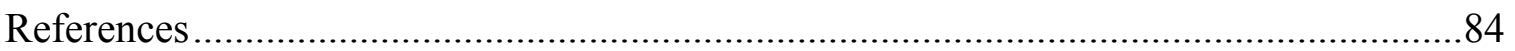

III. PHOTO-DISSOLUTION OF FLOCCULENT, DETRITAL MATERIAL IN AQUATIC ENVIRONMENTS: CONTRIBUTIONS TO THE DISSOLVED

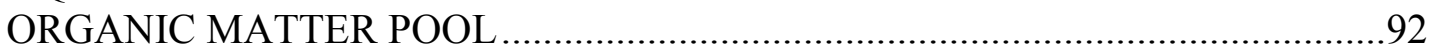

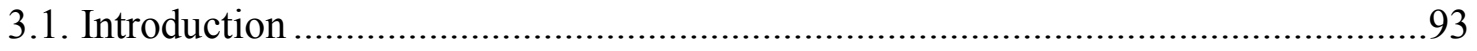

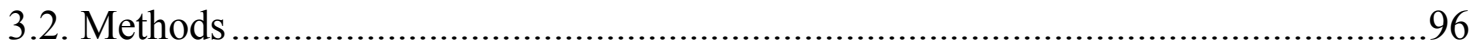

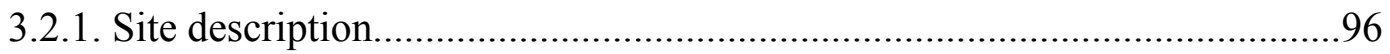

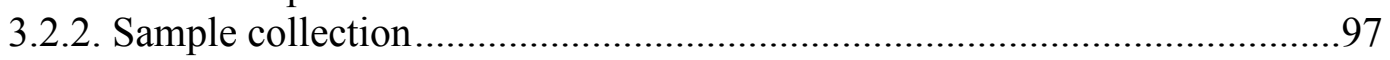

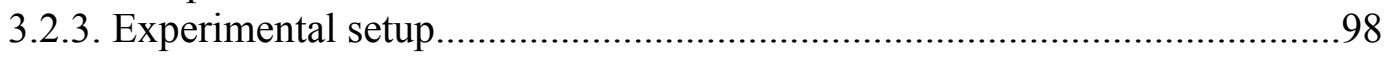

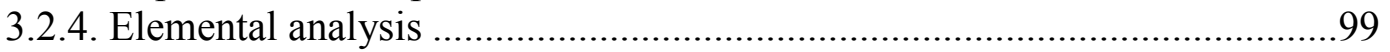

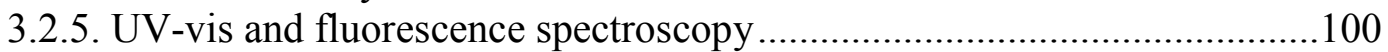

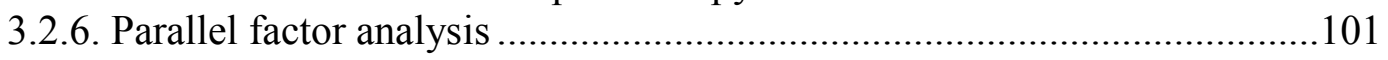

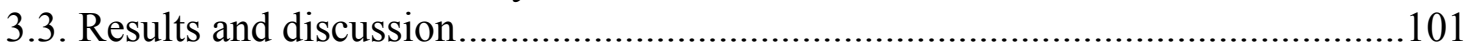

3.3.1. Natural water and floc chemical characteristics ........................................101

3.3.2. Photochemical production of DOC from floc...........................................103

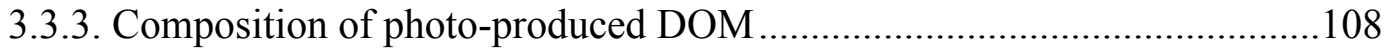

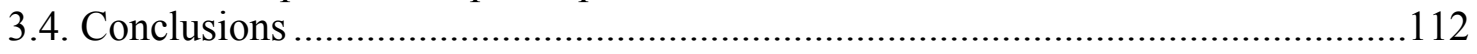


IV. SPATIAL AND SEASONAL DIFFERENCES OF FLOCCULENT DETRITAL MATERIAL RESPIRATION RATES IN A SUBTROPICAL WETLAND ...........119

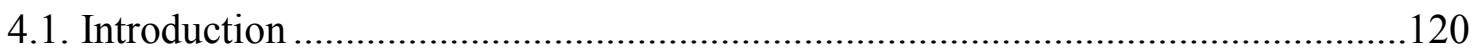

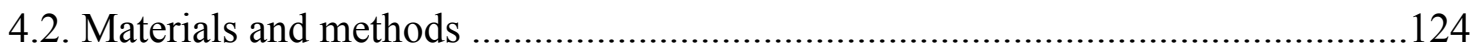

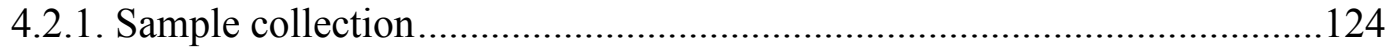

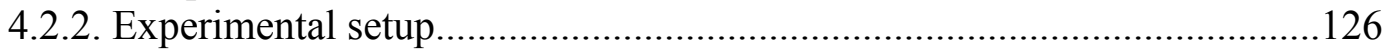

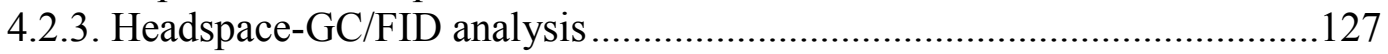

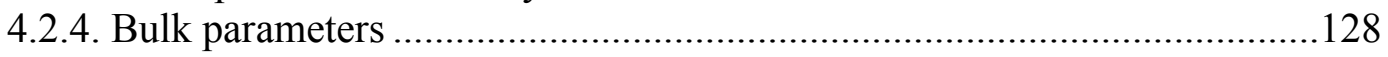

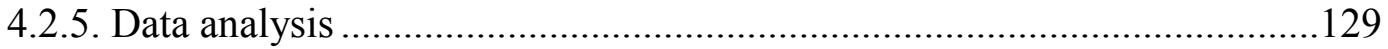

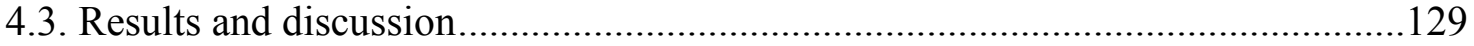

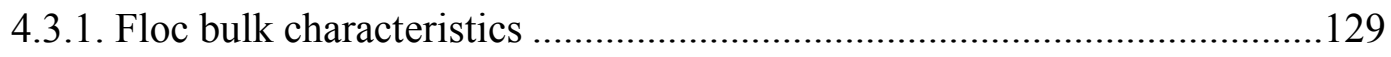

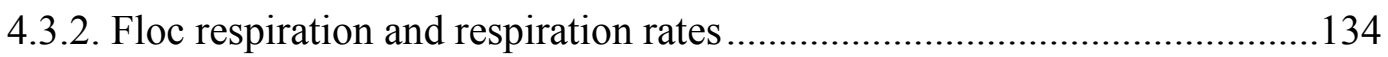

4.3.3. Effects of phosphorus additions on floc respiration ...................................141

4.3.4. Effects of glucose amendments on floc respiration .................................143

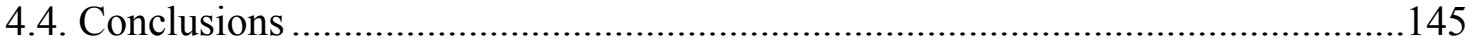

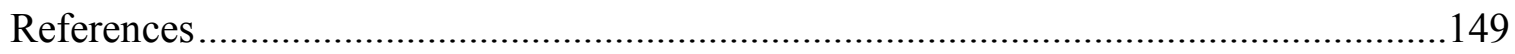

V. CHARACTERIZING RIPARIAN VS. WATERSHED VEGETATION INPUTS TO SEDIMENTS OF SMALL, PRAIRIE STREAMS: A MOLECULAR MARKER

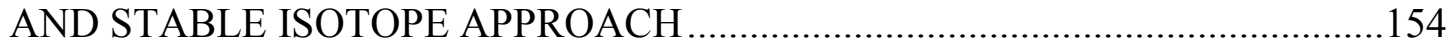

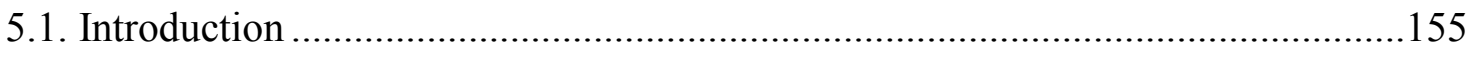

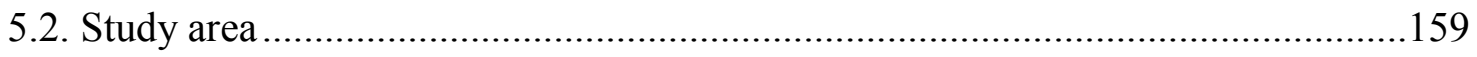

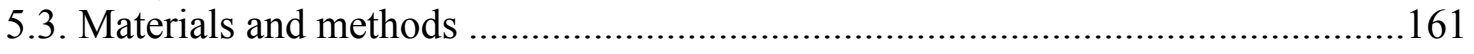

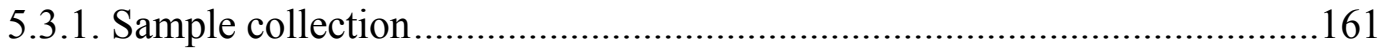

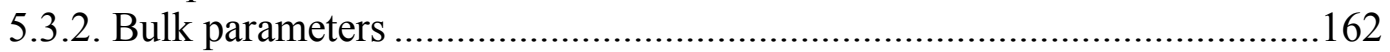

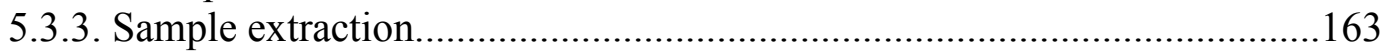

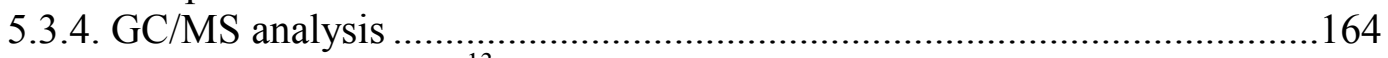

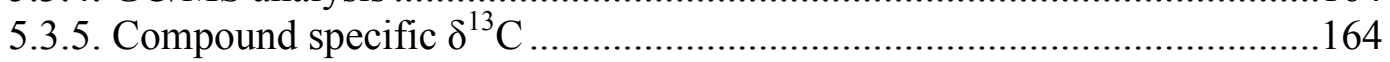

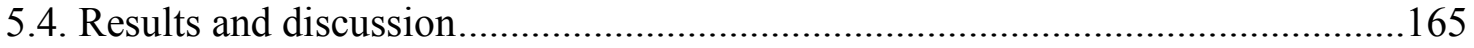

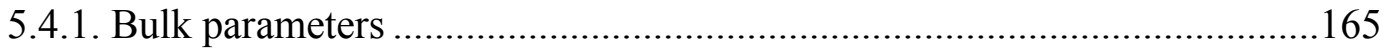

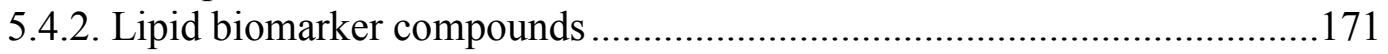

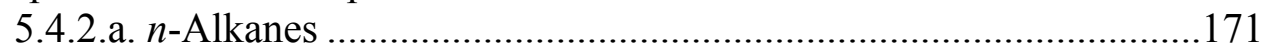

5.4.2.b. Branched $n$-alkanes ...............................................................174

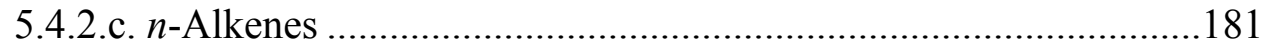

5.4.2.d. Phytadienes ............................................................................182

5.4.2.e. $\mathrm{C}_{25}$ highly branched isoprenoids ................................................187

5.4.2.f. Mono-unsaturated triterpenes …………………..........................190

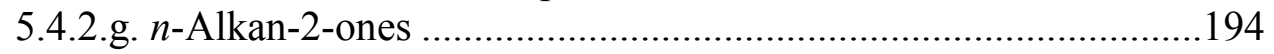

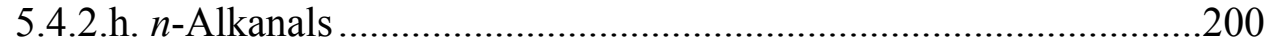

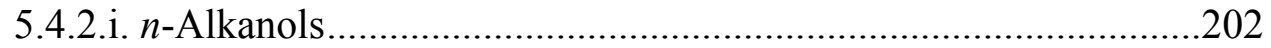

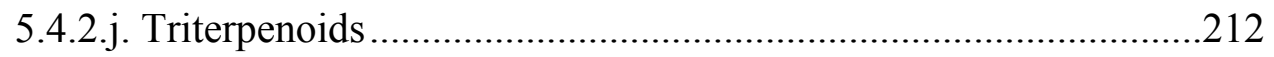

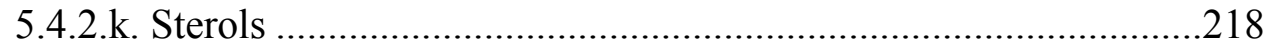

5.4.3. Compound specific isotopes of $n$-alkanes..............................................223 


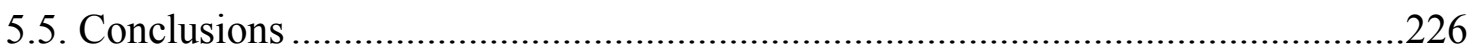

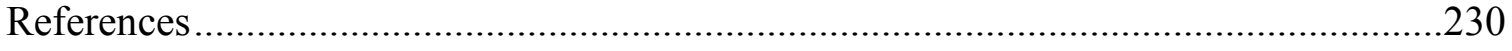

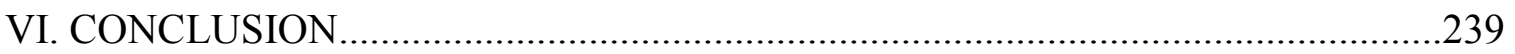

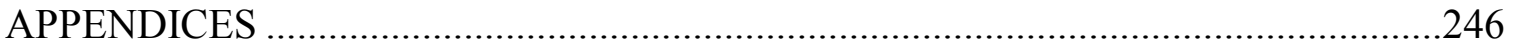

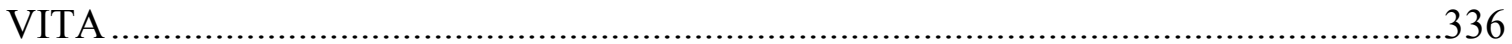




\section{LIST OF TABLES}

TABLE

PAGE

2.1. Solvent profile for RP-HPLC... .21

2.2. Percent organic matter and $\mathrm{P}_{\mathrm{aq}}$ values for typical Everglades' vegetation .51

3.1. Natural water and floc bulk chemical parameters

3.2. Regression analysis for CDOM generation rates.

4.1. Bulk properties of the floc samples .131

4.2. Floc molar ratios

4.3. Cumulative $\mathrm{CO} 2$ evolved and respiration rates of floc and floc samples amended with phosphorus and glucose .136

5.1. Organic carbon, nitrogen, molar ratios and $\delta 13 \mathrm{C}$ of plant and soil samples from the King's Creek watershed. 


\section{LIST OF FIGURES}

FIGURE

PAGE

2.1. Geographic locations of sampling sites along the Shark River Slough and Taylor Slough in Everglades National Park ................................................................. 17

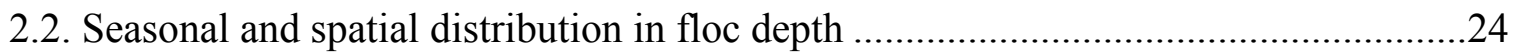

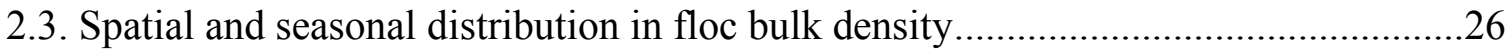

2.4. Organic matter content for the periphyton samples ............................................27

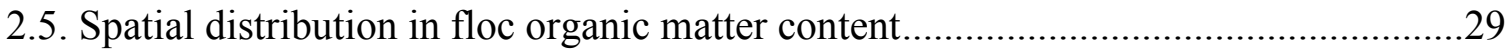

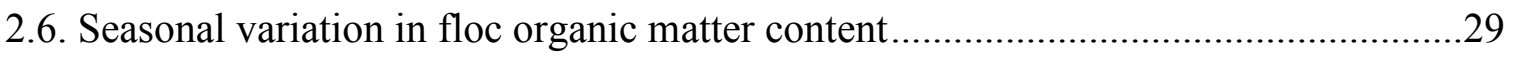

2.7. Seasonal and spatial distribution of total chlorophyll- $a$ and pheopigment content

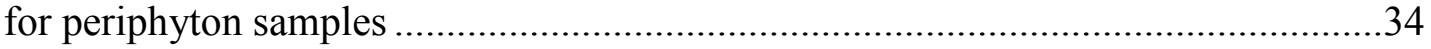

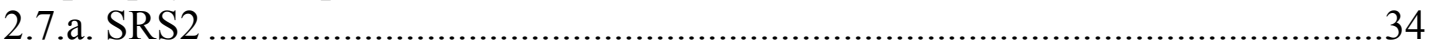

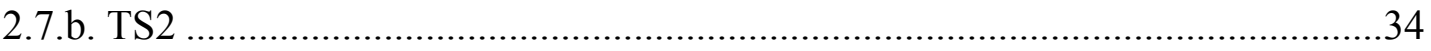

2.8. Spatial and seasonal distribution of total chlorophyll- $a$ and pheopigment content

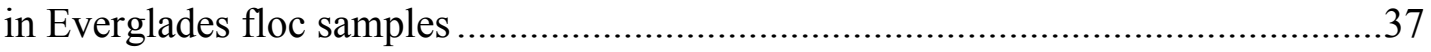

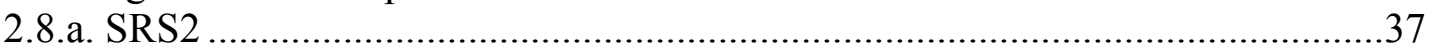

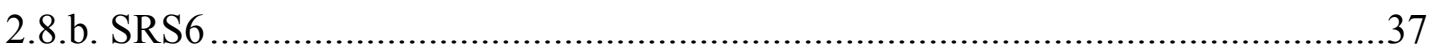

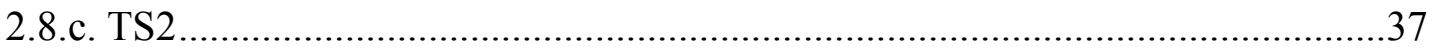

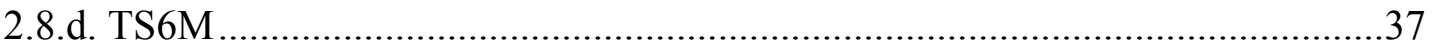

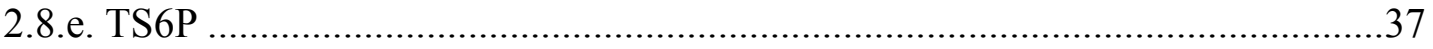

2.9. Seasonal distribution in the chemotaxonomic estimate for the periphyton samples ..38

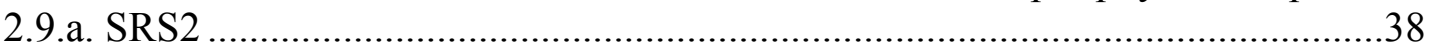

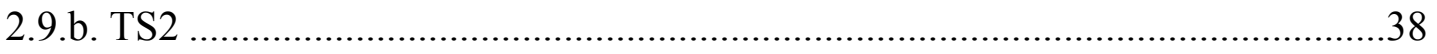

2.10. Seasonal distribution in the chemotaxonomic estimate for the floc samples ..........39

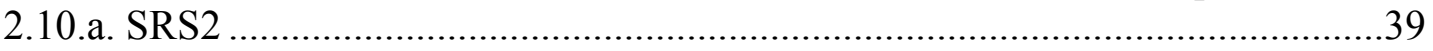

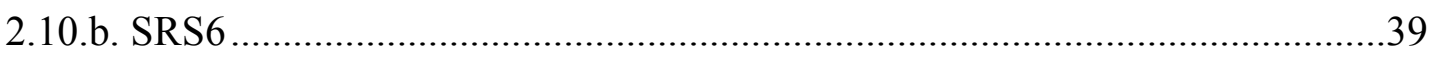

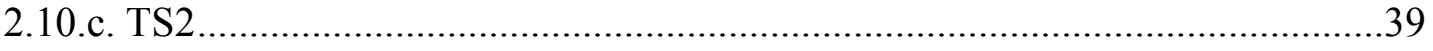

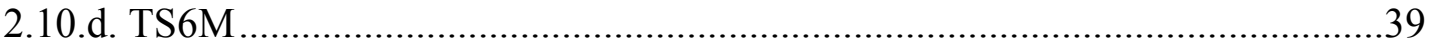

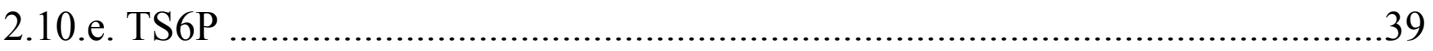


2.11. Compositional linkage between periphyton and floc collected at SRS2

2.12. Seasonal changes in the compositional linkage between periphyton and floc

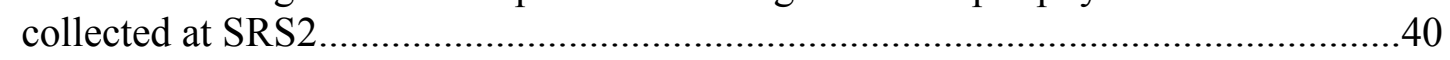

2.13. The $n$-alkane abundance and distribution for typical Everglades' vegetation ..........44

2.14. The $n$-alkane distribution for periphyton samples ........................................45

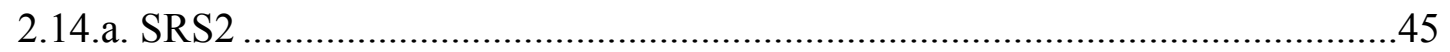

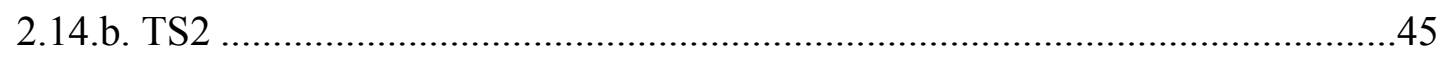

2.15. The $n$-alkane distribution for floc samples .......................................................47

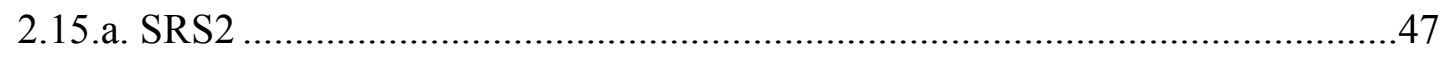

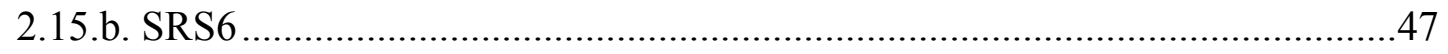

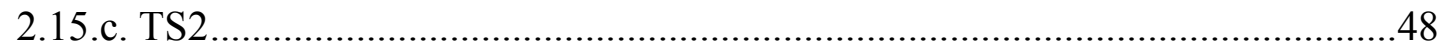

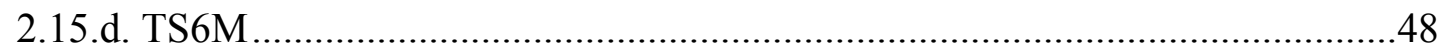

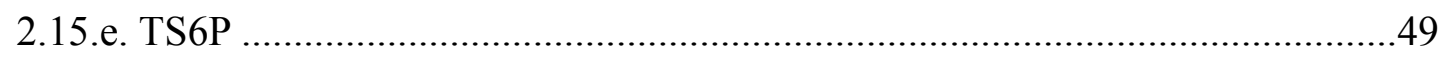

2.16. The $n$-alkane distributions (TIC) of selected vegetation species from the Florida

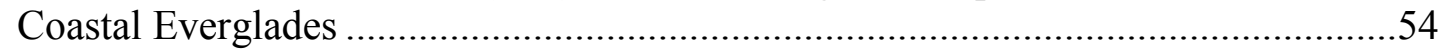

2.17. Spatial and seasonal changes in the $\mathrm{P}_{\mathrm{aq}}$ values of the floc samples .......................55

2.18. The $n$-alkene distribution for typical Everglades' vegetation samples ....................58

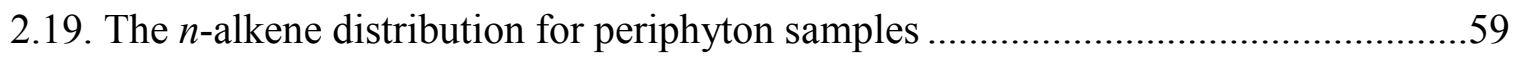

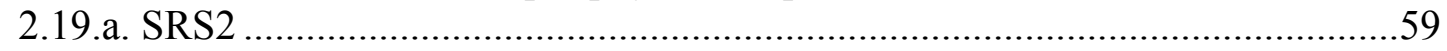

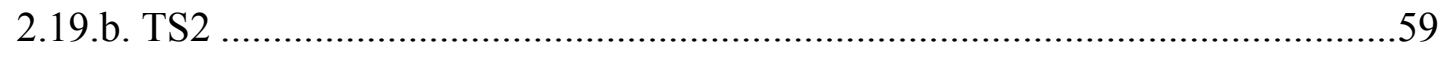

2.20. The $n$-alkene distribution for floc samples ...................................................60

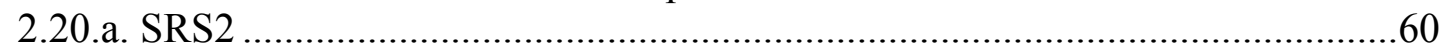

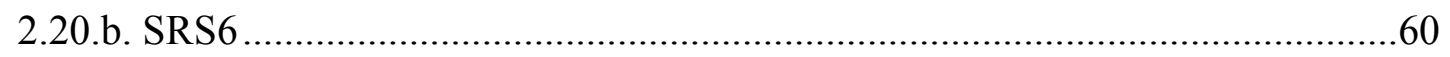

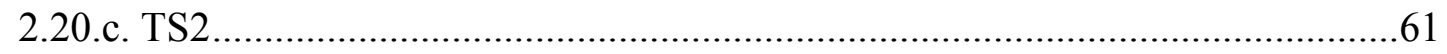

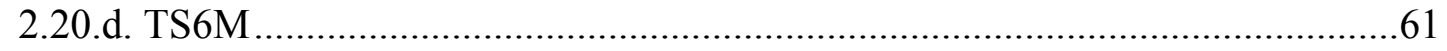

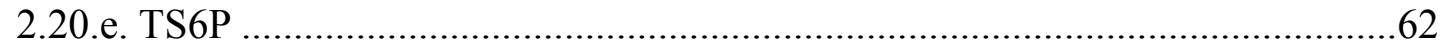

2.21. Concentrations of the $\mathrm{C}_{20} \mathrm{HBI}$ in periphyton mat samples.................................64

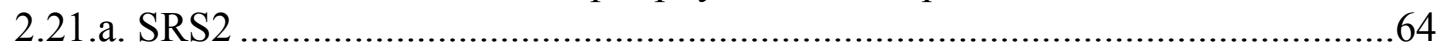

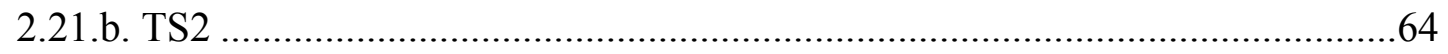

2.22. Spatial and seasonal distribution of the $\mathrm{C}_{20} \mathrm{HBI}$ in Everglades' floc samples........66

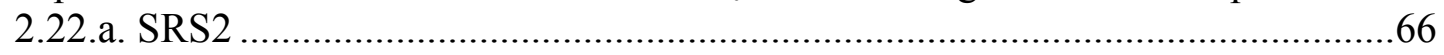

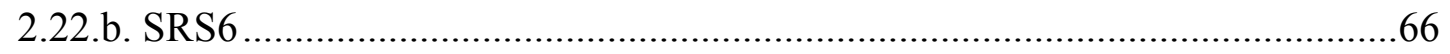

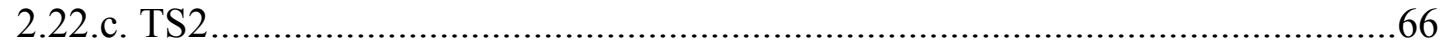


2.23. Seasonal changes in the $\mathrm{C}_{25: 3} \mathrm{HBI}$ concentrations in SRS6 floc

2.24. Seasonal changes in botryococcene concentration for SRS2 periphyton mat samples .70

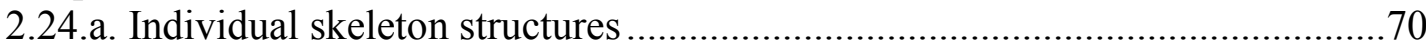

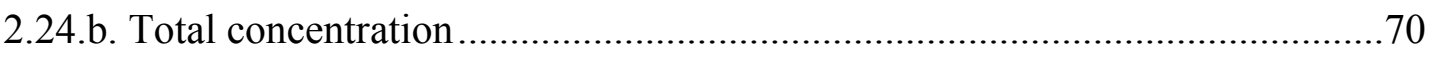

2.25. Molecular structure for the botryococcene compounds based on skeleton 3 ...........70

2.26. Seasonal distribution of total botryococcene concentration for three Everglades

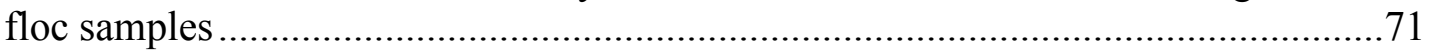

2.27. Seasonal changes in botryococcene concentration for SRS2 floc ...........................72

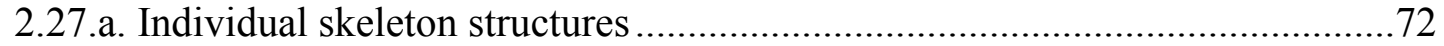

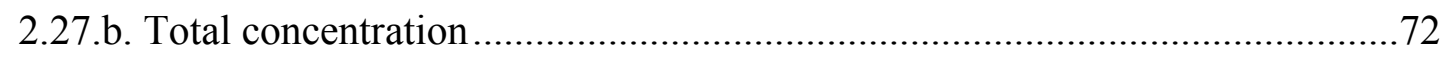

2.28. Spatial distribution of total kaurenes in Everglades' floc samples ...........................74

2.29. Correlations between the $\mathrm{C}_{20} \mathrm{HBI}$ and zeaxanthin .............................................76

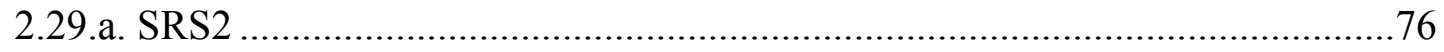

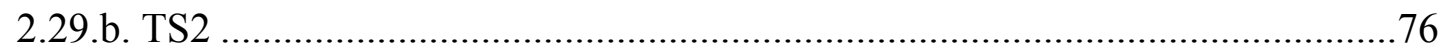

2.30. Correlations between the $\mathrm{C}_{20} \mathrm{HBI}$ and echinenone ……......................................77

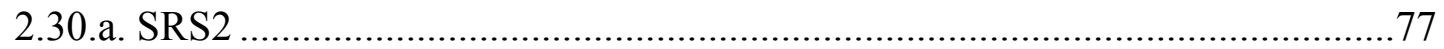

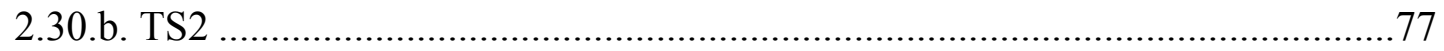

3.1. Florida Coastal Everglades map showing sampling site locations along the Shark

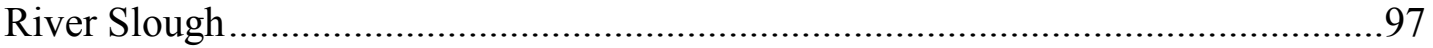

3.2. Photo-dissolution induced changes in DOC concentrations .......................................105

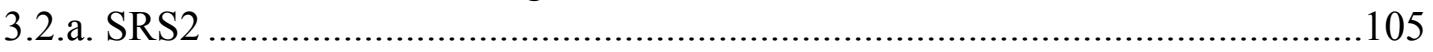

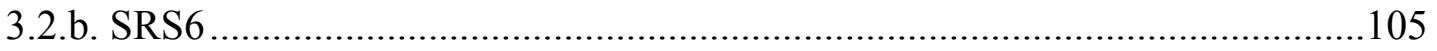

3.3. Photo-production of terrestrial humic- and protein-like components.......................110

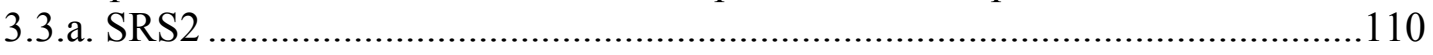

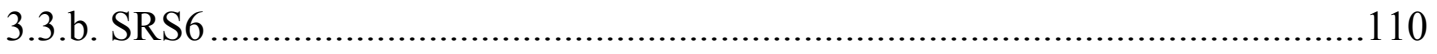

4.1. Map of south Florida showing the compartmentalization of the Everglades and the sampling site locations along the Shark River Slough and Taylor Slough ........125

4.2. Initial TOC content of the floc samples 
4.3. Spatial and seasonal differences in the cumulative $\mathrm{CO}_{2}$ produced from floc.

4.4. Example of the curvilinear relationship between the cumulative $\mathrm{CO}_{2}$ evolved from floc and incubation time

4.5. Significant correlation between $\mathrm{C} / \mathrm{N}$ and cumulative $\mathrm{CO}_{2}$ evolved from floc

4.6. Spatial and seasonal differences in the cumulative $\mathrm{CO}_{2}$ produced from floc amended with phosphorus and glucose

5.1. Geographic locations of the sampling sites along the south branch of the King's Creek watershed in Konza Prairie

5.2. Elemental and isotopic values of bulk organic matter from different sources 168

5.3. The $n$-alkane distributions of samples from the King's Creek watershed 175

5.3.a. Riparian vegetation .175

5.3.b. Grasses 176

5.3.c. Algae and moss 177

5.3.d. Sediments and soils 178

5.4. The branched $n$-alkane distributions of samples from the King's Creek watershed 179

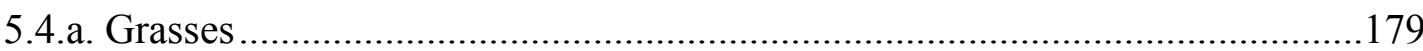

5.4.b. Algae 179

5.4.c. Sediments and soils 180

5.5. The $n$-alkene distributions of samples from the King's Creek watershed ................183

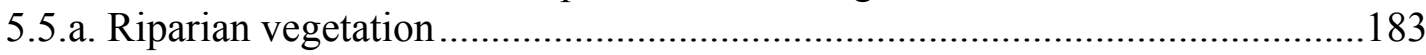

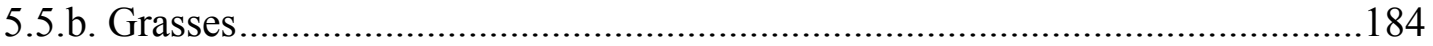

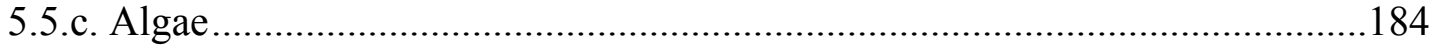

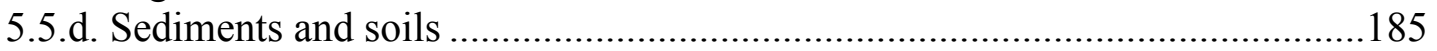

5.6. The phytadiene distributions of samples from the King's Creek watershed ............188

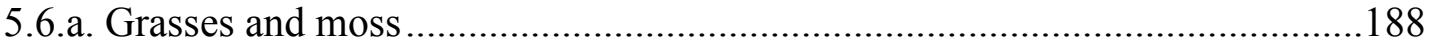

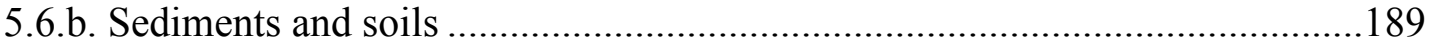

5.7. $\mathrm{C}_{25}$ highly branched isoprenoids in the stream sediments and the three algae samples

5.8. Oleanene distributions of samples from the King's Creek watershed

5.8.a. Total oleanenes

5.8.b. Oleanene relative percent

192


5.9. Hopene distributions of samples from the King's Creek watershed..........................194

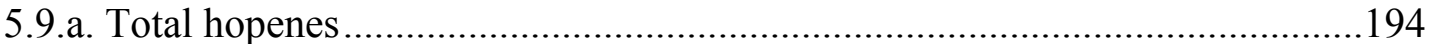

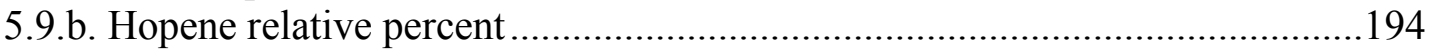

5.10. The $n$-alkan-2-one distributions of samples from the King's Creek watershed .....197

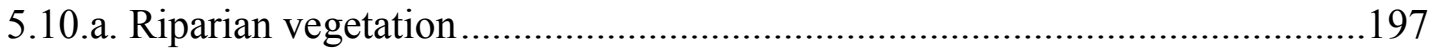

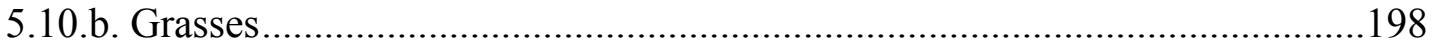

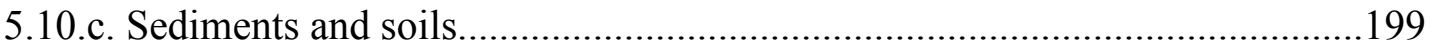

5.11. The $n$-alkanal distributions of samples from the King's Creek watershed.............203

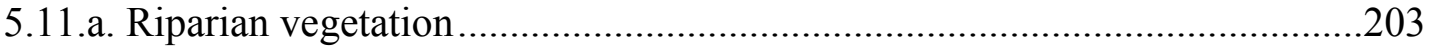

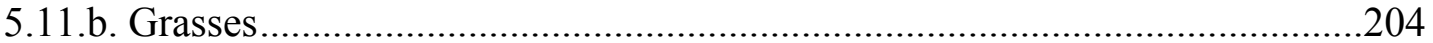

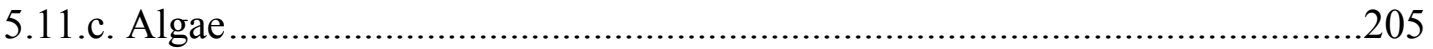

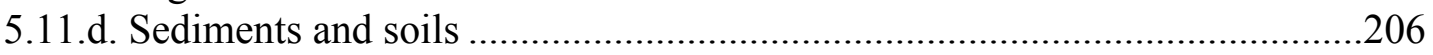

5.12. The $n$-alkanol distributions of samples from the King's Creek watershed.............208

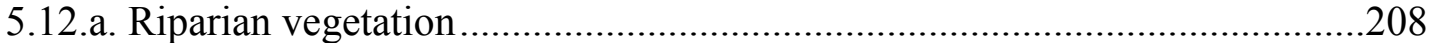

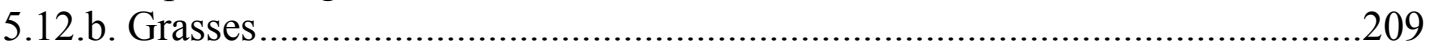

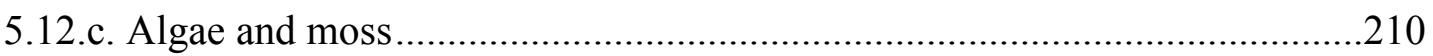

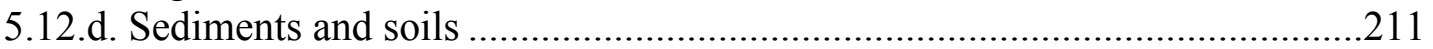

5.13. Total concentration of 3-oxy-triterpenoids of all the samples from the King's

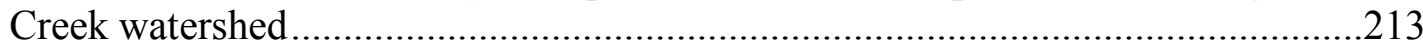

5.14. Total triterpenols in sediments and soils of the King's Creek watershed...............215

5.15. Percent triterpenols of the sediment and soil samples ........................................216

5.16. Total triterpenones in sediments and soils of the King's Creek watershed ............217

5.17. Percent triterpenones of the sediment and soil samples........................................218

5.18. Total sterol distribution in all the samples from the King's Creek watershed........219

5.19. Relative abundance of sterols for all the Konza Prairie samples............................220

5.20. Ternary plot showing the sterol distribution of the King's Creek vegetation, algae, sediment and soil samples

5.21. Long-chain $n$-alkane $\left(\mathrm{C}_{21}-\mathrm{C}_{33}\right)$ compound specific $\delta^{13} \mathrm{C}$ of the riparian vegetation, grass, algae and moss samples of the King's Creek watershed .225

5.22. Long-chain $n$-alkane $\left(\mathrm{C}_{21}-\mathrm{C}_{33}\right)$ compound specific $\delta^{13} \mathrm{C}$ of the sediment and soil samples of the King's Creek watershed .226 
6.1. Conceptual diagram of carbon fluxes from floc collected at SRS2 ......................240 
Chapter I

INTRODUCTION 


\subsection{Introduction:}

The Florida Coastal Everglades (FCE) is the largest subtropical wetland in the United States and covers approximately $7900 \mathrm{~km}^{2}$ from Lake Okeechobee to southern Florida (Richardson, 2009). A large portion of the Everglades is characterized by a ridge and slough landscape believed to have formed in response to a seasonal down slope flow from Lake Okeechobee to the Gulf of Mexico. Slight changes in topography have helped define the hydrological patterns and vegetation cover of this environment, such that the upstream marshes are dominated by freshwater species such as sawgrass (Cladium jamaicense), spikerush (Eleocharis cellulosa) and periphyton, and the coastal areas are dominated by mangroves and other salt tolerant species. Over the last century, anthropogenic activities and active water management (compartmentalization and drainage) have severely altered the original water flow. In addition, nutrient inputs from the Everglades Agricultural Areas (EAA) have changed the oligotrophic nature of this system (particularly in the northern Everglades) which is naturally phosphorus-limited. These activities have greatly affected the Everglades landscape as well as population and ecosystem-level dynamics.

With the aim of restoring the Everglades to their original state, the Comprehensive Everglades Restoration Plan (CERP; www.evergladesplan.org) provides a framework and guide to restore the timing, quality and quantity of water in South Florida, particularly in the Everglades. The restoration plan is expected to take approximately 30 years to complete and will cost an estimated 11.9 billion dollars. In conjunction with other state and government agencies and academic institutions, the 
Florida Coastal Everglades-Long Term Ecological Research (FCE-LTER) program has been trying to understand how the hydrologic changes brought about by the proposed restoration plan will affect ecosystem-level dynamics within the FCE. One of the central questions of FCE research asks how the supply (autochthonous or allochthonous) of particulate organic matter (POM) to the oligohaline ecotone varies seasonally, and how this supply is controlled by hydrological, ecological and climatological processes and their interaction. The proposed increase in water flow through CERP is hypothesized to increase the physical transport of POM to the coastal areas and this will enhance estuarine productivity.

Freshwater ecosystems have been recognized as important components of the global carbon cycle (Cole et al., 2007) and the fluvial export of organic carbon to the ocean has been estimated to be $0.53 \mathrm{Pg} \mathrm{C}_{\text {year }}{ }^{-1}$ (Stallard, 1998). Although these annual fluxes are smaller (about $25 \%$ ) compared to the other components of the global carbon cycle, they play an important role in estuarine and coastal ecological processes (Hopkinson et al., 1995). The flux of material from coastal wetlands to the ocean has also received much attention and its significant influence on coastal productivity has been well recognized (Odum, 1984; Childers et al., 2000; Sutula et al., 2003).

In the FCE ecosystem, most of the POM is not suspended in the water column and instead, is found as a flocculent layer ("floc") above the sediment/soil surface (Noe et al., $2007 a$; Larsen et al., 2009). It is now known that the majority of the phosphorus in this ecosystem is stored in soils and floc and that much of the nutrient cycling is controlled by floc (Noe et al., 2007b). Furthermore, floc is believed to be the basis of food web dynamics in the FCE (Williams et al., 2006). However, not much is known about the 
biogeochemistry of this material (i.e., sources and reactivity). Because floc moves primarily as bed load (Larsen et al., 2009) it is expected that an increase in freshwater inflow will increase the physical transport of floc to the oligohaline ecotone, which might enhance estuarine productivity. The quality of these allochthonous detrital inputs is expected to be controlled by upstream ecological processes. The term "organic matter quality" is generally used in the sense of its biodegradability and ability to support microbial growth (Hopkinson et al., 1998), or as a measure of substrate availability to decomposers (Joffre et al., 2001). In this particular study, the terms "organic matter quality" and "floc quality" were used to describe the composition (sources) and reactivity (photo- and bio-reactivity) of this material in the FCE ecosystem.

To gain a better understanding of the biogeochemistry of this important ecosystem component, the objective of this project was to investigate the quality of floc by determining its biological sources and reactivity on spatial and temporal scales throughout the Florida Coastal Everglades. Specifically, the objectives of this work were to molecularly characterize the OM sources of floc through the use of biomarkers (lipids) and pigment-based chemotaxonomy to assess specific biomass inputs. An attempt was also made to correlate these measurements with similar ones in live periphyton. The distributions of biomass-specific lipid and pigment components in floc will be discussed in chapter 2. To further investigate the dynamics of floc in the FCE, two reactivity studies were performed, a photo- and a bio-reactivity study. The photo-reactivity of floc was determined by quantitatively and qualitatively measuring the dissolved organic matter generated upon solar exposure of this material with the use of UV-Visible and fluorescence spectroscopy. Finally, the bio-reactivity of floc was estimated by 
determining floc respiration through measuring the rate and the cumulative amount of $\mathrm{CO}_{2}$ evolution from incubated floc samples. The effects of phosphorus limitation and floc carbon quality on this process were also investigated. The results of these reactivity studies are discussed in detail in chapters 3 and 4, respectively.

Freshwater ecosystems have been recognized as important quantitative components of the global carbon cycle (Cole et al., 2007; Battin et al., 2009). Globally, these ecosystems receive on the order of $1.9 \mathrm{Pg} \mathrm{C}_{\text {year }}{ }^{-1}$ from the terrestrial landscape of which approximately $0.9 \mathrm{Pg} \mathrm{C}$ year $^{-1}$ is delivered to the oceans (Cole et al., 2007). The transfer of large amounts of dissolved and particulate matter in rivers and streams from terrestrial to estuarine and marine environments is well recognized as an important link in global biogeochemical cycles (Walsh, 1991; Ouyang, 2003; Dagg et al., 2004). Although there have been many studies and improved knowledge on the fluvial fluxes of materials, most commonly only the larger world rivers have usually been taken into account (Meybeck et al., 2003). In fact, not much is known about the dynamics of small headwater streams although their ecological importance has been recognized (Farnsworth et al., 2003; Dodds et al., 2004). Recent studies have reported on the biomarker composition of small stream sediments to assess the relative contribution of OM from autochthonous and allochthonous sources (Jaffé et al., 2001; Mead et al., 2005; Medeiros et al., 2008).

With this in mind, the objective of this project was to characterize the autochthonous and allochthonous sources of OM to small prairie stream sediments in order to assess carbon dynamics in intermittent streams with potential OM inputs from adjacent grasslands, riparian forests and autochthonous plankton production. The King's 
Creek watershed, located in Konza Prairie (Kansas) was selected for this study. The vegetation surrounding these headwater streams is characterized by $\mathrm{C}_{4}$ grasses in the watershed and $\mathrm{C}_{3}$ vascular plants in the riparian area. An attempt was made to distinguish the OM inputs from these different areas by combining the analyses of molecular markers and compound specific stable carbon isotopes. The results of this study will be presented in chapter 5 . 


\section{REFERENCES:}

Battin, T. J., S. Luyssaert, L. A. Kaplan, A. K. Aufdenkampe, A. Richter and L. J. Tranvik. 2009. The boundless carbon cycle. Nature Geoscience 2: 598-600.

Childers, D. L., J. W. Day and H. N. McKellar. 2000. Twenty more years of marsh and estuarine flux studies: revisiting Nixon (1980). In: M. P. Weinstein, D. Q. Kreeger (Eds.), Concepts and controversies in tidal marsh ecology, pp. 385-414.

Cole, J. J., Y. T. Prairie, N. F. Caraco, W. H. McDowell, L. J. Tranvik, R. G. Striegl, C. M. Duarte, P. Kortelainen, J. A. Downing, J. J. Middelburg and J. Melack. 2007. Plumbing the global carbon cycle: Integrating inland waters into the terrestrial carbon budget. Ecosystems 10: 171-184.

Dagg, M., R. Benner, S. Lohrenz and D. Lawrence. 2004. Transformation of dissolved and particulate materials on continental shelves influenced by large rivers: Plume processes. Continental Shelf Research 24: 833-858.

Dodds, W. K., K. Gido, M. R. Whiles, K. M. Fritz and W. J. Matthews. 2004. Life on the edge: The ecology of Great Plains prairie streams. Bioscience 54(3): 205-216.

Farnsworth, K. L. and J. D. Milliman. 2003. Effects of climatic and anthropogenic change on small mountainous rivers: the Salinas River example. Global and Planetary Change 39: 53-64.

Hopkinson, C. S. and J. Vallino. 1995. The nature of watershed perturbations and their influence on estuarine productivity. Estuaries 18: 598-621.

Hopkinson, C. S., I Buffam, J. Hobbie, J. Vallino, M. Perdue, B. Eversmeyer, F. Prahl, J. Covert, R. Hodson, M. A. Moran, E. Smith, J. Baross, B. Crump, S. Findlay and K. Foreman. 1998. Terrestrial inputs of organic matter to coastal ecosystems: An intercomparison of chemical characteristics and bio-availability. Biogeochemistry 43: 211234.

Jaffé, R., R. Mead, M. E. Hernandez, M. C. Peralba, and O. A. DiGuida. 2001. Origin and transport of sedimentary organic matter in two subtropical estuaries: a comparative, biomarker-based study. Organic Geochemistry 32: 507-526.

Joffre, R., G. I. Agren, D. Gillon and E. Bosatta. 2001. Organic matter quality in ecological studies: theory meets experiment. Oikos 93: 451-458.

Larsen, L. G., J. W. Harvey and J. P. Crimaldi. 2009. Morphologic and transport properties of natural organic floc. Water Resources Research 45: W01410, doi: 10.1029/2008WR006990. 
Mead, R., Y. Xu, J. Chong and R. Jaffé. 2005. Sediment and soil organic matter source assessment as revealed by the molecular distribution and carbon isotopic composition of n-alkanes. Organic Geochemistry 36: 363-370.

Medeiros, P. M. and B. R. T. Simoneit. 2008. Multi-biomarker characterization of sedimentary organic carbon in small rivers draining the Northwestern United States. Organic Geochemistry 39: 52-74.

Meybeck, M., L. Laroche, H. H. Dürr and J. P. M. Syvitski. 2003. Global variability of daily total suspended solids and their fluxes in rivers. Global and Planetary Change 39: 65-93.

Noe, G. B., J. W. Harvey and J. E. Saiers. 2007a. Characterization of suspended particles in Everglades wetlands. Limnology and Oceanography 52(3): 1166-1178.

Noe, G. B. and D. L. Childers. 2007. Phosphorus budgets in Everglades wetland ecosystems: The effects of hydrology and nutrient enrichment. Wetlands Ecology and Management 15: 189-205.

Odum, E. P. 1984. The status of three ecosystem-level hypotheses regarding salt marsh estuaries: Tidal subsidy, outwelling and detrital-based food chains. In: V. S. Kennedy (Ed.), Estuarine Perspectives, Academic Press, New York, pp. 265-286.

Ouyang, Y. 2003. Simulating dynamic load of naturally occurring TOC from watershed into a river. Water Research 37: 823-832.

Richardson, C. J. 2009. The Everglades: North America's subtropical wetland. Wetlands Ecology and Management, doi: 10.1007/s11273-009-9156-4.

Stallard, R. F. 1998. Terrestrial sedimentation and the C cycle: Coupling weathering and erosion to carbon storage. Global Biogeochemical Cycles 12: 231-237.

Sutula, M. A., B. C. Perez, E. Reyes, D. L. Childers, S. Davis, J. W. Day, Jr., D. Rudnick and F. Sklar. 2003. Factors affecting spatial and temporal variability in material exchange between the Southern Everglades wetlands and Florida Bay (USA). Estuarine, Coastal and Shelf Science 57: 757-781.

Walsh, J. J. 1991. Importance of continental margin in the marine biogeochemical cycling of carbon and nitrogen. Nature 350: 53-55.

Williams, A. J. and J. C. Trexler. 2006. A preliminary analysis of the correlation of foodweb characteristics with hydrology and nutrient gradients in the southern Everglades. Hydrobiologia 569: 493-504. 
Chapter II

MOLECULAR CHARACTERIZATION OF FLOCCULENT MATERIAL IN THE FLORIDA COASTAL EVERGLADES 


\subsection{Introduction:}

The Florida Coastal Everglades (FCE) is the largest subtropical wetland in the United States covering about $6200 \mathrm{~km}^{2}$ of the South Florida peninsula (Rudnick et al., 1999). The FCE includes extensive fresh and saltwater areas, open prairies and mangrove forests. The characteristic sheet flow of water drains from Lake Okeechobee to the south (Florida Bay) and southwest (Gulf of Mexico) through two main shallow sloughs, namely Taylor Slough and Shark River Slough, respectively. The climatic template of the Everglades is subtropical, characterized by intense wet seasons (June-November) which deliver about $80 \%$ of the total annual precipitation (Childers et al., 2006). Because of the low slope of this landscape, slight changes in elevation can play large roles in the hydrology of a particular location (David, 1996). The duration and depth of flooding (referred to as hydroperiod) have been suggested to be the major hydrologic factor controlling plant distribution (Gunderson, 1994). In fact, typical plant communities of the interior freshwater marshes vary from extensive areas of sawgrass (Cladium jamaicense) in the higher ridges, and spikerush (Eleocharis cellulosa) in the deeper sloughs (Todd et al., 2010). The coastal fringe is characterized by dense mangrove forests. Another important biomass component of the Everglades is calcareous periphyton which can coat vegetation (epiphytic mats) and bottom sediments/soils (benthic mats) (Loveless, 1959), or can grow as thick metaphytic mats (floating mats) on the water surface (Gleason et al., 1974). The term calcareous is used to identify an association of algal filaments with calcium carbonate $\left(\mathrm{CaCO}_{3}\right)$ crystals.

The FCE is a highly oligotrophic system characterized by P-limitation in the freshwater marshes and N-limitation in the coastal fringes. The area where the N-rich 
freshwater mixes with the P-rich coastal water (oligohaline zone), is the most ecologically productive in this environment (Childers et al., 2006). It is believed that the major portion of bio-available nutrients in the FCE is in the organic form, found either as dissolved (DOM) or particulate organic matter (POM; Rudnick et al., 1999). Suspended particulates are not very abundant in the freshwater marshes of the FCE (Childers et al., 2006). Instead, the majority of the POM occurs at the sediment-water interface as flocculent material (floc). The material has a very low bulk density and is typically found as a nearly neutrally buoyant organic layer just above the sediment/soil surface (Leonard et al., 2006). The loosely consolidated floc layer is rarely suspended and forms a relatively static layer over the sediment (soil) bed (Larsen et al., 2009a). These authors found that the low bed shear stress that characterizes the Everglades is near the floc entrainment threshold $\left(1.0 \times 10^{-2} \mathrm{~Pa}\right)$ and so floc dynamics in this environment are transport-limited rather than supply-limited. The transport of this material is governed by the balance between entrainment and settling fluxes which can have direct implications for ecosystem metabolism, materials cycling and landscape evolution (Larsen et al. 2009a).

In general terms, flocculent material or floc represents a complex matrix of microorganisms (generally bacteria), organic particles (higher plant detritus and extracellular polymers), inorganic particles (clays and silts) and substantial inter-floc spaces (pores) as defined by Droppo (2001). The detrital material is an important component of many aquatic ecosystems and may control a variety of biogeochemical processes and food web dynamics. For instance, floc can serve as a habitat for small animals, providing shelter, refugia and breeding sites (Moore et al., 2004). It can regulate 
the overall water quality through physical and/or chemical processes, such as the sorption of nutrients and contaminants on the aggregate surfaces (Ongley et al., 1992). The floc layer can contain large and diverse populations of resident microbes and provide a labile source of carbon to the water column and/or benthos (Simon et al., 2002). Finally, floc can act as a source of organic/inorganic materials to wetland soil/sediment formation (Neto et al., 2006). This process is particularly important in the short-hydroperiod freshwater marshes of the FCE where the incorporation of floc into soils/sediments has been suggested to occur through consolidation during the dry season (Neto et al., 2006). In addition, the redistribution of floc by flowing water has been suggested to regulate the development of this wetland's topography, particularly the ridge and slough landscape (National Research Council, 2003; Larsen et al., 2007), which characterizes much of the freshwater marsh areas of the FCE.

Detrital material, such as floc, has been recognized as a source of energy and nutrients to living organisms in most food webs of aquatic environments (Moore et al., 2004). In the wetlands of the FCE, detritus is expected to play a dominant role in carbon and energy flows. Noe et al. (2003) found that floc is a strong regulator of phosphorus cycling in this oligotrophic environment. Noe et al. (2002) tested the response of several ecosystem components to continuous, low-level phosphorus additions. These authors found that added phosphorus was taken up quickly by suspended floc materials and suggested that this component can play an important role in the biogeochemistry of ecosystem P cycling. Furthermore, floc may be responsible for nutrient transport and cycling via spiraling and microbial activity (Noe et al., 2001). Due to these facts, floc has been suggested to be ecologically important and a bio-available substrate to the 
Everglades' food web ( White et al., 2000; Neto et al., 2006; Williams et al., 2006). However, while much information is available on the physical properties and biogeochemistry of floc particles in fluvial systems (Droppo et al., 1994; Droppo et al., 1997; Droppo et al., 2001), not much is known about the dynamics (i.e. sources and reactivity) of the more organic-enriched floc found in the Everglades.

In the Everglades, floc has been defined as a heterogeneous mixture containing senescing periphyton, decaying macrophyte tissue, soil particles, algae and bacteria (DeBusk et al., 2001; Noe et al., 2003). A biomarker-based study by Neto et al. (2006) showed that floc composition in the FCE is regulated regionally by local vegetation inputs, particularly from periphyton, emergent and submerged plants and terrestrial plant detritus such as mangroves. The authors also found molecular evidence for different degrees of diagenetic reworking of OM and from potential fungal activity. Neto et al. (2006) suggested that the physical transport, incorporation and degradation of OM in floc may be controlled by several factors including hydroperiod, primary productivity, nutrient availability and OM quality, among others. However, they suggest that the dynamics of floc in the FCE are quite complex. Other recent studies have tried to determine the sources of the OM in Everglades' floc. Using an isotopic approach, Troxler et al. (2009) determined that Utricularia species are the primary organic source for flocculent materials in deep water sloughs. Furthermore, Gao et al. (2007) detected novel isoprenoid compounds known as botryococcenes in floc from the FCE and attributed their source to filamentous green algae. However, still very little is known about the sources and dynamics of floc in this environment. 
Water flow in most of the Everglades $\left(0.11\right.$ to $\left.0.50 \mathrm{~cm} \mathrm{~s}^{-1}\right)$ is too slow to entrain significant quantities of floc (Larsen et al., 2009a). Instead, floc is suspended via biological activity in the water column such as bio-turbation from Gambusia holbrooki (mosquito fish) activity, which tends to be highly localized (Larsen et al., 2009b). In addition, floc can be mobilized through storms. While these dynamics suggest that minimal floc transport occurs between the freshwater marshes and coastal mangrove areas, several recent studies (Jaffé et al., 2001; Jaffé et al., 2006) reported on the presence of periphyton and/or floc-derived remains in sedimentary OM in sub-tropical estuaries of the Everglades, suggesting some longer term floc transport to occur. Neto et al. (2006) also provided evidence for the hydrodynamic transport of floc materials. The upcoming restoration efforts brought about by the Comprehensive Everglades Restoration Plan (CERP; www.evergladesplan.org) propose to increase water flow through the entire system, potentially affecting both floc transport and associated biogeochemical dynamics of organic matter in the FCE. This increase in floc transport may be particularly important because the redistribution of floc by flowing water is thought to regulate the development of this wetland's topography which is critical to ecosystem function (National Research Council, 2003; Larsen et al., 2007). Furthermore, an increased transport of detrital OM to the oligohaline ecotone may enhance estuarine productivity (FCE-LTER II proposal; fcelter.fiu.edu).

To obtain a better understanding of Everglades' floc dynamics, the main objective of this study was to determine differences in floc OM composition on both spatial (freshwater marsh vs. mangrove estuary) and temporal (wet vs. dry season) scales. The source characterization of floc OM was carried out through the use of molecular markers 
or biomarkers, while pigment chemotaxonomy was applied for the assessment of recent planktonic inputs to the floc layer. Another objective of this study was to develop possible correlations between specific biological markers that have been detected in floc (specifically, the $\mathrm{C}_{20}$ highly branched isoprenoid and the botryococcene hydrocarbons) and fresh algal components of periphyton mats in order to better quantify OM inputs to floc. In addition, because the occurrence of these compounds is widespread in the FCE and their exact sources are uncertain, this study may allow us to determine their specific biological precursors in this environment.

\subsection{Methods:}

\subsubsection{Sample collection:}

Floc samples were collected along the two main drainage basins of the FCE, namely Shark River Slough (SRS) and Taylor Slough (TS) at sites that have previously been described by the ongoing Florida Coastal Everglades Long Term Ecological Research program (FCE-LTER; fcelter.fiu.edu). Two sites were chosen in freshwater marshes, where SRS2 represents a long-hydroperiod site which is dominated by emergent vegetation such as sawgrass (Cladium jamaicense), Gulf Coast Spikerush (Eleocharis cellulosa) and abundant periphyton mats, typically associated with the Purple Bladderwort (Utricularia purpurea; Gottlieb et al., 2006). In contrast, the other site, TS2, represents a short-hydroperiod, marl prairie site and it is dominated by sawgrass and periphyton mats which are directly associated with the calcium carbonate bedrock (Gottlieb et al., 2006). 
Another two sites were chosen to represent mangrove-dominated estuarine areas. Here the SRS6 site is tidally influenced and located adjacent to the Gulf of Mexico (Childers et al., 2006) and the vegetation is characterized by a mixture of white (Laguncularia racemosa), black (Avicennia germinans) and red mangroves (Rhizophora mangle). The other site, TS6, is located at the mouth of Taylor River, draining into Florida Bay. The TS6 site receives seasonal inputs from an increased freshwater discharge occurring during the wet season and little-to-no water flow during the dry season and saltwater intrusions from Florida Bay during the peak dry season (Davis et al., 2003). The vegetation is composed mainly of dwarf $(<2 \mathrm{~m})$ red mangroves (Ewe et al., 2006). To further determine the contribution of mangrove detritus to the floc, two samples were collected at TS6; (a) TS6M was collected in the dwarf mangrove forest in an area which is also dominated by Saltwort (Batis maritima); (b) TS6P was collected in the middle of a small pond, surrounded by mangroves, but which is also characterized by highly abundant submerged vegetation, such as Muskgrass (Chara). Site locations are shown in Figure 2.1.

Quarterly floc samples were collected from 2007 to 2009, following the methods described by Neto et al. (2006). Briefly, floc samples were collected using a transparent plastic corer (inner diameter of $2.5 \mathrm{~cm}$ ) which was pushed about $10 \mathrm{~cm}$ below the soil/sediment surface. The corer was capped at the top end to create suction and retrieved. The floc and soil/sediment layers were visible in the transparent corer. A plunger with a slightly smaller diameter to that of the core tube was inserted and pushed through the floc until it was resting on top of the consolidated soil/sediment layer. With the plunger still in place, excess water was removed and the corer was tilted to decant the floc into clean, 1 
L Teflon jars. This procedure was repeated at several randomly selected locations at each site enough times to obtain about $1 \mathrm{~L}$ of floc composite for each sampling event. For this sampling protocol, the definition of floc as consisting mostly of decaying macrophyte tissue, soil particles, algae and bacteria (DeBusk et al., 2001), was adopted. All easily suspended materials, potentially including benthic periphyton, resting on top of the consolidated soil/sediment layer in the core were considered part of the floc. Periphyton samples (benthic, epiphytic and metaphytic) from the freshwater sites were also sampled separately and placed in clean zip-lock bags. Plant samples, representative of the local dominant vegetation, were cut from the plant and placed in clean zip-lock bags. All samples were transported to the laboratory on ice where they were frozen and freezedried. The samples were ground and stored in a freezer until prepared for the extraction procedures described below.

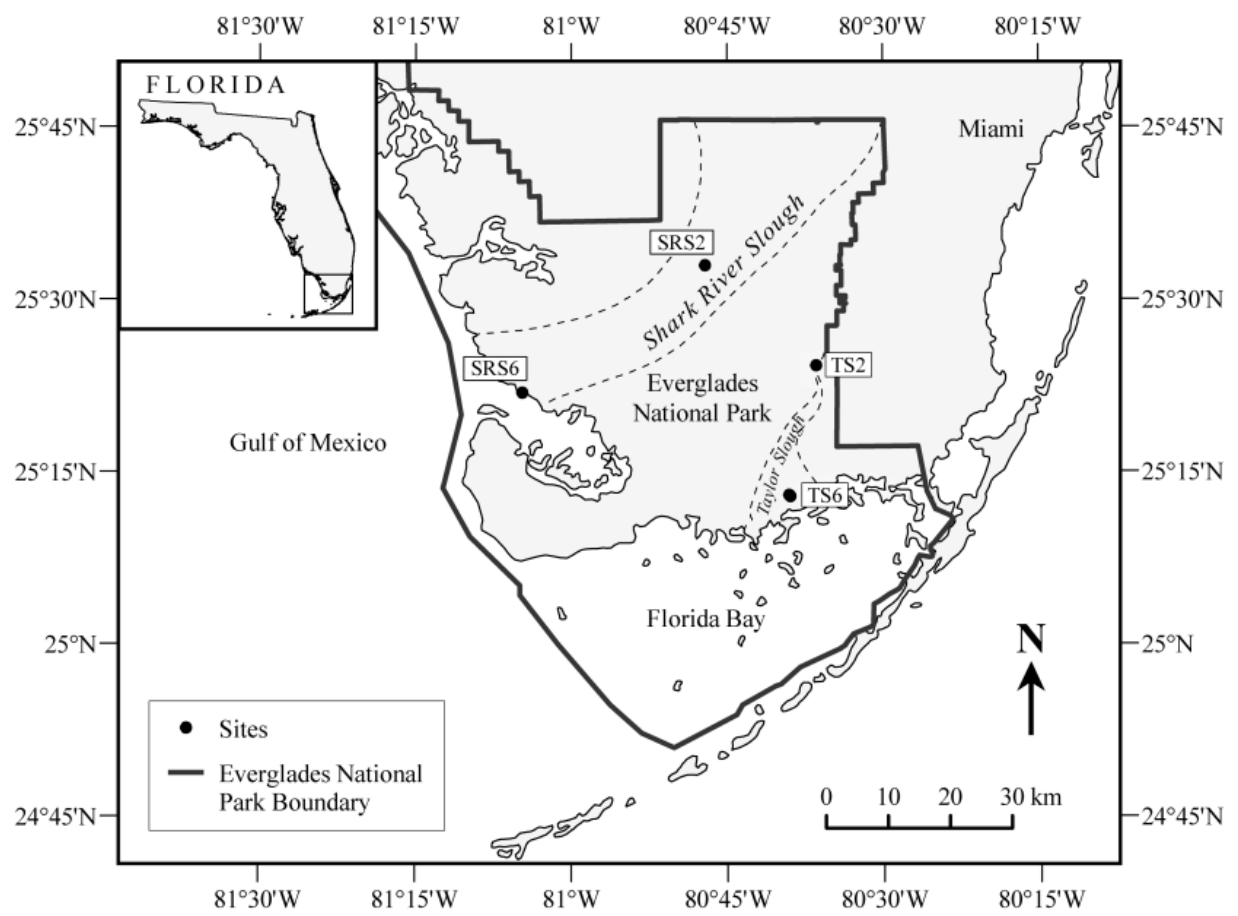

Figure 2.1. Geographic locations of the sampling sites along the Shark River Slough and Taylor Slough in Everglades National Park. 


\subsubsection{Bulk parameters:}

During each sampling event, floc depth was obtained by measuring the sediment and floc height in the core. After the removal of the floc layer, the sediment height was measured again. Floc depth was obtained by subtracting the initial and final height measurements of the material in the corer. Floc bulk density was also measured for all quarterly samples. Floc density was obtained by using the following equations:

Floc bulk density $=$ floc dry weight $(\mathrm{g}) /$ floc volume $\left(\mathrm{cm}^{3}\right)$

The floc dry weight was the weight of the floc obtained after freeze-drying. The floc volume was obtained by using the formula for the volume of a cylinder:

$$
\text { Floc volume }=\pi \mathrm{r}^{2} \mathrm{~h}
$$

where $\pi$ is 3.14 , $\mathrm{r}$ is the radius $(1 / 2$ of i.d.) of the core $(1.25 \mathrm{~cm})$ and $\mathrm{h}$ is the floc height measured in the field $(\mathrm{cm})$.

A subsample was used to obtain the ash free dry weight (AFDW) and the \% organic matter $(\% \mathrm{OM})$ content. Subsamples were dried at $70{ }^{\circ} \mathrm{C}$ to determine the sample dry mass and ashed at $500{ }^{\circ} \mathrm{C}$ for 5 hours to determine the AFDW. The percent OM $(\% \mathrm{OM})$ was obtained by using the following relationships:

$$
\begin{gathered}
\% \operatorname{AFDW}=[\operatorname{AFDW}(\mathrm{g}) / \text { total sample dry mass }(\mathrm{g})] \times 100 \\
\% \mathrm{OM}=100 \%-\% \text { AFDW }
\end{gathered}
$$

\subsubsection{Biomarker analysis:}

Aliquots of freeze-dried floc/periphyton/vegetation samples $(0.5-1.5 \mathrm{~g})$ were Soxhlet extracted with $350 \mathrm{~mL}$ of pure dichloromethane $\left(\mathrm{CH}_{2} \mathrm{Cl}_{2}\right)$ for 24 hours. Activated copper was added to the sample extract to remove elemental sulfur. The extracts were 
concentrated to about $5 \mathrm{~mL}$ on a rotary evaporator and further reduced to about $1 \mathrm{~mL}$ final volume under a stream of nitrogen gas. The total extracts were separated into neutral and acid fractions by saponification using $25 \mathrm{~mL}$ of freshly prepared $1 \mathrm{~N} \mathrm{KOH}$. Anhydrous sodium sulfate $\left(\mathrm{Na}_{2} \mathrm{SO}_{4}\right)$ was added to the resulting fractions to eliminate traces of water (12 hours). The fractions were concentrated on a rotary evaporator and reduced to about $1 \mathrm{~mL}$ under a stream of nitrogen gas. The neutral fraction was further fractionated using silica-gel adsorption chromatography ( $7 \mathrm{~g}$ of $5 \%$ deactivated silica gel, 100-200 mesh, Fisher Scientific) to obtain a total of eight fractions. Only the aliphatic ( $20 \mathrm{~mL}$ hexane) and the aromatic $(15 \mathrm{~mL}$ hexane, $5 \mathrm{~mL}$ toluene) hydrocarbon fractions were analyzed in this study by gas chromatography/mass spectrometry (GC/MS).

An aliquot of $1 \mu \mathrm{L}$ of sample extract was analyzed by GC/MS on an HP $6890 \mathrm{GC}$ coupled with an HP 5730 quadrupole mass selective detector. The GC was fitted with a DB1-MS capillary column ( $30 \mathrm{~m}$ x $0.25 \mathrm{~mm}$ i.d. $\mathrm{x} 0.25 \mu \mathrm{m}$ film thickness) using helium as the carrier gas (flow rate; $1.2 \mathrm{~mL} \mathrm{~min}^{-1}$ ). The $\mathrm{GC}$ oven temperature was kept at $60{ }^{\circ} \mathrm{C}$ for 1 minute, ramped to $300{ }^{\circ} \mathrm{C}$ at a rate of $6{ }^{\circ} \mathrm{C} \mathrm{min}^{-1}$ and held at $300{ }^{\circ} \mathrm{C}$ for 20 minutes. The column was fed directly into the EI source which was operating at an ionization potential of $70 \mathrm{eV}$. The injector temperature was maintained at $280^{\circ} \mathrm{C}$. Samples were injected in the splitless mode (splitless time; 2 minutes) and the mass scan range was set from 50 to $550 \mathrm{Da}$ at a rate of 2.94 scans per second.

The identification of compounds was achieved by comparison with reported mass spectra of authentic standards and with the mass spectral library on the GC/MS data system. All compounds were quantified using the total ion current (TIC) peak area and 
converted to compound mass with the addition of a known amount of internal standard (Squalane; 2,6,10,15,19,23-hexamethyl-tetracosane). Blanks were run between samples showing no background interferences.

\subsubsection{Pigment analysis:}

All sample handling and pigment analyses were performed under dim yellow light conditions to prevent photo-oxidative alteration and isomerization of pigments. Aliquots of freeze-dried floc/periphyton samples (0.2-0.5 g) were extracted according to Hagerthey et al. (2006). Briefly, samples were extracted using $3 \mathrm{~mL}$ of a solvent mixture of methanol/acetone/dimethylformamide/water (MADW; 30:30:30:10, v/v/v/v) containing a known amount of a procedural internal standard (Cu-mesoporphyrin-IXDME). The pigment extractions were performed by grinding $(350-500 \mathrm{rpm})$ at ice bath temperature $\left(\sim 2-3{ }^{\circ} \mathrm{C}\right)$ in a Teflon/glass homogenizer (Kontes "Duall", $\left.5 \mathrm{~mL}\right)$ that had previously been stored in a freezer. The extractant was sonicated in an ice bath for 20-30 seconds and then allowed to steep (soak) at $2-3{ }^{\circ} \mathrm{C}$ for 1 hour. Extracts were recovered by centrifugation and subsequently filtered through a $0.45 \mu \mathrm{m}$ syringe filter. The UV/Vis of the extract was recorded on a Perkin- Elmer Lambda-2 spectrometer (350-800 nm) for an initial assessment of the total pigment yield (Jeffrey et al., 1997).

The sample for reverse-phase high performance liquid chromatography (RPHPLC) was prepared using $1 \mathrm{~mL}$ of filtered extract and $0.125 \mathrm{~mL}$ of an ion pairing solution (ammonium acetate plus tetrabutylammonium acetate prepared according to Mantoura et al., 1983). Lipophilic pigments, chlorophylls and carotenoids were separated by RP-HPLC coupled to full-spectral (190-800 $\mathrm{nm}$ ) photodiode array (PDA) detection. 
RP-HPLC was performed using a $3.9 \times 150 \mathrm{~mm}$ Waters NovaPak 4-micron C18 column, developed with a ternary gradient (Table 2.1). Sample extracts were loaded and injected using a Rheodyne 7125 injector and the solvents were delivered with a ThermoSeparations Products Model 4100 quaternary HPLC pump at $1 \mathrm{~mL}$ per minute.

Table 2.1. Solvent profile used for RP-HPLC. Solvents: "A" $=0.5 \mathrm{M}$ ammonium acetate in methanol/water $(85: 15, \mathrm{v} / \mathrm{v})$; "B" = acetonitrile/water $(90: 10, \mathrm{v} / \mathrm{v}) ; " \mathrm{C} "=$ ethyl acetate.

\begin{tabular}{lccc}
\hline $\begin{array}{l}\text { Time } \\
\text { (minutes) }\end{array}$ & $\begin{array}{c}\text { Solvent } \\
\text { "A" }\end{array}$ & $\begin{array}{c}\text { Solvent } \\
\text { "B" }\end{array}$ & $\begin{array}{c}\text { Solvent } \\
\text { "C" }\end{array}$ \\
\hline 0 & 60 & 40 & 0 \\
5 & 60 & 40 & 0 \\
10 & 0 & 100 & 0 \\
40 & 0 & 30 & 70 \\
45 & 0 & 30 & 70 \\
46 & 0 & 0 & 100 \\
47 & 0 & 100 & 0 \\
48 & 60 & 40 & 0 \\
\hline
\end{tabular}

The quantization of the individual pigments relied on the Beer-Lambert relation and peak areas at the appropriate wavelength $(440 \mathrm{~nm}=$ chlorophylls and carotenoids, $410 \mathrm{~nm}=$ pheopigments, $394 \mathrm{~nm}=$ internal standard and $360 \mathrm{~nm}=$ bacteriochlorophylls $)$ were divided by an extinction coefficient as described in the literature (Jeffrey et al., 1997). The equation which was used for the estimation of algal division contributions (cyanobacteria/chlorophytes/diatoms/dinoflagellates/cryptophytes) to the samples is as follows:

$$
\begin{gathered}
\Sigma \mathrm{CHL} a=\left(\left[1.1 \times \mathrm{ZEA}^{*}\right]+[11 \times \mathrm{ECH}]\right)+(3.2 \times \mathrm{CHL} b)+(1.2 \times \mathrm{FUCO})+(1.5 \times \mathrm{PERI}) \\
+(3.8 \times \mathrm{ALLO})
\end{gathered}
$$


Where ZEA* is the amount of zeaxanthin corrected for ZEA contributions (= [ZEA]-[ECH]) from echinenone (ECH) containing cyanobacteria, $\mathrm{CHL} b$ is chlorophyll- $b$ (chlorophytes), FUCO is fucoxanthin (chrysophytes, especially diatoms), PERI is peridinin (dinoflagellates), and ALLO is alloxanthin (cryptophytes). The total amount of chlorophyll-a ( $\Sigma \mathrm{CHL} a$ ) measured in the individual samples were obtained by taking the sum of chlorophyll- $a$, chlorophyll- $a$-epimer, chlorophyll- $a$-allomer, chlorophyllide- $a$ and pyrochlorophyllide- $a$, which all have the chromophore and spectrum of CHL $a$ per se.

Similarly, the total amount of chlorophyll degradation products ( $\Sigma a$-derivs) was obtained by adding the CHL $a$ derivatives without chelated Mg, namely pheophytin- $a$, pyropheophytin- $a$, pheophorbide- $a$ and pyropheophorbide- $a$, as described in Louda (2008).

The identification of individual pigments was done by comparing the retention time and UV spectrum with those of authentic standards and with those found in the literature (Jeffrey et al., 1997). Examples of some HPLC chromatograms for distinct floc samples, as well as the UV spectra and molecular structure of the main pigments used in this study, are supplied in Appendix 2.1.

\subsection{Results and discussion:}

\subsubsection{Bulk parameters:}

The bulk parameters obtained for all the samples analyzed in this study are summarized in Tables A2.1 and A2.2 found in Appendix 2.2. Floc depth was found to be highly variable, ranging between 1.4 and $9.2 \mathrm{~cm}$ with no apparent spatial or seasonal 
trends (Figure 2.2). The average floc depth at the freshwater site SRS2 was found to be $5.3 \mathrm{~cm}$ in the early wet season (May-July), $6.4 \mathrm{~cm}$ in the late wet season (AugustNovember) and $5.2 \mathrm{~cm}$ in the dry season (December-April). Floc depth measurements at TS2 were only collected when the site was not completely dry and showed slightly lower depth values, compared to SRS2 floc, of $4.4 \mathrm{~cm}$ in the late wet season and $3.6 \mathrm{~cm}$ the dry season. Floc depth was not measured at SRS6 because of the different tide conditions (low vs. high tide) found at that site during the sampling events. The TS6M floc had a low floc depth during the early wet season $(2.7 \mathrm{~cm})$ and remained constant throughout the late wet and dry seasons $(6.0 \mathrm{~cm})$. Finally, TS6P floc had a depth of $4.7 \mathrm{~cm}$ in the early wet season, $6.8 \mathrm{~cm}$ in the late wet season and $7.4 \mathrm{~cm}$ in the dry season. The high error bars associated with the depth measurements indicate that no statistically significant spatial or seasonal differences in this parameter could be determined, except that TS6M was lower compared to TS6P during the early wet season, possibly as a result of enhanced storm activity and associated water movement causing floc re-suspension in the more open and exposed pond area of the fringe mangroves. In addition, the mangrove sites seem to have a lower floc depth during the early wet season compared to the rest of the year. It is possible that early wet is the season with the least floc inputs in this area as Chara die-off during saltwater intrusions (late dry season) could cause enhanced contributions to the floc during the dry season, and enhanced mobilization of upstream detrital materials may be transported to TS6 during the period of high hydrologic head (late wet season) (Jaffe et at., 2001). More data is needed to ascertain these suggestions. 


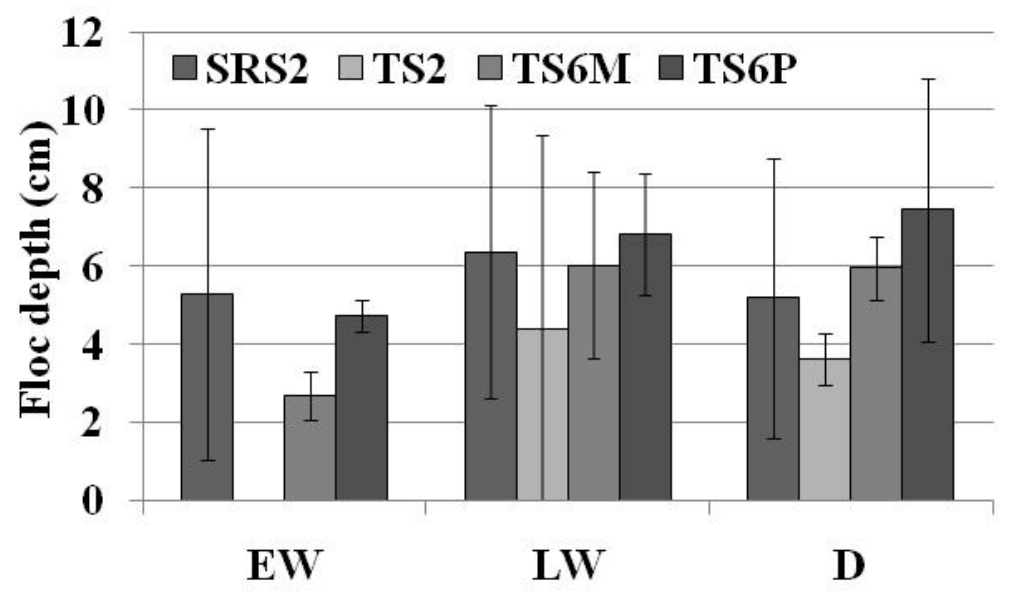

Figure 2.2. Seasonal and spatial distribution in floc depth. Seasons are shown as early wet (EW), late wet (LW) and dry (D) seasons for samples collected in 2007-2009.

Everglades' floc contains large diameter sized aggregates and is highly porous (Larsen et al., 2009a). The porous nature of the material can cause the floc layer to be easily disrupted by slight perturbations of the water column (caused mainly by wind and biological activity) allowing it to be easily re-suspended. As a result of these characteristics, the settling velocity of Everglades' floc particles has been found to be quite low (Larsen et al., 2009a). The re-suspension and low settling velocity might have caused the variability in the floc depth measurements. The floc depth values obtained in the present study are lower than literature values of floc depth ranging between 11 and 17 cm reported for the Water Conservation Areas (WCA; Corstanje et al., 2006). The higher floc depths found in the WCA may be attributed to long-term phosphorus enrichment from the adjacent Everglades Agricultural Areas. Long-term P additions have been shown to increase macrophyte productivity (Miao et al., 1998) and make the floc anoxic, which decreases carbon mineralization (DeBusk et al., 1998), thus resulting in greater pools of floc and soil organic matter. The higher floc depths in the WCA could also be attributed to longer particle settling times in these long hydroperiod areas. However, the 
longest hydroperiod site studied here (SRS2) did not show higher floc depth values compared to the other sites, suggesting that other local drivers may further influence this parameter.

Floc bulk density was also highly variable and showed no particular spatial or seasonal trends (Figure 2.3). The floc collected at SRS2 had density values of $0.23,0.29$ and $0.56 \mathrm{~g} \mathrm{~cm}^{-3}$ during the early wet, late wet and dry seasons, respectively. The TS2 floc had the lowest density value during the early wet season $\left(0.071 \mathrm{~g} \mathrm{~cm}^{-3}\right)$, followed by 0.77 $\mathrm{g} \mathrm{cm}^{-3}$ in the late wet and $0.74 \mathrm{~g} \mathrm{~cm}^{-3}$ in the dry seasons. The TS6M floc density was 0.68 $\mathrm{g} \mathrm{cm}^{-3}$ during the early wet season. The bulk density decreased in the late wet season $\left(0.23 \mathrm{~g} \mathrm{~cm}^{-3}\right)$ and increased again in the dry season $\left(0.66 \mathrm{~g} \mathrm{~cm}^{-3}\right)$. The TS6P floc followed a similar trend; 0.86 and $0.23 \mathrm{~g} \mathrm{~cm}^{-3}$ in the early and late wet seasons and $0.33 \mathrm{~g} \mathrm{~cm}^{-3}$ in the dry season. As in the case of the depth measurements, the high error bars associated with these measurements indicate that no significant spatial or seasonal differences in this parameter could be determined, except that the density at TS6P was higher during the early wet season compared to late wet and dry seasons. This observation seems in agreement with the floc depth data in that fresh additions to the floc layer in late wet and dry season, may result in a less consolidated floc layer, and thus, lower floc density.

The bulk density for the FCE floc samples ranged between 0.03 and $1.4 \mathrm{~g} \mathrm{~cm}^{-3}$. Larsen et al. (2009b) measured the bulk density of floc in the WCA and found it to be $0.013 \mathrm{~g} \mathrm{~cm}^{-3}$. The lower density values observed in the WCA are in agreement with the higher floc depth values found there, which may result in a less consolidated and, consequently, less dense floc layer. The higher density values obtained in the present study may also be due to a lower organic matter content of the floc found in the FCE 
compared to the WCA which is characterized by longer hydroperiods and significant OM accumulation.

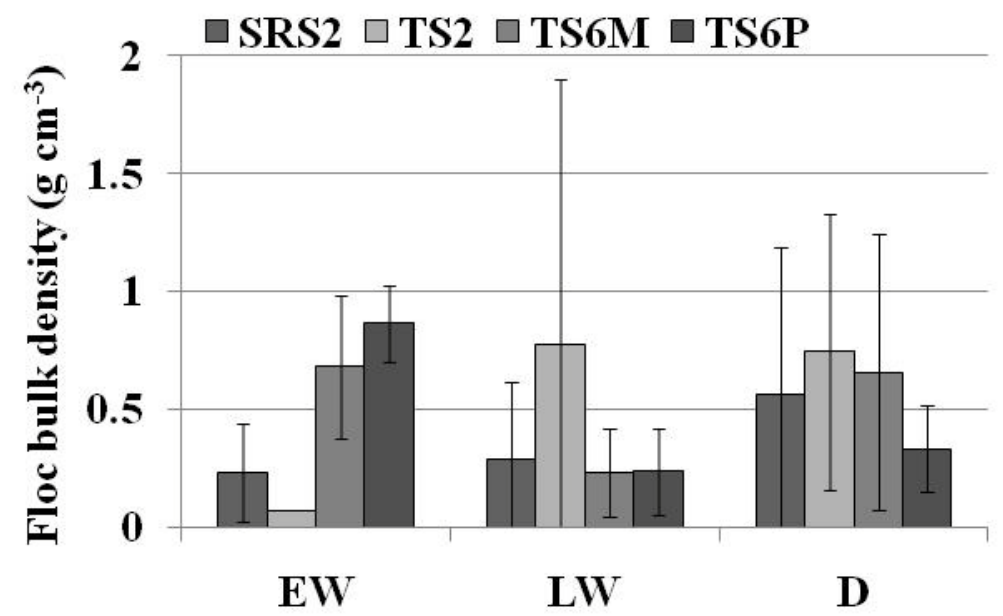

Figure 2.3. Spatial and seasonal distribution in floc bulk density. Seasons are shown as early wet (EW), late wet (LW) and dry (D) seasons for samples collected in 2007-2009.

The OM content of the periphyton and floc samples is summarized in Tables A2.1 and A2.2 found in Appendix 2.2. The periphyton samples collected at SRS2 had a higher OM content (41-76 \%OM) compared to TS2 periphyton (32-37 \%OM; Figure 2.4). In fact, periphyton mats from long-hydroperiod sites have been shown to contain proportionally more OM than periphyton mats found at short-hydroperiod sites (Gottlieb et al., 2006). Several explanations can be proposed for these observed differences: shorthydroperiod mats are benthic and associated with the calcium carbonate bedrock. Thus, the lower values in OM content obtained for TS2 periphyton may result from this calcium carbonate enrichment. Floating, long-hydroperiod periphyton mats are associated with the macrophyte Utricularia purpurea, and as the mat ages, most of the periphyton is lost and settles through the water column to become part of the floc and sediment (Gottlieb et al., 2006). 


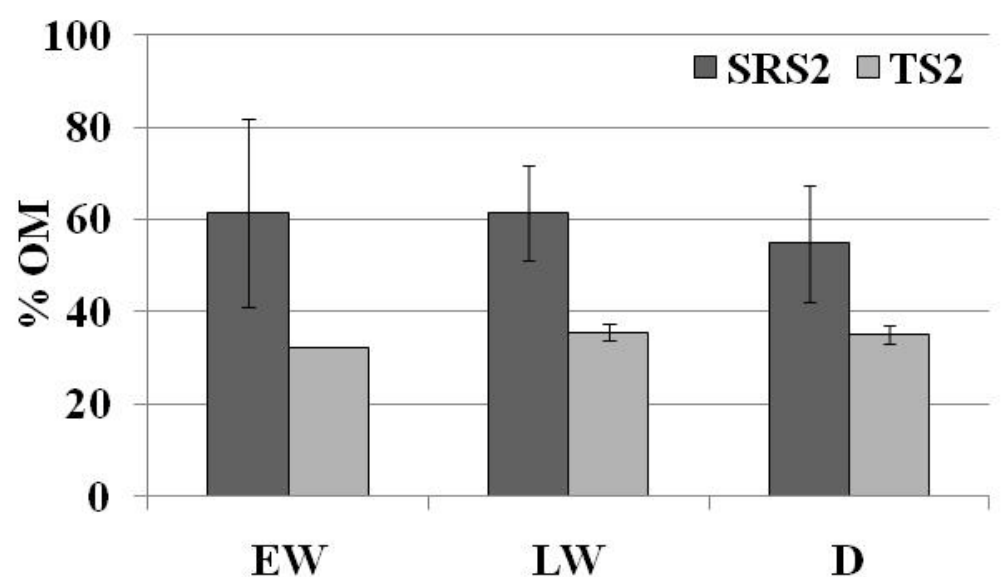

Figure 2.4. Organic matter content $(\% \mathrm{OM})$ for the periphyton samples collected at the two freshwater sites. Seasons are shown as early wet (EW), late wet (LW) and dry (D) seasons for samples collected in 2007-2009.

In agreement with the periphyton data shown above, spatial differences in the floc OM content were clearly observed (Figure 2.5) with SRS2 floc having the highest \%OM (65-83\%) while that of TS2 floc was significantly lower (16-59\%). Lowest floc \%OM values were observed for SRS6 (15-22\%). These higher values in OM content can be attributed to organic rich periphyton inputs and an increased accumulation of $\mathrm{OM}$ at the long hydroperiod site (SRS2). In contrast, the mangrove site (SRS6) is strongly influenced by tidal activity and the floc found there might not have the chance for significant accumulation. In fact, the sediment accretion rate at SRS6 has been estimated to be $0.30 \pm 0.03 \mathrm{~cm}_{\text {year }}{ }^{-1}$ (Castañeda-Moya et al., 2010) while accretion rates in the vicinity of SRS2 have been estimated at $0.50 \mathrm{~cm}_{\text {year }}{ }^{-1}$ (Saunders et al., 2006). In addition, tidal mixing will deposit inorganic sediments at SRS6 diluting the \%OM at this site.

The floc found in the Taylor River seems to be coupled to the marl soils and calcium carbonate bedrock as it was found to contain less \%OM compared to the floc 
found in SRS2. In fact, this location is subject to seasonal dry-out and exposure of the floc to atmospheric conditions, resulting in enhanced oxidation of the $\mathrm{OM}$ and a reduction in the $\% \mathrm{OM}$ content (16 to $59 \%$ ). The unusually high OM content detected in the TS2 floc sample in the late wet season of $2007(59 \%)$ is most likely to the result of a sampling artifact. This particular sample was the first of the TS2 dataset and was collected in an adjacent creek with a higher water level (longer hydroperiod) compared to the marl prairie where the subsequent samples were collected. The area has no periphyton mat growth, is dominated by woody species such as willow (Salix caroliniana), is surrounded by slough species (Eleocharis cellulosa) and usually does not dry down completely allowing for a better chance of $\mathrm{OM}$ accumulation.

In comparison, the floc at TS6M ranged between 27 and $51 \%$ and TS6P between 20 and $32 \%$. These $\% \mathrm{OM}$ values are enriched in comparison with SRS6 floc, even though the TS locations are more marl-like. The higher OM content at the TS6 sites compared to the SRS6 site can be attributed to differential effects of hydroperiod at these two locations (Krauss et al., 2006). While SRS6 is influenced by semidiurnal tides (Childers et al., 2006), TS6 is seasonally inundated and flooded during the entire wet season (Davis et al., 2003). The frequent tidal inundation and re-wetting of the SRS6 site has been shown correlate with higher rates of mangrove leaf litter (Twilley et al., 1986) and belowground biomass (Poret et al., 2007) decomposition. In addition, the environment at TS6 compared to SRS6 is significantly P-limited and as such less subject to OM respiration and associated OM loss in the floc layer. Also, sediments at TS6 are more reducing compared to SRS6 and as such should better preserve OM (Poret et al., 2007). 


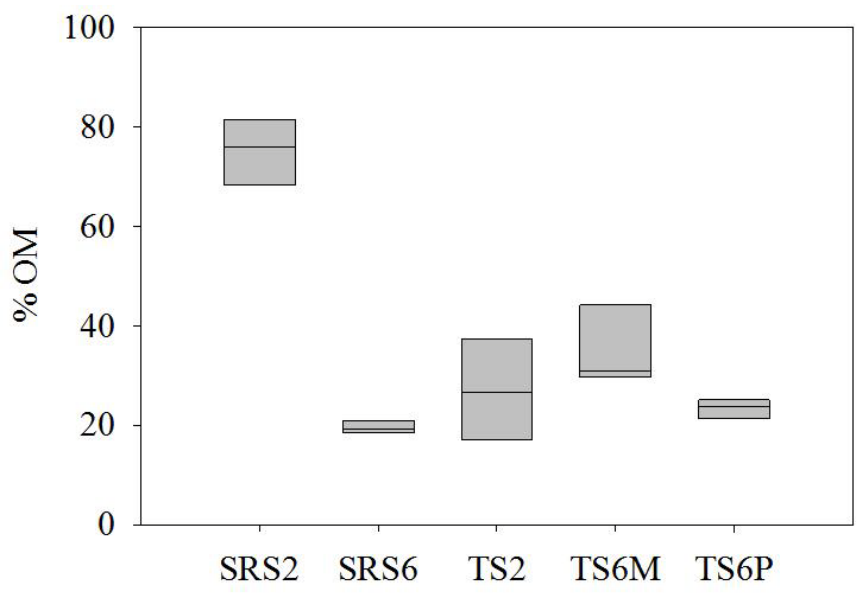

Figure 2.5. Spatial distribution in floc organic matter $(\% \mathrm{OM})$ content shown as a boxand-whisker plot: The central horizontal line in the box is the median and the top and bottom of the box are the $25^{\text {th }}$ and $75^{\text {th }}$ percentiles (quartiles). The $5^{\text {th }}$ and $95^{\text {th }}$ percentiles could not be determined due to insufficient data points.

Seasonal differences in floc OM content were not observed (Figure 2.6). The floc collected at all sites showed a relatively constant OM content throughout the wet and dry seasons suggesting continuous inputs from the local biomass, although the higher $\% \mathrm{OM}$ at TS6M during the late wet season could be related to changes in the mangrove primary productivity (Twilley et al., 1986).

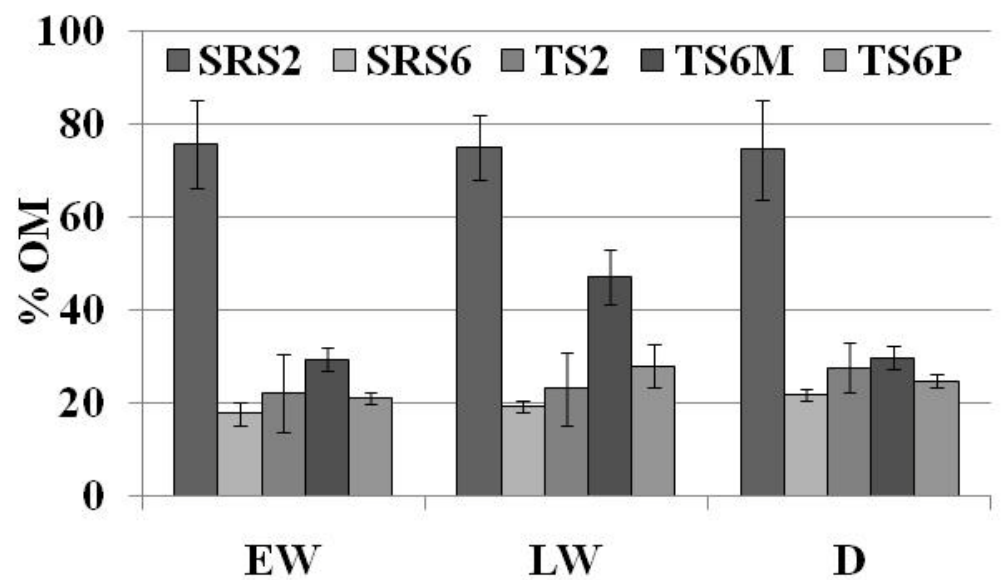

Figure 2.6. Seasonal variation in floc organic matter $(\% \mathrm{OM})$ content. Seasons are shown as early wet (EW), late wet (LW) and dry (D) seasons for samples collected in 20072009. 


\subsubsection{Pigment chemotaxonomy:}

Pigment chemotaxonomy was used in this study to determine the contribution of periphyton algal components to the floc layer and to quantify the live biomass present in the floc. The application of reverse phase-high performance liquid chromatography (RPHPLC) for pigment-based chemotaxonomy has received much attention as an alternative to time consuming microscope-based assessments (Jeffrey et al., 1997). Chromatographic advances, such as the development of ion pairing techniques (Mantoura et al., 1983) have made the separation and identification of a wide range of polar and non-polar pigments possible. Pigment-based chemotaxonomic studies rely on the premise that, once the overall pigment array has been determined, the distribution of the primary (chlorophylls) and secondary/accessory (carotenoids) photosynthetic pigments can be mathematically deconvoluted in ways that reflect the taxonomic makeup of the sampled community (Louda, 2008). In other words, specific pigment biomarkers (selected structures shown in Appendix 2.1) typical of oxygenic photoautotrophs are present in known ratios to a biomass commonality such as Chlorophyll- $a$. The molar ratios for some major algal classes have been reviewed and published elsewhere (Louda, 2008). Briefly, chlorophytes contain chlorophyll- $b$, cyanobacteria contain zeaxanthin and/or echinenone for coccoidal and filamentous cyanobacteria, respectively (Grant et al., 2010), chrysophytes (especially diatoms) contain fucoxanthin, dinoflagellates contain peridinin and cryptophytes contain alloxanthin. Multiple linear regressions derived from the analysis of unialgal cultures, field samples and/or literature values, can allow the relative percentage of each taxon to be calculated. 
CHL $a$ estimates have generally been used as indicators of primary productivity (Desortová, 1981; Bot et al., 1996; Kasprzak et al., 2008). Not surprisingly, the periphyton samples analyzed in this study contained high amounts of CHL $a\left(2.7 \times 10^{3}\right.$ $1.2 \times 10^{4} \mu \mathrm{g} \mathrm{gOM}^{-1}$ for TS2 periphyton and $3.3 \times 10^{3}-1.7 \times 10^{4} \mu \mathrm{gOM}^{-1}$ for SRS2 periphyton; Figures 2.7.a and 2.7.b). The data for the total measured chlorophyll- $a$ ( $\Sigma \mathrm{CHL} a$ ), the total pheopigments ( $\Sigma a$-derivs) and chemotaxonomic estimations determined by the formula described above, for all the periphyton and floc samples are summarized in Tables A2.3 and A2.4 found in Appendix 2.2. Differences in the amount of CHL $a$ in the periphyton samples could be explained by differences in the hydrology and substrate type found at the two sites. The periphyton found in the short hydroperiod prairie marsh (TS2) can grow directly attached to the marl soils or limestone surface (Gottlieb et al., 2006) and production is confined mostly to the flooded season (Ewe et al., 2006). On the other hand, the periphyton found in long hydroperiod site (SRS2) is commonly associated with submerged macrophytes (mainly Utricularia purpurea) and its production is directly linked with the growth patterns of this vegetation which is most prolific in the late wet season. However, late wet season samples (August to November) had lowest CHL $a$ values. The seemingly contradictory trend can be explained by the fact that a significant $\%$ of the $\mathrm{OM}$ in the wet season periphyton mat is derived from Utricularia, as such diluting the periphyton contribution of CHL $a$ on an OM content basis. As a result, the apparent CHL $a$ content at SRS2 is lower during the wet season. The lower CHL $a$ values obtained for the TS2 periphyton samples compared to those at SRS2 are in agreement with the lower OM content and could be explained by the 
lower water levels and complete dry down which can occur at this short hydroperiod site. The resulting dry-down can cause cellular death of the periphyton algal components leading to the degradation of chlorophyll- $a$, thus yielding chlorophyll- $a$ derivatives (Louda et al., 1998). In fact, the amount if $\Sigma a$-derivs was higher for periphyton collected at TS2 (up to $1.4 \times 10^{3} \mu \mathrm{g} \mathrm{gOM}^{-1}$ ) compared to SRS2 (up to $1.1 \times 10^{3} \mu \mathrm{g} \mathrm{gOM}^{-1}$; Figures 2.7.a and 2.7.b).

Because of the degradability of chlorophyll, in flocculent material of the Everglades the CHL $a$ levels have been used as indicators of recent/live planktonic OM inputs (Neto et al., 2006). We found clear spatial differences in the total amount of CHL $a$ as well as in the total amount of pheopigments in the floc samples (Figures 2.8.a-2.8.e). The floc collected at TS6P had the highest amounts of CHL $a\left(1449-2724 \mu \mathrm{g} \mathrm{gOM}^{-1}\right)$ suggesting that microalgal inputs, probably in the form of epiphytic growth on the local macroalgae Chara, are incorporated into the floc. The SRS6 floc contained the lowest amount of CHL $a\left(86-1240 \mu \mathrm{gOM}^{-1}\right)$, indicative of low live algal inputs at that highly shaded and tidally influenced site. Furthermore, the high amounts of $a$-derivs (24-1303 $\mu \mathrm{g} \mathrm{gOM}^{-1}$ ) indicate that the floc found there might have undergone extensive diagenetic reworking and as such is more aged. The SRS2 floc containing the highest amount of $\% \mathrm{OM}$ did not have the highest $\mathrm{CHL} a$ content $\left(27-1055 \mu \mathrm{gOM}^{-1}\right)$ suggesting that living algae are less important contributors to the high concentration of $\mathrm{OM}$ at this site. The lower amounts of CHL $a$ detected in the freshwater floc can also be explained by an increased exposure of this floc to sunlight. The low water levels and dominant vegetation (sawgrass and spikerush) found at the freshwater sites provide minimal shading to the 
floc layer. It is well known that a tremendous portion of the chlorophyll in aquatic ecosystems can be quickly decomposed via photo-oxidation processes (Carpenter et al., 1986; Nelson, 1993).

Significant seasonal differences in the $\Sigma \mathrm{CHL} a$ and $\Sigma a$-derivs content of the floc at each individual site were not observed. However, the ratio of these two parameters was used to determine seasonal changes in live planktonic inputs to the floc layer. At TS2, the contribution of live algae to the floc was found to be highest in the early wet season, and in fact, the periphyton mats at this site have been shown to be most productive at the onset of the wet season (Ewe et al., 2006), contributing live algae to the floc layer. The floc collected at the other freshwater site, SRS2 contained similar amounts of CHL $a$ and its degradation products.

While SRS6 floc also contained similar amounts of CHL $a$ and its degradation products, the mangrove sites in Taylor Slough generally contained higher amounts of live algae. According to the ratio of $\Sigma \mathrm{CHL} a$ and $\Sigma a$-derivs, TS6P floc contains the highest amounts of live algae compared to the other sites. The high amounts of live algae could result from direct inputs of epiphytic growth on Chara or poor environmental conditions for chlorophyll degradation. While the latter is unlikely due to lack of shading at this open-pond site, the former is an interesting observation considering that the freshwater sites commonly feature benthic periphyton mats. This suggests that OM inputs from Chara are significant at the TS6P site. 

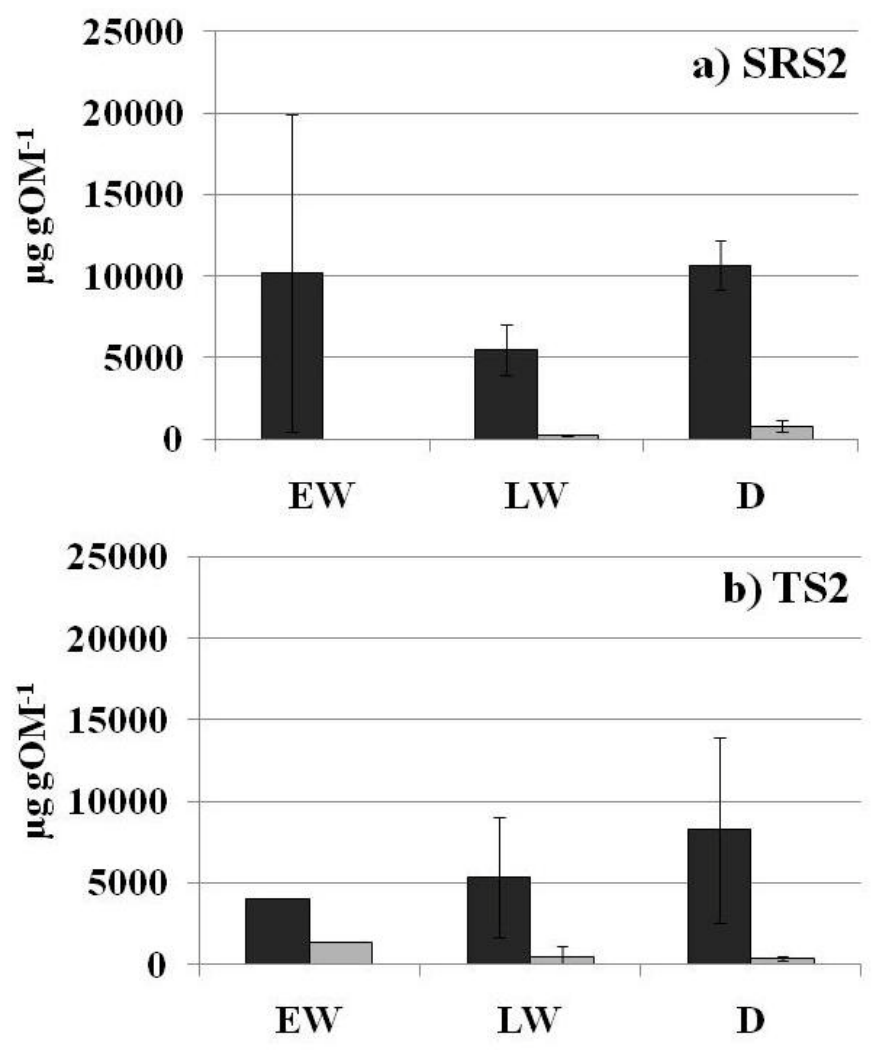

Figure 2.7. Seasonal and spatial distribution of total chlorophyll- $a$ (CHLa; $\mathbf{\square})$ and pheopigment ( $a$-derivs; $\square$ ) content for periphyton samples collected at (a) SRS2 and (b) TS2. Seasons are shown as early wet (EW), late wet (LW) and dry (D) seasons for samples collected in 2007-2009.

The pigment-based chemotaxonomic classification of the periphyton samples revealed that these algal assemblies are dominated by cyanobacteria with smaller contributions from diatoms and Chlorophyta (Figures 2.9.a and 2.9.b). Very clear spatial differences were found in the periphyton community structure between the long and short hydroperiod sites. In agreement with the literature, the periphyton collected at the long hydroperiod site (SRS2) contained more diatoms and chlorophytes compared to that of the short hydroperiod site (TS2; Gottlieb et al., 2006). Seasonal differences were more pronounced for the periphyton collected at SRS2 and followed the patterns described by Vymazal et al. (1995) with diatoms and chlorophytes increasing in the early wet season, 
and cyanobacteria increasing in the late wet and dry seasons. The periphyton collected at TS2 did not show clear seasonal patterns in its taxonomic composition because of the lack of sample present during periods of complete dry-down.

The floc samples were all dominated by cyanobacteria (Figures 2.10.a-2.10.e), except for SRS6 floc which was dominated by diatoms. Based on the low live plankton inputs to the floc at SRS6 this suggests allochthonous contributions of marine-derived inputs from the Gulf of Mexico. In addition to cyanobacteria, chlorophyta and diatoms, the floc samples also contained small amounts of cryptophytes (Table A2.4 found in Appendix 2.2). The floc collected at SRS2 showed a similar chemotaxonomic composition as the periphyton collected at that same site (Figure 2.11). On the basis of the divisional makeup of the periphyton and underlying floc at this freshwater site, there seems to be a strong compositional linkage between the two, suggesting that periphyton is indeed a strong contributor to the floc layer (Gottlieb et al., 2006; Neto et al., 2006). In addition, the seasonal similarity (Figure 2.12) suggests that periphyton detritus incorporation into floc is a relatively fast process. The lack of a strong "seasonal memory" effect in the floc suggests also that its turnover time is quite short.

In contrast to SRS2 floc, the floc collected at TS2 did not show a compositional linkage with the local periphyton mats. In fact, TS2 floc contained more diatoms compared to the local periphyton mat samples. The compositional linkage between periphyton and floc at TS2 might be decoupled as a result of hydroperiod characteristics. In fact, complete dry-down may result in the rapid oxidation of both periphyton and floc materials. In general, the floc from the TS sites did not contain significant amounts of green algae and was clearly dominated by cyanobacteria (Figure 2.10.c). 
Seasonal differences in the floc chemotaxonomic composition were not obvious and were highly variable. While SRS2 floc closely followed the same seasonal patterns of the local periphyton mats, the floc from the three mangrove sites displayed slight seasonal patterns in its chemotaxonomic composition. The SRS6 floc showed an increase in diatom composition during the early wet season and an increase in cyanobacteria during the late wet and dry seasons. The chlorophytes were a smaller component of SRS6 floc and did not show any clear seasonal patterns. The mangrove sites TS6M and TS6P showed very similar chemotaxonomic patterns, especially in their cyanobacteria distribution. The algal component showed no seasonal pattern, suggesting that the floc at these sites receives a constant cyanobacterial input. At TS6M, the diatom and chlorophyta composition were slightly decoupled, with diatoms increasing in the early wet season and the chlorophyta in the late wet season. At TS6P, these two algal components behaved similarly, both increasing in the early wet season. The increase in diatoms observed during the early wet season (May-July) may be attributed to Florida Bay water intrusions. In fact, this mangrove zone of the southern Everglades is characterized by no net water flow from the freshwater marshes from December to May (Davis et al., 2003) and has been shown to receive inputs from Florida Bay during this season (Childers et al., 2006). 

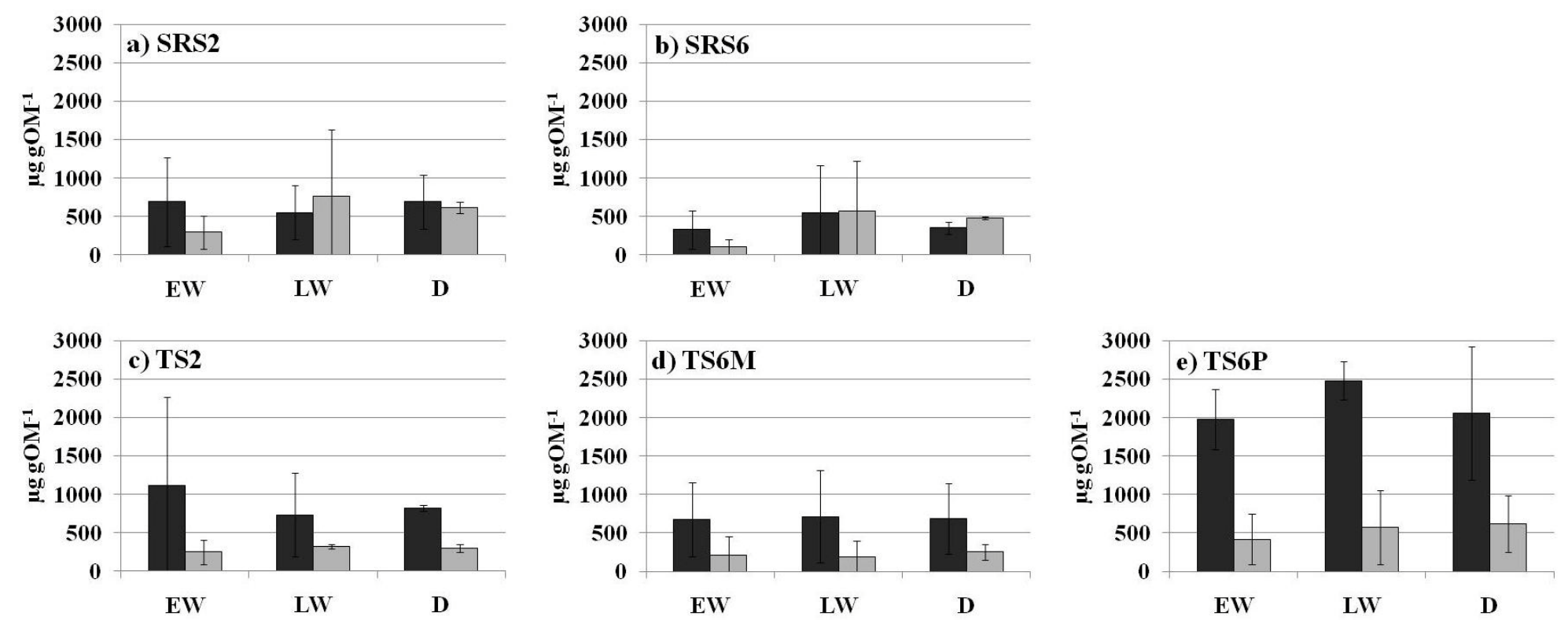

Figure 2.8. Spatial and seasonal distribution of total chlorophyll- $a$ (CHL $a$; $\mathbf{a})$ and pheopigment ( $a$-derivs; $\square)$ content in Everglades floc samples (a: SRS2, b: SRS6, c: TS2, d: TS6M and e: TS6P). Seasons are shown as early wet (EW), late wet (LW) and dry (D) seasons for samples collected in 2007-2009. 

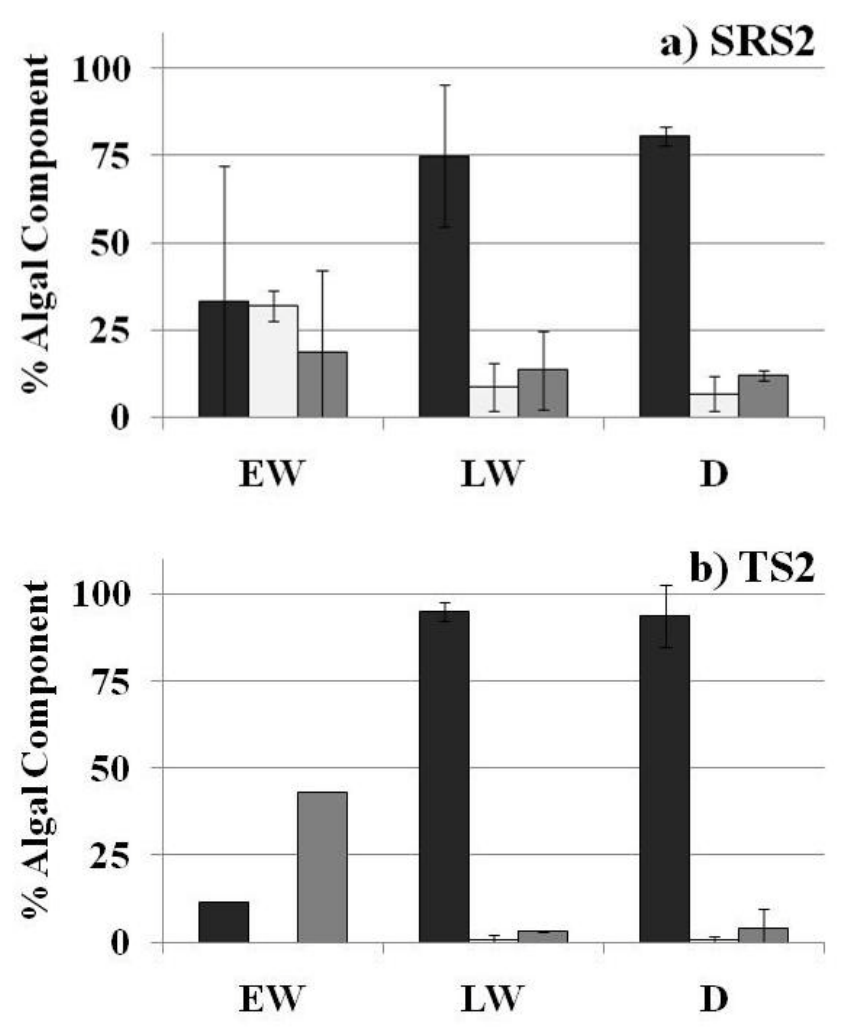

Figure 2.9. Seasonal distribution in the chemotaxonomic estimate (shown as \% of algal component) of (a) SRS2 and (b) TS2 periphyton samples $(\boldsymbol{\square}=$ cyanobacteria, $\square=$ green algae and $\square=$ diatoms). Seasons are shown as early wet (EW), late wet (LW) and dry (D) seasons for samples collected in 2007-2009. 

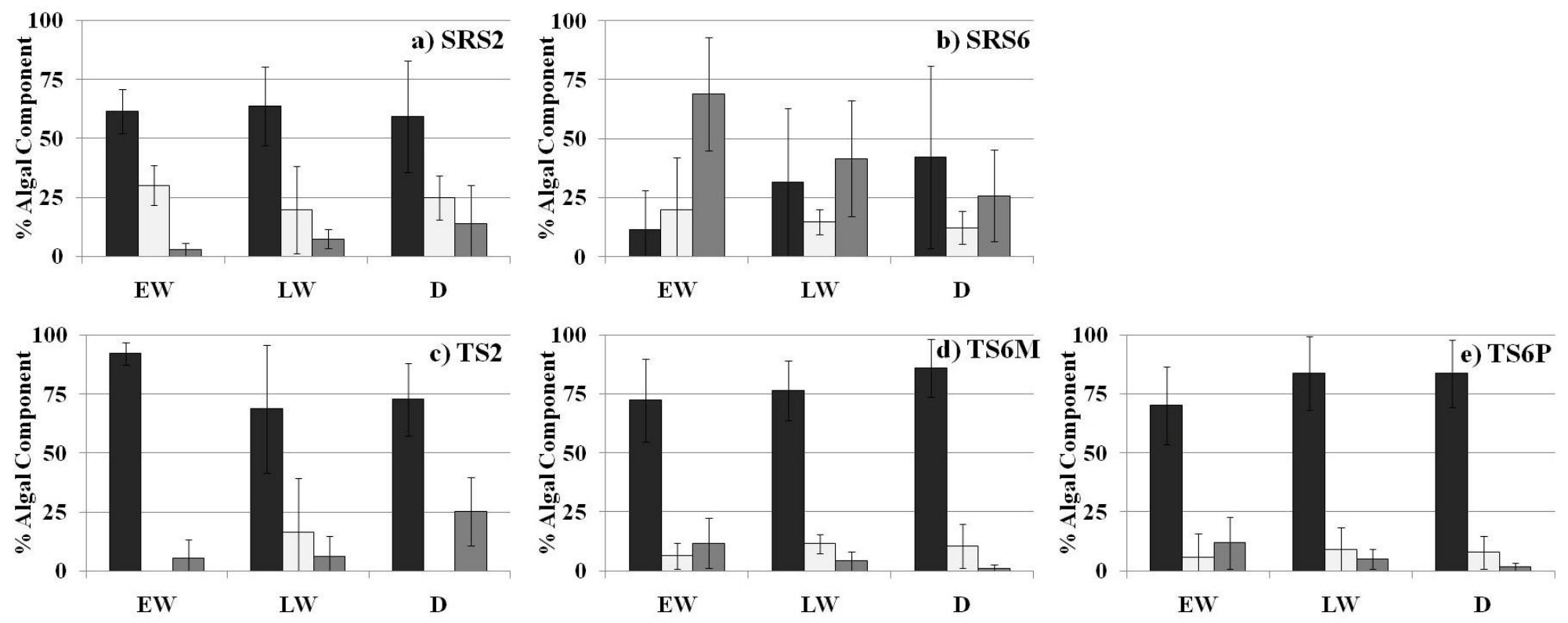

Figure 2.10. Seasonal distribution in the chemotaxonomic estimate (shown as \% of algal component) for SRS2 (a), SRS6 (b), TS2 (c), TS6M (d) and TS6P (e) floc samples ( $\square=$ cyanobacteria, $\square=$ green algae and $\square=$ diatoms). Seasons are shown as early wet (EW), late wet (LW) and dry (D) seasons for samples collected in 2007-2009. 

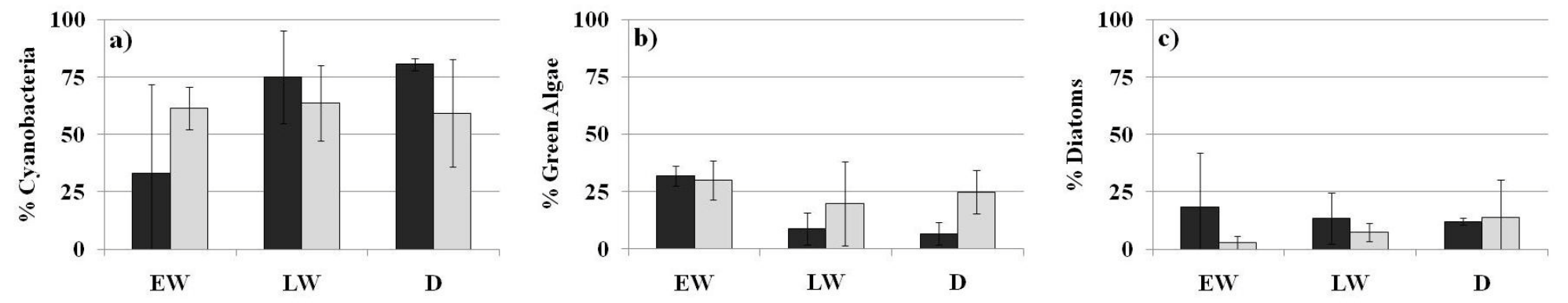

Figure 2.11. Compositional linkage (a; \% cyanobacteria, b; \% green algae and $\mathbf{c} ; \%$ diatoms) between periphyton ( $\square$ ) and floc $(\square)$ collected at SRS2. Seasonal changes are shown as the averages of the samples collected in the early wet (EW), late wet (LW) and dry (D) seasons from 2007 to 2009.
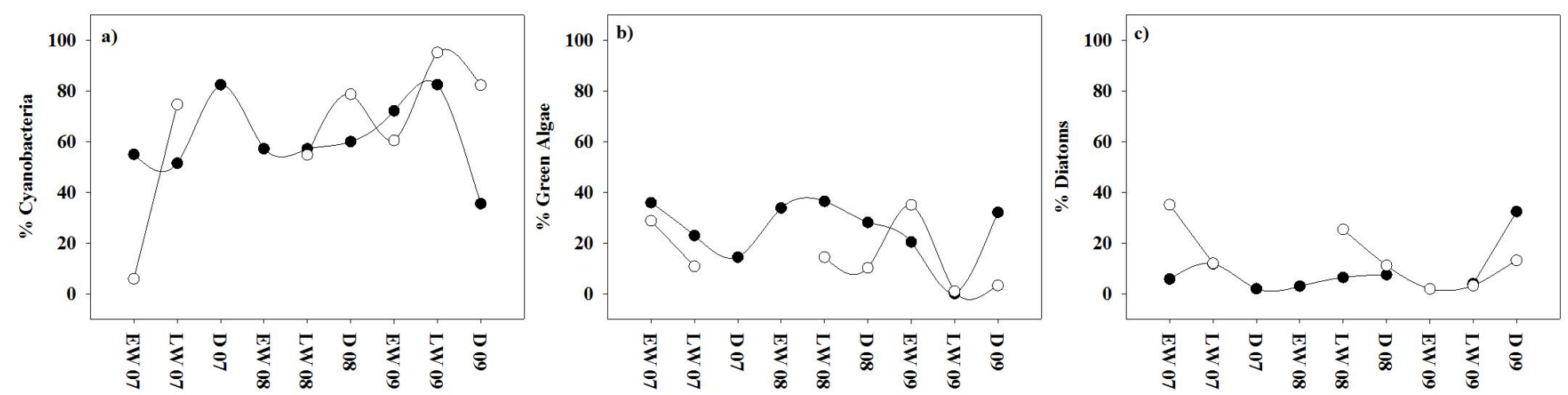

Figure 2.12. Seasonal changes in the compositional linkage (a; \% cyanobacteria, $\mathbf{b} ; \%$ green algae, $\mathbf{c} ; \%$ diatoms) between periphyton (open circles) and floc (closed circles) collected at SRS2. Seasons are shown as early wet (EW), late wet (LW) and dry (D) seasons for samples collected in 2007-2009. 


\subsubsection{Lipid biomarkers:}

The aliphatic and aromatic hydrocarbon fractions of the periphyton and floc samples revealed several lipid classes including $n$-alkanes, $n$-alkenes, $\mathrm{C}_{20}$ and $\mathrm{C}_{25}$ highly branched isoprenoids (HBIs), kaurenes, and botryococcenes, and a series of 3-oxytriterpenoid early diagenetic transformation products were detected in the floc from the mangrove sites. Many of these compounds have previously been reported to occur in floc from the Everglades (Neto et al., 2006). The molecular structures of selected compounds are shown in Appendix 2.3. These compound classes have also previously been reported to occur in sedimentary OM (Jaffé et al., 2001), in particulate organic matter (Xu et al., 2007) and in floc (Neto et al., 2006; Gao et al. 2007) from the FCE. Their spatial distribution in periphyton and floc is described below.

\subsection{3.a. n-Alkanes:}

The $n$-alkane distribution in sediments has widely been applied as a source indicator in organic geochemical studies (Cranwell, 1982; Jaffé et al., 1995; Meyers, 1997; Jaffé et al., 2001; Mead et al. 2005). The vegetation, periphyton and floc samples analyzed in this study contained a homologous series of $n$-alkanes and their concentrations are summarized in Tables A2.5 - A2.11 found in Appendix 2.2.

The plant material analyzed in this study was selected to be representative of the major sources of OM to the floc layer in both the freshwater and the estuarine sites. Some typical distributions of $n$-alkanes in these vegetation samples are shown in Figure 2.13. The relatively high concentration of $n$-alkanes detected in some plant species suggests that aquatic macrophytes are an important source of lipids in this environment. 
Immediately obvious is the fact that submerged/floating species, such as Utricularia purpurea, are enriched in the mid-chain $n$-alkanes $\left(\mathrm{C}_{25}\right)$, while the emergent and terrestrial species contain more of the longer chain homologues. The production of $n$ alkanes with different chain lengths by submerged/floating and emergent aquatic macrophytes has previously been described by Ficken et al. (2000) and has been reported for some Everglades plant species (Mead et al., 2005).

The plant community structure varies widely across the Everglades landscape, and spatial differences in the $n$-alkane distribution of the periphyton samples were found and are summarized in Figures 2.14.a (SRS2) and 2.14.b (TS2). The periphyton samples contained $n$-alkanes ranging from $\mathrm{C}_{14}$ to $\mathrm{C}_{35}$ and showed a $\mathrm{C}_{\max }$ at $\mathrm{C}_{17}$ commonly reported as a highly abundant alkane in plankton (Cranwell, 1982) and in periphyton from the FCE (Jaffé et al., 2001). On the other hand, long chain $n$-alkanes are not expected to be derived from periphyton but reflect higher plant inputs. Generally, the periphyton found at TS2 contained relatively more of the high molecular weight homologues compared to SRS2 periphyton. While the periphyton found at SRS2 is directly associated with floating Utricularia purpurea, the periphyton at TS2 may have incorporated the remains of higher plants in the algal mat. In fact, the ratio of long chain $(\mathrm{C} \geq 20)$ to short chain $(\mathrm{C} \leq 19) n$-alkanes was much lower for the latter (Tables A2.5 and A2.6 in Appendix 2.2). At SRS2, the presence of high molecular weight homologues was more pronounced for samples collected in the early wet season when the Utricularia species associated with the periphyton mats have been found to be most productive (Ewe et al., 2006). The higher error bars associated with the low molecular weight compared to 
the high molecular weight $n$-alkanes (Figures 2.14.a and 2.14.b) indicates the quick degradation of the former compared to the latter compounds.

The $n$-alkane distribution for the different floc samples varied spatially (Figures 2.15.a-2.15.e). All the floc samples contained $n$-alkanes with an odd over even carbon number predominance indicating inputs from the epicuticular waxes of higher plants (Eglinton et al., 1967). These compounds ranged from $\mathrm{C}_{14}$ to $\mathrm{C}_{37}$ and showed different $\mathrm{C}_{\max }$ values. The $n$-alkanes of the SRS2 freshwater floc were bimodally distributed and maximized at $\mathrm{C}_{17}$ and $\mathrm{C}_{27}$, suggesting inputs from the abundant periphyton mats and likely a combination of Utricularia and macrophytes such as spikerush and sawgrass. The $\mathrm{C}_{17} n$-alkane is known to derive from algal/planktonic sources (Cranwell, 1982) and was found to be particularly abundant in the periphyton samples from this freshwater site. The TS2 floc also showed a bimodal distribution of $n$-alkanes with a $\mathrm{C}_{\max }$ at $\mathrm{C}_{17}$ and $\mathrm{C}_{29}$ (Figure 2.15.c) indicative of mixed algal/periphyton and macrophyte OM inputs to the floc layer. Furthermore, the ratio of long to short $n$-alkanes was lower for SRS2 floc compared to TS2 (Tables A2.7 and A2.9), indicating either higher planktonic inputs or a better preservation of the low molecular weight compounds at the longer hydroperiod SRS2 site. It is possible that a higher degradation state of the floc found at TS2 is to the result of the seasonal dry out and exposure to atmospheric conditions at this short hydroperiod site. 


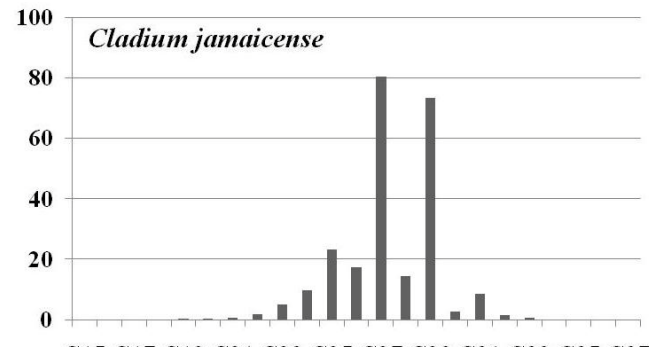

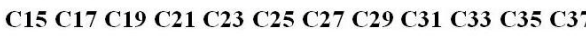
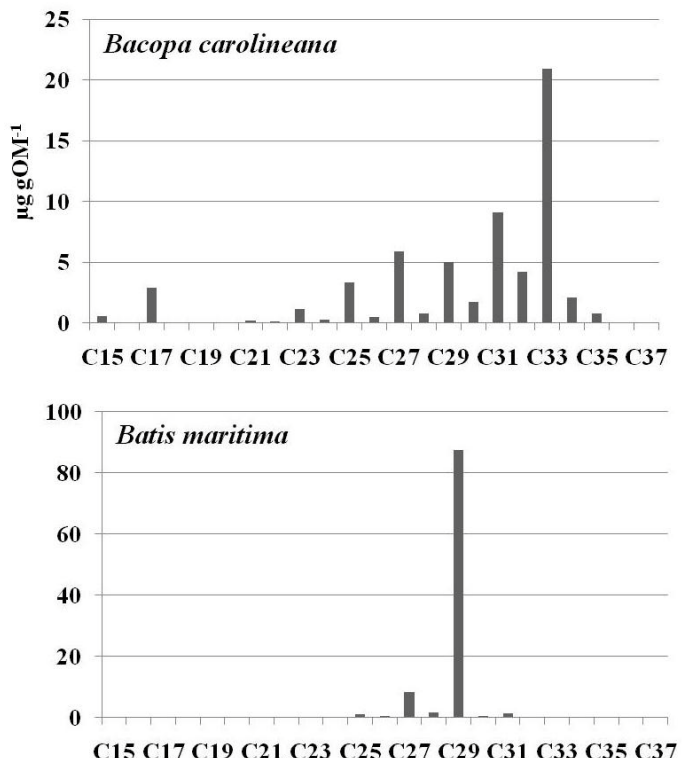

$\mathrm{C} 15 \mathrm{C} 17 \mathrm{C} 19 \mathrm{C} 21 \mathrm{C23} \mathrm{C} 25 \mathrm{C} 27 \mathrm{C29} \mathrm{C} 31 \mathrm{C} 33 \mathrm{C35} \mathrm{C} 37$

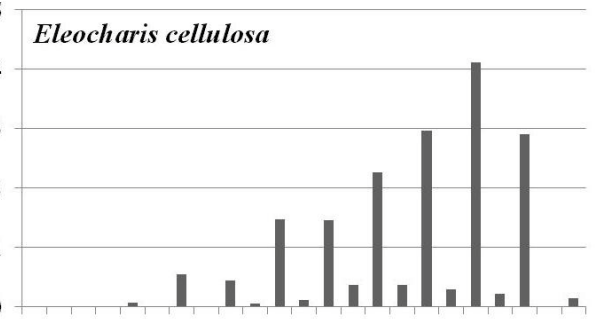

C15 C17 C19 C21 C23 C25 C27 C29 C31 C33 C35 C37

\section{Chara}

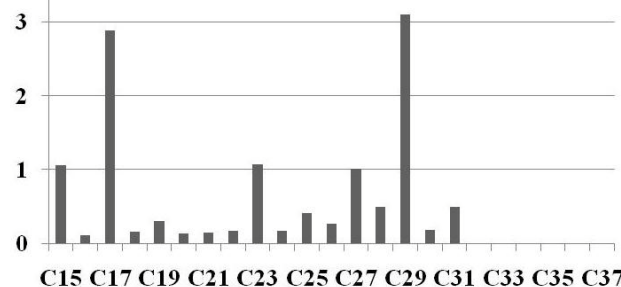

C15 C17 C19 C21 C23 C25 C27 C29 C31 C33 C35 C37

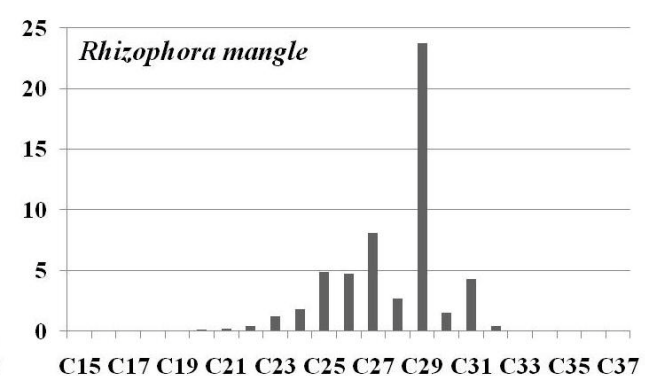

C15 C17 C19 C21 C23 C25 C27 C29 C31 C33 C35 C37

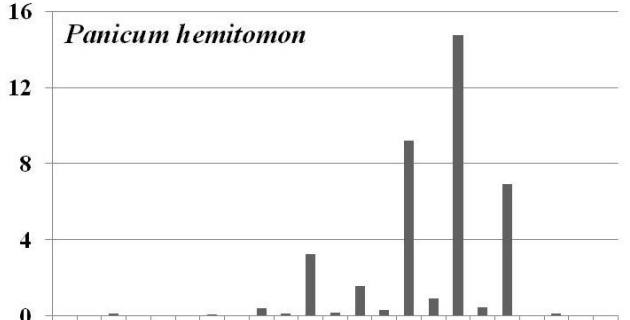

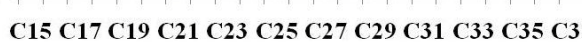

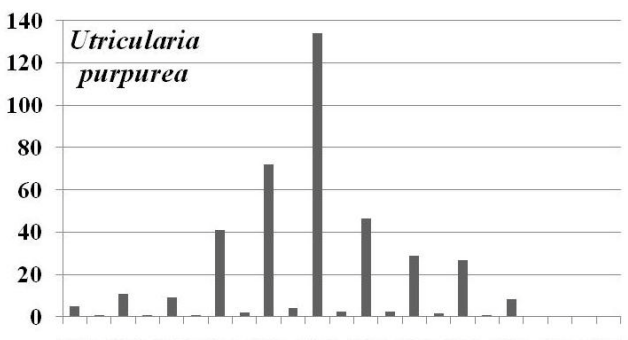

$\mathrm{C} 15 \mathrm{C} 17 \mathrm{C} 19 \mathrm{C} 21 \mathrm{C} 23 \mathrm{C} 25 \mathrm{C} 27 \mathrm{C} 29 \mathrm{C} 31 \mathrm{C} 33 \mathrm{C} 35 \mathrm{C} 37$

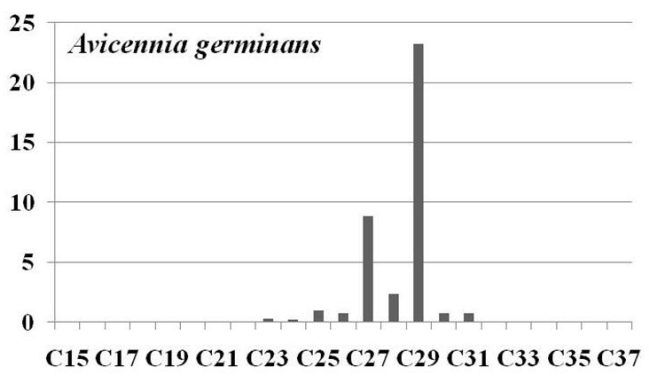

Figure 2.13. The $n$-alkane abundance and distribution for typical Everglades' vegetation (shown on different scales). 

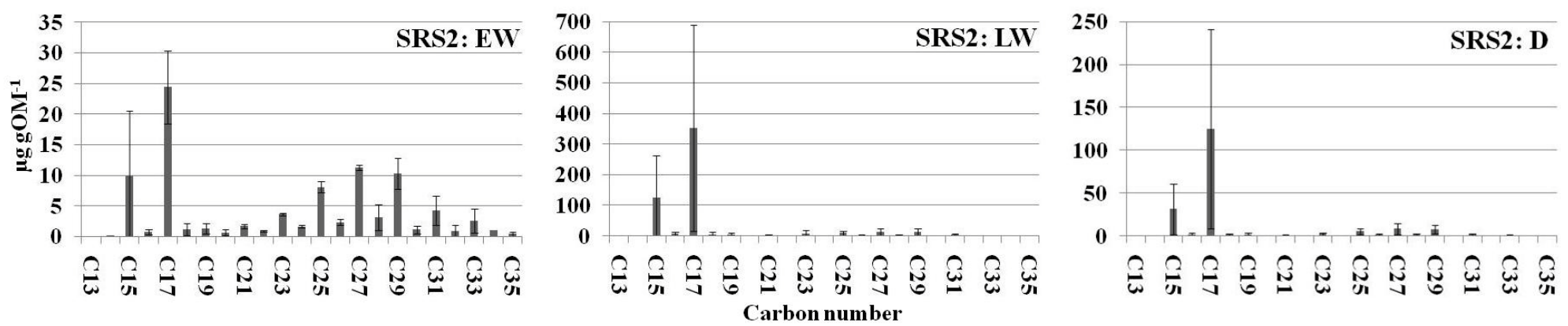

Figure 2.14.a. The $n$-alkane distribution for SRS2 periphyton. The abundance for the various samples is shown at different scales. Seasons are indicated on the top right corner of each graph as early wet (EW), late wet (LW) and dry (D) seasons for samples collected in 2007-2009.
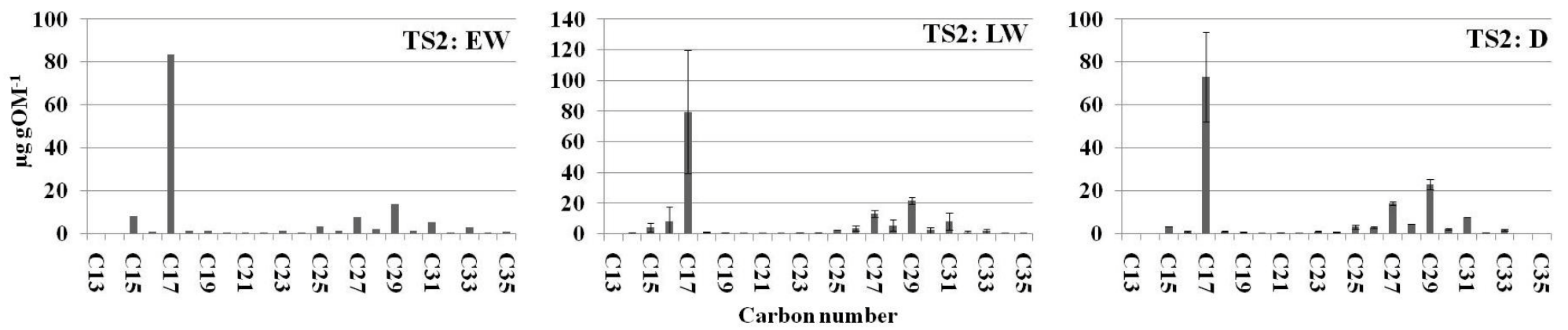

Figure 2.14.b. The $n$-alkane distribution for TS2 periphyton. The abundance for the various samples is shown at different scales. Seasons are indicated on the top right corner of each graph as early wet (EW), late wet (LW) and dry (D) seasons for samples collected in 2007-2009. 
The $n$-alkane composition of the floc collected at the mangrove sites was very different from the freshwater floc. The $n$-alkane distribution for SRS6 floc was unimodal ranging from $\mathrm{C}_{14}$ to $\mathrm{C}_{34}$ and showing a $\mathrm{C}_{\max }$ at $\mathrm{C}_{29}$, typical of higher plant inputs (Eglinton et al., 1967; Figure 2.13). The floc from this site had the highest long/short $n$ alkane ratio (Table A2.8) and the low molecular weight $\mathrm{C}_{17}$ homologue was only present at very low concentrations (up to $2.4 \mu \mathrm{g} \mathrm{gOM}^{-1}$ ), suggesting very low planktonic inputs to the floc at this site and/or a low degree of preservation of planktonic OM, as low molecular weight $n$-alkanes have been suggested to degrade faster than their high molecular weight counterparts (Albaiges et al., 1984). This suggestion is in agreement with the pheopigment data described above where higher amounts of these degradation products were found in the floc from this site. The $n$-alkane distribution of the floc collected at TS6M and TS6P (Tables A2.10 and A2.11) ranged from $\mathrm{C}_{15}$ to $\mathrm{C}_{33}$ with a clear maximum at $\mathrm{C}_{29}$, indicative of mangrove inputs. The $\mathrm{C}_{17}$ homologue was found at low concentrations at TS6M (1.3-26 $\left.\mu \mathrm{g} \mathrm{gOM}^{-1}\right)$ but was expectedly higher at TS6P (1.6$\left.32 \mu \mathrm{g} \mathrm{gOM}^{-1}\right)$, suggesting that the floc found there might receive some planktonic OM inputs, in agreement with the CHL $a$ data described above. Furthermore, the Chara sample collected at TS6P showed a relatively high $\mathrm{C}_{17}$ signal $\left(2.9 \mu \mathrm{g} \mathrm{gOM}^{-1}\right)$, a result of epiphytic growth on this abundant macroalgae, and as such can contribute to the observed distribution in the floc. 

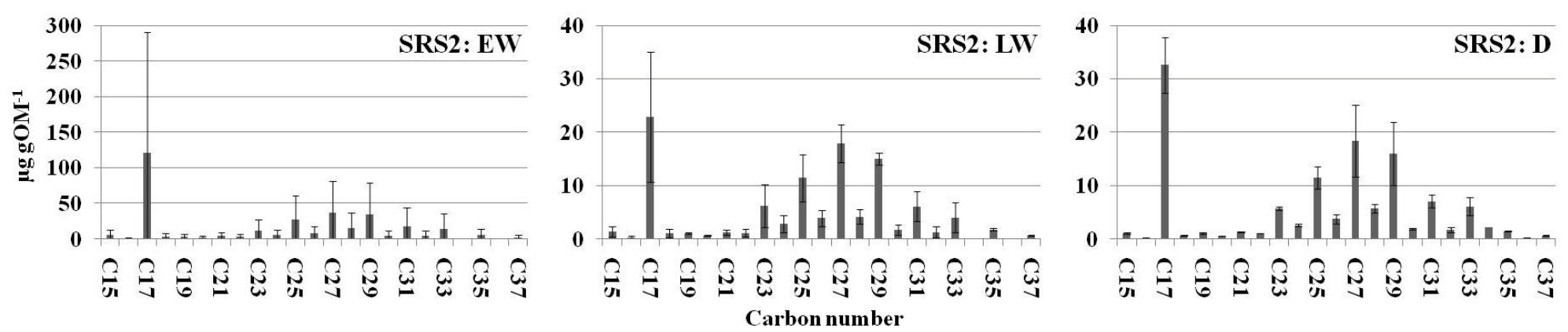

Figure 2.15.a. The $n$-alkane distribution for SRS2 floc samples. The abundance for the various samples is shown on different scales. Seasons are shown as early wet (EW), late wet (LW) and dry (D) seasons for samples collected in 2007-2009.
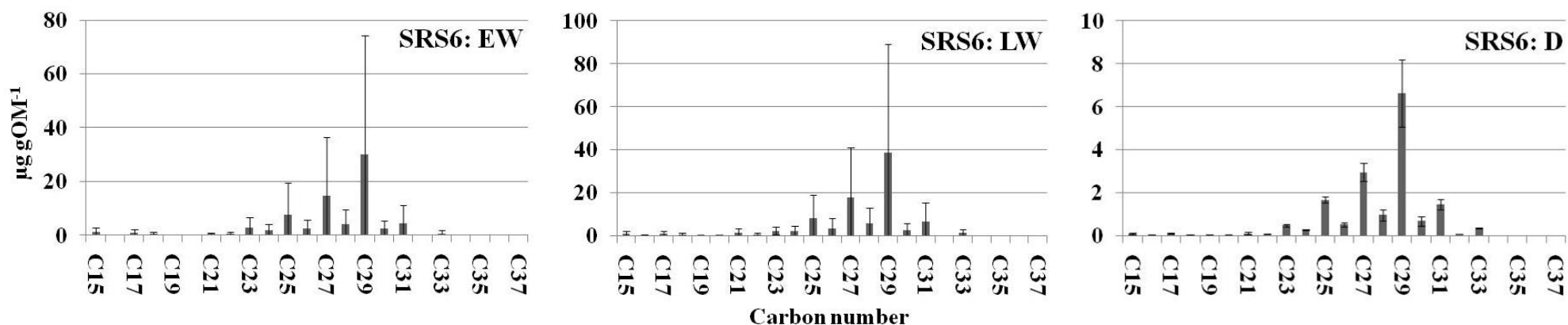

Figure 2.15.b. The $n$-alkane distribution for SRS6 floc samples. The abundance for the various samples is shown on different scales. Seasons are shown as early wet (EW), late wet (LW) and dry (D) seasons for samples collected in 2007-2009. 

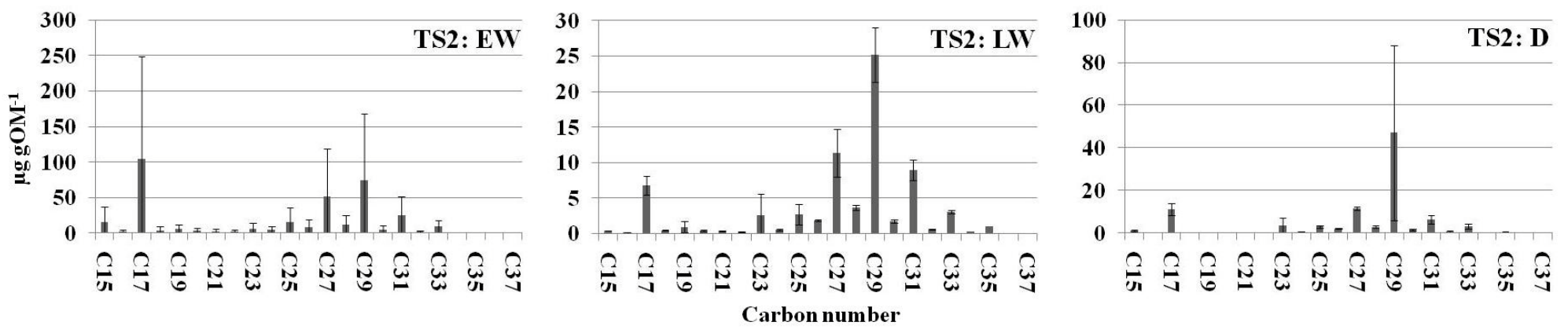

Figure 2.15.c. The $n$-alkane distribution for TS2 floc samples. The abundance for the various samples is shown on different scales. Seasons are shown as early wet (EW), late wet (LW) and dry (D) seasons for samples collected in 2007-2009.
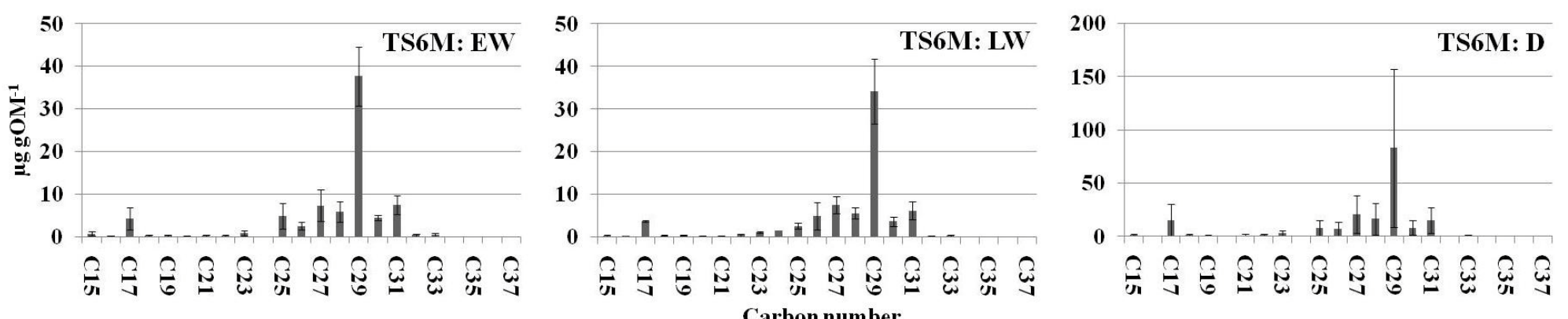

Figure 2.15.d. The $n$-alkane distribution for TS6M floc samples. The abundance for the various samples is shown on different scales. Seasons are shown as early wet (EW), late wet (LW) and dry (D) seasons for samples collected in 2007-2009. 

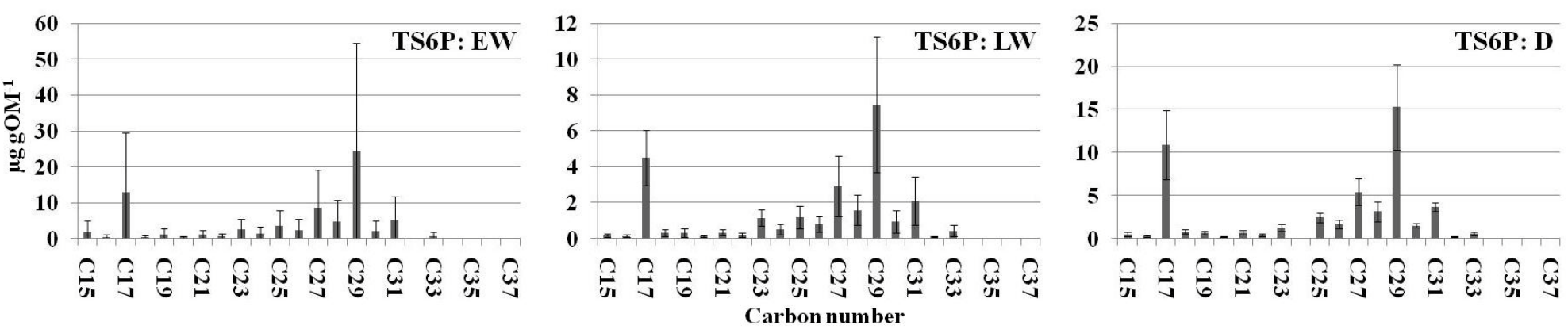

Figure 2.15.e. The $n$-alkane distribution for TS6P floc samples. The abundance for the various samples is shown on different scales. Seasons are shown as early wet (EW), late wet (LW) and dry (D) seasons for samples collected in 2007-2009. 
In order to better apply $n$-alkanes as biomarkers for OM sources in sediments, an aquatic proxy (Paq) has been developed (Ficken et al., 2000; Table 2.2) to distinguish OM from submerged/floating and emergent/terrestrial macrophytes. The proxy has previously been applied in the FCE for sedimentary and soil OM source assessments (Mead et al., 2005) and relies on the fact that submerged/floating plant species have abundant mid-chain $n$-alkanes relative to emergent macrophytes and terrestrial plants, which are enriched in the long-chain homologues. Following the approach developed by Ficken et al. (2000), this $n$-alkane proxy was calculated using the following equation:

$$
\mathrm{P} a q=\left(\mathrm{C}_{23}+\mathrm{C}_{25}\right) /\left(\mathrm{C}_{23}+\mathrm{C}_{25}+\mathrm{C}_{29}+\mathrm{C}_{31}\right)
$$

where $\mathrm{C}_{2 \mathrm{x}}$ is the abundance of the $\mathrm{C}_{2 \mathrm{x}} n$-alkane and the results for local biomass presented in Table 2.2. The $\mathrm{P}_{\mathrm{aq}}$ values of 0.19 and 0.051 obtained for Rhizophora mangle and Avicennia germinans, respectively, fell within the range of $0.01-0.23$ determined by Ficken et al. (2000) for terrestrial plants. While the $\mathrm{P}_{\mathrm{aq}}$ value obtained in this study was much lower than the value of 0.24 reported for Rhizophora mangle (Mead et al., 2005), it agreed with a value of 0.15 reported for Avicennia germinans (Neto et al., 2006). In general, the $\mathrm{P}_{\mathrm{aq}}$ obtained for the terrestrial vegetation was driven by enrichment in the $\mathrm{C}_{29}$ $n$-alkane with small contributions from the $\mathrm{C}_{31}$ homologue. The $\mathrm{P}_{\text {aq }}$ values obtained for the emergent vegetation were also within the range of 0.07-0.61 determined by Ficken et al. (2000) with the clear exception of Batis maritima, which had a $\mathrm{P}_{\mathrm{aq}}$ value of 0.013 , similar to the terrestrial plants. The $\mathrm{P}_{\mathrm{aq}}$ of Cladium jamaicense was found to be higher than the reported literature value of 0.13 (Mead et al., 2005) while the $\mathrm{P}_{\mathrm{aq}}$ of Eleocharis cellulosa was found to be lower (0.51; Mead et al., 2005). Finally, the $\mathrm{P}_{\mathrm{aq}}$ values of the submerged macrophytes were different between the Utricularia purpurea and the Chara. 
The $\mathrm{P}_{\mathrm{aq}}$ value of Utricularia purpurea (0.83) fell within the range of 0.48-0.94 determined by Ficken et al. (2000) and was comparable to the value of 0.85 determined by Mead et al. (2005). The Chara (0.89; Mead et al., 2005) had a much lower $\mathrm{P}_{\mathrm{aq}}$ value of 0.29 . However, while this particular sample contained relatively high amounts of midchain $n$-alkanes (particularly $\mathrm{C}_{23}$ ) it was also enriched in the $\mathrm{C}_{29}$ homologue, thus lowering its $\mathrm{P}_{\mathrm{aq}}$ value.

Table 2.2. Percent organic matter $(\% \mathrm{OM})$ and $\mathrm{P}_{\mathrm{aq}}$ values for typical Everglades' vegetation.

\begin{tabular}{|c|c|c|}
\hline Plants & $\% \mathrm{OM}^{\mathrm{c}}$ & $\mathrm{P}_{\mathrm{aq}}$ \\
\hline \multicolumn{3}{|l|}{ Terrestrial } \\
\hline Rhizophora mangle & $89 \pm 0.12$ & 0.19 \\
\hline Avicennia germinans & $88 \pm 0.17$ & 0.051 \\
\hline Laguncularia racemosa $a^{\mathrm{a}}$ & & 0.15 \\
\hline \multicolumn{3}{|l|}{ Emergent } \\
\hline Eleocharis cellulosa & $95 \pm 0.40$ & 0.27 \\
\hline Cladium jamaicense & $97 \pm 0.11$ & 0.27 \\
\hline Panicum hemitomon & $90 \pm 0.09$ & 0.13 \\
\hline Batis maritma & $65 \pm 0.35$ & 0.013 \\
\hline Bacopa caroliniana & $82 \pm 0.13$ & 0.24 \\
\hline \multicolumn{3}{|l|}{ Submerged } \\
\hline Utricularia purpurea & $91 \pm 0.12$ & 0.83 \\
\hline Utricularia foliosa $a^{\mathrm{a}}$ & & 0.93 \\
\hline Chara & $47 \pm 0.13$ & 0.29 \\
\hline Ruppia maritime $^{\mathrm{b}}$ & & 0.67 \\
\hline \multicolumn{3}{|l|}{ a from Neto et al., (2006) } \\
\hline${ }^{\mathrm{b}}$ from Mead et al., (2005) & & \\
\hline
\end{tabular}

Figure 2.16 shows typical $n$-alkane distributions of a submerged plant (Utricularia purpurea), an emergent plant (Eleocharis cellulosa) and a terrestrial plant (Avicennia germinans) found in the FCE and analyzed in this study. Clear differences in 
the $n$-alkane distribution are observed and shifts in the $\mathrm{C}_{\max }$ from $\mathrm{C}_{25}$ in the submerged plant to $\mathrm{C}_{33}$ and $\mathrm{C}_{29}$ in the emergent and terrestrial plant, respectively, are illustrated.

The $\mathrm{P}_{\mathrm{aq}}$ values for the periphyton samples (Tables A2.5 and A2.6 in Appendix 2.2) also reflected variations in plant community structure between the two freshwater sites. Since the periphyton found at the long hydroperiod site (SRS2) is directly associated with the macrophyte Utricularia purpurea (Gottlieb et al., 2006), the $\mathrm{P}_{\mathrm{aq}}$ (0.29-0.51) was found to be higher than that for the marl prairie counterpart (TS2; 0.0710.19) where this plant is less abundant in periphyton mats (Gottlieb et al., 2006). In fact, Utricularia collected at SRS2 was found to have a $\mathrm{P}_{\mathrm{aq}}$ value of 0.83 (Table 2.2).

This difference in periphyton composition was clearly reflected in the $\mathrm{P}_{\mathrm{aq}}$ values (Figure 2.17) obtained for the floc samples collected at these two freshwater sites (Tables A2.7 and A2.9), where SRS2 floc was found to have a higher $\mathrm{P}_{\mathrm{aq}}(0.32-0.52)$ compared to TS2 floc (0.051-0.22). This is in agreement with previous suggestions (see above) that direct inputs of periphyton to the floc layer were important at both sites. Floc collected at the mangrove sites was also different between the two locations (Tables A2.8, A2.10 and A2.11). The vegetation at SRS6 is dominated by a mixture of white, black and red mangroves (Ewe et al., 2006; Castañeda-Moya et al., 2010); however the relatively high floc $\mathrm{P}_{\mathrm{aq}}$ values (0.18-0.31) indicated a predominant input from the red and possibly white mangroves. Although spatially very close to each other, the floc samples collected at TS6M and TS6P were very different in terms of $\mathrm{P}_{\mathrm{aq}}$ values. Generally speaking, the plant communities at TS6 consist of a combination of freshwater species (sawgrass/spikerush) and red mangrove (<2 m; Ewe et al., 2006; Castañeda-Moya et al., 2010). The $\mathrm{P}_{\mathrm{aq}}$ values at TS6M (0.064-0.19) suggest mixed OM inputs from the red mangroves and possibly 
saltwort (Batis maritima), another dominant salt-tolerant plant reported to occur in brackish areas of the Everglades (Willard et al., 2001). This resulted in a lower $\mathrm{P}_{\mathrm{aq}}$ value compared to TS6P $(0.088-0.36)$ which, in addition to OM inputs from the red mangroves, also receives inputs from the submerged macroalgae Chara $\mathrm{sp} .\left(\mathrm{P}_{\mathrm{aq}}=0.29\right)$ and possibly from the freshwater marsh vegetation through hydrological transport (Jaffe et al., 2001).

Seasonal patterns in the $\mathrm{P}_{\mathrm{aq}} n$-alkane proxy were only observed for the floc collected at SRS2, with higher $\mathrm{P}_{\mathrm{aq}}$ values during the late wet season (Figure 2.17). Utricularia species have been shown to be the main contributors of OM to floc (Troxler et al., 2009) and the higher $\mathrm{P}_{\mathrm{aq}}$ values observed in the late wet season likely correspond to an increase in Utricularia productivity during that time of the year. No consistent seasonal changes were observed for floc at any of the other sites, suggesting that the OM input there is relatively constant.

In summary, the $n$-alkane distribution of the floc samples suggested direct inputs from both periphyton mats and the epicuticular waxes of the local higher plants as well as macroalgae (mostly from Utricularia purpurea and Cladium jamaicense in the freshwater marshes and Rhizophora mangle in the mangrove sites, among others). The floc collected at the two freshwater sites showed an $n$-alkane distribution that was similar to the composition of the periphyton at each site. Differences were found in the amount of periphyton-derived $\mathrm{OM}$ inputs and in the preservation of these low molecular weight compounds, likely due to the different hydrologic regimes at the two sites. In agreement with the $n$-alkane distribution data, the difference in periphyton composition between the two freshwater sites was clearly reflected in the floc $\mathrm{P}_{\mathrm{aq}}$ values. The $\mathrm{P}_{\mathrm{aq}}$ values of the floc at the mangrove sites indicated dominant inputs from Rhizophora mangle, although 
mixed inputs from other aquatic macrophytes were also found. Seasonal changes in the floc $n$-alkane distributions and $\mathrm{P}_{\mathrm{aq}}$ values were most pronounced at SRS2 and generally followed local biomass productivity patterns.
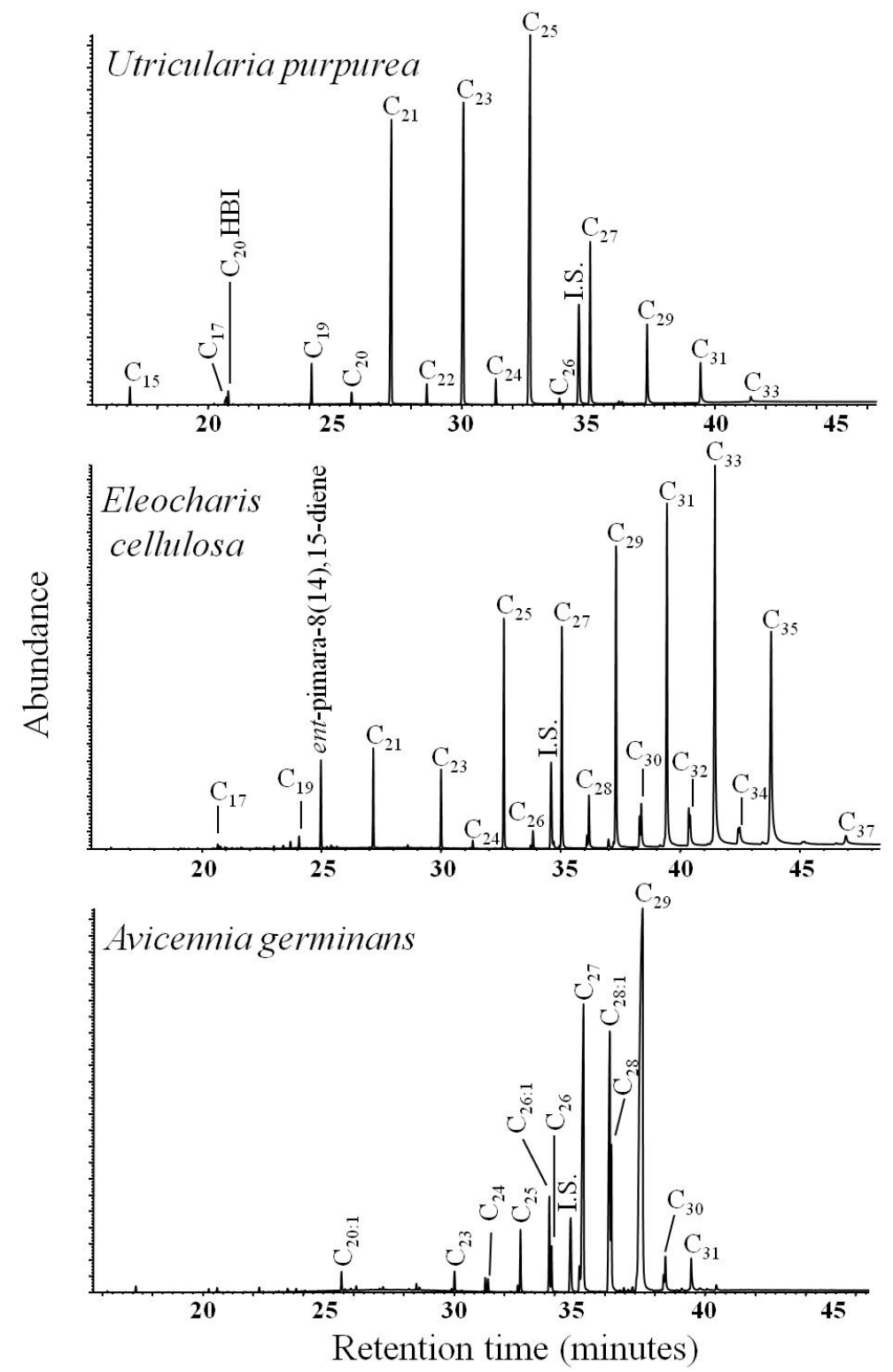

Figure 2.16. The $n$-alkane distributions (TIC) of selected vegetation species from the Florida Coastal Everglades. The presence of low molecular weight $n$-alkanes and the $\mathrm{C}_{20}$ highly branched isoprenoid $\left(\mathrm{C}_{20} \mathrm{HBI}\right)$ in the Utricularia purpurea may derive from the associated periphyton. The compounds eluting prior to the $n$-alkane are the corresponding mono-unsaturated $n$-alkenes. Internal standard (Squalane) $=$ I.S. 


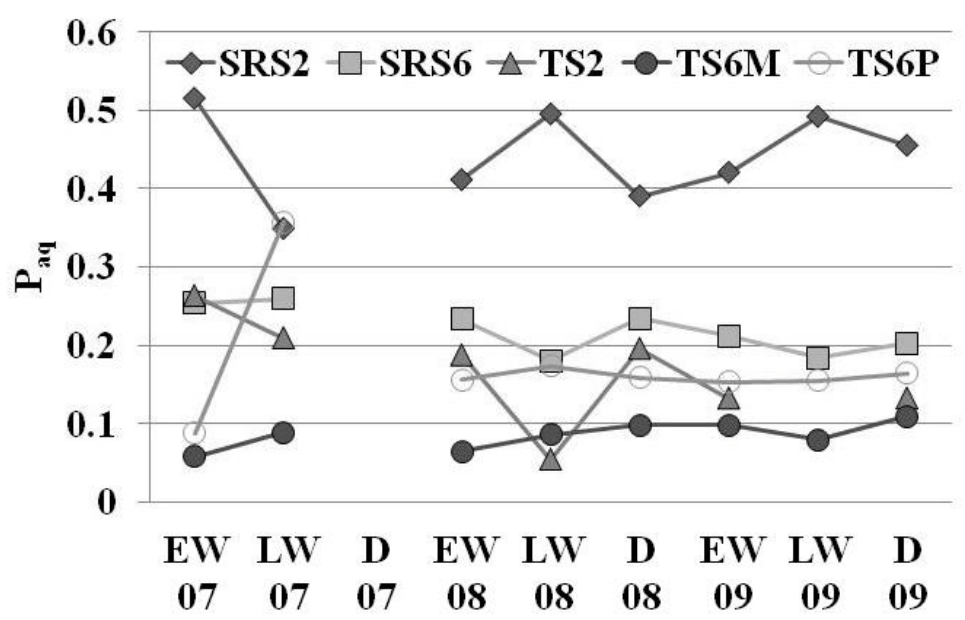

Figure 2.17. Spatial and seasonal changes in the $P_{a q}$ values for the five study sites. Seasons are shown as early wet (EW), late wet (LW) and dry (D) seasons for samples collected in 2007-2009.

\subsection{3.b. Mono-unsaturated n-alkenes:}

In addition to the saturated $n$-alkanes, the samples analyzed in this study also contained a homologous series of mono-unsaturated $n$-alkenes (Tables A2.5-A2.11 found in Appendix 2.2). Although the exact position of the double bond was not determined, these compounds eluted just before the corresponding $n$-alkane and the mass spectrum was compared with those previously reported in the literature. These types of compounds have previously been reported in sediments of the Everglades and were suggested to derive from the microbial transformation of the corresponding $n$-alkanes or from direct biomass inputs (Jaffé et al., 2001). However, these olefins have also been reported in algae (Gelpi et al., 1968) and in plant epicuticular waxes, indicating autochthonous and allochthonous OM inputs to lake sediments, respectively (Cranwell, 1982).

The plant samples analyzed in this study were found to contain a homologous series of $n$-alkenes with a mostly even/odd carbon number predominance (Figure 2.18). Most of the vegetation samples contained $n$-alkenes ranging from $\mathrm{C}_{20}$ to $\mathrm{C}_{33}$, except for 
Chara and Rhizophora mangle leaves which also contained some of the short-chain homologues. In the case of Chara, these short-chain compounds might derive from epiphytic growth on the plant leaves rather than by direct production by the plant. The presence of high amounts of the $\mathrm{C}_{28} n$-alkene in both the black and the red mangrove leaves is of particular interest. While similar distributions have been reported for a coastal macrophyte (J. roemerianus) abundant in more temperate environments (Canuel et al., 1997), the use of the $\mathrm{C}_{28}$ homologue as a mangrove-specific biomarker in the FCE has previously been described (Jaffé et al., 2001).

The periphyton samples collected at the two freshwater sites also contained these mono-unsaturated compounds (Tables A2.5-A2.6 and Figures 2.19.a-2.19.b) and their distribution was generally characterized by an odd/even carbon number predominance. The maximum homologue in the periphyton samples was found at $\mathrm{C}_{17}-\mathrm{C}_{19}$, values that have been reported to occur in microalgae and cyanobacteria (Volkman et al., 1988). The even numbered long chain homologues may be derived from plant tissue trapped in the algal mat. As in the case of the $n$-alkanes, the ratio of long chain $(C \geq 20)$ to short chain $(\mathrm{C} \leq 19) n$-alkenes was generally higher for the TS2 periphyton samples and was highest for samples collected in the late wet season. Also in agreement with the saturated compounds, SRS2 periphyton showed higher ratio values in the early wet season, corresponding to a peak in productivity from the associated Utricularia.

The floc samples contained $n$-alkenes at concentrations that were typically less than $10 \%$ of the $n$-alkanes (Tables A2.7-A2.11 and Figures 2.20.a-2.20.e) possibly as a result of their degradation. The floc collected at SRS2 showed an odd/even carbon number predominance of $n$-alkenes ranging between $\mathrm{C}_{18}$ and $\mathrm{C}_{30}$ with a $\mathrm{C}_{\max }$ at $\mathrm{C}_{27}$. This 
distribution was similar to that of the $n$-alkanes, suggesting that these mono-unsaturated compounds might be produced by the microbial transformation of the parent $n$-alkane compounds (Albaiges et al., 1984). In addition, this $n$-alkene distribution has been observed for peat samples of the FCE (Jaffé et al., 2001). Short chain $n$-alkenes (except for small quantities of $\mathrm{C}_{18}$ and $\mathrm{C}_{19}$ ) were absent from these floc samples, suggesting their preferential degradation in the floc of this freshwater site. The SRS6 floc contained $n$ alkenes ranging from $\mathrm{C}_{22}$ to $\mathrm{C}_{30}$ with an even/odd carbon number predominance and a $\mathrm{C}_{\max }$ at $\mathrm{C}_{28}$. The enrichment of the $\mathrm{C}_{28}$ homologue has been suggested as a marker for mangrove inputs to sediments in this environment (Figure 2.18 and Jaffé et al., 2001). Floc from TS2 contained $n$-alkenes ranging from $\mathrm{C}_{22}$ to $\mathrm{C}_{32}$ with an even/odd carbon number predominance and $\mathrm{C}_{\max }$ also at $\mathrm{C}_{28}$. Sawgrass blades from this same site contained high amounts of $\mathrm{C}_{26}\left(\mathrm{C}_{\max }\right)$ and $\mathrm{C}_{28} n$-alkenes, indicating that this plant may be a source of these compounds to the floc layer. Finally, the floc collected at the TS6 mangrove sites showed an even/odd carbon number predominance and a $\mathrm{C}_{\max }$ at $\mathrm{C}_{28}$, indicative of mangrove inputs.

In summary, low amounts of $n$-alkenes were detected in the all the floc samples and their different distributions in the FCE suggest either microbial transformation of the parent $n$-alkanes (Albaiges et al., 1984) or the preservation and/or recent inputs of higher plant-derived OM (Jaffé et al., 2001). The lower amounts detected compared to the $n$ alkanes, suggests that these compounds are not stable and preferentially degrade in this environment. The absence of the short chain homologues is also indicative of their preferential degradation. 


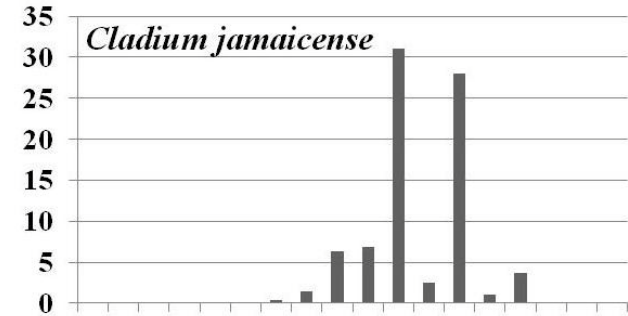

$\mathrm{C} 16 \mathrm{C} 18 \mathrm{C20} \mathrm{C22} \mathrm{C24} \mathrm{C26} \mathrm{C28} \mathrm{C} 30 \mathrm{C} 32$
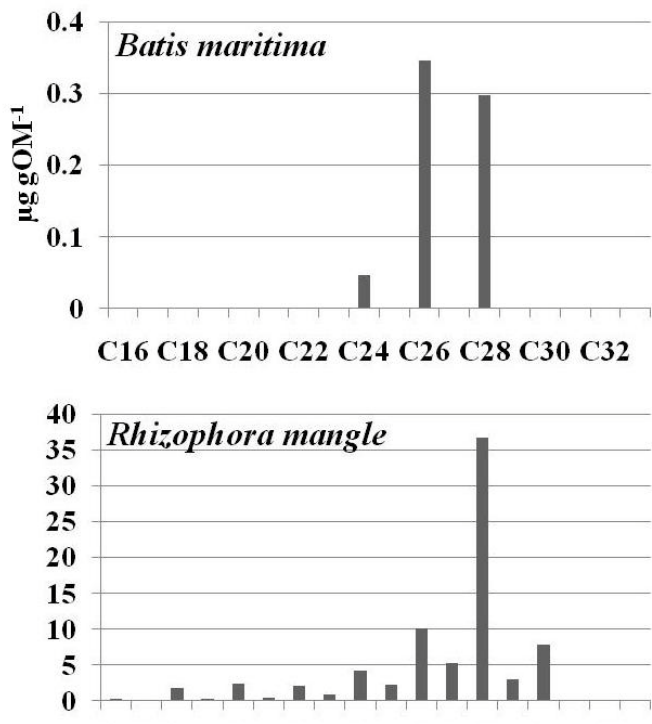

C16 C18 C20 C22 C24 C26 C28 C30 C32
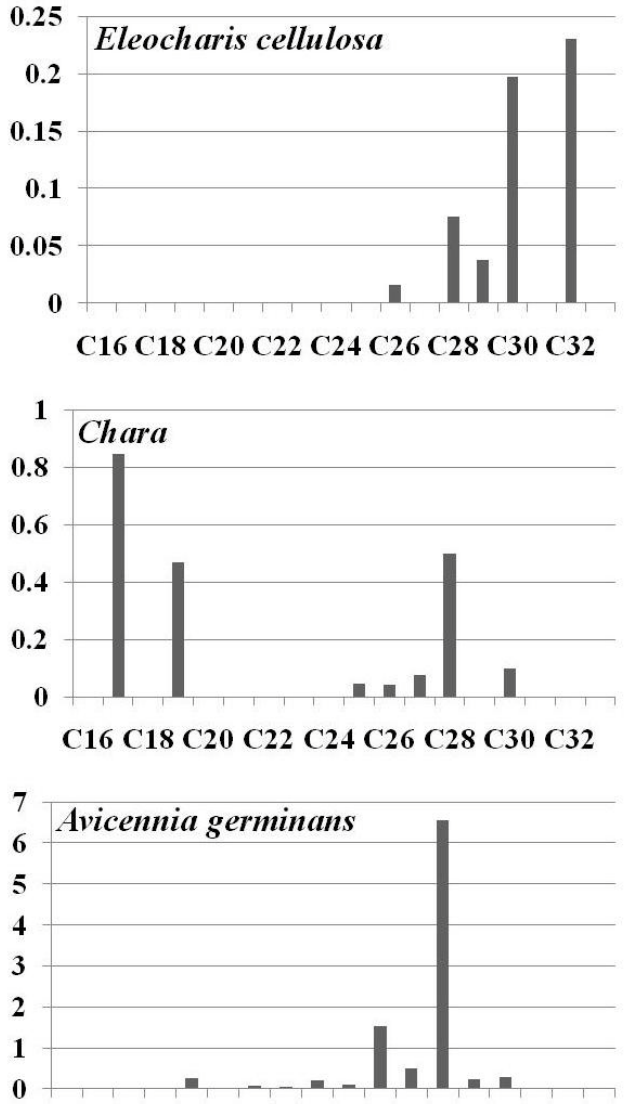

C16 C18 C20 C22 C24 C26 C28 C30 C32

Carbon number

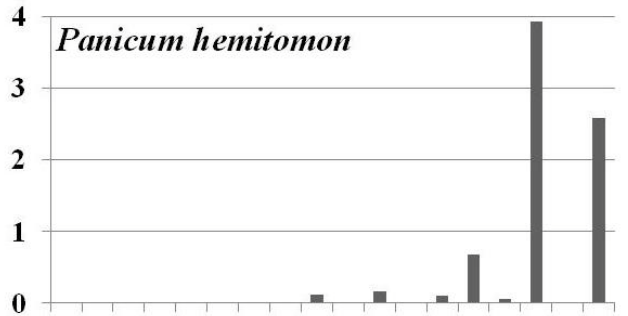

$\mathrm{C} 16 \mathrm{C} 18 \mathrm{C20} \mathrm{C22} \mathrm{C24} \mathrm{C} 26 \mathrm{C28} \mathrm{C} 30 \mathrm{C} 32$

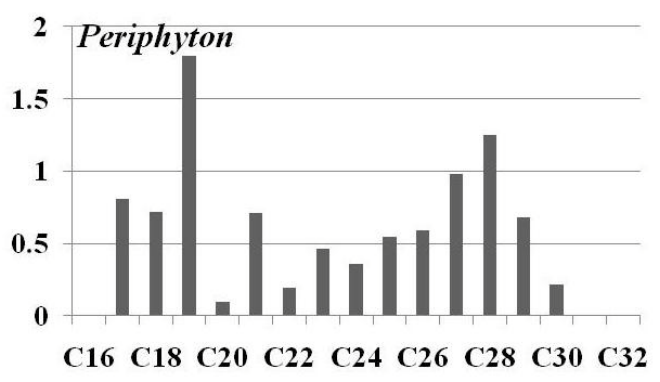

Figure 2.18. The $n$-alkene distribution for typical Everglades' vegetation samples. The abundance for the various samples is shown on different scales. 

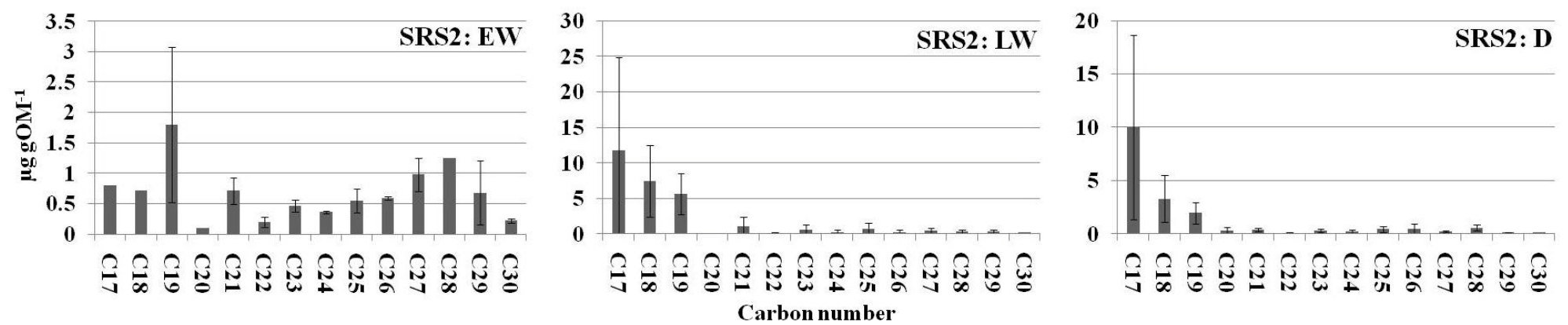

Figure 2.19.a. The $n$-alkene distribution for SRS2 periphyton samples. The abundance for the various samples is shown on different scales. Seasons are indicated on each graph as early wet (EW), late wet (LW) and dry (D) seasons for samples collected in 2007-2009.
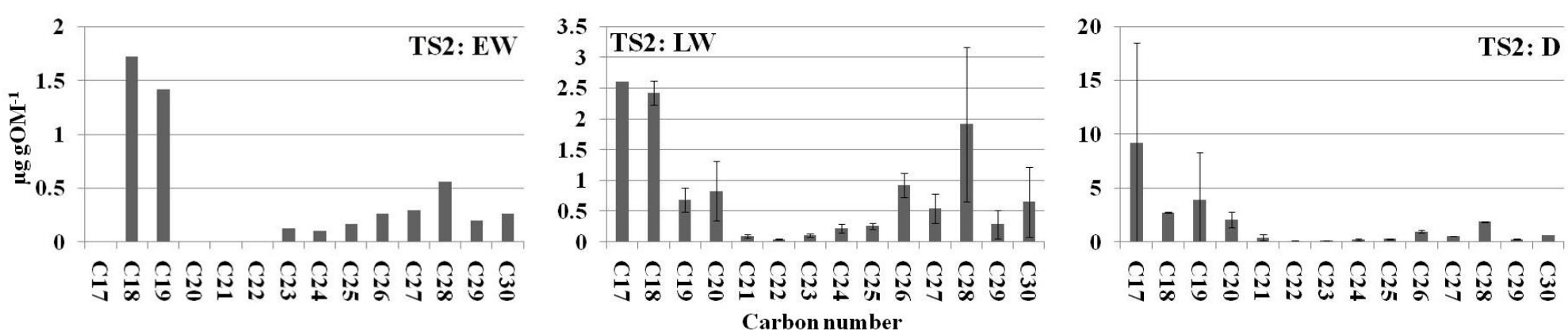

Figure 2.19.b. The $n$-alkene distribution for TS2 periphyton samples. The abundance for the various samples is shown on different scales. Seasons are indicated on each graph as early wet (EW), late wet (LW) and dry (D) seasons for samples collected in 20072009. 

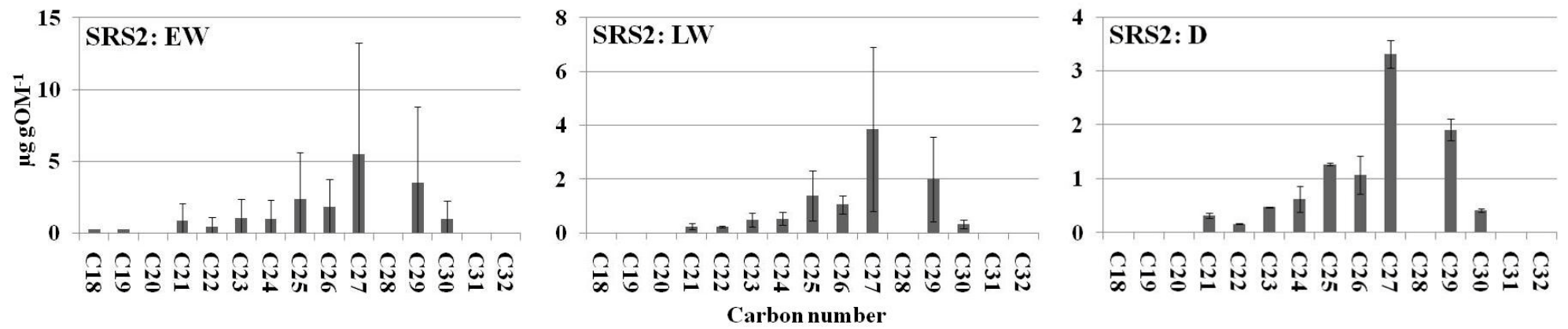

Figure 2.20.a. The $n$-alkene distribution in SRS 2 floc samples. The abundance for the various samples is shown on different scales. Seasons are indicated on the top left corner of each graph as early wet (EW), late wet (LW) and dry (D) seasons for samples collected in 2007-2009.
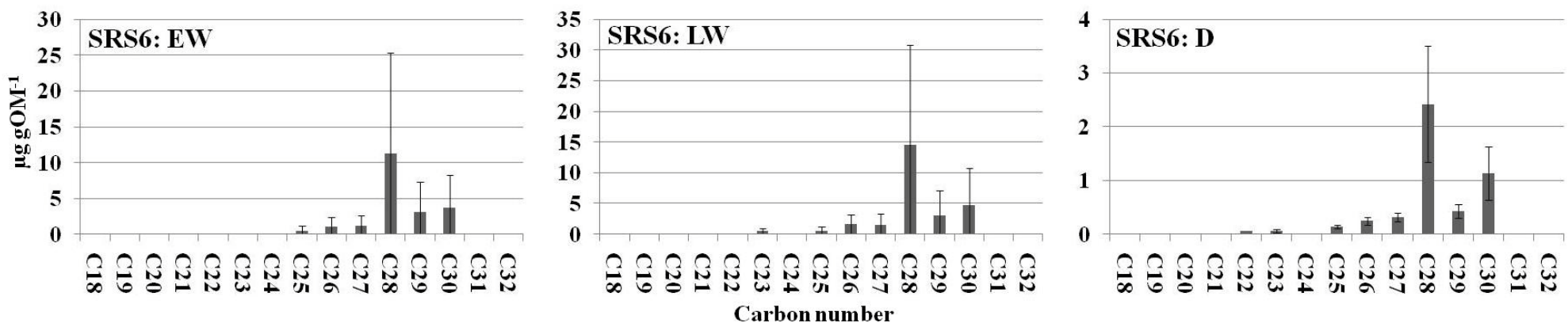

Figure 2.20.b. The $n$-alkene distribution in SRS6 floc samples. The abundance for the various samples is shown on different scales. Seasons are indicated on the top left corner of each graph as early wet (EW), late wet (LW) and dry (D) seasons for samples collected in 2007-2009. 

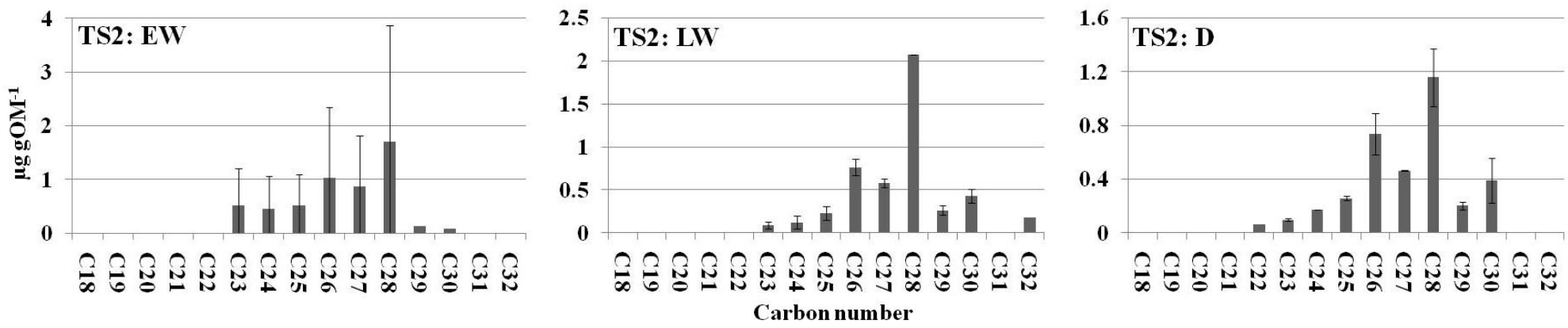

Figure 2.20.c. The $n$-alkene distribution in TS2 floc samples. The abundance for the various samples is shown on different scales. Seasons are indicated on the top left corner of each graph as early wet (EW), late wet (LW) and dry (D) seasons for samples collected in 2007-2009.
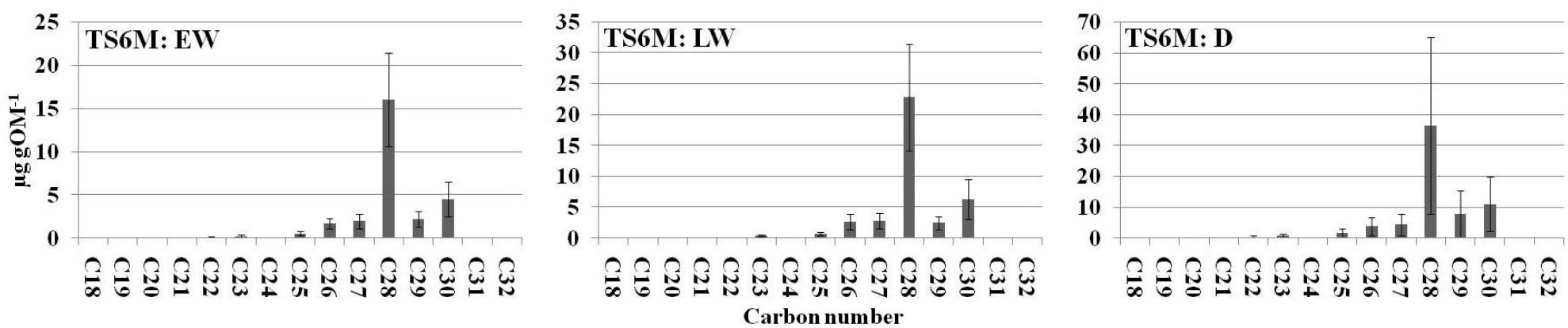

Figure 2.20.d. The $n$-alkene distribution in TS6M floc samples. The abundance for the various samples is shown on different scales. Seasons are indicated on the top left corner of each graph as early wet (EW), late wet (LW) and dry (D) seasons for samples collected in 2007-2009. 

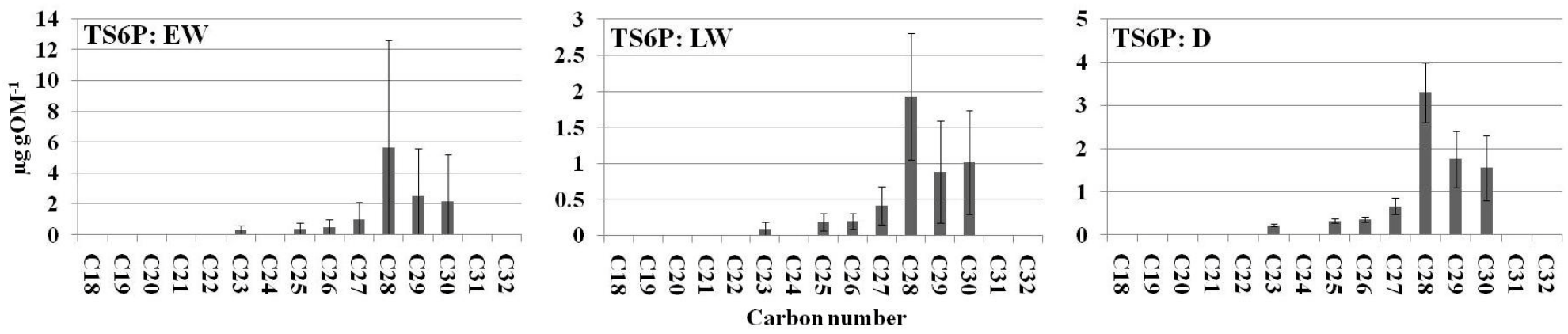

Figure 2.20.e. The $n$-alkene distribution in TS6P floc samples. The abundance for the various samples is shown on different scales. Seasons are indicated on the top left corner of each graph as early wet (EW), late wet (LW) and dry (D) seasons for samples collected in 2007-2009. 


\subsection{3.c. $C_{20}$ and $C_{25}$ highly branched isoprenoids:}

The $\mathrm{C}_{20}$ highly branched isoprenoid (HBI) identified in this study as $2,6,10$ trimethyl-7-(3-methylbutyl)-dodecane has been reported to occur in sediments (Jaffé et al., 2001), particulate organic matter (Xu et al., 2007) and floc (Neto et al., 2006) samples from the Everglades. This compound has been suggested as a marker for periphyton in freshwater marsh areas, particularly from cyanobacteria on the basis of its highly depleted $\delta^{13} \mathrm{C}$ value (Jaffé et al., 2001). The $\mathrm{C}_{20} \mathrm{HBI}$ was only detected in the Utricularia purpurea $\left(157 \mu \mathrm{gOM}^{-1}\right)$ and in the Bacopa carolineana $\left(3.7 \mu \mathrm{g} \mathrm{gOM}^{-1}\right)$ samples, suggesting that this vegetation could have been covered by epiphytic growth at the time of collection. In fact, aquatic macrophytes in the Everglades, such as Utricularia purpurea, are known to be colonized by epiphytic periphyton (Richards, 2001). In agreement with the literature (Jaffé et al., 2001), the periphyton samples analyzed in this study were found to contain significant amounts of the $\mathrm{C}_{20} \mathrm{HBI}$ (Table A2.12 and Figure 2.21).

The periphyton collected at SRS2 (21-419 $\left.\mu \mathrm{g} \mathrm{gOM}^{-1}\right)$ contained much higher amounts of $\mathrm{C}_{20} \mathrm{HBI}$ than the periphyton found at TS2 (10-66 $\left.\mu \mathrm{g} \mathrm{gOM}^{-1}\right)$. This seems to correspond with higher amounts of cyanobacteria derived OM detected at the former $\left(194-4303 \mu \mathrm{g} \mathrm{gOM}^{-1}\right)$ compared to the latter site $\left(35-1909 \mu \mathrm{g} \mathrm{gOM}^{-1}\right)$. As such, a positive correlation was found between the coccoidal cyanobacteria pigment marker zeaxanthin and the $\mathrm{C}_{20} \mathrm{HBI}$ abundance in these samples as discussed in a later section of this dissertation. 


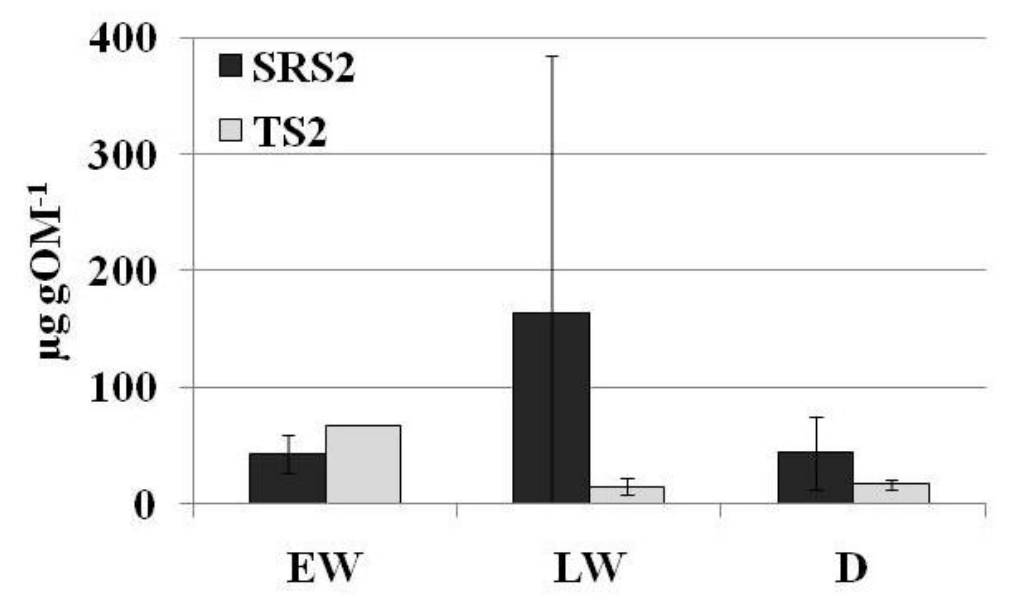

Figure 2.21. Concentrations of the $\mathrm{C}_{20} \mathrm{HBI}$ in SRS2 and TS2 periphyton mat samples. Seasons are shown as early wet (EW), late wet (LW) and dry (D) seasons for samples collected in 2007-2009.

Clear spatial differences in the relative abundance of the $\mathrm{C}_{20} \mathrm{HBI}$ in the floc material were observed (Table A2.13 and Figures 2.22.a-2.22.e). The floc collected at the two freshwater sites contained much higher amounts of $\mathrm{C}_{20} \mathrm{HBI}\left(15-237 \mu \mathrm{g} \mathrm{gOM}^{-1}\right.$ at SRS2 and 2.8-217 $\mu \mathrm{gOMM}^{-1}$ at TS2) compared with the floc collected at the mangrove sites $\left(0.48-20 \mu \mathrm{g} \mathrm{gOM}^{-1}, 2.0-50 \mu \mathrm{g} \mathrm{gOM}^{-1}\right.$ and $1.5-42 \mu \mathrm{g} \mathrm{gOM}^{-1}$ at SRS6, TS6M and TS6P, respectively). The high concentration detected at the freshwater sites has previously been reported for TS floc samples (Neto et al., 2006) and has been attributed to the high concentration of periphyton mat-derived $\mathrm{OM}$ to the floc at these sites compared to the mangrove sites. The total $\mathrm{C}_{20} \mathrm{HBI}$ concentrations for the two freshwater sites are basically equivalent, even though the floc at SRS2 contained more cyanobacteria (13-214 $\mu \mathrm{g} \mathrm{gOM}^{-1}$ at SRS2 vs. $6-25 \mu \mathrm{gOM}^{-1}$ at TS2). It is possible and likely that not all cyanobacteria produce the $\mathrm{C}_{20} \mathrm{HBI}$, and/or that the production of this compound is different under different environmental conditions. The relatively lower amounts of $\mathrm{C}_{20}$ HBIs detected in the mangrove floc may be the result of physical transport of periphyton- 
derived OM from the freshwater marshes (Jaffé et al., 2001 and 2006) or might be derived from autochthonous cyanobacterial primary productivity at the mangrove sites.

The seasonal distribution of the $\mathrm{C}_{20} \mathrm{HBI}$ for all the floc samples showed no clear pattern and a common, but not consistent increase in concentration during the wet season. The floc collected at the two freshwater sites contained higher amounts of the $\mathrm{C}_{20} \mathrm{HBI}$ during the wet season, corresponding with an increase in periphyton productivity (Ewe et al., 2006) and associated cyanobacterial pigments (data presented above). However, the seasonal changes identified for $\mathrm{C}_{20} \mathrm{HBI}$ and the cyanobacterial pigments were not coupled, suggesting that cyanobacteria may produce different concentrations of the $\mathrm{C}_{20}$ HBI under different environmental conditions. The floc from SRS6 contained more $\mathrm{C}_{20}$ HBIs during the early wet season. This seasonal trend was slightly decoupled from the increase in cyanobacteria which occurred in the late wet season (pigment data presented above) and may suggest higher hydrodynamic transport from the freshwater marshes during this season. Finally, the floc from TS6M showed the highest concentration in the dry season of 2008 while TS6P floc had higher amounts in the early wet season of 2008. The absence of clear seasonal patterns at these sites may be indicative of autochthonous cyanobacterial production.

In addition to the $\mathrm{C}_{20} \mathrm{HBI}$, a monocyclic, tri-unsaturated $\mathrm{C}_{25} \mathrm{HBI}$ was detected only in the floc collected at SRS6 (Figure 2.23). This HBI was identified by comparison with published mass spectra (Massé et al., 2004) and has been identified in sediments from the Northwest Atlantic (Farrington et al., 1977), Rhode Island Sound (Boehm et al., 1978) and Puget Sound (Barrick et al., 1981). 

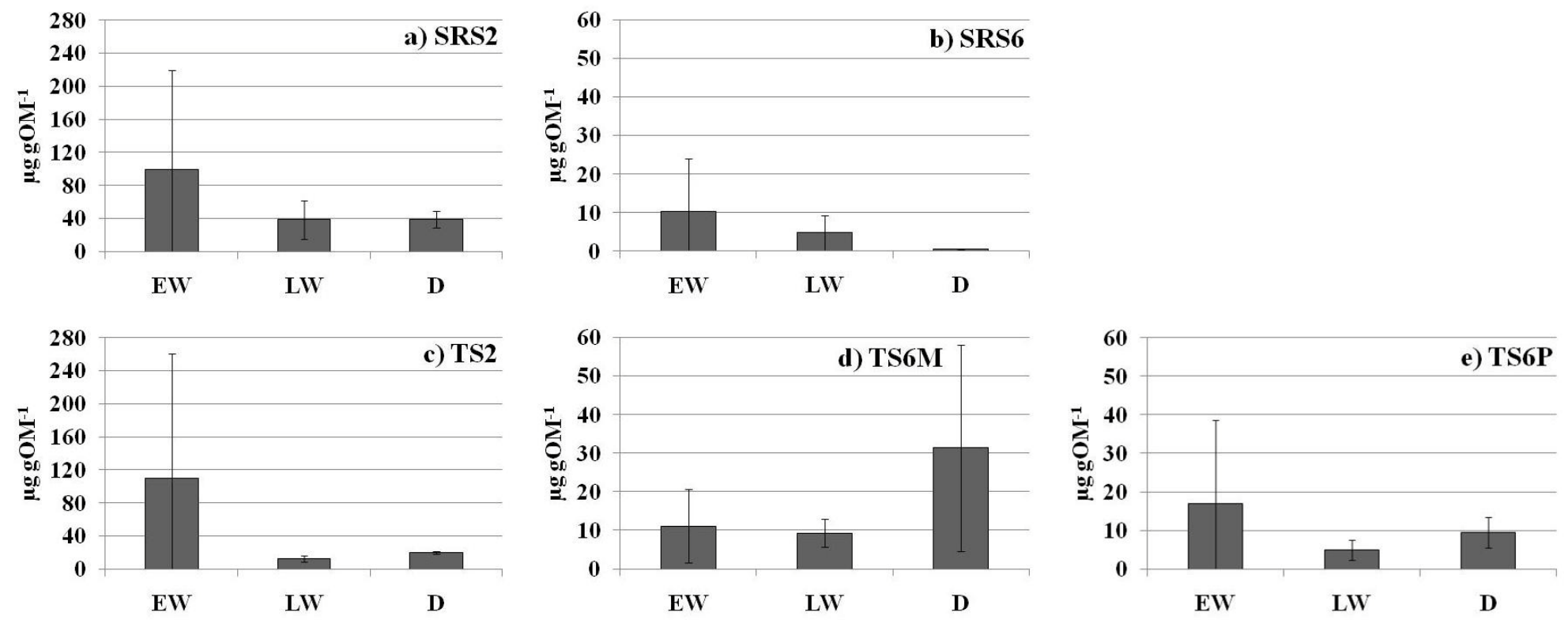

Figure 2.22. Spatial and seasonal distribution of the $\mathrm{C}_{20}$ HBI concentration in Everglades' floc (SRS2 (a), SRS6 (b), TS2 (c), TS6M (d) and TS6P (e)) samples. The abundance for the various samples is shown on different scales. Seasons are shown as early wet (EW), late wet (LW) and dry (D) seasons for samples collected in 2007-2009. 
Recently, this compound was isolated from the marine diatom Rhizosolenia setigera (Belt et al., 2003) and was suggested as a useful marker of marine diatom inputs to sediments. To my knowledge, this compound has never been reported in the Everglades system. In the present study, it was found at concentrations ranging from 0.94 to $28 \mu \mathrm{g} \mathrm{gOM}^{-1}$ in the floc collected at SRS6. Xu et al. (2006) reported the occurrence of saturated, as well as mono- and di-unsaturated $\mathrm{C}_{25}$ HBIs in sediments from Florida Bay. The authors did not detect any $\mathrm{C}_{25}$ alkenes with more than two double bonds and suggested early diagenetic removal of these polyunsaturated compounds and unfavorable environmental conditions for their biosynthetic production. The occurrence of the $\mathrm{C}_{25}$ tri-unsaturated $\mathrm{HBI}$ in floc from SRS6 therefore may suggest fresh allochthonous OM inputs from marine diatoms.

The seasonal distribution of the $\mathrm{C}_{25: 3} \mathrm{HBI}$ followed the same patterns as those for the pigment fucoxanthin (pigment data described above), a molecular marker used to identify diatom inputs to environmental samples (Louda 2008). In fact, a significant linear correlation was found between these two markers (data not shown, $\mathrm{r}^{2}=0.73$ ). Consistently higher concentrations of the $\mathrm{C}_{25: 3} \mathrm{HBI}$ were found in floc collected during the wet season, suggesting inputs that may follow seasonal productivity patterns of this marine diatom species. 


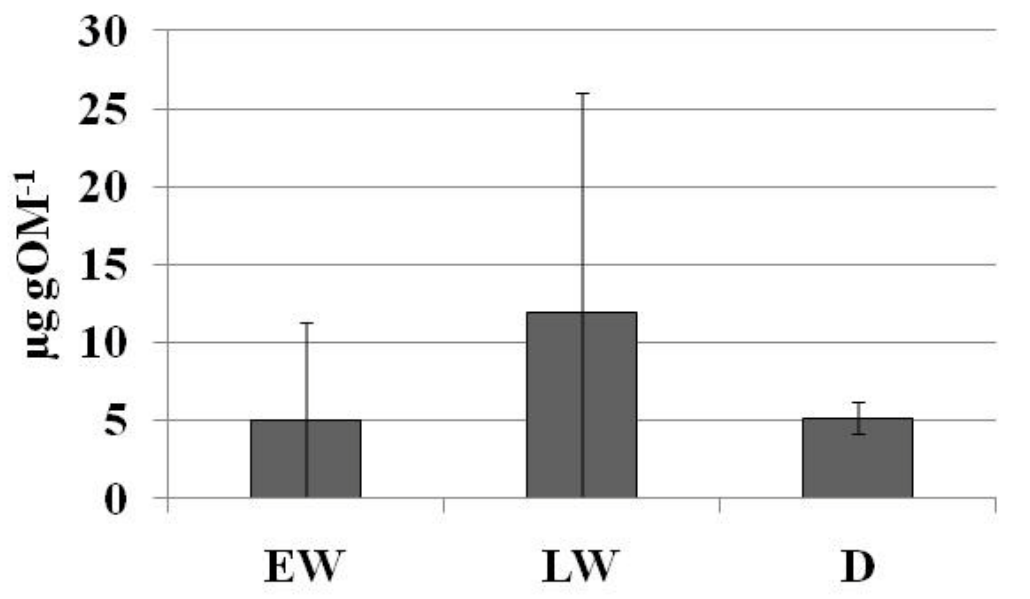

Figure 2.23. Seasonal changes in the $C_{25: 3} \mathrm{HBI}$ concentrations for the SRS6 floc sample. Seasons are shown as early wet (EW), late wet (LW) and dry (D) seasons for samples collected in 2007-2009.

\subsection{3.d. Botryococcene isoprenoids:}

The production of botryococcanes was first reported as biosynthetic products from the unicellular green microalga Botryococcus braunii (Metzger et al. 1999). Botryococcus braunii has been classified into three morphologically similar races, A, B and L according to the types of hydrocarbons they produce (Metzger et al., 1985). Race A produces $n$-alkadienes and trienes with odd carbon numbers ranging from $\mathrm{C}_{23}$ to $\mathrm{C}_{31}$. Race B produces botryococcenes $\left(\mathrm{C}_{n} \mathrm{H}_{2 n-10}, n=30-37\right)$ and a small amount of methylated squalenes ranging from $\mathrm{C}_{31}$ to $\mathrm{C}_{34}$. Finally, race $\mathrm{L}$ produces a single tetraterpenoid, lycopadiene ( $\mathrm{C}_{40}$; Metzger et al., 2005 and references therein). While Botryococcus braunii is widespread in aquatic environments, it has not been reported to occur in the freshwater wetlands of the Everglades, although its microfossils have been described in soil cores from tree islands of SRS (Chmura et al., 2006). Recently, Gao et al. (2007) detected a series of novel botryococcenes with carbon numbers ranging from 32 to 34 and different skeletal structures (Appendix 2.3) in periphyton, floc and soils from the Florida 
Everglades. On the basis of the analysis of periphyton main algal components, the authors assigned filamentous green algae as the most likely source of these compounds in this environment.

A relatively high abundance of botryococcenes, consisting of a suite of cyclic and acyclic hydrocarbons with carbon numbers ranging from 32 to 34 , was identified in the periphyton and floc samples of the present study (Table A2.14 in Appendix 2.2). In the present study, several botryococcenes (identified following the structure and skeleton assignments of Gao et al., 2007) were detected only in the periphyton samples collected from the freshwater SRS2 site (Figure 2.24). Gao et al. (2007) also found these compounds at low concentrations in periphyton mats from the Taylor River however, they were not detected in the present study.

These compounds occurred in total concentrations ranging from 5.5 to $69 \mu \mathrm{g}$ $\mathrm{gOM}^{-1}$ and were dominated by botryococcenes with the skeleton structure $\mathrm{S}-3\left(\mathrm{C}_{33}\right.$; Figure 2.24.a and Gao et al., 2007). The molecular structure of skeleton 3 is shown in Figure 2.25. The complete set of skeleton structures for the botryococcenes found in the FCE is given in Appendix 2.3. No clear seasonal patterns were observed in the botryococcene distribution of the periphyton samples.

Botryococcenes were also detected in some of the floc samples (Table A2.14 and Figure 2.26), namely in the floc collected at SRS2 (10-139 $\left.\mu \mathrm{g} \mathrm{gOM}^{-1}\right)$, TS6M (0.45-7.6 $\left.\mu \mathrm{gOM}^{-1}\right)$ and TS6P $\left(2.7-5.1 \mu \mathrm{g} \mathrm{gOM}^{-1}\right)$. While all the floc samples contained green algae (estimated as total chlorophyll- $b$ ), SRS2 floc contained the highest amounts (10$\left.194 \mu \mathrm{g} \mathrm{gOM}^{-1}\right)$, followed by TS6P floc (42-139 $\left.\mu \mathrm{g} \mathrm{gOM}^{-1}\right)$ and TS6M floc (17-60 $\mu \mathrm{g}$ $\left.\mathrm{gOM}^{-1}\right)$. Thus, the floc at these locations receives input from such organisms. 

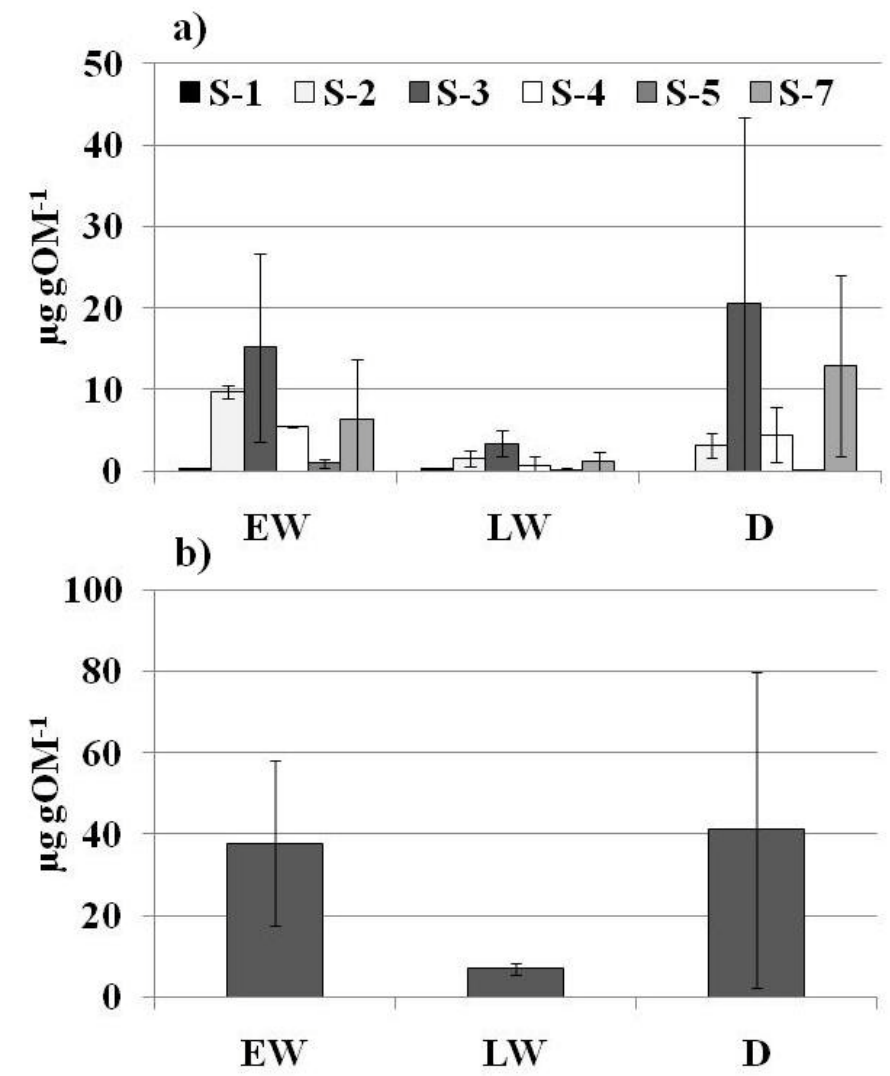

Figure 2.24. Seasonal changes in botryococcene (individual skeleton structures (a) and total (b)) concentration for SRS2 periphyton mats. Skeletal assignments are according to Gao et al., (2007). Seasons are shown as early wet (EW), late wet (LW) and dry (D) seasons for samples collected in 2007-2009.

Figure 2.25. Molecular structure for the botryococcene compounds based on skeleton 3 (according to Gao et al., 2007).

Correlations between botryococcenes and chlorophyll- $b$ are discussed in a later section. Surprisingly, the floc collected at TS2 was found to contain no botryococcenes. In fact, as shown by the chemotaxonomic estimate of the floc from this freshwater site, the amount of green algae was much lower compared to cyanobacteria. 


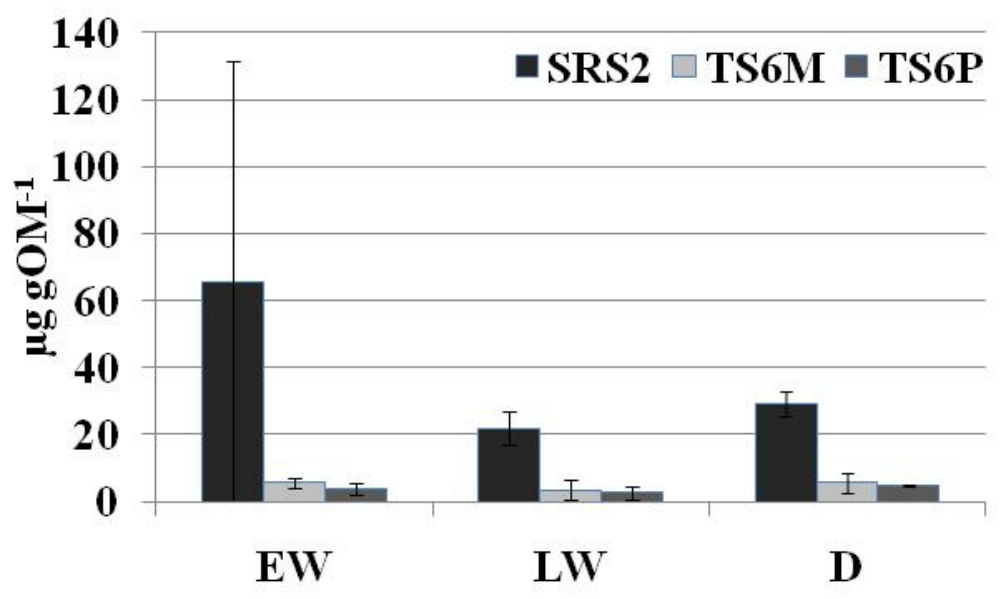

Figure 2.26. Seasonal distribution of total botryococcene concentration (sum of all skeleton structures) for three Everglades' floc samples. Seasons are shown as early wet (EW), late wet (LW) and dry (D) seasons for samples collected in 2007-2009.

On an OM basis, the floc at SRS2 was found to contain more botryococcenes compared to the periphyton collected at that same site (Table A2.14), suggesting that some of these compounds are resistant to early diagenetic transformations and can accumulate and become enriched in this environment. Although these compounds were not detected in the periphyton or floc samples at TS2, the small amounts of botryococcenes found in the floc at the TS mangrove sites, (as in the case of the $\mathrm{C}_{20}$ HBIs), may not be indicative of freshwater periphyton-derived OM transport and may indicate an autochthonous source at the estuarine locations. While the Utricularia samples collected at SRS2 were found to contain a relatively significant amount of botryococcenes (up to $15 \mu \mathrm{g} \mathrm{gOM}^{-1}$ ), the macroalgae found at TS6P (Chara) did not contain any.

As in the case of the periphyton samples, no consistent seasonal patterns were observed in the botryococcene distribution of the SRS2 floc samples, although higher concentrations seem to occur in the early wet season (Figure 2.27). This suggests that the 
production of these compounds by green algae does not follow seasonal patterns of periphyton productivity and may occur only under certain environmental conditions.

a)

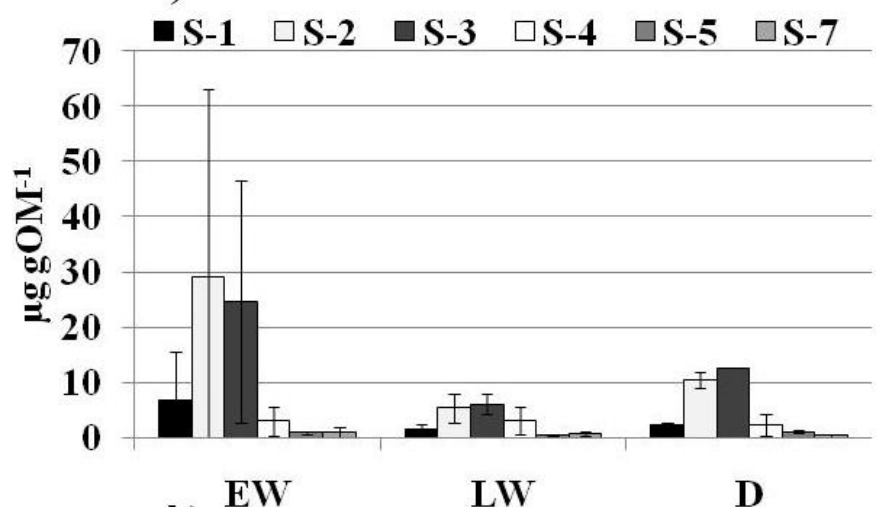

b)

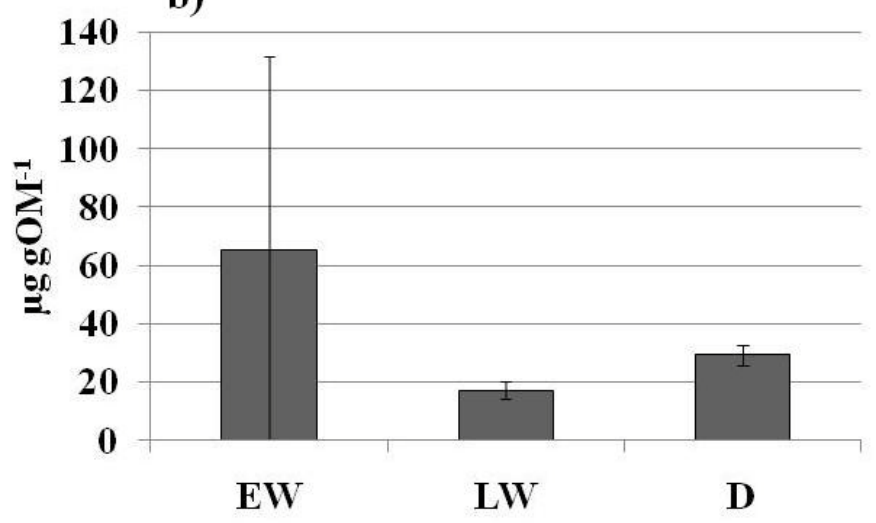

Figure 2.27. Seasonal changes in botryococcene (individual skeleton structures (a) and total (b)) concentration for SRS2 floc. Skeletal assignments are according to Gao et al., (2007). Seasons are shown as early wet (EW), late wet (LW) and dry (D) seasons for samples collected in 2007-2009.

\subsection{3.e. Kaurenes:}

Tetracyclic hydrocarbons known as kaurenes, defined here as the sum of entkaurane, ent-kaur-15-ene and ent-kaur-16-ene (structures shown in Appendix 2.3), were detected in most of the FCE floc samples (Table A2.15 in Appendix 2.2). These compounds are abundant in higher plants where they function as precursors for phytohormones essential for plant growth and development (Li et al., 2000; Xiang et al., 
2004). The application of kaurenes as indicators of higher plants has been reported in geologic peat samples (Venkatesan et al., 1986). A strong association of kaurenes with sawgrass belowground biomass in peat cores of the Everglades has also been reported (Saunders et al., 2006). In fact, these authors found the highest concentrations of kaurenes in Cladium jamaicense root biomass, reporting it to be two orders of magnitude greater than in sawgrass leaves and in leaf and root biomass of Eleocharis. Kaurenes are also known to be biosynthesized by certain fungi under nitrogen limiting conditions (Fernández-Martín et al., 2000) and have been suggested as molecular proxies for fungal activity in Everglades floc (Neto et al., 2006). Although the freshwater wetlands of the Everglades are not nitrogen limited, phosphorus limitation (Childers et al., 2006) might induce fungi to produce these compounds in this environment. However, while the exact source of these compounds in the Everglades remains unknown, by association, they seem to be primarily sawgrass derived.

In the present study, relatively low concentrations of kaurenes were detected in some of the vegetation samples and highest amounts occurred in the sawgrass leaves $(9.2$ $\mu \mathrm{gOM}^{-1}$; no below-ground biomass was analyzed here). In the floc samples (Figure 2.28), the concentration of kaurenes showed no spatial or seasonal trend from the freshwater to the mangrove sites. Figure 2.28 shows the average of all the quarterly floc samples and shows the highest concentrations of kaurenes at TS2 (0.15-3.7 $\left.\mu \mathrm{g} \mathrm{gOM}^{-1}\right)$ and TS6P $\left(0.48-5.0 \mu \mathrm{gOM}^{-1}\right)$. The TS2 floc has been shown to contain kaurenes and might be receiving significant sawgrass-derived OM inputs. Their presence at similar concentrations in the mangrove-dominated floc sample (TS6P) suggests that they may 
also be useful fungal markers in this oligotrophic environment, or transported in detrital form to this location.

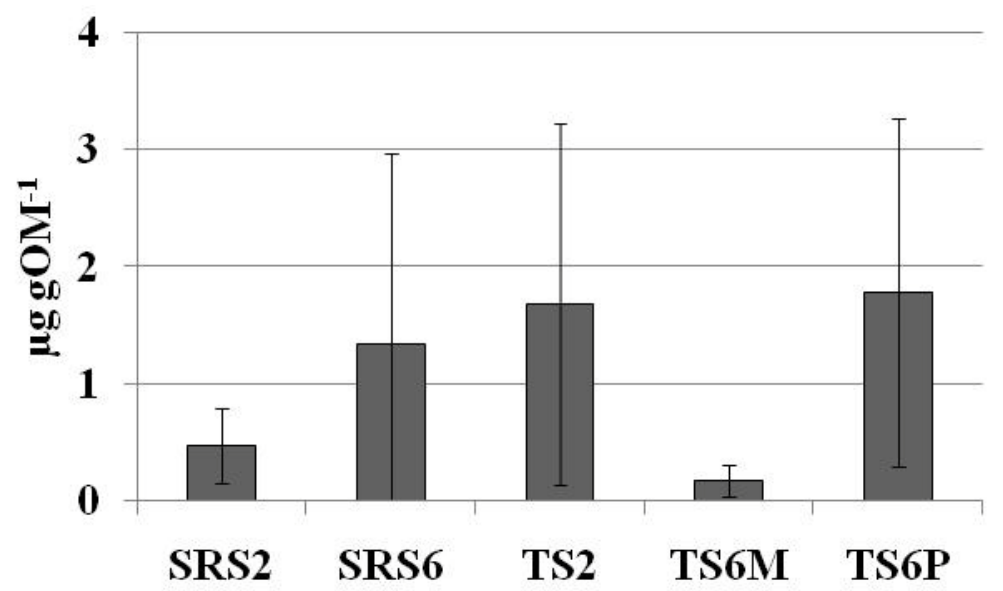

Figure 2.28. Spatial distribution of total kaurenes in Everglades' floc samples. Values are averages of all quarterly samples $(n=11)$.

\subsubsection{Environmental sources of specific biomarkers:}

The $\mathrm{C}_{20} \mathrm{HBI}$ identified in our samples has been previously detected in Everglades soils (Jaffé et al., 2001), suspended particulates of Florida Bay (Xu et al., 2007) and in floc (Neto et al., 2006). High concentrations of this compound have been detected in the freshwater marshes of the FCE compared to the coastal areas and so this compound has been suggested to be an indicator of periphyton-derived OM inputs to sediments (Jaffé et al., 2001 and 2006). Although this compound has frequently been reported in the literature (Gearing et al., 1976; Rowland et al., 1990; Jaffé et al., 2001; Neto et al., 2006; Xu et al., 2007), its exact origin has not yet been established. A diatom source has been suggested because of its structural similarity with the $\mathrm{C}_{25} \mathrm{HBI}$ (Rowland et al., 1990). However, as a result of the more depleted compound-specific $\delta^{13} \mathrm{C}$ isotopic measurement of this HBI (about $-36 \%$ ) compared to diatom-derived $\mathrm{C}_{25}$ HBIs (-19 and -22\%; Canuel et al., 1997), it is believed to be biosynthesized by cyanobacteria (Jaffé et al., 2001), an 
abundant biomass component of Everglades' periphyton mats (taxonomic data presented above; Gottlieb et al., 2006).

In an attempt to confirm the source of this compound in the FCE, correlations were made between the concentration of the $\mathrm{C}_{20} \mathrm{HBI}$ and zeaxanthin in the periphyton samples. Zeaxanthin is a photo-protective pigment (PPP) biosynthesized by coccoidal cyanobacteria (Wright et al., 2006; Louda, 2008; Grant et al., 2010) and is used in chemotaxonomic equations to estimate the total biomass of this algal group in a particular sample. Figures 2.29.a and 2.29.b show the correlations obtained between these two markers in the periphyton samples from SRS2 (Figure 2.29.a; $\mathrm{r}^{2}=0.65$ ) and TS2 (Figure 2.29. $\left.\mathrm{b} ; \mathrm{r}^{2}=0.36\right)$ after removing data for the samples containing very high amounts of $\mathrm{C}_{20}$ HBIs as outliers (Grubb's test, $p=0.05$ ). It has been found that coccoidal cyanobacteria dominate the taxonomic diversity at long hydroperiod sites (Gottlieb et al., 2006) and this may be reflected in the better correlation obtained for SRS2 periphyton compared to TS2. Furthermore, because zeaxanthin is a photo-protective pigment, its concentration in relation to chlorophyll- $a$ is expected to increase in high light environments (Grant et al., 2010). This implies that high light conditions at this long hydroperiod site may be influencing the production of $\mathrm{C}_{20} \mathrm{HBIs}$ by cyanobacteria. The present results simply suggest that under certain environmental conditions, coccoidal cyanobacteria can be considered biological sources of the $\mathrm{C}_{20} \mathrm{HBI}$. 

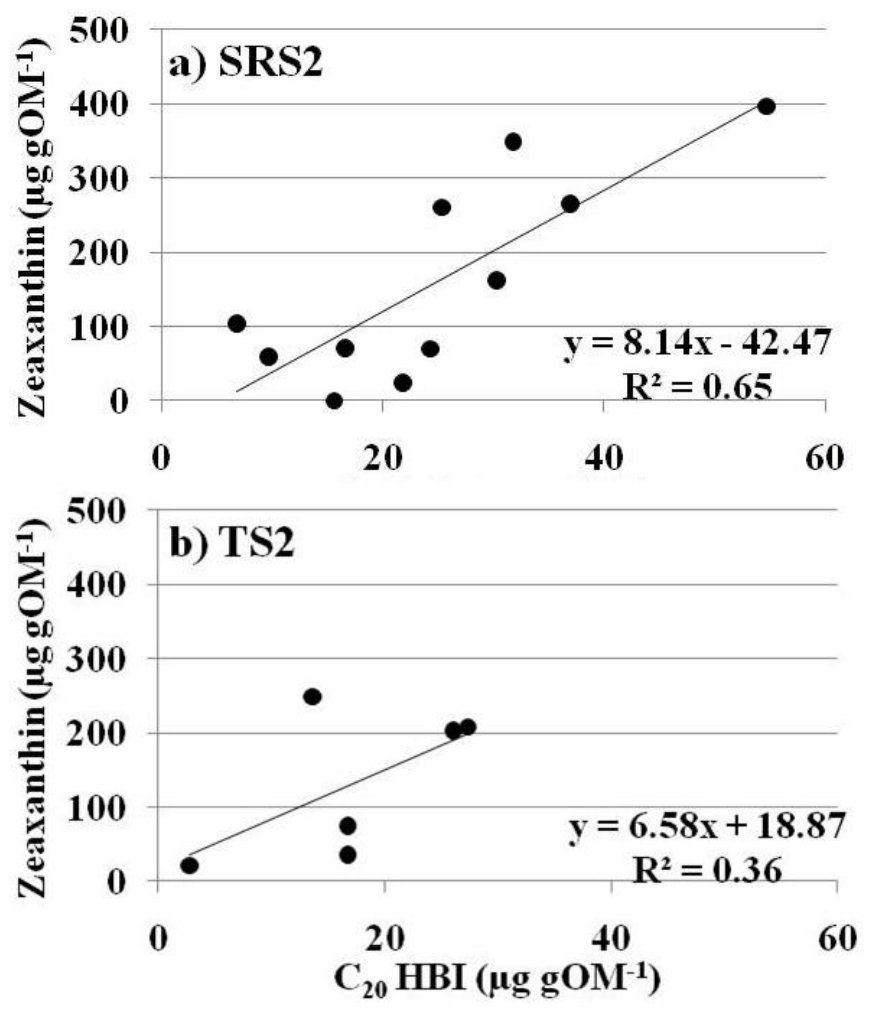

Figure 2.29. Correlations between the $\mathrm{C}_{20} \mathrm{HBI}$ and zeaxanthin $\left(\mu \mathrm{g} \mathrm{gOM}^{-1}\right)$ for $\mathrm{SRS} 2$ (a) and TS2 (b) periphyton samples.

Echinenone, a photosynthetic accessory pigment (PAP) biosynthesized by filamentous cyanobacteria (Grant et al., 2010), was also tested as a possible indicator of cyanobacteria sources of the $\mathrm{C}_{20} \mathrm{HBI}$. While the correlation between the concentration of $\mathrm{C}_{20} \mathrm{HBI}$ and echinenone for the SRS2 periphyton samples was poor (Figure 2.30.a; $\mathrm{r}^{2}=$ 0.09), TS2 periphyton showed a similar correlation to that of zeaxanthin (Figure 2.30.b; $\left.r^{2}=0.31\right)$. This correlation suggests that filamentous cyanobacteria at TS2 may also contribute to the OM in floc. Periphyton mats from short hydroperiod marshes contain higher amounts of calcite-precipitating cyanobacterial filaments compared to long hydroperiod mats (Gottlieb et al., 2006). It has also been found that extended periods of desiccation can cause a decline in filamentous cyanobacteria and an increase in coccoidal 
species (Gottlieb et al., 2005). The implication of these results suggests that cyanobacteria can produce $\mathrm{C}_{20}$ HBIs but the yield may be strongly dependent on the specific environmental conditions. In addition, it seems more likely that the $\mathrm{C}_{20} \mathrm{HBI}$ is produced by coccoidal rather than by filamentous cyanobacteria.

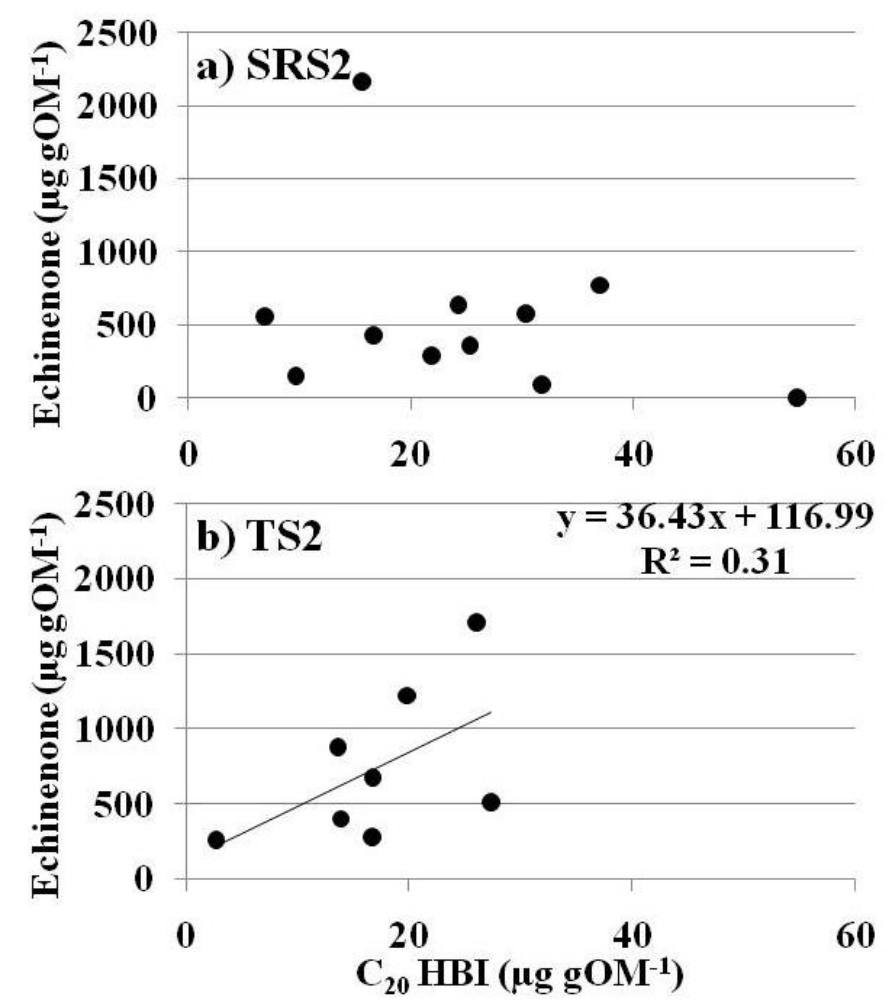

Figure 2.30. Correlations between the $\mathrm{C}_{20} \mathrm{HBI}$ and echinenone $\left(\mu \mathrm{g} \mathrm{gOM}^{-1}\right)$ for SRS2 (a) and TS2 (b) periphyton samples.

Similarly, the source of the botryococcene hydrocarbons in periphyton samples from the FCE was tested. These compounds have been reported in periphyton, floc and soils of the Everglades (Gao et al., 2007). Although most botryococcenes are known to be produced by the microalga Botryococcus braunii (Metzger et al., 1999), this alga species has not been found in the Everglades ecosystem except in one palynological study (Chmura et al., 2006), where microfossils were found in tree island soils. Gao et al. 
(2007) isolated green algae and cyanobacteria from Everglades' periphyton samples, but the authors were not able to detect any botryococcenes. The author suggested that these compounds might be produced by other species of green algae in addition to Botryococcus braunii race B or that this algal species is indeed present in the Everglades, but has never been recorded as such. Furthermore, the compound-specific $\delta^{13} \mathrm{C}$ isotopic values obtained for some of these compounds varied between -36 and -37\%o (Gao et al., 2007) similar to those obtained for the $\mathrm{C}_{20}$ HBI (Jaffé et al., 2001) whose origin is suggested to be from cyanobacteria.

In order to determine the source of these botryococcene hydrocarbons in the FCE, correlations were made between the total amount of botryococcenes (as well as the individual skeleton classes) and chlorophyll- $b$, the pigment marker for chlorophyta (Louda, 2008). Samples that did not contain chlorophyll- $b$ or botryococcenes were removed to improve the correlation. Nonetheless, the resulting correlations were very poor and not significant $(p>0.1)$ with $\mathrm{r}^{2}$ values no higher than 0.2 . These results do not allow us to make any predictions on the biological sources of botryococcenes in the wetlands of the FCE. The sources of these compounds remains elusive and these botryococcanes may be produced by other species of microalgae and, as in the case of the $\mathrm{C}_{20} \mathrm{HBIs}$, may be produced only under certain environmental conditions. Further investigations are needed to determine the sources of these compounds in the FCE.

\subsection{Conclusions:}

Floc bulk properties such as depth and density were found to be highly variable and showed only limited spatial or seasonal trends. Floc from the mangrove site TS6P 
showed lower depth and higher density values in the early wet season, possibly as a result of storm disturbance in the open pond area or inputs from the submerged macroalgae Chara. The generation of longer data sets may allow the detection of clearer trends in the future. On the other hand, the OM content of the floc was found to be spatially different and was highly dependent on hydroperiod and biomass productivity at a particular site.

Significant source differences between the freshwater marshes and the coastal mangrove-dominated areas of the FCE, as well as among freshwater and among mangrove sites were found. The floc in the freshwater marshes receives significant inputs from the local periphyton mats which have previously been suggested to contribute to the underlying floc (Gottlieb et al., 2006). This was particularly true at SRS2 where the chemotaxonomic estimate of the periphyton mats and the underlying floc layer were very similar in composition. This was even the case on a seasonal basis, suggesting that the transfer of periphyton OM to the floc layer is fast and since no obvious "memory" effect was observed at SRS2, the turnover time of floc at this location may also be on a time scale of months.

Some decoupling was observed between the periphyton and floc at TS2, probably because this short-hydroperiod site undergoes periods of complete dry-down which can accelerate the incorporation of the dead periphyton to the floc layer as well as floc into soils. Furthermore, extended periods of desiccation of the periphyton mat may cause the degradation of particular pigments and change the apparent taxonomic composition obtained with HPLC analyses (Hagerthey et al., 2006, Louda, 2008). In addition, desiccation of the periphyton mat may also shift its cyanobacterial population from filamentous to coccoidal (Gottlieb et al., 2005). 
Molecular markers showed that the floc found at the freshwater sites receives significant algal/planktonic inputs ( $\mathrm{C}_{17} n$-alkane, $\mathrm{C}_{20} \mathrm{HBI}$ and botryococcenes) as well as inputs from the local emergent and submerged vegetation such as Cladium jamaicense and Utricularia purpurea, as shown by the different $\mathrm{P}_{\mathrm{aq}}$ values and $n$-alkane distributions. The presence of kaurene compounds in the floc from TS2 may indicate direct inputs from Cladium jamaicense or high fungal activity in the floc at this site. Furthermore, the long over short $n$-alkane ratio for SRS2 floc was lower compared to TS2, suggesting better preservation of $\mathrm{OM}$ at the long hydroperiod site and the presence of more degraded $\mathrm{OM}$ at the short hydroperiod site. This may be caused by seasonal dry-down which results in the exposure of the floc to atmospheric conditions.

In the estuarine areas of the FCE, the floc material is dominated by mangrove detritus inputs, with smaller contributions from other vegetation such as emergent (Batis maritima) and submerged (Chara) plants and autochthonous planktonic productivity. The $\mathrm{C}_{28} n$-alkene, which has previously been used as a marker for direct mangrove inputs to sediments of the FCE (Jaffé et al., 2001), was found at relatively high concentrations in the floc from the estuarine sites. Diagenetic products of mangrove-derived molecular markers were also detected at high concentrations at these sites (data not discussed). The floc collected at SRS6 seems to also receive marine inputs from the Gulf of Mexico, as evidenced from the abundance of diatoms and the occurrence of a $\mathrm{C}_{25: 3} \mathrm{HBI}$ compound, particularly during the late wet season. In fact, this particular compound was not detected in the floc from any other site.

Consistent patterns of seasonal changes in floc OM composition were observed only for some sites applying specific molecular markers. The slight seasonal variations 
that were observed for some molecular markers were likely linked with the primary productivity of the dominant biomass, such as periphyton/Utricularia in the freshwater marshes and mangrove litterfall in the coastal zones. These seasonal changes in floc OM composition may have direct effects on its reactivity in this oligotrophic environment. The incorporation of relatively labile OM components to the floc layer (particularly $n$ alkenes and short-chain $n$-alkanes) may increase its biological availability and affect its overall turnover time. This is particularly true in the wet season, when higher amounts of these compounds are present in the floc. In fact, results presented and discussed in chapter 4 of this dissertation, show that floc OM mineralization rates are fastest in the wet season.

Evidence was found for the hydrological transport of floc material from the freshwater marshes ( $\mathrm{C}_{20} \mathrm{HBIs}$, kaurenes) to the estuarine sites, suggesting contributions to the floc carbon pool and confirming previous suggestions regarding this process (Jaffé et al., 2001; Neto et al., 2006). Seasonal changes in hydrology may affect the transport of this material. In fact, some molecular markers of periphyton-derived inputs were enriched in mangrove samples collected in the early and late wet seasons. The transport from the freshwater marshes of microbially-derived, labile OM in the floc layer may affect ecosystem processes in the oligohaline areas of the FCE. This transport may be enhanced with the upcoming implementation of the Comprehensive Everglades Restoration Plan which aims to increase water flow throughout the system. This increase in freshwater inflow may increase floc transport to the oligohaline areas and enhance estuarine productivity (FCE II proposal, fcelter.fiu.edu). To understand the possible changes in FCE ecosystem processes triggered by Everglades' restoration, it is essential to obtain a 
better knowledge of the biogeochemical dynamics of floc, including its sources, transformations and reactivity.

Floc materials have been suggested to be the main bio-available OM substrate to the detrital food chain in the highly oligotrophic wetlands of the Everglades (Williams et al., 2006). The $\Sigma \mathrm{CHL} a$ estimates and chemotaxonomic composition of floc suggests that this material can contain significant amounts of live algal biomass, especially in the freshwater marshes where it receives more significant periphyton-derived OM inputs. Molecular markers of algal origin, such as the short-chain homologues of $n$-alkanes and $n$-alkenes do not accumulate well in the environment and are quickly degraded (Cranwell et al., 1981). As such, the presence of the $\mathrm{C}_{17} n$-alkane at relatively high concentrations in the floc is also indicative of fresh algal inputs. This compound was detected at much lower concentrations in the mangrove sites where it could originate from autochthonous planktonic organisms.

Finally, an effort was made to determine the biological sources of several compounds that had previously been suggested as specific biomass tracers in this environment. The $\mathrm{C}_{20}$ highly branched isoprenoid (HBI) has been detected in many areas of the Everglades (Jaffé et al., 2001; Neto et al., 2006; Xu et al., 2007), with higher amounts at the freshwater rather than the estuarine sites. The findings of the present study suggest that this compound is derived from periphyton, more specifically from coccoidal cyanobacteria. The correlations between the $\mathrm{C}_{20} \mathrm{HBI}$ and the cyanobacterial pigment, zeaxanthin, suggest that these organisms may in fact be the source of these compounds, 
but the environmental conditions needed to produce them remain unknown. Such conditions are likely controlling much of its seasonal variability.

This is the first detailed study of Everglades' floc OM composition combining pigment chemotaxonomy with the hydrocarbon fraction molecular marker analysis. A preliminary study of Everglades' floc (Neto et al., 2006) showed that its OM composition is highly variable among sites and largely controlled by local vegetation inputs. Molecular evidence of different degrees of diagenetic reworking and fungal activity were also suggested by these authors. In agreement with this study, our results show that floc $\mathrm{OM}$ is derived from the local vegetation at a particular site (mainly periphyton components and local macrophyte litter) and probably generated in situ. However, seasonal changes in pigments for both periphyton and floc were quite similar and are indicative that seasonal changes in floc composition are relatively fast and on a time sale of months, suggesting a relatively short turnover time for this OM pool. Such dynamics can be controlled by a combination of respiration and photo-degradation, transport (which seems limited) and incorporation into surface soils.

Overall, we have begun to better understand the environmental dynamics of floc. However, the processes controlling the composition, abundance, seasonality and transport continue to be quite elusive. A larger, longer-term dataset as that presented here needs to be generated to allow for more detailed statistical evaluations of the origin, fate and transport of floc. 


\section{REFERENCES:}

Albaiges, J., J. Grimalt, J. M. Bayona, R. Riesenbrough, B. deLappe and W. Walker II. 1984. Dissolved, particulate and sedimentary hydrocarbons in a deltaic environment. Organic Geochemistry 6: 237-248.

Barrick, R. C. and J. I. Hedges. 1981. Hydrocarbon geochemistry of the Puget Sound region - II. Sedimentary diterpenoid, steroid and triterpenoid hydrocarbons. Geochimica et Cosmochimica Acta 45: 381-392.

Belt, S. T., G. Massé, W. G. Allard, J. -M. Robert and S. J. Rowland. 2003. Novel monocyclic sester- and triterpenoids from the marine diatom, Rhizosolenia setigera. Tetrahedron Letters 44: 9103-9106.

Boehm, P. D. and J. G. Quinn. 1978. Benthic hydrocarbons of Rhode Island Sound. Estuarine and Coastal Marine Science 6: 471-494.

Bot, P. V. M. and F. Colijn. 1996. A method for estimating primary production from chlorophyll concentrations with results showing trends in the Irish Sea and the Dutch coastal zone. ICES Journal of Marine Science 53: 945-950.

Canuel, E. A., K. H. Freeman and S. G. Wakeham. 1997. Isotopic composition of lipid biomarker compounds in estuarine plants and surface sediments. Limnology and Oceanography 42: 1570-1583.

Carpenter, S. R., M. M. Elser and J. J. Elser. 1986. Chlorophyll production, degradation and sedimentation: Implications for paleolimnology. Limnology and Oceanography 31: 112-124.

Castañeda-Moya, E., R. R. Twilley, V. H. Rivera-Monroy, K. Zhang, S. E. Davis III and M. Ross. 2010. Sediment and nutrient deposition associated with hurricane Wilma in mangroves of the Florida Coastal Everglades. Estuaries and Coasts 33(1): 45-58.

Childers, D. L., J. N. Boyer, S. E. Davis III, C. J. Madden, D. T. Rudnick and F. H. Sklar. 2006. Relating precipitation and water management to nutrient concentrations in the oligotrophic "upside down" estuaries of the Florida Everglades. Limnology \& Oceanography 51(1/2): 602-616.

Chmura, G. L., P. A. Stone and M. S. Ross. 2006. Non-pollen microfossils in Everglades sediments. Review of Palaeobotany \& Palynology 141: 103-119. 
Corstanje, R., S. Grunwald, K. R. Reddy, T. Z. Osborne and S. Newman. 2006. Assessment of the spatial distribution of soil properties in a northern Everglades marsh. Journal of Environmental Quality 35: 938-949.

Cranwell, P. A. 1981. Diagenesis of free and bound lipids in terrestrial detritus deposited in a lacustrine sediment. Organic Geochemistry 3: 79-89.

Cranwell, P. A. 1982. Lipids of aquatic sediments and sedimenting particulates. Progress in Lipid Research 21: 271-308.

David, P. G. 1996. Changes in plant communities relative to hydrologic conditions in the Florida Everglades. Wetlands 16: 15-23.

Davis, III, S. E., C. Corronado-Molina, D. L. Childers and J. W. Day. 2003. Temporally dependent $\mathrm{C}, \mathrm{N}$, and $\mathrm{P}$ dynamics associated with the decay of Rhizophora mangle $\mathrm{L}$. leaf litter in oligotrophic mangrove wetlands of the southern Everglades. Aquatic Botany 75: 199-215.

DeBusk, W. F. and K. R. Reddy. 1998. Turnover of detrital organic carbon in a nutrientimpacted Everglades marsh. Soil Science Society of America Journal 62: 1460-1468.

DeBusk, W. F., S. Newman and K. R. Reddy. 2001. Spatio-temporal patterns of soil phosphorus enrichment in Everglades Water Conservation Area 2A. Journal of Environmental Quality 30: 1438-1446.

Desortová, B. 1981. Relationship between chlorophyll- $a$ concentration and phytoplankton biomass in several reservoirs in Czechoslovakia. Internationale Revue der gesamten Hydrobiologie und Hydrographie 66(2): 153-169.

Droppo, I. G. and E. D. Ongley. 1994. Flocculation of suspended sediment in rivers of southeastern Canada. Water Research 28(8): 1799-1809.

Droppo, I. G., G. G. Leppard, D. T. Flannigan and S. N. Liss. 1997. The freshwater floc: A functional relationship of water and organic and inorganic floc constituents affecting suspended sediment properties. Water, Air and Soil Pollution 99: 43-54.

Droppo, I. G. 2001. Rethinking what constitutes suspended sediment. Hydrological Processes 15: 1551-1564.

Eglinton, G. and R. J. Hamilton. 1967. Leaf epicuticular waxes. Science 156: 1322-1335.

Ewe, S. M. L., E. E. Gaiser, D. L. Childers, D. Iwaniec, V. H. Rivera-Monroy and R. R. Twilley. 2006. Spatial and temporal patterns of aboveground net primary productivity 
(ANPP) along two freshwater-estuarine transects in the Florida Coastal Everglades. Hydrobiologia 569: 459-474.

Farrington, J. W., N. M. Frew, P. M. Gschwend and B. W. Tripp. 1977. Hydrocarbons in cores of northwestern Atlantic coastal and continental margin sediments. Estuarine and Coastal Marine Science 5: 793-808.

Fernández-Martín, R., C. Domenech, E. Cerdá-Olmedo and J. Avalos. 2000. ent-Kaurene and squalene synthesis in Fusarium fujikuroi cell-free extracts. Phytochemistry 54: 723728 .

Ficken, K. J., B. Li, D. L. Swain and G. Eglinton. 2000. An $n$-alkane proxy for the sedimentary input of submerged/floating freshwater aquatic macrophytes. Organic Geochemistry 31: 745-749.

Gao, M., B. R. T. Simoneit, M. Gantar and R. Jaffé. 2007. Occurrence and distribution of novel botryococcenes hydrocarbons in freshwater wetlands of the Florida Everglades. Chemosphere 70: 224-236.

Gearing, P. J., J. N. Gearing, T. F. Lytle and J. S. Lytle. 1976. Hydrocarbons in 60 northeast Gulf of Mexico Shelf sediments: A preliminary study. Geochimica et Cosmochimica Acta 40: 1005-1017.

Gelpi, E., J. Oro, H. J. Schneider and E. O. Bennet. 1968. Olefins of high molecular weight in two microscopic algae. Science 161: 700-702.

Gleason, P. J. and W. Spackman, Jr. 1974. Calcareous periphyton and water chemistry in the Everglades. In: Gleason, P. J. (Ed.), Environments of South Florida: Present and Past. Miami Geological Society, Miami, Florida, pp. 146-181.

Gottlieb, A., J. Richards and E. Gaiser. 2005. Effects of desiccation duration on the community structure and nutrient retention of short and long-hydroperiod Everglades periphyton mats. Aquatic Botany 82: 99-112.

Gottlieb, A. D., J. H. Richards and E. E. Gaiser. 2006. Comparative study of periphyton community structure in long and short-hydroperiod Everglades marshes. Hydrobiologia 569: 195-207.

Grant, C. S. and J. W. Louda. 2010. Microalgal pigment ratios in relation to light intensity: Implications for chemotaxonomy. Aquatic Biology 11: 127-138. 
Gunderson, L. H. 1994. Vegetation of the Everglades: Determinants of community composition. In: Davis, S. M., Ogden, J. C. (Eds.), Everglades: The ecosystem and its restoration. Boca Raton, FL., St. Lucie Press, pp. 323-340.

Hagerthey, S. E., J. W. Louda and P. Mongkronsri. 2006. Evaluation of pigment extraction methods and a recommended protocol for periphyton chlorophyll $a$ determination and chemotaxonomic assessment. Journal of Phycology 42: 1125-1136.

Jaffé, R., G. A. Wolff, A. C. Cabrera and H. Carvajal Chitty. 1995. The biogeochemistry of lipids in rivers of the Orinoco basin. Geochimica et Cosmochimica Acta 59(21): 45074522.

Jaffé, R., R. Mead, M. E. Hernandez, M. C. Peralba and O. A. DiGuida. 2001. Origin and transport of sedimentary organic matter in two subtropical estuaries: A comparative, biomarker-based study. Organic Geochemistry 32: 507-526.

Jaffé, R., A. I. Rushdi, P. M. Medeiros and B. R. T. Simoneit. 2006. Natural product biomarkers as indicators of sources and transport of sedimentary organic matter in a subtropical river. Chemosphere 64: 1870-1884.

Jeffrey, S. W., R. F. C. Mantoura and S. W. Wright, (Eds.). 1997. Phytoplankton pigments in oceanography: Guidelines to modern methods. UNESCO, Paris, pp. 447-554.

Kasprzak, P., J. Padisák, R. Koschel, L. Krienitz and F. Gervais. 2008. Chlorophyll- $a$ concentration across a trophic gradient of lakes: An estimator of phytoplankton biomass? Limnologica-Ecology and Management of Inland Waters 38(3/4): 327-338.

Krauss, K. W., T. W. Doyle, R. R. Twilley, V. H. Rivera-Monroy and J. K. Sullivan. 2006. Evaluating the relative contributions of hydroperiod and soil fertility on growth of south Florida mangroves. Hydrobiologia 569: 311-324.

Larsen, L. G., J. W. Harvey and J. P. Crimaldi. 2007. A delicate balance: Ecohydrological feedbacks governing landscape morphology in a lotic peatland. Ecological Monographs 77(4): 591-614.

Larsen, L. G., J. W. Harvey and J. P. Crimaldi. 2009a. Morphologic and transport properties of natural organic floc. Water Resources Research 45: W01410, doi: 10.1029/2008WR006990.

Larsen, L. G., J. W. Harvey, G. B. Noe and J. P. Crimaldi. 2009b. Predicting organic floc transport dynamics in shallow aquatic ecosystems: Insights from the field, the laboratory and numerical modeling. Water Resources Research 45: W01411, doi: 10.1029/2008WR007221. 
Leonard, L., A. Croft, D. Childers, S. Mitchell-Brucker, H. Solo-Gabriele and M. Ross. 2006. Characteristics of surface-water flows in the ridge and slough landscape of Everglades National Park: Implications for particulate transport. Hydrobiologia 569: 522.

Li, B. L., S. N. Chen, Z. X. Shi and Y. Z. Chen. 2000. ent-Kaurene diterpenoids from Isodon rubescens. Phytochemistry 53(8): 855-859.

Louda, J. W., J. Li, L. Liu, M. Nancy Winfree and E. W. Baker. 1998. Chlorophyll-a degradation during cellular senescence and death. Organic Geochemistry 29: 1233-1251.

Louda, J. W. 2008. HPLC-based chemotaxonomy of Florida Bay phytoplankton: Difficulties in coastal environments. Journal of Liquid Chromatography \& Related Technologies 31: 295-323.

Loveless, C. M. 1959. A study of vegetation in the Florida Everglades. Ecology 40: 1-9. Mantoura, R. F. C. and C. A. Llewellyn. 1983. The rapid determination of algal chlorophyll and carotenoid pigments and their breakdown products in natural waters by reverse-phase high performance liquid chromatography. Analytica Chimica Acta 151: 297-314.

Massé, G., S. T. Belt, W. G. Allard, C. Anthony Lewis, S. G. Wakeham and S. J. Rowland. 2004. Occurrence of novel monocyclic alkenes from diatoms in marine particulate matter and sediments. Organic Geochemistry 35: 813-822.

Mead, R., Y. Xu, J. Chong and R. Jaffé. 2005. Sediment and soil organic matter source assessment as revealed by the molecular distribution and carbon isotopic composition of n-alkanes. Organic Geochemistry 36: 363-370.

Metzger, P., C. Berkaloff, E. Casadevall and A. Coute. 1985. Alkadiene- and botryococcene-producing races of wild strains of Botryococcus braunii. Phytochemistry 24: $2305-2312$.

Metzger, P. and C. Largeau. 1999. Chemicals of Botryococcus braunii. In: Cohen, Z. (Ed.), Chemicals from Microalgae. Taylor \& Francis Inc., Philadelphia, pp. 205-259.

Metzger, P. and C. Largeau. 2005. Botryococcus braunii: A rich source for hydrocarbons and related ether lipids. Applied Microbiology and Biotechnology 66: 486-496.

Meyers, P. A. 1997. Organic geochemical proxies of paleoceanographic, paleolimnologic, and paleoclimatic processes. Organic Geochemistry 27(5/6): 213-250. 
Miao, S. L. and F. H. Sklar. 1998. Biomass and nutrient allocation of sawgrass and cattail along a nutrient gradient in the Florida Everglades. Wetlands Ecology and Management 5: 245-263.

Moore, J. C., E. L. Berlow, D. C. Coleman, P. C. de Ruiter, Q. Dong, A. Hastings, N. Collins Johnson, K. S. McCann, K. Melville, P. J. Morin, K. Nadelhoffer, A. D.

Rosemond, D. M. Post, J. L. Sabo, K. M. Scow, M. J. Vanni and D. H. Wall. 2004.

Detritus, trophic dynamics and biodiversity. Ecology Letters 7: 584-600.

National Research Council. 2003. Does water flow influence Everglades landscape patterns? National Academy, Washington, D. C., pp. 41.

Nelson, J. R. 1993. Rates and possible mechanisms of light-dependent degradation of pigments in detritus derived from phytoplankton. Journal of Marine Research 51: 155179.

Neto, R. R., R. N. Mead, J. W. Louda and R. Jaffé. 2006. Organic biogeochemistry of detrital flocculent material (floc) in a subtropical, coastal wetland. Biogeochemistry 77: 283-304.

Noe, G. B., D. L. Childers and R. D. Jones. 2001. Phosphorus biogeochemistry and the impact of phosphorus enrichment: Why is the Everglades so unique? Ecosystems 4: 603624.

Noe, G. B., D. L. Childers, A. L. Edwards, E. Gaiser, K. Jayachandran, D. Lee, J. Meeder, J. Richards, L. J. Scinto, J. C. Trexler and R. D. Jones. 2002. Short-term changes in phosphorus storage in an oligotrophic Everglades wetland ecosystem receiving experimental nutrient enrichment. Biogeochemistry 59: 239-267.

Noe, G. B., L. J. Scinto, J. Taylor, D. L. Childers and R. D. Jones. 2003. Phosphorus cycling and partitioning in an oligotrophic Everglades wetland ecosystem: A radioisotope tracing study. Freshwater Biology 48: 1993-2008.

Ongley, E. D., B. G. Krishnappan, I. G. Droppo, S. S. Rao and R. J. Maguire. 1992. Cohesive sediment transport: Emerging issues for toxic chemical management. Hydrobiologia 235/236: 177-187.

Poret, N., R. R. Twilley, V. H. Rivera-Monroy and C. Coronado-Molina. 2007. Belowground decomposition of mangrove roots in Florida Coastal Everglades. Estuaries and Coasts 30(3): 491-496.

Richards, J. H. 2001. Bladder function in Utricularia purpurea (Lentilbulariaceae): is carnivory important? American Journal of Botany 88: 170-176. 
Rowland, S. J. and J. N. Robson. 1990. The widespread occurrence of highly branched acyclic $\mathrm{C} 20, \mathrm{C} 25$ and $\mathrm{C} 30$ hydrocarbons in recent sediments and biota - a review. Marine Environmental Research 30: 191-216.

Rudnick, D., Z. Chen, D. Childers, J. Boyer and T. Fontaine. 1999. Phosphorus and nitrogen inputs to Florida Bay: The importance of the Everglades watershed. Estuaries 22(2B): 398-416.

Saunders, C. J., M. Gao, J. A. Lynch, R. Jaffé and D. L. Childers. 2006. Using soil profiles of seeds and molecular markers as proxies for sawgrass and wet prairie slough vegetation in Shark River Slough, Everglades National Park. Hydrobiologia 569: 475492.

Simon, M., H. P. Grossart, B. Schweitzer and H. Ploug. 2002. Microbial ecology of organic aggregates in aquatic ecosystems. Aquatic Microbial Ecology 28: 175-211.

Todd, M. J., R. Muneepeerakul, D. Pumo, S. Azaele, F. Miralles-Wilhelm, A. Rinaldo and I. Rodriguez-Iturbe. 2010. Hydrological drivers of wetland vegetation community distribution within Everglades National Park, Florida. Advances in Water Resources 33: 1279-1289.

Troxler, T. G. and J. H. Richards. 2009. $\delta^{13} \mathrm{C}, \delta^{15} \mathrm{~N}$, carbon, nitrogen and phosphorus as indicators of plant ecophysiology and organic matter pathways in Everglades deep slough, Florida, USA. Aquatic Botany 91: 157-165.

Twilley, R. R., A. E. Lugo and C. Patterson-Zucca. 1986. Litter production and turnover in basin mangrove forests in southwest Florida. Ecology 67: 670-683.

Venkatesan, M. I., E. Ruth and I. R. Kaplan. 1986. Terpenoid hydrocarbons in the Hula peat: Structure and origin. Geochimica et Cosmochimica Acta 50: 1133-1139.

Volkman, J. K., S. M. Barrett, S. I. Blackburn, M. P. Mansour, E. L. Sikes and F. Gelin. 1998. Microalgal biomarkers: A review of recent research developments. Organic Geochemistry 29: 1163-1179.

Vymazal, J. and C. J. Richardson. 1995. Species composition, biomass, and nutrient content of periphyton in the Florida Everglades. Journal of Phycology 31: 343-354.

White, J. R. and K. R. Reddy. 2000. Influence of phosphorus loading on organic nitrogen mineralization of Everglades' soils. Soil Science Society of America Journal 64: 15251534. 
Willard, D. A., L. M. Weimer and W. L. Riegel. 2001. Pollen assemblages as paleoenvironmental proxies in the Florida Everglades. Review of Palaeobotany \& Palynology 113: 213-235.

Williams, A. J. and J. C. Trexler. 2006. A preliminary analysis of the correlation of foodweb characteristics with hydrology and nutrient gradients in the southern Everglades. Hydrobiologia 569: 493-504.

Wright, S. W. and S. W. Jeffrey. 2006. Pigment markers for phytoplankton production. In: The Handbook of Environmental Chemistry, Volume 2N, Springer, pp. 71-104.

Xiang, W., R. T. Li, Z. Y. Wang, S. H. Li, Q. S. Zhao, H. J. Zhang and H. D. Sun. 2004. ent-Kaurene diterpenoids from Isodon oresbius. Phytochemistry 65: 1173-1177.

$\mathrm{Xu}$, Y., R. Jaffé, A. Wachnicka and E. E. Gaiser. 2006. Occurrence of $\mathrm{C}_{25}$ highly branched isoprenoids (HBIs) in Florida Bay: Paleoenvironmental indicators of diatomderived organic matter inputs. Organic Geochemistry 37: 847-859.

$\mathrm{Xu}, \mathrm{Y}$. and R. Jaffé. 2007. Lipid biomarkers in suspended particles from a subtropical estuary: Assessment of seasonal changes in sources and transport of organic matter. Marine Environmental Research 64: 666-678. 


\begin{abstract}
Chapter III*
PHOTO-DISSOLUTION OF FLOCCULENT, DETRITAL MATERIAL IN AQUATIC ENVIRONMENTS: CONTRIBUTIONS TO THE DISSOLVED ORGANIC MATTER POOL
\end{abstract}

*The work described in this chapter has been published by the journal Water Research. 


\subsection{Introduction:}

Dissolved organic matter (DOM) comprises the largest pool of organic matter $(\mathrm{OM})$ in a wide range of aquatic environments and plays a key role in the biogeochemical cycles affecting processes such as metal complexation, $\mathrm{pH}$ buffering, light attenuation, nutrient availability, microbial and phytoplankton activity, and ecosystem productivity (Findlay and Sinsabaugh, 2003). The optical properties of chromophoric DOM (CDOM), the fraction of DOM that absorbs ultraviolet (UV) and visible light, have been extensively investigated in various aquatic ecosystems to determine the sources and transformations of this material in the environment (Coble, 1996; 2007).

Photochemical effects on DOM dynamics have also been studied. CDOM containing numerous chromophoric moieties can undergo important photo-induced processes including photolysis of higher molecular weight to lower molecular weight compounds (Lou et al., 2006), generation of free radicals (Holder Sandvik et al., 2000), photo-mineralization reactions (Clark et al., 2004), and photo-bleaching (Shank et al., 2010). Photo-reactions have also been shown to help in the formation of biologically labile compounds, making the organic material more available for both autotrophic and heterotrophic biological activity (Moran and Zepp, 1997).

More recently, the effects of light on the dissolution of particulate organic matter (POM) have been studied (Kieber et al., 2006; Mayer et al., 2006 and 2009a). It has been well established that POM can absorb light at similar wavelengths as DOM (Kirk, 1980; Kieber et al., 2006) allowing the particulate material to undergo similar photo-induced reactions. Such reactions can induce processes that break down larger molecules into smaller photo-products through the absorption of light (Miller and Moran, 1997). These 
reactions can influence the transition between the particulate and the dissolved phase of organic material (Mayer et al., 2006) and therefore the frequent exposure of particulates and sediments to light can ultimately lead to the transfer of particulate carbon to the dissolved phase. Kieber et al. (2006) irradiated sediments from the Cape Fear River estuary in North Carolina and found that, on average, the dissolved organic carbon (DOC) photo-production rate was $0.0056 \mathrm{mmol} \mathrm{DOC}^{-1}$ dry sediment $\mathrm{h}^{-1}$, and suggested this value was larger than local riverine discharge and benthic flux sources of DOC to the ocean. Mayer et al. (2006) irradiated sediments from the Mississippi River and found that under optimal conditions two thirds of the exposed particulate organic carbon (POC) underwent photo-dissolution after several days. Shank et al. (2011) irradiated suspended sediments from Florida Bay and found that after $24 \mathrm{hrs}$ of light exposure, the DOC concentration increased from 0.5 to $3.0 \mathrm{mgC} \mathrm{L}^{-1}$. This potential generation of DOM through photo-induced mechanisms can play a significant role in organic carbon and other biogeochemical cycles of aquatic environments, affecting both nutrient dynamics (Kieber et al., 2006; Zhang et al., 2009) and biological activity (Miller and Moran, 1997). In the Florida Coastal Everglades (FCE), the majority of the POM occurs at the sediment-water interface as flocculent detritus (floc, 0.02-1.4 $\mathrm{mg} \mathrm{L}^{-1}$ ). This material has been previously studied (Neto et al., 2006; Gao et al., 2007; Larsen et al., 2009; Troxler et al., 2009) and is known to be composed mainly of an assembly of periphyton, higher plant detritus and carbonates. With the application of molecular biomarkers, Neto et al. (2006) found that floc composition is primarily controlled by local vegetation inputs and early diagenetic transformations of OM. Using isotopic characterization, Troxler et al. (2009) determined that detrital remains of Utricularia species comprise the primary 
components of floc materials found in deep sloughs of the FCE. Isoprenoid hydrocarbons known as botryococcenes, and believed to be produced by the microalga Botryococcus braunii or by filamentous green algae, have also been reported in floc from the FCE (Gao et al., 2007). However, little is still known about the biogeochemical dynamics of floc in this environment.

Detritus is known to be a source of energy and nutrients to living organisms in many food webs (Moore et al., 2004). In the FCE, floc and periphyton mats have been proposed as primary energy sources driving local trophic dynamics (Williams et al., 2006). For this reason alone, it is important to understand floc dynamics in the waters of this oligotrophic, subtropical wetland. In the shallow waters of the FCE, floc is naturally re-suspended through wind and bio-turbation (Larsen et al., 2009), allowing it to be exposed to intense sunlight (light penetration in FCE waters can reach $1745 \mu \mathrm{E} \mathrm{cm}^{-2} \mathrm{~s}^{-1}$; F. Tobias, personal communication). In the Everglades, floc is not entrained by water flow (entrainment threshold of $1.0 \times 10^{-2} \mathrm{~Pa}$; Larsen et al., 2009) because the flow is not sufficient for significant floc transport. However, some authors have suggested that floc is mobile enough to reach the estuarine areas of the FCE (Jaffé et al., 2001). With the implementation of the Comprehensive Everglades Restoration Plan (CERP) there will be an increase in water flow through the Shark River Slough (SRS) to the Gulf of Mexico (www.evergladesplan.org). The increase in water delivery can potentially increase floc transport from the freshwater marshes to the mangrove fringe and out to the Gulf, where the flocculent material will be exposed to intense sunlight. Light exposure can initiate a series of reactions and alterations in detrital OM (Kieber et al., 2006; Mayer et al., 2006, $2009 a$ and $2009 b$ ), and therefore in floc, potentially affecting its environmental dynamics 
and ecosystem functions. Thus it is important to determine the photo-chemical reactivity of floc in the FCE and aquatic environments in general, in order to estimate the potential contribution of such processes to the DOM pool and its overall influence on the biogeochemistry of detrital rich ecosystems.

The specific objectives of this study were to quantitatively assess the amount and quality of DOM that is photo-produced from floc of different composition/origin on both spatial and seasonal scales (i.e., freshwater marsh vs. mangrove fringe; wet season vs. dry season).

\subsection{Methods:}

\subsubsection{Site description:}

The Florida Coastal Everglades (FCE) is a subtropical wetland located on the southern tip of the Florida peninsula. The FCE extends west to the Gulf of Mexico and south to Florida Bay. This oligotrophic wetland is characterized by very low dissolved nutrient concentrations in the water column. There are two main drainage basins in the FCE; Shark River Slough (SRS) drains to the southwest coast of Everglades National Park (ENP) and into the Gulf of Mexico, while Taylor Slough (TS) drains to the southeast and into Florida Bay. Water discharge to the southwest coast of ENP through

SRS has been shown to be substantially larger than discharge through TS (Woods, 2010).

Floc samples were collected in SRS at sites that have been previously described by the on-going Florida Coastal Everglades-Long Term Ecological Research program (FCE-LTER), namely at a freshwater marsh site (SRS2) and at an estuarine mangrove site (SRS6) (Figure 3.1). The former is a long hydroperiod site characterized by peat soils 
where the dominant vegetation is Cladium jamaicense (sawgrass), Eleocharis cellulosa (gulfcoast spikerush) and calcareous periphyton, an assemblage of cyanobacteria, green algae, diatoms and higher plant detritus. The latter site, located on the coastal fringe within the mangrove ecotone, is dominated by Rhizophora mangle (red mangrove). This site may receive in addition to the dominant mangrove detritus, some marine OM inputs from seagrasses and phytoplankton (Hernandez et al., 2001) through tidal exchange. Basic water quality and floc parameters are summarized in Table 3.1.

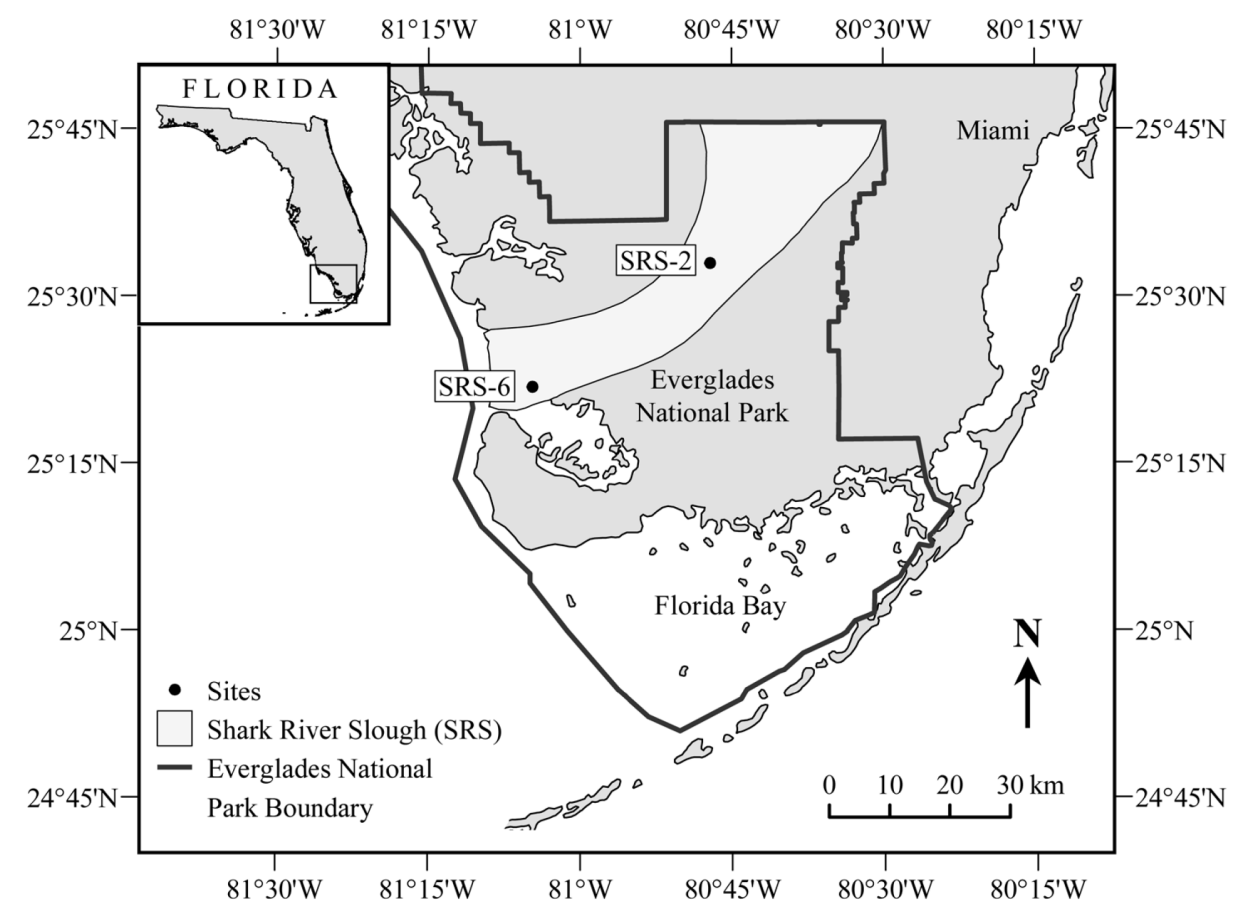

Figure 3.1. Florida Coastal Everglades map showing sampling site locations along the Shark River Slough.

\subsubsection{Sample collection:}

Floc samples were collected according to Neto et al. (2006). Briefly, floc samples were collected using a transparent plastic corer (inner diameter of $2.5 \mathrm{~cm}$ ). The core was pushed about $10 \mathrm{~cm}$ below the sediment surface, capped to create suction, and retrieved. 
The floc layer was visible in the core and was decanted from the consolidated surface of the soil/sediment using a plunger with a smaller diameter to that of the core tube to hold the bottom layer in place. Excess water was decanted and the floc was collected in prerinsed $1 \mathrm{~L}$ Teflon jars (Nalgene). This procedure was repeated at randomly selected locations at each site enough times to obtain about $1 \mathrm{~L}$ of floc composite for each sampling event.

Eight $\mathrm{L}$ of natural water were also collected at each site in Nalgene bottles sequentially pre-washed with $0.5 \mathrm{~N} \mathrm{HCl}$ and $0.1 \mathrm{~N} \mathrm{NaOH}$. Water samples were kept on ice and upon return to the laboratory, they were filtered through pre-combusted $\left(450^{\circ} \mathrm{C}\right.$ for 4 h) $0.7 \mu \mathrm{m}$ glass-fiber filters (GF/F) (Whatman International Ltd.) and $0.22 \mu \mathrm{m}$ Durapore Membrane filters (Millipore) to remove POM from water samples. The filtrate was passed through an activated carbon filter cartridge (Whatman) to remove much of the DOM from the natural water (\%DOC removed was 46-64 \%; \%absorbance at $254 \mathrm{~nm}$ removed was $57-93 \%$ ). The carbon filter cartridge step was needed to reduce the background DOC levels, and thus be able to better determine its photo-generation rates, as Everglades waters are commonly enriched in DOC (Table 3.1).

\subsubsection{Experimental setup:}

Floc samples were mixed with natural water (after DOM removal) to give solutions with a final floc concentration of about $24 \mathrm{~g}$ floc $\mathrm{L}^{-1}$ (dry weight). Such high initial concentrations were used to simulate the floc layer in the natural environment

which can reach concentrations of up to $710 \mathrm{~g}$ floc $\mathrm{L}^{-1}$ (Chapter 2). These solutions were prepared in pre-combusted glass jars (in triplicate), covered with quartz plates for light 
exposure, or wrapped in black plastic bags for dark controls. Light and dark controls were performed in the solar simulator's water circulating bath $\left(26^{\circ} \mathrm{C}\right)$, to maintain similar temperature conditions for all experiments. Flat top glass jars were used instead of beakers to obtain a better seal with the quartz cover plates in order to avoid sample contamination by dust particles. True dark blanks were not performed as poisoning with either mercuric chloride or sodium azide would result in fluorescence quenching. Samples were incubated for different periods of time $(0,0.5,1,2,4$, and 7 days $)$ in a solar simulator (Suntest XLS+, Atlas Material Testing Technology LLC) set at $765 \mathrm{~W} \mathrm{~m}^{-2}$. These conditions correspond to about 1.2 times solar noon in South Florida (Maie et al., 2008). After photo-exposure, samples were filtered $(0.7 \mu \mathrm{m} \mathrm{GF} / \mathrm{F})$ to separate the aqueous phase for DOM analysis, and to recover the detrital fraction. The filtered particulates were dried overnight in a $60^{\circ} \mathrm{C}$ oven and the recovered floc was ground and saved for elemental analysis. The filtrate was analyzed for DOC, total dissolved nitrogen (TDN) and soluble reactive phosphorus (SRP), and the optical properties were examined using UV-vis spectroscopy and excitation emission matrix (EEM) fluorescence spectroscopy.

\subsubsection{Elemental analysis:}

About 8-10 mg of floc sample was weighed in silver cups and de-carbonated by exposure to hydrochloric acid vapors overnight (Harris et al., 2001). Samples were dried in a $60^{\circ} \mathrm{C}$ oven overnight and analyzed for total organic $\mathrm{C}(\% \mathrm{TOC})$ and total $\mathrm{N}(\% \mathrm{TN})$ concentrations. Triplicate samples were measured using a Carlo Erba NA 1500 
nitrogen/carbon analyzer with a reproducibility of $\pm 1.07 \%$ for TOC and $\pm 0.09 \%$ for TN on average.

The DOC concentration was measured with a Shimadzu TOC-V total organic carbon (TOC) analyzer. Prior to analysis, the samples were acidified $(\mathrm{pH}<2)$ and purged with $\mathrm{CO}_{2}$-free air for $5 \mathrm{~min}$ to remove inorganic $\mathrm{C}$. Total dissolved nitrogen (TDN) was measured on an ANTEK 9000 nitrogen analyzer.

\subsection{5. $U V$-vis and fluorescence spectroscopy:}

The UV-visible absorption spectra were obtained using a Varian Cary-50 Bio spectrophotometer at wavelengths between 250 and $800 \mathrm{~nm}$. Samples were measured in a $1 \mathrm{~cm}$ quartz cuvette using Milli-Q ${ }^{\circledR}$ water as the blank.

The EEM fluorescence was measured on a Horiba Jobin-Yvon Fluoromax-3 spectrofluorometer equipped with a 150-W Xenon arc lamp according to Chen et al. (2010) and Yamashita et al. (2010). Briefly, scans were acquired in a $1 \mathrm{~cm}$ quartz cuvette at excitation wavelengths $\left(\lambda_{\text {ex }}\right)$ between 260 and $455 \mathrm{~nm}$ at $5 \mathrm{~nm}$ intervals. Emission wavelengths $\left(\lambda_{\mathrm{em}}\right)$ were scanned from $\lambda_{\mathrm{ex}}+10 \mathrm{~nm}$ to $\lambda_{\mathrm{ex}}+250 \mathrm{~nm}$ at $2 \mathrm{~nm}$ intervals. The individual spectra were concatenated to form a three-dimensional matrix. All spectra were acquired in $S / R$ mode (ratio of the emission signal and the reference excitation lamp output signal) and were corrected for inner filter effects and instrument bias. Finally, fluorescence intensity values were converted to quinine sulfate units (QSU) to facilitate inter-laboratory comparisons. 


\subsubsection{Parallel factor analysis (PARAFAC):}

Parallel factor analysis (PARAFAC) is a three-way multivariate statistical method that has been used to decompose EEMs of complex mixtures into their individual fluorescent components (Stedmon et al., 2003). The EEMs of 75 incubated floc and natural water samples were fitted to an existing PARAFAC model created with $c a 1,400$ surface water samples collected from the Everglades and Florida Bay (Appendix 3.1, Chen et al., 2010). The PARAFAC analysis was performed using MATLAB 7.0.4 (Mathworks, Natick, MA) with the DOMFluor toolbox (Stedmon et al., 2008). Obvious residual peaks were not found after fitting our samples to this eight component model, indicating that the fluorophores produced from the irradiation of floc are similar to those of surface waters from the Everglades. The spectral characteristics of the eight components are summarized below, in results section 3.3.2.

\subsection{Results \& Discussion:}

\subsubsection{Natural water \& floc chemical characteristics:}

Spatial differences in the initial DOC concentration for the two water samples are summarized in Table 3.1. As expected, the higher DOC values were obtained for the freshwater site (SRS2) compared to the mangrove site (SRS6), where a contribution of DOM to the former derive from the abundant macrophytes, periphyton mats and organic rich soils (peat) (Yamashita et al., 2010), while the latter is mostly influenced by mangrove derived sources and diluted by tidal mixing (Jaffé et al., 2004). Seasonal differences were also observed; water collected at the freshwater site was found to have $32.8 \mathrm{mgC} \mathrm{L}^{-1}$ in the dry season and $22.3 \mathrm{mgC} \mathrm{L}^{-1}$ in the wet season. The smaller DOC 
concentration obtained in the wet season could be indicative of a dilution effect because of an increase in rainfall. The DOC content of natural water collected at the mangrove site was found to be seasonally similar, at $6.7 \mathrm{mgC} \mathrm{L}^{-1}$ in the dry season and $7.9 \mathrm{mgC} \mathrm{L}^{-1}$ in the wet season.

Total dissolved nitrogen (TDN) was found to be higher in the natural water at the freshwater site during the dry season, indicative of a concentration effect. In addition, the abundant periphyton mats found at SRS2 contain numerous $\mathrm{N}$-fixing cyanobacteria which may be contributing to the local TDN pool. Soluble reactive phosphorus (SRP) was higher at the mangrove site which receives phosphorus inputs from the adjacent Gulf of Mexico, while the SRS2 site is a typically P-limited FCE freshwater marsh site (Childers et al., 2006).

Table 3.1. Natural water and floc bulk chemical parameters. The density for SRS6 floc could not be measured due to low tide at the time of sample collection.

\begin{tabular}{|c|c|c|c|c|c|c|c|c|}
\hline \multirow[t]{2}{*}{ Site } & \multirow[t]{2}{*}{ Season } & \multicolumn{4}{|c|}{ Natural water } & \multicolumn{3}{|c|}{ Floc } \\
\hline & & Salinity & $\begin{array}{c}\text { DOC } \\
\left(\mathrm{mgC} \mathrm{L}^{-1}\right) \\
\end{array}$ & $\begin{array}{c}\mathrm{TDN} \\
\left(\mathrm{mgN} \mathrm{L}^{-1}\right)\end{array}$ & $\begin{array}{c}\text { SRP } \\
\left(\mathrm{mgP} \mathrm{L}^{-1}\right) \\
\end{array}$ & $\begin{array}{l}\text { Density } \\
\left(\mathrm{g} \mathrm{mL}^{-1}\right) \\
\end{array}$ & $\begin{array}{r}\text { TOC } \\
(\%) \\
\end{array}$ & $\begin{array}{l}\mathrm{TN} \\
(\%) \\
\end{array}$ \\
\hline \multirow[t]{2}{*}{ SRS2 } & Dry & 0 & 32.8 & 1.33 & 0.008 & 0.067 & 25.6 & 3.02 \\
\hline & Wet & 0 & 22.3 & 0.23 & n.a.* & 0.71 & 37.3 & 3.25 \\
\hline \multirow[t]{2}{*}{ SRS6 } & Dry & 34.4 & 6.7 & 0.31 & 0.018 & n.a. & 14.9 & 0.54 \\
\hline & Wet & 17.1 & 7.9 & 0.25 & n.a. & n.a. & 11.4 & 0.41 \\
\hline
\end{tabular}

*n.a. = not analyzed.

The floc collected in the freshwater marsh had higher \%TOC and \% $\%$ compared to the mangrove floc, probably because of increased accumulation of $\mathrm{OM}$ at the former long hydroperiod site. The mangrove site is strongly influenced by tidal activity and the floc found there may not have the opportunity for significant accumulation. In fact, the 
sediment accretion rate at this particular site has been estimated to be $0.30 \pm 0.03 \mathrm{~cm}_{\text {year }}{ }^{-1}$ (Castañeda-Moya et al., 2009) while accretion rates in the SRS2 vicinity have been estimated at $0.50 \mathrm{~cm}^{-1}$ ear $^{-1}$ (Saunders et al., 2006). Floc collected at SRS2 during the wet season had higher \% $\%$ TOC and \% TN than the floc collected in the dry season, indicative of higher inputs from increased local biomass productivity. The floc at SRS6 had a higher $\% \mathrm{TOC}$ and $\% \mathrm{TN}$ in the dry season, probably as a result of a decreased dilution effect, and higher nitrogen immobilization by bacteria associated with leaf litter decomposition (Twilley et al., 1986).

\subsubsection{Photochemical production of DOC from floc:}

Photo-exposure of floc collected at both the freshwater and the mangrove sites caused the generation of significant amounts of DOC (Figure 3.2). Normalized to the initial POC content, the floc collected at the freshwater site (SRS2) photo-generated up to

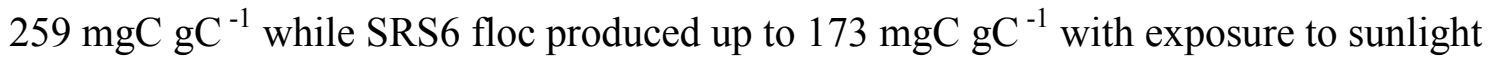
(corrected for dark treatments). This is in agreement with recent studies on the generation of DOM from resuspended sediments in shallow aquatic environments (Shank et al., 2011). Shank et al. (2011) found that upon solar irradiation, the sediments with the highest $\% \mathrm{OC}$ content, exhibited the largest increases in DOC and terrestrial humic components. It should be noted that DOC in surface water samples may photo-degrade during photo-irradiation, and thus, values of photo-produced DOC reported here would be underestimated. However, it is important to mention that floc has been reported to contain some live benthic periphyton, including cyanobacteria (Neto et al., 2006). These organisms upon light exposure could generate DOM through enhanced primary 
productivity. However, it has been reported that microbial activity in solutions exposed to intense sunlight (such as in the solar simulator) is significantly inhibited (Xie and Zafiriou, 2009) and therefore unlikely to make significant contributions to the DOC pool. While the overall trend is one of increasing DOC with exposure time, some variations were observed after several days of light exposure. This was particularly the case for the data from the dry season floc from both locations. While the DOC generation curve for floc from the wet season was relatively constant with time for both freshwater and mangrove floc, the data for floc from the dry season showed a fast increment in DOC generation during the first two and four days for the freshwater and mangrove samples respectively, followed by an overall decrease. These variations in DOC concentration with incubation time could be the result of several mechanisms including re-adsorption onto particles, flocculation (von Wachenfeldt et al., 2009) and/or photo-mineralization of DOC to yield dissolved inorganic carbon (DIC) (Clark et al., 2004), and seem more pronounced for the dry season samples (see Figure 3.2). Regardless of this trend, the difference in DOC production between the two sites suggests enrichment in photo-labile material at the freshwater site (SRS2) compared to the mangrove site (SRS6). The former is dominated by marsh vegetation (sawgrass and spikerush) and abundant periphyton mats which seem to control the main sources of OM to the floc layer (Neto et al., 2006). The organic-rich, peat soils at SRS2 may also contribute OM to the floc layer. As such, floc at SRS2 is expected to be lower in lignin phenol content compared to that at SRS6 where mangrove derived detrital $\mathrm{OM}$ in the form of decaying leaf and root materials are likely the main OM sources to the floc (Neto et al., 2006). Consequently, the floc at SRS6 is expected to feature more biologically recalcitrant organic matter. However, lignin 
phenol is photodegradable (Opsahl and Benner, 1998), and sunlight intensity is not considerably different throughout the year in South Florida. Thus, considering that its lignin phenol content is larger at SRS6 floc the lower reactivity to photo-exposure is somewhat unexpected.
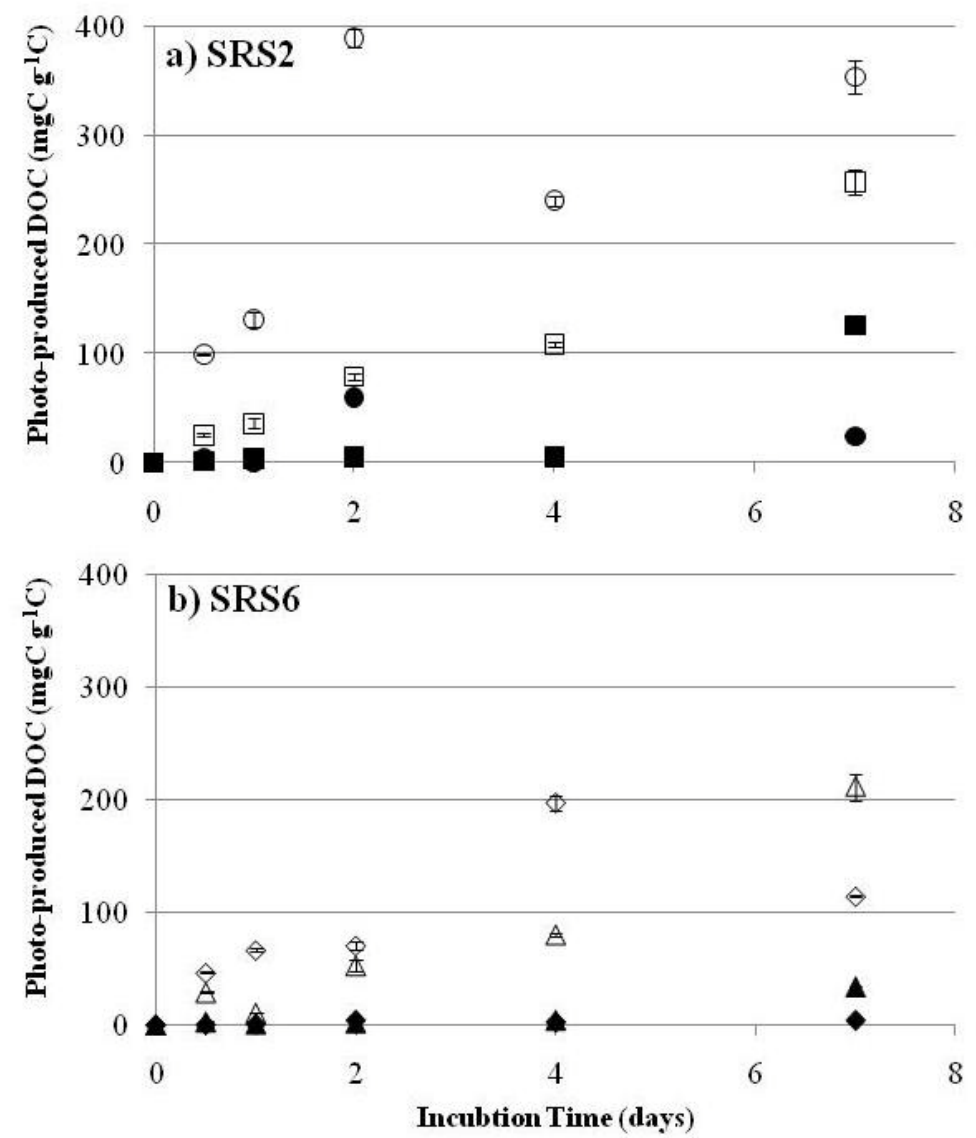

Figure 3.2. Photo-dissolution induced changes in DOC concentrations normalized to initial floc POC content for floc at SRS2 (a) and SRS6 (b). Error bars are for triplicate experiments. Open and filled symbols correspond to light and dark treatments, respectively. ( $\bullet$ : dry and $\mathbf{\square}$ : wet season for SRS2; $\bullet$ : dry and $\boldsymbol{\Delta}$ : wet season for SRS6).

Samples that were incubated under dark conditions also produced measurable

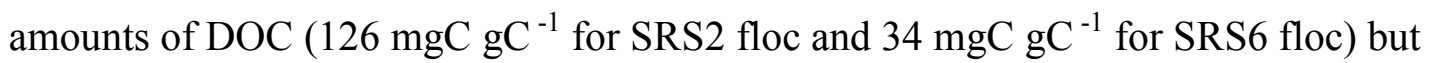
significantly less compared to the photo-exposed samples. While leachates from some 
common Everglades biomass, such as sawgrass and spikerush blades, periphyton and mangrove leaves, have been reported to be important contributors to the DOC pool, leaching between 8 and $51 \mathrm{mgC} \mathrm{g}^{-1}$ of dry biomass during the early stages of decomposition (Maie et al., 2006), the floc from the freshwater site leached up to $79 \mathrm{mgC}$ g dry floc. Such experimental results indicate that leaching from floc may be a more important source of this dissolved material than previously believed, although the photoinduced generation of DOC clearly dominates.

Exposure of flocculent material to artificial sunlight also caused the production of dissolved nutrients at both sites, showing photo-generation of TDN (5.2 and $0.98 \mathrm{mgN} \mathrm{g}^{-1}$ floc for SRS2 and SRS6, respectively) and SRP concentrations (0.07 and $0.19 \mathrm{mgP} \mathrm{g}$ ${ }^{1}$ floc for SRS2 and SRS6, respectively). Because these parameters were only measured for floc collected in the dry season, seasonal effects will not be addressed. However, the photo-generation of DOM-associated $\mathrm{N}$ and $\mathrm{P}$ can greatly affect food web dynamics and biogeochemical cycles, especially in the oligotrophic waters of the FCE where most of the dissolved nutrients are found in the organic form (Noe et al., 2007).

Seasonal differences (wet vs. dry season) in DOC photo-production from floc were also observed (Figure 3.2). Throughout the length of the incubation period, site SRS2 floc collected in the dry season produced $97 \mathrm{mgC} \mathrm{gC}^{-1}$ more than floc collected at the same site in the wet season. Photo-exposure of floc collected at SRS6 during the dry season also produced more DOC during the first 4 days of incubation, but fell below the levels of photo-produced DOC from the wet season floc after 7 days of exposure. Similarly, SRS2 floc from the dry season was significantly more photo-productive of DOC during the first 2 days of exposure (see above). The higher (initial) photo- 
production rates of DOC for the dry season samples may be due to the presence of more degraded, aged $\mathrm{OM}$ in the floc layer during this period. An increase in mangrove litterfall during the wet season has been observed at SRS6 (Twilley et al., 1986), contributing fresher inputs of OM to the floc layer. Similarly, the abundant periphyton mats found at SRS2 have been shown to display an increase in primary productivity at the onset of the wet season (Ewe et al., 2006), contributing significant amounts of more labile, fresh OM to the floc layer. The older, more degraded floc present during the dry season however, seems to be more photo-reactive. This is in agreement with Mayer et al. (2009a) who showed that photo-dissolution is greatly enhanced by microbial decay, suggesting that older, more humified OM is more photo-labile. Therefore, seasonal primary productivity variations may result in changes in the floc OM quality and consequently its photoreactivity.

While Mayer et al. (2006) reported that light exposure of freshwater suspended particulates could result in a loss of $64 \%$ of the POC over a $15 \mathrm{~d}$ period of $6 \mathrm{~h} \mathrm{~d}^{-1}$ irradiation, in the present study, the POC content did not change significantly during incubation of both the light and the dark treatments. This is likely the result of an analytical artifact, since very high initial concentrations of POC (up to $3 \mathrm{gC} \mathrm{L}^{-1}$ ) were used to simulate the natural floc layer conditions. As a result, the POC carbon loss through DOC photo-dissolution was a very small fraction of the total and consequently within the analytical error of the POC analysis. Thus, POC loss data and potential correlations with DOC production are not presented here. However, and in agreement with the literature (Kieber et al., 2006; Mayer et al., 2006 and 2009a) floc exposed to light generated a significant amount of DOC. 


\subsubsection{Composition of photo-produced DOM:}

Fluorescence properties of natural waters have been used for determining the sources of DOM as well as its transformations in different aquatic environments and have been extensively applied for the quantification of fluorescent DOM (FDOM) in natural waters (Coble, 1996). Excitation emission matrix (EEM) fluorescence can provide detailed information on the types of fluorescent compounds present in complex mixtures such as DOM (Coble, 1996). This fluorescence technique has been coupled with parallel factor analysis (PARAFAC), a statistical modeling approach, to decompose the EEMs into individual fluorescent components (Stedmon et al., 2003). Applying this approach, a total of eight fluorescent components had previously been obtained through PARAFAC modeling for the Everglades ecosystem (Appendix 3.1; Chen et al., 2010; Yamashita et al., 2010). The fluorescence characteristics of these components were assigned to be characteristic for terrestrial humic-like ( $\mathrm{C} 1,3$ and 5), microbial humic-like $(\mathrm{C} 4)$, proteinlike (C7 and 8) and two unknown components (C2 and 6) which have recently been suggested to represent a humic-like component derived from soil oxidation and a ubiquitous humic-like component, respectively (Yamashita et al., 2010).

In the present study, the fluorescence intensity of the three humic-like and the two protein-like components were combined into two groups for simplicity reasons. The fluorescence intensity of the three humic-like components, $C 1\left(\lambda_{\mathrm{ex}}=260(345) \mathrm{nm}, \lambda_{\mathrm{em}}=\right.$ $462 \mathrm{~nm}), \mathrm{C} 3\left(\lambda_{\mathrm{ex}}=260(305) \mathrm{nm}, \lambda_{\mathrm{em}}=416 \mathrm{~nm}\right)$ and C5 $\left(\lambda_{\mathrm{ex}}<275(405) \mathrm{nm}, \lambda_{\mathrm{em}}>500\right.$ $\mathrm{nm}$ ), increased for floc samples irradiated with artificial sunlight, suggesting that these components are photo-generated. These three components comprised a large portion (46$70 \%$ after $7 \mathrm{~d}$ of light exposure) of the total fluorescence, suggesting that the majority of 
the CDOM produced from irradiation of floc has humic-like optical characteristics. Two protein-like components were identified, a tyrosine-like component $\left(\mathrm{C} 7 ; \lambda_{\mathrm{ex}}=275 \mathrm{~nm}\right.$, $\left.\lambda_{\mathrm{em}}=326 \mathrm{~nm}\right)$ and a tryptophan-like component $\left(\mathrm{C} 8 ; \lambda_{\mathrm{ex}}=300 \mathrm{~nm}, \lambda_{\mathrm{em}}=342 \mathrm{~nm}\right)$ which also increased during photo-incubation. However, unlike the terrestrial humic-like components, these protein-like components comprised a smaller portion (10-16\% after 7d of light exposure) of the CDOM produced during photo-incubation of floc. The photogeneration of these protein-like components is in agreement with previous findings that tannin compounds leached from abscised mangrove leaves and other types of vegetation can form insoluble complexes with proteins, which upon photo-exposure have been shown to break up and re-release the N-containing compounds (Maie et al., 2008). Fluorescence intensity of protein-like components in DOM has also been reported to be strongly structure dependent (Mayer et al., 1999), and thus, could in part explain an increment in fluorescence intensity after photo-exposure. However, detailed EEMPARAFAC based photo-degradation studies of Everglades DOM have not shown such effects, but instead show a decrease in intensity of protein-like fluorescence with increasing light exposure (Chen and Jaffé, unpublished). Thus, the increase in proteinlike fluorescence observed in this study is most likely the result of photo-dissolution of floc. The increase in TDN during these experiments seems to agree with this suggestion. However, overall, the fluorescence signature was dominated by photo-generated humiclike compounds.

To evaluate the generation rates of the different fluorescent components the sum of the fluorescence intensity of the terrestrial humic-like components $(\mathrm{C} 1,3$ and 5$)$ and 
the protein-like components (C7 and 8), normalized to POC content, versus incubation time were plotted (Figure 3.3).
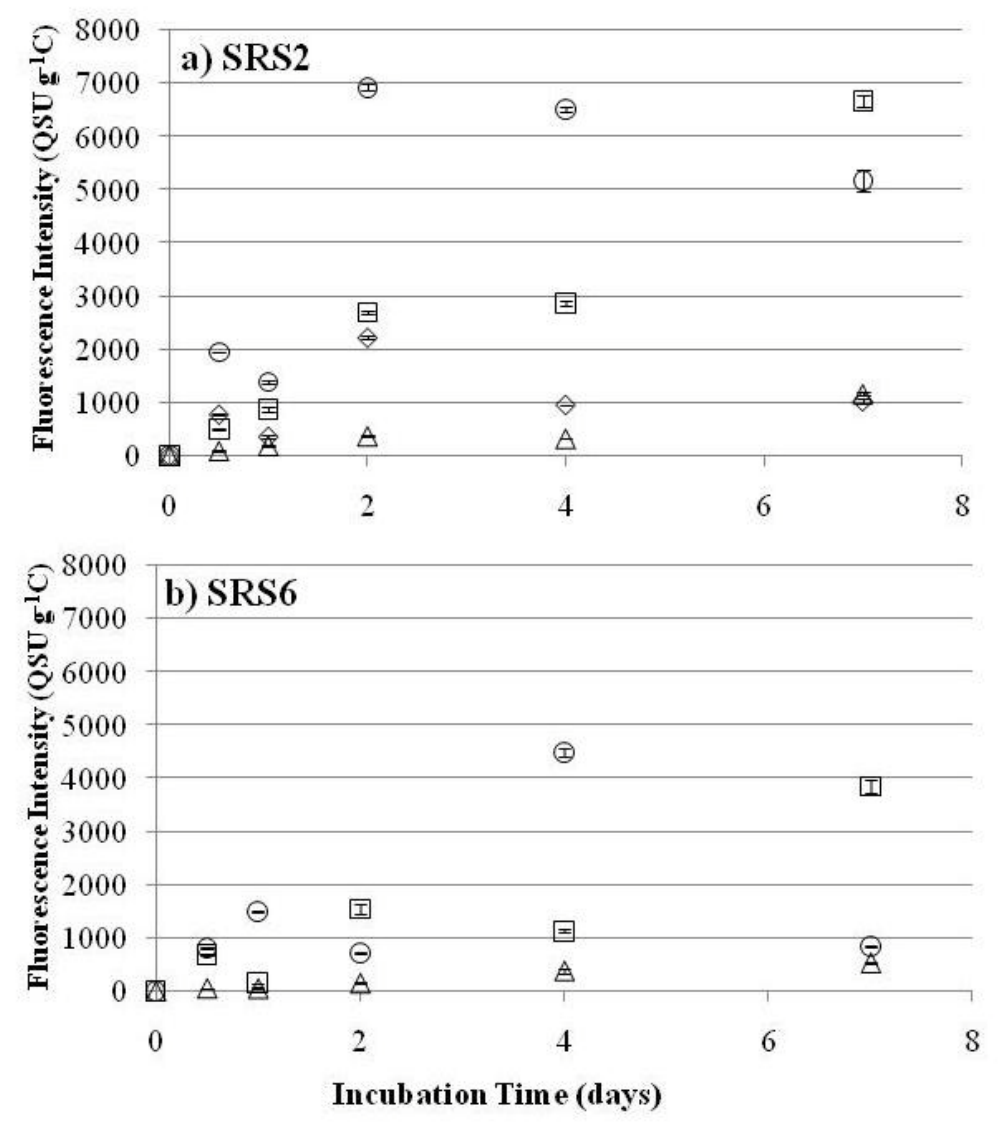

Figure 3.3. Photo-production of terrestrial humic-like components, $\mathrm{C} 1, \mathrm{C} 3$ and $\mathrm{C} 5$ ( $\mathrm{O}$ : Dry season, $\square$ : Wet season) and protein-like components, C7 and C8 ( $\diamond$ : Dry season, $\Delta$ : Wet season) from SRS2 (a) and SRS6 (b) floc. Fluorescence intensities were normalized by initial floc POC content.

Differences in generation rates between samples, PARAFAC components and season are evidenced by significant differences in the slope of the linear correlations shown in Figure 3.3 (see Table 3.2). When exposed to artificial sunlight, the floc collected at SRS2 produced more terrestrial humic-like material compared to the floc collected at SRS6 on a per-g POC basis. Shank et al. (2011) characterized the 
fluorophores generated from photo-irradiation of Florida Bay suspended sediments, and found that the most organic rich sediments exhibited the largest increases in terrestrial humic-like components. Similarly, photo-production of the protein-like components, where the presence of labile floc components from periphyton may be an important source of dissolved nitrogen, was higher in freshwater than in mangrove floc exposure experiments. Seasonal differences were similar to those previously described for DOC (see above), where higher initial (2-4 days) generation of humic- and protein-like components in the dry season was observed (Figure 3.3), suggesting that aged floc is more photo-reactive. Because the maximum photo-production of CDOM differed for the floc collected at the two sites, the slopes of the best-fit line for the linear portion of the experiment were compared (2 days for SRS2 and 4 days for SRS6). The generation of the humic-like and protein-like components was significantly different between sites and between seasons (Table 3.2). Humic-like components were generated at a much faster rate than the protein-like components, and during the wet season, these components were generated at a lower rate than during the dry season. The seasonal difference could be explained by the fact that unprocessed, fresher material incorporated into the floc layer during the wet season, is less photo-reactive, while older, more degraded material found in floc during the dry season is more reactive to sunlight. This statement is in agreement with recent studies by Mayer et al. (2009a) which showed that the photochemical reactivity of algal detritus increases with increasing microbial decay and/or humification of OM. The above data suggests that potentially both OM sources and degree of degradation (age) control the resulting composition of photo-generated DOM. The exact mechanism for these processes is presently not known. 
Table 3.2. Regression analysis for CDOM generation rates, determined for $0-2$ and $0-4$ days for SRS2 and SRS6, respectively. If the slope range between samples overlaps, then they were not statistically different.

\begin{tabular}{ccccccc}
\hline Components & Site & Season & Slope & St.Dev. & $\begin{array}{c}\text { Slope } \\
\text { Range }\end{array}$ & $p$ \\
\hline Humic-like & SRS2 & Dry & 3.30 & 0.88 & $2.4-4.2$ & 0.065 \\
& & Wet & 1.35 & 0.18 & $1.2-1.5$ & 0.018 \\
& \multirow{2}{*}{ SRS6 } & Dry & 1.00 & 0.27 & $0.73-1.3$ & 0.034 \\
& & Wet & 0.28 & 0.17 & $0.11-0.46$ & 0.199 \\
Protein-like & \multirow{2}{*}{ SRS2 } & Dry & 1.03 & 0.35 & $0.68-1.4$ & 0.097 \\
& & Wet & 0.19 & 0.00 & $0.18-0.19$ & $<0.001$ \\
& \multirow{2}{*}{ SRS6 } & Dry & 0.14 & 0.04 & $0.11-0.18$ & 0.027 \\
& & Wet & 0.09 & 0.01 & $0.09-0.10$ & 0.002 \\
\hline
\end{tabular}

\subsection{Conclusions:}

In summary, the data presented above show that flocculent detritus in the FCE generates significant amounts of DOM as well as TDN and SRP when exposed to artificial sunlight. In the shallow waters of the FCE, floc is naturally re-suspended (Larsen et al., 2009), and can easily be exposed to intense sunlight. This re-suspension is particularly critical for floc from freshwater marshes where the dominant vegetation is composed of short grasses and sedges, with minimal tree cover and consequently low shading effects. The resulting light exposure of the floc can aid in the transfer of POM into the dissolved phase through photo-dissolution processes (Kieber et al., 2006; Mayer et al., 2006) and as such fuel the microbial loop. These photo-induced dissolution processes are especially important in the oligotrophic waters of the FCE where the concentrations of dissolved nutrients are naturally very low, but where most of the dissolved $\mathrm{N}$ and $\mathrm{P}$ are in an organic form (Noe et al., 2007). 
Regarding the composition of the photo-generated DOM, terrestrial humic-like components were the main contributors to the $\mathrm{CDOM}$ fluorescence, indicating a preferential photo-dissolution of humic moieties. Shank et al. (2011) reported that terrestrial humic-like components were preferentially photo-desorbed from re-suspended estuarine sediments, indicating that photo-generated materials seem to be preferentially dominated by organics with a more terrigenous character. The generation rate of the terrestrial humic- and protein-like components was higher for floc collected at the freshwater site compared to the mangrove site, suggesting that there are differences in floc composition between the freshwater and mangrove sites that are reflected in differences in their photo-reactivity. Similarly, the generation rate of the terrestrial humic- and protein-like components was higher during dry season than wet season for both sites. It has recently been reported that older, partially degraded material can be significantly more photo-reactive compared to unprocessed, fresh material (Mayer et al., 2009a). Floc receives much of its OM input during the wet season when periphyton mats are more productive and mangrove litterfall increases. Consequently, floc present during the wet season is expected to be fresher, while it is more aged during the dry season, therefore increasing its potential photo-reactivity during the latter. While floc collected during the dry season clearly showed higher photo-dissolution rates during the first 2-4 days of exposure for freshwater and mangrove floc respectively, the overall DOC production after one week of exposure was not too different between wet and dry season samples.

The Florida Coastal Everglades is an oligotrophic subtropical wetland, where detrital carbon pools are critical components of the food web and control to a significant 
extent the trophic dynamics in this system (Williams et al., 2006). The present study suggests that floc photo-dissolution has the potential to generate high amounts of DOC as well as TDN and SRP and thus can affect the biogeochemical cycling and productivity of this system. The efficiency of these photo-dissolution processes is dependent on floc quality, which seems dependent on biomass type inputs and primary productivity on both spatial and temporal scales. Potential changes, such as increased water delivery, particularly through Shark River Slough as a result of the implementation of the Comprehensive Everglades Restoration Plan may induce changes in floc dynamics in this system. A better understanding of the effects of light exposure to POM, suspended sediments or floc is needed to assess carbon dynamics in shallow and/or turbid aquatic ecosystems. 


\section{REFERENCES:}

Castañeda-Moya, E., R. R. Twilley, V. H. Rivera-Monroy, K. Zhang, S. E. Davis III and M. Ross. 2009. Sediment and nutrient deposition associated with hurricane Wilma in mangroves of the Florida Coastal Everglades. Estuaries and Coasts 33(1): 45-58.

Chen, M., R. M. Price, Y. Yamashita and R. Jaffé. 2010. Comparative study of dissolved organic matter from groundwater and surface water in the Florida coastal Everglades using multi-dimensional spectrofluorometry combined with multivariate statistics. Applied Geochemistry 25: 872-880.

Childers, D. L., J. N. Boyer, S. E. Davis, C. J. Madden, D. T. Rudnick and F. H. Sklar. 2006. Relating precipitation and water management to nutrient concentrations in the oligotrophic "upside-down" estuaries of the Florida Everglades. Limnology and Oceanography 51(1/2): 602-616.

Clark, C. D., W. T. Hiscock, F. J. Millero, G. Hitchcock, L. Brand, W. L. Miller, L. Ziolkowski, R. F. Chen and R. G. Zika. 2004. CDOM distribution and $\mathrm{CO}_{2}$ production on the Southwest Florida Shelf. Marine Chemistry 89: 145-167.

Coble, P. G. 1996. Characterization of marine and terrestrial DOM in seawater using excitation-emission matrix spectroscopy. Marine Chemistry 51: 325-346.

Coble, P. G. 2007. Marine optical biogeochemistry: The chemistry of ocean color. Chemical Reviews 107: 402-418.

Ewe, S. M. L., E. E. Gaiser, D. L. Childers, D. Iwaniec, V. H. Rivera-Monroy and R. R. Twilley. 2006. Spatial and temporal patterns of aboveground net primary productivity (ANPP) along two freshwater-estuarine transects in the Florida Coastal Everglades. Hydrobiologia 569: 459-474.

Findlay, S. E. G. and R. L. Sinsabaugh (Eds.). 2003. Aquatic ecosystems: interactivity of dissolved organic matter. San Diego: Academic Press.

Gao, M., B. R. T. Simoneit, M. Gantar and R. Jaffé. 2007. Occurrence and distribution of novel botryococcene hydrocarbons in freshwater wetlands of the Florida Everglades. Chemosphere 70: 224-236.

Harris, D., W. R. Horwath and C. van Kessel. 2001. Acid fumigation of soils to remove carbonates prior to total organic carbon or carbon-13 isotopic analysis. Soil Science Society of America Journal 65: 1853-1856.

Hernandez, M. E., R. Mead, M. C. Peralba and R. Jaffé. 2001. Origin and transport of $n$ alkane-2-ones in a subtropical estuary: potential biomarkers for seagrass-derived organic matter. Organic Geochemistry 32: 21-32. 
Holder Sandvik, S. L., P. Bilski, J. D. Pakulski, C. F. Chignell and R. B. Coffin. 2000. Photogeneration of singlet oxygen and free radicals in dissolved organic matter isolated from the Mississippi and Atchafalaya River plumes. Marine Chemistry 69: 139-152.

Jaffé, R. J., R. Mead, M. E. Hernandez, M. C. Peralba and O. A. DiGuida. 2001. Origin and transport of sedimentary organic matter in two subtropical estuaries: a comparative, biomarker-based study. Organic Geochemistry 32: 507-526.

Jaffé, R., J. N. Boyer, X. Lu, N. Maie, C. Yang, N. M. Scully and S. Mock. 2003. Source characterization of dissolved organic matter in a subtropical mangrove-dominated estuary by fluorescence analysis. Marine Chemistry 84: 195-210.

Kieber, R. J., R. F. Whitehead and S. A. Skrabal. 2006. Photochemical production of dissolved organic carbon from resuspended sediments. Limnology and Oceanography 51(5): 2187-2195.

Kirk, J. T. O. 1980. Spectral absorption properties of natural waters: Contribution of the soluble and particulate fractions to light absorption some inland waters of south-eastern Australia. Australian Journal of Marine and Freshwater Research 31: 287-296.

Larsen, L. G., J. W. Harvey, G. B. Noe and J. P. Crimaldi. 2009. Predicting organic floc transport dynamics in shallow aquatic ecosystems: Insights from the field, the laboratory, and numerical modeling. Water Resources Research 45: W01411, doi: 10.1029/2008WR007221.

Lou, T. and H. Xie. 2006. Photochemical alteration of the molecular weight of dissolved organic matter. Chemosphere 65: 2333-2342.

Maie, N., R. Jaffé, T. Miyoshi and D. L. Childers. 2006. Quantitative and qualitative aspects of dissolved organic carbon leached from senescent plants in an oligotrophic wetland. Biogeochemistry 78: 285-314.

Maie, N., O. Pisani and R. Jaffé. 2008. Mangrove tannins in aquatic ecosystems: Their fate and possible influence on dissolved organic carbon and nitrogen cycling. Limnology and Oceanography 53(1): 160-171.

Mayer, L. M., K., Schick, T. C., Loder III. 1999. Dissolved protein fluorescence in two Maine estuaries. Marine Chemistry 64: 171-179.

Mayer, L. M., L. L. Schick, K. Skorko and E. Boss. 2006. Photodissolution of particulate organic matter from sediments. Limnology and Oceanography 51(2): 1064-1071.

Mayer, L. M., L. L. Schick, K. R. Hardy and M. L. Estapa. 2009a. Photodissolution and other photochemical changes upon irradiation of algal detritus. Limnology and Oceanography 54(5): 1688-1698. 
Mayer, L. M., L. L. Schick, T. S. Bianchi and L. A. Wysocki. 2009b. Photochemical changes in chemical markers of sedimentary organic matter source and age. Marine Chemistry 113: 123-128.

Miller, W. L. and M. A. Moran. 1997. Interaction of photochemical and microbial processes in the degradation of refractory dissolved organic matter from a coastal marine environment. Limnology and Oceanography 42(6): 1317-1324.

Moore, J. C., E. L. Berlow, D. C. Coleman, P. C. de Ruiter, Q. Dong, A. Hastings, N. C. Johnson, K. S. McCann, K. Melville, P. J. Morin, K. Nadelhoffer, A. D. Rosemond, D. M. Post, J. L. Sabo, K. M. Scow. M. J. Vanni and D. H. Wall. 2004. Detritus, trophic dynamics and biodiversity. Ecology Letters 7: 584-600.

Moran, M. A. and R. G. Zepp. 1997. Role of photoreactions in the formation of biologically labile compounds from dissolved organic matter. Limnology and Oceanography 42(6): 1307-1316.

Neto, R. R., R. N. Mead, W. J. Louda and R. Jaffé. 2006. Organic biogeochemistry of detrital flocculent material (floc) in a subtropical, coastal wetland. Biogeochemistry 77: 283-304.

Noe, G. B. and D. L. Childers. 2007. Phosphorus budgets in Everglades wetland ecosystems: the effects of hydrology and nutrient enrichment. Wetlands Ecology and Management 15: 189-205.

Opsahl, S. and R. Benner. 1998. Photochemical reactivity of dissolved lignin in river and ocean waters. Limnology and Oceanography 43: 1297-1304.

Saunders, C. J., M. Gao, J. A. Lynch, R. Jaffé and D. L. Childers. 2006. Using soil profiles of seeds and molecular markers as proxies for sawgrass and wet prairie slough vegetation in Shark River Slough, Everglades National Park. Hydrobiologia 569: 475492.

Shank, G. C., R. G. Zepp, A. Vähätalo, R. Lee and E. Bartels. 2010. Photobleaching kinetics of chromophoric dissolved organic matter derived from mangrove leaf litter and floating Sargassum colonies. Marine Chemistry 119: 162-171.

Shank, G. C., A. Evans, Y. Yamashita and R. Jaffé. 2011. Solar radiation-enhanced dissolution of particulate organic matter from coastal marine sediments. Limnology and Oceanography 56(2): 577-588.

Stedmon, C. A., S. Markager and R. Bro. 2003. Tracing dissolved organic matter in aquatic environments using a new approach to fluorescence spectroscopy. Marine Chemistry 82: 239-254.

Stedmon, C. A. and R. Bro. 2008. Characterizing dissolved organic matter fluorescence with parallel factor analysis: a tutorial. Limnology and Oceanography Methods 6: 572 579. 
Troxler, T. G. and J. Richards. 2009. $\delta^{13} \mathrm{C}, \delta^{15} \mathrm{~N}$, carbon, nitrogen and phosphorus as indicators of plant ecophysiology and organic matter pathways in Everglades deep slough, Florida, USA. Aquatic Botany 91(3): 157-165.

Twilley, R. R., A. E. Lugo and C. Patterson-Zucca. 1986. Litter production and turnover in basin mangrove forests in southwest Florida. Ecology 67(3): 670-683.

von Wachenfeldt, E., D. Bastviken and L. J. Tranvik. 2009. Microbially induced flocculation of allochthonous dissolved organic carbon in lakes. Limnology and Oceanography 54(5): 1811-1818.

Williams, A. J. and J. C. Trexler. 2006. A preliminary analysis of the correlation of foodweb characteristics with hydrology and nutrient gradients in the southern Everglades. Hydrobiologia 569: 493-504.

Woods, J. 2010. Surface water discharge and salinity monitoring of coastal estuaries in Everglades National Park, USA, in support of the Comprehensive Everglades Restoration Plan. Proceedings of the $3^{\text {rd }}$ International Perspective on Current $\&$ Future State of Water Resources \& the Environment, Chennai, India.

Xie, H., O. C., Zafiriou. 2009. Evidence for significant photochemical production of carbon monoxide by particles in coastal and oligotrophic marine waters. Geophysical Research Letters 36: L23606, doi:10.1029/2009GL041158.

Yamashita, Y., L. J. Scinto, N. Maie and R. Jaffé. 2010. Dissolved organic matter characteristics across a subtropical wetland's landscape: Application of optical properties in the assessment of environmental dynamics. Ecosystems 13: 1006-1019.

Zhang, Y., M. A. van Dijk, M. Liu, G. Zhu and B. Qin. 2009. The contribution of phytoplankton degradation to chromophoric dissolved organic matter (CDOM) in eutrophic shallow lakes: Field and experimental evidence. Water Research 43: 46854697. 
Chapter IV

SPATIAL AND SEASONAL DIFFERENCES OF FLOCCULENT DETRITAL MATERIAL RESPIRATION RATES IN A SUBTROPICAL WETLAND 


\subsection{Introduction:}

The decomposition of organic carbon (OC) has been widely studied in terrestrial and aquatic environments (Glaser et al., 2001; Gerbersdorf et al., 2004; Garcia-Pausas et al., 2008; Feng et al., 2008). OC decomposition in wetlands has received much attention because of the complexity of carbon dynamics in these environments and its critical role in the global carbon cycle (Updegraff et al., 1995). The accumulation of OC in wetlands occurs when net primary production (carbon fixation) exceeds decomposition (carbon mineralization or respiration; DeBusk et al., 2003), which in turn, is governed by several environmental factors, such as nutrient availability, temperature, moisture and electron acceptor availability (in particular $\mathrm{O}_{2}$; Reddy et al., 1994). In fact, the decomposition of OC in wetland soils occurs at a much slower rate compared to upland ecosystems, because of occasional anaerobic or sub-oxic conditions that can develop throughout the soil profile as a result of flooding (Amador et al., 1997; DeBusk et al., 2005).

Furthermore, the decomposition rate of $\mathrm{OC}$ in wetland soils has been found to be directly affected by the chemical and physical composition of the organic substrate with potential carbon mineralization rates decreasing with substrate age (DeBusk et al., 1998).

Wetlands are considered important carbon dioxide $\left(\mathrm{CO}_{2}\right)$ sinks and sources of atmospheric methane (Moore et al., 1993). Although wetlands cover only 6-8\% of the earth's land and freshwater surface, they are responsible for about one-third of the global soil organic carbon pool, containing about $450 \times 10^{15} \mathrm{~g}$ of OC (Mitsch et al., 2007). The amount of OC stored in wetland soils, as well as the amount of carbon emitted, is likely to change in response to climate change and anthropogenic disturbance. Because wetlands represent one of the largest biological carbon pools and can play a significant 
role in the global carbon cycle, it is important to understand OC dynamics in these complex environments.

The Florida Coastal Everglades (FCE) is the largest wetland in the United States, covering approximately $7900 \mathrm{~km}^{2}$ from south of Lake Okeechobee to the Gulf of Mexico and Florida Bay. The FCE is also the only subtropical wetland ecosystem in the U.S. that is enrolled in the Ramsar Convention of Wetlands of International Importance (Richardson, 2009). Surface water entering Everglades National Park (ENP) is controlled by a series of levees and canals and come from the Water Conservation Areas (WCA; Figure 4.1), a $3400 \mathrm{~km}^{2}$ area of shallow water reservoirs that connects ENP to the Everglades Agricultural Area (EAA). The EAA is a $2800 \mathrm{~km}^{2}$ area of drained wetlands bordering Lake Okeechobee and is currently used for large-scale production of sugarcane and winter vegetables (Belanger et al., 1989). The water leaving the EAA has a higher TP content $\left(1.16 \mu \mathrm{mol} \mathrm{L}{ }^{-1}\right)$ compared to that found in the interior, more pristine areas of the park $\left(0.19 \mu\right.$ moles L ${ }^{-1}$; Amador et al., 1995). These increased nutrient concentrations in the northern part of the ENP have been shown to affect carbon mineralization rates of peat soils (Amador et al., 1995; DeBusk et al., 1998; Wright et al., 2001) and decomposing plant litter (DeBusk et al., 2005; Corstanje et al., 2006).

While numerous OC mineralization studies have focused on peat soils of the WCAs, not many have discussed another important component of the FCE ecosystem, namely flocculent, detrital material (floc). The FCE is characterized by low quantities of suspended particulate organic matter (POM) with concentrations ranging from 0.7 to 2.7 $\mathrm{mg} \mathrm{L}^{-1}$ (Noe et al., 2007). Instead, the majority of the POM occurs at the sediment-water interface in the form of floc, which can reach concentrations of up to $2.1 \times 10^{6} \mathrm{mg} \mathrm{L}^{-1}$ 
(data presented in Chapter 2 of this dissertation). Floc in the Everglades is an unconsolidated layer of particulate matter, known to be composed mainly of an assembly of periphyton, higher plant detritus and carbonates. Previous studies have shown that the composition of floc is controlled by local vegetation inputs and early diagenetic transformations of OM (Neto et al., 2006). Floc materials found in deep sloughs of the FCE have been shown to contain the detrital remains of some typical local aquatic vegetation such as Utricularia species (Troxler et al., 2009). Furthermore, inputs from filamentous green algae have also been detected in floc from the FCE (Gao et al., 2007). Recent studies on floc transport (Larsen et al., 2009a) have implied its importance in the formation and maintenance of the ridge and slough landscape in the Everglades.

Sufficient water flows for the entrainment of floc (entrainment threshold is $1.0 \times 10^{-2} \mathrm{~Pa}$; Larsen et al. 2009b) from sloughs and ridge margins will help redeposit it into the interior ridges, where it will be incorporated into the peat and contribute to the corrugation of the landscape. In general terms however, floc is believed to have a limited mobility (Larsen et al., 2009a).

The amount of OC present in the floc layer appears to be spatially different in the FCE. Floc found in freshwater deep sloughs, where peat soils are formed mostly by decomposing sawgrass, can have a higher OC content (Troxler and Richards, 2009) compared to floc found in short-hydroperiod marshes characterized by carbonate-rich sediments (Neto et al., 2006). Although not much is known on the accumulation and decomposition dynamics of floc OC, these processes are believed to be governed by nutrient limitation and hydrology (DeBusk et al., 2003). These authors analyzed peat soils from the WCAs and found that soil respiration was relatively high under flooded 
conditions, but that this process was significantly enhanced in drained soils containing high amounts of phosphorus derived from the EAA. It is well known that it is phosphorus, not nitrogen, that limits the rate of soil OC mineralization in Everglades' peat soils (Amador et al., 1993; DeBusk et al., 2003).

The FCE is a naturally oligotrophic wetland that has experienced large changes in ecosystem structure and function as a result of increased anthropogenic nutrient loading and hydrologic changes (Noe et al., 2007a). Nutrient loading (especially phosphorus) in the FCE has been a major concern and has been implicated in causing changes in vegetation as well as changes in peat accretion rates and soil microbial activity (Belanger et al., 1989; Doren et al., 1996; Wright et al., 2001). The enhanced heterotrophic microbial activity that can result from phosphorus loading has the potential to increase OC turnover, leading to an increased supply of bio-available nutrients to emergent macrophytes and periphyton as well as higher nutrient concentrations in the water column (Wright et al., 2001). Phosphorus enrichment has also been shown to alter a large number of important biogeochemical processes in the FCE, such as decomposition of OM (Newman et al., 2001), DOM dynamics (Qualls et al., 2003) and soil organic nitrogen mineralization (White et al., 2000). Floc is known to contain less phosphorus than Everglades' soils (Noe et al., 2007a). The phosphorus stored in the floc can move to the soil by diffusive flux and/or particle settling, enter the water column through diffusion and particle suspension (Noe et al., 2003) or through light-induced dissolution processes (Pisani et al., 2011, in press, Chapter 3 of this dissertation). However, it has been suggested that floc can function as a transient pool of phosphorus before it enters the soil for long-term storage (Noe et al., 2007a). Furthermore, flocculent materials may 
constitute an important component of the detrital food chain in this wetland ecosystem (Williams et al., 2006). Because floc is ubiquitous in the FCE and not much is known about its biogeochemical dynamics in this environment, it is important to understand how bio-reactive it is in terms of $\mathrm{CO}_{2}$ respiration and what effects increased phosphorus loading can have on its bio-reactivity.

The objective of this study was to (1) identify spatial and seasonal differences in the rate of $\mathrm{CO}_{2}$ production (respiration) from flocculent, detrital material in the Everglades, and to (2) determine the effects of increased phosphorus concentrations and (3) substrate quality (glucose) on floc respiration rates.

\subsection{Materials and methods:}

\subsubsection{Sample collection:}

Floc samples were collected at sites previously described by the Florida Coastal Everglades-Long Term Ecological Research (FCE-LTER) program (Figure 4.1; http://fcelter.fiu.edu/). A typical freshwater marsh and fringe mangrove site were chosen along the two main drainage basins of the FCE, namely Taylor Slough (TS; sites TS2 and TS6, respectively) and Shark River Slough (SRS; sites SRS2 and SRS6, respectively).

The freshwater marsh site SRS2 is a long hydroperiod site dominated by sawgrass (Cladium jamaicense), Gulfcoast spikerush (Eleocharis cellulosa) and abundant periphyton mats. The decomposition of dead plant material contributes to the $\mathrm{OM}$ content of the underlying peat soils. Fringe mangrove site SRS6 is tidally-influenced and dominated by red mangroves (Rhizophora mangle). In contrast to the peat dominated Shark River Slough, Taylor Slough is characterized by organic rich calcitic mud soils 
(marl), formed by periphyton that re-precipitate calcium carbonate $\left(\mathrm{CaCO}_{3}\right)$ originally derived from the limestone substrate (Richardson, 2009). Freshwater marsh site TS2 is characterized by short hydroperiod and dominated by sawgrass, spikerush and abundant periphyton mats. Finally, fringe mangrove site TS6 is dominated by red mangroves of small stature ("dwarf" mangroves) and receives seasonally-driven freshwater inputs.

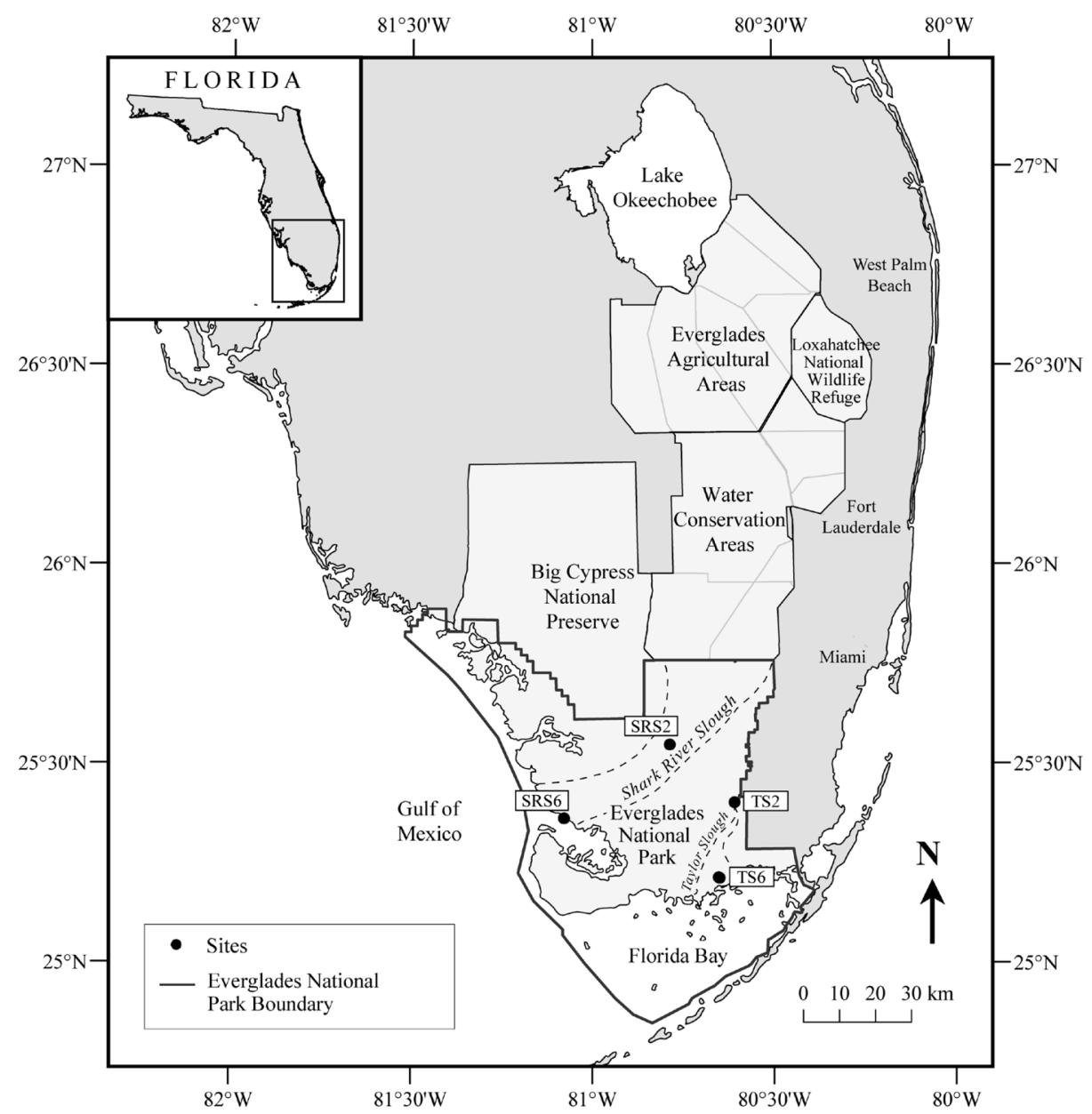

Figure 4.1. A map of south Florida showing the compartmentalization of the Everglades into the Everglades Agricultural Areas (EAA), Loxahatchee National Wildlife Refuge, the Water Conservation Areas (WCA), Big Cypress National Preserve and Everglades National Park (ENP). Within ENP, the sampling locations along the Shark River Slough (SRS) and Taylor Slough (TS) are indicated. 
Floc samples were collected in the dry season (April) and the wet season (October) of 2009 following the procedure described by Neto et al. (2006). Briefly, floc samples were collected using a transparent plastic corer (inner diameter of $2.5 \mathrm{~cm}$ ). The core was pushed about $10 \mathrm{~cm}$ below the sediment surface, capped to create suction, and retrieved. The floc layer was visible in the core and was decanted from the consolidated surface of the soil/sediment using a plunger with a smaller diameter to that of the core tube to hold the bottom layer in place. Excess water was decanted and the floc was collected in pre-rinsed $1 \mathrm{~L}$ Teflon jars (Nalgene). The procedure was repeated at randomly selected locations at each site enough times to obtain about $1 \mathrm{~L}$ of floc composite for each sampling event. The floc samples were transported to the laboratory on ice where they were immediately prepared for analysis and incubation.

\subsubsection{Experimental set-up:}

For the determination of floc respiration rates, five $\mathrm{mL}$ of wet floc was added to $20 \mathrm{~mL}$ pre-combusted $\left(500{ }^{\circ} \mathrm{C}\right.$ for 5 hours $)$ glass vials. The floc was dispensed using a pipette fitted with a plastic tip that was altered to allow unrestricted flow. The vials were capped with rubber septa and sealed with an aluminum metal crimp. The air in the headspace was evacuated and replaced with $\mathrm{CO}_{2}$-free air. The procedure was repeated five times to ensure that no $\mathrm{CO}_{2}$ remained in the headspace. The vials were kept at room temperature in the dark.

To study the effects of phosphorus limitation on floc $\mathrm{CO}_{2}$ production rates, $5 \mathrm{~mL}$ of floc was added to pre-combusted glass vials as described above. Phosphorus was added as a di-potassium phosphate $\left(\mathrm{K}_{2} \mathrm{HPO}_{4}\right)$ solution in amounts necessary to eliminate 
P limitation for the floc at each particular site $\left(0.0068-0.023 \mathrm{~mol} \mathrm{P} \mathrm{L}^{-1}\right.$, final concentration). $\mathrm{P}$ limitation was calculated using the $\mathrm{C} / \mathrm{P}$ ratio of the floc at each site. The $\mathrm{pH}$ of the solution was adjusted with $1 \mathrm{~N} \mathrm{HCl}$ to the initial $\mathrm{pH}$ of the floc, which was always close to neutral ( $\mathrm{pH}$ 7.6-8.0). The vials were capped with rubber septa and sealed with an aluminum metal crimp. The air in the headspace was evacuated and replaced with $\mathrm{CO}_{2}$-free air as described above.

To determine the effects of substrate quality on floc $\mathrm{CO}_{2}$ production rates, glucose was added as a solution containing 0.20 moles $\mathrm{C} \mathrm{L}^{-1}$ to the $5 \mathrm{~mL}$ of floc added to precombusted $20 \mathrm{~mL}$ glass vials, for a final glucose concentration of ca. $0.005 \mathrm{~mol}$ glucose $\mathrm{L}^{-1}$. The vials were capped with rubber septa and sealed with an aluminum metal crimp. The air in the headspace was evacuated and replaced with $\mathrm{CO}_{2}$-free air as described above.

All treatments were prepared in triplicates. The vials were allowed to stand for 15 minutes before the first $\mathrm{CO}_{2}$ analysis was performed through headspace gas chromatography with flame ionization detection $(\mathrm{GC} / \mathrm{FID})$ after conversion of the $\mathrm{CO}_{2}$ to methane. After analysis, the gas in the headspace was replaced with $\mathrm{CO}_{2}$-free air following the procedure described above, and the incubation was resumed. The vials were sampled every 15 minutes for the first hour, then once a day for a total incubation time of one week.

\subsubsection{Headspace-GC/FID analysis:}

Aerobic floc respiration was measured as the amount of $\mathrm{CO}_{2}$ (converted to $\mathrm{CH}_{4}$ ) evolved over time. A $1 \mathrm{~mL}$ aliquot of the headspace gas was removed using an automated 
HP 7694 Headspace Sampler. The sampled gas was injected into an HP 5890 gas chromatograph (GC) fitted with a Hayesep Q, divinylbenzene-packed column (6' x 1/8” x 0.085 ” SS, 80/100 mesh size, Alltech $\left.{ }^{\circledR}\right)$, using nitrogen as the carrier gas (30 psi). $\mathrm{CO}_{2}$ was converted to methane $\left(\mathrm{CH}_{4}\right)$ using a Shimadzu MTN-1 Methanizer kept at $400{ }^{\circ} \mathrm{C}$. The resulting gas was detected and measured with an FID. Injector, column and detector temperatures were kept at 150,100 and $300{ }^{\circ} \mathrm{C}$, respectively. Peak areas for $\mathrm{CH}_{4}$ were determined by electronic integration using E-lab software. The conversion of peak areas to moles of $\mathrm{CO}_{2}$ was made by preparing a calibration curve with known amounts of $\mathrm{CO}_{2}$. After analysis, the gas in the headspace was replaced with $\mathrm{CO}_{2}$-free air following the procedure described above, and the incubation was resumed.

\subsubsection{Bulk parameters:}

Percent organic matter $(\% \mathrm{OM})$ was measured by obtaining the dry weight and the ash free dry weight $\left(5\right.$ hours at $500{ }^{\circ} \mathrm{C}$ ) of the floc samples. A subsample of the dried material was used to estimate the total carbon (TC) and total nitrogen (TN) content of the floc following the methods of Nelson et al. (1996). A subsample of the ashed material was analyzed for TC, yielding total inorganic carbon (TIC). The amount of total organic carbon (TOC) was obtained by using the following relationship:

$$
\mathrm{TC}=\mathrm{TIC}+\mathrm{TOC}(\text { Eq. 1) }
$$

Total phosphorus (TP) was measured following dry ashing according to Solorzano and Sharp (1980). 


\subsubsection{Data analysis:}

The respiration data were fitted to an equation for a kinetic model that best described the pattern of $\mathrm{CO}_{2}$ evolution in floc. A non-linearized power function was used to describe the data as this has previously been shown to provide an acceptable fit to $\mathrm{C}$ mineralization patterns in soils (Saviozzi et al., 1993a). The non-linearized power function that was used is described by the following equation:

$$
\mathrm{C}_{\mathrm{t}}=\mathrm{C}_{0} \mathrm{t}^{\mathrm{k}} \text { (Eq. 2) }
$$

$\mathrm{C}_{\mathrm{t}}$ is the cumulative $\mathrm{C}$ mineralized after time $\mathrm{t}\left(\mu\right.$ moles $\left.\mathrm{C} \mathrm{gOC}^{-1}\right), \mathrm{C}_{0}$ is the potentially mineralizable $\mathrm{C}\left(\mu\right.$ moles $\left.\mathrm{CgOC}^{-1}\right)$, $\mathrm{t}$ is the time from the start of the incubation period (hours) and $\mathrm{k}$ is the mineralization rate constant $\left(\right.$ hours $\left.^{-1}\right)$.

The data obtained were not normal, and a log-transformation was applied to all the values for statistical analysis. A two-way analysis of variance (ANOVA; $p=0.050)$ was then used to determine the effects of location and season on floc respiration rates. The Holm-Sidak method $(\alpha=0.050)$ was used as a post hoc test to determine which factor contributed the most to the differences observed. All statistical analyses were performed on Sigmaplot.

\subsection{Results and discussion:}

\subsubsection{Floc bulk characteristics:}

Significant spatial and seasonal differences in floc bulk properties are summarized in Table 4.1. Differences were observed in the initial OM content of the floc. The floc 
collected in the dry season at the freshwater site (SRS2) contained the most OM (78\%). In agreement with the present data, a high accumulation of floc OM at long-hydroperiod sites has previously been reported (Gottlieb et al., 2006). The floc collected from the freshwater site in Taylor Slough (TS2) contained less OM (40 \%). In fact, soils from this short-hydroperiod site have been classified as marl and are strongly influenced by periphyton-derived calcareous inputs. The two mangrove sites, contained lower amounts of OM (31\% and $23 \%$ for TS6 and SRS6, respectively). While TS6 floc can receive inputs from freshwater submerged vegetation such as Chara sp. and Utricularia sp. (Mead et al., 2005), SRS6 is a tidally influenced site (Childers et al., 2006a) and the OM accumulation at this site may be influenced by hydrological parameters and higher levels of $\mathrm{P}$. Seasonal differences in floc OM content were significant at all sites. Generally, the OM content was higher during the dry season, except for SRS6 floc which had a slightly higher OM content during the wet season. The abundant periphyton mats found at the freshwater sites have shown an increase in primary productivity at the onset of the wet season (Ewe et al., 2006). This might explain the higher amounts of OM found during the dry season in the floc of the two freshwater sites. The higher OM content of the floc collected at TS6 during the dry season might be explained by seasonal inputs of freshwater submerged vegetation or by reduced hydrodynamic transport from the freshwater sites (Davis et al., 2003). 
Table 4.2. Bulk properties of the floc samples used in this study: Organic matter (OM), total organic carbon (TOC), total inorganic carbon (TIC), total nitrogen (TN) and total phosphorus (TP). Data are averages \pm standard errors of triplicate floc samples. Letters indicate means that are significantly different $(p<0.001)$ within each variable.

\begin{tabular}{ccccccc}
\hline Site & Season & OM $^{*}$ & TOC $^{* *}$ & TIC $^{* *}$ & TN** $^{*}$ & TP** \\
\hline SRS2 & Dry & $78^{\mathrm{a}} \pm 1.8$ & $361^{\mathrm{a}} \pm 5.6$ & $50^{\mathrm{a}} \pm 5.3$ & $34^{\mathrm{a}} \pm 0.6$ & $0.45^{\mathrm{a}} \pm 0.0$ \\
& Wet & $66^{\mathrm{b}} \pm 1.1$ & $256^{\mathrm{b}} \pm 6.9$ & $83^{\mathrm{b}} \pm 3.3$ & $24^{\mathrm{b}} \pm 1.0$ & $0.45^{\mathrm{a}} \pm 0.1$ \\
SRS6 & Dry & $23^{\mathrm{c}} \pm 0.2$ & $51^{\mathrm{c}} \pm 1.8$ & $44^{\mathrm{a}} \pm 2.1$ & $1.5^{\mathrm{c}} \pm 0.2$ & $0.48^{\mathrm{a}} \pm 0.0$ \\
& Wet & $26^{\mathrm{d}} \pm 0.5$ & $83^{\mathrm{d}} \pm 7.9$ & $69^{\mathrm{c}} \pm 1.4$ & $4.8^{\mathrm{d}} \pm 0.4$ & $1.2^{\mathrm{b}} \pm 0.1$ \\
TS2 & Dry & $40^{\mathrm{e}} \pm 0.1$ & $137^{\mathrm{e}} \pm 3.6$ & $108^{\mathrm{d}} \pm 2.2$ & $9.9^{\mathrm{e}} \pm 0.3$ & $0.22^{\mathrm{c}} \pm 0.0$ \\
& Wet & $18^{\mathrm{f}} \pm 0.7$ & $58^{\mathrm{f}} \pm 3.9$ & $119^{\mathrm{e}} \pm 0.2$ & $6.4^{\mathrm{f}} \pm 0.6$ & $0.23^{\mathrm{c}} \pm 0.0$ \\
TS6 & Dry & $31^{\mathrm{g}} \pm 0.3$ & $106^{\mathrm{g}} \pm 4.9$ & $110^{\mathrm{d}} \pm 0.0$ & $9.3^{\mathrm{e}} \pm 0.2$ & $0.24^{\mathrm{c}} \pm 0.0$ \\
& Wet & $20^{\mathrm{h}} \pm 0.1$ & $74^{\mathrm{h}} \pm 5.7$ & $113^{\mathrm{d}} \pm 3.7$ & $7.6^{\mathrm{g}} \pm 0.3$ & $0.19^{\mathrm{d}} \pm 0.0$ \\
\hline$*$ units in $\%$ and ** units in mg g dry floc ${ }^{-1}$. & & &
\end{tabular}

The total organic carbon (TOC) content of the floc was found to be spatially and seasonally different (Table 4.1 and Figure 4.2) and significantly correlated with $\% \mathrm{OM}\left(\mathrm{r}^{2}\right.$ $=0.97, p<0.0001)$. The TOC trends can therefore be described as those for $\% \mathrm{OM}$.

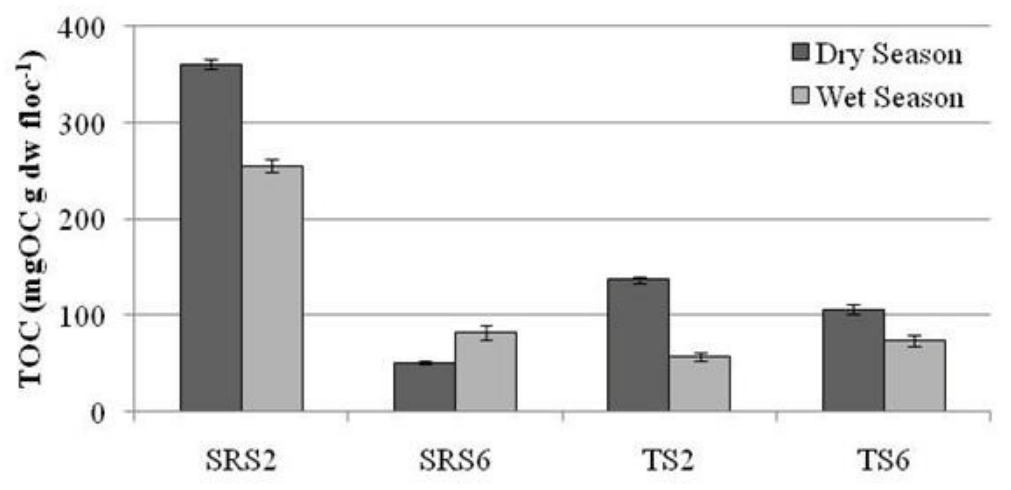

Figure 4.2. Initial TOC content of the floc samples. 
The initial total phosphorus (TP) content of the floc was significantly different between the SRS and the TS sites (Table 4.1). The SRS6 floc collected during the wet season contained the highest TP $\left(1.2 \mathrm{mgP} \mathrm{g}^{-1}\right.$ of dry floc) as this site is known to receive phosphorus inputs from the adjacent Gulf of Mexico. The TS6 floc did not show this enhanced marine input of phosphorus because this site is isolated from the Gulf of Mexico by Florida Bay, whose shallow mud banks hamper the tidal effect and where local seagrass communities consume most of the available P (Fourqurean et al., 1993). Floc from TS2 contained the lowest amount of TP $\left(0.2 \mathrm{mgP} \mathrm{g}^{-1}\right.$ of dry floc $)$ as this is a typical P-limited freshwater site of the FCE. The SRS2 floc contained slightly higher amounts of TP ( $0.45 \mathrm{mgP} \mathrm{g}^{-1}$ of dry floc $)$ and this might be attributed to internal biogeochemical processing associated with longer water residence times (Childers et al., 2006a). It has also been shown that floc found in deep sloughs can contain higher amounts of TP compared to shorter hydroperiod marshes (Noe et al., 2007a). Seasonal differences in TP were only found at the two mangrove sites (Table 4.1). The floc collected at TS6 had higher TP values in the dry season, potentially from subsurface P inputs. Price et al. (2006) reported P-rich brackish groundwater in this region of the FCE during the dry season as a result of groundwater intrusions by marine waters. The floc collected at SRS6 showed higher TP values in the wet season, in agreement with previous findings that SRS estuarine TP increases during the wet season when freshwater inflows are highest (Childers et al., 2006a).

The initial TN content of the floc was different among sites (Table 4.1) and was found to be significantly correlated with the OM content $\left(\mathrm{r}^{2}=0.92, p<0.0001\right)$ suggesting that most of the TN is in an organic form (Noe et al., 2007b). The highest 
amounts of TN were found in the floc collected at SRS2 (34 $\mathrm{mgN} \mathrm{g}^{-1}$ of dry floc) and the lowest amounts were found at SRS6 (4.8 $\mathrm{mgN} \mathrm{g}^{-1}$ of dry floc). This trend has previously been reported for $\mathrm{TN}$ and has been attributed to higher inputs of $\mathrm{N}$-fixing cyanobacteriaderived OM at the freshwater site (Childers et al., 2006a). The TN content of floc from the TS sites was significantly different only during the wet season, with TS2 floc having slightly more TN compared to TS6. Seasonal differences were found for all sites and higher TN values generally occurred during the dry season, except for SRS6 which contained more $\mathrm{TN}$ in the wet season.

The molar carbon to nitrogen ratio $(\mathrm{C} / \mathrm{N})$ can be used to infer sources of $\mathrm{OM}$ in different environments (Meyers, 1997). Higher plant OM usually has $\mathrm{C} / \mathrm{N}$ values $>20$ while microbial OM has $\mathrm{C} / \mathrm{N}$ values of $<10$ (Meyers, 1997; Neto et al., 2006). The floc used for this study had C/N values ranging between 10 (TS2; wet season) and 41 (SRS6; dry season) (Table 4.2). The higher values obtained for the mangrove-derived floc at SRS6, suggest dominant inputs from this vegetation while the lower values obtained for the freshwater floc are indicative of periphyton-derived OM inputs to the floc layer. The low $\mathrm{C} / \mathrm{N}$ values obtained for TS6 floc (11 in the wet season and 13 in the dry season) may indicate inputs from the submerged vegetation. The strong influence of local vegetation on floc composition had previously been reported by Neto et al. (2006). 
Table 4.3. Floc molar ratios. Data are averages \pm standard errors of triplicate floc samples. Letters indicate means that are significantly different $(p<0.001)$ within each variable.

\begin{tabular}{rcccc}
\hline Site & Season & $\mathrm{C} / \mathrm{N}$ & $\mathrm{C} / \mathrm{P}$ & $\mathrm{N} / \mathrm{P}$ \\
\hline SRS2 & Dry & $12^{\mathrm{a}} \pm 0.4$ & $2050^{\mathrm{a}} \pm 91$ & $165^{\mathrm{a}} \pm 2.0$ \\
& Wet & $13^{\mathrm{a}} \pm 0.2$ & $1487^{\mathrm{b}} \pm 162$ & $118^{\mathrm{b}} \pm 15$ \\
SRS6 & Dry & $41^{\mathrm{b}} \pm 5.2$ & $279^{\mathrm{c}} \pm 23$ & $6.9^{\mathrm{c}} \pm 1.4$ \\
& Wet & $20^{\mathrm{c}} \pm 1.0$ & $178^{\mathrm{d}} \pm 24$ & $9.0^{\mathrm{d}} \pm 1.2$ \\
TS2 & Dry & $16^{\mathrm{d}} \pm 0.2$ & $1586^{\mathrm{e}} \pm 49$ & $98^{\mathrm{e}} \pm 2.3$ \\
& Wet & $10^{\mathrm{e}} \pm 1.0$ & $645^{\mathrm{f}} \pm 103$ & $62^{\mathrm{f}} \pm 13$ \\
TS6 & Dry & $13^{\mathrm{a}} \pm 0.4$ & $1129^{\mathrm{g}} \pm 21$ & $85^{\mathrm{e}} \pm 1.1$ \\
& Wet & $11^{\mathrm{ae}} \pm 0.4$ & $1027^{\mathrm{g}} \pm 108$ & $90^{\mathrm{e}} \pm 6.9$ \\
\hline
\end{tabular}

The molar carbon to phosphorus $(\mathrm{C} / \mathrm{P})$ and nitrogen to phosphorus $(\mathrm{N} / \mathrm{P})$ ratios can be used as indicators of the relative availability of $\mathrm{N}$ or $\mathrm{P}$ and the degree of nutrient limitation by either nutrient (Noe et al., 2001). The above results show that the floc collected at the two freshwater sites is the most P-limited (Table 4.2). Floc collected at SRS2 in the dry season showed the highest values (2050 and 165 for C/P and N/P, respectively), indicative of the highly oligotrophic nature of this site. In agreement with the TP data described above, TS6 floc also had high values of C/P and N/P. The floc collected at SRS6 had the lowest values for these ratios, indicative of being the site with the least nutrient limitation.

\subsubsection{Floc respiration and respiration rates:}

The amount of carbon mineralization was determined by measuring the total amount of $\mathrm{CO}_{2}$ and $\mathrm{CH}_{4}$ evolved from floc throughout the incubation period. Because methanogenesis occurs under anoxic conditions, the amount of $\mathrm{CH}_{4}$ generated was negligible (generally less than $0.33 \%$ of the total gases evolved) and is not discussed 
further. Data for $\mathrm{CO}_{2}$ evolution are shown in Table 4.3 and Figure 4.3. The amount of $\mathrm{CO}_{2}$ evolved from floc during the one week incubation period varied both spatially and seasonally (Figure 4.3) and in all cases, the cumulative $\mathrm{CO}_{2}$ evolved showed a curvilinear relationship with time (Figure 4.4 and Appendix 4.1).

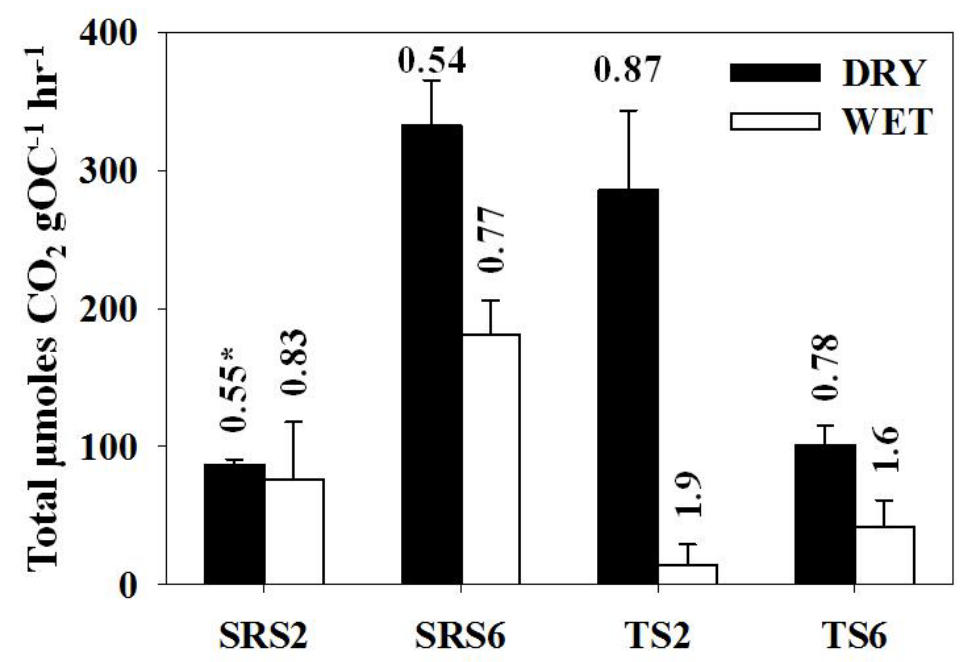

Figure 4.3. Spatial and seasonal differences in the cumulative $\mathrm{CO}_{2}$ produced from floc throughout the incubation period. ${ }^{*}$ Respiration rates $\left(\right.$ days $\left.^{-1}\right)$.

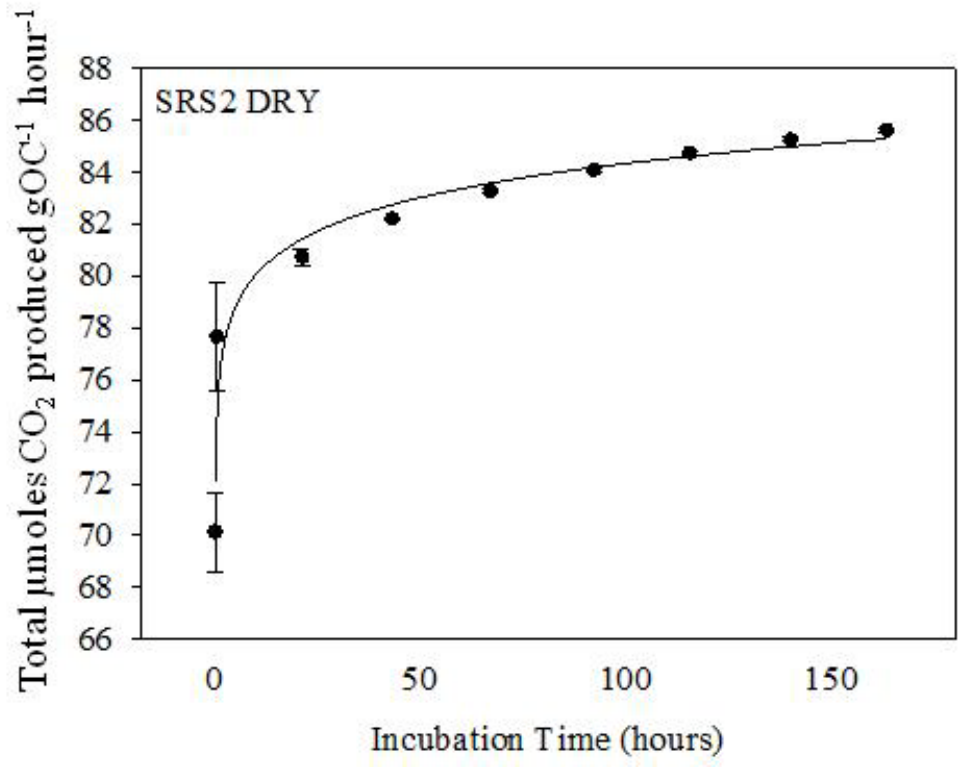

Figure 4.4. An example of the curvilinear relationship between the cumulative $\mathrm{CO}_{2}$ evolved from floc and incubation time. All relationships are shown in Appendix 4.1. 
Table 4.4. Cumulative $\mathrm{CO}_{2}$ evolved and rates of $\mathrm{CO}_{2}$ evolution of floc and floc samples amended with phosphorus and glucose throughout the incubation period. Data are averages \pm standard errors of triplicate floc samples. Letters indicate means that are significantly different $(p<0.001)$ within each variable. The rates were obtained by fitting the data to a kinetic model described by a non-linear power function $(p \leq 0.05)$. The coefficient of determination $\left(r^{2}\right)$ for the best fit lines is shown.

\begin{tabular}{|c|c|c|c|c|c|c|c|c|c|c|}
\hline \multirow[b]{2}{*}{ Site } & \multirow[b]{2}{*}{ Season } & \multicolumn{2}{|c|}{ Floc } & \multirow[b]{2}{*}{$\mathrm{r}^{2}$} & \multicolumn{2}{|c|}{ Floc + phosphorus } & \multirow[b]{2}{*}{$r^{2}$} & \multicolumn{2}{|c|}{ Floc + glucose } & \multirow[b]{2}{*}{$r^{2}$} \\
\hline & & Total $\mathrm{CO}_{2}{ }^{*}$ & Rate** & & Total $\mathrm{CO}_{2}{ }^{*}$ & Rate** & & Total $\mathrm{CO}_{2}{ }^{*}$ & Rate** & \\
\hline \multirow[t]{2}{*}{ SRS2 } & Dry & $86^{\mathrm{a}} \pm 4.5$ & $0.55^{\mathrm{a}} \pm 0.1$ & 0.93 & $221^{\mathrm{a}} \pm 56$ & $0.90^{\mathrm{a}} \pm 0.3$ & 0.82 & $64^{\mathrm{a}} \pm 11$ & $1.3^{\mathrm{a}} \pm 0.2$ & 0.92 \\
\hline & Wet & $76^{a} \pm 41$ & $0.83^{b} \pm 0.2$ & 0.72 & $160^{\mathrm{b}} \pm 13$ & $1.0^{\mathrm{a}} \pm 0.2$ & 0.59 & $72^{\mathrm{a}} \pm 20$ & $0.60^{\mathrm{b}} \pm 0.2$ & 0.85 \\
\hline \multirow[t]{2}{*}{ SRS6 } & Dry & $333^{b} \pm 33$ & $0.54^{\mathrm{a}} \pm 0.0$ & 0.70 & $1167^{\mathrm{c}} \pm 165$ & $0.71^{\mathrm{a}} \pm 0.1$ & 0.58 & $290^{\mathrm{b}} \pm 32$ & $1.0^{\mathrm{a}} \pm 0.0$ & 0.94 \\
\hline & Wet & $181^{\mathrm{c}} \pm 25$ & $0.77^{\mathrm{b}} \pm 0.0$ & 0.57 & $65^{\mathrm{b}} \pm 31$ & $1.2^{\mathrm{ab}} \pm 0.1$ & 0.56 & $32^{\mathrm{c}} \pm 0.0$ & $1.3^{\mathrm{c}} \pm 0.0$ & 0.68 \\
\hline \multirow[t]{2}{*}{ TS2 } & Dry & $285^{\mathrm{b}} \pm 58$ & $0.87^{\mathrm{c}} \pm 0.1$ & 0.74 & $617^{\mathrm{d}} \pm 149$ & $0.89^{\mathrm{a}} \pm 0.0$ & 0.66 & $222^{\mathrm{d}} \pm 37$ & $1.2^{\mathrm{a}} \pm 0.1$ & 0.87 \\
\hline & Wet & $14^{\mathrm{a}} \pm 15$ & $1.9^{\mathrm{d}} \pm 0.0$ & 0.77 & $31^{\mathrm{b}} \pm 43$ & $1.7^{\mathrm{c}} \pm 0.0$ & 0.69 & $12^{\mathrm{e}} \pm 0.7$ & $21^{\mathrm{d}} \pm 3.8$ & 0.99 \\
\hline \multirow[t]{2}{*}{ TS6 } & Dry & $101^{\mathrm{a}} \pm 14$ & $0.78^{\mathrm{c}} \pm 0.1$ & 0.77 & $185^{\mathrm{a}} \pm 31$ & $0.86^{\mathrm{a}} \pm 0.2$ & & $86^{\mathrm{f}} \pm 7.8$ & $1.2^{\mathrm{a}} \pm 0.0$ & 0.93 \\
\hline & Wet & $42^{\mathrm{a}} \pm 20$ & $1.6^{\mathrm{e}} \pm 0.3$ & 0.87 & $65^{\mathrm{b}} \pm 31$ & $2.4^{\mathrm{d}} \pm 0.6$ & 0.81 & $32^{\mathrm{g}} \pm 0.0$ & $3.6^{\mathrm{e}} \pm 0.0$ & 0.93 \\
\hline
\end{tabular}

*total $\mu$ moles $\mathrm{CO}_{2}$ produced $\mathrm{gOC}^{-1} \mathrm{hr}^{-1}$

$* *$ days $^{-1}$ 
Throughout the incubation period, all the floc samples showed a similar pattern with a larger initial release of $\mathrm{CO}_{2}$ as a result of the rapid depletion of the more labile fraction, followed by a slower linear increase with time corresponding to a more refractory fraction. The SRS6 floc collected in the dry season produced the highest amount of $\mathrm{CO}_{2}\left(333 \mu\right.$ moles $\left.\mathrm{CO}_{2} \mathrm{gOC}^{-1} \mathrm{hr}^{-1}\right)$ probably because of the significant phosphorus inputs the floc receives from the adjacent Gulf of Mexico. The TS2 floc collected in the dry season also produced relatively high amounts of $\mathrm{CO}_{2}$ after one week of incubation ( $285 \mu$ moles $\left.\mathrm{CO}_{2} \mathrm{gOC}^{-1} \mathrm{hr}^{-1}\right)$. While the TP of the floc at this site was found to be quite low, the high amounts of $\mathrm{CO}_{2}$ might be attributed to the more labile nature of the periphyton-derived floc found there. However, SRS2 floc which also receives periphyton-derived $\mathrm{OM}$ inputs, produced less $\mathrm{CO}_{2}\left(86 \mu\right.$ moles $\left.\mathrm{CO}_{2} \mathrm{gOC}^{-1} \mathrm{hr}^{-1}\right)$, and this difference might be attributed to the different hydroperiod regimes at the two sites, resulting in accumulations of different types of floc and different diagenetic processing of the associated $\mathrm{OM}$. While overall $\mathrm{C} / \mathrm{N}$ ratios of the floc at the freshwater marsh sites were not very different, they were significantly lower during the dry season for SRS2 compared to TS2 suggesting either an enrichment in higher plant (vs. periphyton) inputs to the floc at TS2 compared to SRS2 or a higher degree of degradation (i.e., loss of $\mathrm{C}$ and retention of $\mathrm{N}$ ) at SRS2 compared to TS2. The latter explanation is more likely where floc at the longer hydroperiod site to be more degraded and aged compared to the short hydroperiod site that is more prone to dry-out and open air oxidation of floc during the dry season. Re-wetting of soils and periphyton mats at the onset of the rainy season will generate fresh, more labile floc at the short hydroperiod sites. In fact, a significant correlation was found between the total amount of $\mathrm{CO}_{2}$ 
evolved from floc and the initial floc $\mathrm{C} / \mathrm{N}$ molar ratio $\left(\mathrm{r}^{2}=0.62, p<0.0001\right.$; Figure 4.5), although there was no correlation with the TOC and TN content in the floc. The $\mathrm{C} / \mathrm{N}$ ratio has been used to predict the rate of decomposition for different organic substrates, with larger $\mathrm{C} / \mathrm{N}$ values leading to slower rates of decomposition (Riffaldi et al., 1996; LeviMinzi et al., 1997).

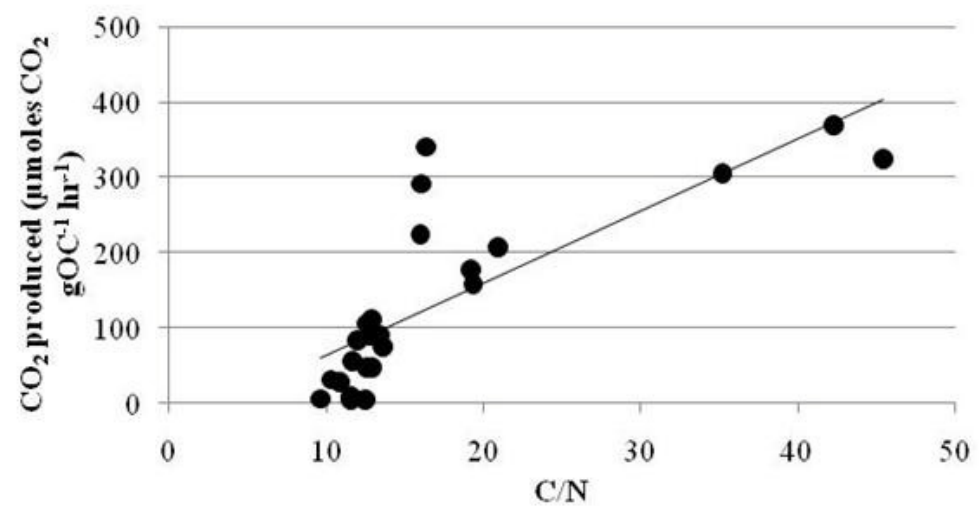

Figure 4.5. Significant correlation between $\mathrm{C} / \mathrm{N}$ and cumulative $\mathrm{CO}_{2}$ evolved from floc $(p<0.0001)$. The equation of the best-fit line is $\mathrm{y}=9.56 \mathrm{x}-31.18$ with a coefficient of determination $\left(\mathrm{r}^{2}\right)$ of 0.62 .

Generally, the floc collected in the dry season produced more $\mathrm{CO}_{2}$ than the floc collected in the wet season, although significant seasonal differences were only found for TS2 and SRS6 floc (Table 4.3). There have been numerous studies on the effects of flooding and water level on the pathways and rates of soil OM mineralization (Happell et al., 1993; Amador et al., 1997; DeBusk et al., 2003). Under flooded conditions, mineralization will proceed through aerobic and anaerobic processes that produce both $\mathrm{CO}_{2}$ and $\mathrm{CH}_{4}$. Under dry conditions, aerobic processes dominate to produce primarily $\mathrm{CO}_{2}$ (Happell et al., 1993). The TS2 floc showed significantly higher amounts of $\mathrm{CO}_{2}$ 
production during the dry season (Figure 4.3), an effect that could be the result of complete dry down during this time of year. Furthermore, recent studies on $\mathrm{CO}_{2}$ exchange in short-hydroperiod Everglades' marshes have shown that ecosystem respiration is significantly higher in the dry season and is controlled by air temperature and photosynthetically active radiation (Schedlbauer et al., 2010).

Data on the time-course of $\mathrm{CO}_{2}$ production from the floc fitting to a non-linear power function kinetic model (Eq. 2) and the coefficients of determination are summarized in Table 4.3 for the original floc, and for the phosphorus and glucose amended incubations. This kinetic model has been used in studies of carbon mineralization of agricultural soils (Saviozzi et al., 1993a; Riffaldi et al., 1996; LeviMinzi et al., 1997), organic material added to soils (Saviozzi et al., 1993b) and for soil nitrogen mineralization studies (Smith et al., 1980).

Spatial differences were found for original (non-amended) floc respiration rates and are summarized in Table 4.3. The respiration rates obtained for floc collected in the dry season were significantly different only between the peat-dominated (SRS) and the carbonate-dominated (TS) sites. The floc collected in TS showed faster respiration rates ( 0.87 and 0.78 days $^{-1}$ for TS2 and TS6 floc, respectively) compared to SRS floc ( 0.55 and 0.54 days $^{-1}$ for SRS2 and SRS6 floc, respectively). The presence and productivity of periphyton mats has been shown to influence OM respiration rates as these algal assemblies can redistribute $\mathrm{O}_{2}$ to the water column. Aeration of the water column can presumably increase the decomposition rate of OM in the floc layer (Amador et al., 2003). In fact, the periphyton mats at TS2 are known to be more productive than those found at SRS2 (Ewe et al., 2006). Differences in respiration rates found between the two 
mangrove sites might be attributed to the different carbon quality of the floc OM. In addition to mangrove leaf detritus, the floc at TS6 also receives inputs from submerged vegetation, thus increasing the labile quality of the floc. This is also suggested by the lower $\mathrm{C} / \mathrm{N}$ values obtained for TS6 floc compared to SRS6 floc. Spatial differences in floc respiration rates were much more pronounced for floc collected in the wet season. TS2 floc showed the fastest respiration rate $\left(1.9\right.$ days $\left.^{-1}\right)$, followed by TS6 floc (1.6 days $\left.{ }^{1}\right)$. The floc collected in SRS showed much slower rates of respiration $(0.83$ and 0.77 days $^{-1}$ for SRS2 and SRS6 floc, respectively).

Seasonal differences in floc respiration rates were observed for all sites (Table 4.3) and were significantly higher for floc collected in the wet season. In the wet season, floc receives fresh inputs from the local vegetation, as shown by lower $\mathrm{C} / \mathrm{N}$ values. The more labile character of the floc OM might explain the faster respiration rates occurring during this season. DeBusk et al. (1998) determined that the potential rates of C mineralization in plant-soil profiles of a Northern Everglades marsh decreased with depth and, consequently, with substrate age. Thus, in agreement with the literature, it appears that fresher floc OM can mineralize at a faster rate compared to older, more refractory OM present in floc during the dry season. Interestingly, the $\mathrm{CO}_{2}$ evolved was more abundant during the dry season (Figure 4.3) suggesting that although rates are higher during the wet season, the available labile carbon pool in the floc is larger during the dry season. 


\subsubsection{Effects of phosphorus additions to floc respiration:}

The cumulative $\mathrm{CO}_{2}$ evolved from floc after the addition of phosphorus showed a similar curvilinear relationship with time as compared to the non-amended sample, with a larger initial release of $\mathrm{CO}_{2}$ followed by a slower increase throughout the incubation period (Appendix 4.1). These data were fitted to the same kinetic model described above (Eq. 2) and the coefficients of determination are summarized in Table 4.3.

Phosphorus $(\mathrm{P})$ is not usually considered a limiting nutrient to $\mathrm{OM}$ decomposition in soils, however the addition of $\mathrm{P}$ to peat soils from the Everglades has been found to increase soil respiration rates (Amador et al., 1993; DeBusk et al., 1998). The objective of this experiment was not to determine the effects of varying P levels on floc respiration, but rather to study the effects of P-limitation on the floc OM respiration. These results suggest that the addition of $\mathrm{P}$ to the floc can cause a significant increase in the total amount of $\mathrm{CO}_{2}$ evolved and this effect is more pronounced in the dry $(84-251 \%$ increase) compared to the wet (58-122\% increase) season (Table 4.3, Figures 4.6.a and 4.6.b). Spatial differences in the amount of $\mathrm{CO}_{2}$ evolved from floc were only found in the dry season. SRS6 floc showed the largest difference in $\mathrm{CO}_{2}$ production $(834 \mu$ moles of $\mathrm{CO}_{2} \mathrm{gOC}^{-1}$ more) with the addition of phosphorus. TS2 floc also showed a high increase (332 $\mu$ moles of $\mathrm{CO}_{2} \mathrm{gOC}^{-1}$ more), followed by SRS2 $\left(135 \mu\right.$ moles of $\mathrm{CO}_{2} \mathrm{gOC}^{-1}$ more) and TS6 floc ( $84 \mu$ moles of $\mathrm{CO}_{2} \mathrm{gOC}^{-1}$ more). The variation in the magnitude of the floc respiration response to $\mathrm{P}$ addition could be due to differences in the OM quality. 


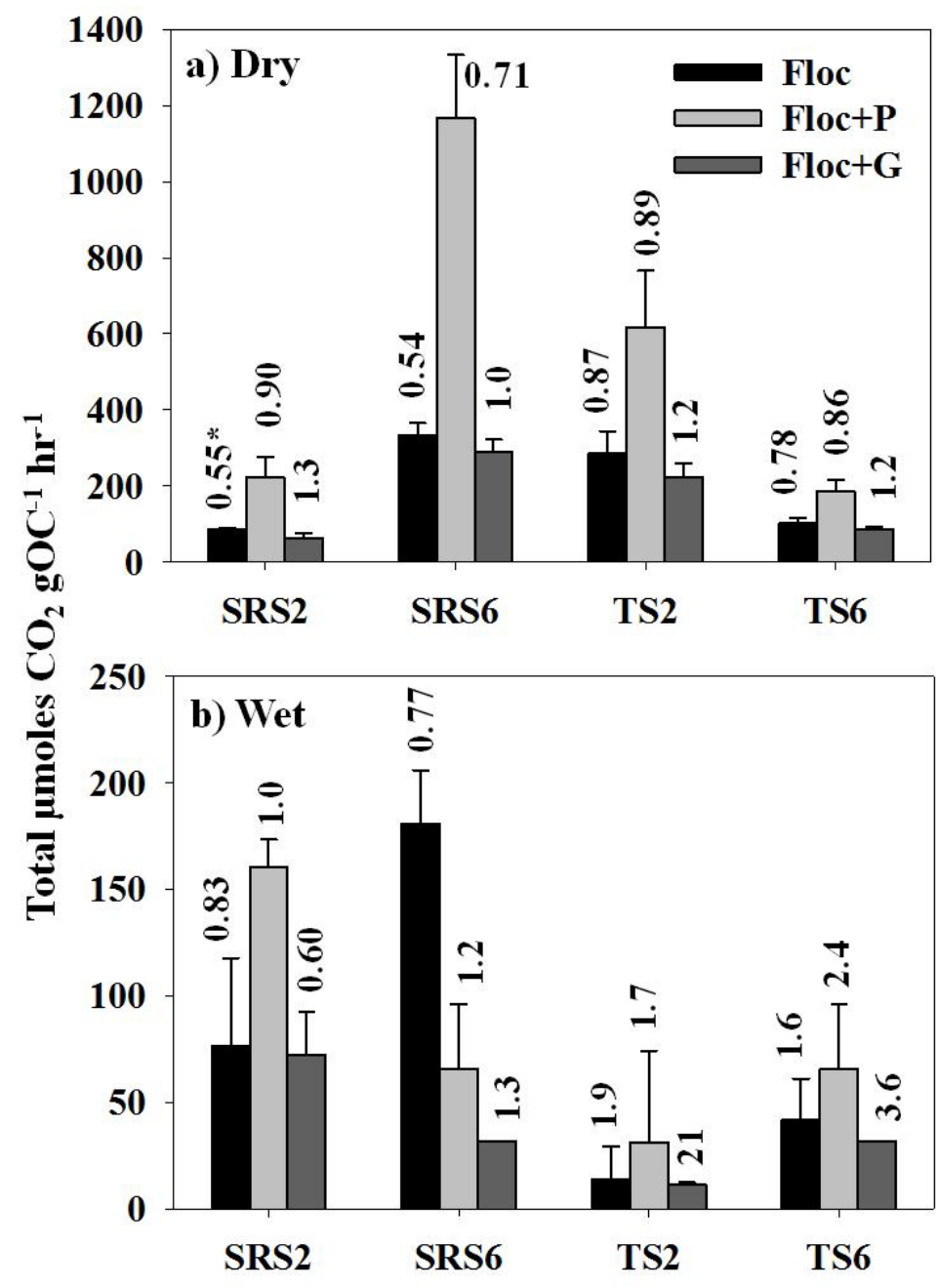

Figure 4.6. Spatial and seasonal ((a) dry season and (b) wet season) differences in the cumulative $\mathrm{CO}_{2}$ produced from floc amended with phosphorus and glucose. *Respiration rates are shown in days ${ }^{-1}$.

Floc respiration rates were also affected by the removal of P-limitation (Table 4.3). Spatial differences in floc respiration rates were only found in the wet season. The respiration rate for floc collected at TS6 was found to be the fastest upon addition of P (2.40 days $\left.{ }^{-1}\right)$, followed by SRS6 (1.24 days $\left.^{-1}\right)$ and SRS2 floc (1.02 days $\left.{ }^{-1}\right)$. The floc from TS2 seemed to respire at only a slightly faster rate compared to phosphorus-limited 
conditions, suggesting that $\mathrm{OM}$ respiration rate is not driven by phosphorus limitation at this site. In general, the addition of $\mathrm{P}$ caused floc respiration rates to increase up to $64 \%$. Seasonal differences in floc respiration rates were found for all sites (except SRS2) and the wet season rates were faster than the dry season rates. In agreement with the data described above, the fresher OM inputs contributed to the floc layer during the wet season might be causing these faster respiration rates, but consistently, $\mathrm{CO}_{2}$ evolved was higher during the dry season.

\subsubsection{Effects of glucose amendments on floc respiration:}

The cumulative $\mathrm{CO}_{2}$ evolved from floc containing the glucose amendments also showed a curvilinear relationship in agreement with the behavior of the original floc and the P-amended floc incubations (Appendix 4.1). These data were fitted to the same kinetic model described above (Eq. 2) and the coefficients of determination are summarized in Table 4.3.

Glucose was added to floc to determine the effects of carbon availability on $\mathrm{CO}_{2}$ evolution and compare glucose-induced, co-metabolism respiration rates. Glucose was chosen as a substrate because it is a readily utilizable $\mathrm{C}$ and energy source for most micro-organisms (Amador et al., 1995). In addition to acetate, glucose has been shown to account for up to $21 \%$ of the endogenous respiration in Everglades soils (Tate, 1979). Glucose was added to the floc samples at a single concentration and the lack of concentration variability of the glucose-amendments in the present study makes it only a qualitative test. However, the results obtained tend to support the hypothesis that floc respiration rates are dependent on both carbon and phosphorus availability. 
The addition of glucose to the different floc samples did not cause an increase in the total amount of $\mathrm{CO}_{2}$ evolved throughout the incubation period (Figures 4.6.a and 4.6.b), suggesting that carbon quality does not control this process. Although the total amount of $\mathrm{CO}_{2}$ produced in the amended samples was less than in the regular floc samples, the spatial pattern was similar.

Glucose-induced $\mathrm{CO}_{2}$ production rates are summarized in Table 4.3. The rates were similar among sites and ranged from 1.01 (SRS6) and 1.31 (SRS2) days ${ }^{-1}$ for floc collected in the dry season (Figure 4.6.a). Rates were more variable in the wet season, with slower rates obtained for SRS2 floc $\left(0.60\right.$ days $\left.^{-1}\right)$ and faster rates for TS2 floc (20.92 days ${ }^{-1}$ ). The differences in the kinetics of $\mathrm{CO}_{2}$ evolution from glucose in the floc samples may be explained by microbial growth where an accelerating initial rate can represent an increase in the microbial population responsible for glucose metabolism. Our findings simply suggest that substrate quality may be a controlling factor of respiration rates from heterotrophic microbial activity in the floc layer. The amendment experiment indicates that the poor substrate quality of floc $\mathrm{OM}$ limits $\mathrm{CO}_{2}$ production rates, and that this limitation is more pronounced in the wet season.

In general terms, Table 4.3 shows that with the exception of SRS6 wet season, all samples showed a significant increment in $\mathrm{CO}_{2}$ evolution and higher or similar respiration rates for $\mathrm{P}$-amended floc, while keeping with the seasonal patterns observed for the non-amended, original floc sample incubations. The glucose amendments did not provide any evidence that co-metabolism would have a significant effect on the turnover of floc in this ecosystem, as both $\mathrm{CO}_{2}$ evolved and reaction rates were similar or occasionally even a little lower compared to the non-amended floc incubation. 


\subsection{Conclusions:}

The present study shows that the total amount of $\mathrm{CO}_{2}$ evolved from floc is highly variable on both spatial and seasonal scales. Floc samples from the freshwater marshes, characterized by low phosphorus concentrations, produced cumulative $\mathrm{CO}_{2}$ amounts ranging from 14 to $285 \mu$ moles $\mathrm{CO}_{2} \mathrm{gOC}^{-1} \mathrm{hr}^{-1}$. The floc samples from the coastal areas containing higher phosphorus concentrations produced significantly more $\mathrm{CO}_{2}$ (42 to 333 $\mu$ moles $\mathrm{CO}_{2} \mathrm{gOC}^{-1} \mathrm{hr}^{-1}$ ). These values are in agreement with recent studies by Wright et al. (2009) who studied the microbial respiration of detritus and peat soils from the northern WCA. These authors found that detrital material can release up to $288 \mu$ moles $\mathrm{CO}_{2} \mathrm{gOC}^{-1} \mathrm{hr}^{-1}$ while low phosphorus soils can release up to $328 \mu$ moles $\mathrm{CO}_{2} \mathrm{gOC}^{-1} \mathrm{hr}^{-1}$. Based on these results, there seems to only be a small difference between soil and floc respiration rates in the FCE. However, increases in P concentrations in the floc layer can cause it to respire more $\mathrm{CO}_{2}$, potentially making it more reactive than soil $\mathrm{OM}$ in this environment. Other recent studies (Wang et al., 2010) have shown that peatlands from the Great Hing' an Mountains in northeastern China can release up to $284 \mu$ moles $\mathrm{CO}_{2} \mathrm{gOC}^{-1}$ $\mathrm{hr}^{-1}$.

The kinetic parameters associated with floc respiration obtained in the present laboratory study suggest that the rates of $\mathrm{CO}_{2}$ production vary on both spatial and seasonal scales. These differences seem to be driven by hydrologic regimes (long vs. short-hydroperiod), productivity of the local vegetation and periphyton, nutrient availability (phosphorus limitation), as well as carbon quality and substrate age. While the total amount of $\mathrm{CO}_{2}$ produced from floc throughout the incubation period was higher in the dry season, the overall production rates were faster in the wet season. This is in 
agreement with previous findings from DeBusk et al. (1998) who found that the mineralization rates of peat $\mathrm{OC}$ decreased with substrate age. Thus, the fresher OM that comprises the floc layer during the wet season respires faster than the more aged floc present during the dry season. Furthermore, the increase in primary productivity occurring during the wet season (especially in the periphyton mats found at the freshwater sites) can aerate the water column and presumably accelerate the respiration rate of the floc layer. However, it seems that from a quantitative point of view, the labile carbon pool in floc is larger during the dry compared to the wet season.

Nutrient enrichment (in the form of phosphorus additions) significantly enhanced floc respiration rates, suggesting that this process is nutrient limited in the FCE. Such findings have previously been reported for peat soils in the WCA (DeBusk et al., 1998). Generally, the addition of phosphorus to floc caused higher amounts of cumulative $\mathrm{CO}_{2}$ evolution (up to $834 \mu$ moles $\mathrm{CO}_{2} \mathrm{gOC}^{-1} \mathrm{hr}^{-1}$ ) compared to low phosphorus soils of the WCA. Significant spatial differences were only found during the wet season when the floc contained more phosphorus (lower $\mathrm{C} / \mathrm{P}$ values). The interaction between flooded/drained conditions and phosphorus enrichment has been summarized by DeBusk et al. (2003) and the relationship between these two factors was described as potentially important with respect to nutrient cycling and energy flow in oligotrophic, nutrientimpacted wetlands that may also be affected by hydrologic alteration, such as the FCE.

These findings allow us to make predictions about floc dynamics in this oligotrophic wetland. Increases in floc phosphorus levels, as a result of agricultural runoff and other anthropogenic activities, can result in a possible shift from aerobic to anaerobic metabolic processes which can ultimately have consequences for nutrient cycling. A shift 
to anaerobic metabolism will result in the utilization of electron acceptors other than $\mathrm{O}_{2}$, such as nitrate and sulfate, leading to increased rates of denitrification and sulfate reduction (Amador et al., 1995). This shift to anaerobic conditions can also result in carbon losses from the system in the form of $\mathrm{CH}_{4}$ gas which is sparingly soluble in water and would be readily lost to the atmosphere. Significant $\mathrm{CH}_{4}$ fluxes have been reported in Everglades' peat soils with high TP contents (Harriss et al., 1988), suggesting that a shift to anaerobic carbon metabolism can occur as a result of elevated phosphorus levels. The present results simply suggest that phosphorus enrichment has the potential to alter carbon metabolism in floc, causing a shift to anaerobic processes that can affect carbon and nutrient cycling in this unique ecosystem.

Finally, the glucose amendment experiment indicated that differences in floc respiration rates are not only to the result of differences in floc nutrient levels, but also to the low carbon quality of the OM comprising the floc. This was further highlighted by the correlation between the total amount of $\mathrm{CO}_{2}$ evolved and the floc $\mathrm{C} / \mathrm{N}$ ratio. Floc samples with low $\mathrm{C} / \mathrm{N}$ values have more $\mathrm{N}$-containing, algal-derived labile $\mathrm{OM}$, and this floc produced more $\mathrm{CO}_{2}$, although the respiration rates were not correlated with this parameter, which can also be affected by OM decomposition/aging.

The Everglades has undergone major human-induced modifications, shifting it from a landscape that was once characterized by unimpeded, slow sheet flow of water to one that is highly managed by $\sim 3000 \mathrm{~km}$ of canals and levees and $>150$ flow control structures (USACE and SFWMD, 1999). These water management activities have reduced water levels and hydroperiod throughout the Everglades (Light et al., 1994), significantly affecting the ecology of this environment. Some of the major consequences 
of the changes in hydrology include alterations in plant community structure as well as nutrient and periphyton dynamics (Childers et al., 2006b; Iwaniec et al., 2006). To minimize these alterations, restoration activities falling under the Comprehensive Everglades Restoration Plan (CERP) have goals which aim to increase water flow, water levels and hydroperiods throughout the Everglades. These impending changes in water management are likely to alter floc dynamics and consequently, $\mathrm{CO}_{2}$ and carbon cycling in the Everglades. The short hydroperiod marshes would be most affected by these hydrologic changes where the resulting longer water residence time may cause the accumulation of more degraded $\mathrm{OM}$ and a decrease in $\mathrm{CO}_{2}$ evolution from the local floc. Recent studies have focused on marsh ecosystem $\mathrm{CO}_{2}$ exchange in the Everglades (Schedlbauer et al., 2010), respiration rates of peat soils in the northern WCAs (DeBusk et al., 2003) and on the $\mathrm{CO}_{2}$ evolved during decomposition of Everglades' leaf litter (DeBusk et al., 2005; Corstanje et al., 2006). However, not much research has been done on floc respiration and this study shows that this process is governed by both nutrient and carbon availability and that it is variable on both spatial and seasonal scales. 


\section{REFERENCES:}

Amador, J. A. and R. D. Jones. 1993. Nutrient limitations on microbial respiration in peat soils with different total phosphorus content. Soil Biology and Biochemistry 25(6): 793 801.

Amador, J. A. and R. D. Jones. 1995. Carbon mineralization in pristine and phosphorusenriched peat soils of the Florida Everglades. Soil Science 159(2): 129-141.

Amador, J. A. and R. D. Jones. 1997. Response of carbon mineralization to combined changes in soil moisture and carbon-phosphorus ratio in a low phosphorus histosol. Soil Science 162(4): 275-282.

Belanger, T. V., D. J. Scheidt and J. R. Platko, II. 1989. Effects of nutrient enrichment on the Florida Everglades. Lake and Reservoir Management 5(1): 101-111.

Childers, D. L., J. N. Boyer, S. E. Davis, J. C. Madden, D. T. Rudnick and F. H. Sklar. $2006 a$. Relating precipitation and water management to nutrient concentrations in the oligotrophic "upside-down" estuaries of the Florida Everglades. Limnology and Oceanography 51(1/2): 602-616.

Childers, D. L., D. Iwaniec, D. Rondeau, G. Rubio, E. Verdon and C. J. Madden. $2006 b$. Responses of sawgrass and spikerush to variation in hydrologic drivers and salinity in Southern Everglades marshes. Hydrobiologia 596: 273-292.

Corstanje, R., K. R. Reddy and K. M. Portier. 2006. Typha latifolia and Cladium jamaicense litter decay in response to exogenous nutrient enrichment. Aquatic Botany 84: 70-78.

DeBusk, W. F. and K. R. Reddy. 1998. Turnover of detrital organic carbon in a nutrientimpacted Everglades marsh. Soil Science Society of America Journal 62: 1460-1468.

DeBusk, W. F. and K. R. Reddy. 2003. Nutrient and hydrology effects on soil respiration in a northern Everglades marsh. Journal of Environmental Quality 32: 702-710.

DeBusk, W. F. and K. R. Reddy. 2005. Litter decomposition and nutrient dynamics in a phosphorus enriched Everglades marsh. Biogeochemistry 75: 217-240.

Davis, III, S. E., C. Corronado-Molina, D. L. Childers and J. W. Day. 2003. Temporally dependent $\mathrm{C}, \mathrm{N}$, and $\mathrm{P}$ dynamics associated with the decay of Rhizophora mangle L. leaf litter in oligotrophic mangrove wetlands of the southern Everglades. Aquatic Botany 75: 199-215.

Doren, R. F., T. V. Armentano, L. D. Whiteaker and R. D. Jones. 1996. Marsh vegetation patterns and soil phosphorus gradients in the Everglades ecosystem. Aquatic Botany 56: 145-163. 
Ewe, S. M. L., E. E. Gaiser, D. L. Childers, D. Iwaniec, V. H. Rivera-Monroy and R. R. Twilley. 2006. Spatial and temporal patterns of aboveground net primary productivity (ANPP) along two freshwater-estuarine transects in the Florida Coastal Everglades. Hydrobiologia 569: 459-474.

Feng, X. and M. J. Simpson. 2008. Temperature responses of individual soil organic matter components. Journal of Geophysical Research 113: DOI: 10.1029/2008JG000743.

Fourqurean, J., W., R. D. Jones and J. C. Zieman. 1993. Processes influencing water column nutrient characteristics and phosphorus limitation of phytoplankton biomass in Florida Bay, FL USA: Inferences from spatial distributions. Estuarine, Coastal and Shelf Science 36: 295-314.

Gao, M., B. R. T. Simoneit, M. Gantar and R. Jaffé. 2007. Occurrence and distribution of novel botryococcenes hydrocarbons in freshwater wetlands of the Florida Everglades. Chemosphere 70: 224-236.

Garcia-Pausas, J., P. Casals, L. Camarero, C. Huguet, R. Thompson, M. T. Sebastià and J. Romanyà. 2008. Factors regulating carbon mineralization in the surface and subsurface soils of Pyrenean mountain grasslands. Soil Biology and Biochemistry 40(11): 28032810 .

Gerbersdorf, S. U., J. Meyercordt and L. A. Meyer-Reil. 2004. Microphytobenthic primary production within the flocculent layer, its fractions and aggregates, studied in two shallow Baltic estuaries of different eutrophic status. Journal of Experimental Marine Biology and Ecology 307: 47-72.

Glaser, B., J. Lehmann, M. Führböter, D. Solomon and W. Zech. 2001. Carbon and nitrogen mineralization in cultivated and natural savanna soils of Northern Tanzania. Biology and Fertility of Soils 33: 301-309.

Gottlieb, A. D., J. H. Richards and E. E. Gaiser. 2006. Comparative study of periphyton community structure in long and short-hydroperiod Everglades marshes. Hydrobiologia 569: 195-207.

Happell, J. D. and J. P. Chanton. 1993. Carbon remineralization in a North Florida swamp forest: Effects of water level on the pathways and rates of soil organic matter decomposition. Global Biogeochemical Cycles 7(3): 475-490.

Iwaniec, D. M., D. L. Childers, D. Rondeau, C. J. Madden and C. Saunders. 2006. Effects of hydrologic and water quality drivers on periphyton dynamics in the southern Everglades. Hydrobiologia 596: 223-235.

Larsen, L. G., J. W. Harvey, G. B. Noe and J. P. Crimaldi. 2009a. Predicting organic floc transport dynamics in shallow aquatic ecosystems: Insights from the field, the laboratory, and numerical modeling. Water Resources Research 45: W01411, doi: 10.1029/2008WR007221. 
Larsen, L. G., J. W. Harvey and J. P. Crimaldi. 2009b. Morphologic and transport properties of natural organic floc. Water Resources Research 45: W01410, doi: 10.1029/2008WR006990.

Levi-Minzi, R., A. Saviozzi, R. Riffaldi and A. Biasci. 1997. Decomposition of a winerysludge as affected by soil characteristics: a laboratory trial. Agrochimica 41(6): 247-251.

Light, S. S. and J. W. Dineen. 1994. Water control in the Everglades: A historical perspective. In: Davis, S. M., Ogden, J. C. (Eds.), Everglades: The Ecosystem and its Restoration. St. Lucie Press, Delray Beach, pp. 47-84.

Mead, R., Y. Xu, J. Chong and R. Jaffé. 2005. Sediment and soil organic matter source assessment as revealed by the molecular distribution and carbon isotopic composition of n-alkanes. Organic Geochemistry 36: 363-370.

Meyers, P. A. 1997. Organic geochemical proxies of paleoceanographic, paleolimnologic, and paleoclimatic processes. Organic Geochemistry 27(5/6): 213-250.

Mitsch, W. J. and J. G. Gosselink. 2007. Wetlands, $4^{\text {th }}$ ed. John Wiley \& Sons, New York.

Moore, T. R. and M. Dalva. 1993. The influence of temperature and water table position on carbon dioxide and methane emissions from laboratory columns of peatland soils. Journal of Soil Science 44: 651-664.

Nelson, D.W. and L. E. Sommers. 1996. Total carbon, organic carbon, and organic matter. P. 961-1010. In D.L. Sparks (ed.) Methods of Soil Analysis No.5 Part 3, Chemical Methods. Soil Science Society of America, Inc. Madison, WI. USA.

Neto, R, R., R. N. Mead, J. W. Louda and R. Jaffé. 2006. Organic biogeochemistry of detrital flocculent material (floc) in a subtropical, coastal wetland. Biogeochemistry doi: 10.1007/s10533-005-5042-1.

Newman, S., H. Kumpf, J. A. Laing and W. C. Kennedy. 2001. Decomposition responses to phosphorus enrichment in an Everglades (USA) slough. Biogeochemistry 54: 229-250.

Noe, G. B., D. L. Childers and R. D. Jones. 2001. Phosphorus biogeochemistry and the impact of phosphorus enrichment: Why is the Everglades so unique? Ecosystems 4: 603624.

Noe, G. B., L. J. Scinto, J. Taylor, D. L. Childers and R. D. Jones. 2003. Phosphorus cycling and partitioning in oligotrophic Everglades wetland ecosystem: A radioisotope tracing study. Freshwater Biology 48: 1993-2008.

Noe, G. B. and D. L. Childers. 2007a. Phosphorus budgets in Everglades wetland ecosystems: the effects of hydrology and nutrient enrichment. Wetlands Ecology and Management 15: 189-205. 
Noe, G. B., J. W. Harvey and J. E. Saiers. 2007b. Characterization of suspended particles in Everglades wetlands. Limnology and Oceanography 52(3): 1166-1178.

Pisani, O., Y. Yamashita and R. Jaffé. Photo-dissolution of flocculent, detrital material in aquatic environments: Contributions to the dissolved organic matter pool. Accepted to Water Research.

Price, R. M., P. K. Swart and J. W. Fourqurean. 2006. Coastal groundwater discharge an additional source of phosphorus for the oligotrophic wetlands of the Everglades. Hydrobiologia 569: 23-36.

Qualls, R. G. and C. J. Richardson. 2003. Factors controlling concentration, export, and decomposition of dissolved organic nutrients in the Everglades of Florida.

Biogeochemistry 62: 197-229.

Reddy, K. R. and E. M. D’Angelo. 1994. Soil processes regulating water quality in wetlands. In: W. J. Mitsch (ed.), Global Wetlands: Old World and New. Elsevier Sci. Publ., Amsterdam. pp. 309-324.

Richardson, C. J. 2009. The Everglades: North America's subtropical wetland. Wetlands Ecology and Management, doi: 10.1007/s11273-009-9156-4.

Riffaldi, R., A. Saviozzi and R. Levi-Minzi. 1996. Carbon mineralization kinetics as influenced by soil properties. Biology and Fertility of Soils 22: 293-298.

Saviozzi, A., R. Riffaldi, R. Levi-Minzi, A. Scagnozzi and G. Vanni. $1993 a$.

Decomposition of vegetation-water sludge in soil. Bioresource Technology 44: 223-228.

Saviozzi, A., R. Levi-Minzi and R. Riffaldi. 1993b. Mineralization parameters from organic materials added to soils as a function of their chemical composition. Bioresource Technology 45: 131-135.

Schedlbauer, J. L., S. F. Oberbauer, G. Starr and K. L. Jimenez. 2010. Seasonal differences in the $\mathrm{CO}_{2}$ exchange of a short-hydroperiod Florida Everglades marsh. Agricultural and Forest Meteorology 150: 994-1006.

Smith, J. L., Schnabel, R. R., B. L. McNeal and G. S. Campbell. 1980. Potential errors in the first-order model for estimating soil nitrogen mineralization potentials. Soil Science Society of America Journal 44: 996-1000.

Solorzano, L. and J. H. Sharp. 1980. Determination of total dissolved phosphorus and particulate phosphorus in natural waters. Limnology and Oceanography 25: 754-758.

Tate, R. L. III. 1979. Effects of flooding on microbial activities in organic soil: Carbon metabolism. Soil Science 128: 267-273.

Troxler, T. G. and J. H. Richards. 2009. $\delta^{13} \mathrm{C}, \delta^{15} \mathrm{~N}$, carbon, nitrogen and phosphorus as indicators of plant ecophysiology and organic matter pathways in Everglades deep slough, Florida, USA. Aquatic Botany 91(3): 157-165. 
Updegraff, K., J. Pastor, S. D. Bridgham and C. A. Johnston. 1995. Environmental and substrate controls over carbon and nitrogen mineralization in northern wetlands.

Ecological Applications 5(1): 151-163.

U. S. Army Corps of Engineers (USACE) and South Florida Water Management District (SFWMD). 1999. Central and Southern Florida Project Comprehensive Review Study, Final Integrated Feasibility Report and Programmatic Environmental Impact Statement. USACE, Jacksonville District, Jacksonville and SFWMD, West Palm Beach, pp. 4033.

Wang, X., X. Li, Y. Hu, J. Lü, J. Sun, Z. Li and H. Shi He. 2010. Potential carbon mineralization of permafrost peatlands in Great Hing'an Mountains, China. Wetlands 30: 747-756.

White, J. R. and K. R. Reddy. 2000. Influence of phosphorus loading on organic nitrogen mineralization of Everglades soils. Soil Science Society of America Journal 64: 15251534.

Williams, A., J. and J. C. Trexler. 2006. A preliminary analysis of the correlation of foodweb characteristics with hydrology and nutrient gradients in the southern Everglades. Hydrobiologia 569: 493-504.

Wright, A. L. and K. R. Reddy. 2001. Heterotrophic microbial activity in Northern Everglades wetland soils. Soil Science Society of America Journal 65: 1856-1864.

Wright, A. L., K. R. Reddy and R. Corstanje. 2009. Patterns of heterotrophic microbial activity in eutrophic and oligotrophic peatlands. European Journal of Soil Biology 45: 131-137. 


\section{Chapter V}

CHARACTERIZING RIPARIAN VS. WATERSHED VEGETATION INPUTS TO

SEDIMENTS OF SMALL, PRAIRIE STREAMS: A MOLECULAR MARKER AND STABLE ISOTOPE APPROACH 


\subsection{Introduction:}

The transport of both dissolved and particulate materials from rivers to coastal areas has been intensely studied (Meade, 1994; Benner et al., 2001; Farnsworth et al. 2003). Large rivers can export significant amounts of total suspended solids (TSS) to coastal environments discharging more than $2000 \times 10^{6}$ tons of suspended materials per year (Farnsworth et al., 2003). The export of TSS has been quantified for some major world rivers such as the Amazon and the Orinoco rivers $\left(1200 \times 10^{6} \mathrm{t}^{\text {year }}{ }^{-1}\right.$ and $150 \mathrm{x}$ $10^{6}$ t year $^{-1}$, respectively; Meade, 1994) and the Mackenzie and the Saint Lawrence rivers $\left(8.02 \times 10^{6} \mathrm{t}\right.$ year $^{-1}$ and $8.89 \times 10^{6} \mathrm{t}$ year $^{-1}$, respectively; Telang et al., 1991). The transport of large amounts of TSS and its associated organic carbon (OC) can have significant effects on processes such as coastal/estuarine nutrient dynamics, aquatic ecosystem productivity and is important in the context of carbon cycling. Although there have been many studies and improved knowledge on fluvial TSS fluxes, only the larger world rivers have usually been taken into account when studying the transfer of materials from land to sea (Meybeck et al., 2003).

The ecological importance of small rivers and streams is now well recognized (Farnsworth et al., 2003; Dodds et al., 2004; Medeiros et al., 2008). Small rivers have a smaller drainage basin for storing flood-driven sediments (Milliman et al., 1992) and they are more likely to respond to event-driven floods (Farnsworth et al., 2003). Compared to their larger counterparts, small basins are more responsive to episodic events and can discharge large portions of their sediment loads in relatively short periods of time, affecting the dispersal and fate of the event-derived sediments (Farnsworth et al., 2003). Furthermore, because the number of small rivers is much greater than that of large ones, 
collectively, these small systems can be responsible for a greater amount of sediment and other materials' delivery to the global ocean (Farnsworth et al., 2003). As such, several recent studies have focused on the characterization of OC exported from small rivers (Blair et al., 2003; Komada et al., 2004 and 2005; Hwang et al., 2005; Leithold et al., 2006). Komada et al. (2004) used a bulk $\Delta^{14} \mathrm{C}$ and $\delta^{13} \mathrm{C}$ isotopic approach to characterize the OC transported by small mountainous rivers in Santa Clara, California. The authors found that allochthonous POC inputs dominated the isotopic signal and attributed the dominance to decreases in microbial production because of light limitation from the riparian vegetation canopy cover. Blair et al. (2003) used an isotopic approach to characterize the POC of the Eel River in northern California and demonstrated that most of the POC exported from these small streams is aged, resulting in significant contributions of ancient sedimentary OC to the global ocean. However, most of these studies focused on the bulk OC isotopic composition and it is now becoming evident that a more detailed characterization, through the molecular identification of individual biomarkers (Jaffé et al., 2001; Medeiros et al., 2008), would provide valuable information on the $\mathrm{OC}$ entering and being transported by small rivers.

Only a few studies have characterized the lipids contained in the OC pool of small stream sediments (Naraoka et al., 1999; Komada et al., 2005). Even fewer studies have looked at the biomarker composition to assess the relative contributions of allochthonous and autochthonous sources of POC to these environments (Jaffé et al., 2001; Mead et al., 2005; Medeiros et al., 2008). Medeiros et al. (2008) analyzed sediments from small streams in the northwestern United States using a multi-biomarker approach. The authors reported that these sediments contained organic compounds from various biogenic 
sources, mainly from terrestrial plants (internal lipids and epicuticular waxes) associated with the riparian zone, as well as microbially derived detritus. Jaffé et al. (2001) studied the origin and transport of organic matter (OM) in two sub-tropical estuaries of South Florida, and reported evidence for the mixing of allochthonous and autochthonous freshwater-derived OM, with marine end-member sources (planktonic and seagrassderived material). Finally, Mead et al. (2005) combined a compound specific stable carbon isotope analysis with an $n$-alkane proxy ( $\mathrm{P}_{\text {aq }}$; Ficken et al., 2000) to differentiate between submerged and emergent/terrestrial vegetation OM inputs to soils and sediments from a sub-tropical river. The authors found that OM inputs in this system are largely controlled by vegetation changes along a freshwater to marine transect.

Although these studies have increased our knowledge of OC transport and cycling in small streams, assessing the environmental dynamics in such systems can be very challenging (Medeiros et al., 2008). Longitudinal changes described for lotic systems by the River Continuum Concept (RCC; Vannote et al., 1980) can be more pronounced for small streams compared to larger rivers (House et al., 2010), making it difficult to study OC dynamics in these environments. The RCC has been described for small prairie streams (Dodds et al., 2004) as a linear landscape in which changes in hydrology are accompanied by changes in vegetation cover. Upstream reaches of small prairie streams are usually characterized by little canopy cover and are dominated by grasses. This results in minimal shade cover of the stream bed which can lead to an increase in autochthonous, microbial production. The lower reaches are typically dominated by riparian forests and thus receive significant allochthonous inputs from leaf litter. 
Molecular biomarkers, in the form of free (solvent-extractable) and bound lipids have been used in determining the sources, transport and diagenetic state of OC in many environments (Jaffé et al., 1996 and 2001; Otto et al., 2005b; Jansen et al., 2006; Xu et al., 2010). Although free lipids usually comprise less than $10 \%$ of the total soil organic matter (SOM), the biomarkers contained in this fraction can give valuable information on the source and degradation of OM (Otto et al., 2005b), allowing for the characterization of OC entering and being transported by small rivers. Biomarkers can provide useful information on OM sources for typical two end member systems (allochthonous/terrestrial vs. autochthonous/microbial). However, the combination of a biomarker approach with compound specific stable carbon isotopic determinations has been successfully applied for ecosystems with complex OM inputs (Dittmar et al., 2001; Jaffé et al., 2001; Mead et al., 2005). The combination of these methods has proven to be a useful technique for characterizing OM produced from biomass utilizing different carbon fixing pathways (Mead et al., 2005). This multi-proxy approach was used here to characterize the sedimentary OC in small prairie streams.

While not much information is available on the OM sources and dynamics of small streams, their ecological importance is now well recognized. Collectively, the large number of small streams may be responsible for a significant amount of sediment delivery to the global ocean (Farnsworth et al., 2003). It is generally assumed that large rivers derive most of their energy from dead OM which is representative of the watershed (Allan et al., 1995). However, only a few studies have identified the sources of OM in small rivers and some of these studies suggest that a larger portion of this material can 
originate from the vegetation comprising the riparian zone rather than from the more extensive watershed (Medeiros et al., 2008).

The main goal of this study was to determine the contribution of autochthonous and allochthonous OM inputs to sediments of small, intermittent, prairie streams. An effort was made to distinguish the allochthonous inputs from an extensive $\mathrm{C}_{4}$ grassdominated watershed from those of $\mathrm{C}_{3}$ vascular plant-dominated riparian area. The King's Creek watershed located in Konza Prairie (Kansas) offers the ideal venue for combining the use of biomarkers and compound specific stable isotopic determinations in an attempt to distinguish between different OM inputs to small prairie stream sediments. A detailed site description of the King's Creek watershed in Konza Prairie is given below.

\subsection{Study area:}

Konza Prairie is located in the Flint Hills regions of the Great Plains, about $10 \mathrm{~km}$ southeast of Manhattan, Kansas. The Flint Hills region is the largest area (1.6 million ha) of unplowed, native tallgrass prairie relative to other grasslands (more than $90 \%$ of the vegetation is composed of grasses). The grassland is characterized by several species of $\mathrm{C}_{4}$ grasses with the dominant one being Andropogon gerardii (Freeman, 1998). In Konza Prairie, the two main watersheds are King's Creek and Shane Creek that converge at McDowell Creek, a tributary of the Kansas River. The riparian area of these creeks is characterized by continuous 10 - to 300-m-wide bands of deciduous forest that extends onto the prairie, covering about $7 \%$ of the site (Abrams, 1986). These riparian forests are dominated by several species of trees (Quercus macrocarpa, Quercus muehlenbergii, and 
Celtis occidentalis), overstory associates (Juglans nigra, and Populus deltoides) and understory shrubs (Cornus drummondi, and Prunus americana), among others (Freeman, 1998). The King's Creek watershed (1,060 ha) is located entirely within the Konza Prairie boundaries $(3,487 \mathrm{ha})$ and its geology, hydrology and biology have been investigated with the Long Term Ecological Research program since 1980 (Knapp and Seastedt, 1998). The watershed-level experimental design at Konza Prairie studies the effects of fire, grazing and climate, as well as the interactions among these factors, on the processes that define the structure and dynamics of this grassland.

The North American prairie is considered one of the most endangered biomes on the continent (Samson et al., 1994). Prairie streams have been heavily affected by agriculture and urbanization, resulting in pollution, hydrologic disturbance and physical modification through channelization and alteration of riparian vegetation (Dodds et al., 2004). The hydrology of prairie streams and its effects on community and ecosystem function has been previously studied and described (Dodds et al., 2000 and 2004). Briefly, these systems are characterized by relatively high numbers of intermittent streams with frequent flooding and drying and relatively low runoff. While the smaller upstream segments are more prone to drying, mid-order and downstream reaches are more prone to intense floods. The downstream change in hydrology is accompanied by changes in types of vegetation cover; upstream reaches are characterized by little canopy cover and leaf litter inputs while lower reaches can develop intense riparian forests. This change in hydrology and vegetation cover leads ecologists to think of prairie stream habitats as linear landscapes in which the riparian area of the upper reaches, dominated by low-growing forbs and grasses, provides minimal shade cover and increases 
autochthonous production in the stream channel. The lower reaches, which are dominated by riparian forests, receive significant allochthonous inputs from leaf litter. These characteristics lead to a downstream increase in ecosystem respiration and a decrease in productivity. This linear gradient of physical and biological conditions, known as the River Continuum Concept (RCC), was first described by Vannote et al. (1980) for lotic systems in general and has been described for prairie streams by Dodds et al. (2004).

\subsection{Materials and methods:}

\subsubsection{Sample collection:}

Grab samples were collected in the southern branch of the King's Creek watershed at the sites shown in Figure 5.1. Wet sediment samples were collected in the stream channel with a stainless steel spoon and immediately placed in pre-combusted $\left(450{ }^{\circ} \mathrm{C}\right.$ for $4 \mathrm{~h}$ ) glass jars with Teflon-lined lids. Four sediment samples were collected in $1^{\text {st }}$ order streams (sites \#3-7) and two were collected in $3^{\text {rd }}$ order streams (sites \#1-2). Two soil samples were collected outside the stream channel; one was collected in the riparian area dominated by trees and other $\mathrm{C}_{3}$ vascular plants. The other was collected in the grass prairie, which is dominated by $\mathrm{C}_{4}$ grasses. Typical vegetation, including fresh leaves and grasses (both $\mathrm{C}_{3}$ and $\mathrm{C}_{4}$ ) was cut from the plant and placed in zip-lock bags. Algal assemblies and mosses growing on rocks in the stream channel were scraped from the rocks and placed in pre-combusted glass jars. A complete list of samples is summarized in Table 5.1. All samples were kept on ice and transported to the laboratory, at Florida International University in Miami, Florida. There, the vegetation samples were rinsed with Milli-Q ${ }^{\circledR}$ water, dried and frozen. All samples were freeze-dried and ground. 


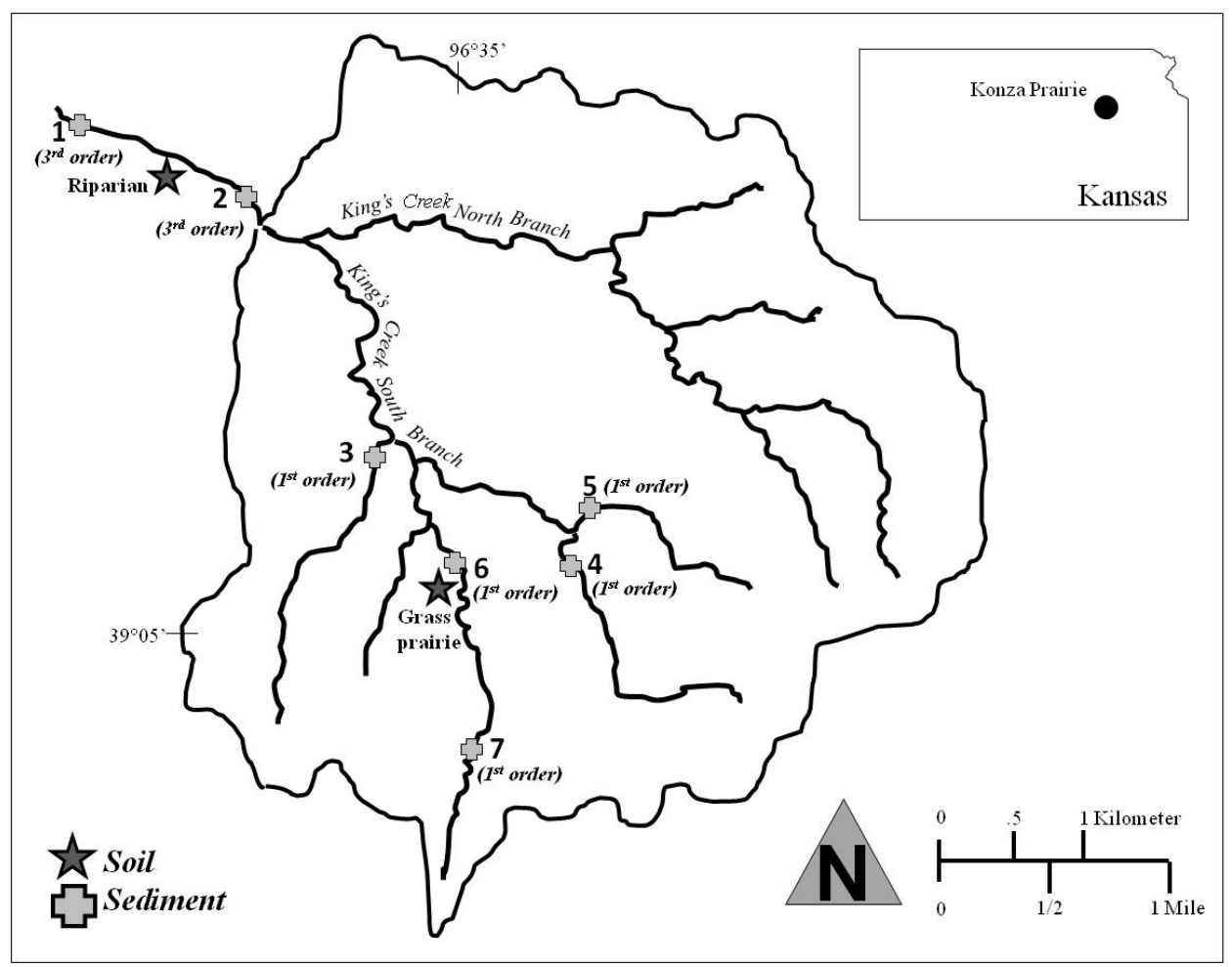

Figure 5.1. Geographic locations of the sampling sites along the south branch of the King's Creek watershed in Konza Prairie.

\subsubsection{Bulk parameters:}

About 2-10 mg of sample (vegetation, sediments and soils) was weighed in silver cups and de-carbonated by exposure to hydrochloric acid vapors overnight (Harris et al., 2001). Samples were dried in a $60^{\circ} \mathrm{C}$ oven overnight and analyzed for total organic carbon (TOC) and total organic nitrogen (TN) concentrations. Triplicate samples were measured on a Carlo Erba NA 1500 Nitrogen/Carbon Analyzer with a reproducibility of $0.73 \%$ for TOC and $0.02 \%$ for TN on average. Bulk stable isotope measurements $\left(\delta^{13} \mathrm{C}\right)$ were performed on triplicate samples using standard Elemental Analyzer Isotope Ratio Mass Spectrometry (EA-IRMS) methods on a Finnigan MAT Delta C IRMS. Carbon 
isotopic values are reported in the standard delta $(\delta)$ notation relative to the internal standard, Vienna Pee Dee Belemnite (PDB):

$$
\delta^{13} \mathrm{C}(\%)=\left[\left({ }^{13} \mathrm{C} /{ }^{12} \mathrm{C}\right)_{\text {sample }}\left({ }^{13} \mathrm{C} /{ }^{12} \mathrm{C}\right) \mathrm{PDB}^{-1}\right] \times 1000
$$

Sample reproducibility for bulk $\delta^{13} \mathrm{C}$ was $0.22 \%$ on average.

\subsubsection{Sample extraction:}

Samples were extracted according to Jaffé et al. (2001). Briefly, sub-samples (vegetation; $\sim 0.5 \mathrm{~g}$ and sediments/soils; $\sim 15 \mathrm{~g}$ ) were Soxhlet extracted with $300 \mathrm{~mL}$ of pure methylene chloride $\left(\mathrm{CH}_{2} \mathrm{Cl}_{2}\right)$ for 24 hours. Activated copper was added to the extract to remove elemental sulfur. The extracts were concentrated to about $5 \mathrm{~mL}$ on a rotary evaporator and further evaporated under a stream of nitrogen gas. The total extracts were saponified twice using $25 \mathrm{~mL}$ of freshly prepared $1.0 \mathrm{~N} \mathrm{KOH}$ solution to separate the acid from the neutral fraction. Anhydrous sodium sulfate $\left(\mathrm{Na}_{2} \mathrm{SO}_{4}\right)$ was added to the resulting fractions to eliminate traces of water (12 hours). The neutral fraction was concentrated on a rotary evaporator and further evaporated under a stream of nitrogen gas to about $1 \mathrm{~mL}$ of extract. The neutral fraction was further fractionated using silica gel adsorption chromatography (7 g of $5 \%$ deactivated silica gel, 100-200 mesh, Fisher Scientific) to obtain a total of eight fractions; aliphatic and aromatic hydrocarbons, wax and methyl esters (not analyzed), aliphatic and triterpenoid ketones and alcohols, sterols, and a polar fraction (not analyzed). The alcohol and sterol fractions were derivatized with bis-trimethylsilyl- $N$-trifluoroacetamide (BSTFA; $50 \mu \mathrm{L}$ ) and Pyridine $\left(20 \mu \mathrm{L} ; 60{ }^{\circ} \mathrm{C}\right.$ for $1 \mathrm{hr}$ ) prior to analysis by gas chromatography-mass spectrometry (GC/MS). 


\subsubsection{GC/MS analysis:}

An aliquot of $1 \mu \mathrm{L}$ of sample extract was analyzed by GC/MS on an HP $6890 \mathrm{GC}$ coupled with an HP 5730 quadrupole mass selective detector. The GC was fitted with a DB-5MS capillary column (30 $\mathrm{m}$ x $0.25 \mathrm{~mm}$ i.d. $\times 0.25 \mu \mathrm{m}$ film thickness) using helium as the carrier gas (flow rate; $1.2 \mathrm{~mL} \mathrm{~min}^{-1}$ ). For the aliphatic hydrocarbon fraction, a DB1-MS capillary column was used. The GC oven temperature was kept at $60{ }^{\circ} \mathrm{C}$ for 1 minute and then ramped to $300{ }^{\circ} \mathrm{C}$ at a rate of $6{ }^{\circ} \mathrm{C} \mathrm{min}-1$ and held at $300{ }^{\circ} \mathrm{C}$ for 20 minutes. The column was fed directly into the EI source which was operating at an ionization potential of $70 \mathrm{eV}$. The injector temperature was maintained at $280{ }^{\circ} \mathrm{C}$. Samples were injected in the splitless mode (splitless time; 2 min) and the mass scan range was set from 50 to $550 \mathrm{Da}$ at a rate of $2.94 \mathrm{scan} \mathrm{s}^{-1}$.

The identification of compounds was achieved by comparison with reported mass spectra of authentic standards and with the mass spectral library on the GC/MS data system. All compounds were quantified using total ion current (TIC) peak area and converted to compound mass with the addition of a known amount of internal standard (Squalane; 2,6,10,15,19,23-hexamethyl-tetracosane). Blanks were run between samples showing no background interferences.

\subsubsection{Compound specific $\delta^{13} C$ :}

The aliphatic hydrocarbon fraction was analyzed by gas chromatography-isotope ratio mass spectrometry (GC-irMS) with a Hewlett-Packard $6890 \mathrm{GC}$ coupled to a Finnigan Mat Delta Plus IRMS using the same GC conditions described above. The isotopic composition of the aliphatic hydrocarbons is reported in $\delta^{13} \mathrm{C}$ notation, as per 
bulk isotope analysis. The reproducibility obtained for the $n$-alkanes was generally less than $\pm 2 \%$. Three known standards $\left(\mathrm{C}_{17}\right.$ and $\mathrm{C}_{29} n$-alkanes and Squalane) were used to calibrate the linearity of the instrument and reproducible values were obtained for a dynamic range of 0.2-12 V (14-127 ng C injected). Therefore, only the peaks that fell into this range are reported.

\subsection{Results and discussion:}

\subsubsection{Bulk parameters:}

Bulk parameters for the vegetation, algae, sediments and soil samples are summarized in Table 5.1. The riparian vegetation leaves had \%OC values ranging from 36 to $47 \%$, values typical of vascular plants (Lallier-Verges et al., 1998). Slight differences in OC content were found between grasses with different photosynthetic pathways. The two $\mathrm{C}_{3}$ grasses had $\% \mathrm{OC}$ values of 35 and $37 \%$ for Prairie Cordgrass and Johnson grass, respectively. The $\mathrm{C}_{4}$ grasses had slightly higher values of 41 and $42 \% \mathrm{OC}$ for Big Bluestem and Eastern Gamma grass, respectively. Although this difference in OC is small, a higher $\mathrm{OC}$ content has been reported for $\mathrm{C}_{4}$ grasses compared to $\mathrm{C}_{3}$ grasses (Dornbush, 2007). The moss sample had a lower \%OC content (17\%OC) compared to other literature reports ( $40 \%$ in mosses collected in the Karst region of SW China; Liu et al., 2010). Compared to the moss, the algal assemblies had lower \%OC values ranging from 7.9 to $13 \% \mathrm{OC}$. Of the $1^{\text {st }}$ order streams, the sediments at site $\# 4$ had the lowest $\% \mathrm{OC}(3.3 \%)$ and site \#3 had the highest ( $4.1 \%)$. Of the $3^{\text {rd }}$ order stream sediments, site $\# 1$ had a $\% \mathrm{OC}$ value of $1.1 \%$ and site $\# 2$ of $2.4 \% \mathrm{OC}$. The higher OC content of the sediments in the upper reaches could indicate a high accumulation of organic matter 
$(\mathrm{OM})$, caused by large inputs from the riparian vegetation comprising the thick canopy cover. The lower reaches of the watershed, which are characterized by occasional flooding (Dodds et al., 2004), may be showing dilution effects with inorganic soil components. The two soil samples had relatively low $\% \mathrm{OC}$ values of 3.3 and $6.3 \%$ for the grass prairie soil and riparian soil, respectively. Such low OC values have been reported for grassland soils (Otto et al., 2005b) and have been attributed among others to burning practices (Kitchen et al., 2009), which are common at this site.

Total nitrogen (\%TN) was also measured for all the samples (Table 5.1). All the riparian trees had similar values ranging from 1.1 to $1.9 \% \mathrm{TN}$, typical values for foliage of Kansas prairie trees which have been reported to have a \% TN content of about $1.1 \%$ (Norris et al., 2001). As in the case for \%OC, there were differences in $\mathrm{TN}$ between $\mathrm{C}_{3}$ and $\mathrm{C}_{4}$ grasses. The $\mathrm{C}_{3}$ grasses had similar values; $1.1 \% \mathrm{TN}$ for Prairie Cordgrass and 1.6 \%TN for Johnson grass. The two $\mathrm{C}_{4}$ grasses both had lower values of $0.90 \% \mathrm{TN}$. Higher values of $\mathrm{TN}$ content have been reported for $\mathrm{C}_{3}$ grasses compared to $\mathrm{C}_{4}$ grasses (Dornbush, 2007). The moss sample had a relatively low \%TN value of $0.93 \%$. Because mosses lack a true root system necessary to acquire $\mathrm{N}$ from the substratum, they rely on direct uptake of atmospherically derived $\mathrm{N}$ and so their $\mathrm{N}$ content varies depending on the amount of deposited $\mathrm{N}$ (Liu et al., 2007). The algae samples had low values of $0.46 \%$ for assembly \#2, and 0.70 for assembly \#3, except for assembly \#1 that had a higher value of $1.5 \% \mathrm{TN}$. The sediments of the $1^{\text {st }}$ order streams had higher $\% \mathrm{TN}$ values (ranging from $0.16 \%$ at site $\# 6$ to $0.29 \%$ at site $\# 3)$ compared to the $3^{\text {rd }}$ order streams $(0.084 \%$ and $0.15 \%$ for sites $\# 1$ and $\# 2$, respectively), probably due to more autochthonous inputs at the latter. The grass prairie soil had a value of $0.22 \% \mathrm{TN}$, while the riparian soil had a 
value of $0.46 \% \mathrm{TN}$. Such low amounts of TN in the soils of Konza Prairie have previously been reported $(0.26 \% \mathrm{TN})$ and have been attributed to constant burning and mowing which is known to lower soil $\mathrm{N}$ availability (Kitchen et al., 2009).

Elemental carbon to nitrogen ratios $(\mathrm{C} / \mathrm{N})$ have been used to estimate the contribution of OM from different sources in a variety of environments such as estuarine sediments (Jaffé et al., 2001), grassland and forest soils (Otto et al., 2005a), Arctic sediments (Belicka et al., 2002) and river sediments (Bianchi et al., 2002). Terrestrial plants, which contain large amounts of cellulose, generally have high $\mathrm{C} / \mathrm{N}$ values of 20 or more while algae, which contain more nitrogen rich compounds such as proteins, generally have low values between 4 and 10 (Meyers, 1997).

In the present study, the riparian vegetation samples had $\mathrm{C} / \mathrm{N}$ values ranging from 22 to 41 (Table 5.1, Figure 5.2), values typical of higher plants. The $C_{3}$ grasses also had similar values to the riparian vegetation. In agreement with the literature (Dornbush, 2007), the $\mathrm{C}_{4}$ grasses, which contained less $\mathrm{N}$ in their tissues, had much higher values of 53 and 55 for Big Bluestem and Eastern Gamma grass, respectively. The moss sample had a $\mathrm{C} / \mathrm{N}$ value of 22 , similar to algal assembly \#2 and \#3. Assembly \#1 had a lower value of 10 , typical of algae samples. The higher $\mathrm{C} / \mathrm{N}$ values obtained for the moss and algae samples could derive from the incorporation of higher plant detrital leaf material in the moss and algal mats. The $\mathrm{C} / \mathrm{N}$ values of the stream sediments were not very different between the $1^{\text {st }}$ and $3^{\text {rd }}$ order streams and ranged from 15 (site \#1) to 24 (site \#6). The slightly higher value obtained at site $\# 6$ may suggest more $\mathrm{C}_{4}$ grass, watershed-derived inputs to the sediments at this site compared to the other sites. The grass prairie soil and the riparian soil sampled had very similar $\mathrm{C} / \mathrm{N}$ values of 18 and 16 respectively. 


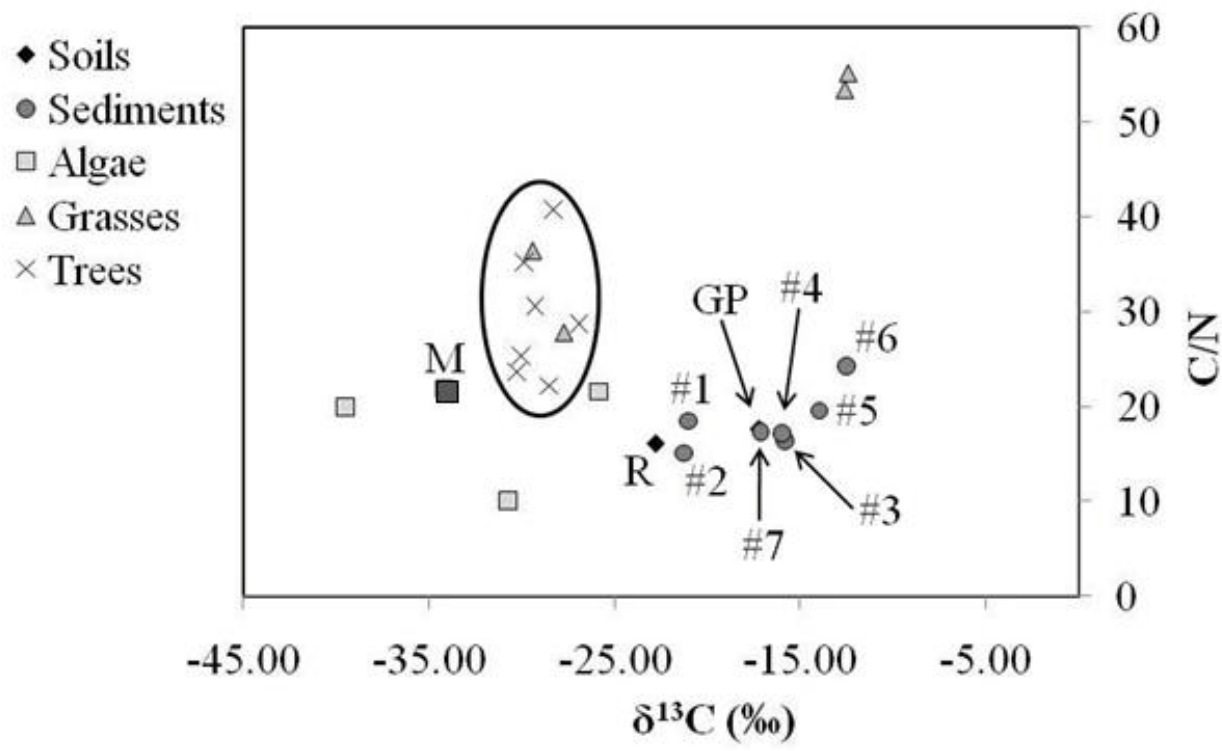

Figure 5.2. Elemental (atomic $\mathrm{C} / \mathrm{N}$ ratio) and isotopic $\left(\delta^{13} \mathrm{C}\right.$ ) values of bulk organic matter from different sources. The data points within the black circle include the riparian trees and the $\mathrm{C}_{3}$ grasses. The labeled data points are $\mathrm{M}=$ moss, $\mathrm{R}=$ riparian soil, $\mathrm{GP}=$ grass prairie soil and sediment samples from sites \#1-\#7.

The application of $\delta^{13} \mathrm{C}$ stable isotopes can be very useful to identify the inputs of OM from biomass utilizing different photosynthetic pathways (Meyers, 1997; Fry, 2006). Plants that follow the Calvin pathway $\left(\mathrm{C}_{3}\right)$ such as trees, shrubs and many grasses, have lower, more depleted $\delta^{13} \mathrm{C}$ values averaging near $-28 \%$, whereas plants that follow the Hatch-Slack pathway $\left(\mathrm{C}_{4}\right)$ such as sugar cane, corn and many grasses, have higher, less depleted values averaging near -13\%o (Bender, 1968; Meyers, 1997). The significant difference in isotopic values arises during photosynthesis as carbon atoms are incorporated into 3-carbon $\left(\mathrm{C}_{3}\right)$ or 4-carbon $\left(\mathrm{C}_{4}\right)$ sugars (Fry, 2006).

Bulk $\delta^{13} \mathrm{C}$ values (Table 5.1, Figure 5.2) for the riparian trees and the $\mathrm{C}_{3}$ grasses ranged from -27 to $-30 \%$, values typical for higher plants. The two $\mathrm{C}_{4}$ grasses had less depleted isotopic values of $-12 \%$. The moss sample had a much more depleted isotopic 
value of $-34 \%$, a value quite different from other literature values of about $-28 \%$ (Liu et al., 2010). The algal assemblies also showed depleted isotopic values ranging from -26 to $-39 \%$. Because freshwater algae utilize dissolved $\mathrm{CO}_{2}$, which is in isotopic equilibrium with atmospheric $\mathrm{CO}_{2}$, their isotopic composition is typically indistinguishable from the OM of the surrounding watershed (Meyers, 1997; Tenzer et al., 1997).

While the sediments collected in the $1^{\text {st }}$ order streams of the upper reaches had a less depleted isotopic signature (-12 to $-17 \%$ ), the two sediments collected in the $3^{\text {rd }}$ order lower reaches of the streams had more depleted isotopic values of $-21 \%$. The more enriched values of the upper reaches could be indicative of inputs from the extensive $\mathrm{C}_{4}$ grasses in the prairie-dominated watershed while the more depleted values of the lower reaches indicate a mixed input from the watershed and the riparian area. The riparian soil had a stable isotopic value of $-23 \%$, showing mixed inputs from higher plants as well as isotopic effects resulting from decomposition of soil organic matter. It has also been found that depleted surface soil $\delta^{13} \mathrm{C}$ values can result when litter inputs to the soil are high (Natelhoffer et al., 1988), as might be the case for riparian soils at Konza Prairie and sediments at stations 1 and 2. The grass prairie soil had a less depleted isotopic value of $17 \%$ probably caused by inputs from the $\mathrm{C}_{4}$ grasses dominating the prairie landscape. 
Table 5.1. Organic carbon (OC), nitrogen $(\mathrm{TN})$, molar ratios $(\mathrm{C} / \mathrm{N})$ and $\delta^{13} \mathrm{C}$ of plant and soil samples from the King's Creek watershed.

\begin{tabular}{|c|c|c|c|c|c|}
\hline Sample & Sample Information & OC* & TN* & $\mathbf{C} / \mathbf{N}$ & $\delta^{13} C^{* *}$ \\
\hline \multicolumn{6}{|l|}{ Riparian vegetation } \\
\hline Bur Oak & Fagaceae Quercus macrocarpa & 41 & 1.9 & 25 & -30.05 \\
\hline Hackberry & Ulmaceae Celtis occidentalis & 37 & 1.8 & 24 & -30.28 \\
\hline Cottonwood & Salicaceae Populus deltoides & 42 & 1.4 & 35 & -29.87 \\
\hline Wild Plum & Rosaceae Prunus americana & 38 & 1.6 & 28 & -26.93 \\
\hline Chinkapin Oak & Fagaceae Quercus muehlenbergii & 47 & 1.8 & 31 & -29.30 \\
\hline Black Walnut & Juglandaceae Juglans nigra & 36 & 1.9 & 22 & -28.55 \\
\hline Roughleaf Dogwood & Cornaceae Cornus drummondii & 39 & 1.1 & 41 & -28.30 \\
\hline \multicolumn{6}{|l|}{ Grasses } \\
\hline Johnson grass & Poaceae Sorghum halepense $\left(\mathrm{C}_{3}\right)$ & 37 & 1.6 & 28 & -27.73 \\
\hline Prairie Cordgrass & Poaceae Spartina pectinata $\left(\mathrm{C}_{3}\right)$ & 35 & 1.1 & 36 & -29.41 \\
\hline Eastern Gamma grass & Poaceae Tripsacum dactyloides $\left(\mathrm{C}_{4}\right)$ & 42 & 0.90 & 55 & -12.44 \\
\hline Big Bluestem grass & Poaceae Andropogon gerardii $\left(\mathrm{C}_{4}\right)$ & 41 & 0.90 & 53 & -12.61 \\
\hline Moss & & 17 & 0.93 & 22 & -34.19 \\
\hline \multicolumn{6}{|l|}{ Algal assemblies } \\
\hline$\# 1$ & & 13 & 1.5 & 10 & -30.74 \\
\hline$\# 2$ & & 7.9 & 0.46 & 20 & -39.53 \\
\hline \#3 & & 13 & 0.70 & 22 & -25.87 \\
\hline \multicolumn{6}{|l|}{ Sediments } \\
\hline Site 1 & $3^{r d}$ order stream & 1.1 & 0.084 & 15 & -21.25 \\
\hline Site 2 & $3^{r d}$ order stream & 2.4 & 0.15 & 18 & -21.05 \\
\hline Site 3 & $1^{s t}$ order stream & 4.1 & 0.29 & 16 & -15.82 \\
\hline Site 4 & $1^{\text {st }}$ order stream & 3.3 & 0.22 & 17 & -15.97 \\
\hline Site 5 & $1^{s t}$ order stream & 3.7 & 0.22 & 20 & -13.97 \\
\hline Site 6 & $1^{s t}$ order stream & 3.3 & 0.16 & 24 & -12.53 \\
\hline Site 7 & $1^{s t}$ order stream & 3.9 & 0.26 & 17 & -17.13 \\
\hline \multicolumn{6}{|l|}{ Soils } \\
\hline Riparian & & 6.3 & 0.46 & 16 & -22.78 \\
\hline Grass prairie & & 3.3 & 0.22 & 18 & -17.20 \\
\hline \multicolumn{6}{|l|}{ *units in $\%$} \\
\hline
\end{tabular}




\subsubsection{Lipid biomarker compounds}

A diverse variety of lipid classes were detected in the samples from Konza Prairie. These compounds were identified as $n$-alkanes, branched $n$-alkanes, $n$-alkenes, phytadienes, highly branched isoprenoid hydrocarbons (HBI), straight chain $n$-alkan-2ones, $n$-alkanals, $n$-alkanols, sterols and higher plant triterpenoids as well as their degradation products. While there was no pattern in the total amount of biomarkers present in the vegetation types (trees vs. grasses vs. algae), the Big Blue Stem grass and the hackberry leaves contained the highest amount of lipids (ca. $5-6 \mathrm{mg} \mathrm{g}^{-1} \mathrm{OC}$ ) while the Prairie Cordgrass contained the smallest $\left(0.41 \mathrm{mg} \mathrm{g}^{-1} \mathrm{OC}\right)$. Although the sediments in the upper reaches of the watershed contained more OC compared to the lower reaches, they were found to contain smaller amounts of total lipids with site $\# 5$ having the lowest ( 0.32 $\mathrm{mg} \mathrm{g}^{-1} \mathrm{OC}$ ) and site $\# 2$ containing the highest amount of lipids ( $\left.2.5 \mathrm{mg} \mathrm{g}^{-1} \mathrm{OC}\right)$. A higher degree of degradation of sedimentary OM may result in lower lipid abundances. Similarities and differences in lipid class concentrations between the different vegetation types and the sediments from the King's Creek watershed are presented and discussed in the following sections.

\subsection{2.a. n-Alkanes:}

The aliphatic fraction of the sample extracts contained a homologous series of straight chain $n$-alkanes, branched $n$-alkanes and mono-unsaturated $n$-alkenes. Significant amounts of phytadienes, $\mathrm{C}_{25}$ highly branched isoprenoid hydrocarbons (HBI) and several triterpenoid degradation products were also identified. The concentrations of these 
compounds for the samples analyzed in this study are summarized in Tables A5.1-A5.4 contained in Appendix 5.1. The chemical structures of selected biomarkers are illustrated in Appendix 5.2.

Homologous series of $n$-alkanes have been used to identify the sources of OM in different environments (Prahl et al., 1984; Ficken et al., 2000; Jaffé et al., 2001). Homologous series of alkanes with a strong odd/even carbon number predominance and a high molecular weight $\mathrm{C}_{\max }$ have been reported to derive from the epicuticular waxes of terrestrial plants (Eglinton and Hamilton, 1967). In contrast, short chain $n$-alkanes are presumed to be mainly from algal/planktonic origin (Cranwell, 1982). As such, the riparian vegetation (Figure 5.3.a) and the grasses (Figure 5.3.b) contained a homologous series of $n$-alkanes that ranged between $\mathrm{C}_{21}$ to $\mathrm{C}_{35}$ with a strong odd/even carbon number predominance. All the tree leaves displayed a $\mathrm{C}_{\max }$ at $\mathrm{C}_{29}$, except for the Black Walnut leaves, which maximized at $\mathrm{C}_{31}$. These $\mathrm{C}_{\max }$ values have been reported as being typical of higher plant leaf waxes (Bi et al., 2005). For two of the grasses, Johnson and Eastern Gamma grass, $\mathrm{C}_{31}$ was the most abundant homologue, while for the Prairie Cordgrass it was $\mathrm{C}_{29}$ and for the Big Bluestem grass, $\mathrm{C}_{27}$. Similar $\mathrm{C}_{\max }$ ranges have been reported for various grasses following different photosynthetic pathways (Bi et al., 2005;

Rommerskirchen et al., 2006; Kuhn et al., 2010).

The moss sample showed an odd/even carbon number predominance with a $\mathrm{C}_{\max }$ at $\mathrm{C}_{29}$ (Figure 5.3.c). In other studies, sphagnum moss species from various environments have been analyzed and were found to have $n$-alkane $C_{\max }$ values ranging from $\mathrm{C}_{23}$ to $\mathrm{C}_{31}$ (Nott et al., 2000; Vonk et al., 2009). As expected, the algae (Figure 5.3.c) showed enrichment in the shorter chain $n$-alkanes, with an overall carbon number range from 
between $\mathrm{C}_{14}$ and $\mathrm{C}_{33}$, also with an odd/even carbon number predominance. While assemblies \#2 and \#3 had a $\mathrm{C}_{\max }$ at $\mathrm{C}_{29}$, they displayed a bimodal distribution with a smaller maximum at $\mathrm{C}_{17}$. The presence of long chain $n$-alkanes has been observed in several species of microalgae (Zegouagh et al., 1998) although a maximum for the high molecular weight homologue $\left(\mathrm{C}_{29}\right)$ could also be to the result of plant debris that can get trapped in the algal mat. Assembly $\# 1$ had a $\mathrm{C}_{\max }$ at $\mathrm{C}_{17}$, typical of algae samples (Cranwell, 1982). Assembly \#1 was also enriched in the $C_{23}$ and the $C_{25}$ homologues which may indicate the presence of emergent or floating vegetation (Ficken et al., 2000) associated with the algal mat.

The sediment samples (Figure 5.3.d) showed a mixed source of OM with no pattern from upper to lower reaches of the watershed. All the sediment samples displayed a strong odd/even bimodal distribution of $n$-alkanes with small amounts of the short chain homologues, indicative of autotrophic/algal inputs. The $\mathrm{C}_{\max }$ for the short chain $n$-alkanes was found at $\mathrm{C}_{17}$, the same as algal assembly $\# 1$, and is therefore indicative of algal inputs to the sediments. The smaller concentrations of short chain $n$-alkanes compared to the long chain homologues are suggestive of preferential degradation of the low molecular weight compounds (Meyers, 1997). The presence of $\mathrm{C}_{17}$ and other short chain $n$-alkanes may therefore be indicative of fresh algal inputs which seem to be higher in the sediments at sites $\# 6, \# 1$ and $\# 4$. The long chain $n$-alkanes in the sediment samples showed a $\mathrm{C}_{\max }$ at $\mathrm{C}_{29}$, indicative of higher plant inputs. Because both grasses and tree leaves displayed this same maximum, we cannot use this particular marker to distinguish between OM inputs from riparian vs. watershed areas. The sediment at site \#5 showed 
enrichment in the $\mathrm{C}_{31}$ and $\mathrm{C}_{33}$ homologues, suggesting that Black Walnut may be contributing to the $\mathrm{OM}$ at this site.

The riparian and grass prairie soils (Figure 5.3.d) both showed a strong odd/even carbon number predominance with a $\mathrm{C}_{\max }$ at $\mathrm{C}_{31}$. Soils from the Prairie Ecozone in Canada were also reported to have $\mathrm{C}_{\max }$ values at $\mathrm{C}_{31}$ and have been associated with higher plant inputs (Otto et al., 2005b). The enrichment in the $\mathrm{C}_{31}$ homologue in the riparian soil $\left(0.085 \mathrm{mg} \mathrm{g}^{-1} \mathrm{OC}\right)$ compared to the grass prairie soil $\left(0.057 \mathrm{mg} \mathrm{g}^{-1} \mathrm{OC}\right)$ may suggest high inputs from the Black Walnut, although the Johnson and Eastern Gamma grass may also be contributing to the soil OM.

\subsection{2.b. Branched n-alkanes:}

Branched (monomethyl) $n$-alkanes are well-known components of crude oils and sediments (Warton et al., 1997) and they have been reported as natural products in plant leaf waxes (Eglinton et al., 1967). In the present study, the highest abundances of branched $n$-alkanes were found in the Big Bluestem grass (Figure 5.4.a; $\mathrm{C}_{25}$ to $\mathrm{C}_{32} ; 0.56$ $\mathrm{mg} \mathrm{g}^{-1} \mathrm{OC}$ ), with a strong even/odd carbon number predominance and a $\mathrm{C}_{\max }$ at $\mathrm{C}_{28}$. Much smaller amounts were detected in the Eastern Gamma grass $\left(\mathrm{C}_{28}\right.$ to $\mathrm{C}_{32} ; 0.0075 \mathrm{mg} \mathrm{g}^{-}$ ${ }^{1} \mathrm{OC}$ ) with a $\mathrm{C}_{\max }$ at $\mathrm{C}_{32}$. The three algae samples also had very small amounts of branched $n$-alkanes with varying $\mathrm{C}_{\max }$ values of $\mathrm{C}_{26}, \mathrm{C}_{28}$ and $\mathrm{C}_{30}$ for assembly \#1, \#3 and $\# 2$, respectively (Figure 5.4.b). Based on this data, it was assumed that the Big Bluestem grass is the major producer of these compounds in this environment and they can therefore be used as markers for this vegetation. 

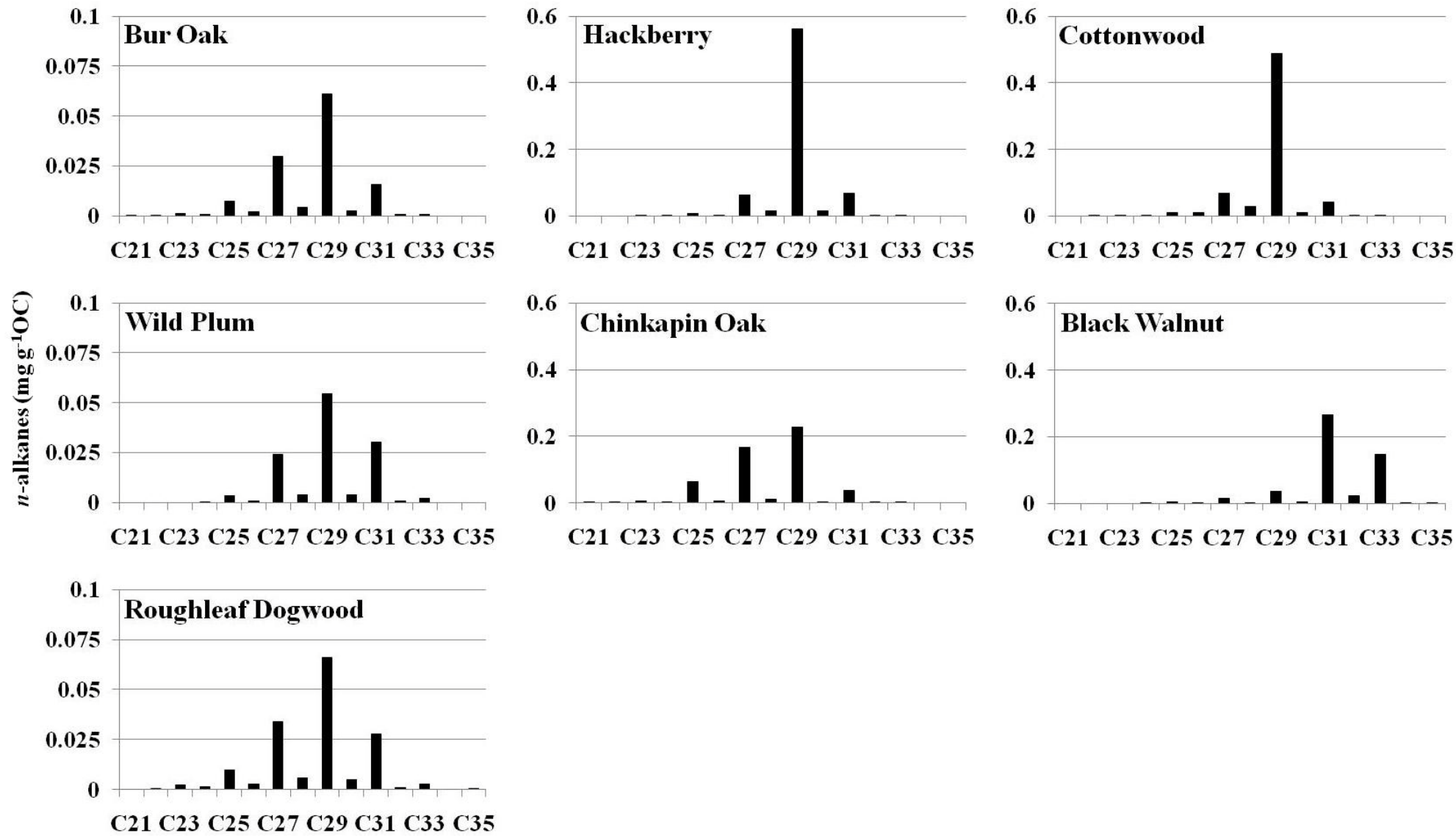

Carbon number

Figure 5.3.a. The $n$-alkane distribution of the riparian vegetation. The abundance is shown on a different scale for the Bur Oak, Wild Plum and Roughleaf Dogwood samples. 


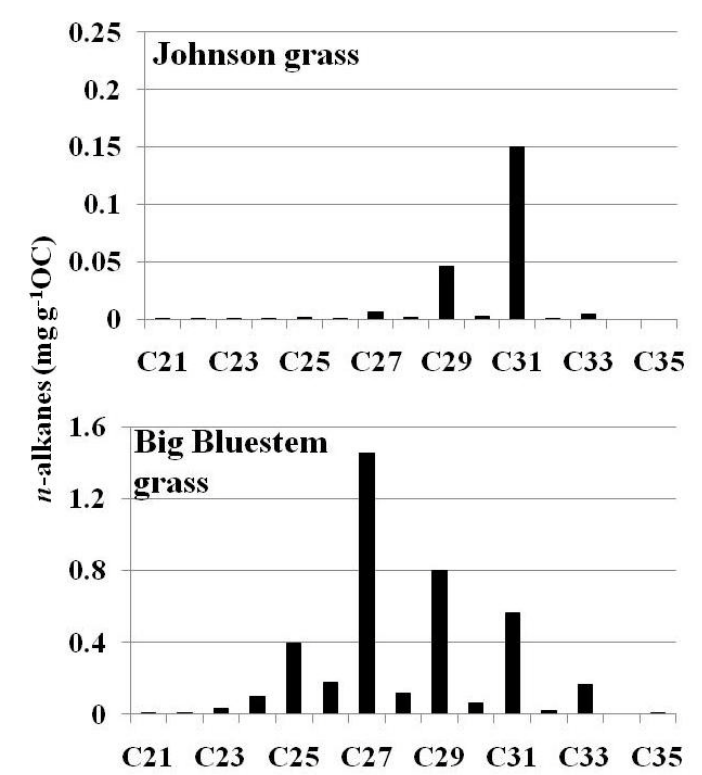

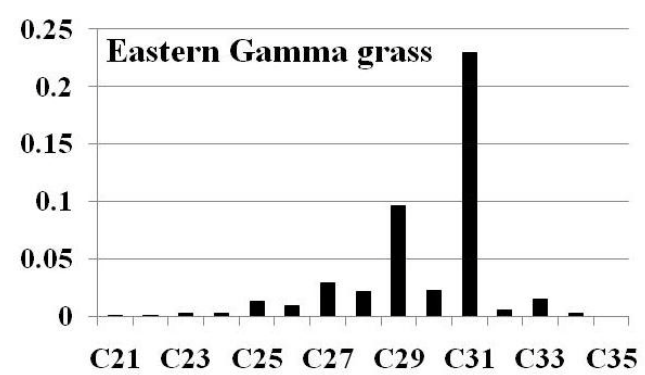

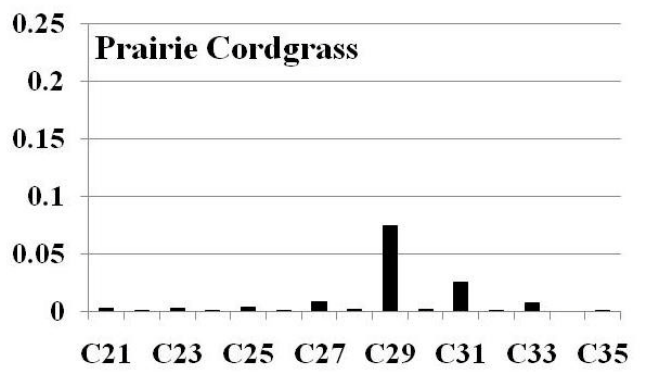

$\begin{array}{lllllllll}C 21 & C 23 & C 25 & C 27 & C 29 & C 31 & C 33 & \mathbf{C} 35\end{array}$

Carbon number

Figure 5.3.b. The $n$-alkane distribution of the grass samples. The abundance is shown on a different scale for the Big Bluestem grass. 

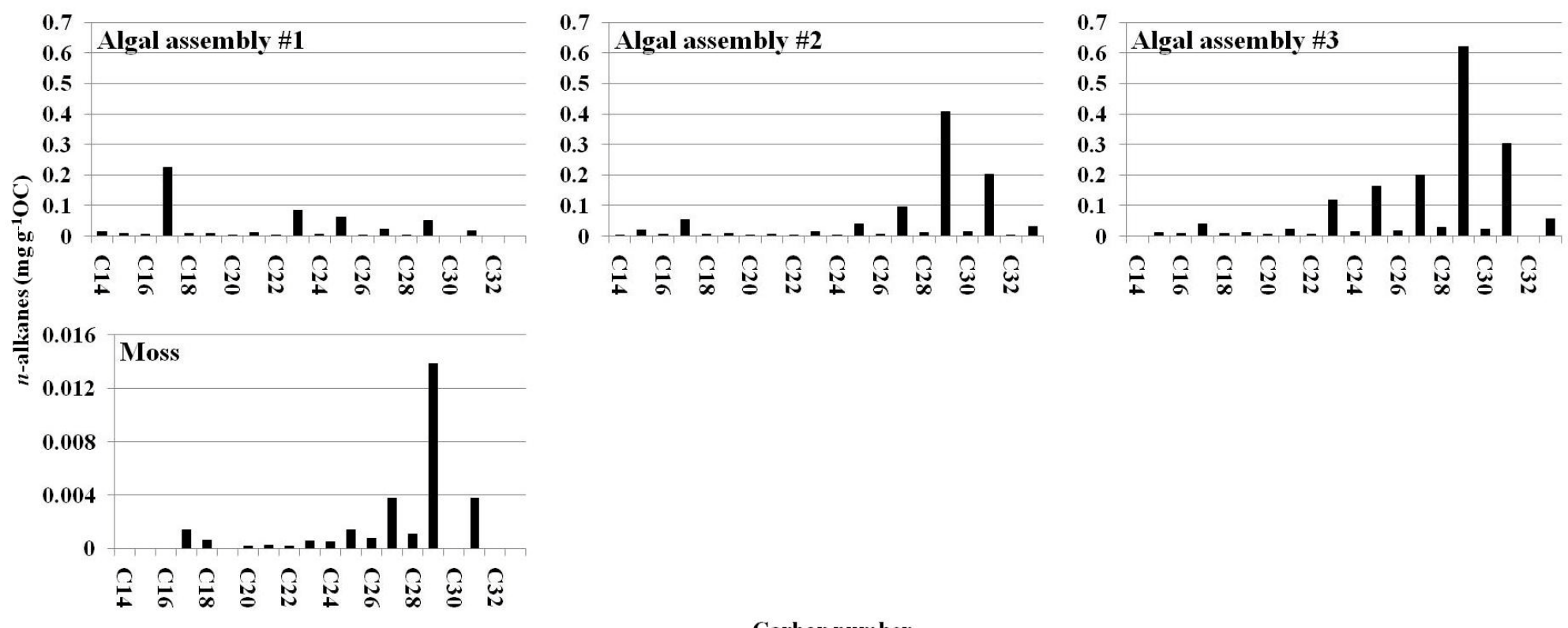

Carbon number

Figure 5.3.c. The $n$-alkane distribution of the moss and algae samples. The abundance is shown on a different scale for the moss sample. 

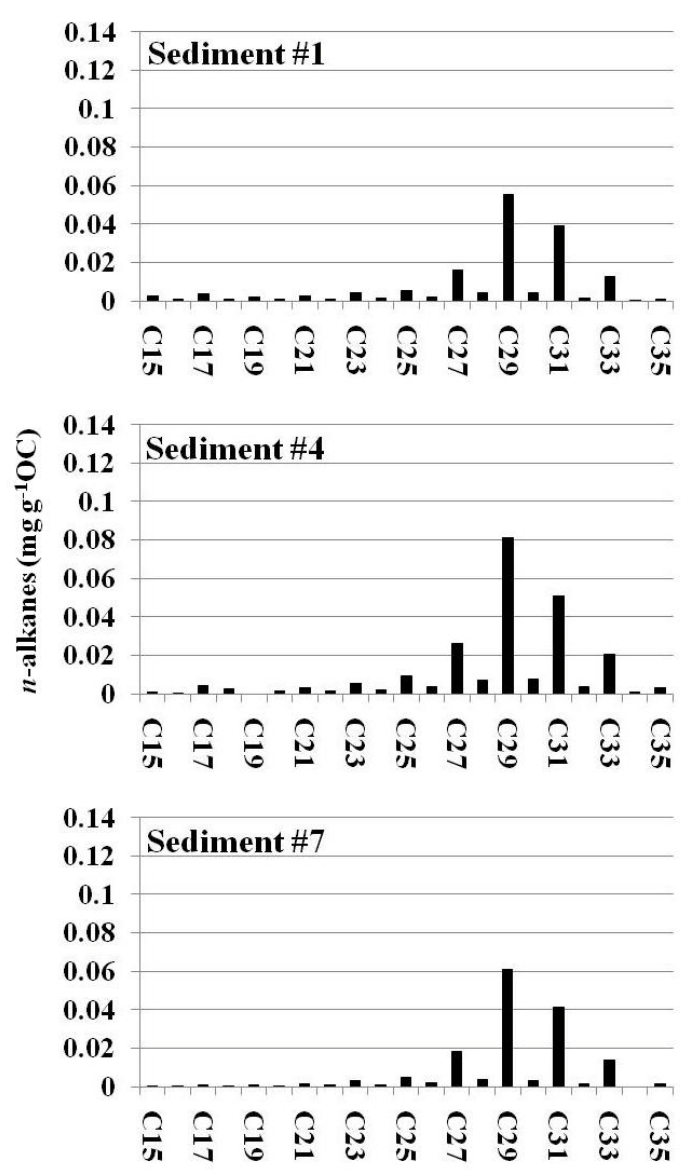
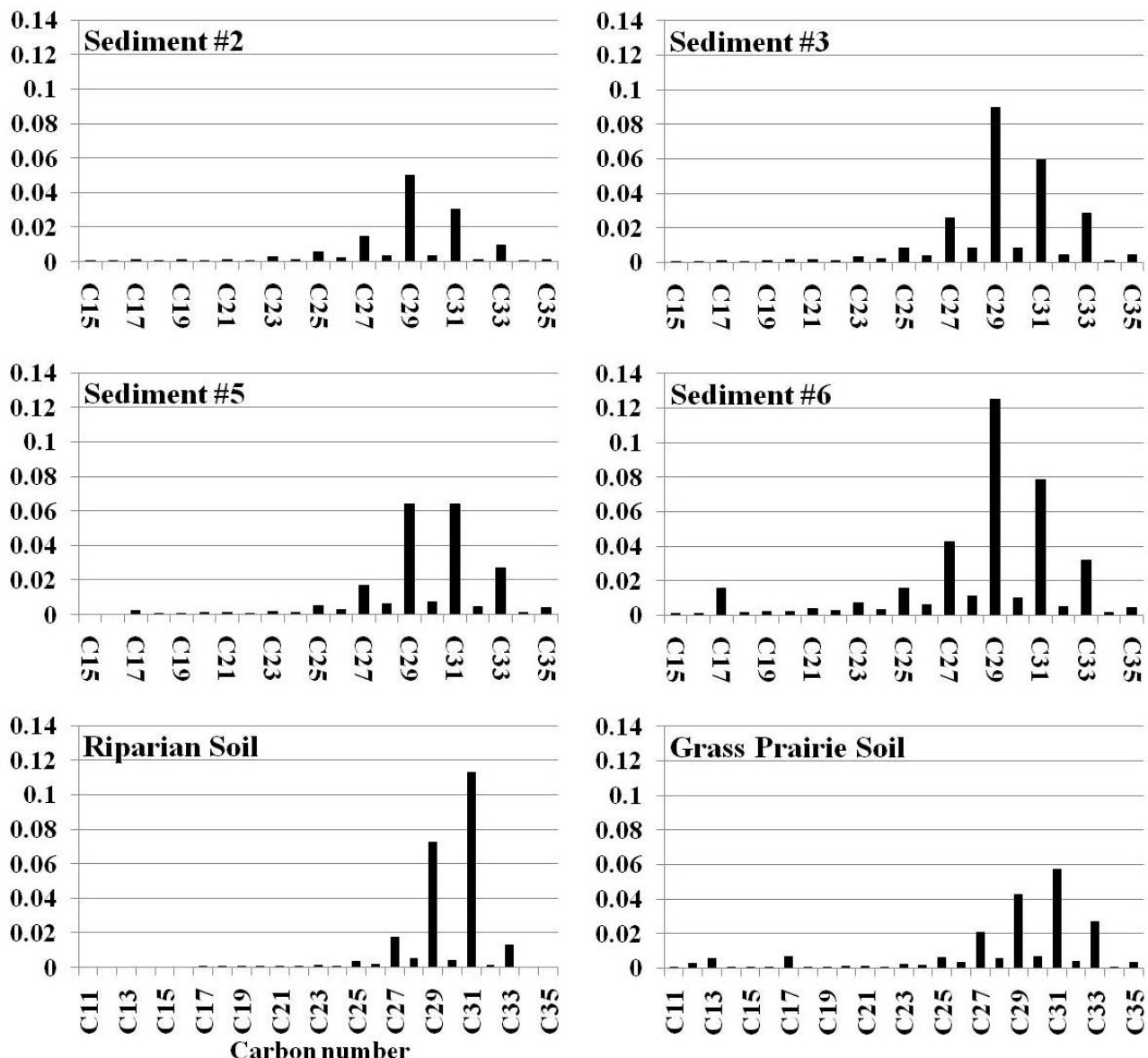

Figure 5.3.d. The $n$-alkane distribution in the sediment and soil samples from the King's Creek watershed. The carbon number range detected in the sediments is $\mathrm{C}_{15}-\mathrm{C}_{35}$ while in the soils is $\mathrm{C}_{11}-\mathrm{C}_{35}$. 
All the sediments, with the exception of site \#6, contained small amounts of branched $n$-alkanes from $\mathrm{C}_{26}$ to $\mathrm{C}_{30}$ (mainly the $\mathrm{C}_{26}, \mathrm{C}_{28}, \mathrm{C}_{29}$ and $\mathrm{C}_{30}$ homologues) showing no consistent patterns of specific OM accumulation (Figure 5.4.c). The $\mathrm{C}_{\max }$ for sites \#1, 2, 3 and 6 was found at $\mathrm{C}_{28}$ while for sites \#4 and 5 it was found at $\mathrm{C}_{30}$. The sediment at site \#7 did not contain any branched $n$-alkanes. While the high levels at site \#6 suggest that this site receives significant inputs from the local grasses, its branched $n$ alkane molecular distribution did not exactly match that of the Big Bluestem grass, as evident by a depletion of the $\mathrm{C}_{28}$ homologue. While small amounts of these markers were found in the grass prairie soil $\left(\mathrm{C}_{28}\right.$ to $\mathrm{C}_{32} ; \mathrm{C}_{\max }$ at $\left.\mathrm{C}_{28}\right)$, they were not detected in the riparian soil.
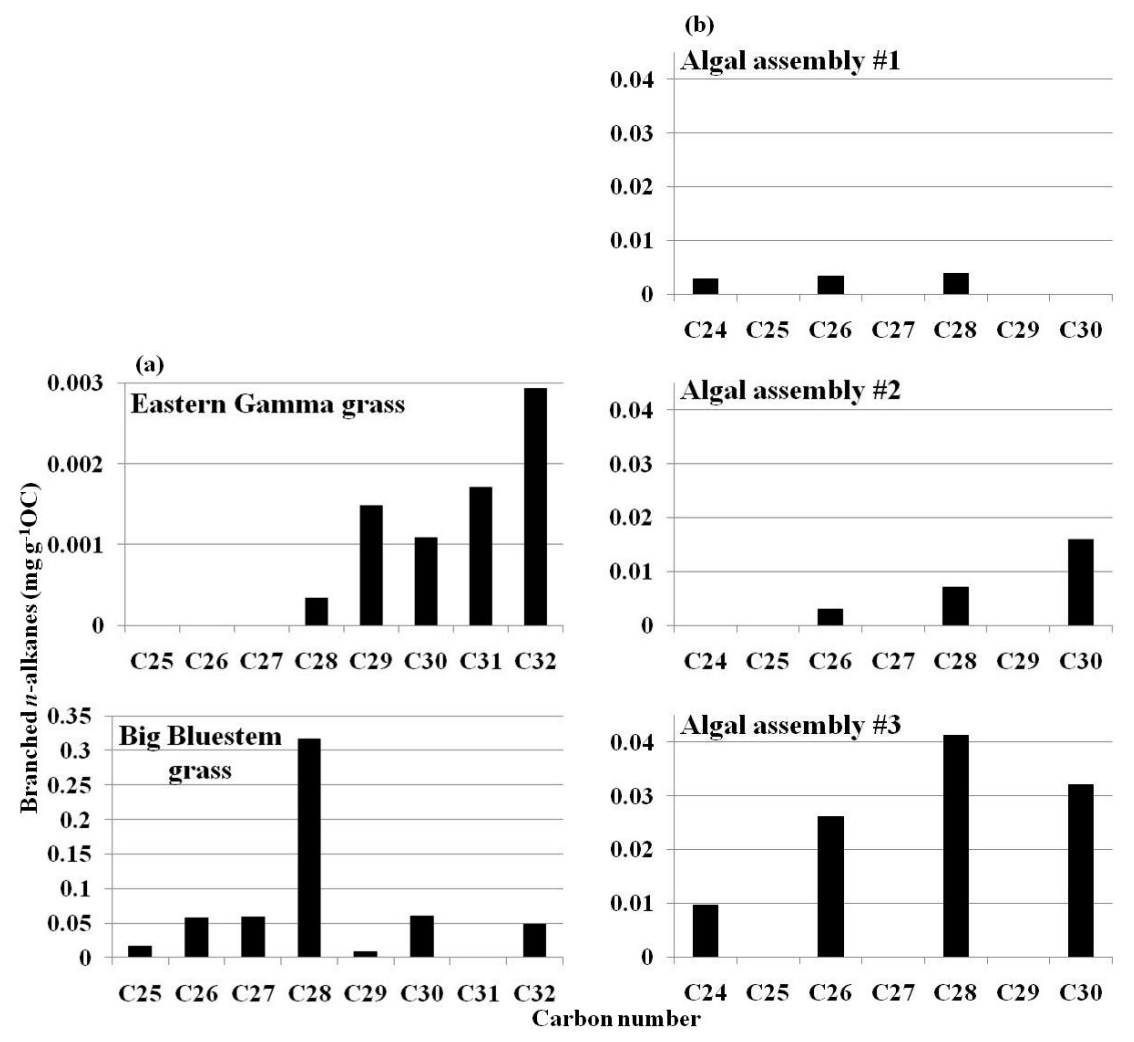

Figure 5.4. The branched $n$-alkane distribution in the grass (a) and algae (b) samples. The abundance of branched $n$-alkanes in the Big Bluestem grass is two orders of magnitude greater compared to the other samples. 

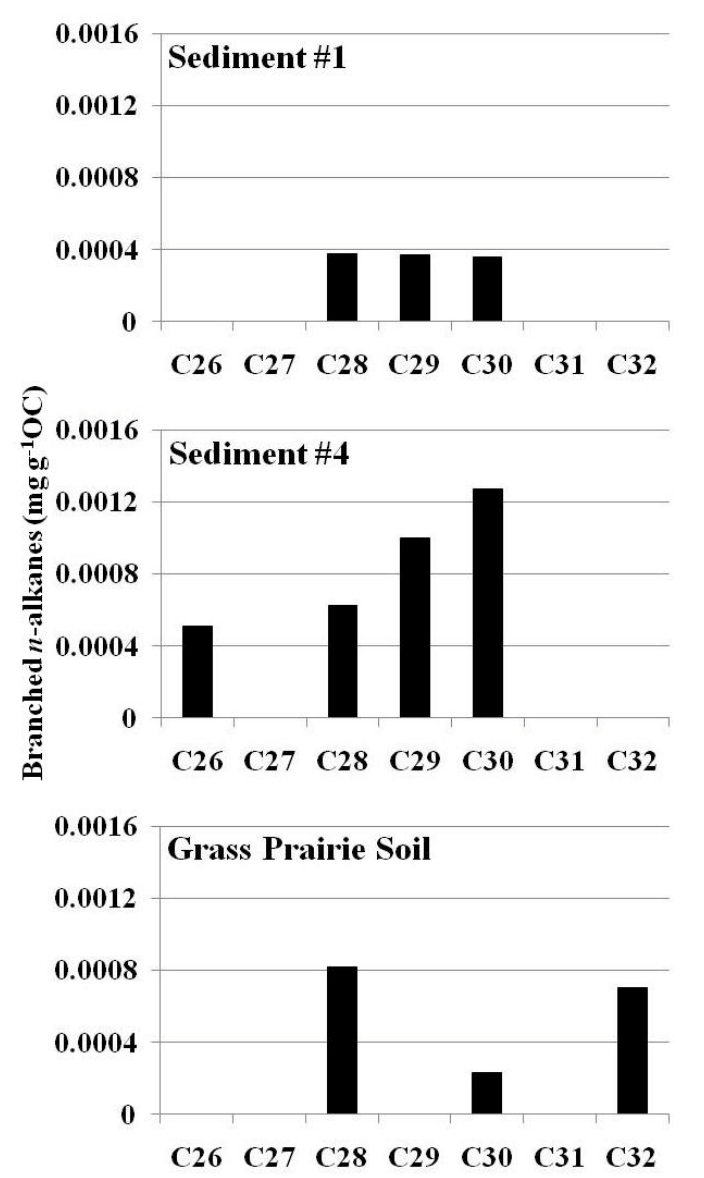
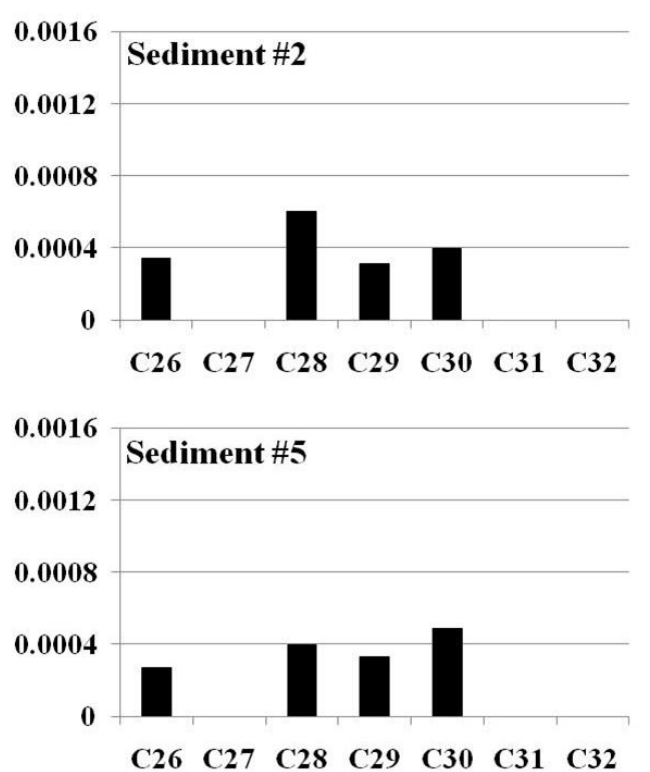

$\begin{array}{lllllll}\mathbf{C} 26 & \mathbf{C} 27 & \mathbf{C} 28 & \mathbf{C} 29 & \mathbf{C} 30 & \mathrm{C} 31 & \mathbf{C} 32\end{array}$
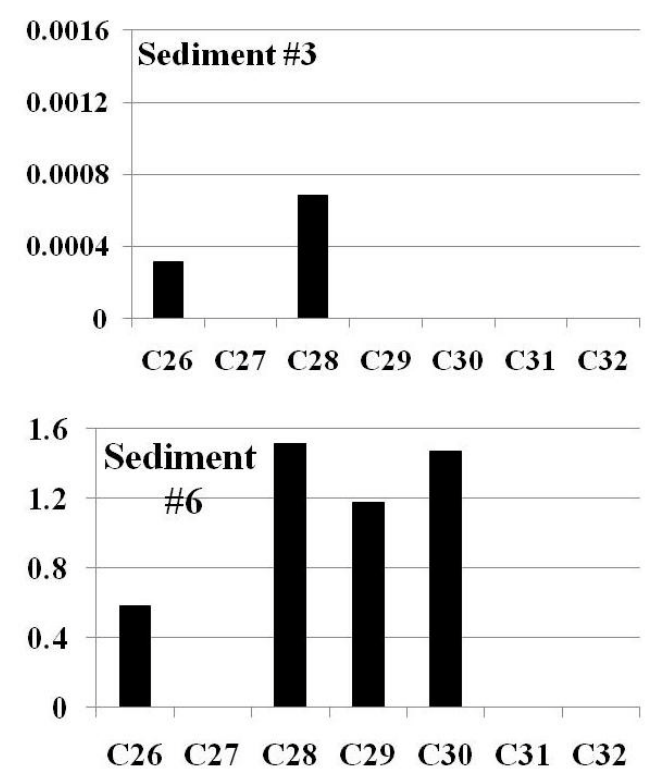

Carbon number

Figure 5.4.c. The branched $n$-alkane distribution in the stream sediments and grass prairie soil. The abundance of branched $n$ alkanes at site \#6 is three orders of magnitude larger compared to the other sites. 


\subsection{2.c. n-Alkenes:}

Homologous series of $n$-alkenes with an even/odd carbon number predominance have been detected in peat soils of Loch Clair, Scotland, and in peat forming plant species, indicating allochthonous OM inputs to lake sediments (Cranwell, 1982). nAlkenes have also been found in sediments of a subtropical estuary in southern Florida and have been suggested to derive from microbial transformations of $n$-alkanes or from direct biomass inputs (Jaffé et al., 2001).

A homologous series of straight chain, mono-unsaturated $n$-alkenes with a mostly even/odd carbon number predominance was found in most of the riparian vegetation samples (Figure 5.5.a). The highest concentrations were found in the $\mathrm{C}_{4}$ grasses (Figure 5.5.b), Big Bluestem $\left(\mathrm{C}_{23}\right.$ to $\left.\mathrm{C}_{32} ; \mathrm{C}_{\max } \mathrm{C}_{26}\right)$ and Eastern Gamma grass $\left(\mathrm{C}_{24}\right.$ to $\mathrm{C}_{31} ; \mathrm{C}_{\max }$ $\left.\mathrm{C}_{30}\right)$. The Cottonwood leaves also contained high concentrations $\left(\mathrm{C}_{22}\right.$ to $\left.\mathrm{C}_{30} ; \mathrm{C}_{\max } \mathrm{C}_{28}\right)$ so this marker is not ideally suited to distinguish between grass and riparian OM inputs to the stream sediments. While the moss sample only contained the $\mathrm{C}_{28} n$-alkene, the algae samples contained only odd $n$-alkenes with assemblies \#1 and \#2 maximizing at $\mathrm{C}_{17}$, and assembly \#3 at $\mathrm{C}_{29}$ (Figure 5.5.c). Monounsaturated $n$-alkenes from $\mathrm{C}_{19}$ to $\mathrm{C}_{29}$ with an odd carbon preference have been reported in microalgae and cyanobacteria (Volkman et al., 1998).

All the sediments (Figure 5.5.d) contained a series of these compounds with highest concentrations usually between the $\mathrm{C}_{26}, \mathrm{C}_{28}$ and $\mathrm{C}_{30}$ homologues. Both riparian and watershed grass vegetation seems to preferentially produce these homologues, and no preferential source can be suggested. Only the Oak samples contained significant amounts of also odd carbon numbered $n$-alkenes, and as such, samples \#4 and \#6 may be 
enriched in OM from this plant. However, these even carbon numbered homologues were also present in the algal assemblies, in addition to the presence of the short chain compounds, particularly $\mathrm{C}_{17}$, may indicate autochthonous $\mathrm{OM}$ inputs to the stream sediments. Both sites \#4 and \#6 were enriched in this short chain homologue. As $n$ alkenes preferentially undergo microbial transformations in aquatic environments (Volkman et al., 1998), the relatively high amounts of $\mathrm{C}_{17}$ found in these sediments may be indicative of relatively fresh algal remains. This is especially true at sites \#1 and \#6 where this short chain homologue was found to be the most abundant.

The soil samples only contained $n$-alkenes with carbon numbers $\mathrm{C}_{28}$ and $\mathrm{C}_{30}$, indicating that these compounds are not stable in the environment and degrade quickly (Volkman et al., 1998; Volkman, 2006). As for the branched $n$-alkanes, the $n$-alkenes did not provide a solid marker to differentiate between riparian and watershed vegetation inputs.

\subsection{2.d. Phytadienes:}

The phytadienes identified in this work were confirmed by comparison with published mass spectra fragmentation patterns (Simoneit et al., 1973; Grossi et al., 1996). Three isomers were detected, neophytadiene (7,11,15-trimethyl-3-methylene-1hexadecene), and (Z)- and (E)-1,3-phytadiene. Phytadienes have been identified in zooplankton and fish (Blumer et al., 1965 and 1969), as volatile constituents of young tree leaves (Fons et al., 1998; Mastelić et al., 2002) and in particulates from a hypereutrophic lake in Venezuela (Jaffé et al., 1996) among others. 

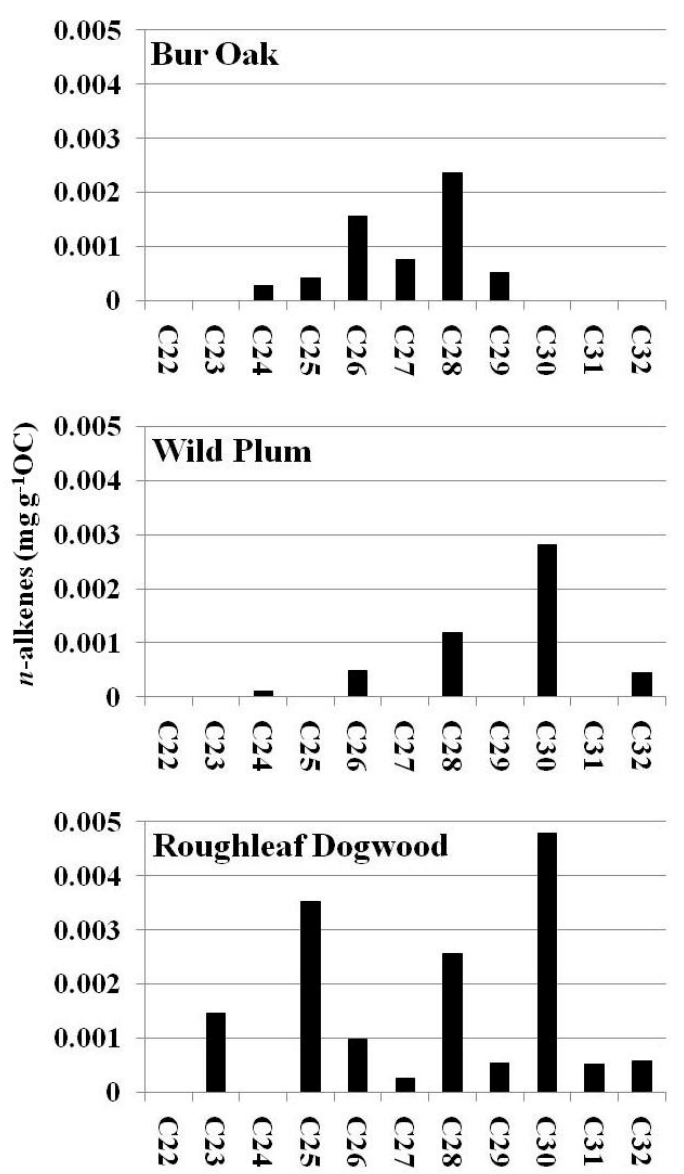
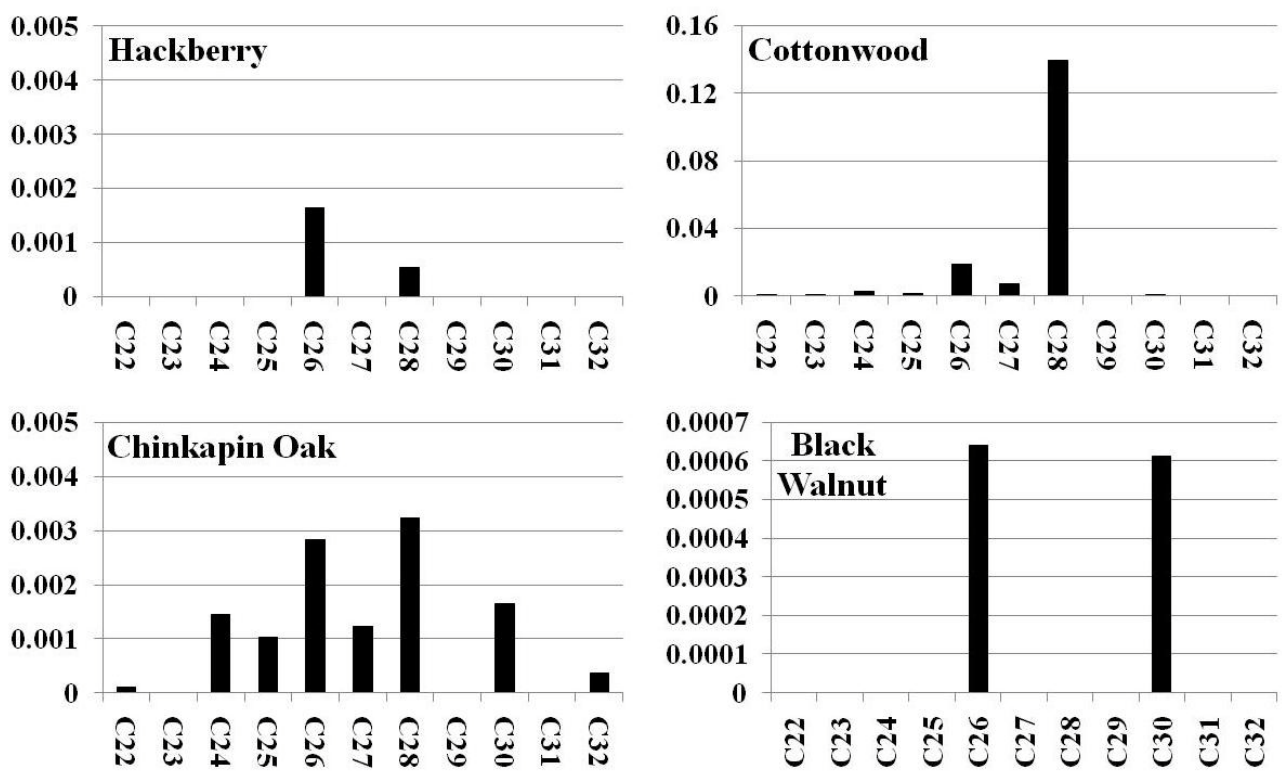
leaves is shown on different scales. 


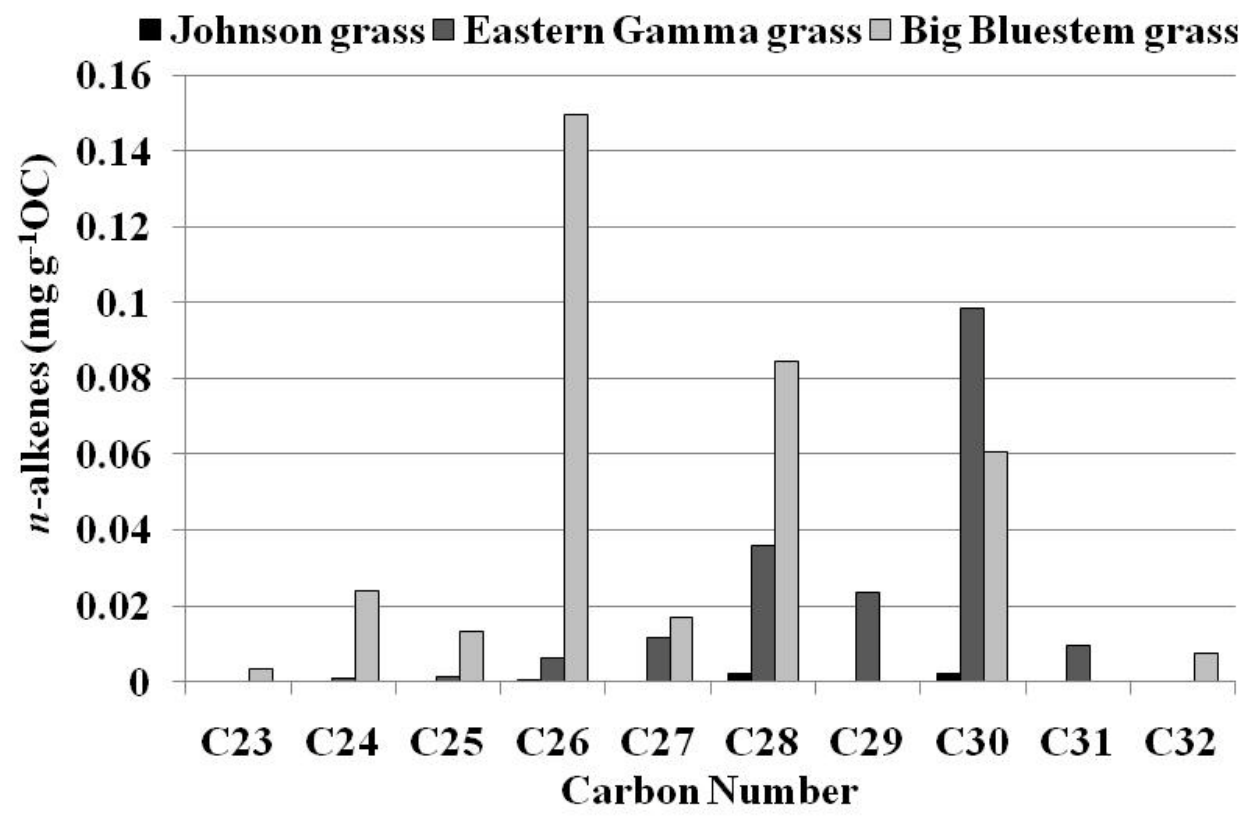

Figure 5.5.b. The $n$-alkene distribution of the grass samples.

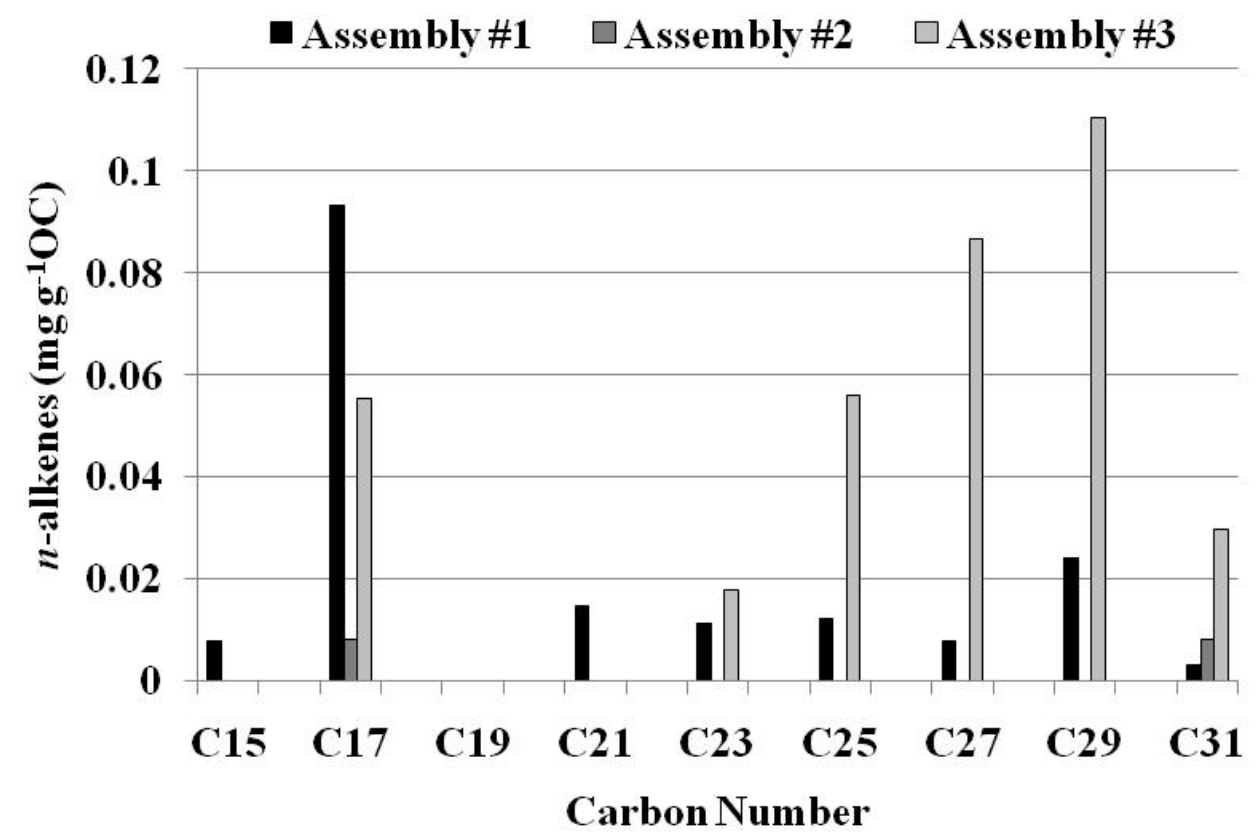

Figure 5.5.c. The $n$-alkene distribution of the algal assemblies collected in the stream channels of the King's Creek watershed. 

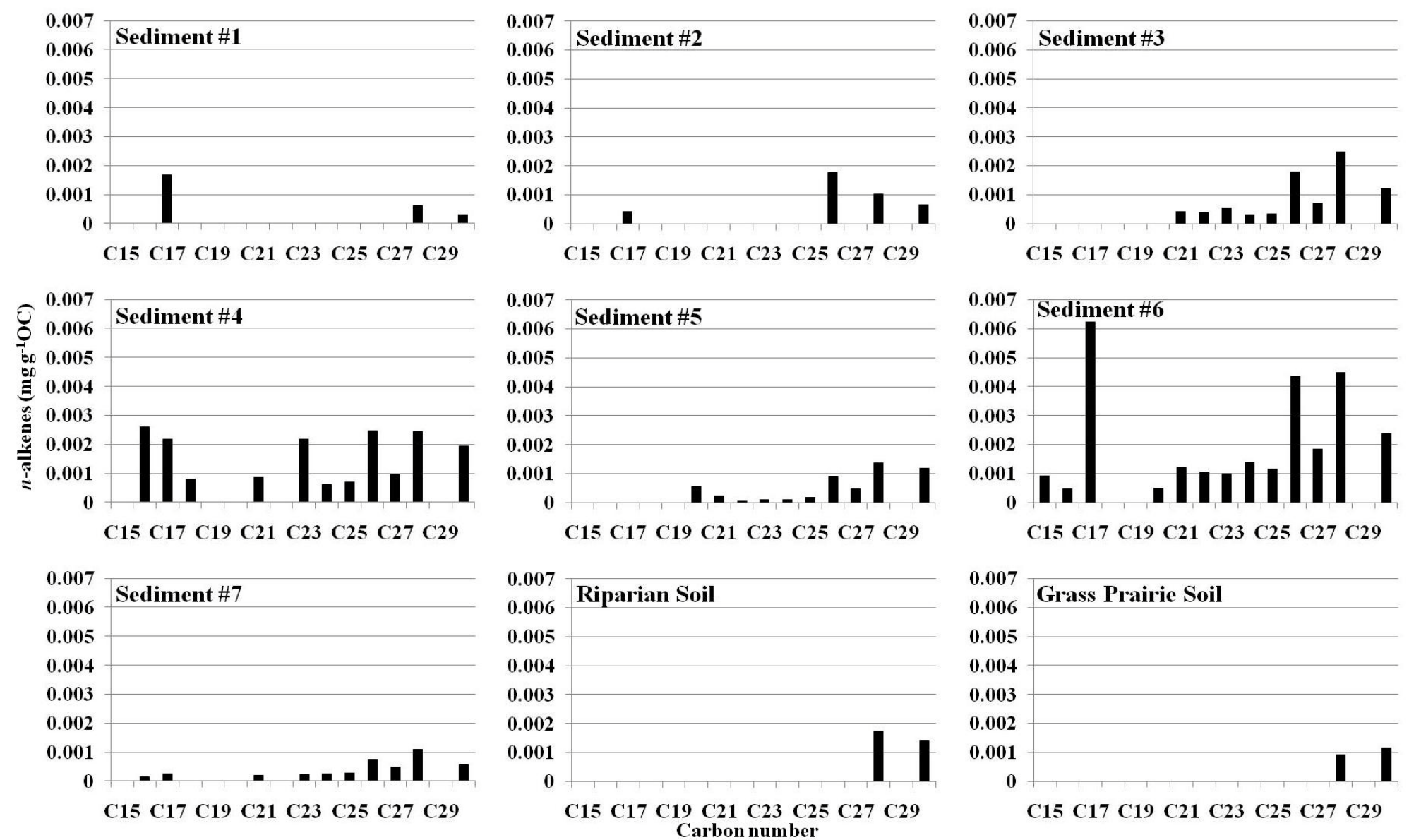

Figure 5.5.d. The $n$-alkene distribution of the King's Creek sediment and soil samples. 
Phytadienes are known to be diagenetic dehydration products of phytol, the side chain of chlorophyll- $a$ (de Leeuw et al., 1977) although they may sometimes be generated artificially during laboratory procedures such as freeze-drying and saponification (Grossi et al., 1996). While they are clearly early diagenetic degradation products, they have been reported to be quite reactive compounds and are expected to be short-lived in sediments without much chance for significant accumulation (Volkman and Maxwell, 1986). For these reasons, they can be used as markers to trace early diagenetic products of OM to aquatic environments.

The highest concentrations of these compounds were found in the Big Bluestem grass, with (Z)-1,3-phytadiene being the most abundant isomer (Figure 5.6.a). They were also present in much smaller concentrations in the Johnson grass and the moss sample, and could serve as indicators of grass inputs to sediments in small prairie streams. In fact, while they were present in the sediment and soil samples, none of the riparian trees or algae contained these compounds.

The concentrations of phytadienes were highest in some sediments from the upper reaches (\#4,6 and 7), with highest amounts at site \#4 (Figure 5.6.b). Their presence may suggest direct inputs from the grasses (probably from the Big Bluestem grass) to these low order streams. Furthermore, their presence may also indicate the preferred accumulation of these early diagenetic compounds in the sediments of these sites. In the lower reaches, smaller amounts of phytadienes were detected, with smallest concentration found at site $\# 2$.

The two soil samples also contained small amounts of phytadienes, with the grass prairie soil having equal amounts of the three isomers, and the riparian soil having twice 
as much of the (Z)- and (E)-1,3-phytadiene isomers compared to the neo- isomer.

Interestingly, although Big Bluestem is the most abundant grass in the watershed adjacent to the riparian areas, the concentrations of phytadienes in the riparian soil were similar to those in the prairie soil, and carbon-normalized concentrations in the sediments were usually much higher than in the soils. This suggests that Big Bluestem is a significant source of phytadienes to the sediments, but also that accumulation of these compounds is preferred in the sediments while this preservation in soils is not favored. As such, it may be better preserved under flood conditions than exposed to atmospheric conditions, and suggests that when present may be preferentially derived from grass detritus and not from remobilized soil organic matter. Interestingly, highest abundances of these compounds were observed in sediments at sites \#4 and \#6, suggesting highest OM inputs from the watershed grass community. These sites also seemed enriched in algal derived OM.

\subsection{2.e. $C_{25}$ highly branched isoprenoids:}

The aromatic hydrocarbon fraction contained several poly-unsaturated $\mathrm{C}_{25}$ highly branched isoprenoids $\left(\mathrm{C}_{25: 2}\right.$ and $\left.\mathrm{C}_{25: 5} \mathrm{HBI}\right)$. These compounds are widely distributed in recent coastal sediments and have been assigned a diatom source (Wraige et al., 1997; Belt et al., 2001; Xu et al., 2006). In the present study, these compounds were identified in the sample extracts of the three algal assemblies and in most of the sediments (Figure 5.7). The three algae samples contained a $\mathrm{C}_{25: 2} \mathrm{HBI}$ that was identified as $2,10,14-$ trimethyl-6-methylene-7-(3'-methylpent-1-enyl)-pentadecane, on the basis of comparisons with published mass spectra (Johns et al., 1999). 

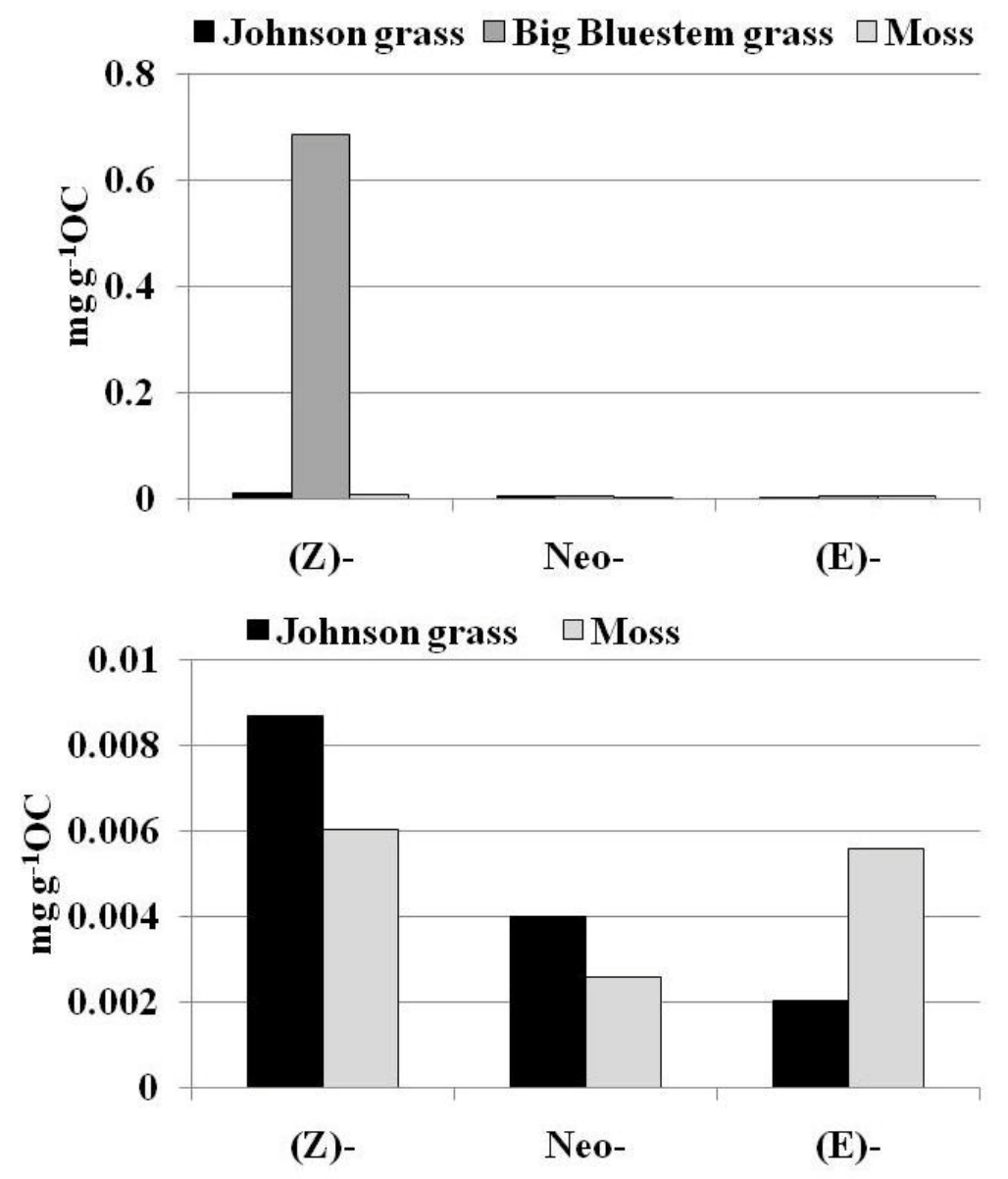

Figure 5.6.a. Phytadiene distribution in the Johnson grass, Big Bluestem grass and moss samples from Konza Prairie. The graph on the bottom shows only the lower concentrations of these compounds in the Johnson grass and the moss compared to the Big Bluestem grass. $(Z)-=(Z)-1,3-$ phytadiene; Neo = Neophytadiene and $(E)-=(E)-1,3-$ phytadiene. 


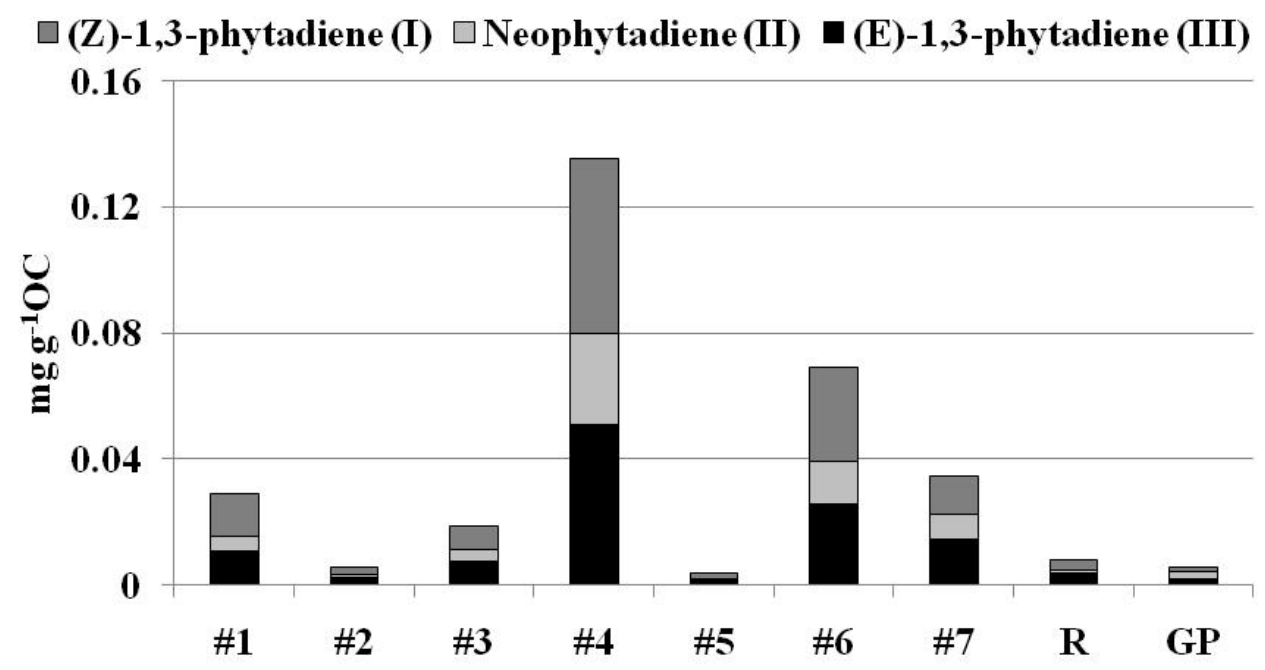

Figure 5.6.b. The distribution of phytadiene isomers in the sediment and soil $(\mathrm{R}=$ riparian, GP = grass prairie) samples from the King's Creek watershed. The numbers in parentheses correspond to the molecular structure shown in Appendix 5.2.

The HBI compound was present at concentrations of 0.02 to $0.03 \mathrm{mg} \mathrm{g}^{-1} \mathrm{OC}$ in the sediment samples, along with two other dienes, one of which was identified as $2,6,10,14$ tetramethyl-7-(3-methylpent-4-enyl)-pentadec-5E-ene by comparison with published mass spectra (Grossi et al., 2004). It is likely that HBIs undergo isomerisation reactions in sediments (Belt et al., 2000), which explains the presence of the two diene isomers in the sediments but not in the algae. Site \#6 showed the highest inputs from algae followed by sites \#1, \#2 and \#4. These compounds were not detected in sediments at site \#5, probably because of insignificant algal growth in the stream at that site. Furthermore, these compounds were not detected in the soil samples.

Another poly-unsaturated isoprenoid, namely the $\mathrm{C}_{25: 5} \mathrm{HBI}$ 2,6,10,14-tetramethyl7-(3-methylpent-4-enyl)-pentadec-2,5,9,13-ene, was found only in two algal assemblies and in the sediments from the lower reaches (\#1 and \#2). This penta-unsaturated HBI compound, also reported to occur in diatoms (Wraige et al., 1997), was only found in the 
sediments at sites \#1 and \#2 indicating autochthonous inputs to the higher order stream sites. Since this compound features the highest degree of unsaturations, it may be expected to be the most unstable of the detected HBIs, which makes it's accumulation at the higher order stream sites \#1 and \#2 somewhat puzzling. It is possible that these locations preferentially accumulate fresh $\mathrm{OM}$ in their sediments or feature better environmental conditions for OM preservation.

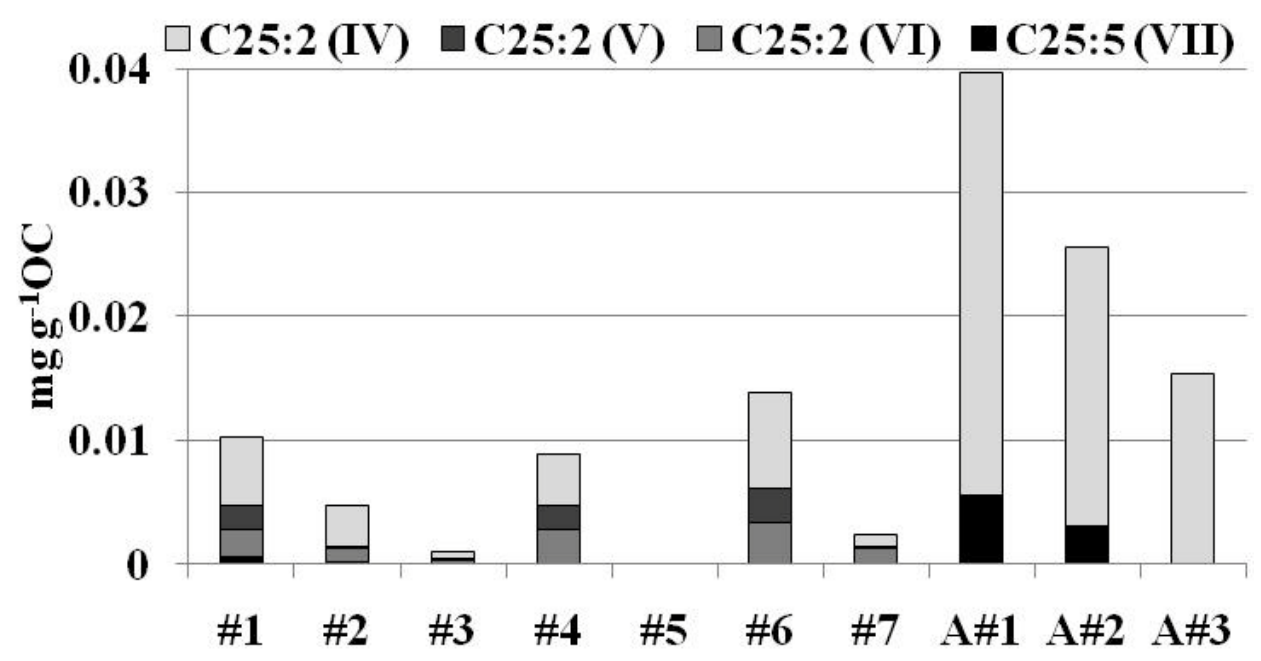

Figure 5.7. $C_{25}$ highly branched isoprenoids in the stream sediments (\#1-\#7) and the three algae samples (A\#1, A\#2, A\#3). The numbers in parentheses correspond to the molecular structure in Appendix 5.2.

\subsection{2.f. Mono-unsaturated triterpenes:}

Several mono-unsaturated triterpenes were detected in the aliphatic and aromatic hydrocarbon fractions of the sample extracts. The compounds identified belonged to the oleanane (olean-13(18)-ene, olean-12-ene and olean-18-ene) and hopane (hop-22(29)ene, hop-17(21)-ene and fern-13(18)-ene) classes. Compounds belonging to the oleanane series are known to be early diagenetic products of 3-oxy-triterpenoids, formed by rapid dehydration of the C-3 alcohol triterpenoid precursor and reduction of the $\Delta^{2}$ double bond 
intermediate (Ten Haven et al., 1992). They have been found in different environments such as Baffin Bay sediments (Ten Haven et al., 1992), Tertiary oils from the Beaufort Sea (Curiale, 1995) and re-suspended sediments from subtropical wetlands (Neto et al., 2006), where they have been used as markers for higher plant inputs (Ten Haven et al., 1992).

Figure 5.8.a shows the total amount of oleanenes detected in the sediment/soil samples. These compounds were found in concentrations ranging between $1.4 \times 10^{-3}$ to $8.4 \times 10^{-3} \mathrm{mg} \mathrm{g}^{-1} \mathrm{OC}$, with highest amounts at site \#3 and lowest amounts at site \#1. The higher amounts of these early diagenetic products found in the upper reaches of the watershed indicate the presence and accumulation of degraded plant-derived OM at these sites. This process may be favored in the upper reaches by a possible association of this OM with fine particles that can easily get trapped in the stream channel and not be transported downstream during periods of high flood. Subsequently, the smaller amounts of these compounds present in the lower reaches (sites \#1 and \#2) indicate minimal downstream transport of fine particles and/or poor environmental conditions for OM degradation.

The two soil samples contained small concentrations of these compounds $(1.3 \mathrm{x}$ $10^{-3} \mathrm{mg} \mathrm{g}^{-1} \mathrm{OC}$ in the grass prairie and $5.6 \times 10^{-4} \mathrm{mg} \mathrm{g}^{-1} \mathrm{OC}$ in the riparian soil), suggesting the low accumulation of these higher plant-derived degradation products in soils from this watershed. 

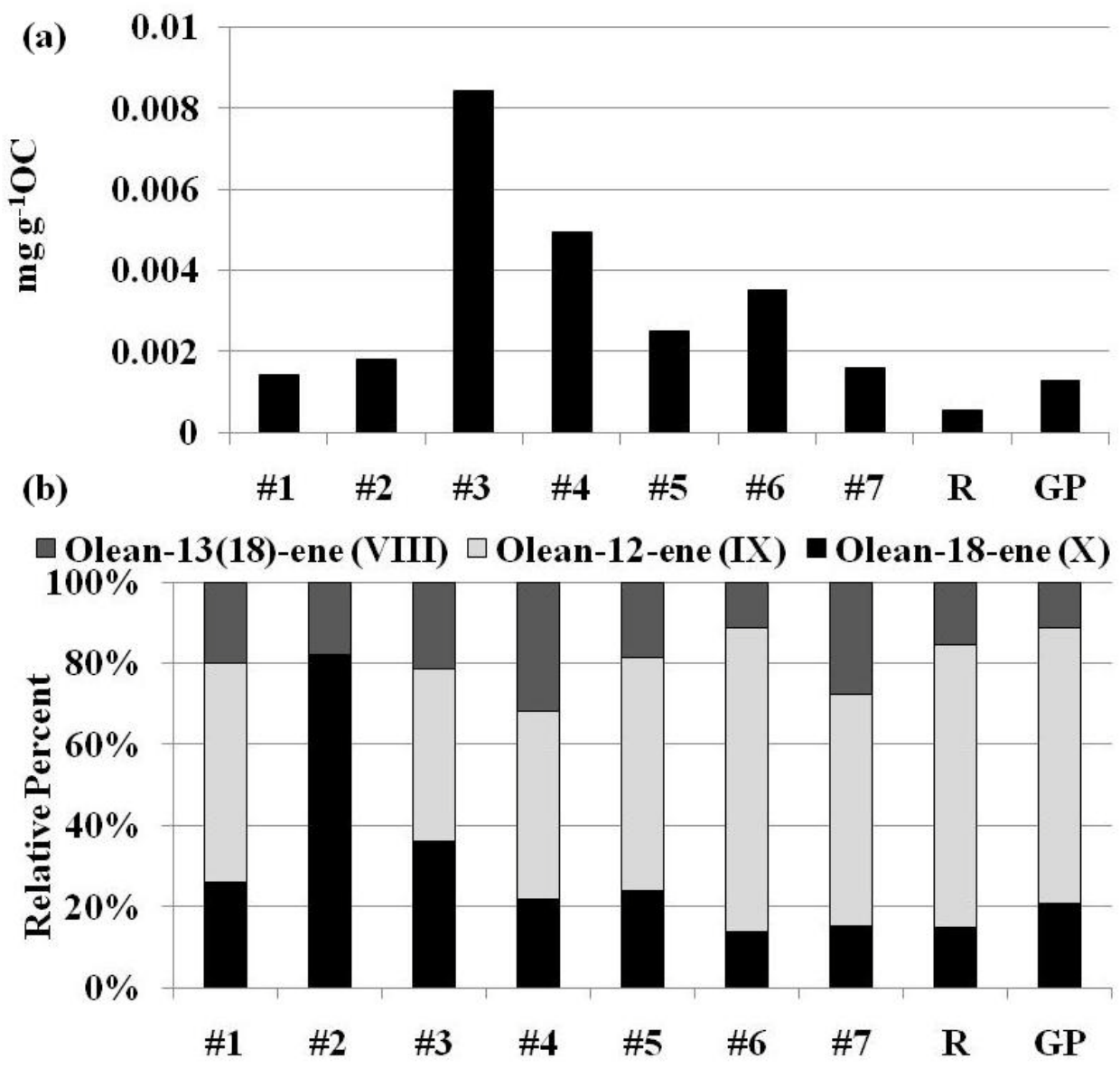

Figure 5.8. Total oleanene distributions (a) and percent oleanene (of the major compounds relative to total triterpenes; (b)) of the sediment (\#1 to \#7) and soil ( $\mathrm{R}=$ riparian, GP = grass prairie) samples. The numbers in parentheses correspond to the molecular structure in Appendix 5.2.

The hopanoids are among the most widespread of all biomarkers and are known to be essential constituents of bacterial membranes (Rohmer et al., 1984; Simoneit, 1986). Apart from their presence in all sedimentary environments, they have also been reported in some ferns and mosses (Huang et al., 2010). While the major source of diploptene $(17 \beta(\mathrm{H})$-hop-22(29)-ene) in sediments is also known to be bacteria (Simoneit, 1986), it has also been found in mosses (Huang et al., 2010). Although Diploptene is more commonly associated with sediments from highly productive environments (i.e. 
higher bacterial activity; Jaffé et al., 1995), it has also been reported in riverine sediments from the Columbia River drainage basin (Prahl et al., 1992) where it was assigned a terrestrial source (soil erosion) on the basis of its compound specific isotopic value. Some diagenetic products of diploptene such as $17 \beta(\mathrm{H})$-hop-21(22)-ene and hop-17(21)-ene have been found in recent sediments (Simoneit, 1986; Hausman and Jaffé, 1996).

At King's Creek, significant amounts of hopenes were found in the moss sample and this compound was detected in all the sediment samples (Figure 5.9). The highest concentrations were found in the upper reaches $\left(8.7 \times 10^{-3} \mathrm{mg} \mathrm{g}^{-1} \mathrm{OC}\right.$ at site \#3) and smaller amounts were detected in the lower reaches $\left(2.5 \times 10^{-3} \mathrm{mg} \mathrm{g}^{-1} \mathrm{OC}\right.$ at site \#2). The relatively higher abundance of hopenes found in the upper reaches of the watershed, may indicate high inputs from the mosses growing in the river bed, higher soil OM inputs as well as preferential accumulation of microbially reworked OM. The lower amounts found in the lower reaches indicate low microbial activity at those sites. These observations are in agreement with the data presented above on the phytadienes, triterpenoid degradation products and HBIs.

The riparian soil contained higher concentrations of hopenes $\left(1.4 \times 10^{-2} \mathrm{mg} \mathrm{g}^{-}\right.$ $\left.{ }^{1} \mathrm{OC}\right)$ compared to the grass prairie soil $\left(3.4 \times 10^{-3} \mathrm{mg} \mathrm{g}^{-1} \mathrm{OC}\right)$, suggesting a higher soil bacterial population in the former soil. 
(a)

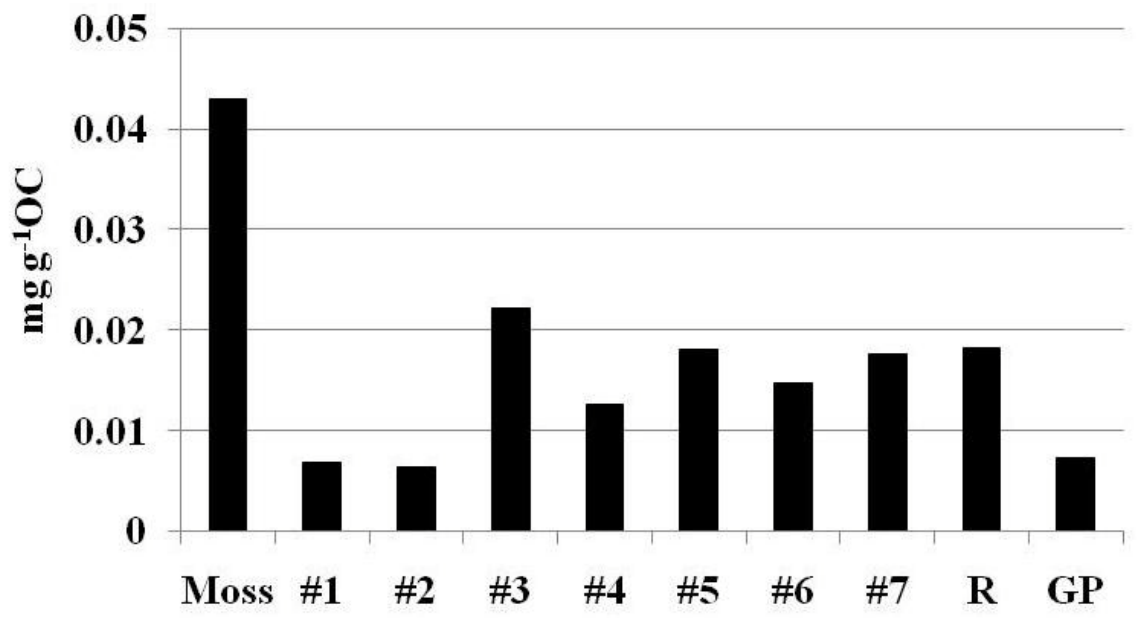

(b)

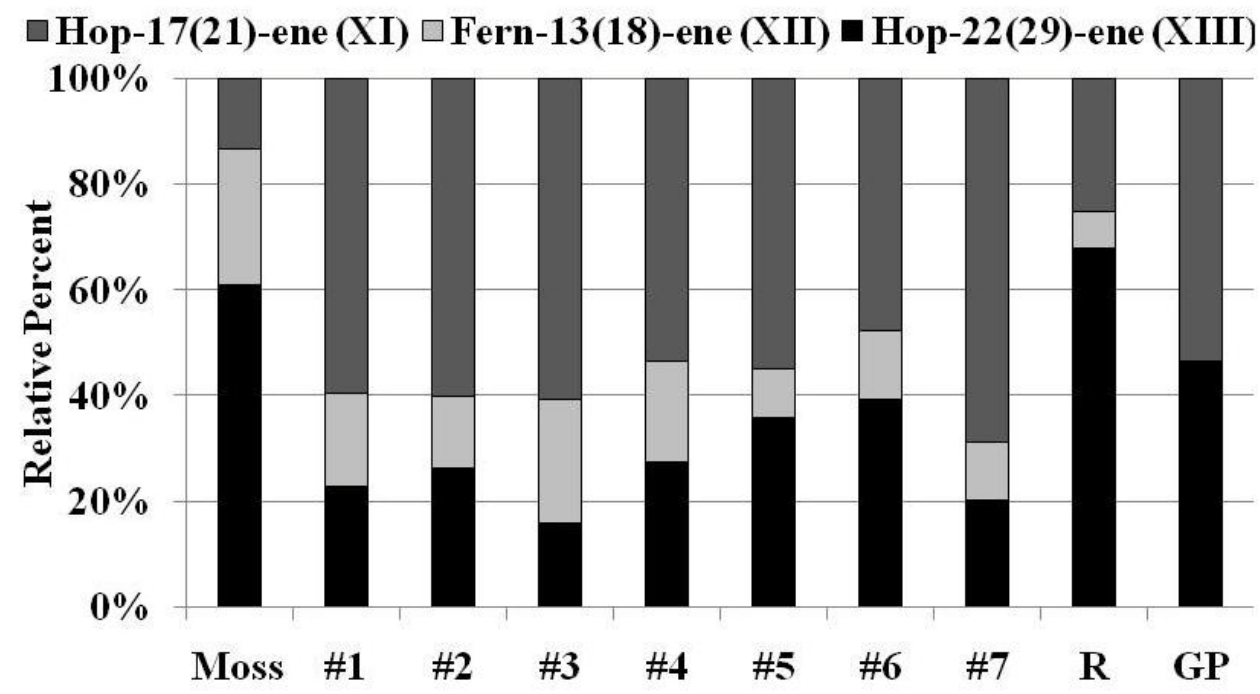

Figure 5.9. Total hopenes (a) and percent hopene (of the major compounds relative to total triterpenes; (b)) of the moss, sediment and soil $(\mathrm{R}=$ riparian, GP = grass prairie) samples. The numbers in parentheses correspond to the molecular structure in Appendix 5.2 .

\subsection{2.g. n-Alkan-2-ones:}

Linear $n$-alkan-2-ones are common compounds found in many aquatic environments including lacustrine (Cranwell, 1981; Yanes et al., 2006), marine (Smith et al., 1983) and estuarine sediments (Hernandez et al., 2001) as well as crop field soils (Rogge et al., 2007). Homologous series with a strong odd/even carbon number 
predominance have been reported in higher plant biomass, suggesting direct biological inputs to sediments (Rieley et al., 1991; Hernandez et al., 2001). The $n$-alkan-2-one distributions for all the samples analyzed in this study are summarized in Tables A5.5A5.8 included in Appendix 5.1.

The riparian tree leaves (Figure 5.10.a) contained aliphatic ketones that ranged between $\mathrm{C}_{14}$ to $\mathrm{C}_{36}$ with an odd/even carbon number predominance and concentrations ranging from $1.8 \times 10^{-3} \mathrm{mg} \mathrm{g}^{-1} \mathrm{OC}$ to $5.8 \times 10^{-3} \mathrm{mg} \mathrm{g}^{-1} \mathrm{OC}$. The $\mathrm{C}_{\max }$ was found to be $\mathrm{C}_{29}$ for Bur Oak, Hackberry and Chinkapin Oak leaves, and $\mathrm{C}_{33}$ for Wild Plum, Black Walnut and Roughleaf Dogwood leaves. The grasses (Figure 5.10.b) also contained $n$-alkan-2ones ranging between $\mathrm{C}_{13}$ to $\mathrm{C}_{35}$ with an odd/even carbon number predominance. The Johnson grass contained the highest amounts of these compounds $\left(4.6 \times 10^{-2} \mathrm{mg} \mathrm{g}^{-1} \mathrm{OC}\right)$, followed by the Big Bluestem grass $\left(1.3 \times 10^{-2} \mathrm{mg} \mathrm{g}^{-1} \mathrm{OC}\right)$ and the Eastern Gamma grass (6.7 x $\left.10^{-3} \mathrm{mg} \mathrm{g}^{-1} \mathrm{OC}\right)$. The $\mathrm{C}_{\max }$ was found to be $\mathrm{C}_{31}$ for all the grasses, except the Big Bluestem grass which had a $\mathrm{C}_{\max }$ of $\mathrm{C}_{29}$. Interestingly, the abundance of the $\mathrm{C}_{21}$ and $\mathrm{C}_{25}$ homologues in the Big Bluestem was also quite high. The moss and the algae samples did not contain any $n$-alkan-2-ones, although they have been reported to occur in microalgae and phytoplankton of different environments (Qu et al., 1999; Bai et al., 2006).

The sediment samples showed a homologous series that ranged between $\mathrm{C}_{12}$ to $\mathrm{C}_{36}$ with an odd/even carbon number predominance (Figure 5.10.c). The $\mathrm{C}_{\max }$ was either $\mathrm{C}_{31}$ or $\mathrm{C}_{33}$ for all sites, except sites \#6 and \#7, which had a $\mathrm{C}_{\max }$ at $\mathrm{C}_{29}$ and $\mathrm{C}_{25}$, respectively. The grass prairie soil contained higher amounts of $n$-alkan-2-ones $\left(3.1 \times 10^{-}\right.$ $\left.{ }^{2} \mathrm{mg} \mathrm{g}^{-1} \mathrm{OC}\right)$ compared to the riparian soil $\left(5.9 \times 10^{-3} \mathrm{mg} \mathrm{g}^{-1} \mathrm{OC}\right)$. The distribution of these aliphatic ketones in the soil samples ranged from $\mathrm{C}_{23}$ to $\mathrm{C}_{33}$ with maximum homologues 
at $\mathrm{C}_{33}$ for the grass prairie soil and $\mathrm{C}_{31}$ for the riparian soil. Site $\# 6$ seems to receive significant OM inputs from the surrounding grasses, especially the Big Bluestem grass. While a $\mathrm{C}_{\max }$ at $\mathrm{C}_{25}$ has been reported as an input from seagrass-derived $\mathrm{OM}$ in sediments of a subtropical estuary (Hernandez et al., 2001) the enrichment in the lower C number homologues at site \#7 is difficult to explain. The sediments from the lower reaches of the watershed contained higher amounts of $n$-alkan-2-ones (up to $0.2 \mathrm{mg} \mathrm{g}^{-1} \mathrm{OC}$ ) suggesting preferential accumulation of this material at these sites. Methyl ketones found in recent sediments have been thought to derive from microbial degradation (Azevedo et al., 2001) or from rapid thermal maturation and $\beta$-oxidation of the corresponding $n$-alkanes (de Leeuw, 1986). However, precursor-product relationships ( $n$-alkanes vs. $n$-alkan-2-ones) were not close enough in this study and direct biological inputs are suggested as the main sources of $n$-alkan-2-ones in the stream sediments.

In addition to the linear $n$-alkan-2-ones, an acyclic ketone, namely 6,10,14trimethylpentadecan-2-one (phytone), was observed in most samples, with highest concentrations in the algae (Tables A5.9-A5.13 in Appendix 5.1). Phytone is believed to be an oxidation product derived from the microbial alteration of phytol (Ikan et al., 1973, Brooks and Maxwell 1974) and has been detected in different sedimentary environments including small streams of the northwestern United States (Medeiros et al., 2008). The algae samples contained two orders of magnitude more phytone than the rest of the vegetation samples and can be considered significant sources of this isoprenoid compound to sediments (Rontani et al., 2003). 

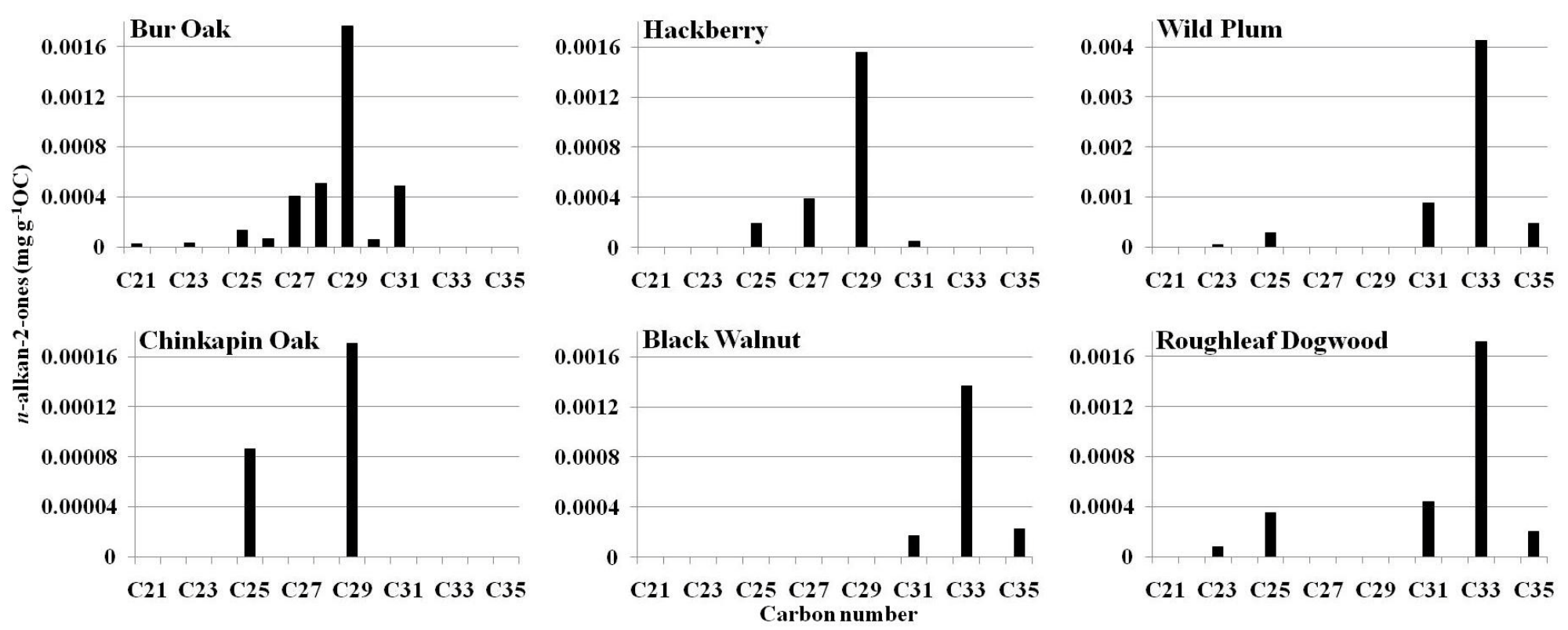

Figure 5.10.a. The $n$-alkan-2-one distribution of the riparian vegetation. The abundance of $n$-alkan-2-ones in the Wild Plum and Chinkapin Oak leaves is shown on different scales. 


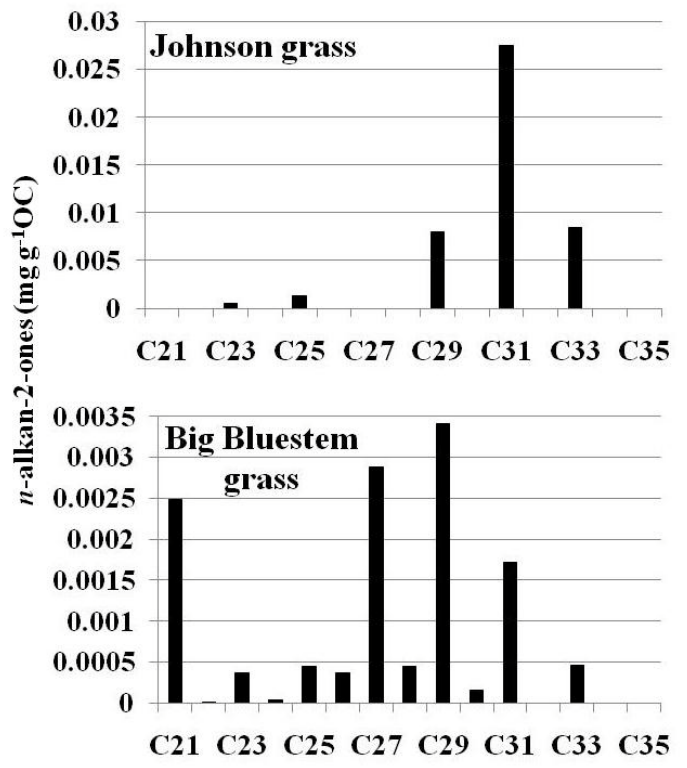

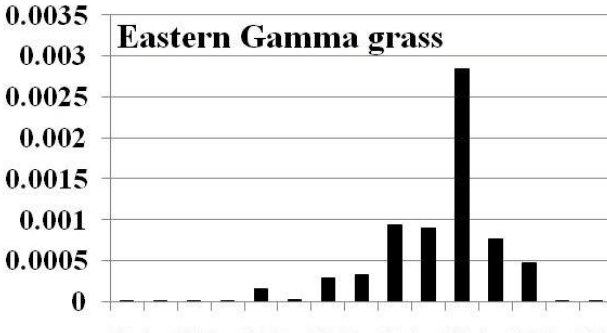

$\begin{array}{llllllll}\mathrm{C} 21 & \mathrm{C} 23 & \mathrm{C} 25 & \mathrm{C} 27 & \mathrm{C} 29 & \mathrm{C} 31 & \mathrm{C} 33 & \mathrm{C} 35\end{array}$

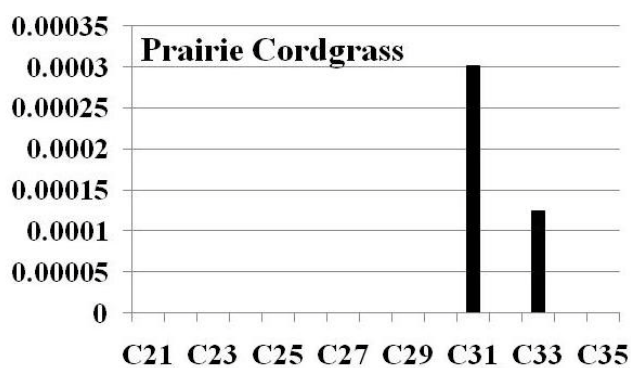

C21 C23 C25 C27 C29 C31 C33 C35

Carbon number

Figure 5.10.b. The $n$-alkan-2-one distribution of the grass samples. The abundance in the Eastern Gamma grass and the Big Bluestem grass is shown on different scales. 

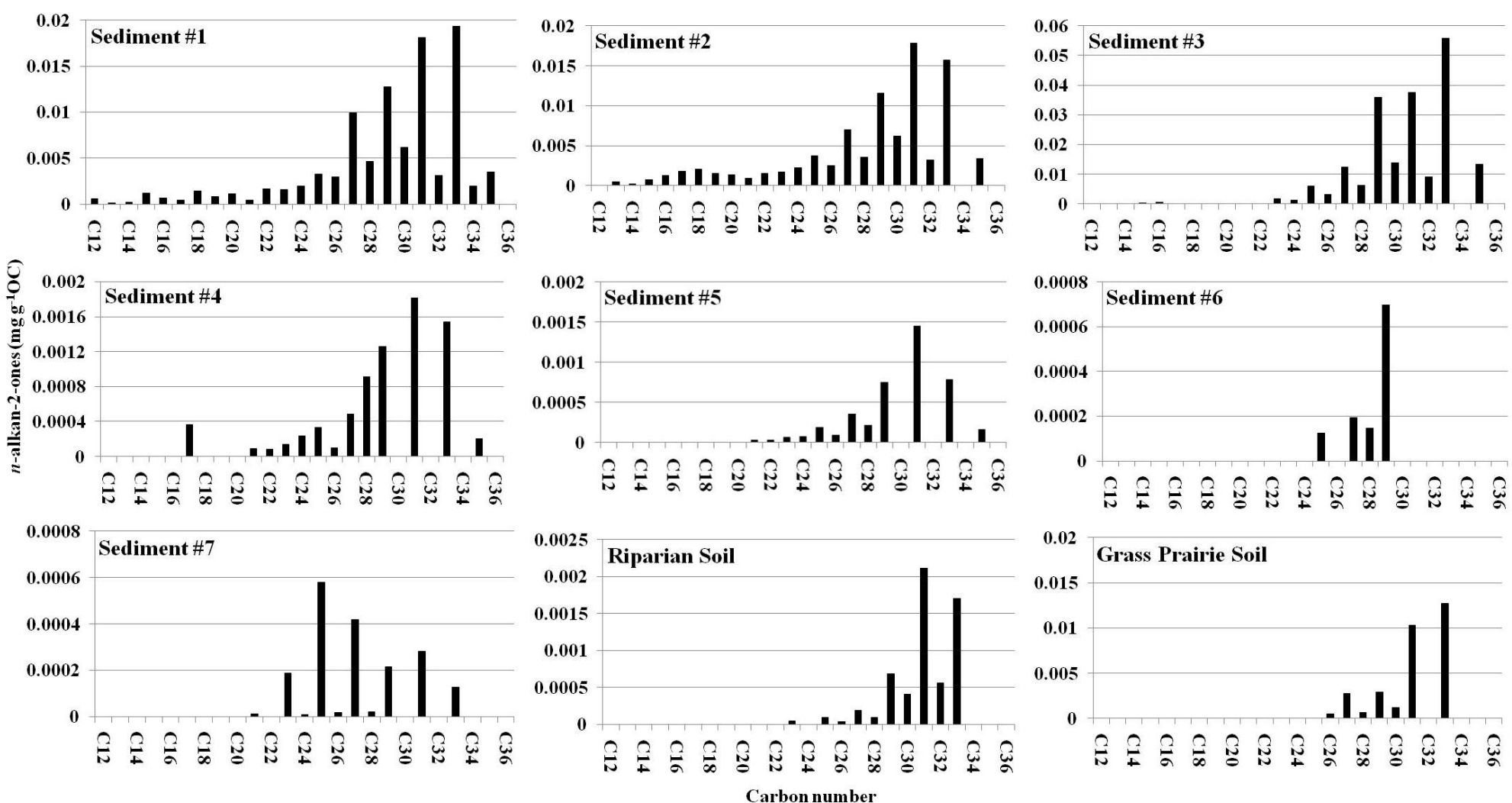

Figure 5.10.c. The $n$-alkan-2-one distribution of the sediment and soil samples from the King's Creek watershed. The abundance of $n$-alkan-2-ones in sites \#3-7 and the riparian soil is shown on different scales. 
The concentrations of phytone increased from the sediments of the upper reaches (1.3 $\times 10^{-3}$ and $4.4 \times 10^{-4} \mathrm{mg} \mathrm{g}^{-1} \mathrm{OC}$ for sites \#4 and \#5, respectively) to those of the lower reaches $\left(9.3 \times 10^{-3}, 8.8 \times 10^{-3}\right.$ and $1.1 \times 10^{-2} \mathrm{mg} \mathrm{g}^{-1} \mathrm{OC}$ for sites \#1, \#2 and \#3, respectively) of the watershed. Site \#3 contained the largest amount of this compound, suggesting the accumulation of degraded $\mathrm{OM}$ at this site as well as autochthonous inputs to the sediments. The sediments at sites \#6 and \#7 did not contain phytone, which could have been transported further upstream during a flash flood event. The grass prairie soil contained more phytone $\left(4.3 \times 10^{-3} \mathrm{mg} \mathrm{g}^{-1} \mathrm{OC}\right)$ compared to the riparian soil $\left(1.6 \times 10^{-3}\right.$ $\mathrm{mg} \mathrm{g}^{-1} \mathrm{OC}$ ). In agreement with data presented above on $\mathrm{C}_{25}$ HBI's and phytadienes, it seems that the lower reaches of the system preferentially accumulate soil and algal OM inputs.

\subsection{2.h. n-Alkanals:}

Homologous series of $n$-alkanals have been reported in lacustrine (Albaigés et al., 1984), coastal (Prahl et al., 1987) and marine sediments (Gogou et al., 2004). The high molecular weight homologues are considered to derive mainly from the epicuticular waxes of higher plants (Eglinton et al., 1967) while the shorter chain homologues are believed to have a planktonic or bacterial source (Gogou et al., 2004). The $n$-alkanal distribution the King's Creek samples are summarized in Tables A5.5-A5.8 in Appendix 5.1 .

Although $n$-alkanals have been considered limited in their usefulness as biomarkers of plant inputs (Jansen et al., 2006), relatively high concentrations of these compounds were found in the riparian tree leaves, especially the Bur Oak $\left(9.6 \times 10^{-2} \mathrm{mg}\right.$ 
$\left.\mathrm{g}^{-1} \mathrm{OC}\right)$, Cottonwood $\left(7.7 \times 10^{-2} \mathrm{mg} \mathrm{g}^{-1} \mathrm{OC}\right)$ and the Chinkapin Oak $\left(1.3 \times 10^{-1} \mathrm{mg} \mathrm{g}^{-1} \mathrm{OC}\right)$ leaves (Figure 5.11.a). These samples displayed a homologous series ranging from $\mathrm{C}_{22}$ to $\mathrm{C}_{32}$ with an even/odd carbon number predominance and a variable $\mathrm{C}_{\max }$ from $\mathrm{C}_{26}$ to $\mathrm{C}_{32}$. The grasses (Figure 5.11.b) also contained $n$-alkanals, with the Johnson and the Big Bluestem grasses producing the most $\left(3.2 \times 10^{-2}\right.$ and $2.8 \times 10^{-2} \mathrm{mg} \mathrm{g}^{-1} \mathrm{OC}$, respectively). The grasses also displayed an even/odd carbon number predominance with a $\mathrm{C}_{\max }$ at $\mathrm{C}_{30}$, except for the Big Bluestem grass which had a $\mathrm{C}_{\max }$ at $\mathrm{C}_{28}$. The moss did not contain any $n$-alkanals. Two of the algae samples contained only small amounts of short chain homologues ranging from $\mathrm{C}_{13}$ to $\mathrm{C}_{20}$ and maximizing at $\mathrm{C}_{15}$ and $\mathrm{C}_{20}$ (Figure 5.11.c). Low molecular weight $n$-alkanals have been used to determine sources of autochthonous inputs to sediments of southwestern Spain (Sánchez-García et al., 2008) and the Eastern Mediterranean Sea (Gogou et al., 2004).

Most of the King's Creek sediment samples showed a bimodal distribution of the $n$-alkanals ranging from $\mathrm{C}_{10}$ to $\mathrm{C}_{32}$, with an even/odd carbon number predominance and a $\mathrm{C}_{\max }$ at $\mathrm{C}_{16}$ and $\mathrm{C}_{30}$ (Figure 5.11.d). The riparian soil had a $\mathrm{C}_{\max }$ typical of higher plants, $\mathrm{C}_{30}$, while the grass prairie soil had a $\mathrm{C}_{\max }$ at $\mathrm{C}_{28}$, showing inputs from the grasses. The low molecular weight compounds are indicative of autochthonous OM inputs (although some riparian vegetation was observed to contain low molecular weight $n$-aldehydes) while the higher molecular weight homologues indicate inputs from leaf waxes of higher plants. Sites \#4, \#5 and \#6 had a $\mathrm{C}_{\max }$ at $\mathrm{C}_{28}$, suggesting more inputs from the Big Bluestem grass. As in the case of the $n$-alkan-2-ones, sites \#1 and \#2 showed a more complex distribution of $n$-aldehyde homologues ranging from $\mathrm{C}_{10}$ to $\mathrm{C}_{30}$. The low molecular weight $\left(<\mathrm{C}_{19}\right)$ vs. high molecular weight $\left(>\mathrm{C}_{20}\right) n$-aldehyde ratios were 
highest for sediments at sites \#1, 2, 3 and 4, but much lower for \#5, 6 and 7, suggesting higher autochthonous OM inputs at the former.

\subsection{2.i. n-Alkanols:}

A homologous series of straight chain $n$-alkanols characterized by a strong even/odd carbon number predominance was identified in most of the samples and their concentrations are summarized in Tables A5.5-A5.8 found in Appendix 5.1. The molecular distribution of $n$-alkanols found in this study has been reported as being characteristic of higher plant OM inputs to sediments (Meyers, 1997). The riparian tree leaves contained $n$-alkanols in the range from $\mathrm{C}_{16}$ to $\mathrm{C}_{36}$, with a strong even/odd carbon number predominance of the $\mathrm{C}_{24}$ to $\mathrm{C}_{30}$ homologues, and concentrations ranging from 7.1 $\times 10^{-2} \mathrm{mg} \mathrm{g}^{-1} \mathrm{OC}$ in the Cottonwood and $2.7 \times 10^{-1} \mathrm{mg} \mathrm{g}^{-1} \mathrm{OC}$ in the Black Walnut leaves (Figure 5.12.a). The $\mathrm{C}_{\max }$ was different for all the tree leaves and was found at $\mathrm{C}_{24}, \mathrm{C}_{26}$, $\mathrm{C}_{28}$ and $\mathrm{C}_{30}$. The grasses contained much lower concentrations of $n$-alkanols $\left(9.7 \times 10^{-3}\right.$ $\mathrm{mg} \mathrm{g}^{-1} \mathrm{OC}$ in Eastern Gamma grass and $3.6 \times 10^{-1} \mathrm{mg} \mathrm{g}^{-1} \mathrm{OC}$ in the Johnson grass) in the range from $\mathrm{C}_{16}$ to $\mathrm{C}_{32}$ with an even/odd carbon number predominance (Figure 5.12.b). The major homologue was found to be $\mathrm{C}_{30}$ for the Johnson and the prairie Cordgrass and $\mathrm{C}_{32}$ for the Gamma and Big Bluestem grass. The maximum homologue occurring at $\mathrm{C}_{32}$ has been reported as being typical of $\mathrm{C}_{4}$ grasses (Rommerskirchen et al., 2006). Only two of the algae samples contained $n$-alkanols with highest concentrations of $2.3 \times 10^{-1} \mathrm{mg} \mathrm{g}^{-}$ ${ }^{1} \mathrm{OC}$ and only even homologues from $\mathrm{C}_{24}$ to $\mathrm{C}_{32}$ and a $\mathrm{C}_{\max }$ at $\mathrm{C}_{30}$ (Figure 5.12.c). 

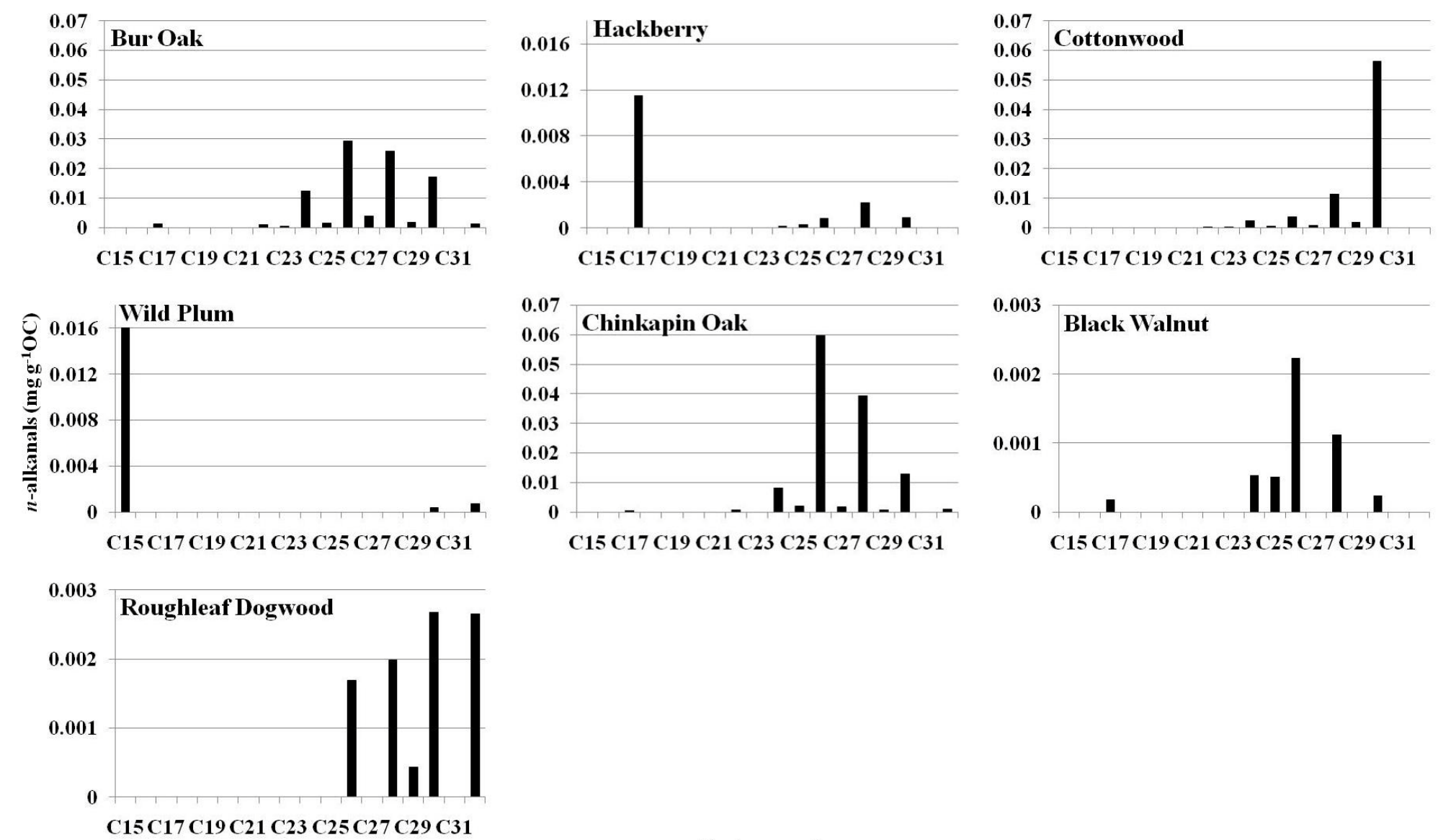

Carbon number

Figure 5.11.a. The $n$-alkanal distribution of the riparian vegetation samples. The abundance in the various vegetation samples is shown on different scales. 

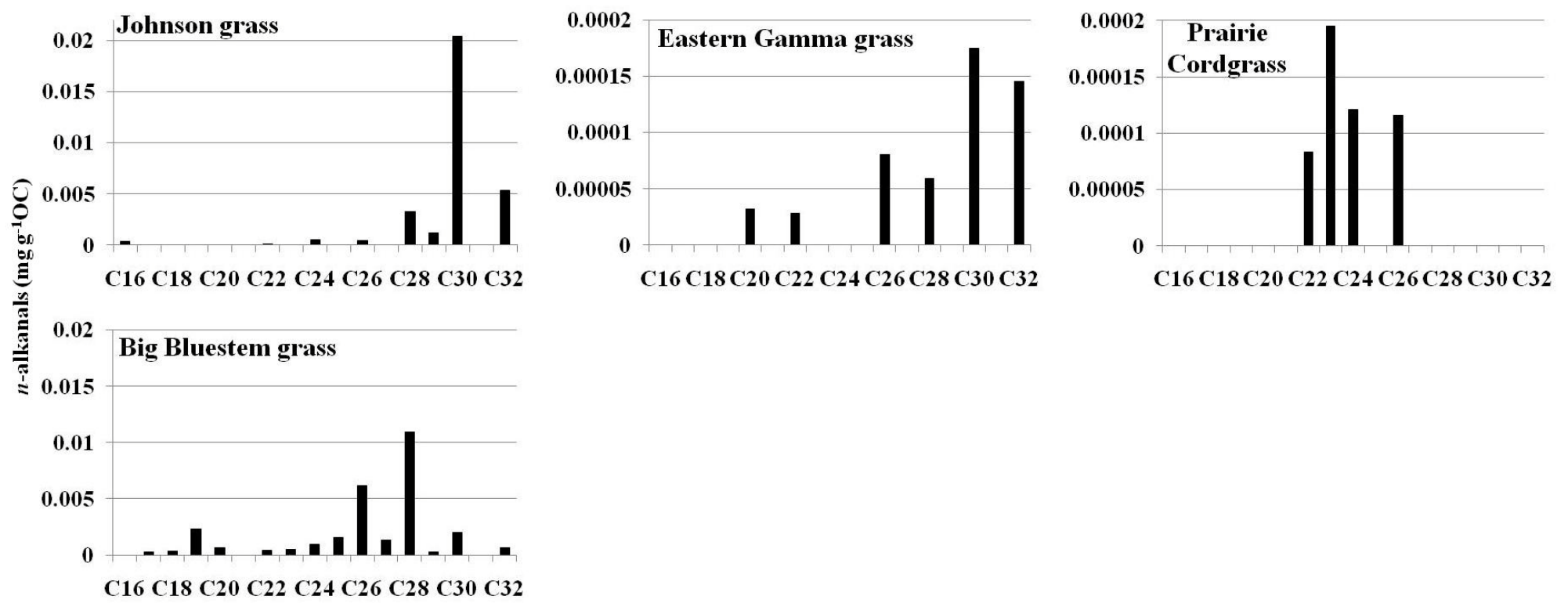

Figure 5.11.b. The $n$-alkanal distribution of the grass samples. The abundance in the Johnson grass and the Big Bluestem grass was two orders of magnitude more compared to the Prairie Cordgrass and Eastern Gamma grass, as shown by the different scales. 


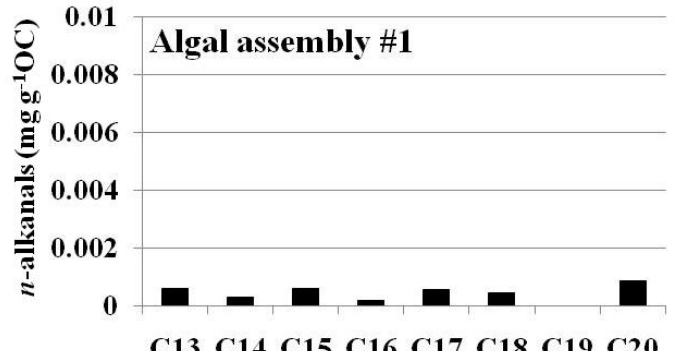

C13 C14 C15 C16 C17 C18 C19 C20

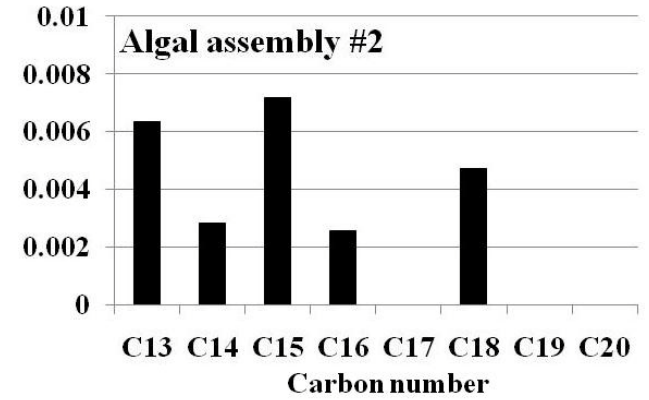

Carbon number

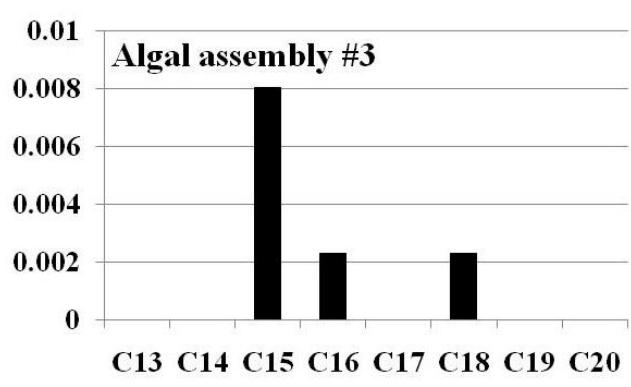

Figure 5.11.c. The $n$-alkanal distribution of the algae samples. 


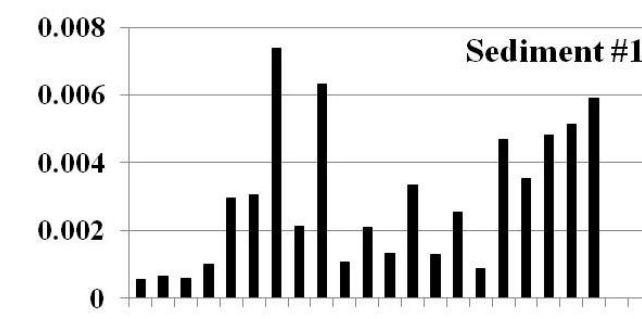

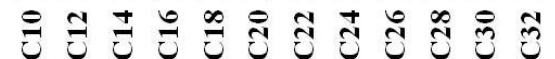
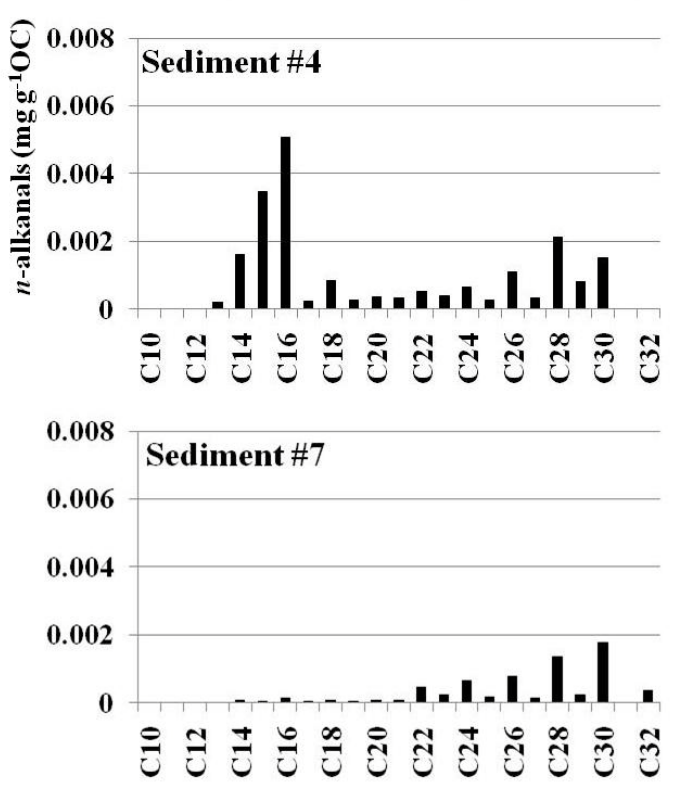

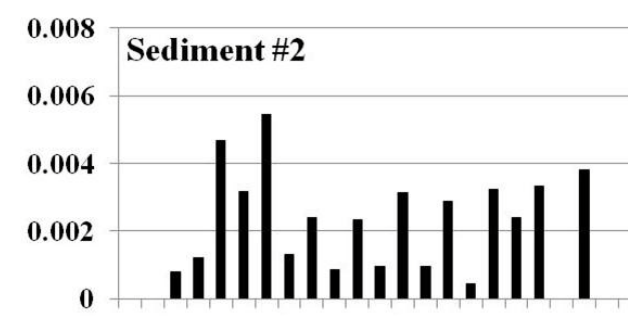

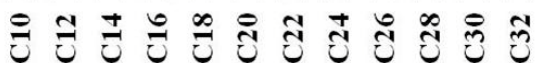
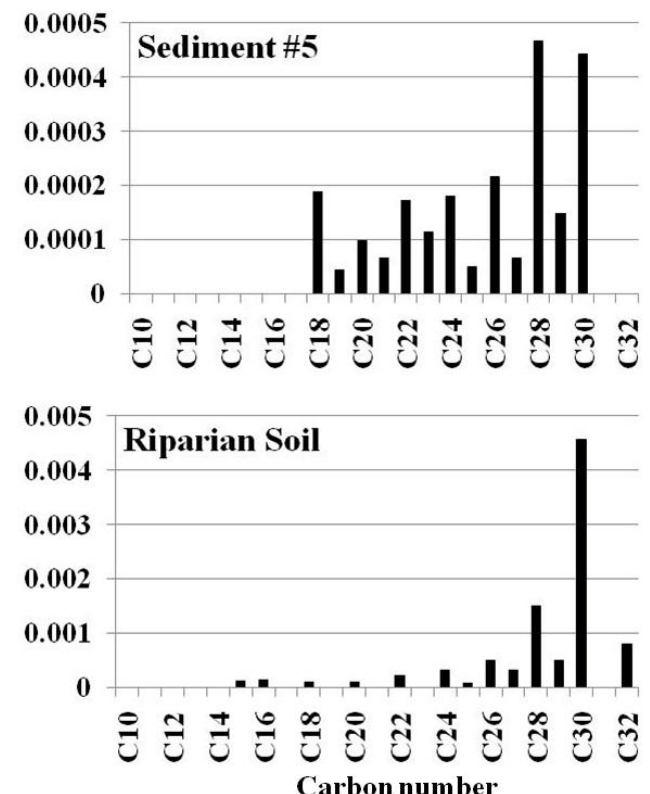
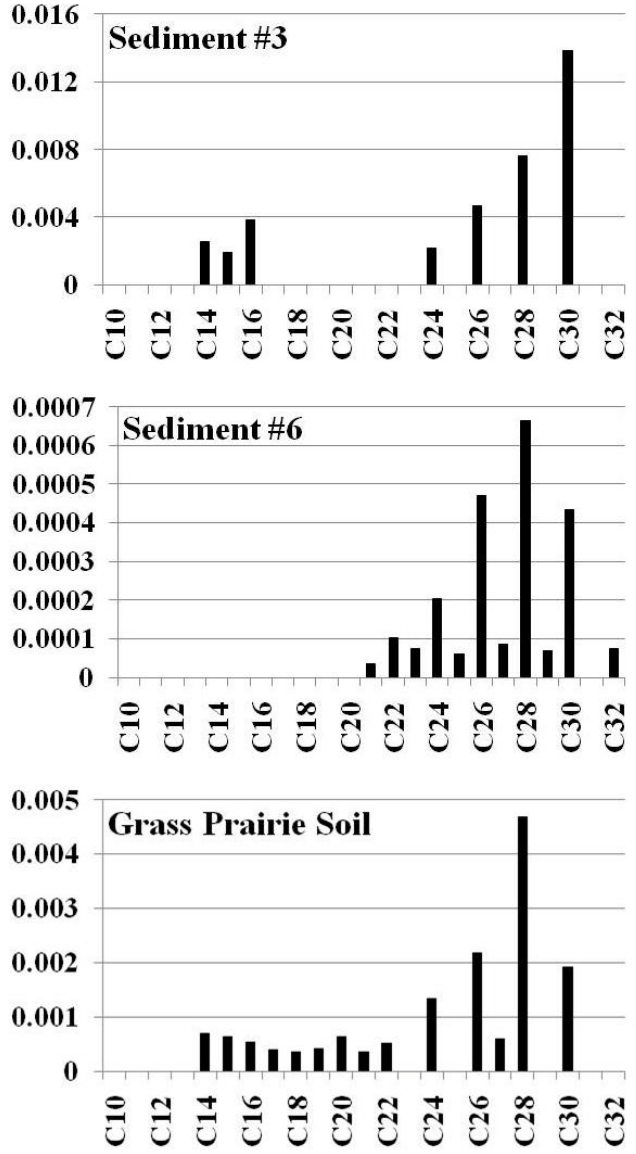

Figure 5.11.d. The $n$-alkanal distribution of the sediments and soils from the King's Creek watershed. The abundance of $n$ alkanals at sites \#3, \#5 and \#6 are shown on different scales. 
The other algal sample contained very small amounts of $n$-alkanols $\left(5.0 \times 10^{-3} \mathrm{mg} \mathrm{g}^{-}\right.$ ${ }^{1} \mathrm{OC}$ ) with a $\mathrm{C}_{\max }$ at $\mathrm{C}_{30}$. The moss sample also contained very small amounts of $n$ alkanols with an even/odd carbon number predominance and $\mathrm{C}_{\max }$ at $\mathrm{C}_{30}$.

The sediment samples contained $n$-alkanols in the range from $\mathrm{C}_{14}$ to $\mathrm{C}_{34}$ with an even/odd carbon number predominance (Figure 5.12.d). Although low molecular weight $n$-alkanols have been attributed to algal or bacterial contributions (Rontani et al., 2005), these compounds were not detected in the algae samples from Konza Prairie. The distribution of $n$-alkanols was bimodal with a $\mathrm{C}_{\max }$ at $\mathrm{C}_{16}$ and one at $\mathrm{C}_{28}$ or $\mathrm{C}_{32}$. Short chain $n$-alkanols were found at sites $\# 1, \# 2, \# 3, \# 5$ and $\# 7$. The riparian soil contained $n$ alkanols in the range from $\mathrm{C}_{18}$ to $\mathrm{C}_{34}$ with an even/odd carbon number predominance and a maximum homologue at $\mathrm{C}_{30}$. In the grass prairie soil, they ranged from $\mathrm{C}_{16}$ to $\mathrm{C}_{34}$ and maximized at $\mathrm{C}_{32}$. The general distribution of the $n$-alkanols suggests ample higher plant OM inputs at all sites. Clear characterization of source differences based on the $n$-alkanol distributions was not possible, although the sediment at site \#5 was most similar to the prairie soil and the relative abundance of low molecular weight $n$-alkanols was highest at stations \#1, 2 and 7. While enrichment in autochthonous OM sources at sites \#1 and 2 has been suggested based on other biomarker distributions (see above) the enrichment in low molecular weight $n$-alkanols at site \#7 has to be derived from grasses. 

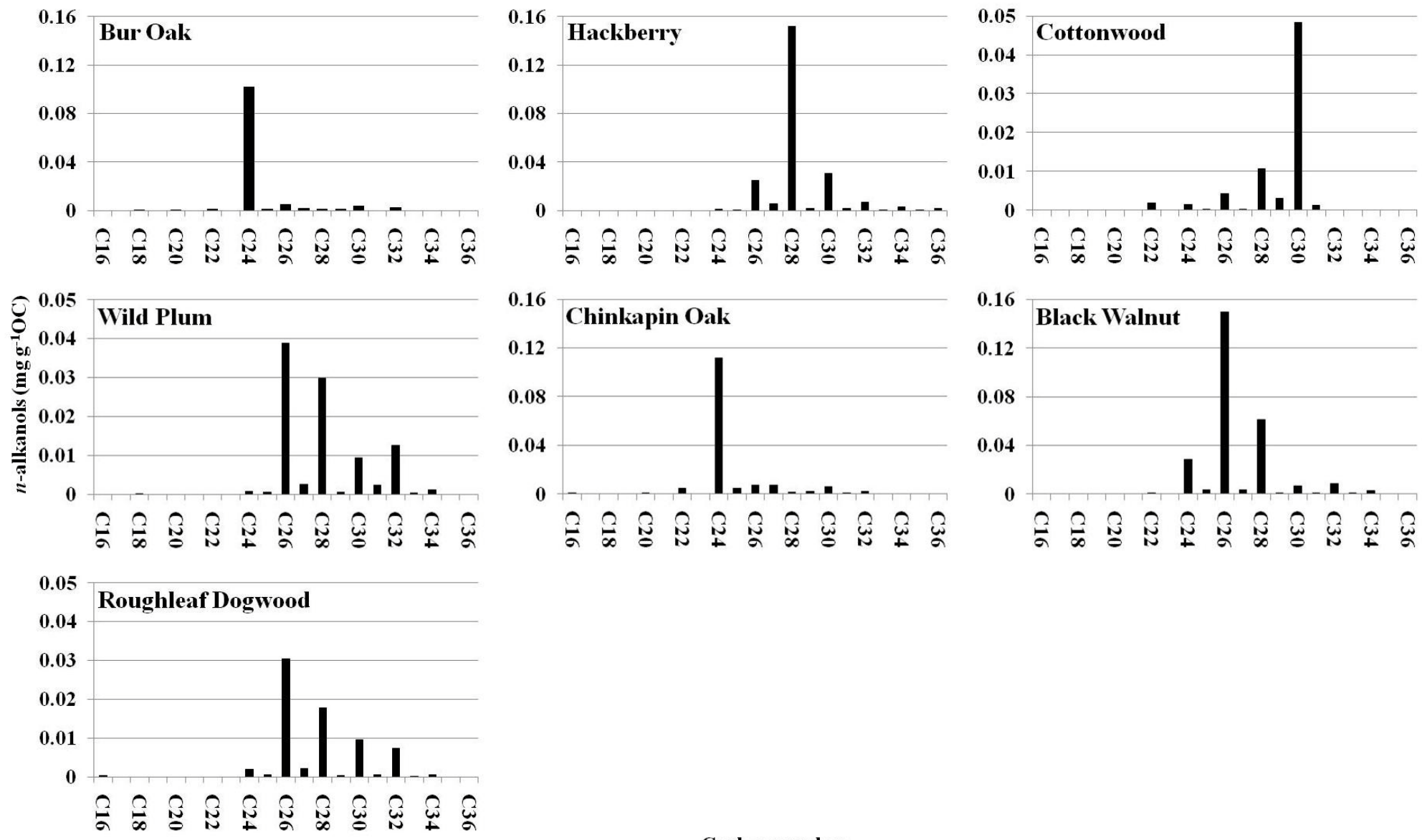

Carbon number

Figure 5.12.a. The $n$-alkanol distribution of the riparian vegetation samples. The abundance of $n$-alkanols in the Cottonwood, Wild Plum and Roughleaf Dogwood leaves is shown on the same scale. 

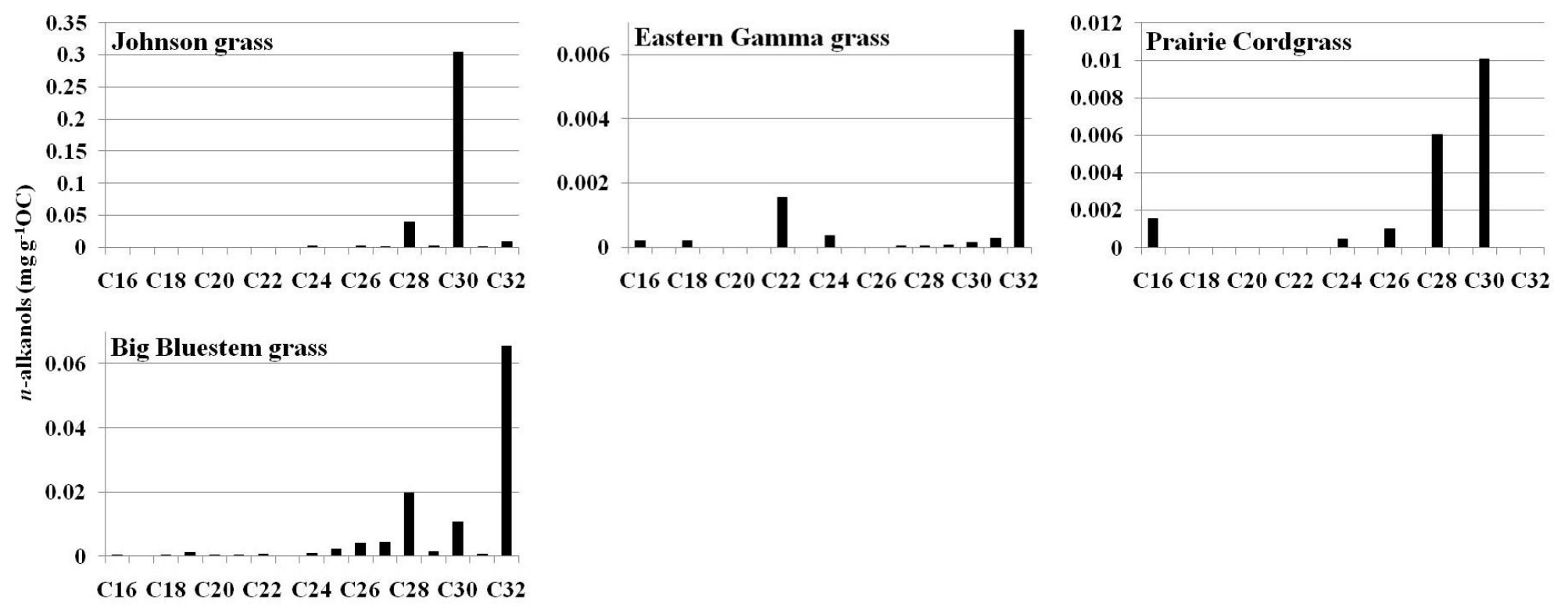

Carbon number

Figure 5.12.b. The $n$-alkanol distribution of the grass samples. 

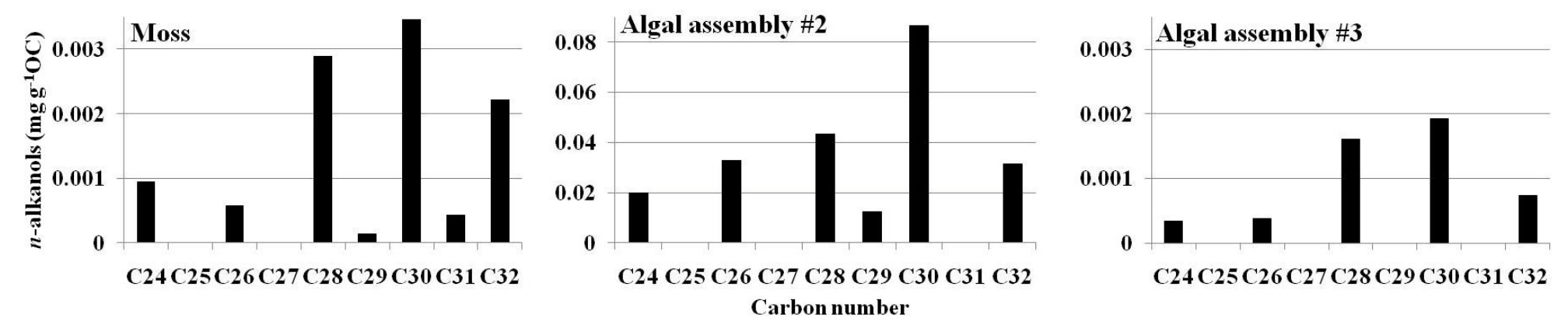

Figure 5.12.c. The $n$-alkanol distribution of the moss and algae samples. Algal Assembly \#1 did not contain any $n$-alkanols. The abundance of $n$-alkanols in Assembly \#2 is shown on a different scale. 

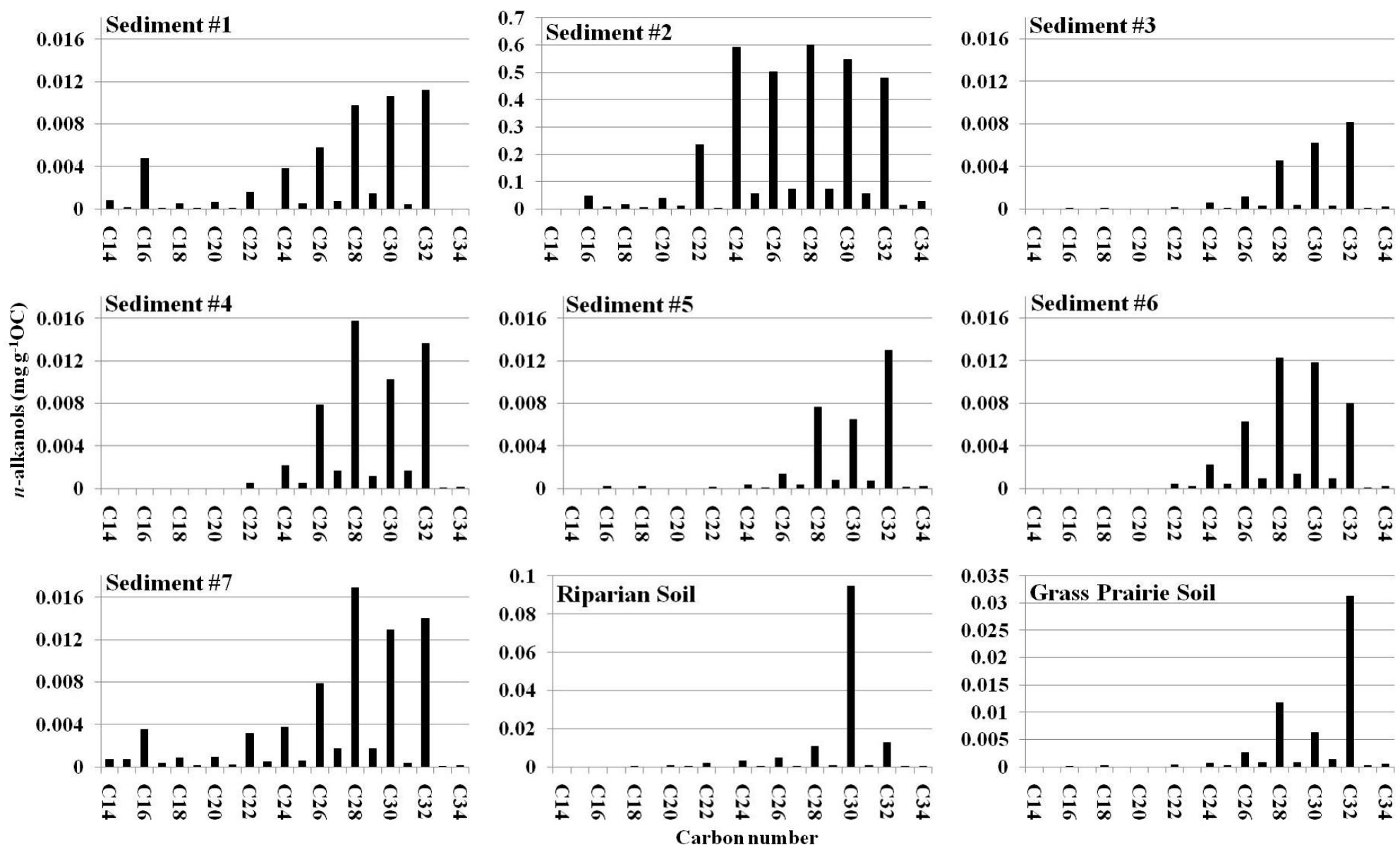

Figure 5.12.d. The $n$-alkanol distribution of the sediment and soil samples from the King's Creek watershed. The abundance at site \#2 was an order of magnitude more compared to the rest of the sediment samples. The abundance of $n$-alkanols in the two soil samples is shown on different scales. 
Phytol, the esterified alcohol side chain in chlorophyll was detected in all the samples (Table A5.9-A5.13 in Appendix 5.1). Phytol can arise from the hydrolysis of bacteriochlorophyll- $a$, but is commonly assigned a planktonic source (Rontani et al., 2005). The highest amount of phytol was found in an algal sample (7.1 $\left.\times 10^{-1} \mathrm{mg} \mathrm{g}^{-1} \mathrm{OC}\right)$ followed by the Eastern Gamma grass $\left(2.3 \times 10^{-1} \mathrm{mg} \mathrm{g}^{-1} \mathrm{OC}\right)$ and the moss sample $(1.6 \mathrm{x}$ $\left.10^{-1} \mathrm{mg} \mathrm{g}^{-1} \mathrm{OC}\right)$. The riparian tree leaves also contained phytol at concentrations ranging from $4.8 \times 10^{-3}$ to $6.6 \times 10^{-2} \mathrm{mg} \mathrm{g}^{-1} \mathrm{OC}$. All the sediment samples contained phytol except for site $\# 2$ and \#3. Highest amounts were found at sites \#4 and \#5 (3.4 x 10 $\left.0^{-3} \mathrm{mg} \mathrm{g}^{-1} \mathrm{OC}\right)$. The presence of this compound in the stream sediments may be interpreted as an input of algal, grass or higher plant origin and is therefore not source specific. Its absence at sites $\# 1$ and \#2 is interesting, but could be related to presumably lower microbial activity at these sites.

\subsection{2.j. Triterpenoids:}

The pentacyclic triterpenoids identified in this study consisted primarily of 3-oxytriterpenols and -triterpenones. Their concentrations are summarized in Tables A5.9A5.13 of Appendix 5.1 as well as in Figure 5.13.a. The chemical structures of selected triterpenoids are illustrated in Appendix 5.2. Many 3-oxy-triterpenoids (oleanane, ursane, fernane, taraxerane, lupane, friedelane, serratane or bauerane skeleton), occur as functionalized precursors (alcohols, acids, ketones, esters) and are characteristic biomarkers originating from higher plants (Simoneit, 1986; Ten Haven et al., 1992; Medeiros et al., 2007). These compounds are known constituents of the cell membrane walls and components of leaf epicuticular waxes (Eglinton et al., 1967). 
The riparian tree leaves contained relatively high concentrations of 3-oxytriterpenoids ( 10 to $76 \%$ of the total extracted lipids) followed by the grasses ( 0.05 to 5 $\%$ ), the algae (5 to $10 \%$ ) and the moss (0.5\%). Although these compound classes have generally been attributed to higher plant matter, small amounts of $\alpha$ - and $\beta$-amyrin (functionalized ursane and oleanane compounds) have also been detected in cyanobacterial mats (Rontani and Volkman, 2005).

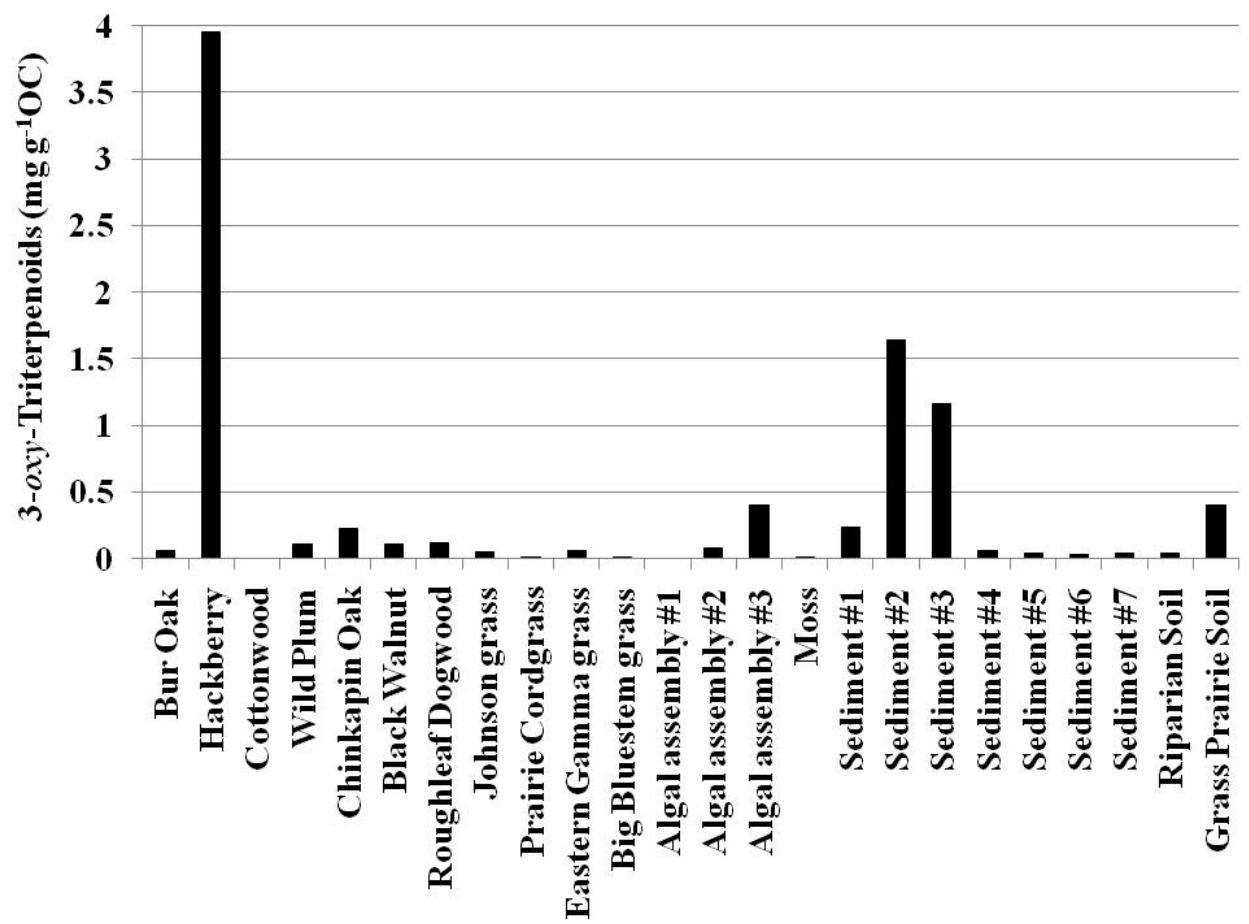

Figure 5.13. Total concentration of 3-oxy-triterpenoids (as the sum of triterpenols and triterpenones) for all the samples analyzed in this study.

Alpha- and $\beta$-amyrin were the major triterpenols present in the tree leaves along with lupeol. Except for the Prairie Cordgrass, the grasses also contained these compounds, although at much smaller concentrations. The moss sample contained small amounts of $\beta$-amyrin, and this can be attributed to plant debris that can get trapped in the moss structure. While the algae sample \#1 did not contain any triterpenols, assembly \#3 
contained significant amounts of these compounds, especially lupeol. Algae are known not to produce such compounds although they have recently been reported in bacterial mats (Rontani and Volkman, 2005). Furthermore, higher plant leaf litter detritus can get trapped in the filamentous algal mat which may be contributing to this signal.

The 3-oxy-triterpenols were found in all the sediments with sites \#2 (1.3 $\mathrm{mg} \mathrm{g}^{-}$ $\left.{ }^{1} \mathrm{OC}\right)$ and $\# 1\left(6.7 \times 10^{-2} \mathrm{mg} \mathrm{g}^{-1} \mathrm{OC}\right)$ containing the highest concentrations (Figure 5.14). Lowest amounts of these higher plant markers were found at site $\# 3\left(2.4 \times 10^{-3} \mathrm{mg} \mathrm{g}^{-}\right.$ $\left.{ }^{1} \mathrm{OC}\right)$. Generally, the sediments of the upper reaches contained less triterpenols than the sediments of the lower reaches. The riparian vegetation of the lower reaches of this watershed is composed mainly of higher plants, such as Bur Oak and Hackberry. On the other hand, the riparian vegetation of the upper reaches is also composed of higher plants, but is less wide and thus with lower standing biomass. The smaller amounts of 3-oxytriterpenols found in the upper reaches may be indicative of increased grass inputs or large detrital OM removal during flash flood periods. In agreement with the triterpene data, the upper reaches of King's Creek seem to accumulate less fresh higher plantderived OM which might be associated with larger, coarse particles and easily transported to the lower reaches during flash floods. The more degraded material, associated with fine sediments, may have a chance to accumulate due to entrapment in the stream channel bed materials.

The soils were very different in their total triterpenol distributions. Strangely, the grass prairie soil contained much more of these plant-derived compounds $\left(2.3 \times 10^{-2} \mathrm{mg}\right.$ $\left.\mathrm{g}^{-1} \mathrm{OC}\right)$ compared to the riparian soil $\left(4.4 \times 10^{-3} \mathrm{mg} \mathrm{g}^{-1} \mathrm{OC}\right)$. 


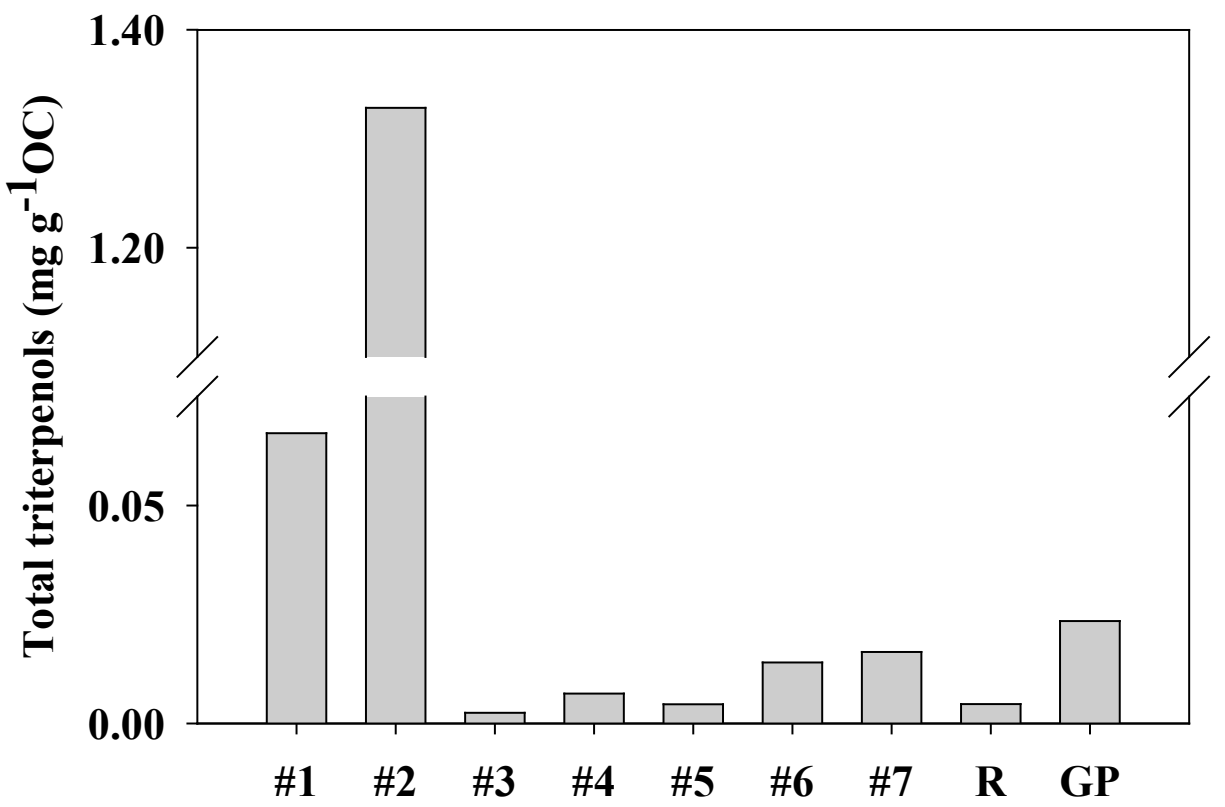

Figure 5.14. Total triterpenols in sediments $(\# 1$ - \#7) and soils $(\mathrm{R}=$ riparian, $\mathrm{GP}=$ grass prairie) of the King's Creek watershed.

The main triterpenols identified in the sediment and soil samples were taraxerol, $\alpha$ - and $\beta$-amyrin, and $3 \alpha$-lupeol (Figure 5.15). While the lower reaches contained relatively more $3 \alpha$-lupeol and taraxerol (also more abundant in the riparian vegetation), the sediments of the upper reaches were more enriched in $\alpha$ - and $\beta$-amyrin (more abundant in the grasses). In agreement with data described previously, the upper reaches of the watershed seem to receive significant OM inputs from the local grasses. This difference in OM inputs seems to be reflected in the two soil samples as well. While the riparian soil only contained taraxerol and $3 \alpha$-lupeol, the grass prairie soil also contained the two amyrin compounds. 


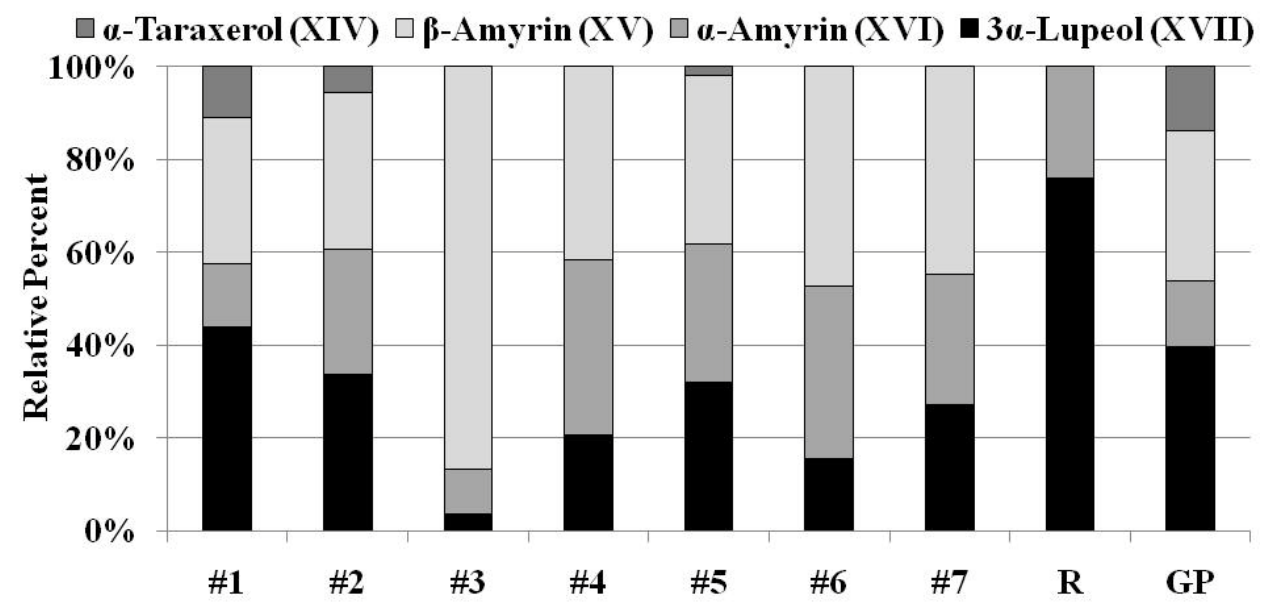

Figure 5.15. Percent triterpenols (of the major compounds relative to total triterpenols) of the sediment and soil $(\mathrm{R}=$ riparian, $\mathrm{GP}=$ grass prairie) samples. The numbers in parentheses correspond to the molecular structures in Appendix 5.2.

The 3-oxy-triterpenones were not very abundant, and in some samples, they were not detected at all (Figure 5.16). In addition to direct biomass inputs, triterpenones are oxidation products of the corresponding triterpenoid precursors with alterations that occur during transport, diagenesis in sedimentary environments, or by thermal transformation processes (Medeiros et al., 2007). The most abundant triterpenones found were $\alpha$ - and $\beta$ amyrone and friedelin, followed by lupenone and germanicone (Figure 5.17). These compounds were most abundant in the Bur Oak, Hackberry, Wild Plum and Roughleaf Dogwood leaves, but they were also found in similar amounts in the Eastern Gamma grass. Small amounts of $\beta$-amyrone were also found in the Johnson grass and the moss sample. Algal assembly \#3 contained $\alpha$-amyrone and friedelin, while \#2 also contained small amounts of $\beta$-amyrone. Since algae are known not to produce these compounds, their presence in these samples may indicate detrital inputs from higher plants. In fact, algal assembly \#1 did not contain any triterpenones. 
All the sediment samples contained triterpenones with the lower stream reaches containing more $\left(8.3 \times 10^{-1} \mathrm{mg} \mathrm{g}^{-1} \mathrm{OC}\right.$ at site $\left.\# 3\right)$ than the upper stream reaches $\left(5.6 \times 10^{-3}\right.$ $\mathrm{mg} \mathrm{g}^{-1} \mathrm{OC}$ at site \#6) of the watershed (Figure 5.16). As in the case for the triterpenol data discussed above, the higher amounts of triterpenones found in the sediments of the lower reaches of the watershed suggest the input of fresh higher plant material at these sites and the presence of more degraded material in the sediments of the upper reaches.

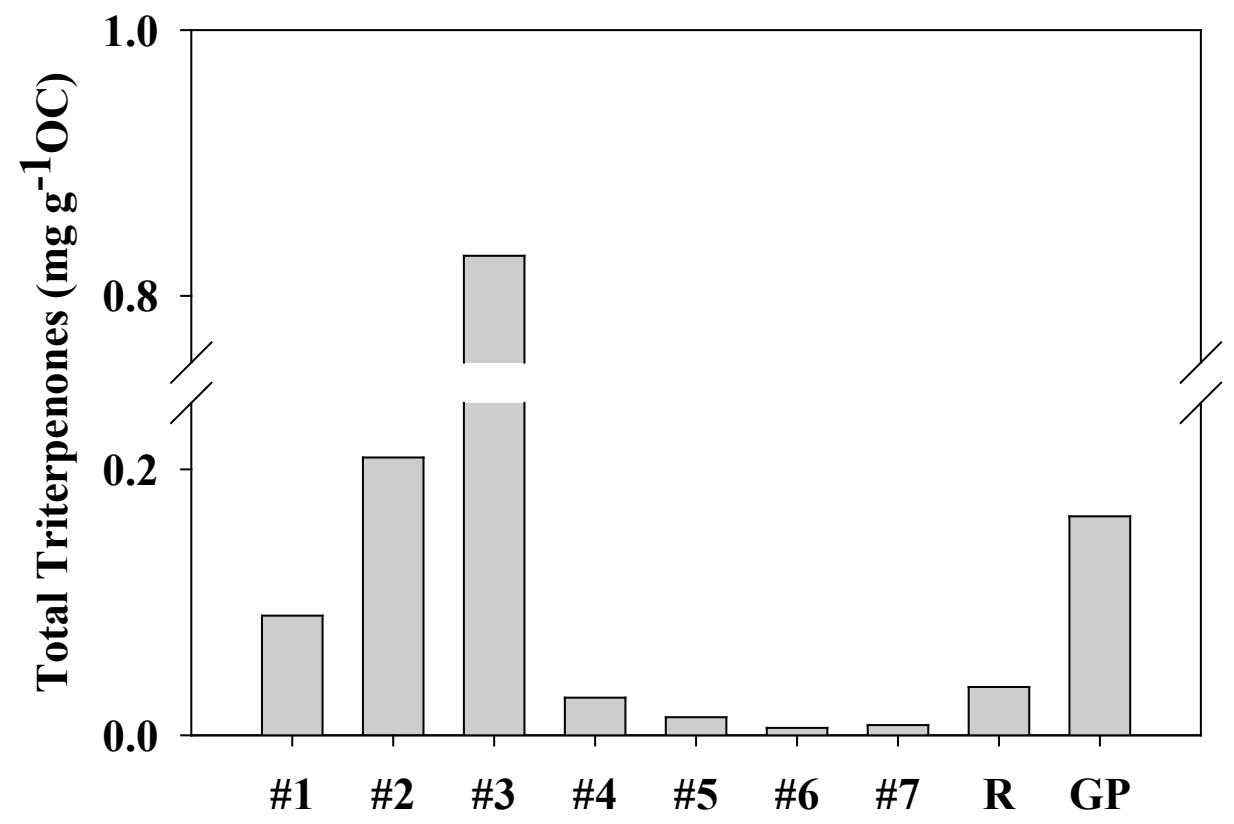

Figure 5.16. Total triterpenones in sediments $(\# 1$ - \#7) and soils $(\mathrm{R}=$ riparian, $\mathrm{GP}=$ grass prairie) of the King's Creek watershed.

The most abundant triterpenones identified in the sediment and soil samples from King's Creek are shown in Figure 5.17. While the upper stream reaches contained more germanicone and $\beta$-amyrone, the lower stream reaches were more enriched in friedelin. The riparian soil contained large amounts of $\alpha$-amyrone while the grass prairie soil was dominated by friedelin. All of these triterpenone markers are indicative of higher plant OM inputs to these sediments and soils. 


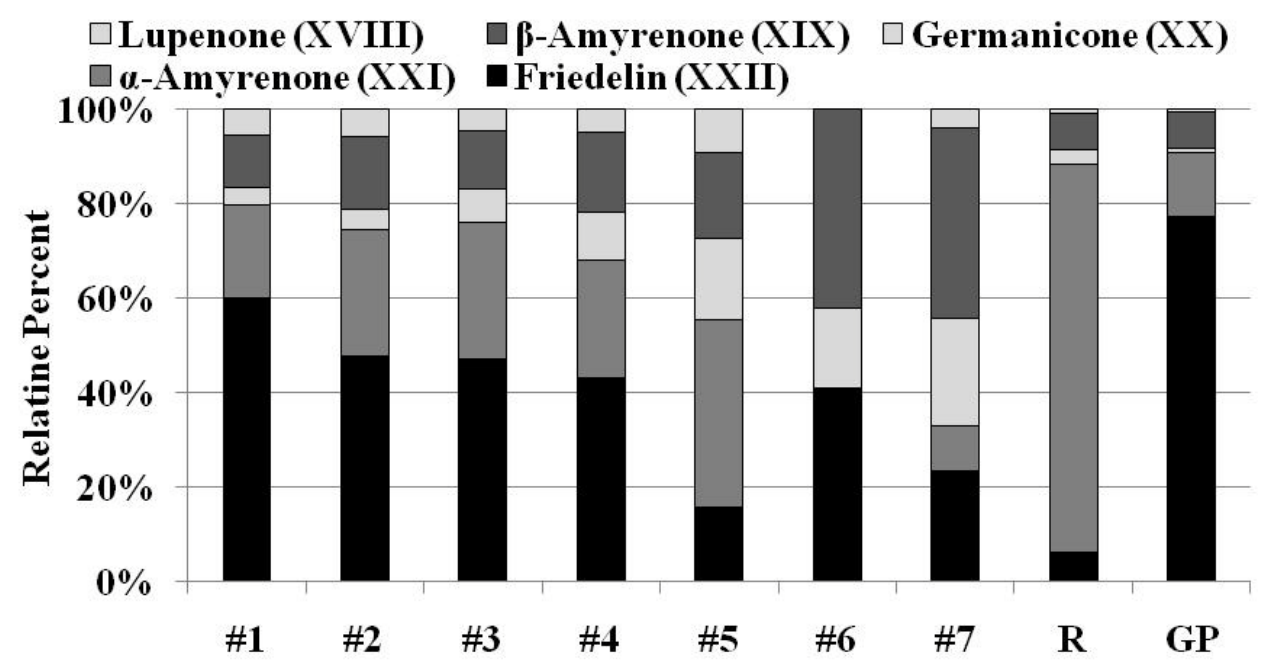

Figure 5.17. Percent triterpenones (of the major compounds relative to total triterpenones) of the sediment (\#1-\#7) and soil ( $\mathrm{R}=$ riparian, $\mathrm{GP}=$ grass prairie) samples from the King's Creek watershed. The numbers in parentheses correspond to the molecular structure in Appendix 5.2.

\subsection{2.k. Sterols:}

The sources of sterols in various sedimentary environments have been well documented (Volkman, 1986; Medeiros et al., 2007). Higher plants are known to produce phytosterols mainly with $\mathrm{C}_{29}$ and $\mathrm{C}_{28}$ skeletons, although many marine algae can also produce these sterols with the same or different alkyl substitutions on the side chain (Volkman, 1986). Some common higher plant sterols are $\beta$-sitosterol (24-ethylcholest-5en-3 $\beta$-ol; $\mathrm{C}_{29} \Delta^{5}$ ), stigmasterol (24-ethylcholesta-5,22-dien-3 $\beta$-ol; $\mathrm{C}_{29} \Delta^{5,22}$ ) and campesterol (24-methylcholest-5-en-3 $\beta$-ol; $\mathrm{C}_{28} \Delta^{5}$ ). The exact source of $\beta$-sitosterol has been debated since it has been found in sediments that only receive phytoplankton inputs indicating an algal source for this sterol (Volkman, 1986). Some common sterols used to determine microalgal inputs include brassicasterol (24-methylcholesta-5,22-dien-3 $\beta$-ol; $\left.\mathrm{C}_{28} \Delta^{5,22}\right)$, 24-methylenecholesterol (24-methylcholesta-5,24(28)-dien-3 $\beta$-ol; $\mathrm{C}_{28} \Delta^{5,24(28)}$ ) and cholesterol (cholest-5-en-3 $\beta$-ol; $\mathrm{C}_{27} \Delta^{5}$ ). However, because sterols are widely 
distributed, care must be exercised when using these compounds to infer sources (Volkman et al., 1998).

The total sterols observed in this study are summarized in Figure 5.18 and Tables A5.14-A5.18 (Appendix 5.1). Some selected structures are shown in Appendix 5.2.

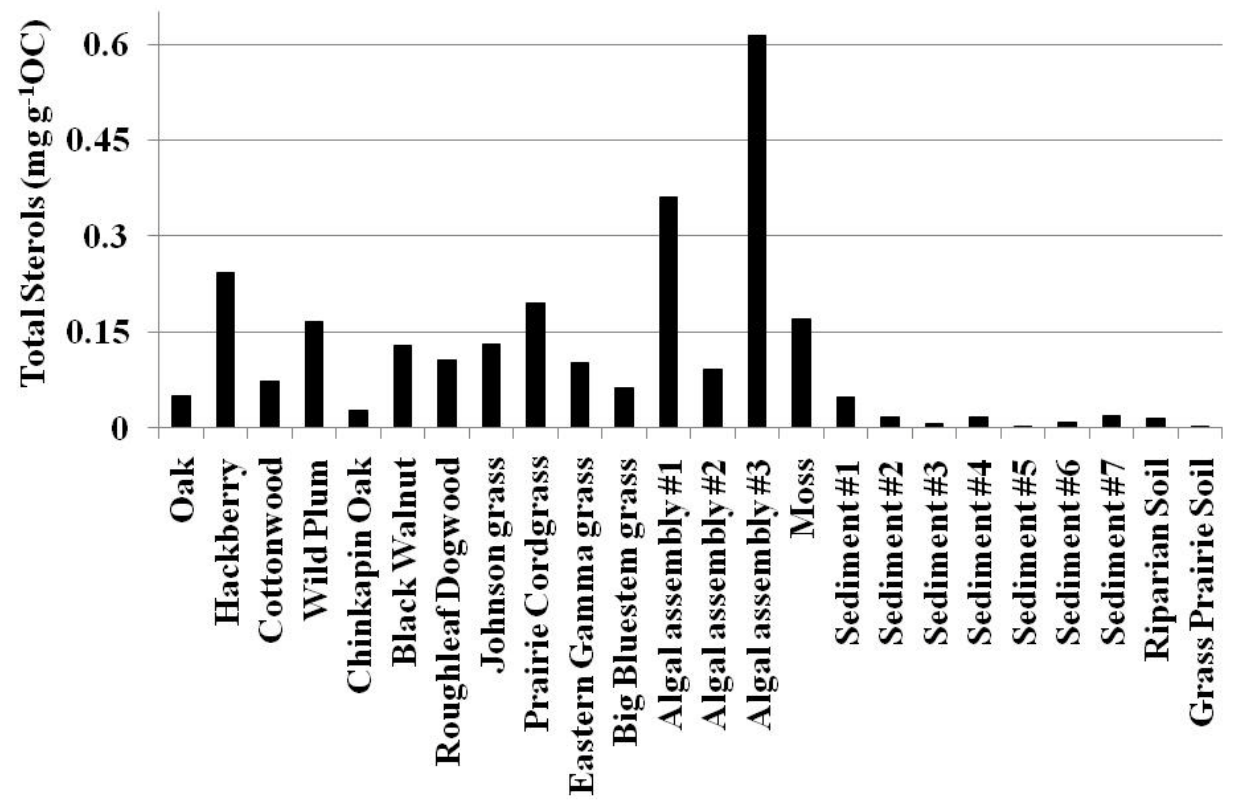

Figure 5.18. Total sterol distribution in all the samples from the King's Creek watershed.

The major sterols were composed of $\beta$-sitosterol, stigmasterol, campesterol, brassicasterol and cholesterol (Figure 5.19). The riparian tree leaves contained relatively high amounts of $\beta$-sitosterol, with the Wild Plum leaves containing the most $\left(1.6 \times 10^{-1}\right.$ $\left.\mathrm{mg} \mathrm{g}^{-1} \mathrm{OC}\right)$ and the Chinkapin Oak leaves containing the least $\left(2.8 \times 10^{-2} \mathrm{mg} \mathrm{g}^{-1} \mathrm{OC}\right)$. This sterol was also very abundant in the grasses $\left(1.6 \times 10^{-1} \mathrm{mg} \mathrm{g}^{-1} \mathrm{OC}\right.$ in Prairie Cordgrass $)$ and in the algae $\left(3.9 \times 10^{-1} \mathrm{mg} \mathrm{g}^{-1} \mathrm{OC}\right.$ in assembly \#3), showing that this sterol is widely distributed and should be used with caution to distinguish inputs from different sources. The sediment samples contained much smaller amounts of $\beta$-sitosterol with no obvious 
pattern from the upper to the lower reaches of the watershed. The highest concentrations were found at site $\# 1\left(1.2 \times 10^{-2} \mathrm{mg} \mathrm{g}^{-1} \mathrm{OC}\right)$ and the lowest at site $\# 5\left(7.5 \times 10^{-4} \mathrm{mg} \mathrm{g}^{-}\right.$ ${ }^{1} \mathrm{OC}$ ). The soils also contained smaller amounts of $\beta$-sitosterol; $1.0 \times 10^{-2} \mathrm{mg} \mathrm{g}^{-1} \mathrm{OC}$ and $6.3 \times 10^{-4} \mathrm{mg} \mathrm{g}^{-1} \mathrm{OC}$ for the riparian and the grass prairie soils, respectively, suggesting more allochthonous inputs to the riparian soil.

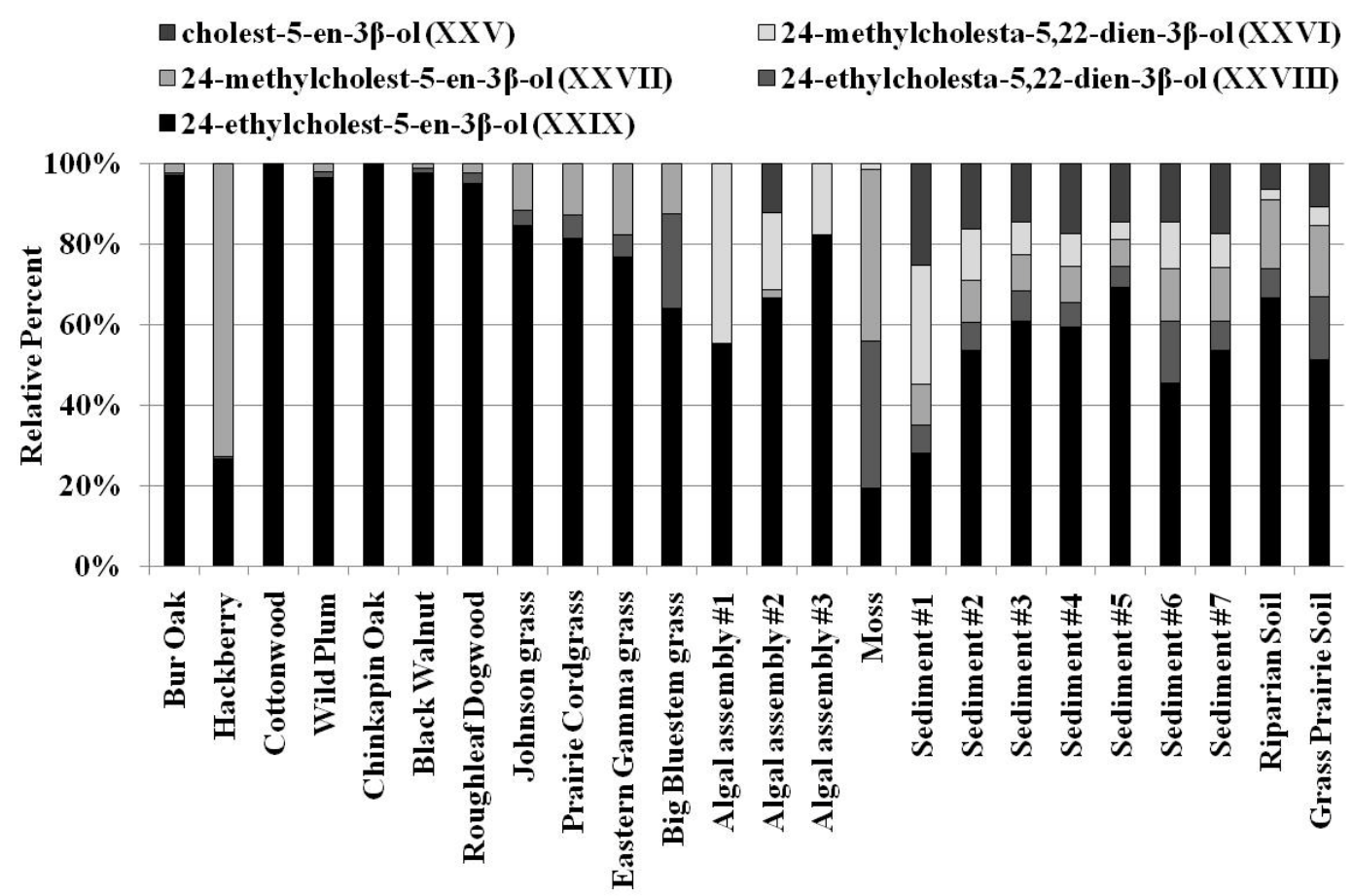

Figure 5.19. Relative abundance of sterols for all the Konza Prairie samples. The numbers in parentheses correspond to the molecular structure in Appendix 5.2.

Brassicasterol has been found in different species of microalgae (Volkman, 1986; Volkman et al., 1998) and can be used as a marker for algal inputs to sediments. This sterol was present in the three algae samples (highest amount was $8.5 \times 10^{-2} \mathrm{mg} \mathrm{g}^{-1} \mathrm{OC}$ in assembly \#3) and the moss sample $\left(2.4 \times 10^{-3} \mathrm{mg} \mathrm{g}^{-1} \mathrm{OC}\right)$, but was not present in any other vegetation sample (Figure 5.19). In fact, this sterol has been reported to occur in 
several species of mosses (Matsuo et al., 1991). Brassicasterol was also present in low concentrations in the sediments; site \#1 contained the most $\left(1.3 \times 10^{-2} \mathrm{mg} \mathrm{g}^{-1} \mathrm{OC}\right)$ and site \#5 contained the least $\left(4.9 \times 10^{-5} \mathrm{mg} \mathrm{g}^{-1} \mathrm{OC}\right)$, suggesting higher autochthonous inputs to the sediments at the former site. Even smaller amounts of brassicasterol were found in the two soil samples; $3.8 \times 10^{-4} \mathrm{mg} \mathrm{g}^{-1} \mathrm{OC}$ in the riparian soil and $5.7 \times 10^{-5} \mathrm{mg} \mathrm{g}^{-1} \mathrm{OC}$ in the grass prairie soil.

Stigmasterol is a major constituent of the $\mathrm{C}_{29}$ sterol distribution of higher plants (Medeiros et al., 2008) and mosses (Matsuo et al., 1991). The highest concentration of this sterol was found in the moss sample $\left(6.0 \times 10^{-2} \mathrm{mg} \mathrm{g}^{-1} \mathrm{OC}\right)$ followed by the Big Bluestem grass $\left(1.4 \times 10^{-2} \mathrm{mg} \mathrm{g}^{-1} \mathrm{OC}\right.$; Figure 5.19). Although this sterol is considered typical of higher plants, it was not the major component and was found in small amounts in the Bur Oak leaves $\left(3.1 \times 10^{-4} \mathrm{mg} \mathrm{g}^{-1} \mathrm{OC}\right)$, Hackberry leaves $\left(1.3 \times 10^{-3} \mathrm{mg} \mathrm{g}^{-1} \mathrm{OC}\right)$, Wild Plum leaves $\left(2.4 \times 10^{-3} \mathrm{mg} \mathrm{g}^{-1} \mathrm{OC}\right)$, Walnut leaves $\left(1.2 \times 10^{-3} \mathrm{mg} \mathrm{g}^{-1} \mathrm{OC}\right)$ and Dogwood shrub leaves $\left(2.8 \times 10^{-3} \mathrm{mg} \mathrm{g}^{-1} \mathrm{OC}\right)$. However, the algae samples did not contain this compound. There was no apparent downstream trend in the sediment stigmasterol distribution. Site \#1 contained the highest amount $\left(1.3 \times 10^{-2} \mathrm{mg} \mathrm{g}^{-1} \mathrm{OC}\right)$ and site \#5 contained the least ( $\left.4.9 \times 10^{-5} \mathrm{mg} \mathrm{g}^{-1} \mathrm{OC}\right)$, suggesting mixed higher plant inputs in the downstream reaches possibly from both riparian and prairie sources. The soil samples contained small amounts of stigmasterol; $3.8 \times 10^{-4} \mathrm{mg} \mathrm{g}^{-1} \mathrm{OC}$ and $5.7 \times 10^{-5} \mathrm{mg} \mathrm{g}^{-1} \mathrm{OC}$ in the riparian and grass soil, respectively.

The $\mathrm{C}_{27}$ sterol cholesterol has been attributed an algal source, as it is present only in small amounts in higher plants compared to aquatic organisms (Smittenberg et al., 2004). However, care must still be taken when assigning sources on the basis of structure 
alone. Cholesterol was only found in algal assembly \#2 $\left(7.9 \times 10^{-3} \mathrm{mg} \mathrm{g}^{-1} \mathrm{OC}\right.$; Figure 5.19), indicating an autochthonous source for this marker. The sediment and soil samples contained this compound with higher concentrations at site \#1 $\left(1.1 \times 10^{-2} \mathrm{mg} \mathrm{g}^{-1} \mathrm{OC}\right)$ and lower concentrations at site $\# 5\left(1.6 \times 10^{-4} \mathrm{mg} \mathrm{g}^{-1} \mathrm{OC}\right)$. The inputs of autochthonous OM in the lower reaches of the watershed clearly dominate. The soil samples contained very low amounts of cholesterol.

A triangular plot of $\mathrm{C}_{27}, \mathrm{C}_{28}$ and $\mathrm{C}_{29}$ sterols can be used to study the sterol distribution (expressed as relative amounts of the different components) in relation to source organisms and environments (Meyers, 1997). Such a plot for this study is shown in Figure 5.20. As expected, the riparian vegetation clustered close to $\mathrm{C}_{29}$, which is typical of higher plants containing high amounts of the $\mathrm{C}_{29}$ sterol, $\beta$-sitosterol. The one exception was the Hackberry leaf sample, which also contained significant amounts of the $\mathrm{C}_{28}$ sterol, campesterol. The four grass samples displayed similar sterol distributions to the riparian vegetation although they also contained some of the $\mathrm{C}_{28}$ sterol, campesterol. Because the algae also contained significant amounts of $\beta$-sitosterol, most of the algae samples clustered close to the higher plants. The one exception was algal assembly \#1 which contained the smallest relative amount of $\mathrm{C}_{29}$ sterols and a much higher phytoplankton signature as a result of the high amounts of $\mathrm{C}_{28}$ sterols such as brassicasterol. The sediment sample from site \#1 showed the highest input from this kind of algae and could be receiving significant autochthonous inputs. The sediments at sites $\# 4$ and \#5 seem to receive most of their OM inputs from the local grasses. Site \#3 is highly influenced by algal assembly \#2. Finally, sites \#2, \#6 and \#7 display similar sterol distributions and receive mixed allochthonous and autochthonous OM inputs. The two 
soil samples contained a relatively high amount of $\mathrm{C}_{29}$ sterols, indicative of OM inputs from higher plants. However, their sterol distribution was similar to that of the grass samples, indicative of inputs from the extensive grass prairie.

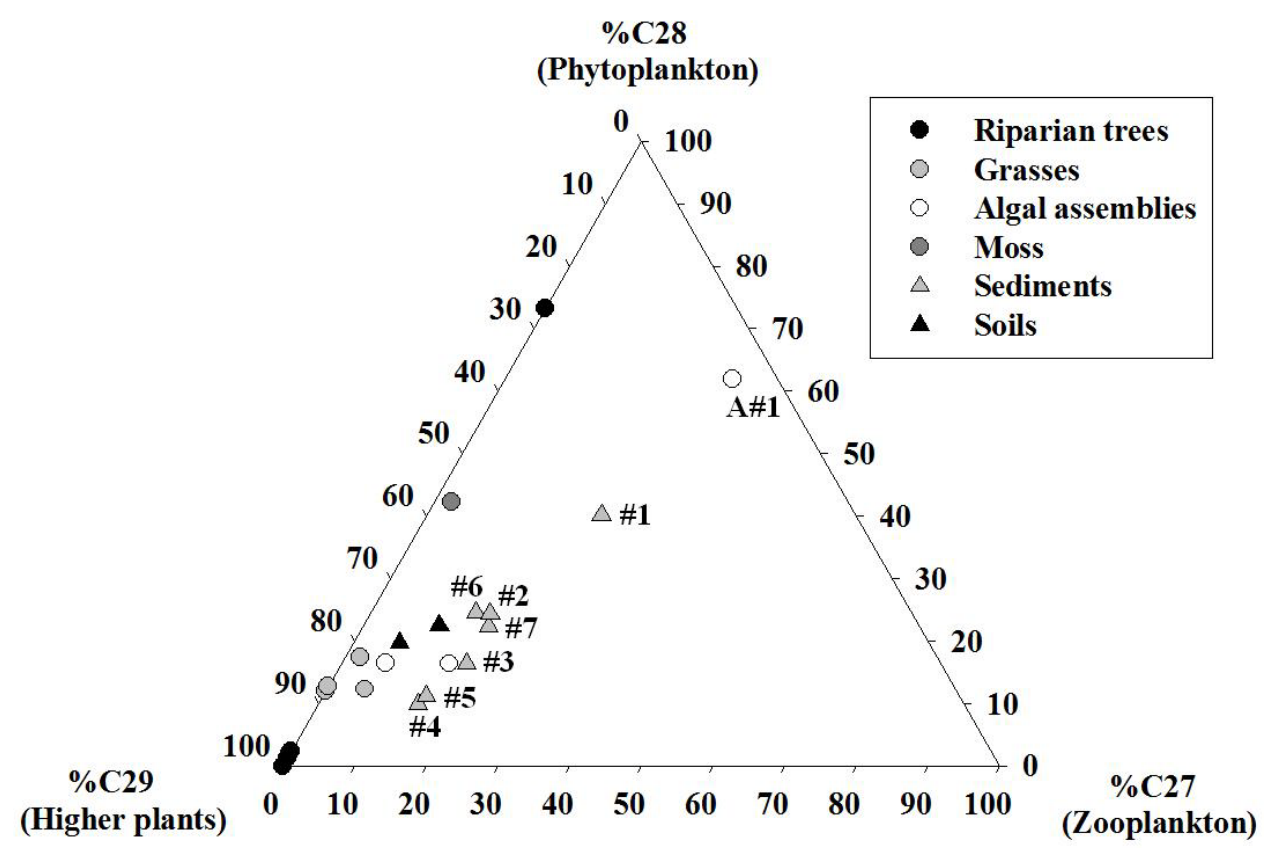

Figure 5.20. Ternary plot showing the sterol distribution of the King's Creek vegetation, algae (A\#1 = algal assembly \#1), sediments (\#1-\#7) and soil samples.

\subsubsection{Compound specific isotopes of n-alkanes:}

Compound specific stable carbon isotopic determinations have been successfully used to complement molecular distribution information on OM source assessments in different environments (Zegouagh et al., 1998; Mead et al., 2005; Sikes et al., 2009). Compound specific isotopes can be particularly useful when characterizing the OM produced from plants following different photosynthetic pathways (O’Leary, 1988; Jaffé et al., 2001). During biosynthesis, the leaf wax lipids of plants become more depleted in

${ }^{13} \mathrm{C}$ compared to the total biomass ( $\sim 10 \%$ in $n$-alkanes; Collister et al., 1994$)$ and so their 
$\delta^{13} \mathrm{C}$ values range between $-32 \%$ and $-39 \%$ in $\mathrm{C}_{3}$ plants and between $-18 \%$ and $-25 \%$ in $\mathrm{C}_{4}$ plants (Rieley et al., 1991 and 1993; Collister et al., 1994). We found that the compound specific $\delta^{13} \mathrm{C}$ values of the individual $n$-alkanes (Tables A5.19-A5.21 in Appendix 5.1, Figure 5.21) were consistent with their origins in waxes of $\mathrm{C}_{3}$ and $\mathrm{C}_{4}$ higher land plants. The $\delta^{13} \mathrm{C}$ values of the riparian vegetation $n$-alkanes ranged between $30.90 \%$ and $-35.49 \%$. The $\mathrm{C}_{3}$ grasses showed slightly more depleted values compared to the riparian vegetation, ranging between $-32.02 \%$ and $-37.44 \%$, while the $\mathrm{C}_{4}$ grasses displayed less depleted values ranging between $-20.21 \%$ and $-27.77 \%$. These values are in agreement with recent determinations of $\delta^{13} \mathrm{C}$ isotopic values of $n$-alkanes from different $\mathrm{C}_{4}$ grass subspecies (Rommerskirchen et al., 2006).

The stable carbon isotopic composition of microalgae can be very variable as a result of fractionation effects derived from the availability of dissolved $\mathrm{CO}_{2}$. Thus, $\delta^{13} \mathrm{C}$ values of microalgae can range from -18 to $-30 \%$ (Zegouagh et al., 1998). The $\mathrm{C}_{17} n$ alkane is considered a typical algal marker and was found to be the most abundant homologue in one of the algae samples analyzed in this study (assembly \#1). The isotopic composition of this hydrocarbon was found to be variable in the three algae samples with values of -40.59 and $-41.07 \%$ for assemblies $\# 2$ and \#1, respectively and a less depleted value of $-33.89 \%$ in assembly $\# 3$. Values of $-39.3 \%$ have been reported for a freshwater cyanobacterium grown in laboratory cultures (Sakata et al., 1997). The long chain $n$ alkanes $\left(\mathrm{C}_{23}\right.$ to $\left.\mathrm{C}_{31}\right)$ present in the algae samples displayed depleted $\delta^{13} \mathrm{C}$ values ranging between $-28.88 \%$ and $-33.98 \%$ (Figure 5.21), similar values that have also been reported in periphyton algal mats of the Florida Coastal Everglades (Mead et al., 2005), and may be associated with higher plant detritus in the algal mats. 


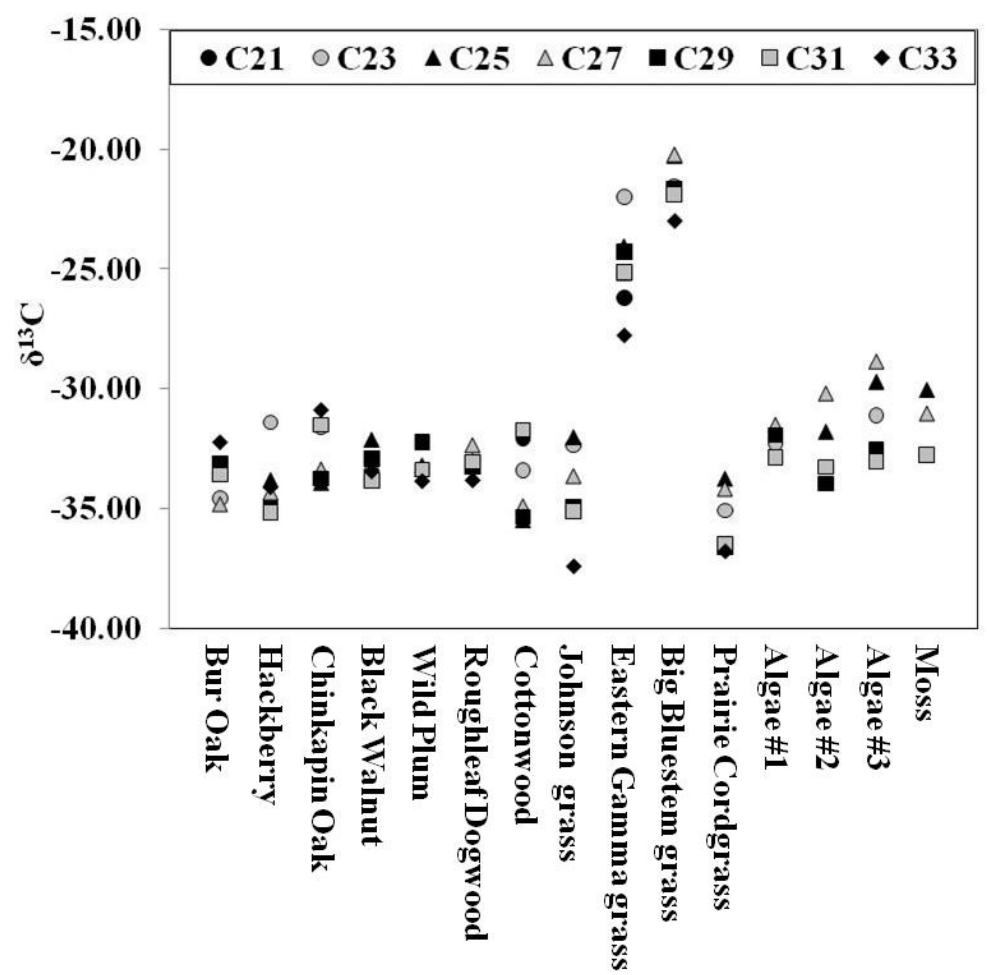

Figure 5.21. Long chain $\left(\mathrm{C}_{21}-\mathrm{C}_{33}\right) n$-alkane compound specific $\delta^{13} \mathrm{C}$ of the riparian vegetation, grass, algae and moss samples of the King's Creek watershed.

The two soil samples showed differences in their long chain $n$-alkane isotopic composition (Figure 5.22). In the grass prairie soil, the $\delta^{13} \mathrm{C}$ of the individual $n$-alkanes were found to be between $-22.62 \%$ and $-28.26 \%$, enriched values typical of the $\mathrm{C}_{4}$ grasses. In fact, the $\mathrm{C}_{27}$ isotopic ratio was found to be $-22.62 \%$ which suggests inputs from the Big Bluestem grasses. The long chain $n$-alkanes of the riparian soil displayed $\delta^{13} \mathrm{C}$ values that ranged from $-28.19 \%$ and $-35.63 \%$. These more depleted values may indicate inputs from $\mathrm{C}_{3}$ riparian plants.

The individual isotopic ratios obtained for the sedimentary $n$-alkanes are reported in Tables A5.19-A5.21 found in Appendix 5.1. Values ranging from -25.38\%o and 41.07\%o were observed, clearly showing OM inputs from different sources. The isotopic ratios of the odd numbered long chain $n$-alkanes $\left(\mathrm{C}_{21}-\mathrm{C}_{33}\right)$ are shown in Figure 5.22 and 
seem to suggest mixed inputs from autochthonous and allochthonous sources. No clear evidence was found for $\mathrm{C}_{4}$ inputs to the sediments at any of the sites, although the $\mathrm{C}_{25}$ and $\mathrm{C}_{27}$ homologues (indicative of Big Bluestem inputs) were commonly a bit more enriched compared to the $\mathrm{C}_{29}, \mathrm{C}_{31}$ and $\mathrm{C}_{33}$ counterparts (higher plants). This was true at all sites except \#7. The data from the specific stable isotope analyses of the n-alkanes suggests that $\mathrm{C}_{4}$ sources (in the form of $n$-alkanes) are not dominant in the sediments of these streams.

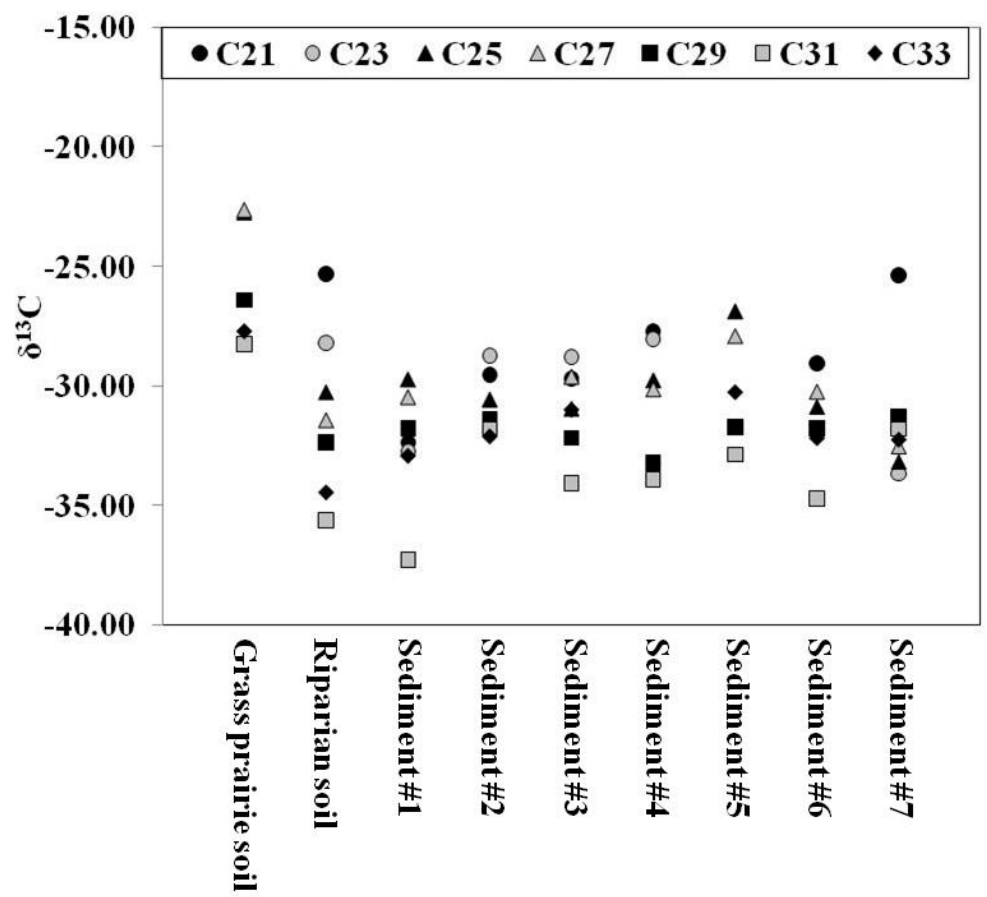

Figure 5.22. Long chain $\left(\mathrm{C}_{21}-\mathrm{C}_{33}\right) n$-alkane compound specific $\delta^{13} \mathrm{C}$ of the sediment and soil samples from the King's Creek watershed.

\subsection{Conclusions:}

Sediment samples from the King's Creek watershed at Konza Prairie were found to contain organic compounds from different natural biogenic sources as well as products indicative of early diagenetic alterations. These sources of OM are mainly epicuticular 
waxes of higher plants as well as significant autochthonous inputs in several parts of the watershed. The combination of molecular markers and compound specific carbon isotopes proved useful in distinguishing sources from biomass utilizing different carbon fixing pathways $\left(\mathrm{C}_{3}\right.$ vs. $\left.\mathrm{C}_{4}\right)$.

The elemental characteristics of the stream sediments suggested different OM inputs between the upper and lower reaches of the watershed. The OC and TN content was higher in the sediments of the upper reaches (sites \#3-7) compared to the lower reaches (sites \#1 and 2). Because the lower reaches are characterized by periods of intense flooding, the differences observed in $\mathrm{OC}$ and $\mathrm{TN}$ content were attributed to possible dilution effects with inorganic soil components at these high order sites. The $\mathrm{C} / \mathrm{N}$ content was very similar between sediments of low and high order streams. While the upper reaches showed a slight influence from the grasses (especially site \#6), the lower reaches seem to receive more algal inputs. However, the sediments from sites \#4 and $\# 6$ also receive enhanced algal inputs. Finally, bulk $\delta^{13} \mathrm{C}$ results suggested that the upper reaches receive $\mathrm{C}_{4}$ grass inputs from the extensive watershed while the lower reaches showed a mixed input from the grasses and the riparian vegetation.

While some biomarkers typical of grasses were detected in sediments of the lower reaches (e.g., branched $n$-alkanes, phytadienes), the OM inputs at these sites seem to be dominated by fresh higher plant detritus, as shown by the higher concentrations of 3-oxytriterpenoids. The upper reaches seem to preferentially accumulate OM from riparian sources that has been subjected to more extensive degradation, and as such show higher presence of phytadienes and triterpenoid degradation products. Bulk carbon isotopic values indicate a mixed input from the grass-dominated watershed in the lower reaches of 
the watershed and this could also be the result of transport of OM during flash flood events. Furthermore, the $n$-alkane compound specific stable carbon isotope analysis of the samples from King's Creek did not suggest that $\mathrm{C}_{4}$ sources are dominating OM inputs to these sediments.

The inputs of autochthonous material to stream sediments can be explained with the River Continuum Concept (RCC), which has been re-defined for small prairie streams (Dodds et al., 2004). The streams at Konza Prairie are characterized by a downstream change in vegetation cover which can greatly influence the growth of stream algal communities. The upstream reaches are characterized by minimal canopy cover and shading of the stream. The canopy openness allows the growth of algal mats on the rocks found in the stream channel. As stream order increases, so does the amount of canopy cover and consequent shading of the stream bed, blocking sunlight and inhibiting the growth of algal mats. However, the increased channel size of the higher order streams may allow sunlight penetration and a subsequent increase in primary productivity in the stream channel. In fact, the $\mathrm{C}_{25: 5}$ highly branched isoprenoids were only detected in the algae samples and the two $3^{\text {rd }}$ order stream sediments, indicating fresh autochthonous inputs at those sites. The sterol distribution at these high-order sites showed higher amounts of brassicasterol, also indicative of autochthonous OM inputs. However, the sediments from the upper reaches of the watershed also contained markers for autochthonous inputs and showed enrichment in the short chain $n$-alkenes (site \#4 and \#6) and $n$-alkanols (site \#7). These results suggest a non-linear RCC for Konza streams in which algal inputs are present in both upper and lower reaches of the watershed with no 
apparent downstream trend. For this reason, care must be taken when using the RCC concept to imply sources of OM to sediments in this type of environment.

The presence of older and partially degraded OM, in the form of phytadienes, hopenes and mono-unsaturated triterpenes in the sediments of the upper reaches (sites \#37) suggest that this degraded material is less mobile and possibly present as small size fractions. The smaller particles can be more efficiently trapped than larger particles and not transported during periods of high floods. Furthermore, these intermittent streams may show an increase in OM degradation during dry periods. On the other hand, the lower reaches of the watershed (sites \#1 and \#2) seem to accumulate fresh litter, mostly as indicated by the high abundance of 3-oxy-triterpenoids. Leaf litter can easily be transported by flash floods and be re-mobilized from the low-order to the higher order sites. These hydrologic trends complicate the characterization of OM transport in this dynamic environment.

The present study shows that the biomarker composition of small streams is very complex and does not follow the typical linear RCC for lotic systems. There was no apparent trend in source-specific biomarkers downstream and this can be attributed to the complicated dynamics of small prairie streams. This study further demonstrates the usefulness of combining different analytical techniques such as molecular markers and compound specific stable isotopes for OM source assessments in dynamic environments. The large number of small streams can export significant amounts of POM from terrestrial to coastal environments, contributing to the estimations of the global ocean carbon cycle. However, while there are not many studies on the detailed characterization of OM in such environments, more work is needed to characterize this material. 


\section{REFERENCES:}

Abrams, M. D. 1986. Historical developments of gallery forests in northeast Kansas. Vegetatio 65: 29-37.

Allan, J. D. 1995. Organic matter in lotic ecosystems. In: Stream Ecology: Structure and Function of Running Waters. $1^{\text {st }}$ edition, Chapman \& Hall, The Netherlands, pp. 259-281.

Azevedo, D. A., C. J. André Zinu, F. R. Aquino Neto and B. R. T. Simoneit. 2001.

Possible origin of acyclic (linear and isoprenoid) and tricyclic terpane methyl ketones in a Tasmanian tasmanite bitumen. Organic Geochemistry 32: 443-448.

Bai, Y., X. Fang, Y. Wang, F. Kenig, Y. Miao and Y. Wang. 2006. Distribution of aliphatic ketones in Chinese soils: Potential environmental implications. Organic Geochemistry 37: 860-869.

Belicka, L. L., R. W. Macdonald, and R. H. Harvey. 2002. Sources and transport of organic carbon to shelf, slope, and basin surface sediments of the Arctic Ocean. Deep Sea Reseach Part I 49: 1463-1483.

Belt, S. T., W. G. Allard, J. Rintatalo, L. A. Johns, A. C. T. van Duin, and S. J. Rowland. 2000. Clay and acid catalysed isomerisation and cyclisation reactions of highly branched isoprenoid (HBI) alkenes: implications for sedimentary reactions and distributions. Geochimica et Cosmochimica Acta 64: 3337-3345.

Belt, S. T., G. Massé, W. G. Allard, J. M. Robert, and S. J. Rowland. 2001. C 25 highly branched isoprenoid alkenes in planktonic diatoms of the Pleurosigma genus. Organic Geochemistry 32: 1271-1275.

Bender, M. M. 1968. Mass spectrometric studies of carbon 13 variations in corn and other grasses. Radiocarbon 10(2): 468-472.

Benner, R. and S. Opsahl. 2001. Molecular indicators of the sources and transformations of dissolved organic matter in the Mississippi river plume. Organic Geochemistry 32(4): 597-611.

Bi, X., G. Sheng, X. Liu, C. Li, and J. Fu. 2005. Molecular and carbon and hydrogen isotopic composition of $n$-alkanes in plant leaf waxes. Organic Geochemistry 36: 1405 1417.

Bianchi, T. S., S. Mitra, and B. A. McKee. 2002. Sources of terrestrially derived organic carbon in lower Mississippi and Louisiana shelf sediments: implications for differential sedimentation and transport at the coastal margin. Marine Chemistry 77(2/3): 211-223.

Blair, N. E., E. L. Leithold, S. T. Ford, K. A. Peeler, J. C. Holmes and D. W. Perkey. 2003. The persistence of memory: the fate of ancient sedimentary organic carbon in a modern sedimentary system. Geochimica et Cosmochica Acta 67: 63-73. 
Blumer, M., and D. W. Thomas. 1965. Phytadienes in zooplankton. Science 147: 11481149.

Blumer, M., J. C. Robertson, J. E. Gordon, and J. Sass. 1969. Phytol-derived $\mathrm{C}_{19}$ di- and triolefinic hydrocarbons in marine zooplankton and fishes. Biochemistry 8(10): 40674074.

Brooks, P. W. and J. R. Maxwell. 1974. Early stage fate of phytol in recent deposited lacustrine sediments. In: Tissot, B., Bienner, F. (Eds.), Advances in Organic Geochemistry, 1973. Editions Technip, Paris, pp. 911-977.

Collister, J. W., G. Rieley, B. Stern, G. Eglinton and B. Fry. 1994. Compound-specific $\delta^{13} \mathrm{C}$ analyses of leaf lipids from plants with differing carbon dioxide metabolisms. Organic Geochemistry 21: 619-627.

Cranwell, P. A. 1981. Diagenesis of free and bound lipids in terrestrial detritus deposited in a lacustrine sediment. Organic Geochemistry 3: 79-89.

Cranwell, P. A. 1982. Lipids of aquatic sediments and sedimenting particulates. Progress in Lipid Research 21(4): 271-308.

Curiale, J. A. 1995. Saturated and olefinic terrigenous triterpenoid hydrocarbons in a biodegraded tertiary oil of northeast Alaska. Organic Geochemistry 23(2): 177-182.

de Leeuw, J. W., B. R. T. Simoneit, J. J.. Boon, W. I. C. Rijpstra, F. de Lange, J. C. W. Van der Leeden, V. A. Correia, A. L. Burlingame, and P. A. Schenk. 1977. Phytol derived compounds in the geosphere. In: Campos, R., Goni, J. (Eds.), Advances in Organic Geochemistry, 1975. pp. 61-79.

de Leeuw, J. W. 1986. Higher-molecular weight markers. In: Johns, R. B. (Ed.), Biological markers in the sedimentary record. Elseviere, New York. pp. 249-260.

Dittmar, T., R. J. Lara and G. Kattner. 2001. River or mangrove. Tracing major organic matter sources in tropical Brazilian waters. Marine Chemistry 73: 253-271.

Dodds, W. K., M. A. Evans-White, N. M. Gerlanc, L. Gray, D. A. Gudder, M. J. Kemp, A. L. López, D. Stagliano, E. A. Strauss, J. L. Tank, M. R. Whiles and W. M. Wollheim. 2000. Quantification of the nitrogen cycle in a prairie stream. Ecosystems 3: 574-589.

Dodds, W. K., K. Gido, M. R. Whiles, K. M. Fritz and W. J. Matthews. 2004. Life on the edge: The ecology of Great Plains prairie streams. Bioscience 54(3): 205-216.

Dornbush, M. E. 2007. Grasses, litter, and their interaction affect microbial biomass and soil enzyme activity. Soil Biology and Biochemistry 39: 2241-2249.

Eglinton, G., and R. J. Hamilton. 1967. Leaf epicuticular waxes. Science 156: 1322-1335. 
Farnsworth, K. L. and J. D. Milliman. 2003. Effects of climatic and anthropogenic change on small mountainous rivers: the Salinas River example. Global and Planetary Change 39: 53-64.

Ficken, K. J., B. Li, D. L. Swain, and G. Eglinton. 2000. An $n$-alkane proxy for the sedimentary input of submerged/floating freshwater aquatic macrophytes. Organic Geochemistry 31: 745-749.

Fons, F., S. Rapior, A. Gargadennec, C. Andary, and J. M. Bessière. 1998. Volatile components of Plantago lanceolata (Plantaginaceae). Acta Botanica Gallica 145(4): 265269.

Freeman, C. C. 1998. The flora of Konza Prairie. A historical review and contemporary patterns. In: Knapp, A. K., Briggs, J. M., Hartnett, D. C., Collins, S. L. (Eds.), Grassland Dynamics. Oxford University Press, New York. pp. 69-80.

Fry, B. 2006. Stable isotope ecology. Springer, New York.

Gogou, a. and G. E. Stephanou. 2004. Marine organic geochemistry of the Eastern Mediterranean: 2. Polar biomarkers in Cretan Sea surficial sediments. Marine Chemistry 85: $1-25$.

Grossi, V., M. Baas, N. Schogt, W. C. M. Klein Breteler, J. W. De Leeuw, and J. F. Rontani. 1996. Formation of phytadienes in the water column: myth or reality? Organic Geochemistry 24: 833-839.

Grossi, V., B. Beker, J. A. J. Geenevasen, S. Schouten, D. Raphel, M. F. Fontaine, J. S. Sinninghe Damsté. 2004. $\mathrm{C}_{25}$ highly branched isoprenoid alkenes from the marine benthic diatom Pleurosigma strigosum. Phytochemistry 65: 3049-3055.

Harris, D., W. R. Horwath, and C. van Kessel. 2001. Acid fumigation of soils to remove carbonates prior to total organic carbon or carbon-13 isotopic analysis. Soil Society of America Journal 65: 1853-1856.

Hernandez, M. E., R. Mead, M. C. Peralba, and R. Jaffé. 2001. Origin and transport of nalkane-2-ones in a subtropical estuary: potential biomarkers for seagrass-derived organic matter. Organic Geochemistry 32: 21-32.

Houser, J. N., D. W. Bierman, R. M. Burdis and L. A. Soeken-Gittinger. 2010. Longitudinal trends and discontinuities in nutrients, chlorophyll, and suspended solids in the Upper Mississippi River: implications for transport, processing, and export by large rivers. Hydrobiologia 651: 127-144.

Huang, X., C. Wang, J. Xue, P. A. Meyers, Z. Zhang, K. Tan, Z. Zhang and S. Xie. 2010. Occurrence of diploptene in moss species from the Dajiuhu Peatland in southern China. Organic Geochemistry 41: 321-324. 
Hwang, J., E. R. M. Druffel and T. Komada. 2005. Transport of organic carbon from the California coast to the slope region: a study of $\Delta^{14} \mathrm{C}$ and $\delta^{13} \mathrm{C}$ signatures of organic compound classes. Global Biogeochemical Cycles 19: GB2018.

doi:10.1029/2004GB002422.

Ikan, R., M. J. Baedecker and I. R. Kaplan. 1973. $\mathrm{C}_{18}$ isoprenoid ketone in Recent marine sediments. Nature 244: 154-155.

Jaffé, R. and K. Hausmann. 1995. Origin and fate of arborinone in sediments of a highly productive lake. Organic Geochemistry 22: 231-235.

Jaffé, R., A. Cabrera, N. Hajje, and H. Carvajal-Chitty. 1996. Organic biogeochemistry of a hypereutrophic tropical, freshwater lake - Part 1: particle associated and dissolved lipids. Organic Geochemistry 25: 227-240.

Jaffé, R., R. Mead, M. E. Hernandez, M. C. Peralba, and O. A. DiGuida. 2001. Origin and transport of sedimentary organic matter in two subtropical estuaries: a comparative, biomarker-based study. Organic Geochemistry 32: 507-526.

Jansen, B., K. G. J. Nierop, J. A. Hageman, A. M. Cleef and J. M. Verstraten. 2006. The straight-chain lipid biomarker composition of plant species responsible for the dominant biomass production along two altitudinal transects in the Ecuadorian Andes. Organic Geochemistry 37: 1514-1536.

Johns, L., E. J. Wraige, S. T. Belt, C. A. Lewis, G. Massé, J. M. Robert, and S. J. Rowland. 1999. Identification of a $\mathrm{C}_{25}$ highly branched isoprenoid (HBI) diene in Antarctic sediments, Antarctic sea-ice diatoms and cultured diatoms. Organic Geochemistry 30: 1471-1475.

Kitchen, D. J., J. M. Blair, and M. A. Callaham Jr. 2009. Annual fire and mowing alter biomass, depth distribution, and $\mathrm{C}$ and $\mathrm{N}$ content of roots and soil in tallgrass prairie. Plant and Soil 323: 235-247.

Knapp, A. K. and T. R. Seastedt. 1998. Grasslands, Konza Prairie, and Long-Term Ecological Research. In: Knapp, A. K., Briggs, J. M., Hartnett, D. C., Collins, S. L. (Eds.), Grassland Dynamics. Oxford University Press, New York. pp. 3-15.

Komada, T., E. R. M. Druffel and S. E. Trumbone. 2004. Oceanic export of relict carbon by small mountainous rivers. Geophysical Research Letters 31: L07504.

doi:10.1029/2004GL019512.

Komada, T., E. R. M. Druffel and J. Hwang. 2005. Sedimentary rocks as sources of ancient organic carbon to the ocean: an investigation through $\Delta^{14} \mathrm{C}$ and $\delta^{13} \mathrm{C}$ signatures of organic compound classes. Global Biogeochemical Cycles 19: GB2017.

doi:10.1029/2004GB002347. 
Kuhn, T. K., E. S. Krull, A. Bowater, K. Grice, and G. Gleixner. 2010. The occurrence of short chain n-alkanes with an even over odd predominance in higher plants and soils. Organic Geochemistry 41: 88-95.

Lallier-Verges, E., B. P. Perrussel, J. R. Disnar, and F. Baltzer. 1998. Relationships between environmental conditions and the diagenetic evolution of organic matter derived from higher plants in a modern mangrove swamp system (Guadeloupe, French West Indies). Organic Geochemistry 29: 1663-1686.

Leithold, E., N. E. Blair and D. W. Perkey. 2006. Geomorphologic controls on the age of particulate organic carbon from small mountainous and upland rivers. Global Biogeochemical Cycles 20: GB3022. doi10.1029/2005GB002677.

Liu, X. Y., H. Y. Xiao, C. Q. Liu, Y. Y. Li, H. W. Xiao, and Y. L. Wang. 2010. Response of stable carbon isotope in epilithic mosses to atmospheric nitrogen deposition.

Environmental Pollution 158: 2273-2281.

Mastelić, J., and I. Jerković. 2002. Volatile constituents from the leaves of young and old Ailanthus altissima (Mill.) Swingle tree. Croatica Chemica Acta 75(1): 189-197.

Matsuo, A. and A. Sato. 1991. Sterols of mosses. Phytochemistry 30: 2305-2306.

Meade, R. H. 1994. Suspended sediments of the modern Amazon and Orinoco rivers. Quaternary International 21: 29-39.

Mead, R., Y. Xu, J. Chong and R. Jaffé. 2005. Sediment and soil organic matter source assessment as revealed by the molecular distribution and carbon isotopic composition of n-alkanes. Organic Geochemistry 36: 363-370.

Medeiros, P. M. and B. R. T. Simoneit. 2007. Gas chromatography coupled to mass spectrometry for analyses of organic compounds and biomarkers as tracers for geological, environmental, and forensic research. Journal of Separation Science 30: 1516-1536.

Medeiros, P. M. and B. R. T. Simoneit. 2008. Multi-biomarker characterization of sedimentary organic carbon in small rivers draining the Northwestern United States. Organic Geochemistry 39: 52-74.

Meybeck, M., L. Laroche, H. H. Dürr and J. P. M. Syvitski. 2003. Global variability of daily total suspended solids and their fluxes in rivers. Global and Planetary Change 39: 65-93.

Meyers, P. 1997. Organic geochemical proxies of paleoceanographic, paleolimnologic, and paleoclimatic processes. Organic Geochemistry 27: 213-250.

Milliman, J. D. and J. M. P. Syvitski. 1992. Geomorphic/tectonic control of sediment transport to the ocean: the importance of small mountainous rivers. Journal of Geology 100: $525-544$. 
Naraoka, H. and R. Ishiwatari. 1999. Carbon isotopic compositions of individual longchain $n$-fatty acids and n-alkanes in sediments from river to open ocean: multiple origins and their occurrence. Geochemical Journal 33: 215-235.

Neto, R. R., R. N. Mead, J. W. Louda, and R. Jaffé. 2006. Organic biogeochemistry of detrital flocculent material (floc) in a subtropical, coastal wetland. Biogeochemistry 77: 283-304.

Nguyen Tu, T. T., S. Derenne, C. Largeau, G. Bardoux and A. Mariotti. 2004. Diagenesis effects on specific carbon isotope composition of plant $n$-alkanes. Organic Geochemistry 35: 317-329.

Norris, M. D., J. M. Blair, L. C. Johnson, and R. B. McKane. 2001. Assessing changes in biomass, productivity, and $\mathrm{C}$ and $\mathrm{N}$ stores following Juniperus virginiana forest expansion into tallgrass prairie. Canadian Journal of Forrest Research 31: 1940-1946.

Nott, C. J., S. Xie, L. A. Avsejs, D. Maddy, F. M. Chambers, and R. P. Evershed. 2000. $\mathrm{n}$-Alkane distributions in ombrotrophic mires as indicators of vegetation change related to climatic variation. Organic Geochemistry 31: 231-235.

O’Leary, M. H. 1988. Carbon isotopes in photosynthesis. Phytochemistry 38: 553-567.

Otto, A., and M. J. Simpson. 2005a. Degradation and preservation of vascular plantderived biomarkers in grassland and forest soils from Western Canada. Biogeochemistry 74: 377-409.

Otto, A., C. Shunthirasingham, and M. J. Simpson. 2005b. A comparison of plant and microbial biomarkers in grassland soils from the Prairie Ecozone of Canada. Organic Geochemistry 36: 425-448.

Prahl, F. G., and R. Carpenter. 1984. Hydrocarbons in Washington coastal sediments. Estuarine, Coastal and Shelf Science 18: 703-720.

Prahl, F. G. and L. A. Pinto. 1987. A geochemical study of long-chain $n$-aldehydes in Washington coastal sediments. Geochimica et Cosmochimica Acta 51: 1573-1582

Prahl, F. G., J. M. Hayes and T. M. Xie. 1992. Diploptene: An indicator of terrigenous organic carbon in Washington coastal sediments. Limnology and Oceanography 37(6): $1290-1300$.

Qu, W., M. Dickman, S. Wang, R. Wu, P. Zhang and J. Chen. 1999. Evidence for an aquatic origin of ketones found in Taihu Lake sediments. Hydrobiologia 397: 149-154.

Rieley, G., R. J. Collier, D. M. Jones and G. Eglinton. 1991. The biogeochemistry of Ellesmere Lake, U.K.-I: Source correlation of leaf wax inputs to the sedimentary lipid record. Organic Geochemistry 17: 901-912. 
Rieley, G., R. J. Collier, D. M. Jones, G. Eglinton, P. A. Eakin and A. E. Fallick. 1991. Sources of sedimentary lipids deduced from stable carbon isotopic analyses of individual compounds. Nature 352: 425-427.

Rieley, G., J. W. Collister, B. Stern and G. Eglinton. 1993. Gas chromatography/isotope ratio mass spectrometry of leaf wax n-alkanes from plants of differing carbon dioxide metabolisms. Rapid Communications in Mass Spectrometry 7: 488-491.

Rogge, W. F., P. M. Medeiros and B. R. T. Simoneit. 2007. Organic marker compounds in surface soils of crop fields from the San Joaquin Valley fugitive dust characterization study. Atmospheric Environment 41: 8183-8204.

Rohmer, M., P. Bouvier-Nave and G. Ourisson. 1984. Distribution of hopanoid triterpenes in prokaryotes. Journal of General Microbiology 130: 1137-1150.

Rommerskirchen, F., A. Plader, G. Eglinton, Y. Chikaraishi, and J. Rullkötter. 2006. Chemotaxonomic significance of distribution and stable carbon isotopic composition of long-chain alkanes and alkan-1-ols in $\mathrm{C}_{4}$ grass waxes. Organic Geochemistry 37: 13031332.

Rontani, J. F. and J. K. Volkman. 2003. Phytol degradation products as biogeochemical tracers in aquatic environments. Organic Geochemistry 34: 1-35.

Rontani, J. F. and J. K. Volkman. 2005. Lipid characterization of coastal hypersaline cyanobacterial mats from the Camargue (France). Organic Geochemistry 36: 251-272.

Sakata, S., J. M. Hayes, A. R. McTaggart, R. A. Evans, K. J. Leckrone and R. K. Togasaki. 1997. Carbon isotopic fractionation associated with lipid biosynthesis by a cyanobacterium: Relevance for interpretation of biomarker records. Geochimica et Cosmochimica Acta 61(24): 5379-5389.

Samson, F. and F. Knopf. 1994. Prairie conservation in North America. Bioscience 44: 418-421.

Sánchez-García, L., J. R. de Andrés, J. A. Martín-Rubí, F. J. González-Vila and O. Polvillo. 2008. Use of lipid biomarker patterns as a proxy of environmental variability in the coastal sedimentary record from the Gulf of Cádiz (SW Spain). Organic Geochemistry 39: 958-964.

Sikes, E. L., M. E. Uhle, S. D. Nodder and M. E. Howard. 2009. Sources of organic matter in a coastal marine environment: Evidence from $n$-alkanes and their $\delta^{13} \mathrm{C}$ distributions in the Hauraki Gulf, New Zealand. Marine Chemistry 113: 149-163.

Simoneit, B. R., W. G. Howells, and A. L. Burlingame. 1973. Preliminary organic geochemical analyses of the Cariaco Trench Site 147 Deep Sea Drilling Project, Leg 15. In: Edgar, N. T., Kaneps, A. G., Herring, J. R. (Eds.), Deep Sea Drilling Project Initial Reports, Volume 15 in Volume 20, pp. 907-934. 
Simoneit. B. R. T. 1986. Cyclic terpenoids of the geosphere. In: Johns, R. B. (Ed.), Biological markers in the sedimentary record. Elseviere, New York. pp. 43-99.

Smith, D. J., G. Eglinton and R. J. Morris. 1983. The lipid chemistry of an interfacial sediment from the Peru continental shelf: Fatty acids, alcohols, aliphatic ketones and hydrocarbons. Geochimica et Cosmochimica Acta 47: 2225-2232.

Smittenberg, R. H., R. D. Pancost, E. C. Hopmans, M. Paetzel and J. S. Sinninghe Damsté. 2004. A 400-year record of environmental change in an euxinic fjord as revealed by the sedimentary biomarker record. Palaeogeography, Palaeoclimatology, Palaeoecology 202(3/4): 331-351.

Telang, S. A., R. Pocklington, A. S. Naidu, E. A. Romankevich, I. I. Gitelson and M. I. Gladyshev. 1991. Carbon and mineral transport in major North American, Russian Arctic, and Siberian rivers: the St. Lawrence, the Mackenzie, the Yukon, the Arctic Alaskan Rivers, the Arctic Basin Rivers in the Soviet Union, and the Yenisei. In: Degens, E. T., Kempe, S., Richey, J. E. (Eds.), Biogeochemistry of major world rivers, John Wiley and Sons, New York.

Ten Haven, H. L., T. M. Peakman and J. Rullkötter. 1992. Early diagenetic transformation of higher-plant triterpenoids in deep-sea sediments from Baffin Bay. Geochimica et Cosmochimica Acta 56: 2001-2024.

Vannote, R. L., G. W. Minshall, K. W. Cummins, J. R. Sedell and C. E. Cushing. 1980. The river continuum concept. Canadian Journal of Fisheries and Aquatic Sciences 37: $130-137$.

Volkman, J. K. and J. R. Maxwell. 1986. Acyclic isoprenoids as biological markers. In: Johns, R. B. (Ed.), Biological markers in the sedimentary record. Elseviere, New York. pp. 1-42.

Volkman, J. K., S. M. Barrett, S. I. Blackburn, M. P. Mansour, E. L. Sikes and F. Gelin. 1998. Microalgal biomarkers: A review of recent research developments. Organic Geochemistry 29:1163-1179.

Volkman, J. K. 2006. Lipid markers for marine organic matter. In Marine Organic Matter: Biomarkers, Isotopes and DNA. Volume 2N: 27-70.

Vonk, J. E., and Ö. Gustafsson. 2009. Calibrating $n$-alkane Sphagnum proxies in subArctic Scandinavia. Organic Geochemistry 40: 1085-1090.

Warton, B., R. Alexander, and R. I. Kagi. 1997. Identification of some single branched alkanes in crude oils. Organic Geochemistry 27(7/8): 465-476.

Wraige, E. J., S. T. Belt, C. A. Lewis, D. A. Cooke, J. M. Robert, G. Massé, and S. J. Rowland. 1997. Variations in structures and distributions of $\mathrm{C}_{25}$ highly branched isoprenoid (HBI) alkenes in cultures of the diatom, Haslea ostrearia (Simonsen). Organic Geochemistry 27: 497-505. 
Xu, Y., R. Jaffé, A. Wachnicka and E. E. Gaiser. 2006. Occurrence of C25 highly branched isoprenoids (HBIs) in Florida Bay: Paleoenvironmental indicators of diatomderived organic matter inputs. Organic Geochemistry 37: 847-859.

Xu, Y., A. J. Simpson, N. Eyles and M. J. Simpson. 2010. Sources and molecular composition of cryoconite organic matter from the Athabasca Glacier, Canadian Rocky Mountains. Organic Geochemistry 41(2): 177-186.

Yanes, C., H. Alvarez and R. Jaffé. 2006. Geochemistry of a tropical lake (Lake Leopoldo) on pseudo-karst topography within the Roraima Group, Guaiana Shield, Venezuela. Applied Geochemistry 21: 870-886.

Zegouagh, Y., S. Derenne, C. Largeau, G. Bardoux and A. Mariotti. 1998. Organic matter sources and early diagenetic alterations in Arctic surface sediments (Lena River delta and Laptev Sea, Eastern Siberia), II. Molecular and isotopic studies of hydrocarbons. Organic Geochemistry 28(9/10): 571-583. 
Chapter VI

CONCLUSION 
The objective of this study was to determine the quality (sources and reactivity) of organic matter (OM) present in flocculent material from the FCE. This was done in order to obtain a preliminary understanding of floc dynamics in this particular system and to be able to predict how these dynamics will respond to the upcoming Everglades restoration plan. To our knowledge, this is the first detailed study of carbon budgets and dynamics in floc from the FCE ecosystem. Figure 6.1 illustrates, as an example, a conceptual carbon budget diagram for floc collected at the long hydroperiod site, SRS2. Although this is just an example and more work is needed to better characterize and quantify these processes in this complex environment, this study allowed for a better understanding of floc OM sources, photo- and bio-reactivity in the FCE.

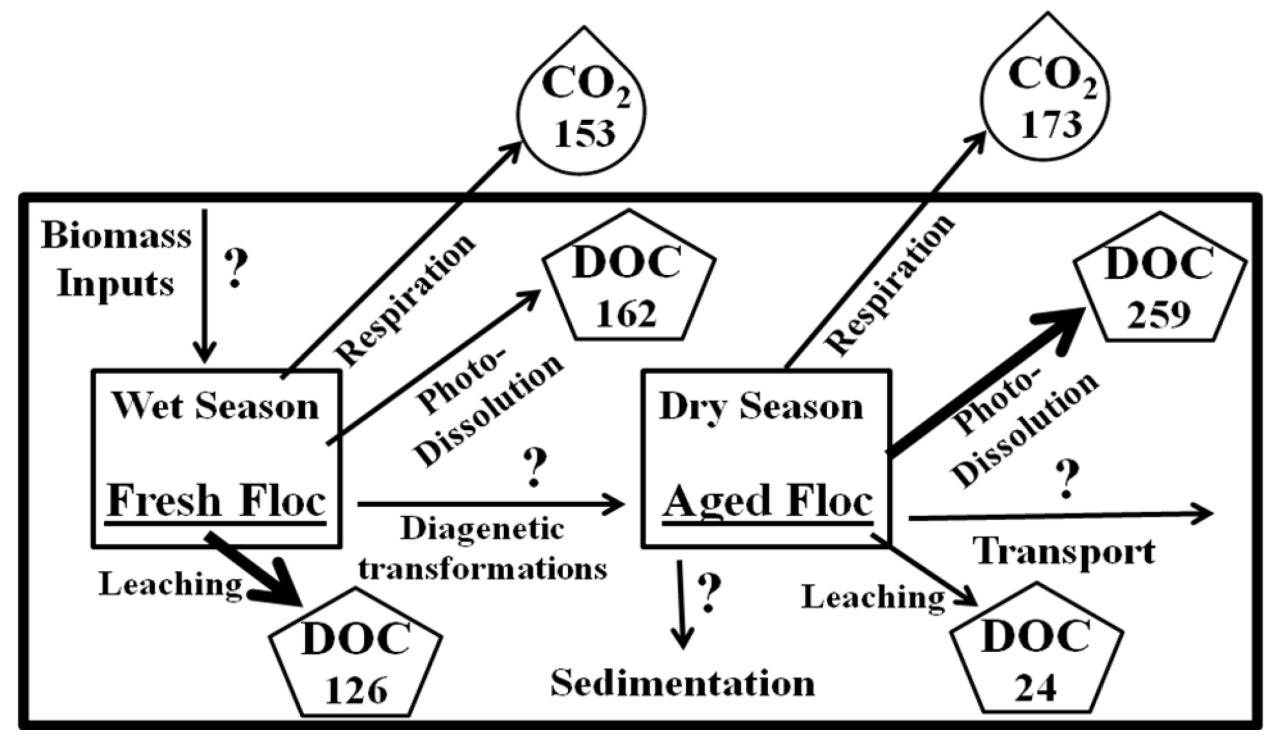

Figure 6.1. Conceptual diagram of carbon fluxes from floc collected at the short

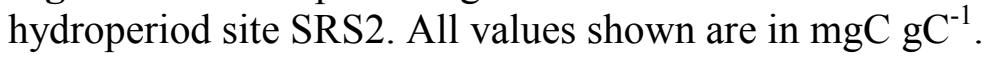

Flocculent material from the FCE receives significant OM inputs from the dominant local biomass and these inputs are highly variable on both spatial and seasonal scales (Chapter 2). The exact quantity of floc OM that is derived from the dominant local 
biomass versus transport from other areas is not known (Figure 6.1) and is likely to change with hydrological and primary productivity patterns. It was found that the floc material from the freshwater marshes is dominated by cyanobacteria and receives inputs from the periphyton mats as well as from other floating and emergent vegetation.

Differences were found in the OM composition of floc between the long (SRS2) and the short (TS2) hydroperiod sites. While TS2 floc receives more periphyton-derived inputs, the floc found at SRS2 showed a better accumulation and preservation of this material. In fact, complete dry-downs occurring during the dry season at the short hydroperiod site can cause oxidation and degradation of the $\mathrm{OM}$ present, leading to a faster incorporation of floc materials to the underlying soil. Furthermore, the floc collected at the long hydroperiod site contained more OM derived from the floating macrophyte Utricularia purpurea while the floc from the short hydroperiod site was dominated by inputs from emergent vegetation such as Cladium jamaicense.

Differences were also found in the OM composition of the floc collected at the two mangrove-dominated estuarine sites. Pigment analysis revealed that the chemotaxonomic composition of floc collected at TS6 is dominated by cyanobacteria, while the floc at SRS6 is dominated by diatoms, most likely deriving from the Gulf of Mexico. Furthermore, the floc from TS6, in particular from the pond site, contains more microbial OM ( $\mathrm{C}_{17} n$-alkane) as well as more live algal compponents (total chlorophylla). Finally, other biomarker analyses $\left(\mathrm{P}_{\mathrm{aq}}\right)$ showed that floc $\mathrm{OM}$ inputs are dominated by mangroves but that other dominant salt-tolerant vegetation, such as Batis maritima and Chara can also contribute to the floc at these estuarine sites. 
The floc reactivity studies allowed for a differentiation of two pools of floc present in the dry and the wet seasons (Figure 6.1). Floc has been found to receive most of its OM inputs during the wet season, when the local biomass is more productive. Therefore, it is expected that the floc found during this time is fresher in composition compared to the older, more degraded and aged material that is present during the dry season. Although floc present in the dry season also receives direct biomass inputs, the OM has likely undergone some diagenetic transformations that can potentially affect both its photo- (Chapter 3) and bio-reactivity (Chapter 4).

In the shallow waters of the FCE, floc is naturally re-suspended through wind and bio-turbation, and so has the chance to be exposed to significant amounts of sunlight. This light exposure can initiate a series of reactions and alterations in floc, potentially affecting its environmental dynamics and ecosystem functions. Thus, it is important to determine the photo-chemical reactivity of floc in the FCE in order to estimate the potential contribution of such processes to the dissolved organic matter (DOM) pool and its overall influence on the biogeochemistry of this ecosystem. It was found that floc can release significant amounts of dissolved materials (dissolved organic carbon; DOC, total dissolved nitrogen; TDN and soluble reactive phosphorus; SRP) when exposed to artificial sunlight. These photo-induced dissolution processes are especially important in the oligotrophic waters of the FCE where the concentrations of dissolved nutrients are naturally very low. Figure 6.1 shows that the photo-induced generation of DOC is higher for floc collected in the dry $\left(259 \mathrm{mgC} \mathrm{gC}^{-1}\right)$ compared to the wet season $\left(162 \mathrm{mgC} \mathrm{gC}^{-1}\right)$. The amount of DOC that is leached from floc (determined from experimental dark controls) however, is higher in the wet $\left(126 \mathrm{mgC} \mathrm{gC}^{-1}\right)$ compared to the dry season 
$\left(24 \mathrm{mgC} \mathrm{gC}^{-1}\right)$ most likely due to the more labile nature of the OM present during the wet season.

Freshwater floc (SRS2) photo-generated more DOM compared to mangrove floc (SRS6) and the generation rate of this material was much higher for floc at the former compared to the latter site. This suggests that there are differences in floc composition between the freshwater and mangrove sites that are reflected in differences in their photoreactivity. Seasonal differences were also found in floc photo-reactivity, with DOM generation rates being much higher in the dry compared to the wet season. This indicates that the more degraded and aged material present in the dry season is much more photoreactive compared to fresher OM found in the wet season (Figure 6.1). In summary, the efficiency of these photo-dissolution processes on floc is dependent on its quality, which seems dependent on biomass type inputs and primary productivity on both spatial and temporal scales.

In terms of bio-reactivity, it was found that the total amount of $\mathrm{CO}_{2}$ evolved from floc is highly variable on both spatial and seasonal scales and that this process is highly dependent on phosphorus limitation. Floc samples from the short hydroperiod freshwater marsh site (TS2) generated more $\mathrm{CO}_{2}$ compared to the long hydroperiod site (SRS2) and the respiration rates were found to be higher for the former compared to the latter site. This observed difference in floc respiration may be due to the different hydrology at the two sites as well as a higher amount of periphyton-derived OM at TS2 compared to SRS2. Furthermore, the periphyton mats at the short hydroperiod site have been shown to be more productive which may be accelerating floc respiration rates. The mangrovedominated sites were also different with SRS6 generating more cumulative $\mathrm{CO}_{2}$ 
compared to TS6. Phosphorus limitation has been shown to have a direct effect on this process and most likely explains this observed difference. However, the floc from TS6 generated $\mathrm{CO}_{2}$ at a faster rate compared to SRS6 likely as a result of the presence of more labile, microbially derived OM at this site.

Finally, seasonal differences in floc respiration rates were also found (Figure 6.1). Generally, more $\mathrm{CO}_{2}$ was generated from floc collected in the dry $\left(173 \mathrm{mgC} \mathrm{gC}^{-1}\right)$

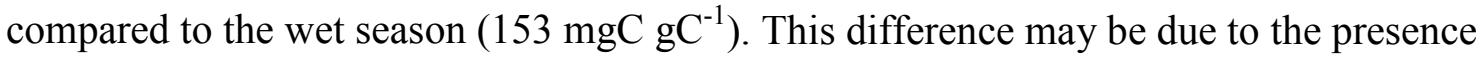
of a larger pool of diagenetically transformed and more respirable floc OM found during the dry season. On the other hand, respiration rates were higher in the wet season, suggesting a higher co-metabolism due to the presence of fresh OM derived from the local biomass. These spatial and seasonal differences seem to be driven by hydrologic regimes (long vs. short-hydroperiod), productivity of the local vegetation and periphyton, nutrient availability (phosphorus limitation), as well as carbon quality and substrate age.

The FCE is an oligotrophic subtropical wetland, where detrital carbon pools are critical components of the food web and control to a significant extent the trophic dynamics in this system. However, floc remains an elusive part of the FCE carbon cycle because of the difficulties associated in measuring its physical transport and reactivity. Potential changes, such as increased water delivery, particularly through Shark River Slough as a result of the implementation of the Comprehensive Everglades Restoration Plan may induce changes in floc dynamics in this system. Figure 6.1 illustrates some of the key carbon fluxes from floc to the dissolved (DOC) and gas $\left(\mathrm{CO}_{2}\right)$ phases and summarizes the seasonal effects on these processes. In order to produce a balanced carbon budget for the FCE, flux numbers need to be associated with the remaining arrows 
shown in this figure. Quantifying direct biomass inputs to the floc layer, as well as its sedimentation and transport from the freshwater marshes to the estuarine ecotone will provide a better understanding of the environmental dynamics of floc, which is needed to accurately assess carbon cycling in the Everglades ecosystem. 
APPENDICES 


\section{Appendix 2.1.}

Typical RP-HPLC chromatograms of periphyton and floc samples from the Florida Coastal Everglades.

\section{Periphyton:}
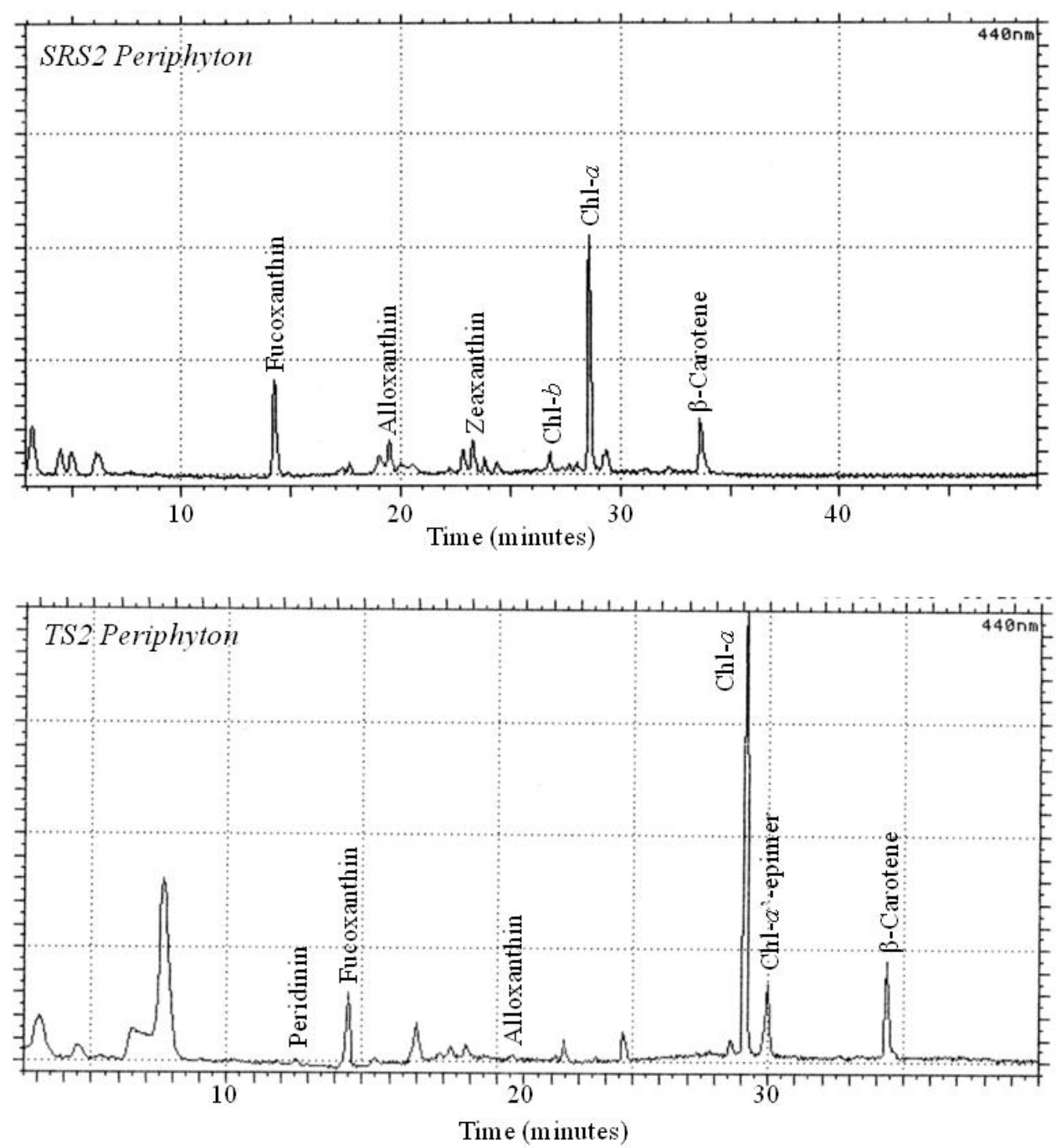
Floc:
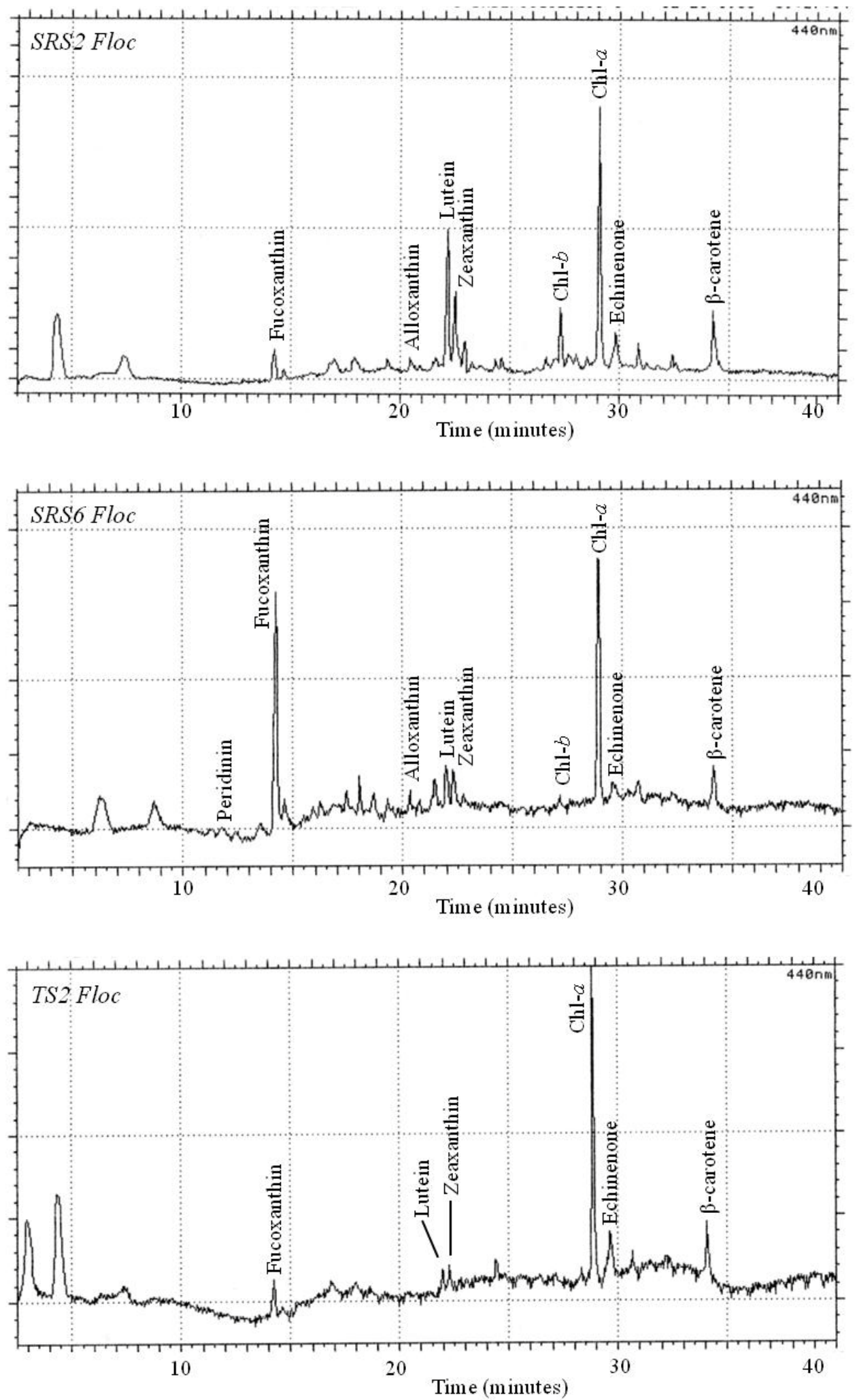

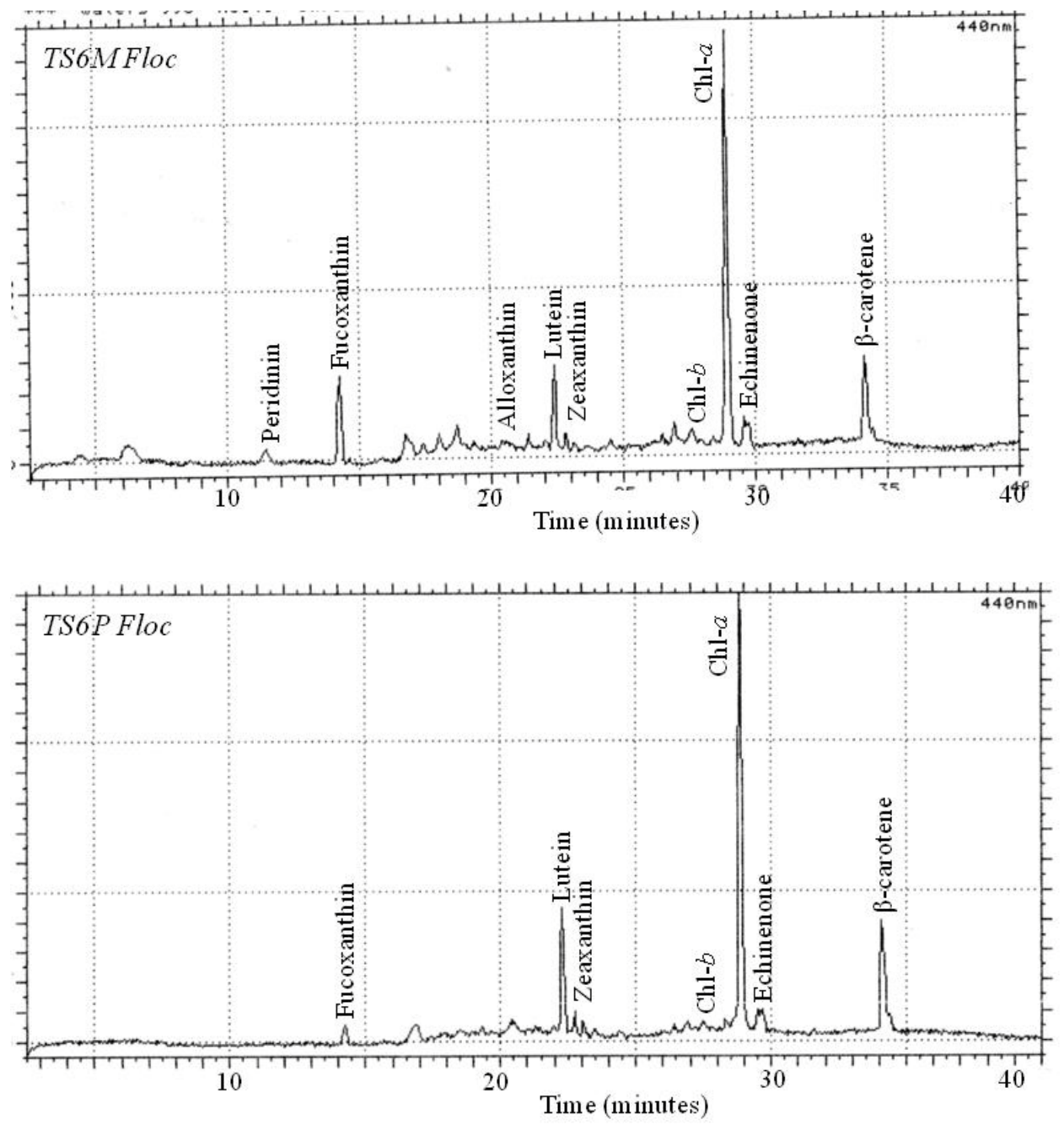

UV-Vis spectra and molecular structures of selected pigment biomarkers:

\section{Primary pigments (chlorophylls):}
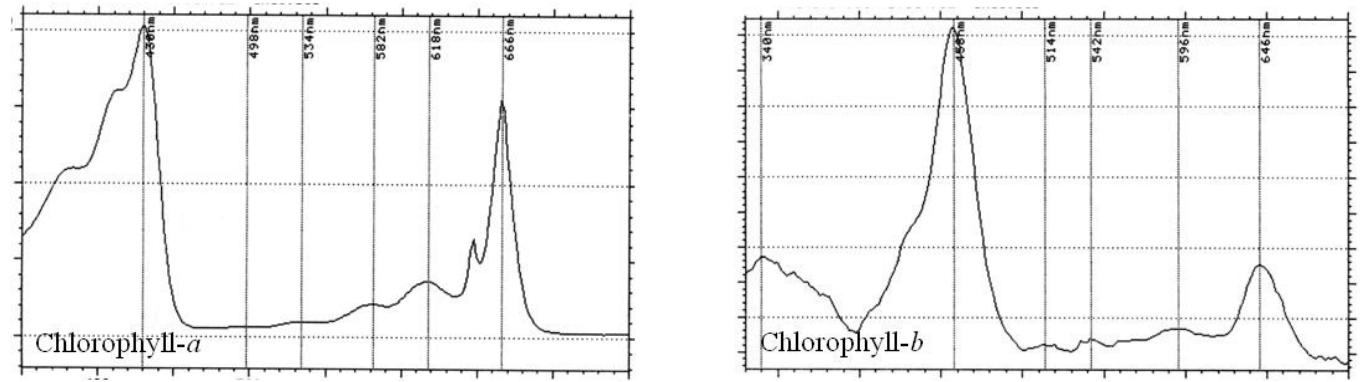


\section{Secondary/accessory pigments (carotenoids):}
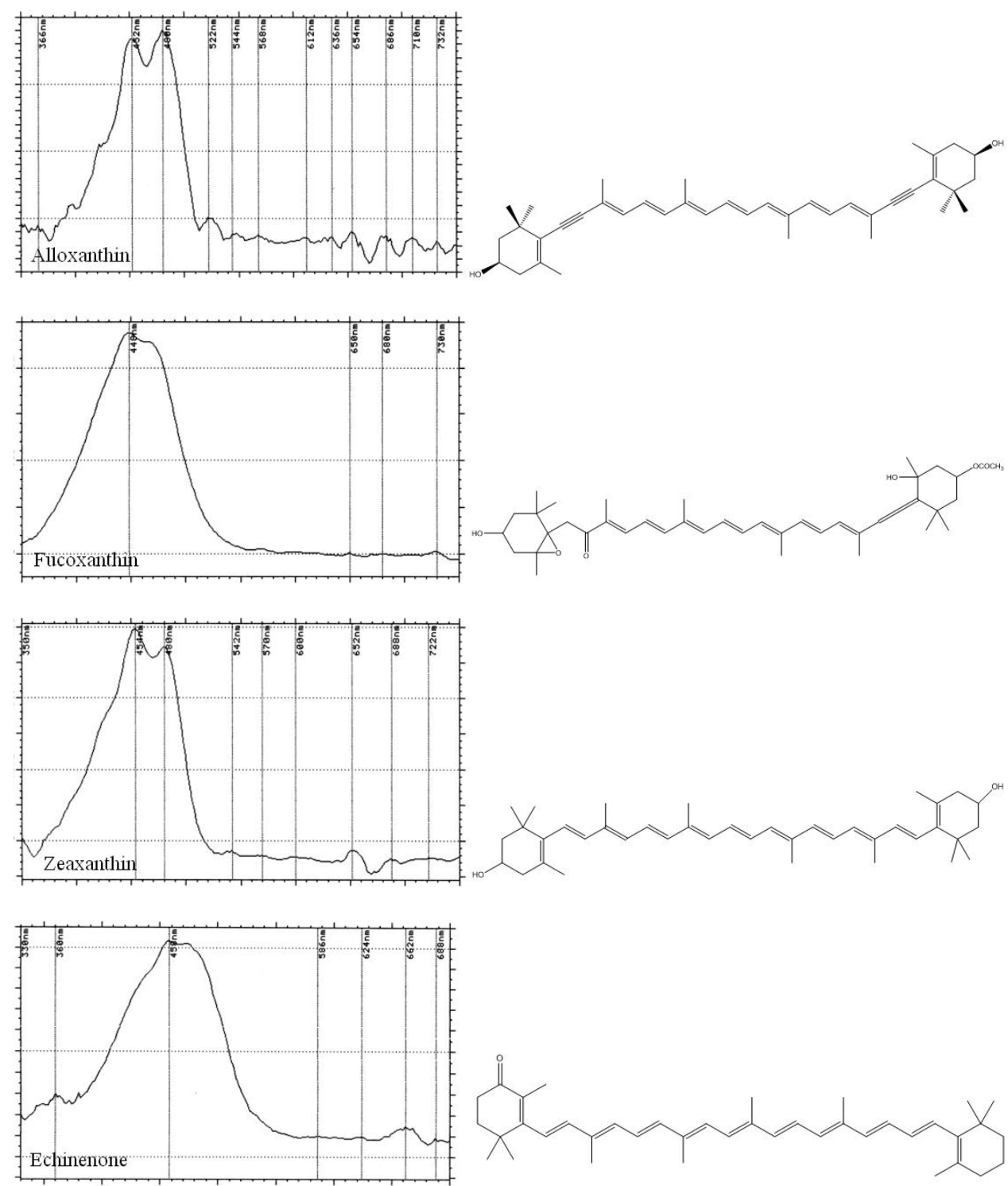
Appendix 2.2. Data tables summarizing bulk parameters (floc depth, density and organic matter content), pigments (chlorophyll- $a$, pheopigments and chemotaxonomic composition) and biomarker ( $n$-alkanes, $n$-alkenes, $\mathrm{C}_{20}$ highly branched isoprenoid, botryococcenes and kaurenes) concentrations in periphyton and floc samples from the Florida Coastal Everglades.

For all of the following tables the sampling season is defined as follows: Early wet (EW; May-July), late wet (LW; August-November) and dry (D; December-May). 
Table A2.1. Bulk parameters (depth, bulk density and \%OM) for Everglades' floc samples.

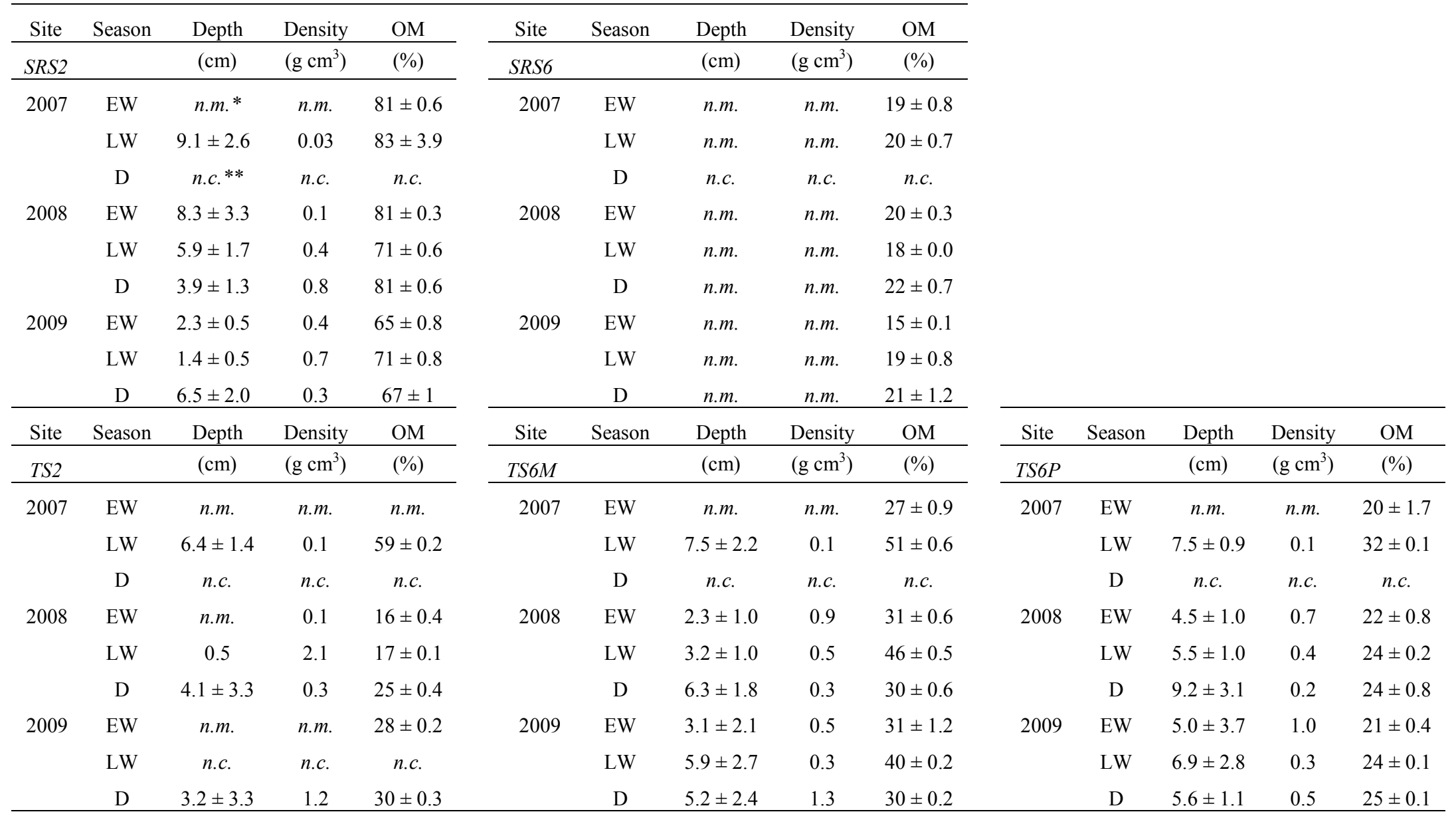

All values are averages \pm standard deviation, except bulk density measurements are single values.

* parameter was not measured.

**sample was not collected. 
Table A2.2. Organic matter content (\%OM) of Everglades' periphyton samples.

\begin{tabular}{|c|c|c|c|c|c|}
\hline Periphyton & Season & $\mathrm{OM}$ & Periphyton & Season & $\mathrm{OM}$ \\
\hline$S R S 2$ & & $(\%)$ & TS2 & & $(\%)$ \\
\hline \multirow[t]{3}{*}{2007} & EW & $47 \pm 0.4$ & 2007 & EW & $32 \pm 0.08$ \\
\hline & LW & $59 \pm 0.8$ & & LW & $35 \pm 0.4$ \\
\hline & D & n.c. ${ }^{*}$ & & D & n.c. \\
\hline \multirow[t]{3}{*}{2008} & EW & n.c. & 2008 & EW & n.c. \\
\hline & LW & $72 \pm 0.6$ & & LW & $37 \pm 0.2$ \\
\hline & D & $61 \pm 0.2$ & & D & $37 \pm 0.2$ \\
\hline \multirow[t]{3}{*}{2009} & EW & $76 \pm 0.6$ & 2009 & EW & n.c. \\
\hline & LW & $55 \pm 0.2$ & & LW & n.c. \\
\hline & D & $41 \pm 0.6$ & & D & $34 \pm 0.1$ \\
\hline
\end{tabular}

All values are averages \pm standard deviations.

*sample was not collected. 
Table A2.3. Concentrations of chlorophyll- $a$ ( $\Sigma \mathrm{CHL} a$ ), pheopigments ( $\Sigma a$-derivs) and chemotaxonomic composition (cyanobacteria, green algae and diatoms) of periphyton samples.

\begin{tabular}{|c|c|c|c|c|c|c|}
\hline & Season & $\Sigma \mathrm{CHL} a$ & $\Sigma a$-derivs & Cyanobacteria & Green Algae & Diatoms \\
\hline$S R S 2$ & & $\left(\mu \mathrm{gOOM}^{-1}\right)$ & $\left(\mu \mathrm{g} \mathrm{gOM}^{-1}\right)$ & $(\%)$ & $(\%)$ & $(\%)$ \\
\hline \multirow[t]{3}{*}{2007} & EW & 17054 & 0 & 5.8 & 29 & 35 \\
\hline & LW & 6606 & 299 & 75 & 11 & 12 \\
\hline & $\mathrm{D}$ & n.c. ${ }^{*}$ & n.c. & n.c. & n.c. & n.c. \\
\hline \multirow[t]{3}{*}{2008} & EW & n.c. & n.c. & n.c. & n.c. & n.c. \\
\hline & LW & 3740 & 242 & 55 & 14 & 25 \\
\hline & $\mathrm{D}$ & 11735 & 1078 & 79 & 10 & 11 \\
\hline \multirow[t]{2}{*}{2009} & EW & 3319 & 0 & 61 & 35 & 1.8 \\
\hline & LW & 6190 & 162 & 95 & 0.9 & 3.1 \\
\hline TS2 & $\mathrm{D}$ & 9571 & 546 & 83 & 4.1 & 11 \\
\hline \multirow[t]{3}{*}{2007} & EW & 4032 & 1355 & 12 & 0 & 43 \\
\hline & LW & 7956 & 918 & 93 & 1.6 & 3.2 \\
\hline & $\mathrm{D}$ & n.c. & n.c. & n.c. & n.c. & n.c. \\
\hline \multirow[t]{3}{*}{2008} & EW & n.c. & n.c. & n.c. & n.c. & n.c. \\
\hline & LW & 2724 & 43 & 97 & 0 & 3.0 \\
\hline & $\mathrm{D}$ & 12266 & 491 & 100 & 0 & 0 \\
\hline \multirow[t]{3}{*}{2009} & EW & n.c. & n.c. & n.c. & n.c. & n.c. \\
\hline & LW & n.c. & n.c. & n.c. & n.c. & n.c. \\
\hline & D & 4230 & 268 & 87 & 1.4 & 7.8 \\
\hline
\end{tabular}

*n.c. $=$ sample was not collected. 
Table A2.4. Concentration of chlorophyll- $a$ ( $\Sigma \mathrm{CHL} a$ ), pheopigments ( $\Sigma a$-derivs) and chemotaxonomic composition (cyanobacteria, green algae and diatoms) floc samples.

\begin{tabular}{|c|c|c|c|c|c|c|c|}
\hline & Season & $\Sigma \mathrm{CHL} a$ & $\Sigma a$-derivs & Cyanobacteria & Green Algae & Diatoms & Cryptophytes \\
\hline SRS2 & & $\left(\mu \mathrm{g} \mathrm{gOM}^{-1}\right)$ & $\left(\mu \mathrm{gOM}^{-1}\right)$ & $(\%)$ & $(\%)$ & $(\%)$ & $(\%)$ \\
\hline \multirow[t]{3}{*}{2007} & EW & 27 & 59 & 55 & 36 & 5.8 & 3.4 \\
\hline & LW & 357 & 1753 & 51 & 23 & 12 & 14 \\
\hline & $\mathrm{D}$ & n.c. ${ }^{*}$ & n.c. & n.c. & n.c. & n.c. & n.c. \\
\hline \multirow[t]{3}{*}{2008} & EW & 1055 & 482 & 57 & 34 & 2.9 & 6.1 \\
\hline & LW & 956 & 416 & 57 & 36 & 6.4 & 0.0 \\
\hline & $\mathrm{D}$ & 445 & 664 & 72 & 21 & 2.0 & 5.0 \\
\hline \multirow[t]{2}{*}{2009} & EW & 992 & 345 & 72 & 20 & 0.0 & 6.5 \\
\hline & LW & 345 & 134 & 83 & 0.0 & 3.9 & 14 \\
\hline SRS6 & $\mathrm{D}$ & 942 & 560 & 47 & 30 & 23 & 0 \\
\hline \multirow[t]{3}{*}{2007} & EW & 103 & 24 & 0.0 & 44 & 56 & 0.0 \\
\hline & LW & 86 & 65 & 67 & 17 & 15 & 1.2 \\
\hline & $\mathrm{D}$ & n.c. & n.c. & n.c. & n.c. & n.c. & n.c. \\
\hline \multirow[t]{3}{*}{2008} & EW & 289 & 90 & 3.2 & 0.0 & 97 & 0.0 \\
\hline & LW & 1240 & 1303 & 22 & 8.8 & 46 & 11 \\
\hline & $\mathrm{D}$ & 404 & 462 & 51 & 4.3 & 37 & 1.5 \\
\hline \multirow[t]{2}{*}{2009} & EW & 590 & 215 & 31 & 15 & 54 & 0.0 \\
\hline & LW & 333 & 331 & 5.7 & 18 & 63 & 6.9 \\
\hline$T S 2$ & D & 295 & 487 & 28 & 18 & 21 & 25 \\
\hline \multirow[t]{3}{*}{2007} & EW & $n . m . * *$ & n.m. & n.m. & n.m. & n.m. & n.m. \\
\hline & LW & 346 & 298 & 50 & 33 & 0.0 & 18 \\
\hline & $\mathrm{D}$ & n.c. & n.c. & n.c. & n.c. & n.c. & n.c. \\
\hline \multirow[t]{3}{*}{2008} & EW & 1927 & 357 & 89 & 0.0 & 11 & 0.0 \\
\hline & LW & 1123 & 344 & 88 & 0.0 & 12 & 0.0 \\
\hline & $\mathrm{D}$ & 849 & 257 & 62 & 0.0 & 36 & 2.5 \\
\hline \multirow[t]{2}{*}{2009} & EW & 308 & 139 & 95 & 0.0 & 0.0 & 4.6 \\
\hline & LW & n.c. & n.c. & n.c. & n.c. & n.c. & n.c. \\
\hline TS6M & $\mathrm{D}$ & 796 & 333 & 84 & 0.0 & 15 & 1.0 \\
\hline \multirow[t]{3}{*}{2007} & EW & 141 & 20 & 56 & 0.0 & 14 & 29 \\
\hline & LW & 233 & 54 & 86 & 7.8 & 2.9 & 2.9 \\
\hline & $\mathrm{D}$ & n.c. & n.c. & n.c. & n.c. & n.c. & n.c. \\
\hline \multirow[t]{3}{*}{2008} & EW & 1077 & 479 & 91 & 8.6 & 0.0 & 0.0 \\
\hline & LW & 1388 & 427 & 62 & 16 & 1.0 & 10 \\
\hline & $\mathrm{D}$ & 365 & 180 & 73 & 0.0 & 25 & 1.7 \\
\hline \multirow[t]{2}{*}{2009} & EW & 808 & 139 & 69 & 10 & 21 & 0.0 \\
\hline & LW & 518 & 74 & 81 & 11 & 8.7 & 0.0 \\
\hline
\end{tabular}


Table A2.4. continued.

\begin{tabular}{cccccccc} 
TS6P & D & 1012 & 325 & 81 & 13 & 1.8 & 3.8 \\
\hline \multirow{2}{*}{2007} & EW & 1523 & 190 & 87 & 0.0 & 0.0 & 13 \\
& LW & 2724 & 223 & 99 & 0.0 & 0.7 & 0.0 \\
& D & n.c. & n.c. & n.c. & n.c. & n.c. & n.c. \\
& EW & 2223 & 266 & 54 & 0.0 & 21 & 24 \\
& LW & 2222 & 378 & 68 & 19 & 9.2 & 1.5 \\
& D & 1449 & 354 & 90 & 3.7 & 0.0 & 5.6 \\
& EW & 2187 & 800 & 69 & 17 & 14 & 0.0 \\
& LW & 2500 & 1127 & 84 & 8.2 & 5.1 & 0.0 \\
& D & 2668 & 878 & 73 & 13 & 4.4 & 10 \\
\hline
\end{tabular}

*sample was not collected.

**parameter was not measured. 
Table A2.5. Concentrations of $n$-alkanes and $n$-alkenes in SRS2 periphyton samples.

\begin{tabular}{|c|c|c|c|c|c|c|c|c|c|c|c|c|c|c|}
\hline \multirow{3}{*}{ Compound } & & & $S R S 2$ & & & & & & & & & & & \\
\hline & \multirow{2}{*}{ Formula } & \multirow{2}{*}{ MW } & \multicolumn{3}{|c|}{2007} & \multirow[b]{2}{*}{ Mean } & \multicolumn{3}{|c|}{2008} & \multirow[b]{2}{*}{ Mean } & \multicolumn{3}{|c|}{2009} & \multirow[b]{2}{*}{ Mean } \\
\hline & & & EW & LW & $\mathrm{D}$ & & EW & LW & $\mathrm{D}$ & & EW & LW & $\mathrm{D}$ & \\
\hline \multicolumn{15}{|l|}{ n-alkanes } \\
\hline Tetradecane & $\mathrm{C}_{14} \mathrm{H}_{30}$ & 198 & 0.13 & 0.28 & n.c. & 0.21 & n.c. & & & & & & & \\
\hline Pentadecane & $\mathrm{C}_{15} \mathrm{H}_{32}$ & 212 & 17 & 81 & n.c. & 49 & n.c. & 279 & 52 & 166 & 2.2 & 14 & 10 & 9.1 \\
\hline Hexadecane & $\mathrm{C}_{16} \mathrm{H}_{34}$ & 226 & 1.0 & 3.8 & n.c. & 2.4 & n.c. & 14 & 3.1 & 8.6 & 0.44 & 1.3 & 0.90 & 0.89 \\
\hline Heptadecane & $\mathrm{C}_{17} \mathrm{H}_{36}$ & 240 & 29 & 267 & n.c. & 148 & n.c. & 724 & 207 & 466 & 20 & 66 & 43 & 43 \\
\hline Octadecane & $\mathrm{C}_{18} \mathrm{H}_{38}$ & 254 & 0.47 & 2.0 & n.c. & 1.2 & n.c. & 14 & 2.6 & 8.4 & 1.8 & 0.85 & 0.51 & 1.1 \\
\hline Nonadecane & $\mathrm{C}_{19} \mathrm{H}_{40}$ & 268 & 0.76 & 2.8 & n.c. & 1.8 & n.c. & 11 & 2.8 & 6.7 & 2.0 & 0.55 & 0.63 & 1.0 \\
\hline Eicosane & $\mathrm{C}_{20} \mathrm{H}_{42}$ & 282 & 0.27 & 0.48 & n.c. & 0.37 & n.c. & 1.6 & 0.33 & 0.97 & 0.99 & 0.075 & 0.13 & 0.40 \\
\hline Heneicosane & $\mathrm{C}_{21} \mathrm{H}_{44}$ & 296 & 1.5 & 1.4 & n.c. & 1.4 & n.c. & 3.8 & 1.0 & 2.4 & 2.0 & 0.20 & 0.57 & 0.91 \\
\hline Docosane & $\mathrm{C}_{22} \mathrm{H}_{46}$ & 310 & 0.78 & 0.63 & n.c. & 0.71 & n.c. & 1.6 & 0.32 & 0.94 & 0.97 & 0.072 & 0.26 & 0.43 \\
\hline Tricosane & $\mathrm{C}_{23} \mathrm{H}_{48}$ & 324 & 3.5 & 4.3 & n.c. & 3.9 & n.c. & 18 & 3.4 & 11 & 3.8 & 0.36 & 1.2 & 1.8 \\
\hline Tetracosane & $\mathrm{C}_{24} \mathrm{H}_{50}$ & 338 & 1.5 & 1.4 & n.c. & 1.5 & n.c. & 2.8 & 0.89 & 1.8 & 1.8 & 0.18 & 0.40 & 0.78 \\
\hline Pentacosane & $\mathrm{C}_{25} \mathrm{H}_{52}$ & 352 & 7.5 & 10 & n.c. & 9.0 & n.c. & 16 & 7.7 & 12 & 8.8 & 0.93 & 2.7 & 4.1 \\
\hline Hexacosane & $\mathrm{C}_{26} \mathrm{H}_{54}$ & 366 & 2.0 & 2.1 & n.c. & 2.1 & n.c. & 4.0 & 1.9 & 3.0 & 2.7 & 0.38 & 0.61 & 1.2 \\
\hline Heptacosane & $\mathrm{C}_{27} \mathrm{H}_{56}$ & 380 & 11 & 13 & n.c. & 12 & n.c. & 25 & 13 & 19 & 12 & 2.1 & 3.7 & 5.8 \\
\hline Octacosane & $\mathrm{C}_{28} \mathrm{H}_{58}$ & 394 & 1.7 & 1.8 & n.c. & 1.7 & n.c. & 4.7 & 2.1 & 3.4 & 4.7 & 0.43 & 0.94 & 2.0 \\
\hline Nonacosane & $\mathrm{C}_{29} \mathrm{H}_{60}$ & 408 & 8.6 & 11 & n.c. & 9.8 & n.c. & 26 & 11 & 18 & 12 & 2.4 & 3.9 & 6.1 \\
\hline Triacontane & $\mathrm{C}_{30} \mathrm{H}_{62}$ & 422 & 0.68 & 0.61 & n.c. & 0.64 & n.c. & 1.5 & 0.40 & 0.94 & 1.5 & 0.12 & 0.21 & 0.62 \\
\hline Hentriacontane & $\mathrm{C}_{31} \mathrm{H}_{64}$ & 436 & 2.6 & 3.0 & n.c. & 2.8 & n.c. & 8.0 & 2.4 & 5.2 & 6.0 & 0.66 & 1.2 & 2.6 \\
\hline Dotriacontane & $\mathrm{C}_{32} \mathrm{H}_{66}$ & 450 & 0.24 & 0.21 & n.c. & 0.23 & n.c. & & 0.19 & 0.19 & 1.6 & & 0.15 & 0.90 \\
\hline Tritriacontane & $\mathrm{C}_{33} \mathrm{H}_{68}$ & 464 & 1.2 & 1.3 & n.c. & 1.2 & n.c. & 2.4 & 1.3 & 1.8 & 4.0 & 0.31 & 0.64 & 1.6 \\
\hline Tetratriacontane & $\mathrm{C}_{34} \mathrm{H}_{70}$ & 478 & 0.99 & 0.64 & n.c. & 0.81 & n.c. & & 0.40 & 0.40 & & & & \\
\hline Pentatriacontane & $\mathrm{C}_{35} \mathrm{H}_{72}$ & 492 & 0.19 & 0.20 & n.c. & 0.20 & n.c. & & 0.14 & 0.14 & 0.60 & & & 0.60 \\
\hline Total & & & 93 & 410 & & 251 & & 1159 & 314 & 736 & 90 & 91 & 72 & 84 \\
\hline $\mathrm{P}_{\mathrm{aq}}{ }^{\mathrm{a}}$ & & & 0.49 & 0.51 & & 0.50 & & 0.51 & 0.46 & 0.48 & 0.41 & 0.29 & 0.44 & 0.38 \\
\hline $\mathrm{CPI}^{\mathrm{b}}$ & & & 8.4 & 28 & & 18 & & 25 & 25 & 25 & 4.4 & 26 & 17 & 16 \\
\hline Long/short $^{\mathrm{c}}$ & & & 0.91 & 0.15 & & 0.53 & & 0.11 & 0.17 & 0.14 & 2.4 & 0.10 & 0.30 & 0.92 \\
\hline
\end{tabular}


Table A2.5. continued.

\begin{tabular}{|c|c|c|c|c|c|c|c|c|c|c|c|c|c|c|}
\hline $\begin{array}{l}\mathrm{C}_{\max } \\
\text { n-alkenes }\end{array}$ & & & 17 & 17 & & 17 & & 17 & 17 & 17 & 17 & 17 & 17 & 17 \\
\hline Heptadecene & $\mathrm{C}_{17} \mathrm{H}_{34}$ & 238 & & & n.c. & & n.c. & 21 & 16 & 19 & 0.81 & 2.5 & 3.9 & 2.4 \\
\hline Octadecene & $\mathrm{C}_{18} \mathrm{H}_{36}$ & 252 & 0.72 & 12 & n.c. & 6.2 & n.c. & 8.8 & 4.8 & 6.8 & & 1.8 & 1.7 & 1.7 \\
\hline Nonadecene & $\mathrm{C}_{19} \mathrm{H}_{38}$ & 266 & 0.89 & 7.2 & n.c. & 4.0 & n.c. & 7.4 & 2.7 & 5.0 & 2.7 & 2.2 & 1.3 & 2.1 \\
\hline Eicosene & $\mathrm{C}_{20} \mathrm{H}_{40}$ & 280 & 0.10 & 0.11 & n.c. & 0.10 & n.c. & & 0.52 & 0.52 & & 0.024 & 0.091 & 0.058 \\
\hline Heneicosene & $\mathrm{C}_{21} \mathrm{H}_{42}$ & 294 & 0.87 & 0.34 & n.c. & 0.60 & n.c. & 2.6 & 0.47 & 1.5 & 0.55 & 0.10 & 0.23 & 0.30 \\
\hline Docosene & $\mathrm{C}_{22} \mathrm{H}_{44}$ & 308 & 0.25 & 0.16 & n.c. & 0.21 & n.c. & & 0.068 & 0.068 & 0.13 & 0.014 & 0.085 & 0.078 \\
\hline Tricosene & $\mathrm{C}_{23} \mathrm{H}_{46}$ & 322 & 0.53 & 0.36 & n.c. & 0.45 & n.c. & 1.4 & 0.43 & 0.90 & 0.40 & 0.083 & 0.16 & 0.21 \\
\hline Tretracosene & $\mathrm{C}_{24} \mathrm{H}_{48}$ & 336 & 0.37 & 0.44 & n.c. & 0.41 & n.c. & & 0.30 & 0.30 & 0.34 & 0.020 & 0.085 & 0.15 \\
\hline Pentacosene & $\mathrm{C}_{25} \mathrm{H}_{50}$ & 350 & 0.41 & 0.35 & n.c. & 0.38 & n.c. & 1.7 & 0.62 & 1.1 & 0.69 & 0.061 & 0.22 & 0.32 \\
\hline Hexacosene & $\mathrm{C}_{26} \mathrm{H}_{52}$ & 364 & 0.61 & 0.44 & n.c. & 0.52 & n.c. & & 0.78 & 0.78 & 0.57 & 0.043 & 0.19 & 0.26 \\
\hline Heptacosene & $\mathrm{C}_{27} \mathrm{H}_{54}$ & 378 & 1.2 & 0.46 & n.c. & 0.82 & n.c. & 0.89 & 0.26 & 0.58 & 0.79 & 0.15 & 0.16 & 0.37 \\
\hline Octacosene & $\mathrm{C}_{28} \mathrm{H}_{56}$ & 392 & 1.2 & 0.54 & n.c. & 0.89 & n.c. & & 0.76 & 0.76 & & 0.089 & 0.34 & 0.22 \\
\hline Nonacosene & $\mathrm{C}_{29} \mathrm{H}_{58}$ & 406 & 0.31 & 0.21 & n.c. & 0.26 & n.c. & 0.61 & 0.11 & 0.36 & 1.0 & 0.037 & 0.075 & 0.39 \\
\hline Triacontene & $\mathrm{C}_{30} \mathrm{H}_{60}$ & 420 & 0.19 & 0.17 & n.c. & 0.18 & n.c. & & 0.13 & 0.13 & 0.25 & & & 0.25 \\
\hline Total & & & 7.7 & 22 & & 15 & & 23 & 12 & 18 & 7.5 & 4.7 & 4.6 & 5.6 \\
\hline $\mathrm{CPI}^{\mathrm{d}}$ & & & 1.2 & 0.66 & & 0.93 & & 4.0 & 2.8 & 3.4 & 5.4 & 2.6 & 2.4 & 3.5 \\
\hline Long/short ${ }^{\mathrm{e}}$ & & & 3.8 & 0.19 & & 2.0 & & 0.19 & 0.19 & 0.19 & 1.4 & 0.096 & 0.24 & 0.56 \\
\hline $\mathrm{C}_{\max }$ & & & 28 & 18 & & 23 & & 17 & 17 & 17 & 19 & 17 & 17 & 18 \\
\hline
\end{tabular}

All values are reported in $\mu \mathrm{g} \mathrm{gOM}^{-1}$.

${ }^{\mathrm{a}} \mathrm{P}_{\mathrm{aq}}=\left(\mathrm{C}_{23}+\mathrm{C}_{25}\right) /\left(\mathrm{C}_{23}+\mathrm{C}_{25}+\mathrm{C}_{29}+\mathrm{C}_{31}\right)$

${ }^{\mathrm{b}} \mathrm{CPI}=\left(\left(\Sigma \mathrm{C}_{15}-\mathrm{C}_{35}\right)_{\text {odd }}\right) /\left(\left(\Sigma \mathrm{C}_{14}-\mathrm{C}_{34}\right)_{\text {even }}\right)$

${ }^{\mathrm{c}}$ Long/short $=\Sigma \mathrm{C} \geq 20 / \Sigma \mathrm{C} \leq 19$

${ }^{\mathrm{d}} \mathrm{CPI}=\left(\left(\Sigma \mathrm{C}_{17}-\mathrm{C}_{29}\right)_{\text {odd }}\right) /\left(\left(\Sigma \mathrm{C}_{18}-\mathrm{C}_{30}\right)_{\text {even }}\right)$

${ }^{\mathrm{e}}$ Long/short $=\Sigma \mathrm{C} \geq 20 / \Sigma \mathrm{C} \leq 19$ 
Table A2.6. Concentrations of $n$-alkanes and $n$-alkenes in TS2 periphyton samples.

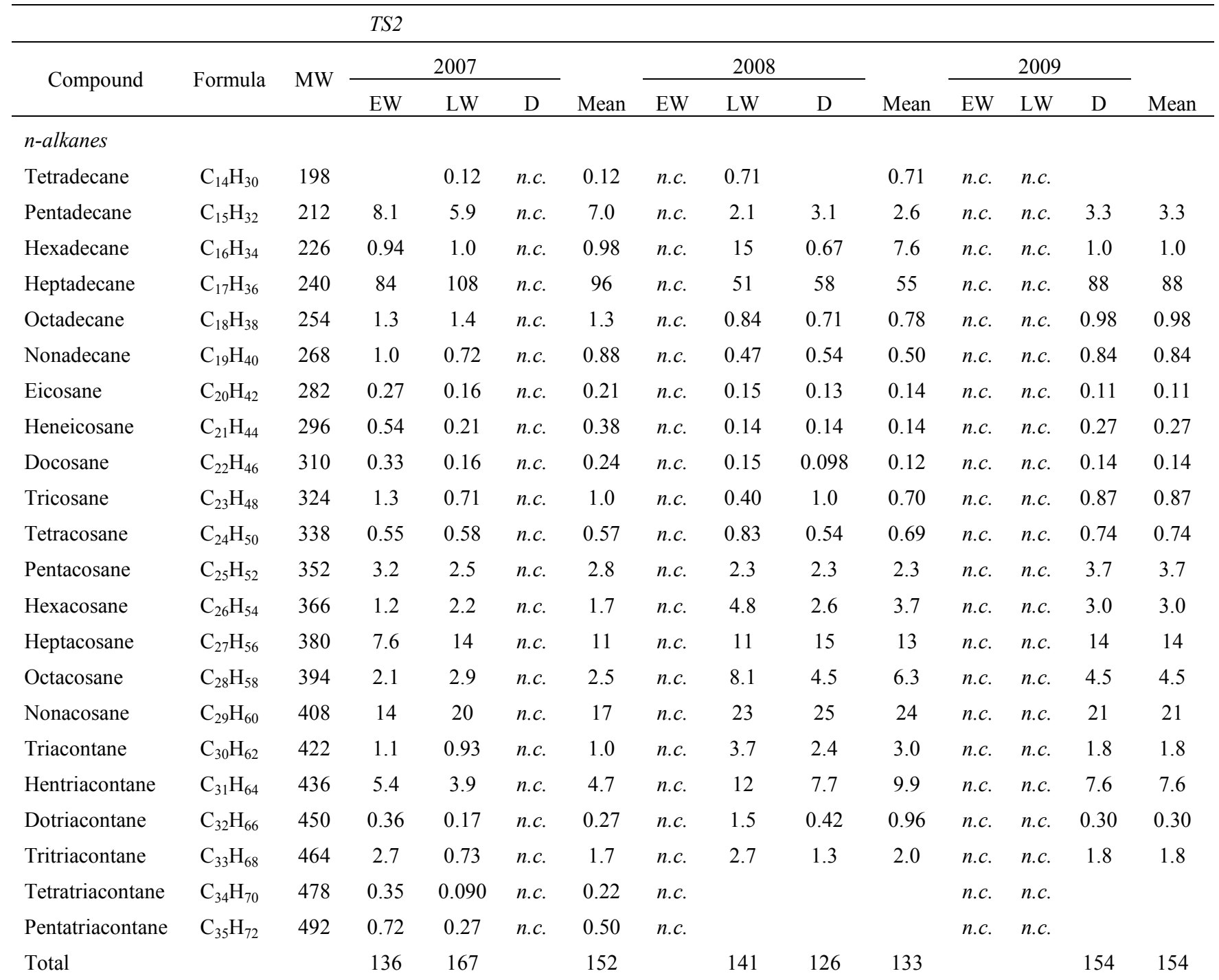


Table A2.6. continued.

\begin{tabular}{|c|c|c|c|c|c|c|c|c|c|c|c|c|c|c|}
\hline $\mathrm{P}_{\mathrm{aq}}^{\mathrm{a}}$ & & & 0.19 & 0.12 & & 0.15 & & 0.071 & 0.093 & 0.082 & & & 0.14 & 0.14 \\
\hline $\mathrm{CPI}^{\mathrm{b}}$ & & & 15 & 16 & & 16 & & 3.0 & 9.4 & 6.2 & & & 11 & 11 \\
\hline Long/short ${ }^{\mathrm{c}}$ & & & 0.44 & 0.43 & & 0.43 & & 1.0 & 0.99 & 1.0 & & & 0.63 & 0.63 \\
\hline $\mathrm{C}_{\max }$ & & & 17 & 17 & & 17 & & 17 & 17 & 17 & & & 17 & 17 \\
\hline \multicolumn{15}{|l|}{ n-alkenes } \\
\hline Heptadecene & $\mathrm{C}_{17} \mathrm{H}_{34}$ & 238 & & & n.c. & & n.c. & 2.6 & 16 & 9.2 & n.c. & n.c. & 2.6 & 2.6 \\
\hline Octadecene & $\mathrm{C}_{18} \mathrm{H}_{36}$ & 252 & 1.7 & 2.3 & n.c. & 2.0 & n.c. & 2.6 & 2.7 & 2.7 & n.c. & n.c. & 2.7 & 2.7 \\
\hline Nonadecene & $\mathrm{C}_{19} \mathrm{H}_{38}$ & 266 & 1.4 & 0.82 & n.c. & 1.1 & n.c. & 0.55 & 0.79 & 0.67 & n.c. & n.c. & 7.0 & 7.0 \\
\hline Eicosene & $\mathrm{C}_{20} \mathrm{H}_{40}$ & 280 & & 1.2 & n.c. & 1.2 & n.c. & 0.48 & 1.5 & 1.0 & n.c. & n.c. & 2.5 & 2.5 \\
\hline Heneicosene & $\mathrm{C}_{21} \mathrm{H}_{42}$ & 294 & & 0.11 & n.c. & 0.11 & n.c. & 0.072 & 0.18 & 0.13 & n.c. & n.c. & 0.63 & 0.63 \\
\hline Docosene & $\mathrm{C}_{22} \mathrm{H}_{44}$ & 308 & & 0.043 & n.c. & 0.043 & n.c. & 0.039 & 0.025 & 0.032 & n.c. & n.c. & 0.13 & 0.13 \\
\hline Tricosene & $\mathrm{C}_{23} \mathrm{H}_{46}$ & 322 & 0.13 & 0.088 & n.c. & 0.11 & n.c. & 0.13 & 0.072 & 0.10 & n.c. & n.c. & 0.12 & 0.12 \\
\hline Tretracosene & $\mathrm{C}_{24} \mathrm{H}_{48}$ & 336 & 0.10 & 0.17 & n.c. & 0.14 & n.c. & 0.27 & 0.14 & 0.20 & n.c. & n.c. & 0.24 & 0.24 \\
\hline Pentacosene & $\mathrm{C}_{25} \mathrm{H}_{50}$ & 350 & 0.16 & 0.22 & n.c. & 0.19 & n.c. & 0.29 & 0.24 & 0.26 & n.c. & n.c. & 0.28 & 0.28 \\
\hline Hexacosene & $\mathrm{C}_{26} \mathrm{H}_{52}$ & 364 & 0.26 & 0.79 & n.c. & 0.53 & n.c. & 1.1 & 0.88 & 0.97 & n.c. & n.c. & 1.0 & 1.0 \\
\hline Heptacosene & $\mathrm{C}_{27} \mathrm{H}_{54}$ & 378 & 0.29 & 0.38 & n.c. & 0.33 & n.c. & 0.71 & 0.55 & 0.63 & n.c. & n.c. & 0.52 & 0.52 \\
\hline Octacosene & $\mathrm{C}_{28} \mathrm{H}_{56}$ & 392 & 0.56 & 1.0 & n.c. & 0.79 & n.c. & 2.8 & 1.8 & 2.3 & n.c. & n.c. & 1.9 & 1.9 \\
\hline Nonacosene & $\mathrm{C}_{29} \mathrm{H}_{58}$ & 406 & 0.20 & 0.12 & n.c. & 0.16 & n.c. & 0.45 & 0.25 & 0.35 & n.c. & n.c. & 0.22 & 0.22 \\
\hline Triacontene & $\mathrm{C}_{30} \mathrm{H}_{60}$ & 420 & 0.26 & 0.25 & n.c. & 0.25 & n.c. & 1.0 & & 1.0 & n.c. & n.c. & 0.58 & 0.58 \\
\hline Total & & & 5.1 & 7.5 & & 6.3 & & 10 & 9.2 & 9.8 & & & 18 & 18 \\
\hline $\mathrm{CPI}^{\mathrm{d}}$ & & & 0.76 & 0.30 & & 0.53 & & 0.58 & 2.5 & 1.5 & & & 1.3 & 1.3 \\
\hline Long/short ${ }^{\mathrm{e}}$ & & & 0.63 & 1.4 & & 1.0 & & 1.3 & 0.29 & 0.79 & & & 0.66 & 0.66 \\
\hline $\mathrm{C}_{\max }$ & & & 18 & 18 & & 18 & & 28 & 17 & 23 & & & 19 & 19 \\
\hline
\end{tabular}

All values are reported in $\mu \mathrm{g} \mathrm{gOM}^{-1}$.

${ }^{\mathrm{a}} \mathrm{P}_{\mathrm{aq}}=\left(\mathrm{C}_{23}+\mathrm{C}_{25}\right) /\left(\mathrm{C}_{23}+\mathrm{C}_{25}+\mathrm{C}_{29}+\mathrm{C}_{31}\right) \quad{ }^{\mathrm{d}} \mathrm{CPI}=\left(\left(\Sigma \mathrm{C}_{17}-\mathrm{C}_{29}\right)_{\text {odd }}\right) /\left(\left(\Sigma \mathrm{C}_{18}-\mathrm{C}_{30}\right)_{\text {even }}\right)$

${ }^{\mathrm{b}} \mathrm{CPI}=\left(\left(\Sigma \mathrm{C}_{15}-\mathrm{C}_{35}\right)_{\text {odd }}\right) /\left(\left(\Sigma \mathrm{C}_{14}-\mathrm{C}_{34}\right)_{\text {even }}\right) \quad{ }^{\mathrm{e}}$ Long/short $=\Sigma \mathrm{C} \geq 20 / \Sigma \mathrm{C} \leq 19$

${ }^{c}$ Long/short $=\Sigma \mathrm{C} \geq 20 / \Sigma \mathrm{C} \leq 19$ 
Table A2.7. Concentrations of $n$-alkanes and $n$-alkenes in SRS2 floc samples.

\begin{tabular}{|c|c|c|c|c|c|c|c|c|c|c|c|c|c|c|}
\hline \multirow{2}{*}{ Compound } & \multirow{2}{*}{ Formula } & \multirow{2}{*}{ MW } & \multicolumn{3}{|c|}{2007} & \multirow[b]{2}{*}{ Mean } & \multicolumn{3}{|c|}{2008} & \multirow[b]{2}{*}{ Mean } & \multicolumn{3}{|c|}{2009} & \multirow[b]{2}{*}{ Mean } \\
\hline & & & EW & LW & $\mathrm{D}$ & & EW & LW & $\mathrm{D}$ & & EW & LW & $\mathrm{D}$ & \\
\hline \multicolumn{15}{|l|}{ n-alkanes } \\
\hline Tetradecane & $\mathrm{C}_{14} \mathrm{H}_{30}$ & 198 & & & n.c. & & & & & & & & & \\
\hline Pentadecane & $\mathrm{C}_{15} \mathrm{H}_{32}$ & 212 & 0.35 & 2.2 & n.c. & 1.3 & 1.5 & 1.6 & 1.2 & 1.4 & 14 & 0.32 & 0.94 & 5.2 \\
\hline Hexadecane & $\mathrm{C}_{16} \mathrm{H}_{34}$ & 226 & 0.11 & 0.57 & n.c. & 0.34 & 0.28 & 0.23 & 0.19 & 0.23 & 1.7 & 0.089 & 0.14 & 0.63 \\
\hline Heptadecane & $\mathrm{C}_{17} \mathrm{H}_{36}$ & 240 & 6.0 & 15 & n.c. & 10 & 39 & 37 & 36 & 37 & 317 & 17 & 29 & 121 \\
\hline Octadecane & $\mathrm{C}_{18} \mathrm{H}_{38}$ & 254 & 0.34 & 2.0 & n.c. & 1.2 & 0.81 & 0.82 & 0.67 & 0.76 & 8.3 & 0.46 & 0.59 & 3.1 \\
\hline Nonadecane & $\mathrm{C}_{19} \mathrm{H}_{40}$ & 268 & 0.43 & 1.2 & n.c. & 0.82 & 0.88 & 1.2 & 1.2 & 1.1 & 7.6 & 0.80 & 0.98 & 3.1 \\
\hline Eicosane & $\mathrm{C}_{20} \mathrm{H}_{42}$ & 282 & 0.29 & 0.48 & n.c. & 0.39 & 0.40 & 0.78 & 0.59 & 0.59 & 4.4 & 0.66 & 0.57 & 1.9 \\
\hline Heneicosane & $\mathrm{C}_{21} \mathrm{H}_{44}$ & 296 & 0.75 & 0.73 & n.c. & 0.74 & 0.97 & 1.6 & 1.4 & 1.3 & 10 & 1.4 & 1.3 & 4.3 \\
\hline Docosane & $\mathrm{C}_{22} \mathrm{H}_{46}$ & 310 & 0.69 & 0.30 & n.c. & 0.49 & 0.46 & 1.6 & 1.0 & 1.0 & 7.1 & 1.5 & 1.1 & 3.2 \\
\hline Tricosane & $\mathrm{C}_{23} \mathrm{H}_{48}$ & 324 & 3.6 & 1.6 & n.c. & 2.6 & 2.5 & 8.5 & 6.0 & 5.7 & 30 & 8.6 & 5.5 & 15 \\
\hline Tetracosane & $\mathrm{C}_{24} \mathrm{H}_{50}$ & 338 & 1.5 & 0.94 & n.c. & 1.2 & 1.3 & 4.0 & 2.7 & 2.7 & 14 & 3.6 & 2.4 & 6.5 \\
\hline Pentacosane & $\mathrm{C}_{25} \mathrm{H}_{52}$ & 352 & 6.8 & 6.4 & n.c. & 6.6 & 7.3 & 14 & 13 & 12 & 67 & 13 & 10 & 30 \\
\hline Hexacosane & $\mathrm{C}_{26} \mathrm{H}_{54}$ & 366 & 1.9 & 2.3 & n.c. & 2.1 & 2.9 & 5.1 & 4.4 & 4.1 & 19 & 4.3 & 3.1 & 8.7 \\
\hline Heptacosane & $\mathrm{C}_{27} \mathrm{H}_{56}$ & 380 & 10 & 14 & n.c. & 12 & 13 & 21 & 23 & 19 & 88 & 19 & 14 & 40 \\
\hline Octacosane & $\mathrm{C}_{28} \mathrm{H}_{58}$ & 394 & 2.1 & 2.6 & n.c. & 2.3 & 4.2 & 5.3 & 6.3 & 5.2 & 40 & 4.6 & 5.2 & 16 \\
\hline Nonacosane & $\mathrm{C}_{29} \mathrm{H}_{60}$ & 408 & 7.2 & 14 & n.c. & 11 & 11 & 16 & 20 & 16 & 85 & 15 & 12 & 37 \\
\hline Triacontane & $\mathrm{C}_{30} \mathrm{H}_{62}$ & 422 & 0.76 & 0.64 & n.c. & 0.70 & 0.73 & 2.3 & 2.0 & 1.7 & 12 & 2.2 & 1.7 & 5.3 \\
\hline Hentriacontane & $\mathrm{C}_{31} \mathrm{H}_{64}$ & 436 & 2.4 & 2.9 & n.c. & 2.7 & 3.1 & 7.4 & 7.9 & 6.1 & 48 & 8.0 & 6.2 & 21 \\
\hline Dotriacontane & $\mathrm{C}_{32} \mathrm{H}_{66}$ & 450 & 0.21 & 0.14 & n.c. & 0.18 & 0.63 & 1.7 & 2.0 & 1.5 & 12 & 2.0 & 1.4 & 5.1 \\
\hline Tritriacontane & $\mathrm{C}_{33} \mathrm{H}_{68}$ & 464 & 1.2 & 0.82 & n.c. & 1.0 & 1.8 & 5.4 & 7.3 & 4.9 & 39 & 5.8 & 4.9 & 16 \\
\hline Tetratriacontane & $\mathrm{C}_{34} \mathrm{H}_{70}$ & 478 & & & n.c. & & & & 2.1 & 2.1 & & & & \\
\hline Pentatriacontane & $\mathrm{C}_{35} \mathrm{H}_{72}$ & 492 & & & n.c. & & 0.26 & 1.5 & 1.4 & 1.1 & 12 & 1.9 & 1.5 & 5.0 \\
\hline Hexatriacontane & $\mathrm{C}_{36} \mathrm{H}_{74}$ & 506 & & & n.c. & & & & 0.064 & 0.064 & & & 0.18 & 0.18 \\
\hline Heptatriacontane & $\mathrm{C}_{37} \mathrm{H}_{76}$ & 520 & & & n.c. & & 0.14 & 0.58 & 0.71 & 0.48 & 4.2 & 0.66 & 0.58 & 1.8 \\
\hline Total & & & 47 & 68 & & 58 & 93 & 138 & 142 & 124 & 839 & 111 & 103 & 351 \\
\hline
\end{tabular}


Table A2.7. continued.

\begin{tabular}{|c|c|c|c|c|c|c|c|c|c|c|c|c|c|c|}
\hline $\mathrm{P}_{\mathrm{aq}}^{\mathrm{a}}$ & & & 0.52 & 0.32 & & 0.42 & 0.41 & 0.49 & 0.40 & 0.44 & 0.42 & 0.49 & 0.46 & 0.46 \\
\hline $\mathrm{CPI}^{\mathrm{b}}$ & & & 4.9 & 5.9 & & 5.4 & 6.9 & 5.3 & 5.4 & 5.9 & 6.1 & 4.7 & 5.3 & 5.4 \\
\hline Long/short ${ }^{\mathrm{c}}$ & & & 5.5 & 2.3 & & 3.9 & 1.2 & 2.4 & 2.6 & 2.1 & 1.4 & 5.0 & 2.2 & 2.9 \\
\hline \multicolumn{15}{|l|}{ n-alkenes } \\
\hline Octadecene & $\mathrm{C}_{18} \mathrm{H}_{36}$ & 252 & 0.24 & & n.c. & 0.24 & & & & & & & & \\
\hline Heneicosene & $\mathrm{C}_{21} \mathrm{H}_{42}$ & 294 & 0.17 & 0.13 & n.c. & 0.15 & 0.22 & 0.35 & 0.29 & 0.29 & 2.3 & 0.23 & 0.35 & 0.94 \\
\hline Docosene & $\mathrm{C}_{22} \mathrm{H}_{44}$ & 308 & 0.060 & & n.c. & 0.060 & 0.085 & 0.25 & 0.17 & 0.17 & 1.2 & 0.21 & 0.15 & 0.51 \\
\hline Tricosene & $\mathrm{C}_{23} \mathrm{H}_{46}$ & 322 & 0.21 & 0.19 & n.c. & 0.20 & 0.40 & 0.65 & 0.47 & 0.51 & 2.5 & 0.59 & 0.46 & 1.2 \\
\hline Tretracosene & $\mathrm{C}_{24} \mathrm{H}_{48}$ & 336 & 0.17 & 0.24 & n.c. & 0.20 & 0.35 & 0.67 & 0.79 & 0.61 & 2.5 & 0.67 & 0.45 & 1.2 \\
\hline Octacosene & $\mathrm{C}_{28} \mathrm{H}_{56}$ & 392 & & & n.c. & & & & & & & & & \\
\hline Nonacosene & $\mathrm{C}_{29} \mathrm{H}_{58}$ & 406 & 0.53 & 0.19 & n.c. & 0.36 & 0.36 & 2.7 & 1.8 & 1.6 & 9.6 & 3.1 & 2.1 & 4.9 \\
\hline Triacontene & $\mathrm{C}_{30} \mathrm{H}_{60}$ & 420 & & 0.14 & n.c. & 0.14 & 0.14 & 0.40 & 0.38 & 0.31 & 1.9 & 0.43 & 0.43 & 0.91 \\
\hline Hentriacontene & $\mathrm{C}_{31} \mathrm{H}_{62}$ & 434 & & & n.c. & & & & & & & & & \\
\hline Dotriacontene & $\mathrm{C}_{32} \mathrm{H}_{64}$ & 448 & & & n.c. & & & & & & & & & \\
\hline Total & & & 3.9 & 2.2 & & 3.0 & 3.6 & 14 & 9.6 & 8.6 & 45 & 14 & 9.5 & 29 \\
\hline $\mathrm{CPI}^{\mathrm{d}}$ & & & 4.0 & 1.1 & & 2.6 & 1.2 & 4.2 & 2.6 & 2.7 & 3.7 & 4.6 & 4.1 & 4.1 \\
\hline $\mathrm{C}_{\max }$ & & & 27 & 26 & & 27 & 26 & 27 & 27 & 27 & 27 & 27 & 27 & 27 \\
\hline
\end{tabular}

All values are reported in $\mu \mathrm{g} \mathrm{gOM}^{-1}$.

${ }^{\mathrm{a}} \mathrm{P}_{\mathrm{aq}}=\left(\mathrm{C}_{23}+\mathrm{C}_{25}\right) /\left(\mathrm{C}_{23}+\mathrm{C}_{25}+\mathrm{C}_{29}+\mathrm{C}_{31}\right)$

${ }^{\mathrm{b}} \mathrm{CPI}=\left(\left(\Sigma \mathrm{C}_{15}-\mathrm{C}_{35}\right)_{\text {odd }}\right) /\left(\left(\Sigma \mathrm{C}_{14}-\mathrm{C}_{34}\right)_{\text {even }}\right)$

${ }^{\mathrm{c}}$ Long/short $=\Sigma \mathrm{C} \geq 20 / \Sigma \mathrm{C} \leq 19$

${ }^{\mathrm{d}} \mathrm{CPI}=\left(\left(\Sigma \mathrm{C}_{17}-\mathrm{C}_{29}\right)_{\text {odd }}\right) /\left(\left(\Sigma \mathrm{C}_{18}-\mathrm{C}_{30}\right)_{\text {even }}\right)$ 
Table A2.8. Concentrations of $n$-alkanes and $n$-alkenes in SRS6 floc samples.

\begin{tabular}{|c|c|c|c|c|c|c|c|c|c|c|c|c|c|c|}
\hline \multirow{2}{*}{ Compound } & \multirow{2}{*}{ Formula } & \multirow{2}{*}{ MW } & \multicolumn{3}{|c|}{2007} & \multirow[b]{2}{*}{ Mean } & \multicolumn{3}{|c|}{2008} & \multirow[b]{2}{*}{ Mean } & \multicolumn{3}{|c|}{2009} & \multirow[b]{2}{*}{ Mean } \\
\hline & & & EW & LW & $\mathrm{D}$ & & EW & LW & $\mathrm{D}$ & & EW & LW & $\mathrm{D}$ & \\
\hline \multicolumn{15}{|l|}{ n-alkanes } \\
\hline Tetradecane & $\mathrm{C}_{14} \mathrm{H}_{30}$ & 198 & 0.016 & & n.c. & 0.016 & & & 0.13 & 0.13 & & & & \\
\hline Pentadecane & $\mathrm{C}_{15} \mathrm{H}_{32}$ & 212 & 0.065 & 0.14 & n.c. & 0.10 & 3.2 & 2.3 & 0.12 & 1.9 & 0.10 & 0.073 & 0.063 & 0.080 \\
\hline Hexadecane & $\mathrm{C}_{16} \mathrm{H}_{34}$ & 226 & 0.057 & 0.062 & n.c. & 0.060 & & 0.31 & 0.046 & 0.18 & 0.031 & & 0.018 & 0.025 \\
\hline Heptadecane & $\mathrm{C}_{17} \mathrm{H}_{36}$ & 240 & 0.073 & 0.18 & n.c. & 0.13 & 2.4 & 2.3 & 0.13 & 1.6 & 0.23 & 0.13 & 0.11 & 0.16 \\
\hline Octadecane & $\mathrm{C}_{18} \mathrm{H}_{38}$ & 254 & 0.095 & & n.c. & 0.095 & 1.4 & 1.1 & 0.041 & 0.86 & 0.054 & 0.030 & 0.028 & 0.037 \\
\hline Nonadecane & $\mathrm{C}_{19} \mathrm{H}_{40}$ & 268 & 0.030 & & n.c. & 0.030 & & & 0.059 & 0.059 & 0.18 & 0.10 & 0.052 & 0.11 \\
\hline Eicosane & $\mathrm{C}_{20} \mathrm{H}_{42}$ & 282 & 0.064 & & n.c. & 0.064 & & & 0.050 & 0.050 & 0.10 & 0.043 & 0.047 & 0.065 \\
\hline Heneicosane & $\mathrm{C}_{21} \mathrm{H}_{44}$ & 296 & 0.055 & 0.14 & n.c. & 0.097 & 1.0 & 3.7 & 0.062 & 1.6 & 0.082 & 0.17 & 0.15 & 0.14 \\
\hline Docosane & $\mathrm{C}_{22} \mathrm{H}_{46}$ & 310 & 0.077 & 0.14 & n.c. & 0.11 & 1.2 & 1.7 & 0.078 & 0.97 & 0.14 & 0.12 & 0.082 & 0.11 \\
\hline Tricosane & $\mathrm{C}_{23} \mathrm{H}_{48}$ & 324 & 0.20 & 2.1 & n.c. & 1.1 & 7.3 & 4.2 & 0.45 & 4.0 & 0.37 & 0.62 & 0.53 & 0.51 \\
\hline Tetracosane & $\mathrm{C}_{24} \mathrm{H}_{50}$ & 338 & 0.22 & 0.44 & n.c. & 0.33 & 4.5 & 4.9 & 0.27 & 3.2 & 0.24 & 0.51 & 0.29 & 0.35 \\
\hline Pentacosane & $\mathrm{C}_{25} \mathrm{H}_{52}$ & 352 & 0.58 & 1.8 & n.c. & 1.2 & 21 & 21 & 1.6 & 14 & 1.3 & 2.5 & 1.8 & 1.8 \\
\hline Hexacosane & $\mathrm{C}_{26} \mathrm{H}_{54}$ & 366 & 0.83 & 0.61 & n.c. & 0.72 & 6.0 & 8.8 & 0.45 & 5.1 & 0.31 & 0.94 & 0.58 & 0.61 \\
\hline Heptacosane & $\mathrm{C}_{27} \mathrm{H}_{56}$ & 380 & 1.8 & 3.4 & n.c. & 2.6 & 40 & 45 & 2.7 & 29 & 2.4 & 4.7 & 3.2 & 3.5 \\
\hline Octacosane & $\mathrm{C}_{28} \mathrm{H}_{58}$ & 394 & 1.6 & 1.4 & n.c. & 1.5 & 10 & 14 & 0.76 & 8.3 & 0.64 & 1.5 & 1.2 & 1.1 \\
\hline Nonacosane & $\mathrm{C}_{29} \mathrm{H}_{60}$ & 408 & 3.3 & 7.7 & n.c. & 5.5 & 81 & 97 & 5.5 & 61 & 5.4 & 11 & 7.7 & 8.1 \\
\hline Triacontane & $\mathrm{C}_{30} \mathrm{H}_{62}$ & 422 & 1.1 & 0.35 & n.c. & 0.74 & 5.7 & 6.4 & 0.52 & 4.2 & 0.37 & 1.0 & 0.84 & 0.74 \\
\hline Hentriacontane & $\mathrm{C}_{31} \mathrm{H}_{64}$ & 436 & 0.32 & 1.0 & n.c. & 0.66 & 12 & 17 & 1.3 & 10 & 0.73 & 2.5 & 1.6 & 1.6 \\
\hline Dotriacontane & $\mathrm{C}_{32} \mathrm{H}_{66}$ & 450 & & & n.c. & & & & 0.11 & 0.11 & & & & \\
\hline Tritriacontane & $\mathrm{C}_{33} \mathrm{H}_{68}$ & 464 & 0.054 & & n.c. & 0.054 & 1.8 & 2.4 & 0.35 & 1.5 & 0.076 & 0.24 & 0.32 & 0.21 \\
\hline Tetratriacontane & $\mathrm{C}_{34} \mathrm{H}_{70}$ & 478 & 0.26 & & n.c. & 0.26 & & & & & & & & \\
\hline Pentatriacontane & $\mathrm{C}_{35} \mathrm{H}_{72}$ & 492 & & & n.c. & & & & & & & & & \\
\hline Hexatriacontane & $\mathrm{C}_{36} \mathrm{H}_{74}$ & 506 & & & n.c. & & & & & & & & & \\
\hline Heptatriacontane & $\mathrm{C}_{37} \mathrm{H}_{76}$ & 520 & & & n.c. & & & & & & & & & \\
\hline
\end{tabular}


Table A2.8. continued.

\begin{tabular}{|c|c|c|c|c|c|c|c|c|c|c|c|c|c|c|}
\hline Total & & & 11 & 19 & & 15 & 199 & 231 & 15 & 148 & 13 & 26.53 & 19 & 19 \\
\hline $\mathrm{P}_{\mathrm{aq}}^{\mathrm{a}}$ & & & 0.18 & 0.31 & & 0.24 & 0.23 & 0.18 & 0.23 & 0.21 & 0.21 & 0.18 & 0.20 & 0.20 \\
\hline $\mathrm{CPI}^{\mathrm{b}}$ & & & 1.5 & 5.6 & & 3.5 & 5.8 & 5.2 & 5.0 & 5.3 & 5.8 & 5.3 & 5.1 & 5.4 \\
\hline Long/short ${ }^{c}$ & & & 31 & 49 & & 40 & 27 & 37 & 27 & 31 & 20 & 78 & 67 & 55 \\
\hline $\mathrm{C}_{\max }$ & & & 29 & 29 & & 29 & 29 & 29 & 29 & 29 & 29 & 29 & 29 & 29 \\
\hline \multicolumn{15}{|l|}{ n-alkenes } \\
\hline Octadecene & $\mathrm{C}_{18} \mathrm{H}_{36}$ & 252 & & & n.c. & & & & & & & & & \\
\hline Nonadecene & $\mathrm{C}_{19} \mathrm{H}_{38}$ & 266 & & & n.c. & & & & & & & & & \\
\hline Eicosene & $\mathrm{C}_{20} \mathrm{H}_{40}$ & 280 & & & n.c. & & & & & & & & & \\
\hline Heneicosene & $\mathrm{C}_{21} \mathrm{H}_{42}$ & 294 & & & n.c. & & & & & & & & & \\
\hline Docosene & $\mathrm{C}_{22} \mathrm{H}_{44}$ & 308 & & & n.c. & & & & 0.056 & 0.056 & & 0.057 & & 0.057 \\
\hline Tricosene & $\mathrm{C}_{23} \mathrm{H}_{46}$ & 322 & & & n.c. & & & 0.79 & 0.073 & 0.43 & & 0.11 & 0.033 & 0.071 \\
\hline Tretracosene & $\mathrm{C}_{24} \mathrm{H}_{48}$ & 336 & & 0.11 & n.c. & 0.11 & & & & & & & & \\
\hline Pentacosene & $\mathrm{C}_{25} \mathrm{H}_{50}$ & 350 & & 0.085 & n.c. & 0.085 & 1.00 & 1.2 & 0.12 & 0.79 & 0.032 & 0.23 & 0.16 & 0.14 \\
\hline Hexacosene & $\mathrm{C}_{26} \mathrm{H}_{52}$ & 364 & 0.12 & 0.77 & n.c. & 0.44 & 2.0 & 3.4 & 0.20 & 1.9 & 0.14 & 0.62 & 0.30 & 0.35 \\
\hline Heptacosene & $\mathrm{C}_{27} \mathrm{H}_{54}$ & 378 & 0.075 & 0.38 & n.c. & 0.23 & 2.2 & 3.6 & 0.26 & 2.0 & 0.14 & 0.56 & 0.37 & 0.36 \\
\hline Octacosene & $\mathrm{C}_{28} \mathrm{H}_{56}$ & 392 & 0.52 & 5.2 & n.c. & 2.8 & 21 & 33 & 1.7 & 19 & 1.3 & 4.9 & 3.2 & 3.2 \\
\hline Nonacosene & $\mathrm{C}_{29} \mathrm{H}_{58}$ & 406 & 0.092 & 0.53 & n.c. & 0.31 & 6.1 & 7.8 & 0.33 & 4.8 & 0.17 & 0.63 & 0.52 & 0.44 \\
\hline Triacontene & $\mathrm{C}_{30} \mathrm{H}_{60}$ & 420 & 0.22 & 0.74 & n.c. & 0.48 & 7.0 & 12 & 0.78 & 6.5 & 0.34 & 1.5 & 1.5 & 1.1 \\
\hline Hentriacontene & $\mathrm{C}_{31} \mathrm{H}_{62}$ & 434 & & & n.c. & & & & & & & & & \\
\hline Dotriacontene & $\mathrm{C}_{32} \mathrm{H}_{64}$ & 448 & & & n.c. & & & & & & & & & \\
\hline Total & & & 1.0 & 7.8 & & 4.4 & 39 & 62 & 3.5 & 35 & 2.2 & 8.7 & 6.1 & 5.6 \\
\hline $\mathrm{CPI}^{\mathrm{c}}$ & & & 0.20 & 0.15 & & 0.17 & 0.31 & 0.28 & 0.29 & 0.29 & 0.18 & 0.22 & 0.22 & 0.21 \\
\hline $\mathrm{C}_{\max }$ & & & 28 & 28 & & 28 & 28 & 28 & 28 & 28 & 28 & 28 & 28 & 28 \\
\hline
\end{tabular}

All values are reported in $\mu \mathrm{g} \mathrm{gOM}^{-1}$.

${ }^{a} \mathrm{P}_{\text {aq }}=\left(\mathrm{C}_{23}+\mathrm{C}_{25}\right) /\left(\mathrm{C}_{23}+\mathrm{C}_{25}+\mathrm{C}_{29}+\mathrm{C}_{31}\right) \quad \quad{ }^{\mathrm{c}}$ Long/short $=\Sigma \mathrm{C} \geq 20 / \Sigma \mathrm{C} \leq 19$

${ }^{\mathrm{b}} \mathrm{CPI}=\left(\left(\left(\Sigma \mathrm{C}_{15}-\mathrm{C}_{35}\right)_{\text {odd }}\right) /\left(\left(\Sigma \mathrm{C}_{14}-\mathrm{C}_{34}\right)_{\text {even }}\right) \quad{ }^{\mathrm{d}} \mathrm{CPI}=\left(\left(\left(\Sigma \mathrm{C}_{17}-\mathrm{C}_{29}\right)_{\text {odd }}\right) /\left(\left(\Sigma \mathrm{C}_{18}-\mathrm{C}_{30}\right)_{\text {even }}\right)\right.\right.$ 
Table A2.9. Concentrations of $n$-alkanes and $n$-alkenes in TS2 floc samples.

\begin{tabular}{|c|c|c|c|c|c|c|c|c|c|c|c|c|c|c|}
\hline \multirow{2}{*}{ Compound } & \multirow{2}{*}{ Formula } & \multirow{2}{*}{ MW } & \multicolumn{3}{|c|}{2007} & \multirow[b]{2}{*}{ Mean } & \multicolumn{3}{|c|}{2008} & \multirow[b]{2}{*}{ Mean } & \multicolumn{3}{|c|}{2009} & \multirow[b]{2}{*}{ Mean } \\
\hline & & & EW & LW & D & & EW & LW & D & & EW & LW & D & \\
\hline \multicolumn{15}{|l|}{ n-alkanes } \\
\hline Tetradecane & $\mathrm{C}_{14} \mathrm{H}_{30}$ & 198 & n.m. & 0.032 & n.c. & 0.032 & & & & & & n.c. & & \\
\hline Pentadecane & $\mathrm{C}_{15} \mathrm{H}_{32}$ & 212 & n.m. & 0.34 & n.c. & 0.34 & 30 & 0.36 & 1.2 & 11 & 0.13 & n.c. & 0.77 & 0.45 \\
\hline Hexadecane & $\mathrm{C}_{16} \mathrm{H}_{34}$ & 226 & n.m. & 0.14 & n.c. & 0.14 & 3.4 & 0.094 & 0.17 & 1.2 & 0.044 & n.c. & 0.15 & 0.10 \\
\hline Heptadecane & $\mathrm{C}_{17} \mathrm{H}_{36}$ & 240 & n.m. & 5.9 & n.c. & 5.9 & 207 & 7.8 & 13 & 76 & 2.4 & n.c. & 9.1 & 5.7 \\
\hline Octadecane & $\mathrm{C}_{18} \mathrm{H}_{38}$ & 254 & n.m. & 0.52 & n.c. & 0.52 & 7.5 & 0.38 & 0.34 & 2.7 & 0.10 & n.c. & 0.35 & 0.23 \\
\hline Nonadecane & $\mathrm{C}_{19} \mathrm{H}_{40}$ & 268 & n.m. & 1.4 & n.c. & 1.4 & 10 & 0.33 & 0.27 & 3.6 & 0.10 & n.c. & 0.33 & 0.21 \\
\hline Eicosane & $\mathrm{C}_{20} \mathrm{H}_{42}$ & 282 & n.m. & 0.47 & n.c. & 0.47 & 5.8 & 0.31 & 0.21 & 2.1 & 0.14 & n.c. & 0.19 & 0.17 \\
\hline Heneicosane & $\mathrm{C}_{21} \mathrm{H}_{44}$ & 296 & n.m. & 0.38 & n.c. & 0.38 & 5.0 & 0.31 & 0.29 & 1.9 & 0.18 & n.c. & 0.26 & 0.22 \\
\hline Docosane & $\mathrm{C}_{22} \mathrm{H}_{46}$ & 310 & n.m. & 0.20 & n.c. & 0.20 & 3.9 & 0.22 & 0.20 & 1.4 & 0.21 & n.c. & 0.18 & 0.20 \\
\hline Tricosane & $\mathrm{C}_{23} \mathrm{H}_{48}$ & 324 & n.m. & 4.7 & n.c. & 4.7 & 12 & 0.42 & 6.0 & 6.2 & 0.47 & n.c. & 0.71 & 0.59 \\
\hline Tetracosane & $\mathrm{C}_{24} \mathrm{H}_{50}$ & 338 & n.m. & 0.62 & n.c. & 0.62 & 7.9 & 0.43 & 0.71 & 3.0 & 0.40 & n.c. & 0.62 & 0.51 \\
\hline Pentacosane & $\mathrm{C}_{25} \mathrm{H}_{52}$ & 352 & n.m. & 3.7 & n.c. & 3.7 & 30 & 1.6 & 2.5 & 11 & 1.4 & n.c. & 3.2 & 2.3 \\
\hline Hexacosane & $\mathrm{C}_{26} \mathrm{H}_{54}$ & 366 & n.m. & 2.0 & n.c. & 2.0 & 16 & 1.8 & 1.7 & 6.5 & 0.72 & n.c. & 2.1 & 1.4 \\
\hline Heptacosane & $\mathrm{C}_{27} \mathrm{H}_{56}$ & 380 & n.m. & 14 & n.c. & 14 & 100 & 9.0 & 11 & 40 & 4.4 & n.c. & 12 & 8.2 \\
\hline Octacosane & $\mathrm{C}_{28} \mathrm{H}_{58}$ & 394 & n.m. & 3.4 & n.c. & 3.4 & 21 & 3.8 & 2.4 & 9.2 & 1.1 & n.c. & 3.2 & 2.1 \\
\hline Nonacosane & $\mathrm{C}_{29} \mathrm{H}_{60}$ & 408 & n.m. & 22 & n.c. & 22 & 140 & 28 & 76 & 81 & 7.5 & n.c. & 18 & 13 \\
\hline Triacontane & $\mathrm{C}_{30} \mathrm{H}_{62}$ & 422 & n.m. & 1.5 & n.c. & 1.5 & 9.1 & 1.9 & 1.1 & 4.0 & 1.0 & n.c. & 1.9 & 1.4 \\
\hline Hentriacontane & $\mathrm{C}_{31} \mathrm{H}_{64}$ & 436 & n.m. & 7.9 & n.c. & 7.9 & 44 & 10 & 4.8 & 20 & 5.7 & n.c. & 7.7 & 6.7 \\
\hline Dotriacontane & $\mathrm{C}_{32} \mathrm{H}_{66}$ & 450 & n.m. & 0.62 & n.c. & 0.62 & 2.7 & 0.58 & 0.35 & 1.2 & 0.56 & n.c. & 0.96 & 0.76 \\
\hline Tritriacontane & $\mathrm{C}_{33} \mathrm{H}_{68}$ & 464 & n.m. & 3.2 & n.c. & 3.2 & 15 & 2.9 & 2.1 & 6.6 & 3.2 & n.c. & 3.8 & 3.5 \\
\hline Tetratriacontane & $\mathrm{C}_{34} \mathrm{H}_{70}$ & 478 & n.m. & 0.30 & n.c. & 0.30 & & & 0.30 & 0.30 & 0.20 & n.c. & 0.29 & 0.25 \\
\hline Pentatriacontane & $\mathrm{C}_{35} \mathrm{H}_{72}$ & 492 & n.m. & 1.0 & n.c. & 1.0 & & & 0.27 & 0.27 & 0.34 & n.c. & 0.49 & 0.42 \\
\hline Hexatriacontane & $\mathrm{C}_{36} \mathrm{H}_{74}$ & 506 & n.m. & & n.c. & & & & & & & n.c. & & \\
\hline Heptatriacontane & $\mathrm{C}_{37} \mathrm{H}_{76}$ & 520 & n.m. & & n.c. & & & & & & & n.c. & & \\
\hline
\end{tabular}


Table A2.9. continued.

\begin{tabular}{|c|c|c|c|c|c|c|c|c|c|c|c|c|c|c|}
\hline $\mathrm{P}_{\mathrm{aq}}^{\mathrm{a}}$ & & & & 0.22 & & 0.22 & 0.19 & 0.051 & 0.10 & 0.11 & 0.12 & & 0.13 & 0.13 \\
\hline $\mathrm{CPI}^{\mathrm{b}}$ & & & & 6.6 & & 6.6 & 7.7 & 6.3 & 16 & 9.9 & 5.7 & & 5.7 & 5.7 \\
\hline Long/short ${ }^{\mathrm{c}}$ & & & & 7.9 & & 7.9 & 1.6 & 6.9 & 7.4 & 5.3 & 10 & & 5.2 & 7.6 \\
\hline \multicolumn{15}{|l|}{ n-alkenes } \\
\hline Octadecene & $\mathrm{C}_{18} \mathrm{H}_{36}$ & 252 & n.m. & & n.c. & & & & & & & n.c. & & \\
\hline Heneicosene & $\mathrm{C}_{21} \mathrm{H}_{42}$ & 294 & n.m. & & n.c. & & & & & & & n.c. & & \\
\hline Docosene & $\mathrm{C}_{22} \mathrm{H}_{44}$ & 308 & n.m. & & n.c. & & & & & & & n.c. & 0.063 & 0.063 \\
\hline Tricosene & $\mathrm{C}_{23} \mathrm{H}_{46}$ & 322 & n.m. & 0.12 & n.c. & 0.12 & 1.0 & 0.060 & 0.093 & 0.38 & 0.045 & n.c. & 0.10 & 0.074 \\
\hline Tretracosene & $\mathrm{C}_{24} \mathrm{H}_{48}$ & 336 & n.m. & 0.17 & n.c. & 0.17 & 0.88 & 0.068 & 0.17 & 0.37 & 0.035 & n.c. & 0.17 & 0.10 \\
\hline Octacosene & $\mathrm{C}_{28} \mathrm{H}_{56}$ & 392 & n.m. & 2.1 & n.c. & 2.1 & 3.2 & 2.1 & 1.0 & 2.1 & 0.17 & n.c. & 1.3 & 0.74 \\
\hline Nonacosene & $\mathrm{C}_{29} \mathrm{H}_{58}$ & 406 & n.m. & 0.22 & n.c. & 0.22 & & 0.30 & 0.18 & 0.24 & 0.12 & n.c. & 0.22 & 0.17 \\
\hline Triacontene & $\mathrm{C}_{30} \mathrm{H}_{60}$ & 420 & n.m. & 0.37 & n.c. & 0.37 & & 0.48 & 0.27 & 0.38 & 0.074 & n.c. & 0.51 & 0.29 \\
\hline Hentriacontene & $\mathrm{C}_{31} \mathrm{H}_{62}$ & 434 & n.m. & & n.c. & & & & & & & n.c. & & \\
\hline Dotriacontene & $\mathrm{C}_{32} \mathrm{H}_{64}$ & 448 & n.m. & 0.18 & n.c. & 0.18 & & & & & & n.c. & & \\
\hline Total & & & & 4.7 & & 4.7 & 9.5 & 4.6 & 3.1 & 5.7 & 0.8 & & 4.0 & 2.4 \\
\hline $\mathrm{CPI}^{\mathrm{c}}$ & & & & 0.34 & & 0.34 & 0.57 & 0.33 & 0.47 & 0.46 & 1.17 & & 0.36 & 0.77 \\
\hline $\mathrm{C}_{\max }$ & & & & 28 & & 28 & 28 & 28 & 28 & 28 & 27 & & 28 & 28 \\
\hline
\end{tabular}

All values are reported in $\mu \mathrm{g} \mathrm{gOM}^{-1}$.

${ }^{\mathrm{a}} \mathrm{P}_{\mathrm{aq}}=\left(\mathrm{C}_{23}+\mathrm{C}_{25}\right) /\left(\mathrm{C}_{23}+\mathrm{C}_{25}+\mathrm{C}_{29}+\mathrm{C}_{31}\right)$

${ }^{\mathrm{b}} \mathrm{CPI}=\left(\left(\Sigma \mathrm{C}_{15}-\mathrm{C}_{35}\right)_{\text {odd }}\right) /\left(\left(\Sigma \mathrm{C}_{14}-\mathrm{C}_{34}\right)_{\text {even }}\right)$

${ }^{\mathrm{c}}$ Long/short $=\Sigma \mathrm{C} \geq 20 / \Sigma \mathrm{C} \leq 19$

${ }^{\mathrm{d}} \mathrm{CPI}=\left(\left(\left(\mathrm{C}_{17}-\mathrm{C}_{29}\right)_{\text {odd }}\right) /\left(\left(\Sigma \mathrm{C}_{18}-\mathrm{C}_{30}\right)_{\text {even }}\right)\right.$ 
Table A2.10. Concentrations of $n$-alkanes and $n$-alkenes in TS6M floc samples.

\begin{tabular}{|c|c|c|c|c|c|c|c|c|c|c|c|c|c|c|}
\hline \multirow{2}{*}{ Compound } & \multirow{2}{*}{ Formula } & \multirow{2}{*}{ MW } & \multicolumn{3}{|c|}{2007} & \multirow[b]{2}{*}{ Mean } & \multicolumn{3}{|c|}{2008} & \multirow[b]{2}{*}{ Mean } & \multicolumn{3}{|c|}{2009} & \multirow[b]{2}{*}{ Mean } \\
\hline & & & EW & LW & D & & EW & LW & $\mathrm{D}$ & & EW & LW & $\mathrm{D}$ & \\
\hline \multicolumn{15}{|l|}{ n-alkanes } \\
\hline Tetradecane & $\mathrm{C}_{14} \mathrm{H}_{30}$ & 198 & & & n.c. & & & & & & & & & \\
\hline Pentadecane & $\mathrm{C}_{15} \mathrm{H}_{32}$ & 212 & 0.11 & 0.19 & n.c. & 0.15 & 1.1 & 0.49 & 2.1 & 1.2 & 0.75 & 0.25 & 0.34 & 0.45 \\
\hline Hexadecane & $\mathrm{C}_{16} \mathrm{H}_{34}$ & 226 & 0.040 & 0.092 & n.c. & 0.066 & 0.19 & 0.12 & 0.69 & 0.33 & 0.19 & 0.087 & 0.12 & 0.13 \\
\hline Heptadecane & $\mathrm{C}_{17} \mathrm{H}_{36}$ & 240 & 1.3 & 3.6 & n.c. & 2.5 & 5.2 & 3.9 & 26 & 12 & 6.3 & 3.4 & 4.6 & 4.7 \\
\hline Octadecane & $\mathrm{C}_{18} \mathrm{H}_{38}$ & 254 & 0.072 & 0.25 & n.c. & 0.16 & 0.29 & 0.43 & 1.7 & 0.82 & 0.42 & 0.25 & 0.66 & 0.44 \\
\hline Nonadecane & $\mathrm{C}_{19} \mathrm{H}_{40}$ & 268 & 0.062 & 0.27 & n.c. & 0.16 & 0.15 & 0.45 & 1.3 & 0.62 & 0.35 & 0.20 & 0.28 & 0.28 \\
\hline Eicosane & $\mathrm{C}_{20} \mathrm{H}_{42}$ & 282 & 0.040 & 0.24 & n.c. & 0.14 & 0.14 & 0.34 & 0.73 & 0.40 & 0.15 & 0.090 & 0.12 & 0.12 \\
\hline Heneicosane & $\mathrm{C}_{21} \mathrm{H}_{44}$ & 296 & 0.098 & 0.26 & n.c. & 0.18 & 0.23 & 0.32 & 1.8 & 0.77 & 0.41 & 0.25 & 0.31 & 0.32 \\
\hline Docosane & $\mathrm{C}_{22} \mathrm{H}_{46}$ & 310 & 0.073 & 0.20 & n.c. & 0.14 & 0.27 & 0.62 & 1.9 & 0.92 & 0.43 & 0.27 & 0.31 & 0.34 \\
\hline Tricosane & $\mathrm{C}_{23} \mathrm{H}_{48}$ & 324 & 0.21 & 1.1 & n.c. & 0.66 & 0.94 & 1.3 & 5.0 & 2.4 & 1.3 & 0.88 & 1.4 & 1.2 \\
\hline Tetracosane & $\mathrm{C}_{24} \mathrm{H}_{50}$ & 338 & & 1.5 & n.c. & 1.5 & & & & & & & & \\
\hline Pentacosane & $\mathrm{C}_{25} \mathrm{H}_{52}$ & 352 & 8.3 & 1.8 & n.c. & 5.0 & 2.7 & 3.1 & 13 & 6.3 & 3.7 & 2.6 & 3.0 & 3.1 \\
\hline Hexacosane & $\mathrm{C}_{26} \mathrm{H}_{54}$ & 366 & 1.5 & 8.6 & n.c. & 5.1 & 2.5 & 2.9 & 11 & 5.6 & 3.4 & 3.0 & 2.6 & 3.0 \\
\hline Heptacosane & $\mathrm{C}_{27} \mathrm{H}_{56}$ & 380 & 3.3 & 5.3 & n.c. & 4.3 & 8.2 & 9.1 & 33 & 17 & 10 & 7.9 & 8.0 & 8.8 \\
\hline Octacosane & $\mathrm{C}_{28} \mathrm{H}_{58}$ & 394 & 3.0 & 4.2 & n.c. & 3.6 & 6.7 & 6.7 & 27 & 13 & 7.6 & 5.7 & 5.9 & 6.4 \\
\hline Nonacosane & $\mathrm{C}_{29} \mathrm{H}_{60}$ & 408 & 31 & 26 & n.c. & 29 & 45 & 41 & 135 & 74 & 37 & 35 & 31 & 34 \\
\hline Triacontane & $\mathrm{C}_{30} \mathrm{H}_{62}$ & 422 & 3.9 & 2.4 & n.c. & 3.1 & 4.4 & 4.6 & 13 & 7.4 & 5.0 & 3.9 & 3.3 & 4.1 \\
\hline Hentriacontane & $\mathrm{C}_{31} \mathrm{H}_{64}$ & 436 & 4.9 & 3.9 & n.c. & 4.4 & 8.2 & 7.8 & 23 & 13 & 9.1 & 6.8 & 6.4 & 7.4 \\
\hline Dotriacontane & $\mathrm{C}_{32} \mathrm{H}_{66}$ & 450 & & & n.c. & & 0.12 & 0.18 & 0.74 & 0.35 & 0.50 & 0.17 & 0.22 & 0.30 \\
\hline Tritriacontane & $\mathrm{C}_{33} \mathrm{H}_{68}$ & 464 & & 0.049 & n.c. & 0.049 & 0.16 & 0.39 & 1.2 & 0.58 & 0.77 & 0.28 & 0.44 & 0.49 \\
\hline Tetratriacontane & $\mathrm{C}_{34} \mathrm{H}_{70}$ & 478 & & & n.c. & & & & & & & & & \\
\hline Pentatriacontane & $\mathrm{C}_{35} \mathrm{H}_{72}$ & 492 & & & n.c. & & & & & & & & & \\
\hline Hexatriacontane & $\mathrm{C}_{36} \mathrm{H}_{74}$ & 506 & & & n.c. & & & & & & & & & \\
\hline Heptatriacontane & $\mathrm{C}_{37} \mathrm{H}_{76}$ & 520 & & & n.c. & & & & & & & & & \\
\hline Total & & & 58 & 60 & & 59 & 86 & 84 & 300 & 157 & 88 & 71 & 69 & 76 \\
\hline
\end{tabular}


Table A2.10. continued.

\begin{tabular}{|c|c|c|c|c|c|c|c|c|c|c|c|c|c|c|}
\hline $\mathrm{P}_{\mathrm{aq}}^{\mathrm{a}}$ & & & 0.19 & 0.087 & & 0.14 & 0.064 & 0.082 & 0.10 & 0.083 & 0.10 & 0.078 & 0.11 & 0.094 \\
\hline $\mathrm{CPI}^{\mathrm{b}}$ & & & 5.7 & 2.4 & & 4.1 & 4.9 & 4.3 & 4.2 & 4.5 & 4.0 & 4.3 & 4.2 & 4.1 \\
\hline Long/short ${ }^{\mathrm{c}}$ & & & 35 & 13 & & 24 & 11 & 15 & 8 & 11 & 10 & 16 & 11 & 12 \\
\hline $\mathrm{C}_{\max }$ & & & 29 & 29 & & 29 & 29 & 29 & 29 & 29 & 29 & 29 & 29 & 29 \\
\hline \multicolumn{15}{|l|}{ n-alkenes } \\
\hline Octadecene & $\mathrm{C}_{18} \mathrm{H}_{36}$ & 252 & & & n.c. & & & & & & & & & \\
\hline Nonadecene & $\mathrm{C}_{19} \mathrm{H}_{38}$ & 266 & & & n.c. & & & & & & & & & \\
\hline Eicosene & $\mathrm{C}_{20} \mathrm{H}_{40}$ & 280 & & & n.c. & & & & & & & & & \\
\hline Heneicosene & $\mathrm{C}_{21} \mathrm{H}_{42}$ & 294 & & 0.074 & n.c. & 0.074 & & & & & & & & \\
\hline Docosene & $\mathrm{C}_{22} \mathrm{H}_{44}$ & 308 & 0.052 & 0.063 & n.c. & 0.058 & 0.11 & & 0.60 & 0.35 & 0.20 & 0.11 & 0.11 & 0.14 \\
\hline Tricosene & $\mathrm{C}_{23} \mathrm{H}_{46}$ & 322 & 0.055 & 0.15 & n.c. & 0.10 & 0.19 & 0.38 & 1.2 & 0.58 & 0.37 & 0.39 & 0.26 & 0.34 \\
\hline Tretracosene & $\mathrm{C}_{24} \mathrm{H}_{48}$ & 336 & & & n.c. & & & & & & & & & \\
\hline Pentacosene & $\mathrm{C}_{25} \mathrm{H}_{50}$ & 350 & 0.24 & 0.34 & n.c. & 0.29 & 0.54 & 0.91 & 2.5 & 1.3 & 0.76 & 0.79 & 0.58 & 0.71 \\
\hline Hexacosene & $\mathrm{C}_{26} \mathrm{H}_{52}$ & 364 & 0.98 & 1.2 & n.c. & 1.1 & 2.0 & 3.5 & 5.9 & 3.8 & 2.0 & 3.1 & 1.8 & 2.3 \\
\hline Heptacosene & $\mathrm{C}_{27} \mathrm{H}_{54}$ & 378 & 0.99 & 1.3 & n.c. & 1.2 & 2.2 & 3.7 & 6.7 & 4.2 & 2.6 & 3.2 & 1.9 & 2.6 \\
\hline Octacosene & $\mathrm{C}_{28} \mathrm{H}_{56}$ & 392 & 10 & 13 & n.c. & 12 & 21 & 29 & 57 & 36 & 17 & 26 & 16 & 20 \\
\hline Nonacosene & $\mathrm{C}_{29} \mathrm{H}_{58}$ & 406 & 1.3 & 1.3 & n.c. & 1.3 & 2.4 & 3.4 & 13 & 6.3 & 3.1 & 2.6 & 2.5 & 2.7 \\
\hline Triacontene & $\mathrm{C}_{30} \mathrm{H}_{60}$ & 420 & 2.2 & 2.6 & n.c. & 2.4 & 5.2 & 8.5 & 17 & 10 & 6.0 & 7.7 & 4.7 & 6.2 \\
\hline Hentriacontene & $\mathrm{C}_{31} \mathrm{H}_{62}$ & 434 & & & n.c. & & & & & & & & & \\
\hline Dotriacontene & $\mathrm{C}_{32} \mathrm{H}_{64}$ & 448 & & & n.c. & & & & & & & & & \\
\hline Total & & & 16 & 20 & & 18 & 33 & 50 & 104 & 62 & 33 & 44 & 28 & 35 \\
\hline $\mathrm{CPI}^{\mathrm{c}}$ & & & 0.19 & 0.19 & & 0.19 & 0.19 & 0.20 & 0.29 & 0.23 & 0.26 & 0.19 & 0.23 & 0.2 \\
\hline $\mathrm{C}_{\max }$ & & & 28 & 28 & & 28 & 28 & 28 & 28 & 28 & 28 & 28 & 28 & 28 \\
\hline \multicolumn{15}{|c|}{ All values are reported in $\mu \mathrm{g} \mathrm{gOM}{ }^{-1}$. } \\
\hline \multicolumn{15}{|c|}{${ }^{\mathrm{a}} \mathrm{P}_{\mathrm{aq}}=\left(\mathrm{C}_{23}+\mathrm{C}_{25}\right) /\left(\mathrm{C}_{23}+\mathrm{C}_{25}+\mathrm{C}_{29}+\mathrm{C}_{31}\right)$} \\
\hline \multicolumn{15}{|c|}{${ }^{\mathrm{b}} \mathrm{CPI}=\left(\left(\Sigma \mathrm{C}_{15}-\mathrm{C}_{35}\right)_{\text {odd }}\right) /\left(\left(\Sigma \mathrm{C}_{14}-\mathrm{C}_{34}\right)_{\text {even }}\right)$} \\
\hline \multicolumn{15}{|c|}{${ }^{\mathrm{c}}$ Long/short $=\Sigma \mathrm{C} \geq 20 / \Sigma \mathrm{C} \leq 19$} \\
\hline${ }^{\mathrm{d}} \mathrm{CPI}=\left(\left(\Sigma \mathrm{C}_{17}-\mathrm{C}_{29}\right)\right.$ & $/\left(\left(\Sigma \mathrm{C}_{18}-\mathrm{C}\right.\right.$ & & & & & & & & & & & & & \\
\hline
\end{tabular}


Table A2.11. Concentrations of $n$-alkanes and $n$-alkenes in TS6P floc samples.

\begin{tabular}{|c|c|c|c|c|c|c|c|c|c|c|c|c|c|c|}
\hline \multirow{2}{*}{ Compound } & \multirow{2}{*}{ Formula } & \multirow{2}{*}{ MW } & \multicolumn{3}{|c|}{2007} & \multirow[b]{2}{*}{ Mean } & \multicolumn{3}{|c|}{2008} & \multirow[b]{2}{*}{ Mean } & \multicolumn{3}{|c|}{2009} & \multirow[b]{2}{*}{ Mean } \\
\hline & & & EW & LW & D & & EW & LW & D & & EW & LW & $\mathrm{D}$ & \\
\hline \multicolumn{15}{|l|}{ n-alkanes } \\
\hline Tetradecane & $\mathrm{C}_{14} \mathrm{H}_{30}$ & 198 & & & & & & & & & & & & \\
\hline Pentadecane & $\mathrm{C}_{15} \mathrm{H}_{32}$ & 212 & 0.061 & 0.086 & n.c. & 0.073 & 5.4 & 0.21 & 0.65 & 2.1 & 0.50 & 0.27 & 0.34 & 0.37 \\
\hline Hexadecane & $\mathrm{C}_{16} \mathrm{H}_{34}$ & 226 & 0.041 & 0.075 & n.c. & 0.058 & 1.2 & 0.17 & 0.35 & 0.59 & 0.18 & 0.18 & 0.21 & 0.19 \\
\hline Heptadecane & $\mathrm{C}_{17} \mathrm{H}_{36}$ & 240 & 1.6 & 2.8 & n.c. & 2.2 & 32 & 5.1 & 14 & 17 & 5.0 & 5.6 & 8.0 & 6.2 \\
\hline Octadecane & $\mathrm{C}_{18} \mathrm{H}_{38}$ & 254 & 0.11 & 0.18 & n.c. & 0.15 & 0.85 & 0.28 & 0.99 & 0.70 & 0.40 & 0.55 & 0.61 & 0.52 \\
\hline Nonadecane & $\mathrm{C}_{19} \mathrm{H}_{40}$ & 268 & 0.091 & 0.073 & n.c. & 0.082 & 3.2 & 0.52 & 0.79 & 1.5 & 0.39 & 0.35 & 0.48 & 0.41 \\
\hline Eicosane & $\mathrm{C}_{20} \mathrm{H}_{42}$ & 282 & 0.045 & 0.098 & n.c. & 0.071 & 0.80 & 0.18 & 0.24 & 0.40 & 0.12 & 0.094 & 0.15 & 0.12 \\
\hline Heneicosane & $\mathrm{C}_{21} \mathrm{H}_{44}$ & 296 & 0.12 & 0.14 & n.c. & 0.13 & 2.6 & 0.46 & 0.87 & 1.3 & 0.41 & 0.41 & 0.50 & 0.44 \\
\hline Docosane & $\mathrm{C}_{22} \mathrm{H}_{46}$ & 310 & 0.059 & 0.079 & n.c. & 0.069 & 1.6 & 0.27 & 0.50 & 0.78 & 0.27 & 0.23 & 0.31 & 0.27 \\
\hline Tricosane & $\mathrm{C}_{23} \mathrm{H}_{48}$ & 324 & & 1.6 & n.c. & 1.6 & 4.7 & 1.1 & 1.5 & 2.4 & 0.75 & 0.72 & 0.95 & 0.81 \\
\hline Tetracosane & $\mathrm{C}_{24} \mathrm{H}_{50}$ & 338 & 0.080 & 0.19 & n.c. & 0.14 & 3.6 & 0.69 & 1.1 & 1.8 & 0.64 & 0.66 & 0.80 & 0.70 \\
\hline Pentacosane & $\mathrm{C}_{25} \mathrm{H}_{52}$ & 352 & 0.35 & 0.44 & n.c. & 0.40 & 8.5 & 1.6 & 2.8 & 4.3 & 1.7 & 1.5 & 2.0 & 1.7 \\
\hline Hexacosane & $\mathrm{C}_{26} \mathrm{H}_{54}$ & 366 & 0.24 & 0.31 & n.c. & 0.28 & 6.0 & 1.1 & 2.0 & 3.0 & 1.1 & 1.0 & 1.3 & 1.1 \\
\hline Heptacosane & $\mathrm{C}_{27} \mathrm{H}_{56}$ & 380 & 0.98 & 1.0 & n.c. & 0.99 & 21 & 3.6 & 6.5 & 10 & 3.9 & 4.2 & 4.3 & 4.1 \\
\hline Octacosane & $\mathrm{C}_{28} \mathrm{H}_{58}$ & 394 & 0.46 & 0.61 & n.c. & 0.53 & 12 & 2.0 & 4.0 & 5.9 & 2.2 & 2.1 & 2.3 & 2.2 \\
\hline Nonacosane & $\mathrm{C}_{29} \mathrm{H}_{60}$ & 408 & 3.1 & 3.1 & n.c. & 3.1 & 59 & 10 & 19 & 29 & 11 & 9.3 & 12 & 11 \\
\hline Triacontane & $\mathrm{C}_{30} \mathrm{H}_{62}$ & 422 & 0.12 & 0.23 & n.c. & 0.17 & 5.4 & 1.2 & 1.7 & 2.8 & 1.1 & 1.4 & 1.3 & 1.3 \\
\hline Hentriacontane & $\mathrm{C}_{31} \mathrm{H}_{64}$ & 436 & 0.52 & 0.55 & n.c. & 0.54 & 13 & 3.1 & 4.0 & 6.6 & 2.7 & 2.6 & 3.3 & 2.9 \\
\hline Dotriacontane & $\mathrm{C}_{32} \mathrm{H}_{66}$ & 450 & & & n.c. & & & 0.12 & 0.26 & 0.19 & & 0.089 & 0.20 & 0.15 \\
\hline Tritriacontane & $\mathrm{C}_{33} \mathrm{H}_{68}$ & 464 & 0.071 & 0.054 & n.c. & 0.062 & 2.0 & 0.58 & 0.73 & 1.1 & 0.25 & 0.61 & 0.45 & 0.44 \\
\hline Tetratriacontane & $\mathrm{C}_{34} \mathrm{H}_{70}$ & 478 & & & n.c. & & & & & & & & & \\
\hline Pentatriacontane & $\mathrm{C}_{35} \mathrm{H}_{72}$ & 492 & & & n.c. & & & & & & & & & \\
\hline Hexatriacontane & $\mathrm{C}_{36} \mathrm{H}_{74}$ & 506 & & & n.c. & & & & & & & & & \\
\hline $\begin{array}{l}\text { Heptatriacontane } \\
\text { Total }\end{array}$ & $\mathrm{C}_{37} \mathrm{H}_{76}$ & 520 & 8.1 & 12 & n.c. & 9.9 & 182 & 32 & 61 & 92 & 33 & 32 & 39 & 35 \\
\hline
\end{tabular}


Table A2.11. continued.

\begin{tabular}{|c|c|c|c|c|c|c|c|c|c|c|c|c|c|c|}
\hline $\mathrm{P}_{\mathrm{aq}}^{\mathrm{a}}$ & & & 0.088 & 0.36 & & 0.23 & 0.16 & 0.17 & 0.16 & 0.16 & 0.15 & 0.15 & 0.16 & 0.16 \\
\hline $\mathrm{CPI}^{\mathrm{b}}$ & & & 6.0 & 5.6 & & 5.8 & 4.9 & 4.3 & 4.6 & 4.6 & 4.4 & 4.0 & 4.4 & 4.3 \\
\hline Long/short ${ }^{\mathrm{c}}$ & & & 3.3 & 2.7 & & 3.0 & 3.3 & 4.1 & 2.7 & 3.4 & 4.1 & 3.6 & 3.1 & 3.6 \\
\hline $\mathrm{C}_{\max }$ & & & 29 & 29 & & 29 & 29 & 29 & 29 & 29 & 29 & 29 & 29 & 29 \\
\hline \multicolumn{15}{|l|}{ n-alkenes } \\
\hline Octadecene & $\mathrm{C}_{18} \mathrm{H}_{36}$ & 252 & & & n.c. & & & & & & & & & \\
\hline Nonadecene & $\mathrm{C}_{19} \mathrm{H}_{38}$ & 266 & & & n.c. & & & & & & & & & \\
\hline Eicosene & $\mathrm{C}_{20} \mathrm{H}_{40}$ & 280 & & & n.c. & & & & & & & & & \\
\hline Heneicosene & $\mathrm{C}_{21} \mathrm{H}_{42}$ & 294 & & & n.c. & & & & & & & & & \\
\hline Docosene & $\mathrm{C}_{22} \mathrm{H}_{44}$ & 308 & & & n.c. & & & & & & & & & \\
\hline Tricosene & $\mathrm{C}_{23} \mathrm{H}_{46}$ & 322 & & 0.023 & n.c. & 0.023 & 0.51 & 0.16 & 0.25 & 0.31 & 0.088 & & 0.20 & 0.15 \\
\hline Tretracosene & $\mathrm{C}_{24} \mathrm{H}_{48}$ & 336 & & & n.c. & & & & & & & & & \\
\hline Pentacosene & $\mathrm{C}_{25} \mathrm{H}_{50}$ & 350 & 0.029 & 0.056 & n.c. & 0.043 & 0.84 & 0.22 & 0.36 & 0.47 & 0.21 & 0.28 & 0.29 & 0.26 \\
\hline Hexacosene & $\mathrm{C}_{26} \mathrm{H}_{52}$ & 364 & 0.056 & 0.070 & n.c. & 0.063 & 1.0 & 0.26 & 0.39 & 0.56 & 0.28 & 0.25 & 0.32 & 0.29 \\
\hline Heptacosene & $\mathrm{C}_{27} \mathrm{H}_{54}$ & 378 & 0.21 & 0.12 & n.c. & 0.17 & 2.3 & 0.51 & 0.79 & 1.2 & 0.45 & 0.63 & 0.53 & 0.54 \\
\hline Octacosene & $\mathrm{C}_{28} \mathrm{H}_{56}$ & 392 & 0.70 & 0.94 & n.c. & 0.82 & 14 & 2.3 & 3.8 & 6.5 & 2.6 & 2.6 & 2.8 & 2.7 \\
\hline Nonacosene & $\mathrm{C}_{29} \mathrm{H}_{58}$ & 406 & 0.24 & 0.064 & n.c. & 0.15 & 6.1 & 1.4 & 2.2 & 3.2 & 1.2 & 1.2 & 1.3 & 1.2 \\
\hline Triacontene & $\mathrm{C}_{30} \mathrm{H}_{60}$ & 420 & 0.16 & 0.23 & n.c. & 0.20 & 5.6 & 1.2 & 2.1 & 3.0 & 0.79 & 1.7 & 1.0 & 1.2 \\
\hline Hentriacontene & $\mathrm{C}_{31} \mathrm{H}_{62}$ & 434 & & & n.c. & & & & & & & & & \\
\hline Dotriacontene & $\mathrm{C}_{32} \mathrm{H}_{64}$ & 448 & & & n.c. & & & & & & & & & \\
\hline Total & & & 1.4 & 1.5 & & 1.4 & 30 & 5.9 & 10 & 15 & 5.6 & 6.6 & 6.5 & 6.2 \\
\hline $\mathrm{CPI}^{\mathrm{c}}$ & & & 0.53 & 0.21 & & 0.37 & 0.48 & 0.61 & 0.58 & 0.56 & 0.52 & 0.47 & 0.56 & 0.52 \\
\hline $\mathrm{C}_{\max }$ & & & 28 & 28 & & 28 & 28 & 28 & 28 & 28 & 28 & 28 & 28 & 28 \\
\hline
\end{tabular}

All values are reported in $\mu \mathrm{g} \mathrm{gOM}^{-1}$.

${ }^{\mathrm{a}} \mathrm{P}_{\mathrm{aq}}=\left(\mathrm{C}_{23}+\mathrm{C}_{25}\right) /\left(\mathrm{C}_{23}+\mathrm{C}_{25}+\mathrm{C}_{29}+\mathrm{C}_{31}\right)$

${ }^{\mathrm{b}} \mathrm{CPI}=\left(\left(\Sigma \mathrm{C}_{15}-\mathrm{C}_{35}\right)_{\text {odd }}\right) /\left(\left(\Sigma \mathrm{C}_{14}-\mathrm{C}_{34}\right)_{\text {even }}\right)$

${ }^{\mathrm{c}}$ Long/short $=\Sigma \mathrm{C} \geq 20 / \Sigma \mathrm{C} \leq 19$

${ }^{\mathrm{d}} \mathrm{CPI}=\left(\left(\Sigma \mathrm{C}_{17}-\mathrm{C}_{29}\right)_{\text {odd }}\right) /\left(\left(\Sigma \mathrm{C}_{18}-\mathrm{C}_{30}\right)_{\text {even }}\right)$ 
Table A2.12. Concentration of the $\mathrm{C}_{20} \mathrm{HBI}$ in periphyton samples from SRS2 and TS2.

\begin{tabular}{cccccc}
\hline \multirow{2}{*}{$S R S 2$} & Season & $\mathrm{C}_{20} \mathrm{HBI}$ & & Season & $\mathrm{C}_{20} \mathrm{HBI}$ \\
\cline { 2 - 6 } & & $\left(\mu \mathrm{gOM}^{-1}\right)$ & $T S 2$ & & $\left(\mu \mathrm{gOM}^{-1}\right)$ \\
\hline 2007 & $\mathrm{EW}$ & 55 & 2007 & $\mathrm{EW}$ & 66 \\
& $\mathrm{LW}$ & 46 & & $\mathrm{LW}$ & 20 \\
\multirow{6}{*}{2008} & $\mathrm{D}$ & n.c. & & $\mathrm{D}$ & n.c. \\
& $\mathrm{EW}$ & n.c. & \multirow{2}{*}{2008} & $\mathrm{EW}$ & n.c. \\
& $\mathrm{LW}$ & 419 & & $\mathrm{LW}$ & 10 \\
2009 & $\mathrm{D}$ & 66 & & $\mathrm{D}$ & 20 \\
& $\mathrm{EW}$ & 32 & \multirow{2}{*}{2009} & $\mathrm{EW}$ & n.c. \\
& $\mathrm{LW}$ & 24 & & LW & n.c. \\
& $\mathrm{D}$ & 21 & & $\mathrm{D}$ & 14 \\
\hline
\end{tabular}

Table A2.13. Concentration of the $\mathrm{C}_{20} \mathrm{HBI}$ in Everglades' floc samples.

\begin{tabular}{|c|c|c|c|c|c|c|c|c|}
\hline & Season & $\mathrm{C}_{20} \mathrm{HBI}$ & & Season & $\mathrm{C}_{20} \mathrm{HBI}$ & & & \\
\hline SRS2 & & $\left(\mu \mathrm{gOOM}^{-1}\right)$ & SRS6 & & $\left(\mu \mathrm{gOM}^{-1}\right)$ & & & \\
\hline \multirow{3}{*}{2007} & EW & 46 & 2007 & EW & $n . d$. & & & \\
\hline & LW & 65 & & LW & 0.75 & & & \\
\hline & $\mathrm{D}$ & n.c. ${ }^{*}$ & & $\mathrm{D}$ & n.c. & & & \\
\hline \multirow[t]{3}{*}{2008} & EW & 15 & 2008 & EW & 20 & & & \\
\hline & LW & 26 & & LW & 9.8 & & & \\
\hline & $\mathrm{D}$ & 46 & & $\mathrm{D}$ & 0.67 & & & \\
\hline \multirow[t]{4}{*}{2009} & EW & 237 & 2009 & EW & 0.60 & & & \\
\hline & LW & 25 & & LW & 3.7 & & & \\
\hline & $\mathrm{D}$ & 32 & & $\mathrm{D}$ & 0.48 & & & \\
\hline & Season & $\mathrm{C}_{20} \mathrm{HBI}$ & & Season & $\mathrm{C}_{20} \mathrm{HBI}$ & & Season & $\mathrm{C}_{20} \mathrm{HBI}$ \\
\hline$T S 2$ & & $\left(\mu \mathrm{gOOM}^{-1}\right)$ & TS6M & & $\left(\mu \mathrm{g} \mathrm{gOM}^{-1}\right)$ & $T S C$ & & $\left(\mu \mathrm{g} \mathrm{gOM}^{-1}\right)$ \\
\hline \multirow[t]{3}{*}{2007} & EW & & 2007 & EW & 2.0 & 2007 & EW & 1.5 \\
\hline & LW & 16 & & LW & 5.0 & & LW & 2.0 \\
\hline & $\mathrm{D}$ & n.c. & & $\mathrm{D}$ & n.c. & & $\mathrm{D}$ & n.c. \\
\hline \multirow[t]{3}{*}{2008} & EW & 217 & 2008 & EW & 10 & 2008 & EW & 42 \\
\hline & LW & 10 & & LW & 12 & & LW & 6.7 \\
\hline & $\mathrm{D}$ & 21 & & $\mathrm{D}$ & 50 & & $\mathrm{D}$ & 12 \\
\hline \multirow[t]{3}{*}{2009} & EW & 2.8 & 2009 & EW & 21 & 2009 & EW & 8.0 \\
\hline & LW & n.c. & & LW & 11 & & LW & 6.1 \\
\hline & $\mathrm{D}$ & 18 & & $\mathrm{D}$ & 12 & & $\mathrm{D}$ & 6.6 \\
\hline
\end{tabular}


Table A2.14. Concentration of botryococcenes in periphyton (SRS2) and floc (SRS2, TS6M and TS6P) samples. All values are reported in $\mu \mathrm{g} \mathrm{gOM}^{-1}$.

\begin{tabular}{|c|c|c|c|c|c|c|c|c|c|c|}
\hline \multicolumn{2}{|c|}{ SRS2 Periphyton } & S-1 & S-2 & S-3 & S-4 & S-5 & S-6 & S-7 & S-8 & Total \\
\hline \multirow[t]{3}{*}{2007} & EW & 0.22 & 9.2 & 7.0 & 5.5 & 0.53 & 0.00 & 1.1 & 0.00 & 24 \\
\hline & LW & 0.33 & 1.7 & 2.5 & 1.9 & 0.33 & 0.00 & 0.14 & 0.00 & 7.0 \\
\hline & $\mathrm{D}$ & n.c. & n.c. & n.c. & n.c. & n.c. & n.c. & n.c. & n.c. & n.c. \\
\hline \multirow[t]{3}{*}{2008} & EW & n.c. & n.c. & n.c. & n.c. & n.c. & n.c. & n.c. & n.c. & n.c. \\
\hline & LW & 0.00 & 2.3 & 2.4 & 0.14 & 0.00 & 0.00 & 0.75 & 0.00 & 5.5 \\
\hline & $\mathrm{D}$ & 0.00 & 2.0 & 4.4 & 2.1 & 0.12 & 0.00 & 5.1 & 0.00 & 14 \\
\hline \multirow[t]{2}{*}{2009} & EW & 0.00 & 10 & 23 & 5.6 & 1.3 & 0.00 & 12 & 0.00 & 52 \\
\hline & LW & 0.00 & 0.41 & 5.3 & 0.00 & 0.00 & 0.00 & 2.6 & 0.00 & 8.3 \\
\hline SRS2 Floc & $\mathrm{D}$ & 0.00 & 4.2 & 37 & 6.8 & 0.080 & 0.00 & 21 & 0.00 & 69 \\
\hline \multirow[t]{3}{*}{2007} & EW & 1.2 & 4.0 & 4.1 & 0.13 & 0.62 & 0.00 & 0.00 & 0.41 & 10 \\
\hline & LW & 0.67 & 2.2 & 4.0 & 5.8 & 0.68 & 0.00 & 0.49 & 0.00 & 14 \\
\hline & $\mathrm{D}$ & n.c. & n.c. & n.c. & n.c. & n.c. & n.c. & n.c. & n.c. & n.c. \\
\hline \multirow[t]{3}{*}{2008} & EW & 2.1 & 15 & 22 & 5.2 & 1.1 & 0.00 & 1.0 & 0.00 & 47 \\
\hline & LW & 2.0 & 7.0 & 7.7 & 1.4 & 0.29 & 0.00 & 0.65 & 0.00 & 19 \\
\hline & $\mathrm{D}$ & 2.6 & 11 & 13 & 3.7 & 1.2 & 0.00 & 0.18 & 0.00 & 32 \\
\hline \multirow[t]{2}{*}{2009} & EW & 17 & 68 & 48 & 3.6 & 0.86 & 0.00 & 1.8 & 0.00 & 139 \\
\hline & LW & 2.0 & 6.8 & 6.3 & 1.9 & 0.49 & 0.00 & 1.2 & 0.00 & 19 \\
\hline TS6M Floc & $\mathrm{D}$ & 2.2 & 9.3 & 13 & 0.85 & 0.87 & 0.34 & 0.44 & 0.00 & 27 \\
\hline \multirow[t]{3}{*}{2007} & $\mathrm{EW}$ & 0.00 & 0.00 & 0.00 & 0.00 & 0.00 & 0.00 & 0.00 & 0.00 & 0.00 \\
\hline & LW & 0.00 & 0.00 & 0.38 & 0.00 & 0.00 & 0.00 & 0.062 & 0.00 & 0.45 \\
\hline & $\mathrm{D}$ & n.c. & n.c. & n.c. & n.c. & n.c. & n.c. & n.c. & n.c. & n.c. \\
\hline \multirow[t]{3}{*}{2008} & EW & 0.00 & 0.00 & 3.8 & 0.00 & 0.00 & 0.00 & 3.0 & 0.00 & 6.8 \\
\hline & LW & 0.00 & 0.00 & 3.9 & 0.00 & 0.00 & 0.00 & 2.7 & 0.00 & 6.6 \\
\hline & $\mathrm{D}$ & 0.00 & 0.00 & 5.0 & 0.00 & 0.00 & 0.00 & 2.6 & 0.00 & 7.6 \\
\hline \multirow[t]{2}{*}{2009} & EW & 0.00 & 0.00 & 2.9 & 0.00 & 0.00 & 0.00 & 1.5 & 0.00 & 4.4 \\
\hline & LW & 0.00 & 0.00 & 2.0 & 0.00 & 0.00 & 0.00 & 0.90 & 0.00 & 2.9 \\
\hline TS6P Floc & $\mathrm{D}$ & 0.00 & 0.00 & 2.5 & 0.00 & 0.00 & 0.00 & 1.1 & 0.00 & 3.6 \\
\hline \multirow[t]{3}{*}{2007} & EW & 0.00 & 0.00 & 0.00 & 0.00 & 0.00 & 0.00 & 0.00 & 0.00 & 0.00 \\
\hline & LW & 0.00 & 0.00 & 0.18 & 0.00 & 0.00 & 0.00 & 0.088 & 0.00 & 0.27 \\
\hline & $\mathrm{D}$ & n.c. & n.c. & n.c. & n.c. & n.c. & n.c. & n.c. & n.c. & n.c. \\
\hline \multirow[t]{3}{*}{2008} & EW & 0.00 & 0.00 & 3.0 & 0.53 & 0.00 & 0.00 & 1.6 & 0.00 & 5.1 \\
\hline & LW & 0.00 & 0.00 & 2.5 & 0.83 & 0.00 & 0.00 & 1.3 & 0.00 & 4.6 \\
\hline & $\mathrm{D}$ & 0.00 & 0.00 & 2.5 & 0.68 & 0.00 & 0.00 & 1.4 & 0.00 & 4.5 \\
\hline \multirow[t]{3}{*}{2009} & EW & 0.00 & 0.00 & 1.4 & 0.46 & 0.00 & 0.00 & 0.61 & 0.00 & 2.5 \\
\hline & LW & 0.00 & 0.00 & 2.2 & 0.63 & 0.00 & 0.00 & 0.00 & 0.00 & 2.8 \\
\hline & $\mathrm{D}$ & 0.00 & 0.00 & 2.8 & 0.68 & 0.086 & 0.00 & 1.2 & 0.00 & 4.8 \\
\hline
\end{tabular}


Table A2.15. Concentration of kaurenes in Everglades' floc samples.

\begin{tabular}{|c|c|c|c|c|c|c|c|c|}
\hline$S R S 2$ & Season & Kaurenes & SRS6 & Season & Kaurenes & & & \\
\hline \multirow[t]{3}{*}{2007} & EW & 0.17 & 2007 & EW & & & & \\
\hline & LW & 0.030 & & LW & & & & \\
\hline & $\mathrm{D}$ & n.c. ${ }^{*}$ & & $\mathrm{D}$ & n.c. & & & \\
\hline \multirow[t]{3}{*}{2008} & EW & $n . d$. & 2008 & EW & 3.8 & & & \\
\hline & LW & 0.44 & & LW & 3.0 & & & \\
\hline & $\mathrm{D}$ & 0.93 & & $\mathrm{D}$ & 0.16 & & & \\
\hline \multirow[t]{3}{*}{2009} & EW & 0.80 & 2009 & EW & 0.19 & & & \\
\hline & LW & 0.49 & & LW & 0.33 & & & \\
\hline & $\mathrm{D}$ & 0.38 & & $\mathrm{D}$ & 0.46 & & & \\
\hline TS2 & Season & Kaurenes & TS6M & Season & Kaurenes & TS6P & Season & Kaurenes \\
\hline \multirow[t]{3}{*}{2007} & EW & & 2007 & EW & 0.10 & 2007 & EW & 2.4 \\
\hline & LW & 0.61 & & LW & 0.027 & & LW & 0.48 \\
\hline & $\mathrm{D}$ & n.c. & & $\mathrm{D}$ & n.c. & & $\mathrm{D}$ & n.c. \\
\hline \multirow[t]{3}{*}{2008} & EW & 3.5 & 2008 & EW & n.d. & 2008 & EW & 5.0 \\
\hline & LW & 0.15 & & LW & n.d. & & LW & 0.94 \\
\hline & $\mathrm{D}$ & 3.7 & & $\mathrm{D}$ & 0.42 & & $\mathrm{D}$ & 2.3 \\
\hline \multirow[t]{3}{*}{2009} & EW & 0.67 & 2009 & EW & 0.19 & 2009 & EW & 1.1 \\
\hline & LW & n.c. & & LW & 0.17 & & LW & 1.0 \\
\hline & $\mathrm{D}$ & 1.5 & & $\mathrm{D}$ & 0.10 & & $\mathrm{D}$ & 0.94 \\
\hline
\end{tabular}

All values in $\mu \mathrm{g} \mathrm{gOM}^{-1}$.

*sample was not collected. 
Appendix 2.3. Typical gas chromatograms of the floc samples from the Florida Coastal Everglades.
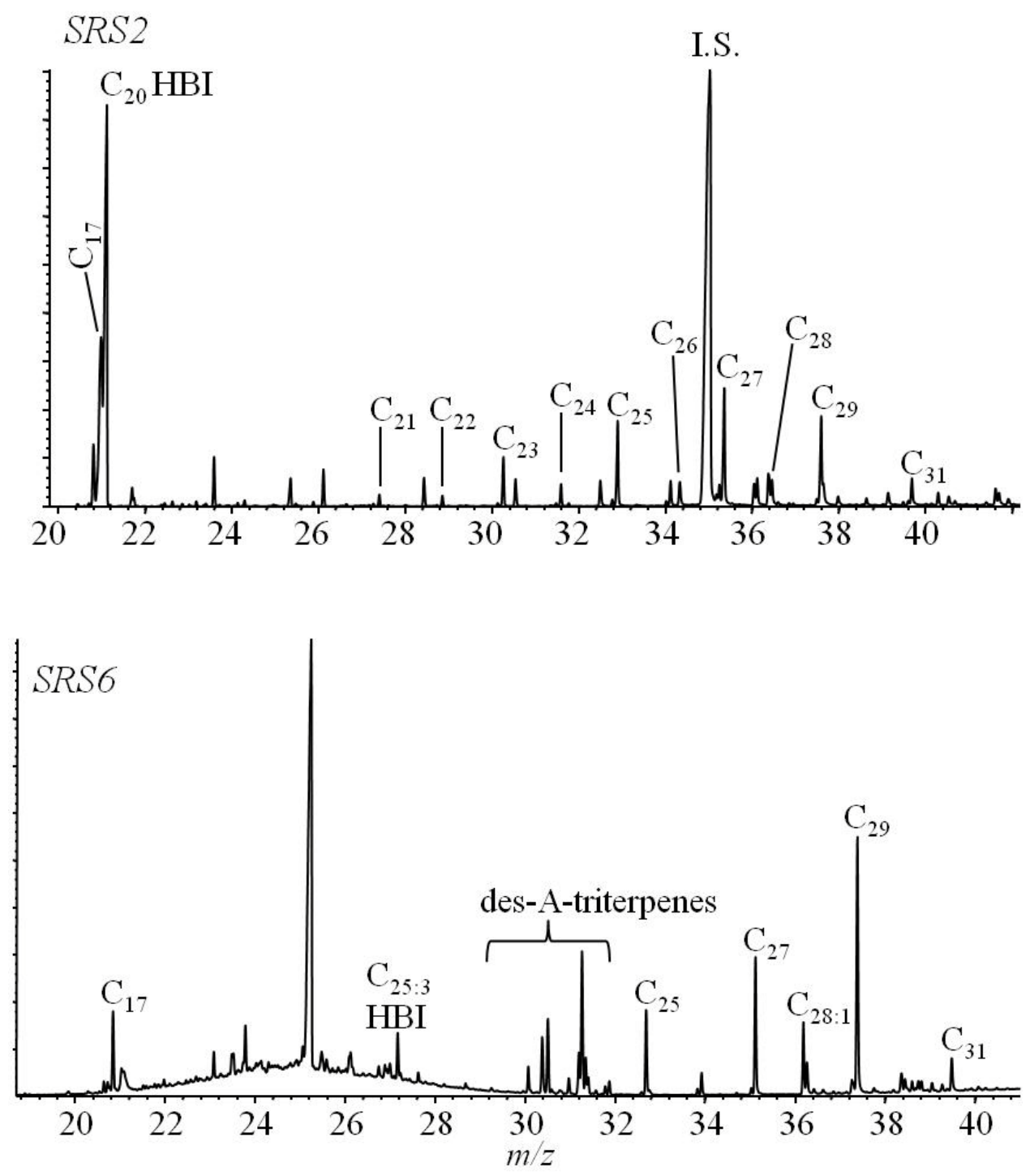

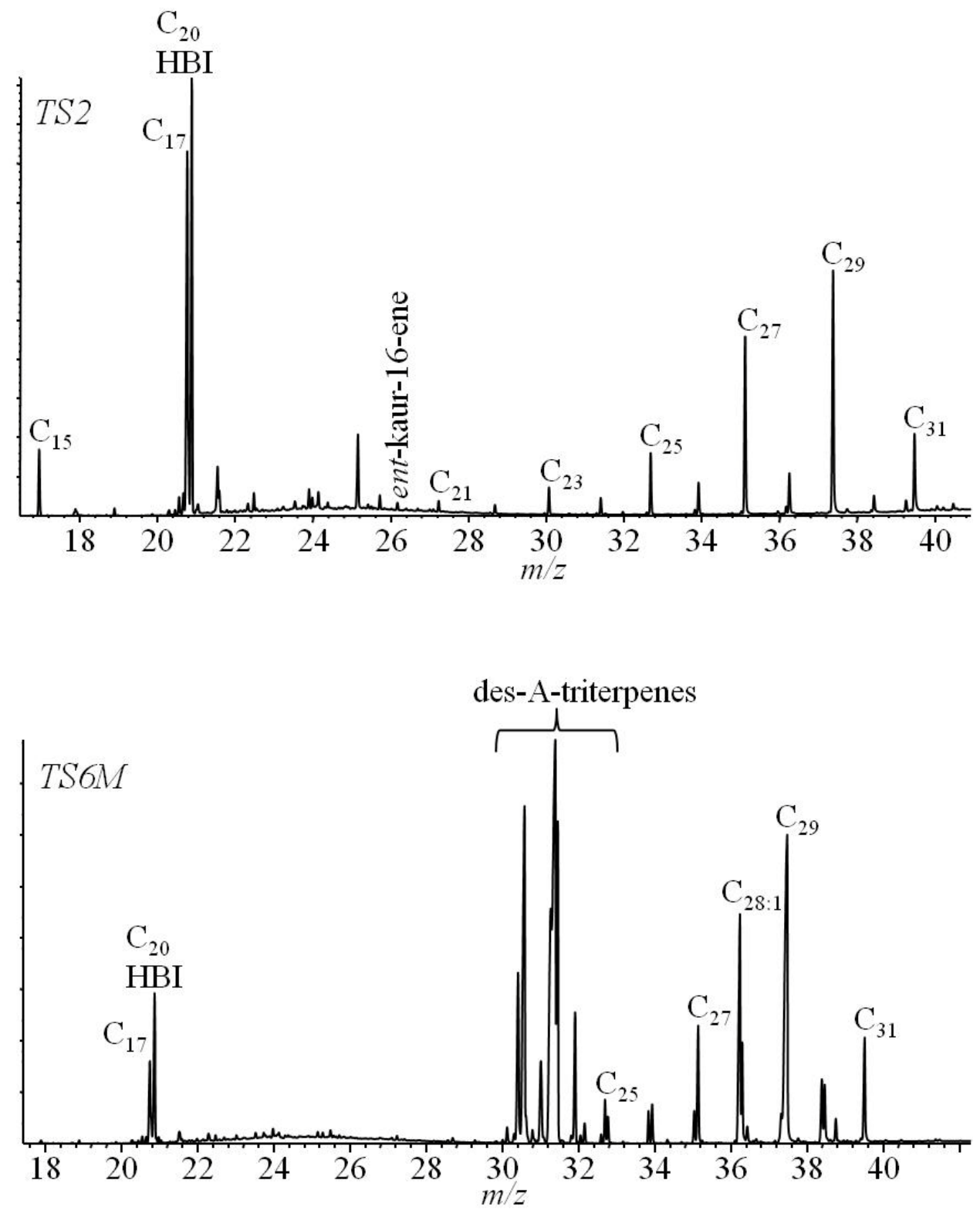


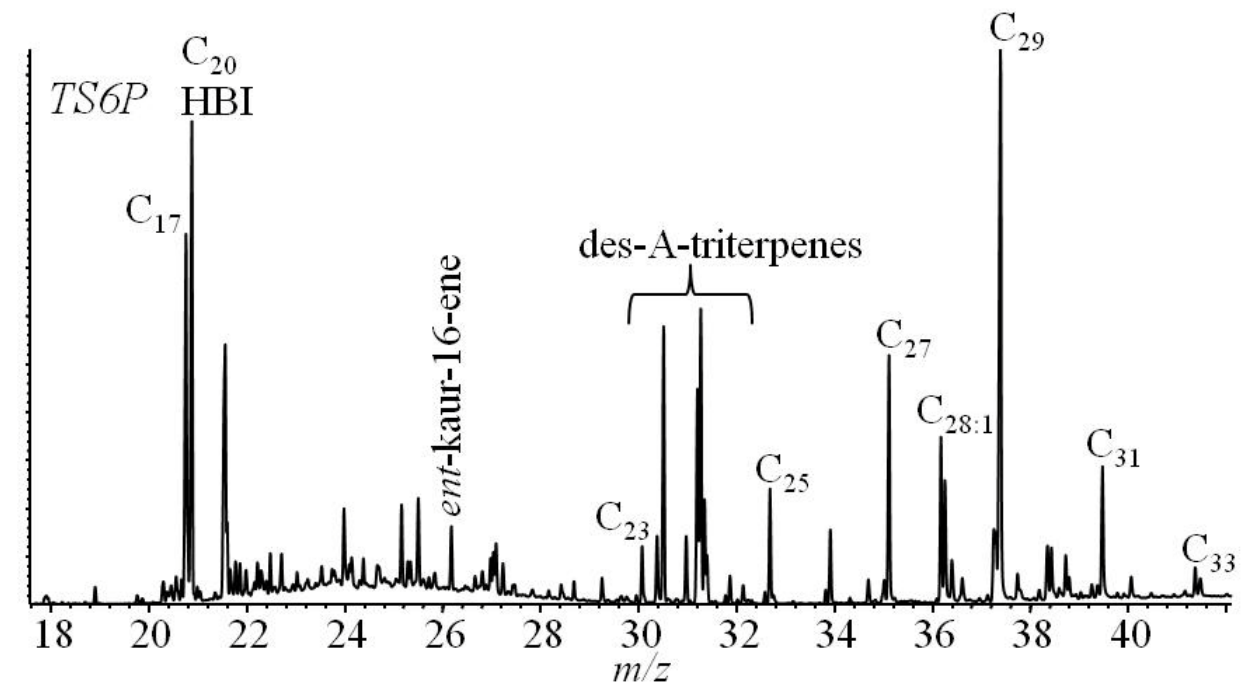

Chemical structures of selected biomarkers:

\section{Highly branched isoprenoids:}

$\mathrm{C}_{20}$

$\mathrm{C}_{25: 3}$ 


\section{Botryococcane skeletons:}

S-1 $\left(C_{32}\right)$

S-2 $\left(C_{34}\right)$

$\mathrm{S}-3\left(\mathrm{C}_{33}\right)$

S-4 $\left(C_{34}\right)$

$\mathrm{S}-5\left(\mathrm{C}_{34}\right)$

S-6 $\left(C_{34}\right)$

S-7 $\left(C_{32}\right)$

S-8 $\left(C_{33}\right)$

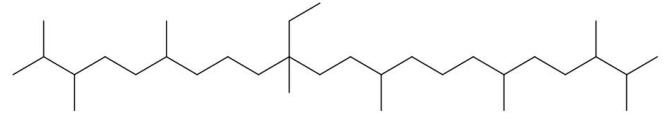


Kaurenes:

ent-kaurane

ent-kaur-15-ene

ent-kaur-16-ene 
Appendix 3.1. Supporting information for the eight fluorophore components obtained with the FCE-PARAFAC model.

Validation of the eight components. The light and dark grey lines show the excitation and emission loadings, respectively. The results of two independent models (split half analysis) are shown and were found to be adequate to describe the data.
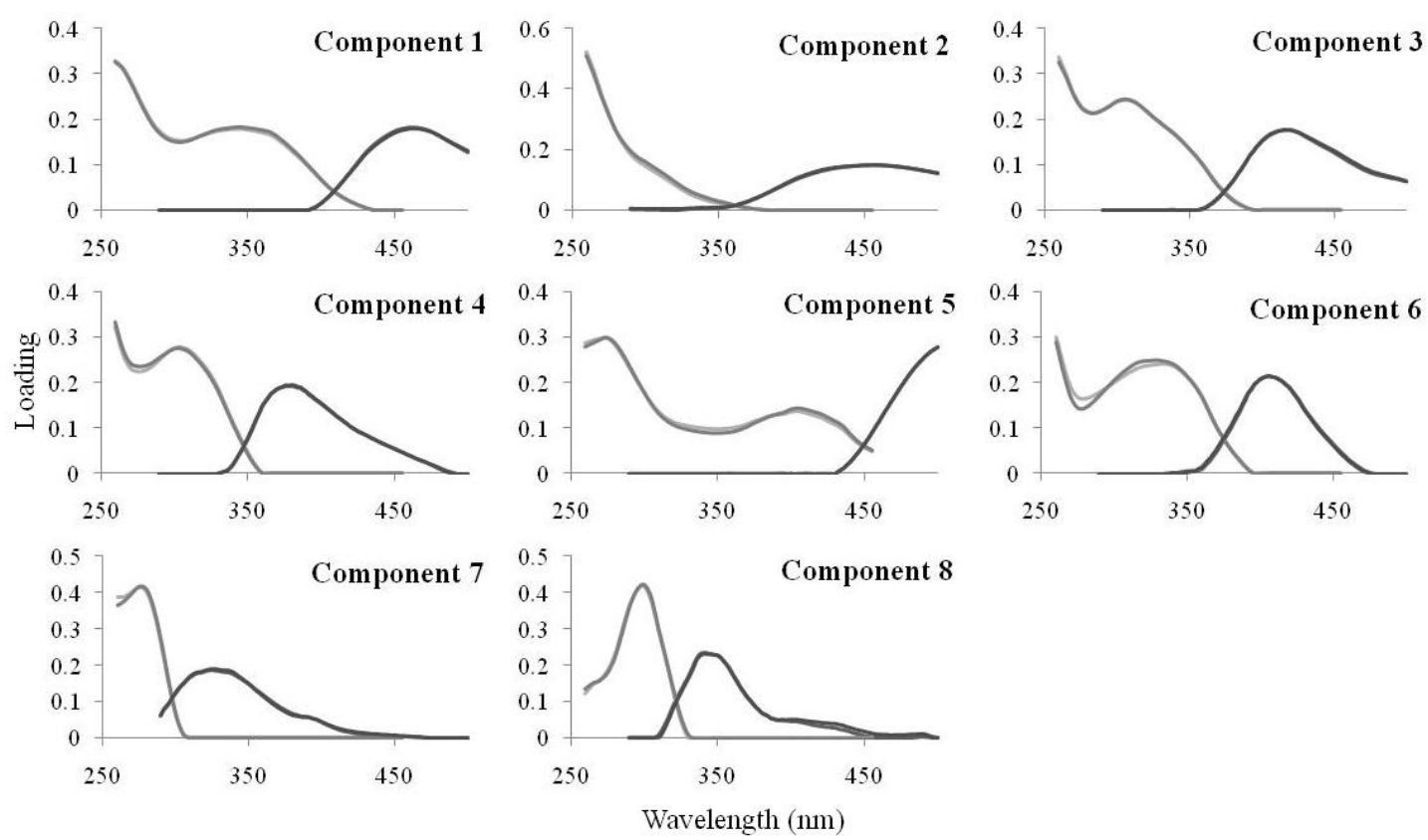
Excitation-emission matrix (EEM) spectra of modeled components 1-8 (a-h).
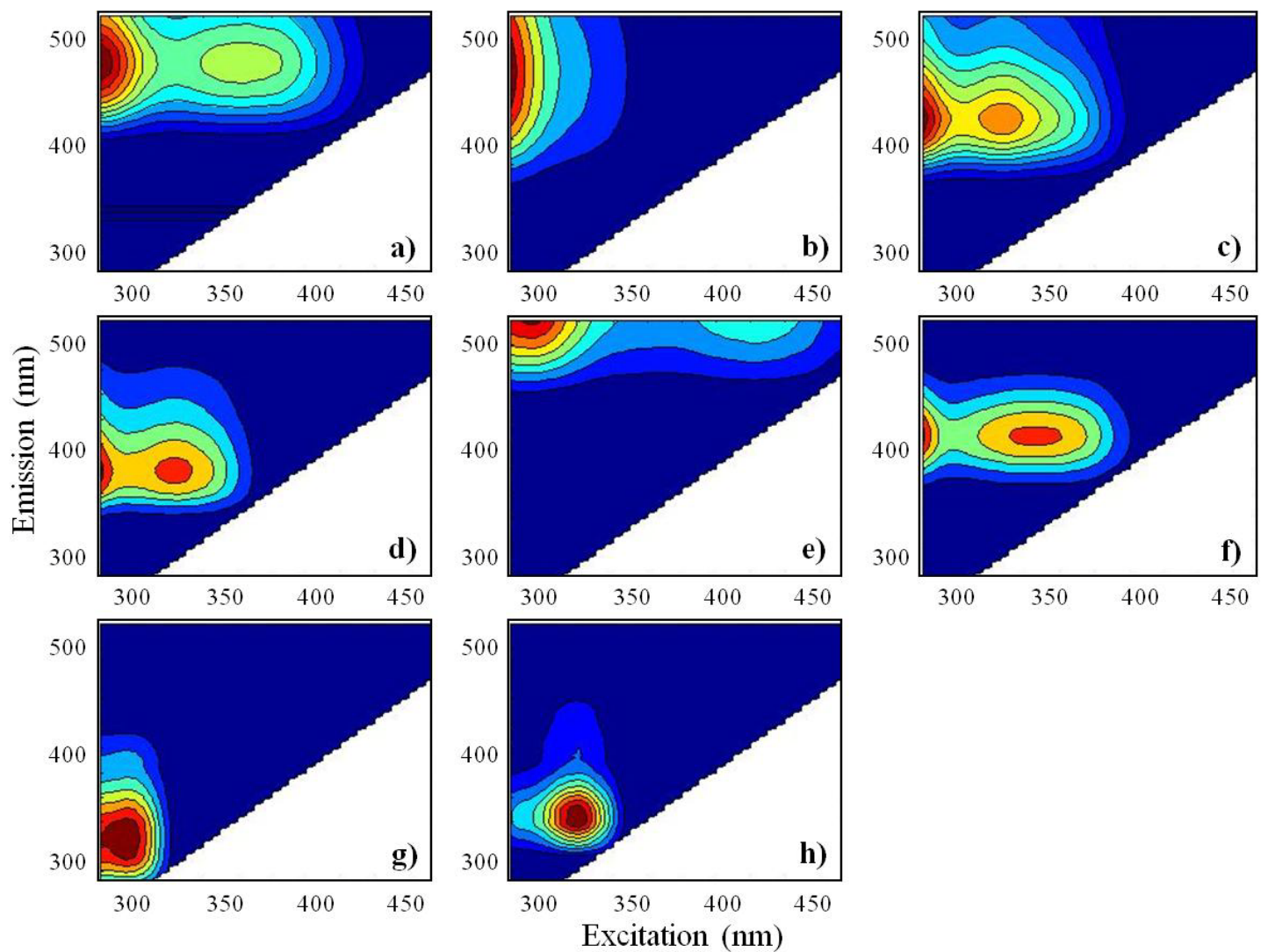

Characteristics of the eight components derived from the FCE PARAFAC model.

\begin{tabular}{ccccccc}
\hline Component & $\begin{array}{c}\text { Excitation } \\
\text { max. }\end{array}$ & $\begin{array}{c}\text { Emission } \\
\text { max. }\end{array}$ & $\begin{array}{c}\text { Coble et al. } \\
(1998)\end{array}$ & $\begin{array}{c}\text { Stedmon et al. } \\
(2005)^{*}\end{array}$ & $\begin{array}{c}\text { Cory et al. } \\
(2005)\end{array}$ & $\begin{array}{c}\text { Yamashita } \\
\text { et al. (2008) }\end{array}$ \\
\hline 1 & $<260(345)$ & 462 & A/C & 4 (Ter/Aut) & C1** or SQ2** & C5 (Micro) \\
2 & $<260$ & 454 & A & 1 (Ter) & Q2 & C3 (Ter) \\
3 & $<260(305)$ & 416 & C or M & 3 (Ter) & C10 & C1 (Ter) \\
4 & $<260(305)$ & 376 & M & 6 (Ant) & C3** or Q3** & C4 (Micro) \\
5 & $275(405)$ & $>500$ & - & 2 (Ter/Aut) & SQ1 & C2 (Ter) \\
6 & 325 & 406 & C or M & 5 (Ter/Ant) & SQ3**? & C6 (Ter?)? \\
7 & 275 & 326 & B & 8 (Aut) & Tyr & C8 (Protein) \\
8 & 300 & 342 & T & 7 (Aut) & Trp & C7 (Protein) \\
\hline
\end{tabular}

* Ter, Aut and Ant correspond to terrestrial, autochthonous and anthropogenic origin, respectively.

** were identified in the Antarctic data set only (Cory and McKnight, 2005), indicating microbial origin. 
Appendix 4.1. Cumulative $\mathrm{CO}_{2}$ evolution curves for floc and amended floc samples.
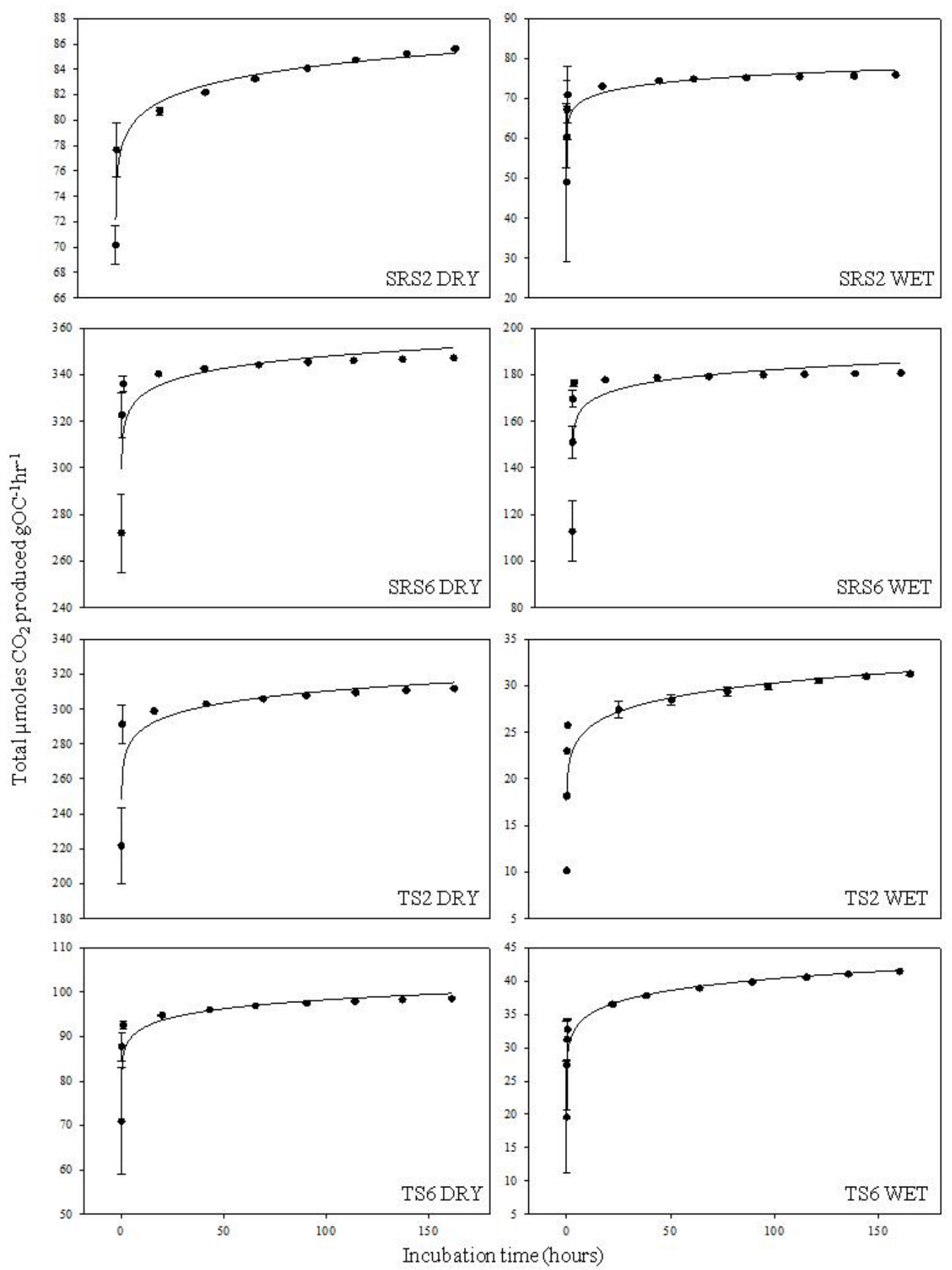

Figure A4.1. Cumulative $\mathrm{CO}_{2}$ evolution curves for floc. The amount of $\mathrm{CO}_{2}$ evolved over time is shown on a different scale for the various samples. 

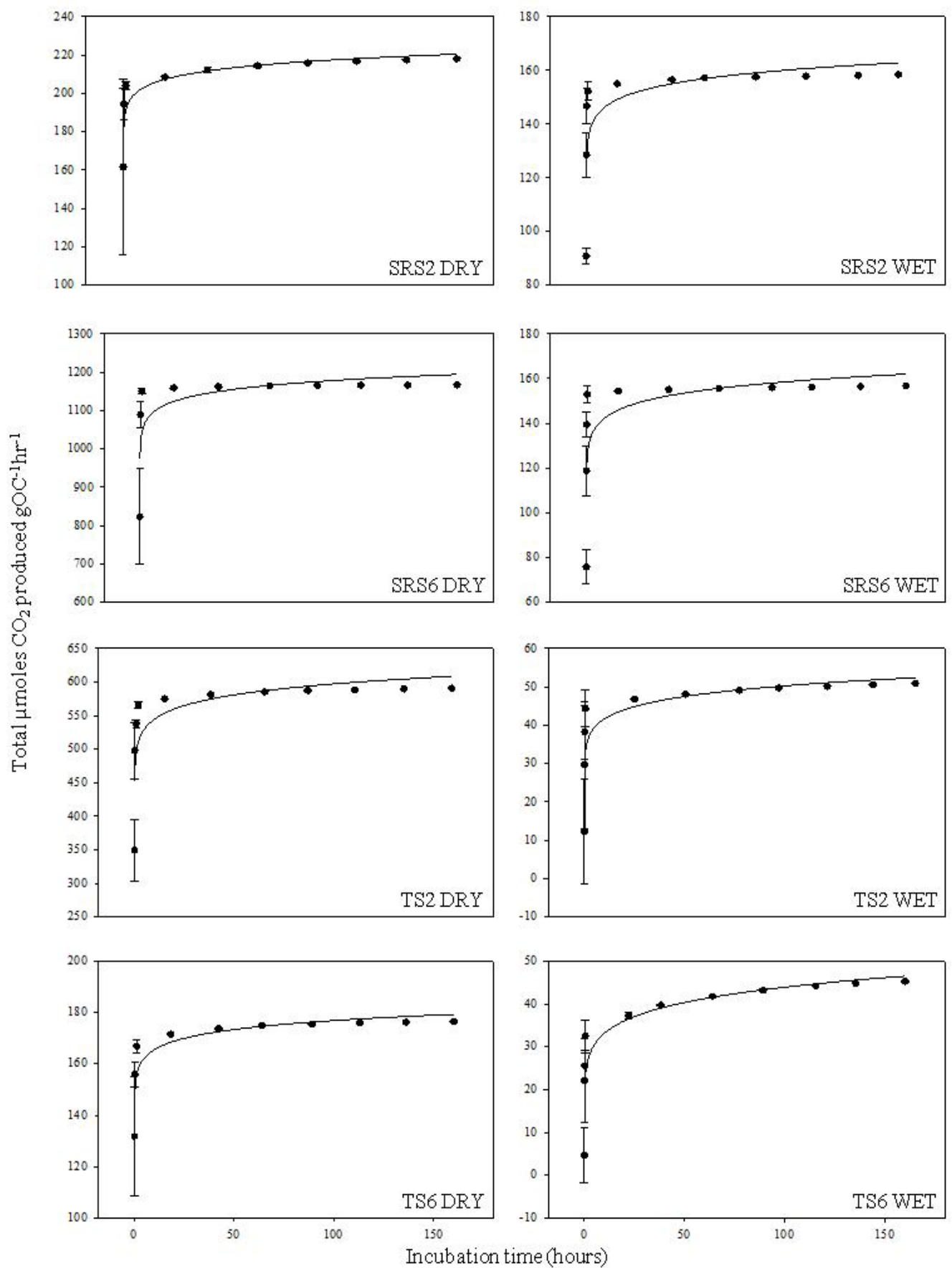

Figure A4.2. Cumulative $\mathrm{CO}_{2}$ evolution curves for floc samples amended with phosphorus. The amount of $\mathrm{CO}_{2}$ evolved over time is shown on a different scale for the various samples. 

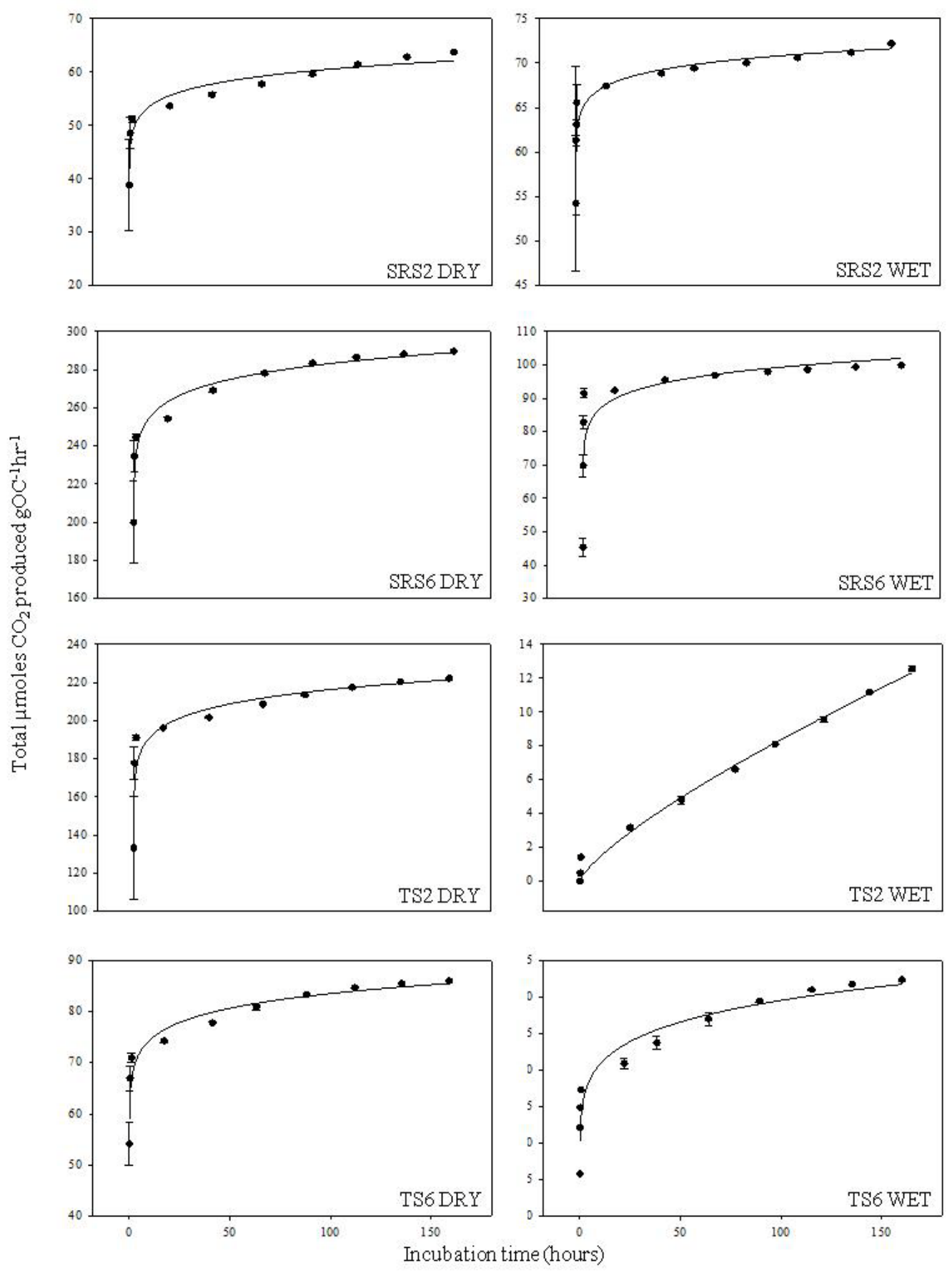

Figure A4.3. Cumulative $\mathrm{CO}_{2}$ evolution curves for floc samples amended with glucose. The amount of $\mathrm{CO}_{2}$ evolved over time is shown on a different scale for the various samples. 
Appendix 5.1. Tables summarizing the concentrations of all biomarkers (aliphatic hydrocarbons, aromatic hydrocarbons, oxygenated compounds including triterpenoids and sterols) detected in samples from the King's Creek watershed in Konza Prairie.

Table A5.1. Concentrations of $n$-alkanes and $n$-alkenes in the riparian vegetation samples.

\begin{tabular}{|c|c|c|c|c|c|c|c|c|c|c|}
\hline \multirow[t]{2}{*}{ Sample type: } & & & \multicolumn{8}{|c|}{ Riparian Vegetation } \\
\hline & & & $\begin{array}{l}\text { Bur } \\
\text { Oak }\end{array}$ & Hackberry & Cottonwood & $\begin{array}{l}\text { Wild } \\
\text { Plum }\end{array}$ & $\begin{array}{l}\text { Chinkapin } \\
\text { Oak }\end{array}$ & $\begin{array}{c}\text { Black } \\
\text { Walnut }\end{array}$ & $\begin{array}{l}\text { Roughleaf } \\
\text { Dogwood }\end{array}$ & Mean \\
\hline n-Alkanes & Formula & $M W$ & & & & & & & & \\
\hline Undecane & $\mathrm{C}_{11} \mathrm{H}_{24}$ & 156 & & & & & & & & \\
\hline Dodecane & $\mathrm{C}_{12} \mathrm{H}_{26}$ & 170 & & & & & & & & \\
\hline Tridecane & $\mathrm{C}_{13} \mathrm{H}_{28}$ & 184 & & & & & & & & \\
\hline Tetradecane & $\mathrm{C}_{14} \mathrm{H}_{30}$ & 198 & & & & 0.000093 & & & & 0.000093 \\
\hline Pentadecane & $\mathrm{C}_{15} \mathrm{H}_{32}$ & 212 & & & & 0.00014 & & 0.00011 & & 0.00013 \\
\hline Hexadecane & $\mathrm{C}_{16} \mathrm{H}_{34}$ & 226 & & & & & & & & \\
\hline Heptadecane & $\mathrm{C}_{17} \mathrm{H}_{36}$ & 240 & & & & & & & & \\
\hline Octadecane & $\mathrm{C}_{18} \mathrm{H}_{38}$ & 254 & & & & & & & & \\
\hline Nonadecane & $\mathrm{C}_{19} \mathrm{H}_{40}$ & 268 & & & & & & & & \\
\hline Eicosane & $\mathrm{C}_{20} \mathrm{H}_{42}$ & 282 & & & & & & & & \\
\hline Heneicosane & $\mathrm{C}_{21} \mathrm{H}_{44}$ & 296 & 0.00012 & & & & 0.00027 & & & 0.00019 \\
\hline Docosane & $\mathrm{C}_{22} \mathrm{H}_{46}$ & 310 & 0.00013 & & 0.00033 & & 0.00032 & & 0.00017 & 0.00024 \\
\hline Tricosane & $\mathrm{C}_{23} \mathrm{H}_{48}$ & 324 & 0.0012 & 0.00079 & 0.0030 & & 0.0063 & & 0.0024 & 0.0027 \\
\hline Tetracosane & $\mathrm{C}_{24} \mathrm{H}_{50}$ & 338 & 0.00070 & 0.00049 & 0.0021 & 0.00035 & 0.0030 & 0.00023 & 0.0013 & 0.0012 \\
\hline Pentacosane & $\mathrm{C}_{25} \mathrm{H}_{52}$ & 352 & 0.0072 & 0.0065 & 0.0090 & 0.0034 & 0.064 & 0.0039 & 0.0098 & 0.015 \\
\hline Hexacosane & $\mathrm{C}_{26} \mathrm{H}_{54}$ & 366 & 0.0021 & 0.0025 & 0.0097 & 0.00091 & 0.0056 & 0.00047 & 0.0026 & 0.0034 \\
\hline Heptacosane & $\mathrm{C}_{27} \mathrm{H}_{56}$ & 380 & 0.030 & 0.062 & 0.069 & 0.024 & 0.17 & 0.015 & 0.034 & 0.057 \\
\hline Octacosane & $\mathrm{C}_{28} \mathrm{H}_{58}$ & 394 & 0.0042 & 0.016 & 0.030 & 0.0037 & 0.010 & 0.00093 & 0.0058 & 0.010 \\
\hline Nonacosane & $\mathrm{C}_{29} \mathrm{H}_{60}$ & 408 & 0.061 & 0.56 & 0.49 & 0.055 & 0.23 & 0.035 & 0.066 & 0.21 \\
\hline Triacontane & $\mathrm{C}_{30} \mathrm{H}_{62}$ & 422 & 0.0026 & 0.015 & 0.0098 & 0.0039 & 0.0037 & 0.0047 & 0.0051 & 0.0064 \\
\hline Hentriacontane & $\mathrm{C}_{31} \mathrm{H}_{64}$ & 436 & 0.016 & 0.067 & 0.041 & 0.030 & 0.036 & 0.26 & 0.028 & 0.069 \\
\hline Dotriacontane & $\mathrm{C}_{32} \mathrm{H}_{66}$ & 450 & 0.00096 & 0.00070 & 0.0011 & 0.00099 & 0.00062 & 0.022 & 0.00096 & 0.0039 \\
\hline
\end{tabular}


Table A5.1. continued.

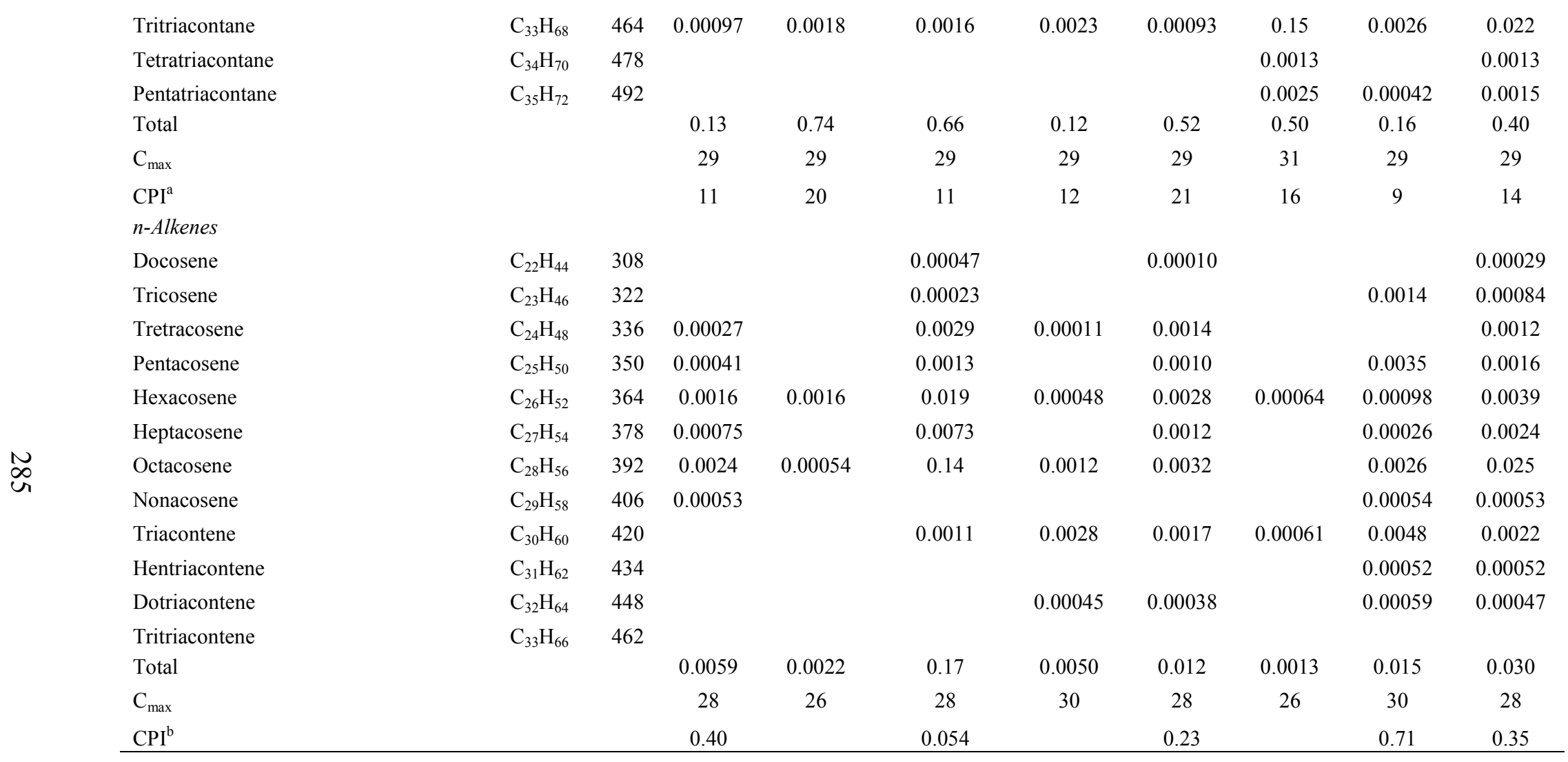

All values are reported in $\mathrm{mg} \mathrm{g}^{-1} \mathrm{OC}$.

${ }^{\mathrm{a}} \mathrm{CPI}=\left[\left(\mathrm{C}_{11}-\mathrm{C}_{35}\right)_{\text {odd }} /\left(\mathrm{C}_{12}-\mathrm{C}_{34}\right)_{\text {even }}\right]$

${ }^{\mathrm{b}} \mathrm{CPI}=\left[\left(\mathrm{C}_{15}-\mathrm{C}_{33}\right)_{\text {odd }} /\left(\mathrm{C}_{16}-\mathrm{C}_{32}\right)_{\text {even }}\right]$ 
Table A5.2. Concentrations of $n$-alkanes, branched $n$-alkanes, $n$-alkenes, phytadienes, highly branched isoprenoids and triterpenes in the grass, moss and algae samples.

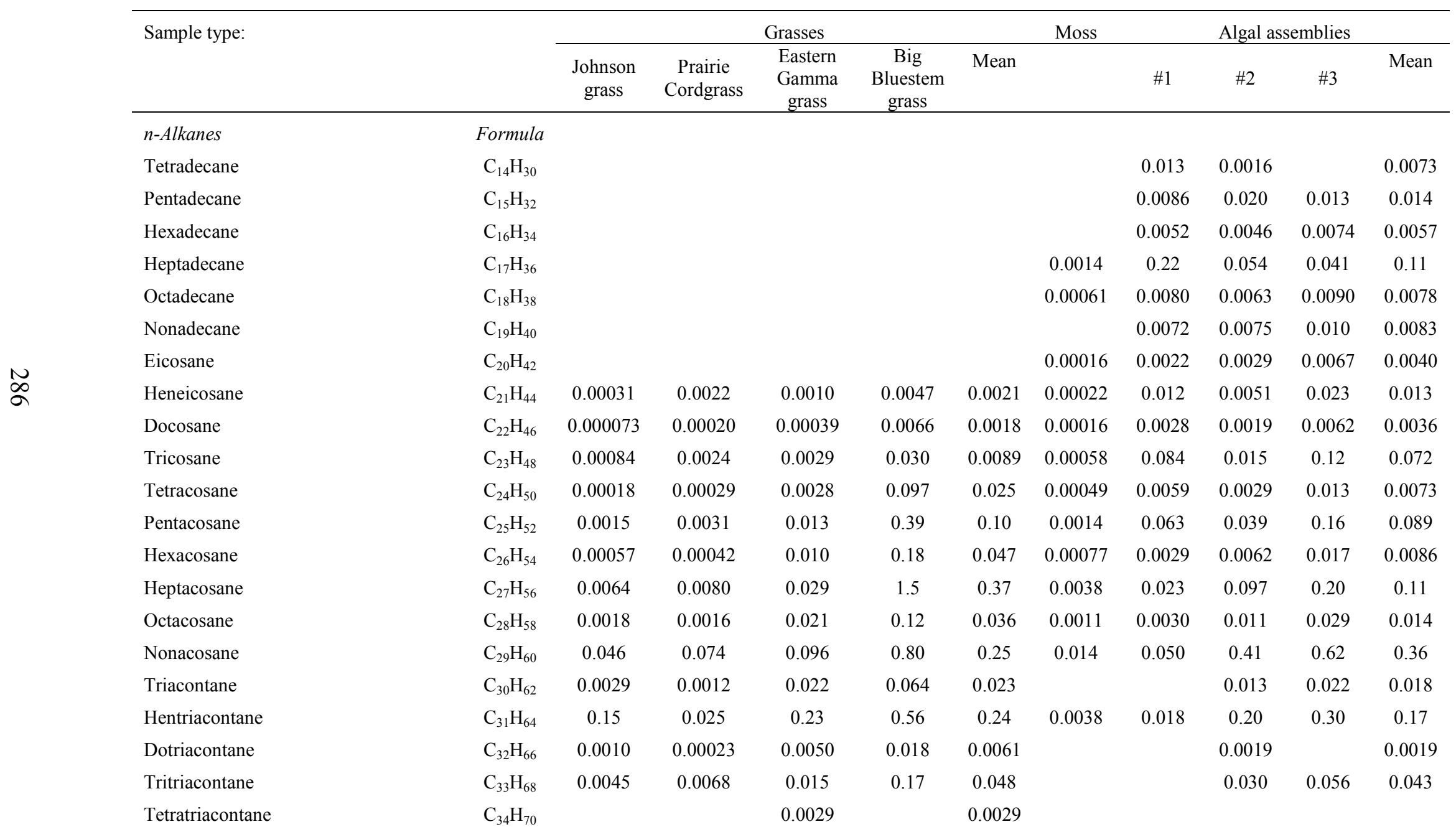


Table A5.2. continued.

$\begin{array}{ll}\text { Pentatriacontane } & \mathrm{C}_{35} \mathrm{H}_{72} \\ \text { Total } & \\ \mathrm{C}_{\text {max }} & \\ \mathrm{CPI}^{\mathrm{a}} & \\ \text { Branched n-Alkanes } & \\ \text { 2-methyl-tetracosane } & \\ \text { 2-methyl-pentacosane } & \mathrm{C}_{25} \mathrm{H}_{52} \\ \text { 2-methyl-hexacosane } & \mathrm{C}_{26} \mathrm{H}_{54} \\ \text { 2-methyl-heptacosane } & \mathrm{C}_{27} \mathrm{H}_{56} \\ \text { 2-methyl-octacosane } & \mathrm{C}_{28} \mathrm{H}_{58} \\ \text { 2-methyl-nonacosane } & \mathrm{C}_{29} \mathrm{H}_{60} \\ \text { 2-methyl-triacontane } & \mathrm{C}_{30} \mathrm{H}_{62} \\ \text { 2-methyl-hentriacontane } & \mathrm{C}_{31} \mathrm{H}_{64} \\ \text { 2-methyl-dotriacontane } & \mathrm{C}_{32} \mathrm{H}_{66} \\ \text { Total } & \mathrm{C}_{33} \mathrm{H}_{68} \\ \text { C max } & \\ \text { CPI } & \\ \text { n-Alkenes } & \\ \text { Pentadecene } & \\ \text { Hexadecene } & \mathrm{C}_{23} \mathrm{H}_{46} \\ \text { Heptadecene } & \mathrm{C}_{10} \mathrm{H}_{38} \\ \text { Octadecene } & \mathrm{C}_{20} \mathrm{H}_{40} \\ \text { Nonadecene } & \mathrm{C}_{21} \mathrm{H}_{42} \\ \text { Eicosene } & \mathrm{C}_{22} \mathrm{H}_{44} \\ \text { Heneicosene } & \mathrm{C}_{16} \mathrm{H}_{32} \\ \text { Tricosene } & \mathrm{C}_{34} \mathrm{H}_{30} \\ & \\ & \\ & \\ & \end{array}$

$\begin{array}{ccc} & 0.00073 & \\ 0.22 & 0.13 & 0.45 \\ 31 & 29 & 31 \\ 30 & 31 & 6.3\end{array}$

$0.0090 \quad 0.0049$

$\begin{array}{lcccccc}3.9 & 1.2 & 0.028 & 0.53 & 0.93 & 1.7 & 1.0 \\ 27 & 30 & 29 & 17 & 29 & 29 & 25 \\ 7.1 & 19 & 15 & 20 & 35 & 36 & 30\end{array}$

$\begin{array}{lll}0.0029 & 0.0096 & 0.0062\end{array}$

$0.016 \quad 0.016$

$0.057 \quad 0.057$

$0.059 \quad 0.059$

$\begin{array}{lll}0.00034 & 0.32 & 0.16\end{array}$

$\begin{array}{lll}0.0015 & 0.0079 & 0.0047\end{array}$

$\begin{array}{lll}0.0011 & 0.060 & 0.031\end{array}$

$0.0017 \quad 0.0017$

$\begin{array}{lll}0.0029 & 0.048 \quad 0.025\end{array}$

$\begin{array}{lll}0.0075 & 0.56 & 0.29\end{array}$

$32 \quad 28 \quad 30$

$\begin{array}{lll}0.73 & 0.17 & 0.45\end{array}$

$\begin{array}{cccc}0.0034 & 0.0030 & 0.026 & 0.011 \\ 0.0038 & 0.0071 & 0.041 & 0.017 \\ & & & \\ & 0.016 & 0.032 & 0.024 \\ & & & \\ 0.010 & 0.026 & 0.11 & 0.048 \\ 28 & 30 & 28 & 29\end{array}$

$0.0078 \quad 0.0078$

$\begin{array}{llll}0.093 & 0.0081 & 0.055 & 0.052\end{array}$

$0.015 \quad 0.015$

$\begin{array}{lllll}0.0032 & 0.0032 & 0.011 & 0.018 & 0.014\end{array}$


Table A5.2. continued.

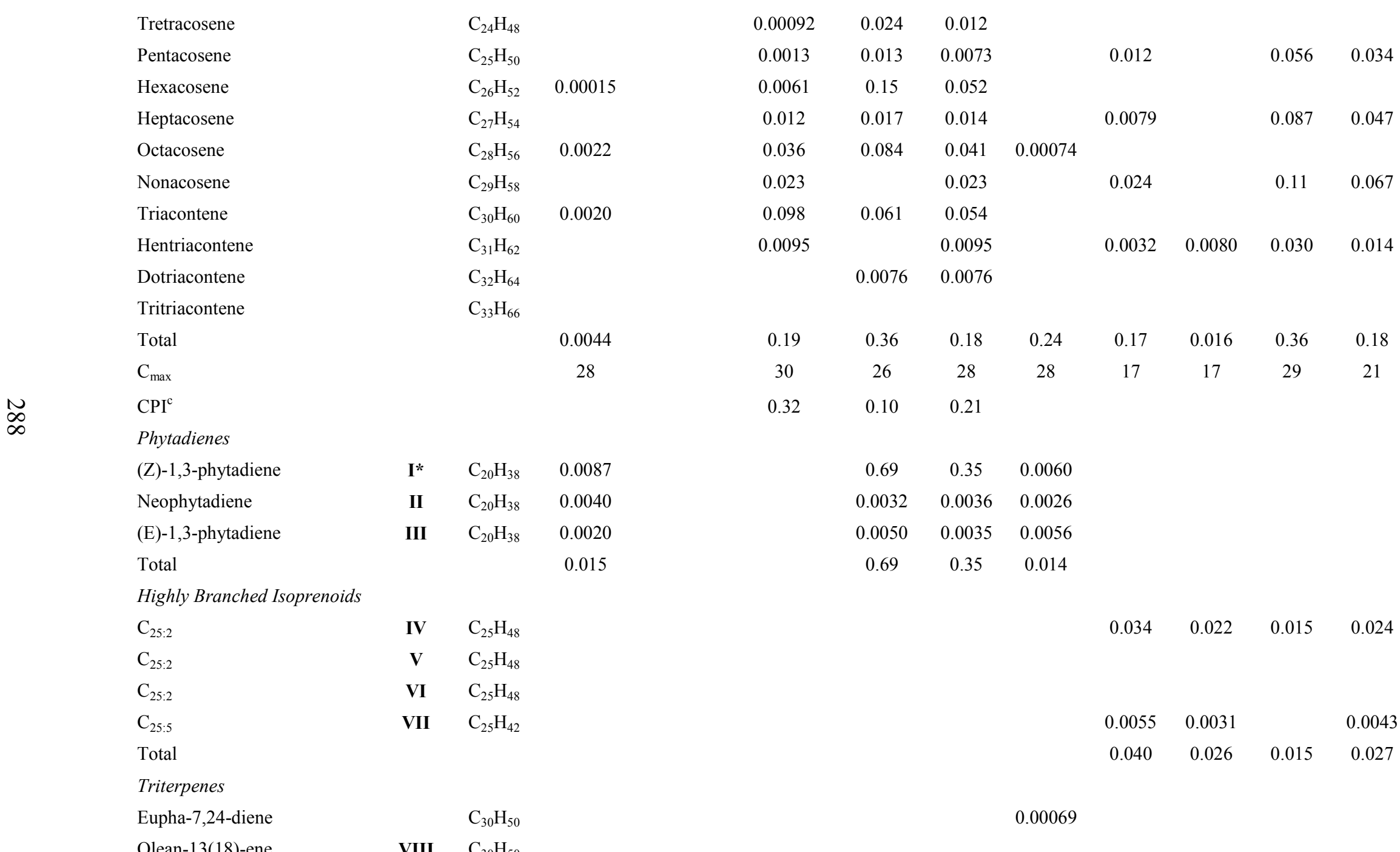


Table A5.2. continued.

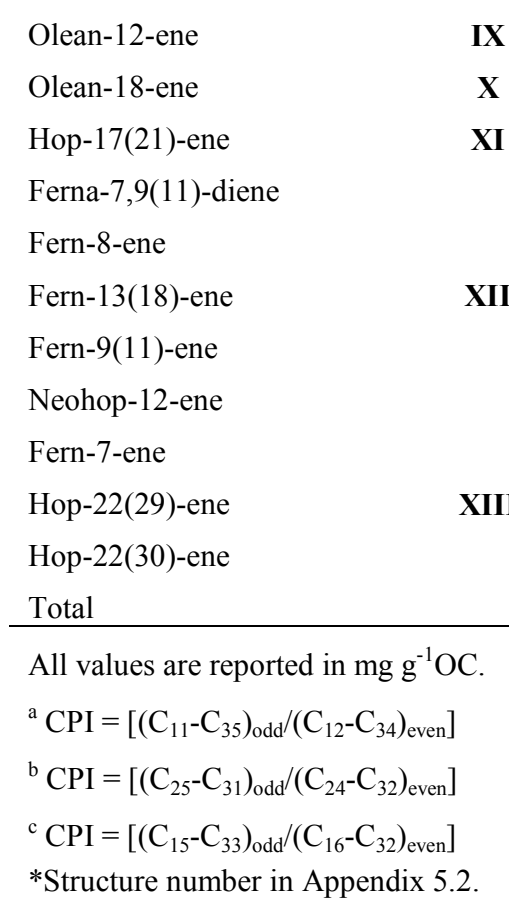

IX $\quad \mathrm{C}_{30} \mathrm{H}_{50}$

X $\quad \mathrm{C}_{30} \mathrm{H}_{50}$

$\begin{array}{lll}\text { XI } \quad \mathrm{C}_{30} \mathrm{H}_{50} & 0.0058\end{array}$

$\mathrm{C}_{30} \mathrm{H}_{48} \quad 0.0016$

$\mathrm{C}_{30} \mathrm{H}_{50} \quad 0.0042$

$\begin{array}{lll}\text { XII } \quad \mathrm{C}_{30} \mathrm{H}_{50} & 0.011\end{array}$

$\begin{array}{ll}\mathrm{C}_{30} \mathrm{H}_{50} & 0.056\end{array}$

$\mathrm{C}_{30} \mathrm{H}_{50} \quad 0.0028$

$\mathrm{C}_{30} \mathrm{H}_{50} \quad 0.012$

XIII $\mathrm{C}_{30} \mathrm{H}_{50} \quad 0.026$

$\begin{array}{ll}\mathrm{C}_{30} \mathrm{H}_{50} & 0.0017\end{array}$

*Structure number in Appendix 5.2 
Table A5.3. Concentrations of $n$-alkanes, branched $n$-alkanes, $n$-alkenes, phytadienes, highly branched isoprenoids and triterpenes in sediments from the King's Creek watershed in Konza Prairie.

\begin{tabular}{|c|c|c|c|c|c|c|c|c|c|c|}
\hline \multirow[t]{2}{*}{ Sample type: } & & & \multicolumn{8}{|c|}{ Sediments } \\
\hline & & & Site 1 & Site 2 & Site 3 & Site 4 & Site 5 & Site 6 & Site 7 & Mean \\
\hline n-Alkanes & Formula & $M W$ & & & & & & & & \\
\hline Pentadecane & $\mathrm{C}_{15} \mathrm{H}_{32}$ & 212 & 0.0023 & 0.00043 & 0.00061 & 0.00091 & & 0.00096 & 0.00030 & 0.00092 \\
\hline Hexadecane & $\mathrm{C}_{16} \mathrm{H}_{34}$ & 226 & 0.00060 & 0.00017 & 0.00026 & 0.00058 & & 0.00084 & 0.00013 & 0.00043 \\
\hline Heptadecane & $\mathrm{C}_{17} \mathrm{H}_{36}$ & 240 & 0.0037 & 0.0012 & 0.00090 & 0.0040 & 0.0023 & 0.015 & 0.00091 & 0.0040 \\
\hline Octadecane & $\mathrm{C}_{18} \mathrm{H}_{38}$ & 254 & 0.00085 & 0.00042 & 0.00055 & 0.0023 & 0.00053 & 0.0015 & 0.00028 & 0.00093 \\
\hline Nonadecane & $\mathrm{C}_{19} \mathrm{H}_{40}$ & 268 & 0.0017 & 0.0012 & 0.00098 & & 0.00037 & 0.0024 & 0.00072 & 0.0012 \\
\hline Eicosane & $\mathrm{C}_{20} \mathrm{H}_{42}$ & 282 & 0.00081 & 0.00072 & 0.0013 & 0.0012 & 0.00088 & 0.0020 & 0.00044 & 0.0011 \\
\hline Heneicosane & $\mathrm{C}_{21} \mathrm{H}_{44}$ & 296 & 0.0023 & 0.0013 & 0.0013 & 0.0029 & 0.00089 & 0.0038 & 0.0012 & 0.0020 \\
\hline Docosane & $\mathrm{C}_{22} \mathrm{H}_{46}$ & 310 & 0.00083 & 0.00074 & 0.0012 & 0.0016 & 0.00069 & 0.0025 & 0.00079 & 0.0012 \\
\hline Tricosane & $\mathrm{C}_{23} \mathrm{H}_{48}$ & 324 & 0.0044 & 0.0027 & 0.0031 & 0.0053 & 0.0020 & 0.0073 & 0.0030 & 0.0039 \\
\hline Tetracosane & $\mathrm{C}_{24} \mathrm{H}_{50}$ & 338 & 0.0012 & 0.0011 & 0.0019 & 0.0023 & 0.0012 & 0.0034 & 0.0011 & 0.0017 \\
\hline Pentacosane & $\mathrm{C}_{25} \mathrm{H}_{52}$ & 352 & 0.0054 & 0.0058 & 0.0083 & 0.0095 & 0.0048 & 0.016 & 0.0050 & 0.0078 \\
\hline Hexacosane & $\mathrm{C}_{26} \mathrm{H}_{54}$ & 366 & 0.0022 & 0.0020 & 0.0039 & 0.0039 & 0.0027 & 0.0062 & 0.0022 & 0.0033 \\
\hline Heptacosane & $\mathrm{C}_{27} \mathrm{H}_{56}$ & 380 & 0.016 & 0.015 & 0.026 & 0.026 & 0.017 & 0.043 & 0.018 & 0.023 \\
\hline Octacosane & $\mathrm{C}_{28} \mathrm{H}_{58}$ & 394 & 0.0041 & 0.0035 & 0.0082 & 0.0069 & 0.0060 & 0.011 & 0.0039 & 0.0063 \\
\hline Nonacosane & $\mathrm{C}_{29} \mathrm{H}_{60}$ & 408 & 0.056 & 0.050 & 0.090 & 0.081 & 0.064 & 0.12 & 0.061 & 0.075 \\
\hline Triacontane & $\mathrm{C}_{30} \mathrm{H}_{62}$ & 422 & 0.0041 & 0.0036 & 0.0084 & 0.0074 & 0.0074 & 0.0099 & 0.0031 & 0.0063 \\
\hline Hentriacontane & $\mathrm{C}_{31} \mathrm{H}_{64}$ & 436 & 0.039 & 0.030 & 0.059 & 0.051 & 0.064 & 0.079 & 0.041 & 0.052 \\
\hline Dotriacontane & $\mathrm{C}_{32} \mathrm{H}_{66}$ & 450 & 0.0015 & 0.0013 & 0.0046 & 0.0037 & 0.0043 & 0.0052 & 0.0016 & 0.0032 \\
\hline Tritriacontane & $\mathrm{C}_{33} \mathrm{H}_{68}$ & 464 & 0.013 & 0.0098 & 0.028 & 0.021 & 0.027 & 0.032 & 0.014 & 0.021 \\
\hline Tetratriacontane & $\mathrm{C}_{34} \mathrm{H}_{70}$ & 478 & 0.00036 & 0.00034 & 0.0011 & 0.0010 & 0.0010 & 0.0013 & & 0.00088 \\
\hline Pentatriacontane & $\mathrm{C}_{35} \mathrm{H}_{72}$ & 492 & 0.00069 & 0.0012 & 0.0042 & 0.0031 & 0.0042 & 0.0042 & 0.0016 & 0.0027 \\
\hline
\end{tabular}


Table A5.3. continued.

Total

$\mathrm{C}_{\max }$

$\mathrm{CPI}^{\mathrm{a}}$

Branched n-Alkanes

2-methyl-hexacosane

2-methyl-heptacosane

2-methyl-octacosane

2-methyl-nonacosane

2-methyl-triacontane

Total

$\mathrm{C}_{\max }$

$\mathrm{CPI}^{\mathrm{b}}$

n-Alkenes

Pentadecene

Hexadecene

Heptadecene

Octadecene

Nonadecene

Eicosene

Heneicosene

Docosene

Tricosene

Tretracosene

Pentacosene

Hexacosene

Heptacosene

Octacosene

\begin{tabular}{|c|c|c|c|c|c|c|c|}
\hline 0.16 & 0.13 & 0.25 & 0.24 & 0.21 & 0.37 & 0.16 & 0.22 \\
\hline 29 & 29 & 29 & 29 & 29 & 29 & 29 & 29 \\
\hline \multirow[t]{2}{*}{8.7} & 8.7 & 7.2 & 6.7 & 7.5 & 7.5 & 10 & 8.1 \\
\hline & 0.00034 & 0.00031 & 0.00051 & 0.00027 & 0.58 & & 0.12 \\
\hline 0.00038 & 0.00060 & 0.00068 & 0.00062 & 0.00040 & 1.5 & & 0.25 \\
\hline 0.00037 & 0.00031 & & 0.0010 & 0.00033 & 1.2 & & 0.24 \\
\hline 0.00036 & 0.00040 & & 0.0013 & 0.00049 & 1.5 & & 0.29 \\
\hline 0.0011 & 0.0016 & 0.0010 & 0.0034 & 0.0015 & 4.7 & & 0.79 \\
\hline 28 & 28 & 28 & 30 & 30 & 28 & & 29 \\
\hline \multirow[t]{3}{*}{0.51} & 0.23 & & 0.41 & 0.29 & 0.33 & & 0.35 \\
\hline & & & & & 0.00092 & & 0.00092 \\
\hline & & & 0.0026 & & 0.00046 & 0.00013 & 0.0011 \\
\hline \multirow[t]{10}{*}{0.0017} & 0.00042 & & 0.0022 & & 0.0062 & 0.00024 & 0.0021 \\
\hline & & & 0.00081 & & & & 0.00081 \\
\hline & & & & 0.00055 & 0.00048 & & 0.00052 \\
\hline & & 0.00041 & 0.00087 & 0.00023 & 0.0012 & 0.00020 & 0.00058 \\
\hline & & 0.00038 & & 0.000060 & 0.0011 & & 0.00050 \\
\hline & & 0.00055 & 0.0022 & 0.000088 & 0.00099 & 0.00021 & 0.00080 \\
\hline & & 0.00031 & 0.00061 & 0.000093 & 0.0014 & 0.00023 & 0.00053 \\
\hline & & 0.00033 & 0.00070 & 0.000179962 & 0.0012 & 0.00028 & 0.00053 \\
\hline & 0.0018 & 0.0018 & 0.0025 & 0.00090 & 0.0044 & 0.00076 & 0.0020 \\
\hline & & 0.00071 & 0.00097 & 0.00048 & 0.0018 & 0.00048 & 0.00090 \\
\hline 0.00061 & 0.0010 & 0.0025 & 0.0024 & 0.0014 & 0.0045 & 0.0011 & 0.0019 \\
\hline
\end{tabular}


Table A5.3. continued.

\begin{tabular}{|c|c|c|c|c|c|c|c|c|c|c|c|}
\hline Nonacosene & & $\mathrm{C}_{29} \mathrm{H}_{58}$ & 406 & & & & & & & & \\
\hline Triacontene & & $\mathrm{C}_{30} \mathrm{H}_{60}$ & 420 & 0.00031 & 0.00065 & 0.0012 & 0.0019 & 0.0012 & 0.0024 & 0.00057 & 0.0012 \\
\hline Total & & & & 0.0026 & 0.0038 & 0.0081 & 0.018 & 0.0051 & 0.027 & 0.0042 & 0.0098 \\
\hline $\mathrm{C}_{\max }$ & & & & 28 & 26 & 28 & 26 & 28 & 17 & 28 & 26 \\
\hline $\mathrm{CPI}^{\mathrm{c}}$ & & & & 1.8 & 0.12 & 0.32 & 0.63 & 0.23 & 0.85 & 0.50 & 0.64 \\
\hline Phytadienes & & & & & & & & & & & \\
\hline (Z)-1,3-phytadiene & $\mathbf{I}^{*}$ & $\mathrm{C}_{20} \mathrm{H}_{38}$ & 278 & 0.013 & 0.0023 & 0.0075 & 0.056 & 0.0016 & 0.030 & 0.012 & 0.018 \\
\hline Neophytadiene & II & $\mathrm{C}_{20} \mathrm{H}_{38}$ & 278 & 0.0047 & 0.00086 & 0.0035 & 0.029 & 0.00057 & 0.013 & 0.0077 & 0.0085 \\
\hline (E)-1,3-phytadiene & III & $\mathrm{C}_{20} \mathrm{H}_{38}$ & 278 & 0.011 & 0.0026 & 0.0076 & 0.051 & 0.0016 & 0.026 & 0.015 & 0.016 \\
\hline Total & & & & 0.029 & 0.0058 & 0.019 & 0.14 & 0.0037 & 0.069 & 0.035 & 0.042 \\
\hline$H B I s$ & & & & & & & & & & & \\
\hline $\mathrm{C}_{25: 2}$ & IV & $\mathrm{C}_{25} \mathrm{H}_{48}$ & 348 & 0.0055 & 0.0033 & 0.00053 & 0.0041 & & 0.0078 & 0.00099 & 0.0037 \\
\hline $\mathrm{C}_{25: 2}$ & $\mathbf{V}$ & $\mathrm{C}_{25} \mathrm{H}_{48}$ & 348 & 0.0020 & 0.00014 & 0.00019 & 0.0020 & & 0.0028 & 0.00013 & 0.0012 \\
\hline $\mathrm{C}_{25: 2}$ & VI & $\mathrm{C}_{25} \mathrm{H}_{48}$ & 348 & 0.0022 & 0.0010 & 0.00024 & 0.0028 & & 0.0033 & 0.0012 & 0.0018 \\
\hline $\mathrm{C}_{25: 5}$ & VII & $\mathrm{C}_{25} \mathrm{H}_{42}$ & 342 & 0.00052 & 0.00022 & & & & & & 0.00037 \\
\hline Total & & & & 0.010 & 0.0047 & 0.00096 & 0.0088 & & 0.014 & 0.0024 & 0.0068 \\
\hline Triterpenes & & & & & & & & & & & \\
\hline Eupha-7,24-diene & & $\mathrm{C}_{30} \mathrm{H}_{50}$ & 410 & & & & & & & & \\
\hline Olean-13(18)-ene & VIII & $\mathrm{C}_{30} \mathrm{H}_{50}$ & 410 & 0.00029 & 0.00032 & 0.0018 & 0.0016 & 0.00046 & 0.00039 & 0.00044 & 0.00075 \\
\hline Olean-12-ene & IX & $\mathrm{C}_{30} \mathrm{H}_{50}$ & 410 & 0.00077 & & 0.0036 & 0.0023 & 0.0014 & 0.0026 & 0.00092 & 0.0019 \\
\hline Olean-18-ene & $\mathbf{X}$ & $\mathrm{C}_{30} \mathrm{H}_{50}$ & 410 & 0.00037 & 0.0015 & 0.0030 & 0.0011 & 0.00059 & 0.00048 & 0.00024 & 0.0010 \\
\hline Hop-17(21)-ene & XI & $\mathrm{C}_{30} \mathrm{H}_{50}$ & 410 & 0.0041 & 0.0039 & 0.013 & 0.0067 & 0.010 & 0.0070 & 0.012 & 0.0082 \\
\hline Ferna-7,9(11)-diene & & $\mathrm{C}_{30} \mathrm{H}_{48}$ & 408 & & & & & & & & \\
\hline Fern-8-ene & & $\mathrm{C}_{30} \mathrm{H}_{50}$ & 410 & & & & & & & & \\
\hline Fern-13(18)-ene & XII & $\mathrm{C}_{30} \mathrm{H}_{50}$ & 410 & 0.0012 & 0.00085 & 0.0051 & 0.0024 & 0.0016 & 0.0019 & 0.0019 & 0.0022 \\
\hline Fern-9(11)-ene & & $\mathrm{C}_{30} \mathrm{H}_{50}$ & 410 & & & & & & & & \\
\hline Neohop-12-ene & & $\mathrm{C}_{30} \mathrm{H}_{50}$ & 410 & & & & & & & & \\
\hline
\end{tabular}


Table A5.3. continued.

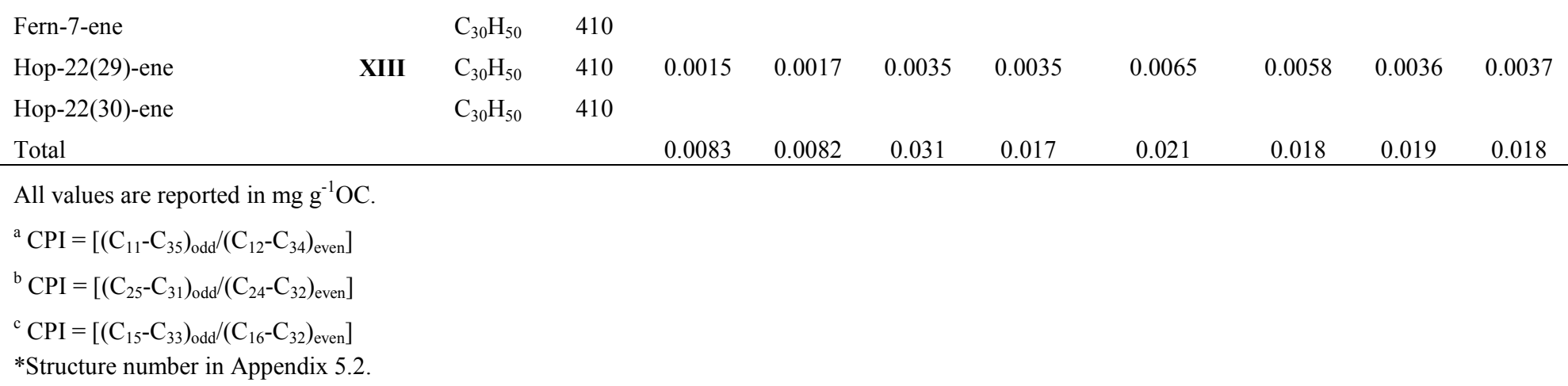


Table A5.4. Concentrations of $n$-alkanes, branched $n$-alkanes, $n$-alkenes, phytadienes and triterpenes in soil samples.

\begin{tabular}{|c|c|c|c|c|c|c|}
\hline & \multicolumn{3}{|l|}{ Sample type: } & \multicolumn{3}{|c|}{ Soils } \\
\hline & & & & Riparian & $\begin{array}{c}\text { Grass } \\
\text { prairie }\end{array}$ & Mean \\
\hline \multirow{23}{*}{$\underset{\perp}{N}$} & n-Alkanes & Formula & $M W$ & & & \\
\hline & Undecane & $\mathrm{C}_{11} \mathrm{H}_{24}$ & 156 & & 0.00032 & 0.00032 \\
\hline & Dodecane & $\mathrm{C}_{12} \mathrm{H}_{26}$ & 170 & & 0.0025 & 0.0025 \\
\hline & Tridecane & $\mathrm{C}_{13} \mathrm{H}_{28}$ & 184 & & 0.0058 & 0.0058 \\
\hline & Tetradecane & $\mathrm{C}_{14} \mathrm{H}_{30}$ & 198 & & 0.00059 & 0.00059 \\
\hline & Pentadecane & $\mathrm{C}_{15} \mathrm{H}_{32}$ & 212 & & 0.00073 & 0.00073 \\
\hline & Hexadecane & $\mathrm{C}_{16} \mathrm{H}_{34}$ & 226 & & 0.00046 & 0.00046 \\
\hline & Heptadecane & $\mathrm{C}_{17} \mathrm{H}_{36}$ & 240 & 0.00032 & 0.0068 & 0.0036 \\
\hline & Octadecane & $\mathrm{C}_{18} \mathrm{H}_{38}$ & 254 & 0.00024 & 0.00062 & 0.00043 \\
\hline & Nonadecane & $\mathrm{C}_{19} \mathrm{H}_{40}$ & 268 & 0.00029 & 0.00050 & 0.00040 \\
\hline & Eicosane & $\mathrm{C}_{20} \mathrm{H}_{42}$ & 282 & 0.00037 & 0.00085 & 0.00061 \\
\hline & Heneicosane & $\mathrm{C}_{21} \mathrm{H}_{44}$ & 296 & 0.00052 & 0.00082 & 0.00067 \\
\hline & Docosane & $\mathrm{C}_{22} \mathrm{H}_{46}$ & 310 & 0.00036 & 0.00072 & 0.00054 \\
\hline & Tricosane & $\mathrm{C}_{23} \mathrm{H}_{48}$ & 324 & 0.0013 & 0.0021 & 0.0017 \\
\hline & Tetracosane & $\mathrm{C}_{24} \mathrm{H}_{50}$ & 338 & 0.00064 & 0.0014 & 0.0010 \\
\hline & Pentacosane & $\mathrm{C}_{25} \mathrm{H}_{52}$ & 352 & 0.0036 & 0.0059 & 0.0047 \\
\hline & Hexacosane & $\mathrm{C}_{26} \mathrm{H}_{54}$ & 366 & 0.0019 & 0.0033 & 0.0026 \\
\hline & Heptacosane & $\mathrm{C}_{27} \mathrm{H}_{56}$ & 380 & 0.017 & 0.020 & 0.019 \\
\hline & Octacosane & $\mathrm{C}_{28} \mathrm{H}_{58}$ & 394 & 0.0054 & 0.0057 & 0.0055 \\
\hline & Nonacosane & $\mathrm{C}_{29} \mathrm{H}_{60}$ & 408 & 0.072 & 0.042 & 0.057 \\
\hline & Triacontane & $\mathrm{C}_{30} \mathrm{H}_{62}$ & 422 & 0.0039 & 0.0068 & 0.0054 \\
\hline & Hentriacontane & $\mathrm{C}_{31} \mathrm{H}_{64}$ & 436 & 0.11 & 0.057 & 0.085 \\
\hline & Dotriacontane & $\mathrm{C}_{32} \mathrm{H}_{66}$ & 450 & 0.0012 & 0.0039 & 0.0025 \\
\hline
\end{tabular}


Table A5.4. continued.

Tritriacontane
Tetratriacontane
Pentatriacontane
Total
$\mathrm{C}_{\text {max }}$
CPI $^{\mathrm{a}}$
Branched $n$-Alkanes $_{\text {2-methyl-octacosane }}$
2-methyl-nonacosane
2-methyl-triacontane
2-methyl-hentriacontane
2-methyl-dotriacontane
Total
$\mathrm{C}_{\text {max }}$
CPI
n-Alkenes
Octacosene
Nonacosene
Triacontene
Total
$\mathrm{C}_{\text {max }}$
CPI
Phytadienes
(Z)-1,3-phytadiene
Neophytadiene
(E)-1,3-phytadiene
Total

$\begin{array}{ccccc}\mathrm{C}_{33} \mathrm{H}_{68} & 464 & 0.013 & 0.027 & 0.020 \\ \mathrm{C}_{34} \mathrm{H}_{70} & 478 & & 0.00062 & 0.00062 \\ \mathrm{C}_{35} \mathrm{H}_{72} & 492 & & 0.0032 & 0.0032 \\ & & 0.24 & 0.20 & 0.22 \\ & & 31 & 31 & 31 \\ & & 13 & 6.4 & 9.8\end{array}$

$\mathrm{C}_{29} \mathrm{H}_{60} \quad 408$

$\mathrm{C}_{30} \mathrm{H}_{62} \quad 422$

$\mathrm{C}_{31} \mathrm{H}_{64} \quad 436$

$\mathrm{C}_{32} \mathrm{H}_{66} \quad 450$

$\mathrm{C}_{33} \mathrm{H}_{68} \quad 464$

$0.00082 \quad 0.00082$

$0.00023 \quad 0.00023$

$0.00070 \quad 0.00070$

$0.0010 \quad 0.0010$

$28 \quad 28$

$\begin{array}{ccccc}\mathrm{C}_{28} \mathrm{H}_{56} & 392 & 0.0017 & 0.00091 & 0.0013 \\ \mathrm{C}_{29} \mathrm{H}_{58} & 406 & & & \\ \mathrm{C}_{30} \mathrm{H}_{60} & 420 & 0.0014 & 0.0011 & 0.0013 \\ & & 0.0031 & 0.0021 & 0.0026 \\ & & 28 & 30 & 29\end{array}$

$\begin{array}{cccccc}\text { I* } & \mathrm{C}_{20} \mathrm{H}_{38} & 278 & 0.0033 & 0.0018 & 0.0025 \\ \text { II } & \mathrm{C}_{20} \mathrm{H}_{38} & 278 & 0.00094 & 0.0020 & 0.0015 \\ \text { III } & \mathrm{C}_{20} \mathrm{H}_{38} & 278 & 0.0036 & 0.0021 & 0.0028 \\ & & & 0.0079 & 0.0059 & 0.0069\end{array}$


Table A5.4. continued.

\begin{tabular}{|c|c|c|c|c|c|c|}
\hline Eupha-7,24-diene & & $\mathrm{C}_{30} \mathrm{H}_{50}$ & 410 & & & \\
\hline Olean-13(18)-ene & VIII & $\mathrm{C}_{30} \mathrm{H}_{50}$ & 410 & 0.000087 & 0.00015 & 0.00012 \\
\hline Olean-12-ene & IX & $\mathrm{C}_{30} \mathrm{H}_{50}$ & 410 & 0.00039 & 0.00086 & 0.00063 \\
\hline Olean-18-ene & $\mathbf{X}$ & $\mathrm{C}_{30} \mathrm{H}_{50}$ & 410 & 0.000082 & 0.00027 & 0.00017 \\
\hline Hop-17(21)-ene & $\mathbf{X I}$ & $\mathrm{C}_{30} \mathrm{H}_{50}$ & 410 & 0.0046 & 0.0039 & 0.0042 \\
\hline Ferna-7,9(11)-diene & & $\mathrm{C}_{30} \mathrm{H}_{48}$ & 408 & & 0.0024 & 0.0024 \\
\hline Fern-8-ene & & $\mathrm{C}_{30} \mathrm{H}_{50}$ & 410 & & & \\
\hline Fern-13(18)-ene & XII & $\mathrm{C}_{30} \mathrm{H}_{50}$ & 410 & 0.0013 & & 0.0013 \\
\hline Fern-9(11)-ene & & $\mathrm{C}_{30} \mathrm{H}_{50}$ & 410 & & & \\
\hline Neohop-12-ene & & $\mathrm{C}_{30} \mathrm{H}_{50}$ & 410 & & & \\
\hline Fern-7-ene & & $\mathrm{C}_{30} \mathrm{H}_{50}$ & 410 & & & \\
\hline Hop-22(29)-ene & XIII & $\mathrm{C}_{30} \mathrm{H}_{50}$ & 410 & 0.012 & 0.0034 & 0.0078 \\
\hline Hop-22(30)-ene & & $\mathrm{C}_{30} \mathrm{H}_{50}$ & 410 & & & \\
\hline Total & & & & 0.019 & 0.011 & 0.015 \\
\hline
\end{tabular}

All values are reported in $\mathrm{mg} \mathrm{g}^{-1} \mathrm{OC}$.

${ }^{\text {a }} \mathrm{CPI}=\left[\left(\mathrm{C}_{11}-\mathrm{C}_{35}\right)_{\text {odd }} /\left(\mathrm{C}_{12}-\mathrm{C}_{34}\right)_{\text {even }}\right]$

${ }^{\mathrm{b}} \mathrm{CPI}=\left[\left(\mathrm{C}_{25}-\mathrm{C}_{31}\right)_{\text {odd }} /\left(\mathrm{C}_{24}-\mathrm{C}_{32}\right)_{\text {even }}\right]$

${ }^{\mathrm{c}} \mathrm{CPI}=\left[\left(\mathrm{C}_{15}-\mathrm{C}_{33}\right)_{\text {odd }} /\left(\mathrm{C}_{16}-\mathrm{C}_{32}\right)_{\text {even }}\right]$

*Structure number in Appendix 5.2. 
Table A5.5. Concentrations of $n$-alkan-2-ones, $n$-alkanals and $n$-alkanols in the riparian vegetation samples.

\begin{tabular}{|c|c|c|c|c|c|c|c|c|c|c|}
\hline \multirow[t]{2}{*}{ Sample type: } & & & \multicolumn{8}{|c|}{ Riparian vegetation } \\
\hline & & & $\begin{array}{l}\text { Bur } \\
\text { Oak }\end{array}$ & Hackberry & Cottonwood & $\begin{array}{l}\text { Wild } \\
\text { Plum }\end{array}$ & $\begin{array}{c}\text { Chinkapin } \\
\text { Oak }\end{array}$ & $\begin{array}{c}\text { Black } \\
\text { Walnut }\end{array}$ & $\begin{array}{l}\text { Roughleaf } \\
\text { Dogwood }\end{array}$ & Mean \\
\hline n-Alkan-2-ones & Formula & $M W$ & & & & & & & & \\
\hline Heneicosan-2-one & $\mathrm{C}_{21} \mathrm{H}_{42} \mathrm{O}$ & 310 & 0.000027 & & & & & & & 0.000027 \\
\hline Docosan-2-one & $\mathrm{C}_{22} \mathrm{H}_{44} \mathrm{O}$ & 324 & & & & & & & & \\
\hline Tricosan-2-one & $\mathrm{C}_{23} \mathrm{H}_{46} \mathrm{O}$ & 338 & 0.000028 & & & 0.000055 & & & 0.000079 & 0.000054 \\
\hline Tetracosan-2-one & $\mathrm{C}_{24} \mathrm{H}_{48} \mathrm{O}$ & 352 & & & & & & & & \\
\hline Pentacosan-2-one & $\mathrm{C}_{25} \mathrm{H}_{50} \mathrm{O}$ & 366 & 0.00013 & 0.00019 & & 0.00028 & 0.000086 & & 0.00035 & 0.00021 \\
\hline Hexacosan-2-one & $\mathrm{C}_{26} \mathrm{H}_{52} \mathrm{O}$ & 380 & 0.000064 & & & & & & & 0.000064 \\
\hline Heptacosan-2-one & $\mathrm{C}_{27} \mathrm{H}_{54} \mathrm{O}$ & 394 & 0.00040 & 0.00039 & & & & & & 0.00040 \\
\hline Octacosan-2-one & $\mathrm{C}_{28} \mathrm{H}_{56} \mathrm{O}$ & 408 & 0.00050 & & & & & & & 0.00050 \\
\hline Nonacosan-2-one & $\mathrm{C}_{29} \mathrm{H}_{58} \mathrm{O}$ & 422 & 0.0018 & 0.0016 & & & 0.00017 & & & 0.0012 \\
\hline Triacontan-2-one & $\mathrm{C}_{30} \mathrm{H}_{60} \mathrm{O}$ & 436 & 0.000055 & & & & & & & 0.000055 \\
\hline Hentriacontan-2-one & $\mathrm{C}_{31} \mathrm{H}_{62} \mathrm{O}$ & 450 & 0.00049 & 0.000051 & & 0.00088 & & 0.00017 & 0.00044 & 0.00040 \\
\hline Dotriacontan-2-one & $\mathrm{C}_{32} \mathrm{H}_{64} \mathrm{O}$ & 464 & & & & & & & & \\
\hline Tritriacontan-2-one & $\mathrm{C}_{33} \mathrm{H}_{66} \mathrm{O}$ & 478 & & & & 0.0041 & & 0.0014 & 0.0017 & 0.0024 \\
\hline Tetratriacontan-2-one & $\mathrm{C}_{34} \mathrm{H}_{68} \mathrm{O}$ & 492 & & & & & & & & \\
\hline Pentatriacontan-2-one & $\mathrm{C}_{35} \mathrm{H}_{70} \mathrm{O}$ & 506 & & & & 0.00047 & & 0.00022 & 0.00020 & 0.00030 \\
\hline Total & & & 0.0035 & 0.0022 & & 0.0058 & 0.00026 & 0.0018 & 0.0028 & 0.0027 \\
\hline $\mathrm{C}_{\max }$ & & & 29 & 29 & & 33 & 29 & 33 & 33 & 31 \\
\hline $\mathrm{CPI}^{\mathrm{a}}$ & & & 4.6 & & & & & & & 4.6 \\
\hline \multicolumn{11}{|l|}{ n-Alkanals } \\
\hline Pentadecanal & $\mathrm{C}_{15} \mathrm{H}_{30} \mathrm{O}$ & 226 & & & & 0.016 & & & & 0.016 \\
\hline Hexadecanal & $\mathrm{C}_{16} \mathrm{H}_{32} \mathrm{O}$ & 240 & & & & & & & & \\
\hline Heptadecanal & $\mathrm{C}_{17} \mathrm{H}_{34} \mathrm{O}$ & 254 & 0.0013 & 0.011 & & & 0.00049 & 0.00018 & & 0.0034 \\
\hline Octadecanal & $\mathrm{C}_{18} \mathrm{H}_{36} \mathrm{O}$ & 268 & & & & & & & & \\
\hline Nonadecanal & $\mathrm{C}_{19} \mathrm{H}_{38} \mathrm{O}$ & 282 & & & & & & & & \\
\hline Eicosanal & $\mathrm{C}_{20} \mathrm{H}_{40} \mathrm{O}$ & 296 & & & & & & & & \\
\hline
\end{tabular}


Table A5.5. continued.

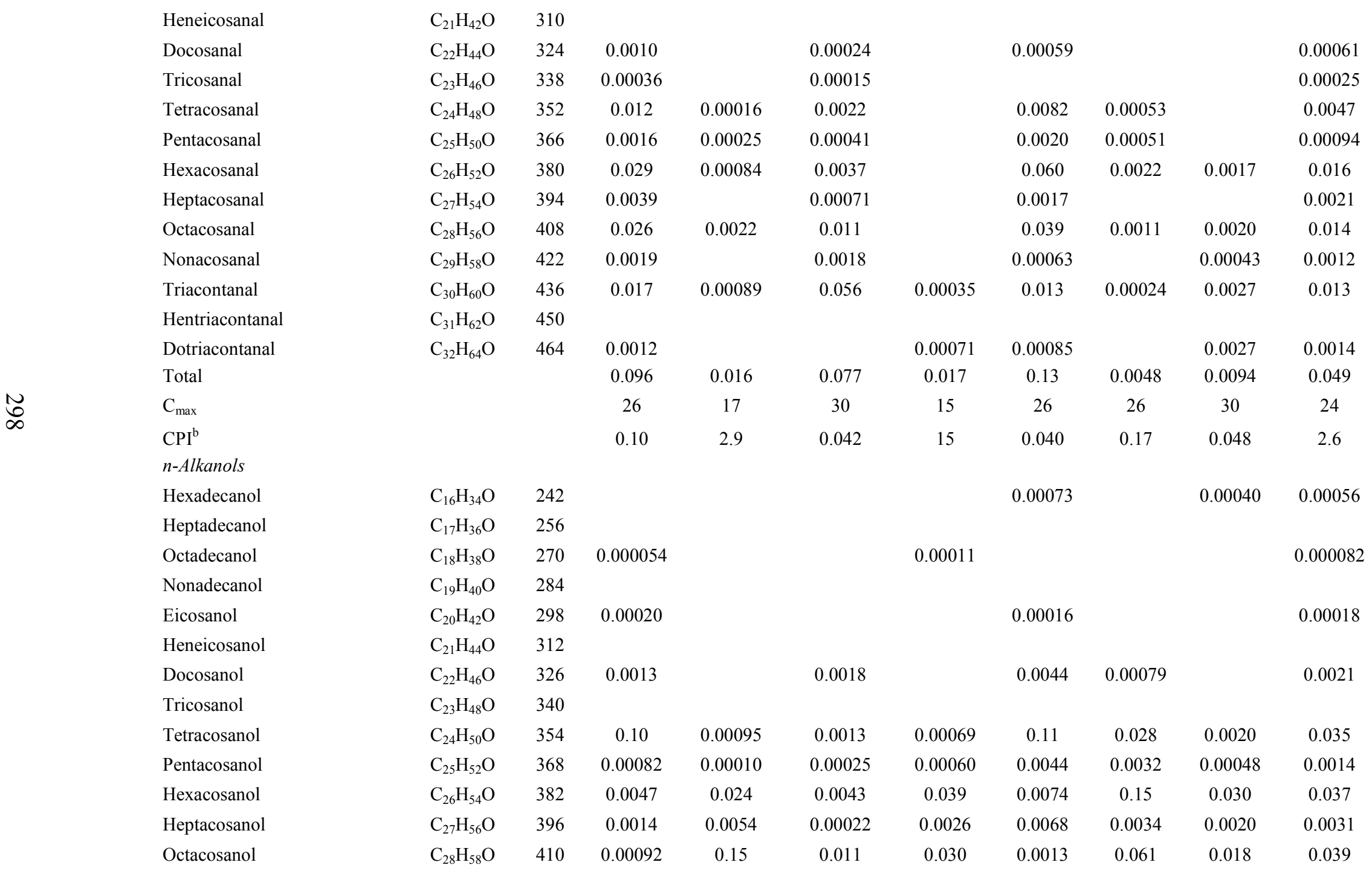


Table A5.5. continued.

\begin{tabular}{|c|c|c|c|c|c|c|c|c|c|c|}
\hline Nonacosanol & $\mathrm{C}_{29} \mathrm{H}_{60} \mathrm{O}$ & 424 & 0.00085 & 0.0013 & 0.0030 & 0.00059 & 0.0021 & 0.00025 & 0.00025 & 0.0012 \\
\hline Triacontanol & $\mathrm{C}_{30} \mathrm{H}_{62} \mathrm{O}$ & 438 & 0.0033 & 0.031 & 0.048 & 0.0094 & 0.0060 & 0.0068 & 0.0095 & 0.016 \\
\hline Hentriacontanol & $\mathrm{C}_{31} \mathrm{H}_{64} \mathrm{O}$ & 452 & & 0.0015 & 0.0012 & 0.0023 & 0.00044 & 0.00019 & 0.00061 & 0.0010 \\
\hline Dotriacontanol & $\mathrm{C}_{32} \mathrm{H}_{66} \mathrm{O}$ & 466 & 0.0020 & 0.0067 & & 0.013 & 0.0019 & 0.0087 & 0.0073 & 0.0065 \\
\hline Tritriacontanol & $\mathrm{C}_{33} \mathrm{H}_{68} \mathrm{O}$ & 480 & & 0.00045 & & 0.00036 & & 0.00027 & 0.00018 & 0.00032 \\
\hline Tetratriacontanol & $\mathrm{C}_{34} \mathrm{H}_{70} \mathrm{O}$ & 494 & & 0.0029 & & 0.0011 & & 0.0030 & 0.00043 & 0.0019 \\
\hline Pentatriacontanol & $\mathrm{C}_{35} \mathrm{H}_{72} \mathrm{O}$ & 508 & & 0.00032 & & & & & & 0.00032 \\
\hline Hexatriacontanol & $\mathrm{C}_{36} \mathrm{H}_{74} \mathrm{O}$ & 522 & & 0.0016 & & & & & & 0.0016 \\
\hline Total & & & 0.12 & 0.23 & 0.071 & 0.099 & 0.15 & 0.27 & 0.071 & 0.14 \\
\hline $\mathrm{C}_{\max }$ & & & 24 & 28 & 30 & 26 & 24 & 26 & 26 & 26 \\
\hline $\mathrm{CPI}^{\mathrm{c}}$ & & & 0.027 & 0.042 & 0.069 & 0.070 & 0.10 & 0.028 & 0.052 & 0.055 \\
\hline
\end{tabular}

All values are reported in $\mathrm{mg} \mathrm{g}^{-1} \mathrm{OC}$. 
Table A5.6. Concentrations of $n$-alkan-2-ones, $n$-alkanals and $n$-alkanols in the grass, moss and algae samples.

\begin{tabular}{|c|c|c|c|c|c|c|c|c|c|c|c|c|}
\hline \multirow[t]{2}{*}{ Sample type: } & & & \multicolumn{5}{|c|}{ Grasses } & \multirow[t]{2}{*}{ Moss } & \multicolumn{4}{|c|}{ Algal assemblies } \\
\hline & & & $\begin{array}{l}\text { Johnson } \\
\text { grass }\end{array}$ & $\begin{array}{c}\text { Prairie } \\
\text { Cordgrass }\end{array}$ & $\begin{array}{c}\text { Eastern } \\
\text { Gamma } \\
\text { grass }\end{array}$ & $\begin{array}{c}\text { Big } \\
\text { Bluestem } \\
\text { grass } \\
\end{array}$ & Mean & & $\# 1$ & $\# 2$ & $\# 3$ & Mean \\
\hline n-Alkan-2-ones & Formula & $M W$ & & & & & & & & & & \\
\hline Heneicosan-2-one & $\mathrm{C}_{21} \mathrm{H}_{42} \mathrm{O}$ & 310 & & & 0.0000040 & 0.0025 & 0.0012 & & & & & \\
\hline Docosan-2-one & $\mathrm{C}_{22} \mathrm{H}_{44} \mathrm{O}$ & 324 & & & 0.0000012 & 0.0000097 & 0.0000054 & & & & & \\
\hline Tricosan-2-one & $\mathrm{C}_{23} \mathrm{H}_{46} \mathrm{O}$ & 338 & 0.00049 & & 0.0000087 & 0.00036 & 0.00029 & & & & & \\
\hline Tetracosan-2-one & $\mathrm{C}_{24} \mathrm{H}_{48} \mathrm{O}$ & 352 & & & 0.0000041 & 0.000041 & 0.000023 & & & & & \\
\hline Pentacosan-2-one & $\mathrm{C}_{25} \mathrm{H}_{50} \mathrm{O}$ & 366 & 0.0013 & & 0.00016 & 0.00044 & 0.00064 & & & & & \\
\hline Hexacosan-2-one & $\mathrm{C}_{26} \mathrm{H}_{52} \mathrm{O}$ & 380 & & & 0.000018 & 0.00037 & 0.00020 & & & & & \\
\hline Heptacosan-2-one & $\mathrm{C}_{27} \mathrm{H}_{54} \mathrm{O}$ & 394 & & & 0.00029 & 0.0029 & 0.0016 & & & & & \\
\hline Octacosan-2-one & $\mathrm{C}_{28} \mathrm{H}_{56} \mathrm{O}$ & 408 & & & 0.00032 & 0.00045 & 0.00038 & & & & & \\
\hline Nonacosan-2-one & $\mathrm{C}_{29} \mathrm{H}_{58} \mathrm{O}$ & 422 & 0.0080 & & 0.00094 & 0.0034 & 0.0041 & & & & & \\
\hline Triacontan-2-one & $\mathrm{C}_{30} \mathrm{H}_{60} \mathrm{O}$ & 436 & & & 0.00090 & 0.00015 & 0.00053 & & & & & \\
\hline Hentriacontan-2-one & $\mathrm{C}_{31} \mathrm{H}_{62} \mathrm{O}$ & 450 & 0.027 & 0.00030 & 0.0028 & 0.0017 & 0.0081 & & & & & \\
\hline Dotriacontan-2-one & $\mathrm{C}_{32} \mathrm{H}_{64} \mathrm{O}$ & 464 & & & 0.00077 & & 0.00077 & & & & & \\
\hline Tritriacontan-2-one & $\mathrm{C}_{33} \mathrm{H}_{66} \mathrm{O}$ & 478 & 0.0085 & 0.00012 & 0.00047 & 0.00046 & 0.0024 & & & & & \\
\hline Tetratriacontan-2-one & $\mathrm{C}_{34} \mathrm{H}_{68} \mathrm{O}$ & 492 & & & 0.0000065 & & 0.0000065 & & & & & \\
\hline Pentatriacontan-2-one & $\mathrm{C}_{35} \mathrm{H}_{70} \mathrm{O}$ & 506 & & & 0.0000025 & & 0.0000025 & & & & & \\
\hline Total & & & 0.046 & 0.00043 & 0.0067 & 0.013 & 0.016 & & & & & \\
\hline $\mathrm{C}_{\max }$ & & & 31 & 31 & 31 & 29 & 31 & & & & & \\
\hline $\mathrm{CPI}^{\mathrm{a}}$ & & & & & 2.3 & 11.5 & 6.9 & & & & & \\
\hline n-Alkanals & & & & & & & & & & & & \\
\hline Decanal & $\mathrm{C}_{10} \mathrm{H}_{20} \mathrm{O}$ & 156 & & & & & & & & & & \\
\hline Hendecanal & $\mathrm{C}_{11} \mathrm{H}_{22} \mathrm{O}$ & 170 & & & & & & & & & & \\
\hline Docedacanal & $\mathrm{C}_{12} \mathrm{H}_{24} \mathrm{O}$ & 184 & & & & & & & & & & \\
\hline
\end{tabular}


Table A5.6. continued.

\begin{tabular}{|c|c|c|c|c|c|c|c|c|c|c|c|}
\hline Tridecanal & $\mathrm{C}_{13} \mathrm{H}_{26} \mathrm{O}$ & 198 & & & & & & 0.00059 & 0.0063 & & 0.0035 \\
\hline Tetradecanal & $\mathrm{C}_{14} \mathrm{H}_{28} \mathrm{O}$ & 212 & & & & & & 0.00030 & 0.0028 & & 0.0016 \\
\hline Pentadecanal & $\mathrm{C}_{15} \mathrm{H}_{30} \mathrm{O}$ & 226 & & & & & & 0.00059 & 0.0072 & 0.0080 & 0.0053 \\
\hline Hexadecanal & $\mathrm{C}_{16} \mathrm{H}_{32} \mathrm{O}$ & 240 & 0.00040 & & & & 0.00040 & 0.00016 & 0.0026 & 0.0023 & 0.0017 \\
\hline Heptadecanal & $\mathrm{C}_{17} \mathrm{H}_{34} \mathrm{O}$ & 254 & & & & 0.00027 & 0.00027 & 0.00057 & & & 0.00057 \\
\hline Octadecanal & $\mathrm{C}_{18} \mathrm{H}_{36} \mathrm{O}$ & 268 & & & & 0.00031 & 0.00031 & 0.00042 & 0.0047 & 0.0023 & 0.0025 \\
\hline Nonadecanal & $\mathrm{C}_{19} \mathrm{H}_{38} \mathrm{O}$ & 282 & & & & 0.0023 & 0.0023 & & & & \\
\hline Eicosanal & $\mathrm{C}_{20} \mathrm{H}_{40} \mathrm{O}$ & 296 & & & 0.000032 & 0.00067 & 0.00035 & 0.00084 & & & 0.00084 \\
\hline Heneicosanal & $\mathrm{C}_{21} \mathrm{H}_{42} \mathrm{O}$ & 310 & & & & & & & & & \\
\hline Docosanal & $\mathrm{C}_{22} \mathrm{H}_{44} \mathrm{O}$ & 324 & 0.00013 & 0.000083 & 0.000028 & 0.00041 & 0.00016 & & & & \\
\hline Tricosanal & $\mathrm{C}_{23} \mathrm{H}_{46} \mathrm{O}$ & 338 & & 0.00020 & & 0.00051 & 0.00035 & & & & \\
\hline Tetracosanal & $\mathrm{C}_{24} \mathrm{H}_{48} \mathrm{O}$ & 352 & 0.00056 & 0.00012 & & 0.00098 & 0.00055 & & & & \\
\hline Pentacosanal & $\mathrm{C}_{25} \mathrm{H}_{50} \mathrm{O}$ & 366 & & & & 0.0015 & 0.0015 & & & & \\
\hline Hexacosanal & $\mathrm{C}_{26} \mathrm{H}_{52} \mathrm{O}$ & 380 & 0.00041 & 0.00012 & 0.000081 & 0.0062 & 0.0017 & & & & \\
\hline Heptacosanal & $\mathrm{C}_{27} \mathrm{H}_{54} \mathrm{O}$ & 394 & & & & 0.0014 & 0.0014 & & & & \\
\hline Octacosanal & $\mathrm{C}_{28} \mathrm{H}_{56} \mathrm{O}$ & 408 & 0.0033 & & 0.000059 & 0.011 & 0.0048 & & & & \\
\hline Nonacosanal & $\mathrm{C}_{29} \mathrm{H}_{58} \mathrm{O}$ & 422 & 0.0012 & & & 0.00029 & 0.00075 & & & & \\
\hline Triacontanal & $\mathrm{C}_{30} \mathrm{H}_{60} \mathrm{O}$ & 436 & 0.020 & & 0.00017 & 0.0020 & 0.0075 & & & & \\
\hline Hentriacontanal & $\mathrm{C}_{31} \mathrm{H}_{62} \mathrm{O}$ & 450 & & & & & & & & & \\
\hline Dotriacontanal & $\mathrm{C}_{32} \mathrm{H}_{64} \mathrm{O}$ & 464 & 0.0054 & & 0.00015 & 0.00063 & 0.0020 & & & & \\
\hline Total & & & 0.032 & 0.00051 & 0.00052 & 0.028 & 0.015 & 0.0035 & 0.024 & 0.013 & 0.013 \\
\hline $\mathrm{C}_{\max }$ & & & 30 & 23 & 30 & 28 & 28 & 20 & 15 & 15 & 17 \\
\hline $\mathrm{CPI}^{\mathrm{b}}$ & & & 0.040 & 0.61 & & 0.28 & 0.31 & 1.0 & 1.3 & 1.7 & 1.4 \\
\hline n-Alkanols & & & & & & & & & & & \\
\hline Hexadecanol & $\mathrm{C}_{16} \mathrm{H}_{34} \mathrm{O}$ & 242 & & 0.0015 & 0.00021 & 0.00034 & 0.00070 & & & & \\
\hline Heptadecanol & $\mathrm{C}_{17} \mathrm{H}_{36} \mathrm{O}$ & 256 & & & & & & & & & \\
\hline Octadecanol & $\mathrm{C}_{18} \mathrm{H}_{38} \mathrm{O}$ & 270 & & & 0.00019 & 0.00027 & 0.00023 & & & & \\
\hline
\end{tabular}


Table A5.6. continued.

\begin{tabular}{|c|c|c|c|c|c|c|c|c|c|c|c|}
\hline Nonadecanol & $\mathrm{C}_{19} \mathrm{H}_{40} \mathrm{O}$ & 284 & & & & 0.0011 & 0.0011 & & & & \\
\hline Eicosanol & $\mathrm{C}_{20} \mathrm{H}_{42} \mathrm{O}$ & 298 & & & & 0.00012 & 0.00012 & & & & \\
\hline Heneicosanol & $\mathrm{C}_{21} \mathrm{H}_{44} \mathrm{O}$ & 312 & & & & 0.00015 & 0.00015 & & & & \\
\hline Docosanol & $\mathrm{C}_{22} \mathrm{H}_{46} \mathrm{O}$ & 326 & & & 0.0016 & 0.00054 & 0.0010 & & & & \\
\hline Tricosanol & $\mathrm{C}_{23} \mathrm{H}_{48} \mathrm{O}$ & 340 & & & & & & & & & \\
\hline Tetracosanol & $\mathrm{C}_{24} \mathrm{H}_{50} \mathrm{O}$ & 354 & 0.0020 & 0.00044 & 0.00037 & 0.00091 & 0.00092 & 0.00095 & 0.020 & 0.00034 & 0.010 \\
\hline Pentacosanol & $\mathrm{C}_{25} \mathrm{H}_{52} \mathrm{O}$ & 368 & & & & 0.0021 & 0.0021 & & & & \\
\hline Hexacosanol & $\mathrm{C}_{26} \mathrm{H}_{54} \mathrm{O}$ & 382 & 0.0030 & 0.0010 & & 0.0039 & 0.0026 & 0.00058 & 0.033 & 0.00037 & 0.017 \\
\hline Heptacosanol & $\mathrm{C}_{27} \mathrm{H}_{56} \mathrm{O}$ & 396 & 0.00031 & & 0.000037 & 0.0042 & 0.0015 & & & & \\
\hline Octacosanol & $\mathrm{C}_{28} \mathrm{H}_{58} \mathrm{O}$ & 410 & 0.039 & 0.0060 & 0.000046 & 0.020 & 0.016 & 0.0029 & 0.043 & 0.0016 & 0.023 \\
\hline Nonacosanol & $\mathrm{C}_{29} \mathrm{H}_{60} \mathrm{O}$ & 424 & 0.0019 & & 0.000072 & 0.0013 & 0.0011 & 0.00014 & 0.012 & & 0.012 \\
\hline Triacontanol & $\mathrm{C}_{30} \mathrm{H}_{62} \mathrm{O}$ & 438 & 0.30 & 0.010 & 0.00014 & 0.011 & 0.081 & 0.0035 & 0.087 & 0.0019 & 0.044 \\
\hline Hentriacontanol & $\mathrm{C}_{31} \mathrm{H}_{64} \mathrm{O}$ & 452 & 0.0014 & & 0.00029 & 0.00073 & 0.00080 & 0.00043 & & & \\
\hline Dotriacontanol & $\mathrm{C}_{32} \mathrm{H}_{66} \mathrm{O}$ & 466 & 0.0092 & & 0.0068 & 0.065 & 0.027 & 0.0022 & 0.031 & 0.00074 & 0.016 \\
\hline Total & & & 0.36 & 0.019 & 0.0097 & 0.11 & 0.13 & 0.011 & 0.23 & 0.0050 & 0.12 \\
\hline $\mathrm{C}_{\max }$ & & & 30 & 30 & 32 & 32 & 31 & 30 & 30 & 30 & 30 \\
\hline $\mathrm{CPI}^{\mathrm{c}}$ & & & 0.010 & & 0.043 & 0.094 & 0.049 & 0.056 & 0.057 & & 0.057 \\
\hline
\end{tabular}

All values are reported in $\mathrm{mg} \mathrm{g}^{-1} \mathrm{OC}$.

${ }^{\text {a }} \mathrm{CPI}=\left[\left(\mathrm{C}_{13}-\mathrm{C}_{35}\right)_{\text {odd }} /\left(\mathrm{C}_{12}-\mathrm{C}_{34}\right)_{\text {even }}\right]$

${ }^{\mathrm{b}} \mathrm{CPI}=\left[\left(\mathrm{C}_{11}-\mathrm{C}_{31}\right)_{\text {odd }} /\left(\mathrm{C}_{10}-\mathrm{C}_{32}\right)_{\text {even }}\right]$

${ }^{\mathrm{c}} \mathrm{CPI}=\left[\left(\mathrm{C}_{13}-\mathrm{C}_{35}\right)_{\text {odd }} /\left(\mathrm{C}_{14}-\mathrm{C}_{36}\right)_{\text {even }}\right]$ 
Table A5.7. Concentrations of $n$-alkan-2-ones, $n$-alkanals and $n$-alkanols in the sediment samples from the King's Creek watershed.

\begin{tabular}{|c|c|c|c|c|c|c|c|c|c|c|}
\hline \multirow[t]{2}{*}{ Sample type: } & & & \multicolumn{8}{|c|}{ Sediments } \\
\hline & & & Site 1 & Site 2 & Site 3 & Site 4 & Site 5 & Site 6 & Site 7 & Mean \\
\hline n-Alkan-2-ones & Formula & $M W$ & & & & & & & & \\
\hline Dodecan-2-one & $\mathrm{C}_{12} \mathrm{H}_{24} \mathrm{O}$ & 184 & 0.00057 & & & & & & & 0.00057 \\
\hline Tridecan-2-one & $\mathrm{C}_{13} \mathrm{H}_{26} \mathrm{O}$ & 198 & 0.00013 & 0.00045 & & & & & & 0.00029 \\
\hline Tetradecan-2-one & $\mathrm{C}_{14} \mathrm{H}_{28} \mathrm{O}$ & 212 & 0.00021 & 0.00021 & & & & & & 0.00021 \\
\hline Pentadecan-2-one & $\mathrm{C}_{15} \mathrm{H}_{30} \mathrm{O}$ & 226 & 0.0012 & 0.00074 & 0.00012 & & & & & 0.00069 \\
\hline Hexadecan-2-one & $\mathrm{C}_{16} \mathrm{H}_{32} \mathrm{O}$ & 240 & 0.00062 & 0.0013 & 0.00066 & & & & & 0.00085 \\
\hline Heptadecan-2-one & $\mathrm{C}_{17} \mathrm{H}_{34} \mathrm{O}$ & 254 & 0.00045 & 0.0018 & & 0.00037 & & & & 0.00086 \\
\hline Octadecan-2-one & $\mathrm{C}_{18} \mathrm{H}_{36} \mathrm{O}$ & 268 & 0.0014 & 0.0021 & & & & & & 0.0017 \\
\hline Nonadecan-2-one & $\mathrm{C}_{19} \mathrm{H}_{38} \mathrm{O}$ & 282 & 0.00083 & 0.0015 & & & & & & 0.0012 \\
\hline Eicosan-2-one & $\mathrm{C}_{20} \mathrm{H}_{40} \mathrm{O}$ & 296 & 0.0011 & 0.0014 & & & & & & 0.0013 \\
\hline Heneicosan-2-one & $\mathrm{C}_{21} \mathrm{H}_{42} \mathrm{O}$ & 310 & 0.00046 & 0.00090 & & 0.000086 & 0.000027 & & 0.000011 & 0.00030 \\
\hline Docosan-2-one & $\mathrm{C}_{22} \mathrm{H}_{44} \mathrm{O}$ & 324 & 0.0017 & 0.0015 & & 0.000084 & 0.000028 & & & 0.00083 \\
\hline Tricosan-2-one & $\mathrm{C}_{23} \mathrm{H}_{46} \mathrm{O}$ & 338 & 0.0016 & 0.0017 & 0.0018 & 0.00014 & 0.000068 & & 0.00019 & 0.00090 \\
\hline Tetracosan-2-one & $\mathrm{C}_{24} \mathrm{H}_{48} \mathrm{O}$ & 352 & 0.0019 & 0.0023 & 0.0013 & 0.00023 & 0.000070 & & 0.0000098 & 0.00097 \\
\hline Pentacosan-2-one & $\mathrm{C}_{25} \mathrm{H}_{50} \mathrm{O}$ & 366 & 0.0032 & 0.0037 & 0.0060 & 0.00033 & 0.00018 & 0.00012 & 0.00058 & 0.0020 \\
\hline Hexacosan-2-one & $\mathrm{C}_{26} \mathrm{H}_{52} \mathrm{O}$ & 380 & 0.0030 & 0.0025 & 0.0032 & 0.000098 & 0.000095 & & 0.000019 & 0.0015 \\
\hline Heptacosan-2-one & $\mathrm{C}_{27} \mathrm{H}_{54} \mathrm{O}$ & 394 & 0.0099 & 0.0070 & 0.012 & 0.00049 & 0.00035 & 0.00020 & 0.00042 & 0.0044 \\
\hline Octacosan-2-one & $\mathrm{C}_{28} \mathrm{H}_{56} \mathrm{O}$ & 408 & 0.0046 & 0.0035 & 0.0064 & 0.00091 & 0.00021 & 0.00015 & 0.000020 & 0.0023 \\
\hline Nonacosan-2-one & $\mathrm{C}_{29} \mathrm{H}_{58} \mathrm{O}$ & 422 & 0.013 & 0.012 & 0.036 & 0.0013 & 0.00075 & 0.00070 & 0.00021 & 0.0090 \\
\hline Triacontan-2-one & $\mathrm{C}_{30} \mathrm{H}_{60} \mathrm{O}$ & 436 & 0.0062 & 0.0062 & 0.014 & & & & & 0.0087 \\
\hline Hentriacontan-2-one & $\mathrm{C}_{31} \mathrm{H}_{62} \mathrm{O}$ & 450 & 0.018 & 0.018 & 0.038 & 0.0018 & 0.0014 & & 0.00028 & 0.013 \\
\hline Dotriacontan-2-one & $\mathrm{C}_{32} \mathrm{H}_{64} \mathrm{O}$ & 464 & 0.0031 & 0.0032 & 0.0091 & & & & & 0.0051 \\
\hline Tritriacontan-2-one & $\mathrm{C}_{33} \mathrm{H}_{66} \mathrm{O}$ & 478 & 0.019 & 0.016 & 0.056 & 0.0015 & 0.00079 & & 0.00013 & 0.016 \\
\hline
\end{tabular}


Table A5.7. continued.

\begin{tabular}{|c|c|c|c|c|c|c|c|c|c|c|}
\hline Tetratriacontan-2-one & $\mathrm{C}_{34} \mathrm{H}_{68} \mathrm{O}$ & 492 & 0.0019 & & & & & & & 0.0019 \\
\hline Pentatriacontan-2-one & $\mathrm{C}_{35} \mathrm{H}_{70} \mathrm{O}$ & 506 & 0.0035 & 0.0033 & 0.013 & 0.00020 & 0.00016 & & & 0.0041 \\
\hline Total & & & 0.098 & 0.090 & 0.20 & 0.0076 & 0.0042 & 0.0012 & 0.0019 & 0.057 \\
\hline $\mathrm{C}_{\max }$ & & & 33 & 31 & 33 & 31 & 31 & 29 & 25 & 30 \\
\hline $\mathrm{CPI}^{\mathrm{a}}$ & & & 0.37 & 0.36 & 0.21 & 0.21 & 0.11 & 0.14 & 0.027 & 0.20 \\
\hline \multicolumn{11}{|l|}{ n-Alkanals } \\
\hline Decanal & $\mathrm{C}_{10} \mathrm{H}_{20} \mathrm{O}$ & 156 & 0.00054 & & & & & & & 0.00054 \\
\hline Hendecanal & $\mathrm{C}_{11} \mathrm{H}_{22} \mathrm{O}$ & 170 & 0.00063 & & & & & & & 0.00063 \\
\hline Docedacanal & $\mathrm{C}_{12} \mathrm{H}_{24} \mathrm{O}$ & 184 & 0.00058 & 0.00078 & & & & & & 0.00068 \\
\hline Tridecanal & $\mathrm{C}_{13} \mathrm{H}_{26} \mathrm{O}$ & 198 & 0.00099 & 0.0012 & & 0.00020 & & & & 0.00080 \\
\hline Tetradecanal & $\mathrm{C}_{14} \mathrm{H}_{28} \mathrm{O}$ & 212 & 0.0029 & 0.0047 & 0.0025 & 0.0016 & & & 0.000050 & 0.0024 \\
\hline Pentadecanal & $\mathrm{C}_{15} \mathrm{H}_{30} \mathrm{O}$ & 226 & 0.0031 & 0.0032 & 0.0019 & 0.0035 & & & 0.000034 & 0.0023 \\
\hline Hexadecanal & $\mathrm{C}_{16} \mathrm{H}_{32} \mathrm{O}$ & 240 & 0.0074 & 0.0054 & 0.0038 & 0.0051 & & & 0.00014 & 0.0044 \\
\hline Heptadecanal & $\mathrm{C}_{17} \mathrm{H}_{34} \mathrm{O}$ & 254 & 0.0021 & 0.0013 & & 0.00024 & & & 0.000032 & 0.00093 \\
\hline Octadecanal & $\mathrm{C}_{18} \mathrm{H}_{36} \mathrm{O}$ & 268 & 0.0063 & 0.0024 & & 0.00083 & 0.00019 & & 0.000054 & 0.0020 \\
\hline Nonadecanal & $\mathrm{C}_{19} \mathrm{H}_{38} \mathrm{O}$ & 282 & 0.0011 & 0.00085 & & 0.00024 & 0.000043 & & 0.000027 & 0.00044 \\
\hline Eicosanal & $\mathrm{C}_{20} \mathrm{H}_{40} \mathrm{O}$ & 296 & 0.0021 & 0.0023 & & 0.00035 & 0.00010 & & 0.000055 & 0.00099 \\
\hline Heneicosanal & $\mathrm{C}_{21} \mathrm{H}_{42} \mathrm{O}$ & 310 & 0.0013 & 0.00094 & & 0.00031 & 0.000066 & 0.000036 & 0.000076 & 0.00046 \\
\hline Docosanal & $\mathrm{C}_{22} \mathrm{H}_{44} \mathrm{O}$ & 324 & 0.0033 & 0.0031 & & 0.00053 & 0.00017 & 0.00010 & 0.00045 & 0.0013 \\
\hline Tricosanal & $\mathrm{C}_{23} \mathrm{H}_{46} \mathrm{O}$ & 338 & 0.0013 & 0.0010 & & 0.00038 & 0.00011 & 0.000074 & 0.00023 & 0.00051 \\
\hline Tetracosanal & $\mathrm{C}_{24} \mathrm{H}_{48} \mathrm{O}$ & 352 & 0.0025 & 0.0029 & 0.0021 & 0.00065 & 0.00018 & 0.00020 & 0.00063 & 0.0013 \\
\hline Pentacosanal & $\mathrm{C}_{25} \mathrm{H}_{50} \mathrm{O}$ & 366 & 0.00085 & 0.00046 & & 0.00027 & 0.000049 & 0.000060 & 0.00015 & 0.00031 \\
\hline Hexacosanal & $\mathrm{C}_{26} \mathrm{H}_{52} \mathrm{O}$ & 380 & 0.0047 & 0.0032 & 0.0047 & 0.0011 & 0.00022 & 0.00047 & 0.00076 & 0.0022 \\
\hline Heptacosanal & $\mathrm{C}_{27} \mathrm{H}_{54} \mathrm{O}$ & 394 & 0.0035 & 0.0024 & & 0.00033 & 0.000066 & 0.000085 & 0.00013 & 0.0011 \\
\hline Octacosanal & $\mathrm{C}_{28} \mathrm{H}_{56} \mathrm{O}$ & 408 & 0.0048 & 0.0033 & 0.0076 & 0.0021 & 0.00047 & 0.00066 & 0.0014 & 0.0029 \\
\hline Nonacosanal & $\mathrm{C}_{29} \mathrm{H}_{58} \mathrm{O}$ & 422 & 0.0051 & & & 0.00081 & 0.00015 & 0.000068 & 0.00021 & 0.0013 \\
\hline Triacontanal & $\mathrm{C}_{30} \mathrm{H}_{60} \mathrm{O}$ & 436 & 0.0059 & 0.0038 & 0.014 & 0.0015 & 0.00044 & 0.00043 & 0.0018 & 0.0040 \\
\hline
\end{tabular}


Table A5.7. continued.

\begin{tabular}{|c|c|c|c|c|c|c|c|c|c|c|}
\hline Hentriacontanal & $\mathrm{C}_{31} \mathrm{H}_{62} \mathrm{O}$ & 450 & & & & & & & & \\
\hline Dotriacontanal & $\mathrm{C}_{32} \mathrm{H}_{64} \mathrm{O}$ & 464 & & & & & & 0.000074 & 0.00035 & 0.00021 \\
\hline Total & & & 0.061 & 0.043 & 0.037 & 0.020 & 0.0022 & 0.0023 & 0.0065 & 0.025 \\
\hline $\mathrm{C}_{\max }$ & & & 16 & 16 & 30 & 16 & 28 & 28 & 28 & 23 \\
\hline $\mathrm{CPI}^{\mathrm{b}}$ & & & 0.49 & 0.35 & 0.055 & 0.45 & 0.28 & 0.17 & 0.16 & 0.28 \\
\hline \multicolumn{11}{|l|}{ n-Alkanols } \\
\hline Tetradecanol & $\mathrm{C}_{14} \mathrm{H}_{30} \mathrm{O}$ & 214 & 0.00075 & & & & & & 0.00071 & 0.00073 \\
\hline Pentadecanol & $\mathrm{C}_{15} \mathrm{H}_{32} \mathrm{O}$ & 228 & 0.00014 & & & & & & 0.00069 & 0.00042 \\
\hline Hexadecanol & $\mathrm{C}_{16} \mathrm{H}_{34} \mathrm{O}$ & 242 & 0.0047 & 0.048 & 0.000050 & & 0.00019 & & 0.0035 & 0.011 \\
\hline Heptadecanol & $\mathrm{C}_{17} \mathrm{H}_{36} \mathrm{O}$ & 256 & 0.000071 & 0.0075 & & & & & 0.00037 & 0.0027 \\
\hline Octadecanol & $\mathrm{C}_{18} \mathrm{H}_{38} \mathrm{O}$ & 270 & 0.00051 & 0.017 & 0.000049 & & 0.00021 & & 0.00086 & 0.0037 \\
\hline Nonadecanol & $\mathrm{C}_{19} \mathrm{H}_{40} \mathrm{O}$ & 284 & 0.000081 & 0.0038 & & & & & 0.00010 & 0.0013 \\
\hline Eicosanol & $\mathrm{C}_{20} \mathrm{H}_{42} \mathrm{O}$ & 298 & 0.00060 & 0.037 & & & & & 0.00091 & 0.013 \\
\hline Heneicosanol & $\mathrm{C}_{21} \mathrm{H}_{44} \mathrm{O}$ & 312 & 0.000074 & 0.011 & & & & & 0.00017 & 0.0037 \\
\hline Docosanol & $\mathrm{C}_{22} \mathrm{H}_{46} \mathrm{O}$ & 326 & 0.0016 & 0.24 & 0.00010 & 0.00048 & 0.00016 & 0.00041 & 0.0031 & 0.034 \\
\hline Tricosanol & $\mathrm{C}_{23} \mathrm{H}_{48} \mathrm{O}$ & 340 & & 0.0014 & & & & 0.00019 & 0.00049 & 0.00069 \\
\hline Tetracosanol & $\mathrm{C}_{24} \mathrm{H}_{50} \mathrm{O}$ & 354 & 0.0038 & 0.59 & 0.00054 & 0.0021 & 0.00035 & 0.0022 & 0.0038 & 0.086 \\
\hline Pentacosanol & $\mathrm{C}_{25} \mathrm{H}_{52} \mathrm{O}$ & 368 & 0.00048 & 0.054 & 0.000047 & 0.00052 & 0.000055 & 0.00042 & 0.00053 & 0.0081 \\
\hline Hexacosanol & $\mathrm{C}_{26} \mathrm{H}_{54} \mathrm{O}$ & 382 & 0.0057 & 0.50 & 0.0011 & 0.0078 & 0.0013 & 0.0062 & 0.0079 & 0.076 \\
\hline Heptacosanol & $\mathrm{C}_{27} \mathrm{H}_{56} \mathrm{O}$ & 396 & 0.00071 & 0.073 & 0.00025 & 0.0017 & 0.00032 & 0.00088 & 0.0017 & 0.011 \\
\hline Octacosanol & $\mathrm{C}_{28} \mathrm{H}_{58} \mathrm{O}$ & 410 & 0.0097 & 0.60 & 0.0045 & 0.016 & 0.0076 & 0.012 & 0.017 & 0.095 \\
\hline Nonacosanol & $\mathrm{C}_{29} \mathrm{H}_{60} \mathrm{O}$ & 424 & 0.0014 & 0.073 & 0.00036 & 0.0012 & 0.00080 & 0.0013 & 0.0017 & 0.011 \\
\hline Triacontanol & $\mathrm{C}_{30} \mathrm{H}_{62} \mathrm{O}$ & 438 & 0.011 & 0.55 & 0.0061 & 0.010 & 0.0065 & 0.012 & 0.013 & 0.087 \\
\hline Hentriacontanol & $\mathrm{C}_{31} \mathrm{H}_{64} \mathrm{O}$ & 452 & 0.00040 & 0.055 & 0.00028 & 0.0016 & 0.00068 & 0.00093 & 0.00034 & 0.0085 \\
\hline Dotriacontanol & $\mathrm{C}_{32} \mathrm{H}_{66} \mathrm{O}$ & 466 & 0.011 & 0.48 & 0.0081 & 0.014 & 0.013 & 0.0080 & 0.014 & 0.078 \\
\hline Tritriacontanol & $\mathrm{C}_{33} \mathrm{H}_{68} \mathrm{O}$ & 480 & & 0.014 & 0.000069 & 0.000056 & 0.00010 & 0.000064 & 0.000064 & 0.0024 \\
\hline Tetratriacontanol & $\mathrm{C}_{34} \mathrm{H}_{70} \mathrm{O}$ & 494 & & 0.028 & 0.00018 & 0.00011 & 0.00020 & 0.00016 & 0.00015 & 0.0048 \\
\hline
\end{tabular}


Table A5.7. continued.

\begin{tabular}{|c|c|c|c|c|c|c|c|c|c|c|}
\hline Pentatriacontanol & $\mathrm{C}_{35} \mathrm{H}_{72} \mathrm{O}$ & 508 & & & & & & & & \\
\hline Hexatriacontanol & $\mathrm{C}_{36} \mathrm{H}_{74} \mathrm{O}$ & 522 & & & & & & & & \\
\hline Total & & & 0.053 & 3.4 & 0.022 & 0.055 & 0.031 & 0.045 & 0.071 & 0.52 \\
\hline $\mathrm{C}_{\max }$ & & & 32 & 28 & 32 & 28 & 32 & 28 & 28 & 30 \\
\hline $\mathrm{CPI}^{\mathrm{c}}$ & & & 0.068 & 0.095 & 0.048 & 0.10 & 0.066 & 0.093 & 0.096 & 0.081 \\
\hline \multicolumn{11}{|c|}{ All values are reported in $\mathrm{mg} \mathrm{g}^{-1} \mathrm{OC}$. } \\
\hline \multicolumn{11}{|c|}{${ }^{\mathrm{a}} \mathrm{CPI}=\left[\left(\mathrm{C}_{13}-\mathrm{C}_{35}\right)_{\text {odd }} /\left(\mathrm{C}_{12}-\mathrm{C}_{34}\right)_{\text {even }}\right]$} \\
\hline \multicolumn{11}{|c|}{${ }^{\mathrm{b}} \mathrm{CPI}=\left[\left(\mathrm{C}_{11}-\mathrm{C}_{31}\right)_{\text {odd }} /\left(\mathrm{C}_{10}-\mathrm{C}_{32}\right)_{\text {even }}\right]$} \\
\hline${ }^{\mathrm{c}} \mathrm{CPI}=\left[\left(\mathrm{C}_{13}-\mathrm{C}_{35}\right)_{\mathrm{o}}\right.$ & $\left.\left.\mathrm{C}_{36}\right)_{\text {even }}\right]$ & & & & & & & & & \\
\hline
\end{tabular}


Table A5.8. Concentrations of $n$-alkan-2-ones, $n$-alkanals and $n$-alkanols in the soil samples from the King's Creek watershed.

\begin{tabular}{|c|c|c|c|c|c|}
\hline \multirow[t]{2}{*}{ Sample type: } & & & \multicolumn{3}{|c|}{ Soils } \\
\hline & & & Riparian & $\begin{array}{l}\text { Grass } \\
\text { prairie }\end{array}$ & Mean \\
\hline n-Alkan-2-ones & Formula & $M W$ & & & \\
\hline Tricosan-2-one & $\mathrm{C}_{23} \mathrm{H}_{46} \mathrm{O}$ & 338 & 0.000049 & & 0.000049 \\
\hline Tetracosan-2-one & $\mathrm{C}_{24} \mathrm{H}_{48} \mathrm{O}$ & 352 & & & \\
\hline Pentacosan-2-one & $\mathrm{C}_{25} \mathrm{H}_{50} \mathrm{O}$ & 366 & 0.000095 & & 0.000095 \\
\hline Hexacosan-2-one & $\mathrm{C}_{26} \mathrm{H}_{52} \mathrm{O}$ & 380 & 0.000036 & 0.00047 & 0.00025 \\
\hline Heptacosan-2-one & $\mathrm{C}_{27} \mathrm{H}_{54} \mathrm{O}$ & 394 & 0.00018 & 0.0027 & 0.0015 \\
\hline Octacosan-2-one & $\mathrm{C}_{28} \mathrm{H}_{56} \mathrm{O}$ & 408 & 0.000089 & 0.00068 & 0.00039 \\
\hline Nonacosan-2-one & $\mathrm{C}_{29} \mathrm{H}_{58} \mathrm{O}$ & 422 & 0.00068 & 0.0029 & 0.0018 \\
\hline Triacontan-2-one & $\mathrm{C}_{30} \mathrm{H}_{60} \mathrm{O}$ & 436 & 0.00041 & 0.0012 & 0.00080 \\
\hline Hentriacontan-2-one & $\mathrm{C}_{31} \mathrm{H}_{62} \mathrm{O}$ & 450 & 0.0021 & 0.010 & 0.0062 \\
\hline Dotriacontan-2-one & $\mathrm{C}_{32} \mathrm{H}_{64} \mathrm{O}$ & 464 & 0.00056 & & 0.00056 \\
\hline Tritriacontan-2-one & $\mathrm{C}_{33} \mathrm{H}_{66} \mathrm{O}$ & 478 & 0.0017 & 0.013 & 0.0072 \\
\hline Tetratriacontan-2-one & $\mathrm{C}_{34} \mathrm{H}_{68} \mathrm{O}$ & 492 & & & \\
\hline Pentatriacontan-2-one & $\mathrm{C}_{35} \mathrm{H}_{70} \mathrm{O}$ & 506 & & & \\
\hline Total & & & 0.0059 & 0.031 & 0.018 \\
\hline $\mathrm{C}_{\max }$ & & & 31 & 33 & 32 \\
\hline $\mathrm{CPI}^{\mathrm{a}}$ & & & 0.23 & 12 & 6.2 \\
\hline \multicolumn{6}{|l|}{ n-Alkanals } \\
\hline Tetradecanal & $\mathrm{C}_{14} \mathrm{H}_{28} \mathrm{O}$ & 212 & & 0.00070 & 0.00070 \\
\hline Pentadecanal & $\mathrm{C}_{15} \mathrm{H}_{30} \mathrm{O}$ & 226 & 0.00012 & 0.00063 & 0.00037 \\
\hline Hexadecanal & $\mathrm{C}_{16} \mathrm{H}_{32} \mathrm{O}$ & 240 & 0.00014 & 0.00053 & 0.00033 \\
\hline Heptadecanal & $\mathrm{C}_{17} \mathrm{H}_{34} \mathrm{O}$ & 254 & & 0.00039 & 0.00039 \\
\hline Octadecanal & $\mathrm{C}_{18} \mathrm{H}_{36} \mathrm{O}$ & 268 & 0.000087 & 0.00035 & 0.00022 \\
\hline Nonadecanal & $\mathrm{C}_{19} \mathrm{H}_{38} \mathrm{O}$ & 282 & & 0.00041 & 0.00041 \\
\hline Eicosanal & $\mathrm{C}_{20} \mathrm{H}_{40} \mathrm{O}$ & 296 & 0.000095 & 0.00063 & 0.00036 \\
\hline Heneicosanal & $\mathrm{C}_{21} \mathrm{H}_{42} \mathrm{O}$ & 310 & & 0.00035 & 0.00035 \\
\hline Docosanal & $\mathrm{C}_{22} \mathrm{H}_{44} \mathrm{O}$ & 324 & 0.00022 & 0.00052 & 0.00037 \\
\hline Tricosanal & $\mathrm{C}_{23} \mathrm{H}_{46} \mathrm{O}$ & 338 & & & \\
\hline Tetracosanal & $\mathrm{C}_{24} \mathrm{H}_{48} \mathrm{O}$ & 352 & 0.00032 & 0.0013 & 0.00083 \\
\hline Pentacosanal & $\mathrm{C}_{25} \mathrm{H}_{50} \mathrm{O}$ & 366 & 0.000081 & & 0.000081 \\
\hline Hexacosanal & $\mathrm{C}_{26} \mathrm{H}_{52} \mathrm{O}$ & 380 & 0.00050 & 0.0022 & 0.0013 \\
\hline Heptacosanal & $\mathrm{C}_{27} \mathrm{H}_{54} \mathrm{O}$ & 394 & 0.00032 & 0.00059 & 0.00045 \\
\hline Octacosanal & $\mathrm{C}_{28} \mathrm{H}_{56} \mathrm{O}$ & 408 & 0.0015 & 0.0047 & 0.0031 \\
\hline Nonacosanal & $\mathrm{C}_{29} \mathrm{H}_{58} \mathrm{O}$ & 422 & 0.00050 & & 0.00050 \\
\hline Triacontanal & $\mathrm{C}_{30} \mathrm{H}_{60} \mathrm{O}$ & 436 & 0.0046 & 0.0019 & 0.0032 \\
\hline Hentriacontanal & $\mathrm{C}_{31} \mathrm{H}_{62} \mathrm{O}$ & 450 & & & \\
\hline
\end{tabular}


Table A5.8. continued.

\begin{tabular}{|c|c|c|c|c|c|}
\hline Dotriacontanal & $\mathrm{C}_{32} \mathrm{H}_{64} \mathrm{O}$ & 464 & 0.00079 & & 0.00079 \\
\hline Total & & & 0.0092 & 0.015 & 0.012 \\
\hline $\mathrm{C}_{\max }$ & & & 30 & 28 & 29 \\
\hline $\mathrm{CPI}^{\mathrm{b}}$ & & & 0.12 & 0.18 & 0.15 \\
\hline \multicolumn{6}{|l|}{ n-Alkanols } \\
\hline Hexadecanol & $\mathrm{C}_{16} \mathrm{H}_{34} \mathrm{O}$ & 242 & & 0.000082 & 0.000082 \\
\hline Heptadecanol & $\mathrm{C}_{17} \mathrm{H}_{36} \mathrm{O}$ & 256 & & & \\
\hline Octadecanol & $\mathrm{C}_{18} \mathrm{H}_{38} \mathrm{O}$ & 270 & 0.00024 & 0.00025 & 0.00024 \\
\hline Nonadecanol & $\mathrm{C}_{19} \mathrm{H}_{40} \mathrm{O}$ & 284 & & & \\
\hline Eicosanol & $\mathrm{C}_{20} \mathrm{H}_{42} \mathrm{O}$ & 298 & 0.00085 & & \\
\hline Heneicosanol & $\mathrm{C}_{21} \mathrm{H}_{44} \mathrm{O}$ & 312 & 0.000075 & & \\
\hline Docosanol & $\mathrm{C}_{22} \mathrm{H}_{46} \mathrm{O}$ & 326 & 0.0019 & 0.00033 & 0.0011 \\
\hline Tricosanol & $\mathrm{C}_{23} \mathrm{H}_{48} \mathrm{O}$ & 340 & & & \\
\hline Tetracosanol & $\mathrm{C}_{24} \mathrm{H}_{50} \mathrm{O}$ & 354 & 0.0032 & 0.00065 & 0.0019 \\
\hline Pentacosanol & $\mathrm{C}_{25} \mathrm{H}_{52} \mathrm{O}$ & 368 & 0.00021 & 0.00019 & 0.00020 \\
\hline Hexacosanol & $\mathrm{C}_{26} \mathrm{H}_{54} \mathrm{O}$ & 382 & 0.0045 & 0.0026 & 0.0036 \\
\hline Heptacosanol & $\mathrm{C}_{27} \mathrm{H}_{56} \mathrm{O}$ & 396 & 0.00038 & 0.00074 & 0.00056 \\
\hline Octacosanol & $\mathrm{C}_{28} \mathrm{H}_{58} \mathrm{O}$ & 410 & 0.011 & 0.012 & 0.011 \\
\hline Nonacosanol & $\mathrm{C}_{29} \mathrm{H}_{60} \mathrm{O}$ & 424 & 0.00070 & 0.00078 & 0.00074 \\
\hline Triacontanol & $\mathrm{C}_{30} \mathrm{H}_{62} \mathrm{O}$ & 438 & 0.094 & 0.0063 & 0.050 \\
\hline Hentriacontanol & $\mathrm{C}_{31} \mathrm{H}_{64} \mathrm{O}$ & 452 & 0.00092 & 0.0014 & 0.0012 \\
\hline Dotriacontanol & $\mathrm{C}_{32} \mathrm{H}_{66} \mathrm{O}$ & 466 & 0.013 & 0.031 & 0.022 \\
\hline Tritriacontanol & $\mathrm{C}_{33} \mathrm{H}_{68} \mathrm{O}$ & 480 & 0.00011 & 0.00026 & 0.00018 \\
\hline Tetratriacontanol & $\mathrm{C}_{34} \mathrm{H}_{70} \mathrm{O}$ & 494 & 0.00045 & 0.00046 & 0.00046 \\
\hline Total & & & 0.13 & 0.057 & 0.094 \\
\hline $\mathrm{C}_{\max }$ & & & 30 & 32 & 31 \\
\hline $\mathrm{CPI}^{\mathrm{c}}$ & & & 0.019 & 0.063 & 0.041 \\
\hline
\end{tabular}

All values are reported in $\mathrm{mg} \mathrm{g}^{-1} \mathrm{OC}$.

${ }^{a} \mathrm{CPI}=\left[\left(\mathrm{C}_{13}-\mathrm{C}_{35}\right)_{\text {odd }} /\left(\mathrm{C}_{12}-\mathrm{C}_{34}\right)_{\text {even }}\right]$

${ }^{\mathrm{b}} \mathrm{CPI}=\left[\left(\mathrm{C}_{11}-\mathrm{C}_{31}\right)_{\text {odd }} /\left(\mathrm{C}_{10}-\mathrm{C}_{32}\right)_{\text {even }}\right]$

${ }^{\mathrm{c}} \mathrm{CPI}=\left[\left(\mathrm{C}_{13}-\mathrm{C}_{35}\right)_{\text {odd }}\left(\mathrm{C}_{14}-\mathrm{C}_{36}\right)_{\text {even }}\right]$ 
Table A5.9. Concentrations of triterpenoids and other oxygenated compounds in the riparian vegetation samples.

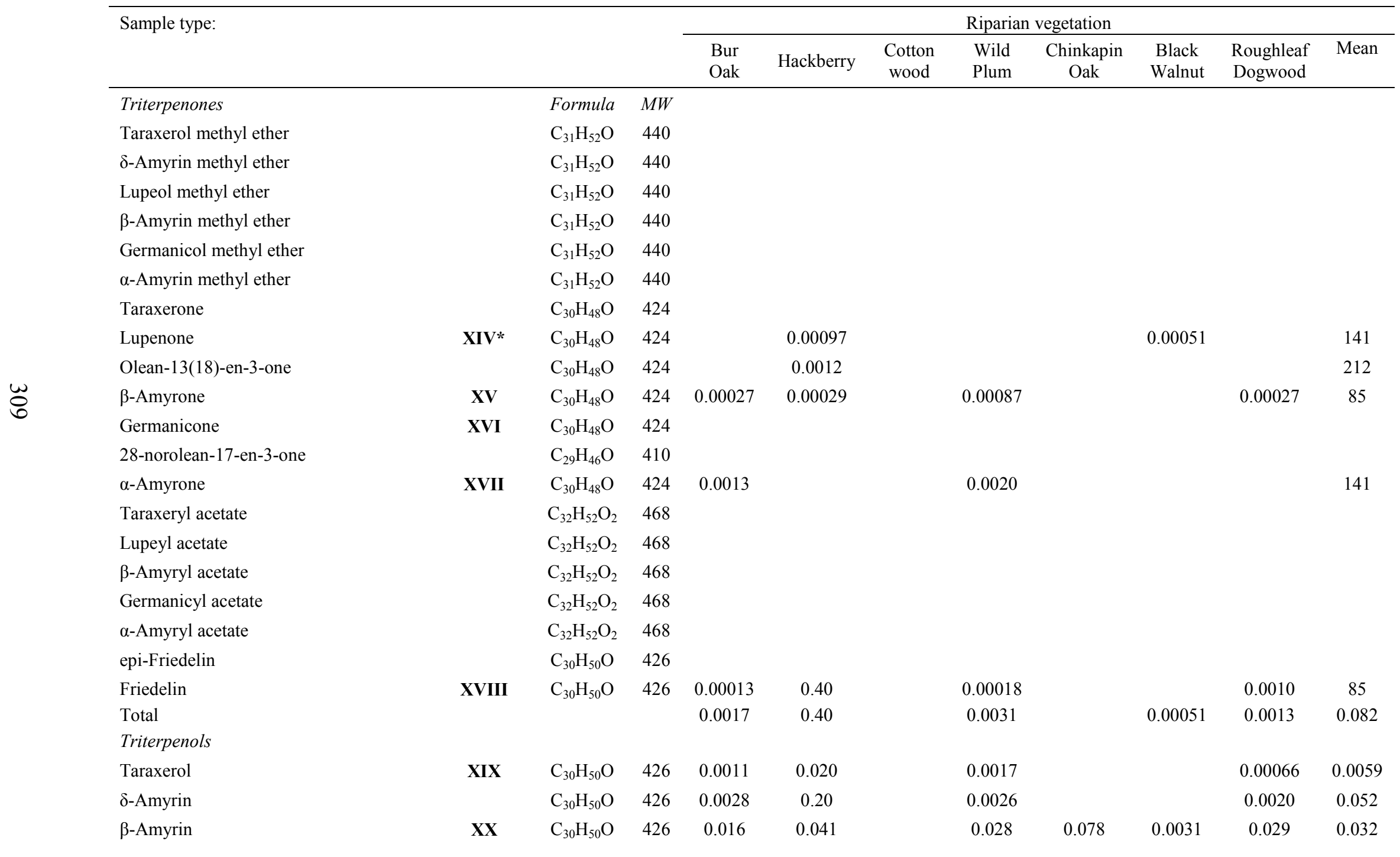


Table A5.9. continued.

\begin{tabular}{|c|c|c|c|c|c|c|c|c|c|c|c|}
\hline Germanicol & & $\mathrm{C}_{30} \mathrm{H}_{50} \mathrm{O}$ & 426 & & & & & 0.0042 & & & 0.0042 \\
\hline$\alpha$-Amyrin & XXI & $\mathrm{C}_{30} \mathrm{H}_{50} \mathrm{O}$ & 426 & 0.018 & 0.041 & & 0.052 & 0.13 & 0.032 & 0.041 & 0.052 \\
\hline $3 \alpha$-Lupeol & XXII & $\mathrm{C}_{30} \mathrm{H}_{50} \mathrm{O}$ & 426 & 0.024 & 0.15 & & 0.020 & 0.011 & 0.072 & 0.039 & 0.053 \\
\hline $3 \beta$-Lupeol & & $\mathrm{C}_{30} \mathrm{H}_{50} \mathrm{O}$ & 426 & 0.00098 & & & 0.0016 & 0.00077 & & 0.00090 & 0.0011 \\
\hline epi-Friedelanol & & $\mathrm{C}_{30} \mathrm{H}_{52} \mathrm{O}$ & 428 & & 0.60 & & & & & & 0.60 \\
\hline Friedelanol & & $\mathrm{C}_{30} \mathrm{H}_{52} \mathrm{O}$ & 428 & & 2.5 & & & & & & 2.5 \\
\hline Total & & & & 0.063 & 3.6 & & 0.11 & 0.22 & 0.11 & 0.11 & 0.69 \\
\hline Other Compounds & & & & & & & & & & & \\
\hline Phytone & XXIII & $\mathrm{C}_{18} \mathrm{H}_{36} \mathrm{O}$ & 268 & 0.0026 & 0.0011 & 0.0018 & 0.0058 & 0.0013 & 0.0019 & 0.0030 & 0.0025 \\
\hline Phytol & XXIV & $\mathrm{C}_{20} \mathrm{H}_{40} \mathrm{O}$ & 296 & 0.0072 & 0.0048 & 0.013 & 0.019 & 0.011 & 0.033 & 0.066 & 0.022 \\
\hline 4,8,12,16-tetramethylheptadecan-4-olide & & $\mathrm{C}_{21} \mathrm{H}_{40} \mathrm{O}_{2}$ & 324 & 0.00042 & 0.000087 & 0.0014 & 0.0019 & 0.0011 & 0.0061 & 0.0021 & 0.0019 \\
\hline d-tocopherol & & $\mathrm{C}_{27} \mathrm{H}_{46} \mathrm{O}_{2}$ & 402 & 0.0063 & & & & & & & 0.0063 \\
\hline d-tocopherol ethyl ether & & $\mathrm{C}_{29} \mathrm{H}_{50} \mathrm{O}_{2}$ & 430 & 0.0017 & & & & & & & 0.0017 \\
\hline$\alpha$-tocopherol & & $\mathrm{C}_{29} \mathrm{H}_{50} \mathrm{O}_{2}$ & 430 & 0.0036 & 0.0059 & & 0.0065 & 0.0010 & 0.0034 & 0.0062 & 0.0044 \\
\hline$\alpha$-tocopherol ethyl ether & & $\mathrm{C}_{31} \mathrm{H}_{54} \mathrm{O}_{2}$ & 458 & 0.0084 & & & 0.0011 & 0.00073 & 0.00080 & 0.0074 & 0.0037 \\
\hline$\alpha$-tocopherol acetate & & $\mathrm{C}_{31} \mathrm{H}_{52} \mathrm{O}_{3}$ & 472 & & & & & & & & \\
\hline Total & & & & 0.030 & 0.012 & 0.016 & 0.034 & 0.016 & 0.045 & 0.085 & 0.034 \\
\hline
\end{tabular}

All values are reported in $\mathrm{mg} \mathrm{g}^{-1} \mathrm{OC}$.

*Structure number in Appendix 5.2. 
Table A5.10. Concentrations of triterpenoids and other oxygenated compounds in the grass samples.

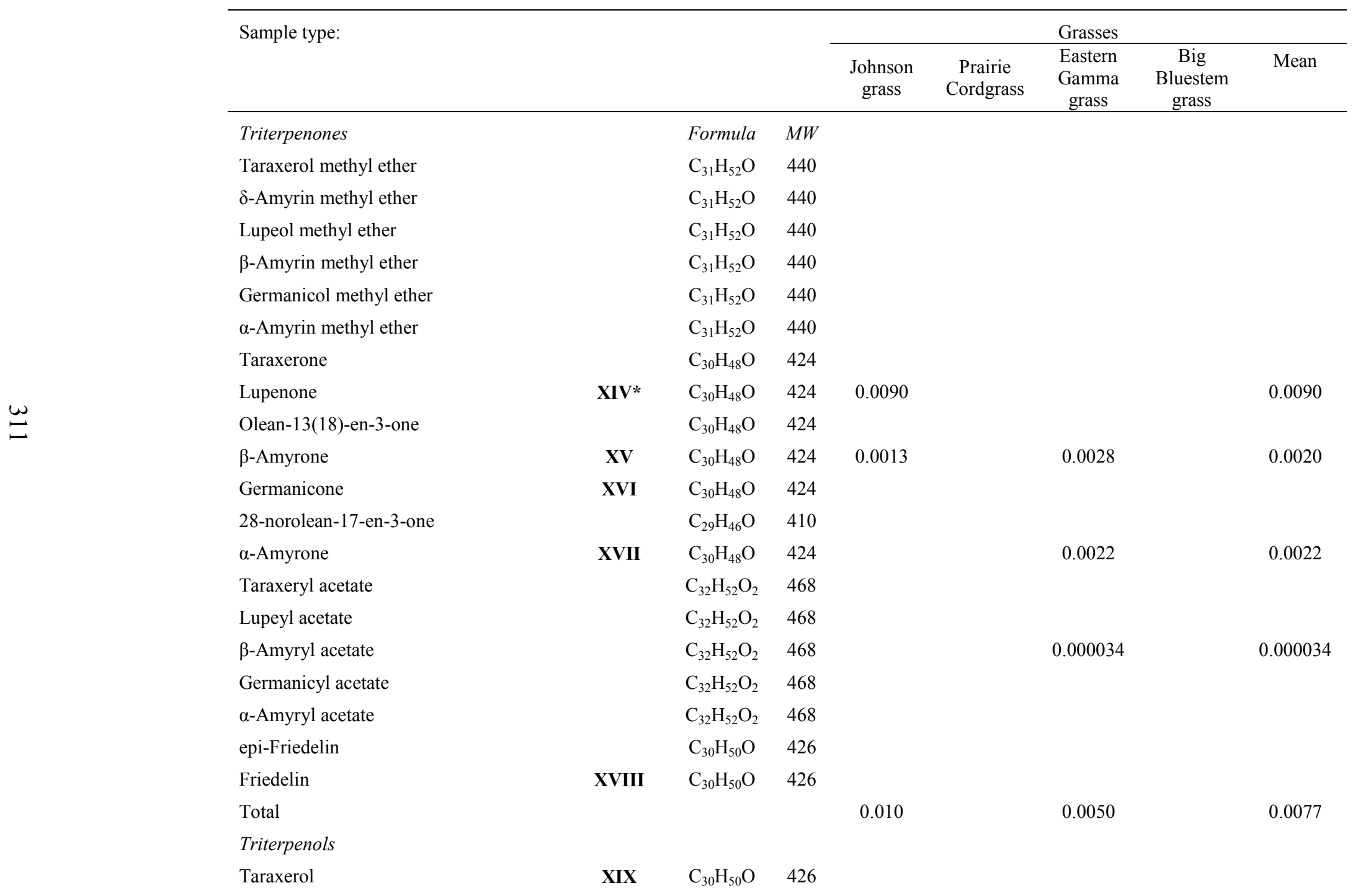


Table A5.10. continued.

\begin{tabular}{|c|c|c|c|c|c|c|c|c|}
\hline$\delta$-Amyrin & & $\mathrm{C}_{30} \mathrm{H}_{50} \mathrm{O}$ & 426 & & & & & \\
\hline$\beta$-Amyrin & $\mathbf{X X}$ & $\mathrm{C}_{30} \mathrm{H}_{50} \mathrm{O}$ & 426 & 0.0028 & & 0.018 & 0.0017 & 0.0075 \\
\hline Germanicol & & $\mathrm{C}_{30} \mathrm{H}_{50} \mathrm{O}$ & 426 & & & & & \\
\hline$\alpha$-Amyrin & XXI & $\mathrm{C}_{30} \mathrm{H}_{50} \mathrm{O}$ & 426 & 0.010 & & 0.033 & 0.00098 & 0.015 \\
\hline $3 \alpha$-Lupeol & XXII & $\mathrm{C}_{30} \mathrm{H}_{50} \mathrm{O}$ & 426 & 0.025 & & 0.0018 & & 0.013 \\
\hline 3ß-Lupeol & & $\mathrm{C}_{30} \mathrm{H}_{50} \mathrm{O}$ & 426 & & 0.0075 & & & 0.0075 \\
\hline epi-Friedelanol & & $\mathrm{C}_{30} \mathrm{H}_{52} \mathrm{O}$ & 428 & & & & & \\
\hline Friedelanol & & $\mathrm{C}_{30} \mathrm{H}_{52} \mathrm{O}$ & 428 & & & & & \\
\hline Total & & & & 0.038 & 0.0075 & 0.053 & 0.0026 & 0.025 \\
\hline \multicolumn{9}{|l|}{ Other Compounds } \\
\hline Phytone & XXIII & $\mathrm{C}_{18} \mathrm{H}_{36} \mathrm{O}$ & 268 & 0.022 & 0.0030 & 0.0036 & 0.0046 & 0.0082 \\
\hline Phytol & XXIV & $\mathrm{C}_{20} \mathrm{H}_{40} \mathrm{O}$ & 296 & 0.066 & 0.039 & 0.23 & 0.078 & 0.10 \\
\hline 4,8,12,16-tetramethylheptadecan-4-olide & & $\mathrm{C}_{21} \mathrm{H}_{40} \mathrm{O}_{2}$ & 324 & 0.00067 & 0.0029 & 0.0024 & 0.00040 & 0.0016 \\
\hline d-tocopherol & & $\mathrm{C}_{27} \mathrm{H}_{46} \mathrm{O}_{2}$ & 402 & & & & & \\
\hline d-tocopherol ethyl ether & & $\mathrm{C}_{29} \mathrm{H}_{50} \mathrm{O}_{2}$ & 430 & & & & & \\
\hline$\alpha$-tocopherol & & $\mathrm{C}_{29} \mathrm{H}_{50} \mathrm{O}_{2}$ & 430 & 0.0030 & 0.0062 & 0.0034 & 0.0010 & 0.0034 \\
\hline$\alpha$-tocopherol ethyl ether & & $\mathrm{C}_{31} \mathrm{H}_{54} \mathrm{O}_{2}$ & 458 & 0.0013 & 0.011 & 0.00052 & 0.0016 & 0.0035 \\
\hline$\alpha$-tocopherol acetate & & $\mathrm{C}_{31} \mathrm{H}_{52} \mathrm{O}_{3}$ & 472 & 0.0021 & & 0.000068 & & 0.0011 \\
\hline Total & & & & 0.092 & 0.061 & 0.24 & 0.085 & 0.12 \\
\hline
\end{tabular}

All values are reported in $\mathrm{mg} \mathrm{g}^{-1} \mathrm{OC}$.

*Structure number in Appendix 5.2. 
Table A5.11. Concentrations of triterpenoids and other oxygenated compounds in the moss and algae samples.

\begin{tabular}{|c|c|c|c|c|c|c|c|c|}
\hline \multirow[t]{2}{*}{ Sample type: } & & & & \multirow[t]{2}{*}{ Moss } & \multicolumn{4}{|c|}{ Algal assemblies } \\
\hline & & & & & $\# 1$ & $\# 2$ & $\# 3$ & Mean \\
\hline Triterpenones & & Formula & $M W$ & & & & & \\
\hline Taraxerol methyl ether & & $\mathrm{C}_{31} \mathrm{H}_{52} \mathrm{O}$ & 440 & & & 0.0063 & 0.030 & 0.018 \\
\hline$\delta$-Amyrin methyl ether & & $\mathrm{C}_{31} \mathrm{H}_{52} \mathrm{O}$ & 440 & & & & & \\
\hline Lupeol methyl ether & & $\mathrm{C}_{31} \mathrm{H}_{52} \mathrm{O}$ & 440 & & & & & \\
\hline$\beta$-Amyrin methyl ether & & $\mathrm{C}_{31} \mathrm{H}_{52} \mathrm{O}$ & 440 & & & & & \\
\hline Germanicol methyl ether & & $\mathrm{C}_{31} \mathrm{H}_{52} \mathrm{O}$ & 440 & & & & 0.015 & 0.015 \\
\hline$\alpha$-Amyrin methyl ether & & $\mathrm{C}_{31} \mathrm{H}_{52} \mathrm{O}$ & 440 & & & & & \\
\hline Taraxerone & & $\mathrm{C}_{30} \mathrm{H}_{48} \mathrm{O}$ & 424 & & & & & \\
\hline Lupenone & XIV* & $\mathrm{C}_{30} \mathrm{H}_{48} \mathrm{O}$ & 424 & 0.0014 & & & & \\
\hline Olean-13(18)-en-3-one & & $\mathrm{C}_{30} \mathrm{H}_{48} \mathrm{O}$ & 424 & & & & & \\
\hline$\beta$-Amyrone & $\mathbf{X V}$ & $\mathrm{C}_{30} \mathrm{H}_{48} \mathrm{O}$ & 424 & 0.00056 & & 0.0074 & & 0.0074 \\
\hline Germanicone & XVI & $\mathrm{C}_{30} \mathrm{H}_{48} \mathrm{O}$ & 424 & & & & & \\
\hline 28-norolean-17-en-3-one & & $\mathrm{C}_{29} \mathrm{H}_{46} \mathrm{O}$ & 410 & & & & & \\
\hline$\alpha$-Amyrone & XVII & $\mathrm{C}_{30} \mathrm{H}_{48} \mathrm{O}$ & 424 & & & 0.030 & 0.18 & 0.11 \\
\hline Taraxeryl acetate & & $\mathrm{C}_{32} \mathrm{H}_{52} \mathrm{O}_{2}$ & 468 & & & & 0.015 & 0.015 \\
\hline Lupeyl acetate & & $\mathrm{C}_{32} \mathrm{H}_{52} \mathrm{O}_{2}$ & 468 & & & & & \\
\hline$\beta$-Amyryl acetate & & $\mathrm{C}_{32} \mathrm{H}_{52} \mathrm{O}_{2}$ & 468 & & & & 0.012 & 0.012 \\
\hline Germanicyl acetate & & $\mathrm{C}_{32} \mathrm{H}_{52} \mathrm{O}_{2}$ & 468 & & & & & \\
\hline$\alpha$-Amyryl acetate & & $\mathrm{C}_{32} \mathrm{H}_{52} \mathrm{O}_{2}$ & 468 & & & & 0.057 & 0.057 \\
\hline epi-Friedelin & & $\mathrm{C}_{30} \mathrm{H}_{50} \mathrm{O}$ & 426 & & & & 0.0085 & 0.0085 \\
\hline Friedelin & XVIII & $\mathrm{C}_{30} \mathrm{H}_{50} \mathrm{O}$ & 426 & 0.0015 & & 0.011 & 0.020 & 0.016 \\
\hline Total & & & & 0.0034 & & 0.054 & 0.34 & 0.20 \\
\hline
\end{tabular}


Table A5.11. continued.

\begin{tabular}{|c|c|c|c|c|c|c|c|c|}
\hline Taraxerol & XIX & $\mathrm{C}_{30} \mathrm{H}_{50} \mathrm{O}$ & 426 & & & & & \\
\hline$\delta$-Amyrin & & $\mathrm{C}_{30} \mathrm{H}_{50} \mathrm{O}$ & 426 & & & & & \\
\hline$\beta$-Amyrin & $\mathbf{X X}$ & $\mathrm{C}_{30} \mathrm{H}_{50} \mathrm{O}$ & 426 & 0.00029 & & 0.0067 & 0.022 & 0.014 \\
\hline Germanicol & & $\mathrm{C}_{30} \mathrm{H}_{50} \mathrm{O}$ & 426 & & & & & \\
\hline$\alpha$-Amyrin & XXI & $\mathrm{C}_{30} \mathrm{H}_{50} \mathrm{O}$ & 426 & & & 0.0062 & 0.0098 & 0.0080 \\
\hline $3 \alpha$-Lupeol & XXII & $\mathrm{C}_{30} \mathrm{H}_{50} \mathrm{O}$ & 426 & & & & 0.033 & 0.033 \\
\hline $3 \beta$-Lupeol & & $\mathrm{C}_{30} \mathrm{H}_{50} \mathrm{O}$ & 426 & & & & & \\
\hline epi-Friedelanol & & $\mathrm{C}_{30} \mathrm{H}_{52} \mathrm{O}$ & 428 & 0.00067 & & 0.016 & & 0.016 \\
\hline Friedelanol & & $\mathrm{C}_{30} \mathrm{H}_{52} \mathrm{O}$ & 428 & & & & & \\
\hline Total & & & & 0.00096 & & 0.029 & 0.065 & 0.047 \\
\hline \multicolumn{9}{|l|}{ Other Compounds } \\
\hline Phytone & XXIII & $\mathrm{C}_{18} \mathrm{H}_{36} \mathrm{O}$ & 268 & 0.023 & 0.11 & 0.28 & 0.22 & 0.20 \\
\hline Phytol & XXIV & $\mathrm{C}_{20} \mathrm{H}_{40} \mathrm{O}$ & 296 & 0.16 & 0.71 & 0.0030 & 0.13 & 0.28 \\
\hline 4,8,12,16-tetramethylheptadecan-4-olide & & $\mathrm{C}_{21} \mathrm{H}_{40} \mathrm{O}_{2}$ & 324 & 0.0039 & 0.0023 & 0.0044 & 0.0014 & 0.0027 \\
\hline d-tocopherol & & $\mathrm{C}_{27} \mathrm{H}_{46} \mathrm{O}_{2}$ & 402 & & & & & \\
\hline d-tocopherol ethyl ether & & $\mathrm{C}_{29} \mathrm{H}_{50} \mathrm{O}_{2}$ & 430 & & & & & \\
\hline$\alpha$-tocopherol & & $\mathrm{C}_{29} \mathrm{H}_{50} \mathrm{O}_{2}$ & 430 & 0.0019 & & & 0.016 & 0.016 \\
\hline$\alpha$-tocopherol ethyl ether & & $\mathrm{C}_{31} \mathrm{H}_{54} \mathrm{O}_{2}$ & 458 & 0.0028 & & 0.0057 & 0.0016 & 0.0037 \\
\hline$\alpha$-tocopherol acetate & & $\mathrm{C}_{31} \mathrm{H}_{52} \mathrm{O}_{3}$ & 472 & & & & & \\
\hline Total & & & & 0.19 & 0.82 & 0.29 & 0.37 & 0.49 \\
\hline
\end{tabular}

All values are reported in $\mathrm{mg} \mathrm{g}^{-1} \mathrm{OC}$.

*Structure number in Appendix 5.2. 
Table A5.12. Concentrations of triterpenoids and other oxygenated compounds in the sediment samples from the King's Creek watershed.

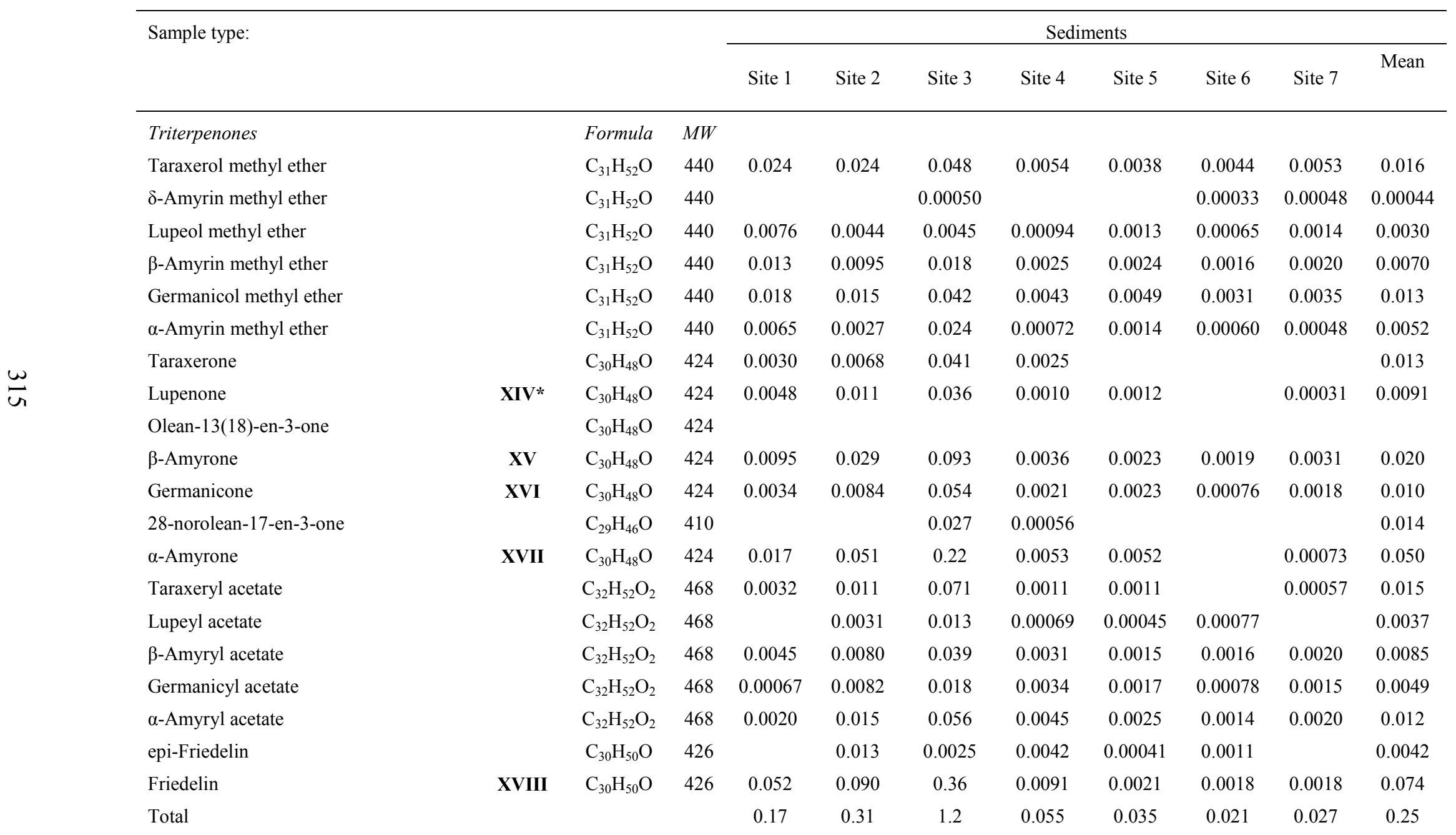


Table A5.12. continued.

Triterpenols
Taraxerol
$\delta$-Amyrin
$\beta$-Amyrin
Germanicol
$\alpha$-Amyrin
$3 \alpha$-Lupeol
3ß-Lupeol
epi-Friedelanol
Friedelanol
Total
Other Compounds
Phytone
Phytol
4,8,12,16-tetramethylheptadecan-4-olide
d-tocopherol
d-tocopherol ethyl ether
$\alpha$-tocopherol
$\alpha$-tocopherol ethyl ether
$\alpha$-tocopherol acetate

$\begin{array}{ccccccccccc}\text { XIX } & \mathrm{C}_{30} \mathrm{H}_{50} \mathrm{O} & 426 & 0.0031 & 0.039 & & & 0.000064 & & & 0.014 \\ & \mathrm{C}_{30} \mathrm{H}_{50} \mathrm{O} & 426 & 0.0027 & 0.11 & & & 0.00042 & 0.00050 & 0.00057 & 0.024 \\ \text { XX } & \mathrm{C}_{30} \mathrm{H}_{50} \mathrm{O} & 426 & 0.0088 & 0.24 & 0.00041 & 0.0022 & 0.0012 & 0.0053 & 0.0058 & 0.038 \\ & \mathrm{C}_{30} \mathrm{H}_{50} \mathrm{O} & 426 & & 0.093 & 0.000053 & 0.00085 & 0.00012 & 0.0011 & 0.0018 & 0.016 \\ \text { XXI } & \mathrm{C}_{30} \mathrm{H}_{50} \mathrm{O} & 426 & 0.0054 & 0.19 & 0.000046 & 0.0020 & 0.0010 & 0.0041 & 0.0036 & 0.029 \\ \text { XXII } & \mathrm{C}_{30} \mathrm{H}_{50} \mathrm{O} & 426 & 0.0038 & 0.24 & 0.000018 & 0.0011 & 0.0011 & 0.0017 & 0.0035 & 0.036 \\ & \mathrm{C}_{30} \mathrm{H}_{50} \mathrm{O} & 426 & 0.012 & 0.046 & 0.000028 & 0.00063 & 0.00052 & 0.0012 & 0.0012 & 0.0089 \\ & \mathrm{C}_{30} \mathrm{H}_{52} \mathrm{O} & 428 & 0.030 & 0.33 & 0.00021 & & & & & 0.12 \\ & \mathrm{C}_{30} \mathrm{H}_{52} \mathrm{O} & 428 & 0.00049 & 0.040 & 0.0016 & & & & & 0.014 \\ & & & 0.067 & 1.3 & 0.0024 & 0.0068 & 0.0044 & 0.014 & 0.016 & 0.21 \\ & & & & & & & & & & \\ \text { XXIII } & \mathrm{C}_{18} \mathrm{H}_{36} \mathrm{O} & 268 & 0.0093 & 0.0088 & 0.011 & 0.0013 & 0.00044 & & & 0.0062 \\ \text { XXIV } & \mathrm{C}_{20} \mathrm{H}_{40} \mathrm{O} & 296 & 0.0014 & & & 0.0034 & 0.0034 & 0.0010 & 0.00083 & 0.0020 \\ & \mathrm{C}_{21} \mathrm{H}_{40} \mathrm{O}_{2} & 324 & & 0.0030 & & 0.00027 & & 0.00036 & & 0.0012 \\ & \mathrm{C}_{27} \mathrm{H}_{40} \mathrm{O}_{2} & 402 & & & & & & & & \\ & \mathrm{C}_{29} \mathrm{H}_{50} \mathrm{O}_{2} & 430 & & & & & & & & \\ & \mathrm{C}_{29} \mathrm{H}_{50} \mathrm{O}_{2} & 430 & 0.00071 & & & & & & & 0.00071 \\ & \mathrm{C}_{31} \mathrm{H}_{54} \mathrm{O}_{2} & 458 & & & & & & & & \end{array}$

All values are reported in $\mathrm{mg} \mathrm{g}^{-1} \mathrm{OC}$.

*Structure number in Appendix 5.2. 
Table A5.13. Concentrations of triterpenoids and other oxygenated compounds in the soil samples from the King's Creek watershed.

\begin{tabular}{|c|c|c|c|c|c|c|}
\hline \multirow[t]{2}{*}{ Sample type: } & & & & \multicolumn{3}{|c|}{ Soils } \\
\hline & & & & Riparian & $\begin{array}{l}\text { Grass } \\
\text { prairie }\end{array}$ & Mean \\
\hline Triterpenones & & Formula & $M W$ & & & \\
\hline Taraxerol methyl ether & & $\mathrm{C}_{31} \mathrm{H}_{52} \mathrm{O}$ & 440 & 0.00075 & 0.12 & 0.061 \\
\hline$\delta$-Amyrin methyl ether & & $\mathrm{C}_{31} \mathrm{H}_{52} \mathrm{O}$ & 440 & & & \\
\hline Lupeol methyl ether & & $\mathrm{C}_{31} \mathrm{H}_{52} \mathrm{O}$ & 440 & & 0.00087 & 0.00087 \\
\hline$\beta$-Amyrin methyl ether & & $\mathrm{C}_{31} \mathrm{H}_{52} \mathrm{O}$ & 440 & 0.00029 & 0.010 & 0.0052 \\
\hline Germanicol methyl ether & & $\mathrm{C}_{31} \mathrm{H}_{52} \mathrm{O}$ & 440 & 0.00055 & 0.055 & 0.028 \\
\hline$\alpha$-Amyrin methyl ether & & $\mathrm{C}_{31} \mathrm{H}_{52} \mathrm{O}$ & 440 & 0.00033 & 0.0036 & 0.0020 \\
\hline Taraxerone & & $\mathrm{C}_{30} \mathrm{H}_{48} \mathrm{O}$ & 424 & & 0.0015 & 0.0015 \\
\hline Lupenone & XIV* & $\mathrm{C}_{30} \mathrm{H}_{48} \mathrm{O}$ & 424 & 0.00031 & 0.00082 & 0.00057 \\
\hline Olean-13(18)-en-3-one & & $\mathrm{C}_{30} \mathrm{H}_{48} \mathrm{O}$ & 424 & & & \\
\hline$\beta$-Amyrone & XV & $\mathrm{C}_{30} \mathrm{H}_{48} \mathrm{O}$ & 424 & 0.0028 & 0.012 & 0.0076 \\
\hline Germanicone & XVI & $\mathrm{C}_{30} \mathrm{H}_{48} \mathrm{O}$ & 424 & 0.0012 & 0.0015 & 0.0013 \\
\hline 28-norolean-17-en-3-one & & $\mathrm{C}_{29} \mathrm{H}_{46} \mathrm{O}$ & 410 & & & \\
\hline$\alpha$-Amyrone & XVII & $\mathrm{C}_{30} \mathrm{H}_{48} \mathrm{O}$ & 424 & 0.030 & 0.022 & 0.026 \\
\hline Taraxeryl acetate & & $\mathrm{C}_{32} \mathrm{H}_{52} \mathrm{O}_{2}$ & 468 & & 0.0086 & 0.0086 \\
\hline Lupeyl acetate & & $\mathrm{C}_{32} \mathrm{H}_{52} \mathrm{O}_{2}$ & 468 & & 0.00078 & 0.00078 \\
\hline$\beta$-Amyryl acetate & & $\mathrm{C}_{32} \mathrm{H}_{52} \mathrm{O}_{2}$ & 468 & & 0.0018 & 0.0018 \\
\hline Germanicyl acetate & & $\mathrm{C}_{32} \mathrm{H}_{52} \mathrm{O}_{2}$ & 468 & & 0.00054 & 0.00054 \\
\hline$\alpha$-Amyryl acetate & & $\mathrm{C}_{32} \mathrm{H}_{52} \mathrm{O}_{2}$ & 468 & & 0.0074 & 0.0074 \\
\hline epi-Friedelin & & $\mathrm{C}_{30} \mathrm{H}_{50} \mathrm{O}$ & 426 & & & \\
\hline Friedelin & XVIII & $\mathrm{C}_{30} \mathrm{H}_{50} \mathrm{O}$ & 426 & 0.0023 & 0.13 & 0.064 \\
\hline Total & & & & 0.038 & 0.38 & 0.21 \\
\hline
\end{tabular}


Table A5.13. continued.

\begin{tabular}{|c|c|c|c|c|c|c|}
\hline \multicolumn{7}{|l|}{ Triterpenols } \\
\hline Taraxerol & XIX & $\mathrm{C}_{30} \mathrm{H}_{50} \mathrm{O}$ & 426 & & 0.00094 & 0.00094 \\
\hline$\delta$-Amyrin & & $\mathrm{C}_{30} \mathrm{H}_{50} \mathrm{O}$ & 426 & & 0.00071 & 0.00071 \\
\hline$\beta$-Amyrin & $\mathbf{X X}$ & $\mathrm{C}_{30} \mathrm{H}_{50} \mathrm{O}$ & 426 & & 0.0022 & 0.0022 \\
\hline Germanicol & & $\mathrm{C}_{30} \mathrm{H}_{50} \mathrm{O}$ & 426 & 0.00061 & & 0.00061 \\
\hline$\alpha$-Amyrin & XXI & $\mathrm{C}_{30} \mathrm{H}_{50} \mathrm{O}$ & 426 & 0.00092 & 0.00096 & 0.00094 \\
\hline $3 \alpha$-Lupeol & XXII & $\mathrm{C}_{30} \mathrm{H}_{50} \mathrm{O}$ & 426 & 0.0029 & 0.0027 & 0.0028 \\
\hline $3 \beta$-Lupeol & & $\mathrm{C}_{30} \mathrm{H}_{50} \mathrm{O}$ & 426 & & & \\
\hline epi-Friedelanol & & $\mathrm{C}_{30} \mathrm{H}_{52} \mathrm{O}$ & 428 & & & \\
\hline Friedelanol & & $\mathrm{C}_{30} \mathrm{H}_{52} \mathrm{O}$ & 428 & & 0.016 & 0.016 \\
\hline Total & & & & 0.0044 & 0.023 & 0.014 \\
\hline \multicolumn{7}{|l|}{ Other Compounds } \\
\hline Phytone & XXIII & $\mathrm{C}_{18} \mathrm{H}_{36} \mathrm{O}$ & 268 & 0.0016 & 0.0043 & 0.0029 \\
\hline Phytol & XXIV & $\mathrm{C}_{20} \mathrm{H}_{40} \mathrm{O}$ & 296 & 0.00014 & & 0.00014 \\
\hline 4,8,12,16-tetramethylheptadecan-4-olide & & $\mathrm{C}_{21} \mathrm{H}_{40} \mathrm{O}_{2}$ & 324 & 0.00027 & & 0.00027 \\
\hline d-tocopherol & & $\mathrm{C}_{27} \mathrm{H}_{46} \mathrm{O}_{2}$ & 402 & & & \\
\hline d-tocopherol ethyl ether & & $\mathrm{C}_{29} \mathrm{H}_{50} \mathrm{O}_{2}$ & 430 & & & \\
\hline$\alpha$-tocopherol & & $\mathrm{C}_{29} \mathrm{H}_{50} \mathrm{O}_{2}$ & 430 & & & \\
\hline$\alpha$-tocopherol ethyl ether & & $\mathrm{C}_{31} \mathrm{H}_{54} \mathrm{O}_{2}$ & 458 & & & \\
\hline$\alpha$-tocopherol acetate & & $\mathrm{C}_{31} \mathrm{H}_{52} \mathrm{O}_{3}$ & 472 & & & \\
\hline Total & & & & 0.0020 & 0.0043 & 0.0031 \\
\hline
\end{tabular}

All values are reported in $\mathrm{mg} \mathrm{g}^{-1} \mathrm{OC}$.

*Structure number in Appendix 5.2. 
Table A5.14. Concentrations of sterols in the riparian vegetation samples.

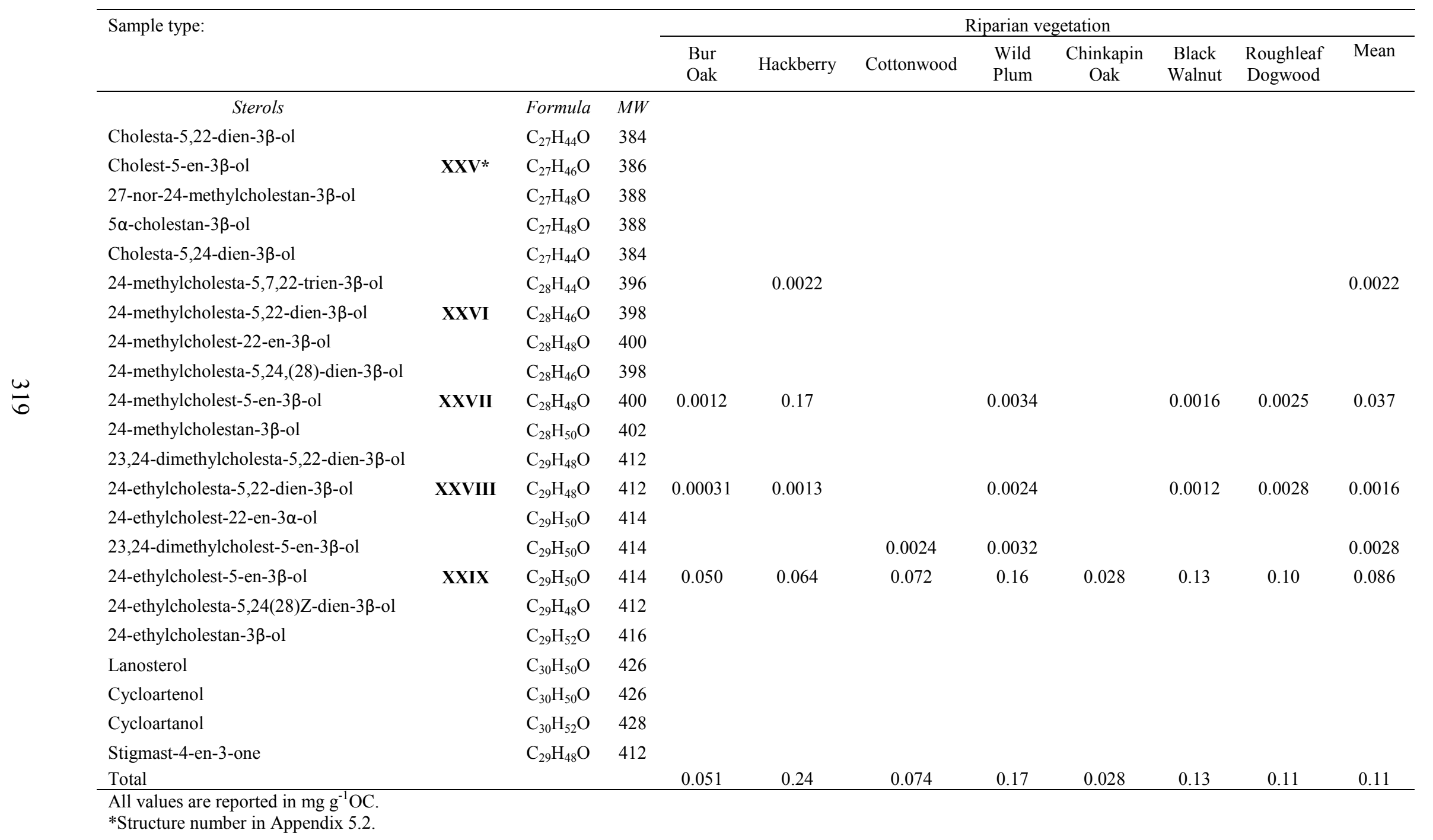


Table A5.15. Concentration of sterols in Konza Prairie grass samples.

\begin{tabular}{|c|c|c|c|c|c|c|c|c|}
\hline \multirow[t]{2}{*}{ Sample type: } & & & & \multicolumn{5}{|c|}{ Grasses } \\
\hline & & & & $\begin{array}{c}\text { Johnson } \\
\text { grass }\end{array}$ & $\begin{array}{c}\text { Prairie } \\
\text { Cordgrass }\end{array}$ & $\begin{array}{c}\text { Eastern } \\
\text { Gamma grass }\end{array}$ & $\begin{array}{l}\text { Big Bluestem } \\
\text { grass }\end{array}$ & Mean \\
\hline Sterols & & Formula & $M W$ & & & & & \\
\hline Cholesta-5,22-dien-3 $\beta$-ol & & $\mathrm{C}_{27} \mathrm{H}_{44} \mathrm{O}$ & 384 & & & & & \\
\hline Cholest-5-en-3ß-ol & $\mathbf{X X V *}$ & $\mathrm{C}_{27} \mathrm{H}_{46} \mathrm{O}$ & 386 & & & 0.0022 & 0.0034 & 0.0028 \\
\hline 27-nor-24-methylcholestan-3 $\beta$-ol & & $\mathrm{C}_{27} \mathrm{H}_{48} \mathrm{O}$ & 388 & & & & & \\
\hline $5 \alpha$-cholestan- $3 \beta$-ol & & $\mathrm{C}_{27} \mathrm{H}_{48} \mathrm{O}$ & 388 & & & & & \\
\hline Cholesta-5,24-dien-3 $\beta$-ol & & $\mathrm{C}_{27} \mathrm{H}_{44} \mathrm{O}$ & 384 & & & & & \\
\hline 24-methylcholesta-5,7,22-trien-3 $\beta$-ol & & $\mathrm{C}_{28} \mathrm{H}_{44} \mathrm{O}$ & 396 & & & & & \\
\hline 24-methylcholesta-5,22-dien-3ß-ol & XXVI & $\mathrm{C}_{28} \mathrm{H}_{46} \mathrm{O}$ & 398 & & & & & \\
\hline 24-methylcholest-22-en-3 $\beta$-ol & & $\mathrm{C}_{28} \mathrm{H}_{48} \mathrm{O}$ & 400 & & & & & \\
\hline 24-methylcholesta-5,24,(28)-dien-3ß-ol & & $\mathrm{C}_{28} \mathrm{H}_{46} \mathrm{O}$ & 398 & & & & & \\
\hline 24-methylcholest-5-en-3 $\beta$-ol & XXVII & $\mathrm{C}_{28} \mathrm{H}_{48} \mathrm{O}$ & 400 & 0.015 & 0.025 & 0.018 & 0.0075 & 0.016 \\
\hline 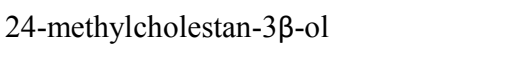 & & $\mathrm{C}_{28} \mathrm{H}_{50} \mathrm{O}$ & 402 & 0.00039 & 0.00018 & & 0.00028 & 0.00028 \\
\hline 23,24-dimethylcholesta-5,22-dien-3 $\beta$-ol & & $\mathrm{C}_{29} \mathrm{H}_{48} \mathrm{O}$ & 412 & & & & & \\
\hline 24-ethylcholesta-5,22-dien-3ß-ol & XXVIII & $\mathrm{C}_{29} \mathrm{H}_{48} \mathrm{O}$ & 412 & 0.0049 & 0.011 & 0.0056 & 0.014 & 0.0089 \\
\hline 24-ethylcholest-22-en-3 $\alpha$-ol & & $\mathrm{C}_{29} \mathrm{H}_{50} \mathrm{O}$ & 414 & & & & 0.00019 & 0.000194 \\
\hline 23,24-dimethylcholest-5-en-3ß-ol & & $\mathrm{C}_{29} \mathrm{H}_{50} \mathrm{O}$ & 414 & & & & & \\
\hline 24-ethylcholest-5-en-3ß-ol & XXIX & $\mathrm{C}_{29} \mathrm{H}_{50} \mathrm{O}$ & 414 & 0.11 & 0.16 & 0.077 & 0.038 & 0.096 \\
\hline 24-ethylcholesta-5,24(28)Z-dien-3ß-ol & & $\mathrm{C}_{29} \mathrm{H}_{48} \mathrm{O}$ & 412 & & & & & \\
\hline 24-ethylcholestan-3 $\beta$-ol & & $\mathrm{C}_{29} \mathrm{H}_{52} \mathrm{O}$ & 416 & & & & & \\
\hline Lanosterol & & $\mathrm{C}_{30} \mathrm{H}_{50} \mathrm{O}$ & 426 & & & 0.0033 & & 0.0033 \\
\hline Cycloartenol & & $\mathrm{C}_{30} \mathrm{H}_{50} \mathrm{O}$ & 426 & & & & & \\
\hline Cycloartanol & & $\mathrm{C}_{30} \mathrm{H}_{52} \mathrm{O}$ & 428 & & & & & \\
\hline Stigmast-4-en-3-one & & $\mathrm{C}_{29} \mathrm{H}_{48} \mathrm{O}$ & 412 & 0.0023 & 0.00079 & & & 0.0015 \\
\hline
\end{tabular}


Table A5.15. continued.

Total

All values are reported in $\mathrm{mg} \mathrm{g}^{-1} \mathrm{OC}$.

*Structure number in Appendix 5.2.

0.13 
Table A5.16. Concentrations of sterols in the moss and algae samples.

\begin{tabular}{|c|c|c|c|c|c|c|c|c|}
\hline \multirow[t]{2}{*}{ Sample type: } & & & & \multirow[t]{2}{*}{ Moss } & \multicolumn{4}{|c|}{ Algal assemblies } \\
\hline & & & & & $\# 1$ & $\# 2$ & $\# 3$ & Mean \\
\hline Sterols & & Formula & $M W$ & & & & & \\
\hline Cholesta-5,22-dien-3 $\beta$-ol & & $\mathrm{C}_{27} \mathrm{H}_{44} \mathrm{O}$ & 384 & & & & & \\
\hline 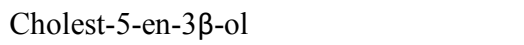 & $\mathrm{XXV}^{*}$ & $\mathrm{C}_{27} \mathrm{H}_{46} \mathrm{O}$ & 386 & 0.0042 & 0.046 & 0.0059 & 0.038 & 0.030 \\
\hline 27-nor-24-methylcholestan-3 $\beta$-ol & & $\mathrm{C}_{27} \mathrm{H}_{48} \mathrm{O}$ & 388 & & & & & \\
\hline $5 \alpha$-cholestan- $3 \beta-\mathrm{ol}$ & & $\mathrm{C}_{27} \mathrm{H}_{48} \mathrm{O}$ & 388 & & & & & \\
\hline Cholesta-5,24-dien-3ß-ol & & $\mathrm{C}_{27} \mathrm{H}_{44} \mathrm{O}$ & 384 & & 0.069 & & & 0.069 \\
\hline 24-methylcholesta-5,7,22-trien-3 $\beta$-ol & & $\mathrm{C}_{28} \mathrm{H}_{44} \mathrm{O}$ & 396 & & & & & \\
\hline 24-methylcholesta-5,22-dien-3ß-ol & XXVI & $\mathrm{C}_{28} \mathrm{H}_{46} \mathrm{O}$ & 398 & 0.0024 & 0.018 & & 0.085 & 0.052 \\
\hline 24-methylcholest-22-en-3 3 -ol & & $\mathrm{C}_{28} \mathrm{H}_{48} \mathrm{O}$ & 400 & & & & & \\
\hline 24-methylcholesta-5,24,(28)-dien-3ß-ol & & $\mathrm{C}_{28} \mathrm{H}_{46} \mathrm{O}$ & 398 & & 0.21 & 0.00034 & 0.016 & 0.074 \\
\hline 24-methylcholest-5-en-3 $\beta$-ol & XXVII & $\mathrm{C}_{28} \mathrm{H}_{48} \mathrm{O}$ & 400 & 0.070 & & 0.0012 & & 0.0012 \\
\hline 24-methylcholestan-3 $\beta$-ol & & $\mathrm{C}_{28} \mathrm{H}_{50} \mathrm{O}$ & 402 & & & 0.00073 & & 0.00073 \\
\hline 23,24-dimethylcholesta-5,22-dien-3 $\beta$-ol & & $\mathrm{C}_{29} \mathrm{H}_{48} \mathrm{O}$ & 412 & & & & & \\
\hline 24-ethylcholesta-5,22-dien-3ß-ol & XXVIII & $\mathrm{C}_{29} \mathrm{H}_{48} \mathrm{O}$ & 412 & 0.060 & & & & \\
\hline 24-ethylcholest-22-en-3 $\alpha$-ol & & $\mathrm{C}_{29} \mathrm{H}_{50} \mathrm{O}$ & 414 & & & & & \\
\hline 23,24-dimethylcholest-5-en-3 3 -ol & & $\mathrm{C}_{29} \mathrm{H}_{50} \mathrm{O}$ & 414 & & & & & \\
\hline 24-ethylcholest-5-en-3 $\beta$-ol & XXIX & $\mathrm{C}_{29} \mathrm{H}_{50} \mathrm{O}$ & 414 & 0.032 & 0.023 & 0.044 & 0.39 & 0.15 \\
\hline 24-ethylcholesta-5,24(28)Z-dien-3 $\beta$-ol & & $\mathrm{C}_{29} \mathrm{H}_{48} \mathrm{O}$ & 412 & 0.0034 & & & 0.081 & 0.081 \\
\hline 24-ethylcholestan-3 $\beta$-ol & & $\mathrm{C}_{29} \mathrm{H}_{52} \mathrm{O}$ & 416 & & & & & \\
\hline Lanosterol & & $\mathrm{C}_{30} \mathrm{H}_{50} \mathrm{O}$ & 426 & & 0.14 & & 0.0065 & 0.075 \\
\hline Cycloartenol & & $\mathrm{C}_{30} \mathrm{H}_{50} \mathrm{O}$ & 426 & & 0.16 & & & 0.16 \\
\hline Cycloartanol & & $\mathrm{C}_{30} \mathrm{H}_{52} \mathrm{O}$ & 428 & & 0.91 & & 0.10 & 0.51 \\
\hline Stigmast-4-en-3-one & & $\mathrm{C}_{29} \mathrm{H}_{48} \mathrm{O}$ & 412 & 0.00032 & & 0.13 & 0.0028 & 0.064 \\
\hline
\end{tabular}


Table A5.16. continued.

Total

All values are reported in $\mathrm{mg} \mathrm{g}^{-1} \mathrm{OC}$.

*Structure number in Appendix 5.2. 
Table A5.17. Concentrations of sterols in the sediment samples from the King's Creek watershed.

\begin{tabular}{|c|c|c|c|c|c|c|c|c|c|c|c|}
\hline \multirow[t]{2}{*}{ Sample type: } & & & & \multicolumn{8}{|c|}{ Sediments } \\
\hline & & & & Site 1 & Site 2 & Site 3 & Site 4 & Site 5 & Site 6 & Site 7 & Mean \\
\hline Sterols & & Formula & $M W$ & & & & & & & & \\
\hline Cholesta-5,22-dien-3ß-ol & & $\mathrm{C}_{27} \mathrm{H}_{44} \mathrm{O}$ & 384 & 0.0012 & & & & & & & 0.0012 \\
\hline Cholest-5-en-3ß-ol & $\mathbf{X X V *}$ & $\mathrm{C}_{27} \mathrm{H}_{46} \mathrm{O}$ & 386 & 0.011 & 0.0025 & 0.0011 & 0.0018 & 0.00016 & 0.0013 & 0.0034 & 0.0030 \\
\hline 27-nor-24-methylcholestan-3 $\beta$-ol & & $\mathrm{C}_{27} \mathrm{H}_{48} \mathrm{O}$ & 388 & 0.0020 & & & & & & & 0.0020 \\
\hline $5 \alpha$-cholestan-3 3 -ol & & $\mathrm{C}_{27} \mathrm{H}_{48} \mathrm{O}$ & 388 & & 0.00056 & 0.00027 & 0.00066 & & & & 0.00050 \\
\hline Cholesta-5,24-dien-3ß-ol & & $\mathrm{C}_{27} \mathrm{H}_{44} \mathrm{O}$ & 384 & & & & & & & & \\
\hline 24-methylcholesta-5,7,22-trien-3 $\beta$-ol & & $\mathrm{C}_{28} \mathrm{H}_{44} \mathrm{O}$ & 396 & & & & & & & & \\
\hline 24-methylcholesta-5,22-dien-3ß-ol & XXVI & $\mathrm{C}_{28} \mathrm{H}_{46} \mathrm{O}$ & 398 & 0.013 & 0.0020 & 0.00062 & 0.00084 & 0.000049 & 0.00099 & 0.0017 & 0.0027 \\
\hline 24-methylcholest-22-en-3 $\beta$-ol & & $\mathrm{C}_{28} \mathrm{H}_{48} \mathrm{O}$ & 400 & 0.00048 & 0.00012 & & & & & & 0.00030 \\
\hline 24-methylcholesta-5,24,(28)-dien-3ß-ol & & $\mathrm{C}_{28} \mathrm{H}_{46} \mathrm{O}$ & 398 & 0.0016 & & & & & & & 0.0016 \\
\hline 24-methylcholest-5-en-3 $\beta$-ol & XXVII & $\mathrm{C}_{28} \mathrm{H}_{48} \mathrm{O}$ & 400 & 0.0043 & 0.0016 & 0.00066 & 0.00093 & 0.000072 & 0.0011 & 0.0027 & 0.0016 \\
\hline 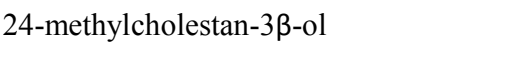 & & $\mathrm{C}_{28} \mathrm{H}_{50} \mathrm{O}$ & 402 & 0.00064 & 0.00021 & & & & & 0.0006578 & 0.00050 \\
\hline 23,24-dimethylcholesta-5,22-dien-3 $\beta$-ol & & $\mathrm{C}_{29} \mathrm{H}_{48} \mathrm{O}$ & 412 & 0.00025 & & & & & & & 0.00025 \\
\hline 24-ethylcholesta-5,22-dien-3ß-ol & XXVIII & $\mathrm{C}_{29} \mathrm{H}_{48} \mathrm{O}$ & 412 & 0.0029 & 0.0011 & 0.00057 & 0.00064 & 0.000057 & 0.0013 & 0.0014 & 0.0012 \\
\hline 24-ethylcholest-22-en-3 $\alpha$-ol & & $\mathrm{C}_{29} \mathrm{H}_{50} \mathrm{O}$ & 414 & & 0.000058 & & & & & & 0.000058 \\
\hline 23,24-dimethylcholest-5-en-3ß-ol & & $\mathrm{C}_{29} \mathrm{H}_{50} \mathrm{O}$ & 414 & & & & 0.0068 & & & & 0.0068 \\
\hline 24-ethylcholest-5-en-3ß-ol & XXIX & $\mathrm{C}_{29} \mathrm{H}_{50} \mathrm{O}$ & 414 & 0.012 & 0.0083 & 0.0046 & 0.0062 & 0.00075 & 0.0039 & 0.011 & 0.0066 \\
\hline 24-ethylcholesta-5,24(28)Z-dien-3 $\beta$-ol & & $\mathrm{C}_{29} \mathrm{H}_{48} \mathrm{O}$ & 412 & 0.00041 & & & & & & & 0.00041 \\
\hline 24-ethylcholestan-3 $\beta$-ol & & $\mathrm{C}_{29} \mathrm{H}_{52} \mathrm{O}$ & 416 & 0.0019 & 0.0012 & & & & & & 0.0015 \\
\hline Lanosterol & & $\mathrm{C}_{30} \mathrm{H}_{50} \mathrm{O}$ & 426 & & & & & & & & \\
\hline Cycloartenol & & $\mathrm{C}_{30} \mathrm{H}_{50} \mathrm{O}$ & 426 & & & & & & & & \\
\hline Cycloartanol & & $\mathrm{C}_{30} \mathrm{H}_{52} \mathrm{O}$ & 428 & & & & & & & & \\
\hline Stigmast-4-en-3-one & & $\mathrm{C}_{29} \mathrm{H}_{48} \mathrm{O}$ & 412 & 0.014 & & 0.00067 & 0.00085 & 0.00063 & 0.00075 & 0.0012 & 0.0030 \\
\hline
\end{tabular}


Table A5.17. continued.

Total

0.065

0.018

0.0085

0.019

0.0017

0.0093

0.022

values are reported in $\mathrm{mg} \mathrm{g}^{-1} \mathrm{OC}$.

*Structure number in Appendix 5.2. 
Table A5.18. Concentrations of sterols in the soil samples from the King's Creek watershed.

\begin{tabular}{|c|c|c|c|c|c|c|}
\hline \multirow[t]{2}{*}{ Sample type: } & & & & \multicolumn{3}{|c|}{ Soils } \\
\hline & & & & Riparian & $\begin{array}{c}\text { Grass } \\
\text { prairie }\end{array}$ & Mean \\
\hline Sterols & & Formula & $M W$ & & & \\
\hline Cholesta-5,22-dien-3 $\beta$-ol & & $\mathrm{C}_{27} \mathrm{H}_{44} \mathrm{O}$ & 384 & & & \\
\hline Cholest-5-en-3ß-ol & $\mathbf{X X V} *$ & $\mathrm{C}_{27} \mathrm{H}_{46} \mathrm{O}$ & 386 & 0.00099 & 0.00013 & 0.00056 \\
\hline 27-nor-24-methylcholestan-3ß-ol & & $\mathrm{C}_{27} \mathrm{H}_{48} \mathrm{O}$ & 388 & & & \\
\hline $5 \alpha$-cholestan- $3 \beta$-ol & & $\mathrm{C}_{27} \mathrm{H}_{48} \mathrm{O}$ & 388 & & & \\
\hline Cholesta-5,24-dien-3ß-ol & & $\mathrm{C}_{27} \mathrm{H}_{44} \mathrm{O}$ & 384 & & & \\
\hline 24-methylcholesta-5,7,22-trien-3 3 -ol & & $\mathrm{C}_{28} \mathrm{H}_{44} \mathrm{O}$ & 396 & & & \\
\hline 24-methylcholesta-5,22-dien-3ß-ol & XXVI & $\mathrm{C}_{28} \mathrm{H}_{46} \mathrm{O}$ & 398 & 0.00038 & 0.000057 & 0.00022 \\
\hline 24-methylcholest-22-en-3ß-ol & & $\mathrm{C}_{28} \mathrm{H}_{48} \mathrm{O}$ & 400 & & & \\
\hline 24-methylcholesta-5,24,(28)-dien-3ß-ol & & $\mathrm{C}_{28} \mathrm{H}_{46} \mathrm{O}$ & 398 & & & \\
\hline 24-methylcholest-5-en-3 $\beta$-ol & XXVII & $\mathrm{C}_{28} \mathrm{H}_{48} \mathrm{O}$ & 400 & 0.0027 & 0.00022 & 0.0014 \\
\hline 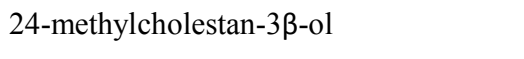 & & $\mathrm{C}_{28} \mathrm{H}_{50} \mathrm{O}$ & 402 & & & \\
\hline 23,24-dimethylcholesta-5,22-dien-3 $\beta$-ol & & $\mathrm{C}_{29} \mathrm{H}_{48} \mathrm{O}$ & 412 & & & \\
\hline 24-ethylcholesta-5,22-dien-3 $\beta$-ol & XXVIII & $\mathrm{C}_{29} \mathrm{H}_{48} \mathrm{O}$ & 412 & 0.0011 & 0.00019 & 0.00064 \\
\hline 24-ethylcholest-22-en-3 $\alpha$-ol & & $\mathrm{C}_{29} \mathrm{H}_{50} \mathrm{O}$ & 414 & & & \\
\hline 23,24-dimethylcholest-5-en-3ß-ol & & $\mathrm{C}_{29} \mathrm{H}_{50} \mathrm{O}$ & 414 & & & \\
\hline 24-ethylcholest-5-en-3ß-ol & XXIX & $\mathrm{C}_{29} \mathrm{H}_{50} \mathrm{O}$ & 414 & 0.010 & 0.00062 & 0.0054 \\
\hline 24-ethylcholesta-5,24(28)Z-dien-3ß-ol & & $\mathrm{C}_{29} \mathrm{H}_{48} \mathrm{O}$ & 412 & & & \\
\hline 24-ethylcholestan-3 $\beta$-ol & & $\mathrm{C}_{29} \mathrm{H}_{52} \mathrm{O}$ & 416 & & & \\
\hline Lanosterol & & $\mathrm{C}_{30} \mathrm{H}_{50} \mathrm{O}$ & 426 & & & \\
\hline Cycloartenol & & $\mathrm{C}_{30} \mathrm{H}_{50} \mathrm{O}$ & 426 & & & \\
\hline Cycloartanol & & $\mathrm{C}_{30} \mathrm{H}_{52} \mathrm{O}$ & 428 & & & \\
\hline Stigmast-4-en-3-one & & $\mathrm{C}_{29} \mathrm{H}_{48} \mathrm{O}$ & 412 & 0.0057 & & 0.0057 \\
\hline
\end{tabular}


Table A5.18. continued.

Total
All values are reported in $\mathrm{mg} \mathrm{g}^{-1} \mathrm{OC}$.
*Structure number in Appendix 5.2.

Table A5.19. Compound specific stable carbon isotopic composition of short chain $n$-alkanes $(\mathrm{C} \leq 20)$ in Konza Prairie samples.

\begin{tabular}{|c|c|c|c|c|c|c|c|c|c|c|c|c|c|}
\hline Sample type & Name & $\mathrm{C}_{15}$ & & $\mathrm{C}_{16}$ & & $\mathrm{C}_{17}$ & & $\mathrm{C}_{18}$ & & $\mathrm{C}_{19}$ & & $\mathrm{C}_{20}$ & \\
\hline \multirow[t]{3}{*}{ Algal assemblies } & $\# 1$ & -35.78 & \pm 0.26 & -34.13 & n.a. & -41.07 & \pm 0.68 & -31.22 & n.a. & -31.90 & n.a. & -26.48 & n.a. \\
\hline & $\# 2$ & -31.98 & n.a.*** & n.d. & & -40.59 & \pm 0.41 & n.d. & & n.d. & & n.d. & \\
\hline & $\# 3$ & n.d.* & & n.d. & & -33.89 & n.a. & n.d. & & n.d. & & -23.39 & n.a. \\
\hline \multirow[t]{7}{*}{ Sediments } & Site 1 & -34.56 & \pm 0.28 & -27.83 & n.a. & -36.99 & \pm 0.98 & -26.67 & n.a. & -30.71 & \pm 0.74 & -26.53 & n.a. \\
\hline & Site 2 & -41.07 & \pm 1.82 & -29.33 & n.a. & -37.54 & \pm 0.46 & -29.90 & \pm 0.15 & -31.45 & \pm 0.92 & -27.79 & \pm 0.61 \\
\hline & Site 3 & -26.77 & n.a. & -25.95 & n.a. & -29.84 & n.a. & -26.70 & n.a. & -26.67 & n.a. & -28.53 & n.a. \\
\hline & Site 4 & -32.92 & \pm 0.55 & -30.92 & \pm 0.67 & -37.32 & \pm 0.87 & -35.37 & \pm 1.06 & n.d. & & -27.70 & n.a. \\
\hline & Site 5 & n.p. $* *$ & & n.p. & & -33.32 & \pm 0.02 & n.d. & & n.d. & & n.d. & \\
\hline & Site 6 & -34.81 & n.a. & -29.81 & n.a. & -34.46 & \pm 0.76 & -31.92 & \pm 1.10 & -27.49 & \pm 0.02 & n.d. & \\
\hline & Site 7 & -39.67 & \pm 0.29 & n.d. & & n.d. & & n.d. & & -27.42 & n.a. & n.d. & \\
\hline \multirow[t]{2}{*}{ Soils } & Grass prairie & n.d. & & n.d. & & -31.61 & \pm 0.33 & n.d. & & n.d. & & -27.60 & n.a. \\
\hline & Riparian & n.p. & & n.p. & & n.d. & & n.d. & & -27.17 & n.a. & -27.01 & n.a. \\
\hline
\end{tabular}

All values reported in $\% \pm$ standard deviation.

*n-alkane not detected.

$* * n$-alkane not present in sample.

*** Standard deviation is not available: only one replicate was obtained and no error could be calculated. 
Table A5.20. Compound specific stable carbon isotopic composition of mid chain $n$-alkanes $\left(\mathrm{C}_{21}-\mathrm{C}_{26}\right)$ in Konza Prairie samples.

\begin{tabular}{|c|c|c|c|c|c|c|c|c|c|c|c|c|c|}
\hline Sample type & Name & $\mathrm{C}_{21}$ & & $\mathrm{C}_{22}$ & & $\mathrm{C}_{23}$ & & $\mathrm{C}_{24}$ & & $\mathrm{C}_{25}$ & & $\mathrm{C}_{26}$ & \\
\hline \multirow[t]{7}{*}{ Riparian vegetation $\left(\mathrm{C}_{3}\right)$} & Bur Oak & n.d.* & & n.d. & & -34.59 & \pm 1.98 & -40.82 & \pm 0.50 & -33.24 & \pm 1.23 & -34.22 & \pm 1.60 \\
\hline & Hackberry & n.d. & & n.d. & & -31.41 & n.a. & n.d. & & -33.81 & \pm 1.24 & -34.69 & \pm 0.33 \\
\hline & Chinkapin Oak & n.d. & & n.d. & & -31.61 & \pm 0.67 & -33.46 & n.a. & -33.92 & \pm 0.45 & -34.10 & \pm 0.61 \\
\hline & Black Walnut & n.d. & & n.d. & & n.d. & & n.d. & & -32.13 & \pm 0.46 & n.d. & \\
\hline & Wild Plum & n.d. & & n.d. & & n.d. & & n.d. & & -33.20 & \pm 0.01 & n.d. & \\
\hline & Roughleaf Dogwood & n.d. & & n.d. & & -33.13 & n.a. & -32.59 & \pm 0.77 & -33.01 & \pm 0.60 & -31.65 & \pm 0.58 \\
\hline & Cottonwood & n.d. & & -32.08 & \pm 1.79 & -31.45 & \pm 1.23 & -33.40 & n.a. & -34.98 & \pm 0.84 & -35.49 & \pm 1.03 \\
\hline \multirow[t]{2}{*}{ Grasses $\left(\mathrm{C}_{3}\right)$} & Johnson grass & n.d. & & n.d. & & -32.38 & n.a. & n.d. & & -32.02 & \pm 0.60 & -33.91 & \pm 0.30 \\
\hline & Prairie Cordgrass & -28.34 & & n.d. & & -35.09 & \pm 0.92 & n.d. & & -33.75 & \pm 1.12 & $n . d$. & \\
\hline \multirow[t]{2}{*}{ Grasses $\left(\mathrm{C}_{4}\right)$} & Eastern Gamma grass & -26.21 & \pm 0.66 & -28.51 & n.a. & -22.00 & \pm 1.80 & -24.39 & \pm 0.74 & -24.06 & \pm 0.90 & -24.22 & \pm 0.66 \\
\hline & Big Bluestem grass & n.d. & & -25.96 & n.a. & -21.54 & \pm 0.34 & -21.23 & \pm 1.57 & -20.29 & \pm 1.01 & -20.22 & \pm 0.97 \\
\hline Moss & Moss & n.d. & & n.d. & & n.d. & & n.d. & & -30.05 & & $n . d$. & \\
\hline \multirow[t]{3}{*}{ Algal assemblies } & $\# 1$ & n.d. & & n.d. & & -32.30 & \pm 0.85 & n.d. & & -31.76 & \pm 0.14 & n.d. & \\
\hline & $\# 2$ & n.d. & & n.d. & & n.d. & & n.d. & & -31.80 & n.a. & n.d. & \\
\hline & $\# 3$ & n.d. & & n.d. & & -31.12 & n.a. & n.d. & & -29.71 & \pm 0.11 & $n . d$. & \\
\hline \multirow[t]{7}{*}{ Sediments } & Site 1 & -32.36 & n.a.* & n.d. & & -32.75 & n.a. & n.d. & & -29.74 & \pm 0.51 & -29.77 & n.a. \\
\hline & Site 2 & -29.52 & \pm 1.51 & -29.31 & \pm 0.58 & -28.73 & \pm 1.14 & -28.87 & \pm 0.41 & -30.59 & \pm 0.78 & -30.89 & \pm 0.22 \\
\hline & Site 3 & -29.71 & n.a. & -27.39 & n.a. & -28.80 & \pm 1.05 & -29.42 & n.a. & -30.98 & n.a. & -28.82 & \pm 0.33 \\
\hline & Site 4 & -27.72 & n.a. & -27.10 & \pm 1.04 & -28.04 & \pm 0.94 & -27.85 & \pm 1.44 & -29.78 & \pm 0.91 & -29.95 & \pm 0.65 \\
\hline & Site 5 & n.d. & & $n . d$. & & n.d. & & n.d. & & -26.87 & \pm 0.57 & n.d. & \\
\hline & Site 6 & -29.05 & \pm 0.89 & -30.07 & n.a. & n.d. & & -30.36 & \pm 1.62 & -30.89 & \pm 1.71 & n.d. & \\
\hline & Site 7 & -25.38 & n.a. & n.d. & & -33.68 & n.a. & -33.36 & n.a. & -33.20 & n.a. & -30.69 & n.a. \\
\hline \multirow[t]{2}{*}{ Soils } & Grass prairie & n.d. & & n.d. & & n.d. & & -25.41 & n.a. & -22.72 & \pm 0.42 & n.d. & \\
\hline & Riparian & -25.30 & n.a. & n.d. & & -28.19 & n.a. & n.d. & & -30.28 & \pm 0.48 & -31.24 & \pm 0.30 \\
\hline
\end{tabular}

* $n$-alkane not detected.

** Not available: only one replicate was obtained and no standard deviation could be calculated. 
Table A5.21. Compound specific stable carbon isotopic composition of long chain $n$-alkanes $\left(\mathrm{C}_{27}-\mathrm{C}_{35}\right)$ in Konza Prairie samples.

\begin{tabular}{|c|c|c|c|c|c|c|c|c|c|c|c|}
\hline Sample type & Name & $\mathrm{C}_{27}$ & & $\mathrm{C}_{28}$ & & $\mathrm{C}_{29}$ & & $\mathrm{C}_{30}$ & & $\mathrm{C}_{31}$ & \\
\hline \multirow[t]{7}{*}{ Riparian vegetation $\left(\mathrm{C}_{3}\right)$} & Bur Oak & -34.86 & \pm 0.74 & -34.69 & \pm 1.41 & -33.14 & \pm 0.36 & -33.60 & \pm 0.55 & -33.61 & \pm 0.70 \\
\hline & Hackberry & -34.37 & \pm 1.02 & -35.06 & \pm 0.67 & -35.02 & \pm 0.20 & -35.59 & \pm 0.61 & -35.18 & \pm 0.59 \\
\hline & Chinkapin Oak & -33.39 & n.a. & -33.72 & \pm 0.19 & -33.76 & \pm 1.15 & -33.64 & \pm 0.18 & -31.52 & \pm 0.92 \\
\hline & Black Walnut & -33.12 & \pm 0.96 & n.d. & & -32.93 & \pm 0.80 & -34.77 & \pm 0.26 & -33.85 & n.a. \\
\hline & Wild Plum & -33.38 & \pm 1.14 & -33.77 & \pm 0.56 & -32.25 & \pm 1.58 & -34.08 & \pm 1.20 & -33.38 & \pm 1.53 \\
\hline & Roughleaf Dogwood & -32.38 & \pm 0.62 & -33.38 & \pm 1.09 & -33.27 & \pm 0.86 & -34.62 & \pm 0.54 & -33.07 & \pm 0.38 \\
\hline & Cottonwood & -35.24 & \pm 0.90 & -34.94 & \pm 1.80 & -34.99 & \pm 0.43 & -35.37 & \pm 1.33 & -34.36 & \pm 1.32 \\
\hline \multirow[t]{2}{*}{ Grasses $\left(\mathrm{C}_{3}\right)$} & Johnson grass & -33.67 & \pm 0.23 & -35.24 & \pm 1.49 & -34.96 & \pm 0.70 & -35.63 & \pm 1.81 & -35.13 & \pm 0.57 \\
\hline & Prairie Cordgrass & -34.21 & \pm 0.95 & -36.86 & n.a. & -36.63 & \pm 0.82 & -29.91 & n.a. & -36.52 & \pm 0.97 \\
\hline \multirow[t]{2}{*}{ Grasses $\left(\mathrm{C}_{4}\right)$} & Eastern Gamma grass & -25.17 & \pm 0.61 & -24.16 & \pm 0.70 & -24.30 & \pm 0.58 & -25.70 & \pm 0.86 & -25.16 & \pm 1.70 \\
\hline & Big Bluestem grass & -20.21 & \pm 0.93 & -20.75 & \pm 0.39 & -21.66 & \pm 0.22 & -21.21 & \pm 0.98 & -21.88 & \pm 0.68 \\
\hline Moss & Moss & -31.05 & \pm 0.62 & -31.28 & n.a. & -32.80 & \pm 0.37 & n.d. & & -32.77 & \pm 0.13 \\
\hline \multirow[t]{3}{*}{ Algal assemblies } & $\# 1$ & -31.53 & \pm 0.11 & n.d. & & -31.95 & \pm 0.64 & n.d. & & -32.89 & \pm 0.21 \\
\hline & $\# 2$ & -30.21 & \pm 0.31 & n.d. & & -33.98 & \pm 0.13 & n.d. & & -33.28 & \pm 0.12 \\
\hline & $\# 3$ & -28.88 & \pm 0.46 & n.d. & & -32.53 & \pm 0.33 & n.d. & & -33.06 & \pm 0.05 \\
\hline \multirow[t]{7}{*}{ Sediments } & Site 1 & -30.45 & \pm 1.14 & -31.25 & n.a. & -31.78 & \pm 0.96 & -29.84 & n.a. & -37.29 & \pm 1.25 \\
\hline & Site 2 & -31.62 & \pm 0.53 & -32.05 & \pm 0.78 & -31.40 & \pm 0.53 & -30.78 & \pm 0.92 & -31.80 & \pm 0.73 \\
\hline & Site 3 & -29.59 & \pm 1.41 & -31.97 & \pm 1.39 & -32.18 & \pm 0.96 & -30.06 & \pm 0.46 & -34.07 & n.a. \\
\hline & Site 4 & -30.12 & \pm 1.13 & -27.70 & \pm 0.08 & -33.23 & \pm 0.40 & -24.29 & \pm 0.45 & -33.94 & \pm 2.02 \\
\hline & Site 5 & -27.90 & \pm 0.51 & -30.61 & \pm 0.41 & -31.73 & \pm 0.88 & -30.03 & \pm 0.04 & -32.88 & \pm 0.78 \\
\hline & Site 6 & -30.22 & \pm 0.44 & -32.57 & \pm 1.05 & -31.80 & \pm 1.25 & -30.29 & \pm 0.51 & -34.73 & \pm 0.60 \\
\hline & Site 7 & -32.51 & n.a. & -31.72 & \pm 1.24 & -31.28 & \pm 0.34 & -30.50 & \pm 0.96 & -31.80 & \pm 1.44 \\
\hline \multirow[t]{2}{*}{ Soils } & Grass prairie & -22.62 & \pm 0.45 & -23.42 & \pm 0.34 & -26.40 & \pm 0.19 & -24.90 & \pm 0.08 & -28.26 & \pm 0.84 \\
\hline & Riparian & -31.41 & \pm 0.11 & -34.52 & \pm 1.05 & -32.38 & \pm 1.23 & -32.43 & \pm 0.98 & -35.63 & \pm 1.69 \\
\hline
\end{tabular}


Table A5.21. continued.

\begin{tabular}{|c|c|c|c|c|c|c|c|c|c|}
\hline Sample type & Name & $\mathrm{C}_{32}$ & & $\mathrm{C}_{33}$ & & $\mathrm{C}_{34}$ & & $\mathrm{C}_{35}$ & \\
\hline \multirow[t]{7}{*}{ Riparian vegetation $\left(\mathrm{C}_{3}\right)$} & Bur Oak & -35.78 & n.a. & -32.25 & \pm 1.93 & n.d. & & n.d. & \\
\hline & Hackberry & -35.43 & n.a. & -34.13 & n.a. & n.d. & & n.d. & \\
\hline & Chinkapin Oak & $n . d$. & & -30.90 & \pm 0.31 & n.d. & & n.d. & \\
\hline & Black Walnut & -31.35 & \pm 1.27 & -33.46 & \pm 1.14 & -30.11 & n.a. & -32.20 & n.a. \\
\hline & Wild Plum & n.d. & & -33.88 & n.a. & n.d. & & n.d. & \\
\hline & Roughleaf Dogwood & -36.35 & n.a. & -33.84 & \pm 0.91 & n.d. & & n.d. & \\
\hline & Cottonwood & -31.74 & n.a. & -30.70 & n.a. & n.d. & & n.d. & \\
\hline \multirow[t]{2}{*}{ Grasses $\left(C_{3}\right)$} & Johnson grass & -34.49 & \pm 1.95 & -37.44 & \pm 1.06 & n.d. & & n.d. & \\
\hline & Prairie Cordgrass & $n . d$. & & -36.82 & \pm 0.22 & n.d. & & -34.76 & \\
\hline \multirow[t]{2}{*}{ Grasses $\left(\mathrm{C}_{4}\right)$} & Eastern Gamma grass & -27.58 & \pm 1.11 & -27.77 & \pm 0.72 & -26.32 & \pm 0.79 & n.d. & \\
\hline & Big Bluestem grass & -22.68 & \pm 0.88 & -22.98 & \pm 0.86 & n.d. & & -23.38 & \\
\hline Moss & Moss & $n . d$. & & n.d. & & n.d. & & n.d. & \\
\hline \multirow[t]{3}{*}{ Algal assemblies } & $\# 1$ & n.d. & & n.d. & & n.d. & & n.d. & \\
\hline & $\# 2$ & n.d. & & n.d. & & n.d. & & n.d. & \\
\hline & $\# 3$ & n.d. & & n.d. & & n.d. & & n.d. & \\
\hline \multirow[t]{7}{*}{ Sediments } & Site 1 & -37.05 & n.a. & -32.92 & \pm 0.20 & n.d. & & n.d. & \\
\hline & Site 2 & -28.70 & n.a. & -32.11 & \pm 2.00 & -27.92 & n.a. & -28.66 & n.a. \\
\hline & Site 3 & -33.30 & \pm 0.02 & -31.00 & \pm 1.69 & -25.72 & n.a. & -31.48 & \pm 1.16 \\
\hline & Site 4 & -26.37 & n.a. & -33.23 & \pm 0.97 & -25.04 & n.a. & -25.14 & n.a. \\
\hline & Site 5 & -27.68 & n.a. & -30.26 & \pm 0.89 & -26.54 & n.a. & -26.30 & n.a. \\
\hline & Site 6 & -29.58 & n.a. & -32.18 & \pm 1.73 & -26.86 & n.a. & -30.37 & \pm 1.62 \\
\hline & Site 7 & -31.11 & n.a. & -32.25 & \pm 1.81 & n.d. & & -32.38 & \pm 1.99 \\
\hline \multirow[t]{2}{*}{ Soils } & Grass prairie & -25.88 & n.a. & -27.73 & \pm 0.54 & n.d. & & -26.71 & n.a. \\
\hline & Riparian & -32.93 & \pm 1.09 & -34.45 & \pm 0.38 & n.d. & & n.d. & \\
\hline
\end{tabular}

*n-alkane not detected.

** Not available: only one replicate was obtained and no standard deviation could be calculated. 
Appendix 5.2. Chemical structures of selected biomarkers.

\section{Phytadienes:}

I

II

III

$\underline{C}_{25}$ Highly branched isoprenoids:

IV V 
Mono-unsaturated triterpenes:

VIII IX

$\mathbf{X}$

XI XII

XIII 
Triterpenones:

XIV XV

XVI

XVII

XVIII 
Triterpenols:

XIX

XX

XXI

XXII

Oxygenated acyclic isoprenoids:

XXIII

XXIV 
Sterols:

XXV

XXVI

XXVII

XXVIII

XXIX 
VITA

\section{OLIVA PISANI}

November 5, 1981

2000-2002

2002-2005

2003

2004, 2005

2008-2009

2010
Born, Florence, Italy

A.A., Chemistry

Miami Dade College

Miami, Florida

B.S., Chemistry

Florida International University

Miami, Florida

George Barley Undergraduate Fellowship for

Everglades Research

Florida International University

Miami, Florida

Environmental Science Research Internship Program Florida International University

Miami, Florida

Florida Coastal Everglades-Long Term

Ecological Research Student Group President

Florida International University

Miami, Florida

Dissertation Year Fellowship

Florida International University

Miami, Florida

\section{PUBLICATIONS AND PRESENTATIONS}

N. Maie, O. Pisani, R. Jaffé. 2008. Mangrove tannins in aquatic ecosystems: Their fate and possible influence on dissolved organic carbon and nitrogen cycling. Limnology and Oceanography 53(1): 160-171.

N. Maie, N. M. Scully, O. Pisani, R. Jaffé. 2007. Examination of protein-like fluorophores in colored dissolved organic matter (CDOM) in a wetland and coastal environment. Water Research 41(3): 563-570. 
O. Pisani, Y. Yamashita, R. Jaffé. 2011. Photo-dissolution of flocculent, detrital material in aquatic environments: Contributions to the dissolved organic carbon pool. Water Research 45(13): 3836-3844.

O. Pisani, Y. Yamashita and R. Jaffé, (September 2009, May and July 2010). Photoinduced generation of DOM from floc in the Shark River Slough of the Florida Coastal Everglades (FCE). Presented at the Long Term Ecological Research Network All Scientists Meeting, Estes Park, CO, The Florida Meeting \& Exposition, Tampa, FL and the Greater Everglades Ecosystem Restoration meeting, Naples, FL.

O. Pisani, L. J. Scinto, W. Louda and R. Jaffé, (March and May 2009). Chemical characterization of flocculent material (floc) in the Florida Coastal Everglades Preliminary results. Presented at the Long Term Ecological Research All Scientists Meeting, Miami, FL and The Florida Meeting and Exposition, Orlando, FL. 